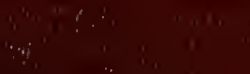

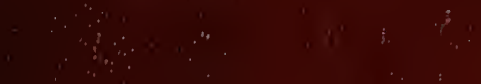

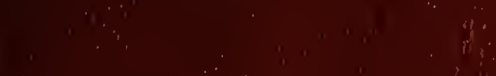

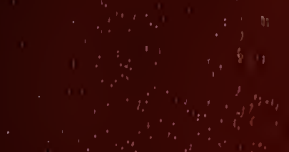

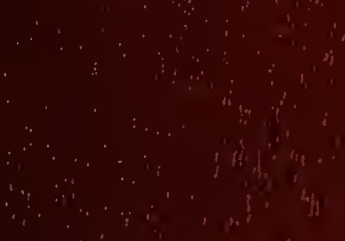

$\because \quad \because \because,+1$

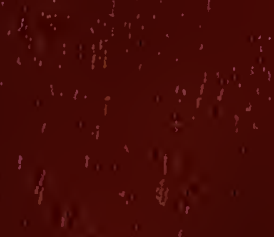



for

. 110

it

20

(n)

(astis

$(\mathrm{cos}$

(n) 20

(n) $-$

(e)

(2)

$(f-2) \quad(0)$

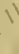

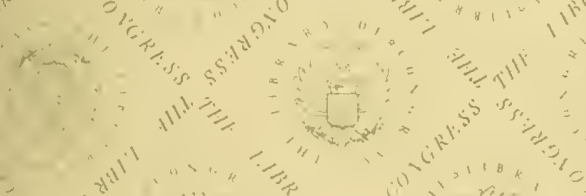

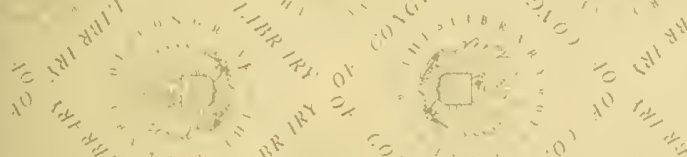
"xit"

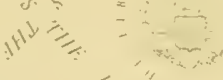

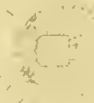

- $1 x^{1} \div$

, 

PARASITES AND PARASITOSIS OF THE DOMESTIC ANIMALS 


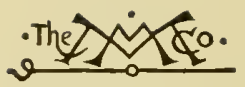

THE MACMILLAN COMPANY

NEW YORK - BOSTON - CHICAGO DALLAS

ATLANTA - SAN ERANCISCO

MACMILLAN \& CO., Limited

LONDON - BOMBAY - CALCUTTA

MELBOURNE

THE MaCMILLAN CO. OF CANADA, Lto. TORONTO 


\section{PARASITES AND PARASITOSIS}

OF THE

\section{DOMESTIC ANIMALS}

THE ZOÖLOGY AND CONTROL OF THE ANIMAL PARASITES AND THE PATHOGENESIS AND TREATMENT OF PARASITIC DISEASES

BY

B. M. UNDERHILL, V.M.D.

PROFESSOR OF PARASITOLOGY AND INSTRUCTOR IN ZOOLOGY AND HISTOLOGY, SCHOOL OF VETERINARY MEDICLNE, UNIVERSITY OF PENNSY'LVANIA, ZOÖLOGIST, DIVISION OF LABORATORIES, PENNSYLVANIA STATE BUREAU OF ANIMAL INDUSTRY

WITH 180 ILLUSTRATIONS

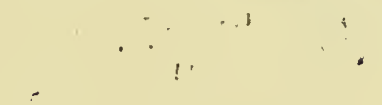

\section{Jiru Hark \\ THE MACMILLAN COMPANY}

1920

All riphts reserced 
Copyright, 1920

BY THE MACMILLAN COMPANI

Set up and printed. Published April, 1920

JUN -21920

(C) 1571175 


\section{PREFACE}

In the preparation of this work the author has aimed to present clearly, concisely, and in orderly manner such matter pertaining to the subject at hand as seems most essential to the needs of the student and the practitioner. Notwithstanding its elementary character, the present rapid advances in parasitology have necessitated numerous changes and additions to the manuscript during its preparation. New species and unsettling facts and theories as to some which are not new are, in these days of intensive research, frequently being brought to light and reported upon. Some of these findings represent or lead to a distinct advance and, though the observations be in certain cases upon obscure and in themselves unimportant species, they may, by analogy, shed valuable light upon life histories and modes of infection of related forms known to be injurious to domestic animals and man. So frequent are these steps forward that it might ahost seem better to leave comparative parasitology at the present time to the fragmental attention it has mainly received, and possibly it is to this view that the lack of a recent American volume upon the subject may be attributed. Be that as it may, this book is not intended to be compreheusive, and it contains but little discussion, historical or otherwise, of investigations in the fiekd of medical zoölogy, -limitations which may, in measure, contribute to it a longer period of usefulness in its present form than could be hoped for in an exhaustive treatise. With but few exceptions, the parasites considered are those most likely to be met with and as to which most of the facts pertaining to their biology and pathogenicity have been well established.

The treatment of the subject is based upon the advantages of presenting it with at least a rudimental attention to the biologic principles involved in parasitism, a knowledge of which is requisite to the proper conception of parasitology and certainly essential to intelligently applied measures of control. The direct and lucid style of the text throughout will, it is hoped, bring these briefly considered fundamentals before the reader in their true bearing upon the whole subject and render the book particularly acceptable to the general practitioner as well as to the student.

Teachers will appreciate that laboratory work should supplement the class-room method of study. Of course the student should in every case see the parasite under consideration in so far as this is possible. Methods of laboratory technique and the selection of trpe specimens for 
dissection should, in the author's opinion, be left to the teacher, who should certainly be the one best qualified to formulate the course adapted to his needs. No general outline, therefore, as to laboratory methods has been attempted.

If, as has been said, origiuality is not the best recommendation for a work of this kind, the author feels quite sure that its defects cannot to any great extent be attributed to that source. His observations in the fielel and laboratory have been utilized in the preparation of the book, but contribute nothing to its pages that is advanced or aggressively critical. Excluding.the first three chapters, so much of the subjectmatter has been drawn from the published results of the labors of others that the numerous sources cannot well be enumerated here. Acknowledgments are especially due to bulletins and articles upon various topics of parasitology written by workers in federal and state bureaus of experimental research. Other sources which have been relied upon and freely used are: M. Neveu-Lemaire's Parasitologic des Animaux Domestiques; Helms' Medical and Teterinary Entonology; Riley and Johannsen's IIandbook of Medical Entomology; Calkins' Protozoölogy; Neumann's Purasites and Parasitic Discases of the Domesticated Animals; Bram's Animal Parasites of Man; The Journal of Parasitology; The American Edition of IIutyra and Marck, and Osborn's Economic Zoölogy.

The author wishes to express his sincere appreciation and thanks to his laboratory coworker, Dr. Fred Boerner, Jr., for his assistance in the collertion of specimens and in the examination of pathologic material; also to Dr. William J. Lentz for his reading and valuable criticism of parts of the manuseript, and to Dr. C. P. Fitch for his helpful suggestions as to soures of reference.

Illustrations for a $\pi$ ork of this character will be an aid to the text in proportion as they are exact and well chosen. For the sturly of morphologic characteristics photographs of actual specimens are often too obscure in detail, and accurate drawings or line sketches are, as a rule, of gleater service. It will be observed that many of the figures in this book are taken from publications issuer by the United States Department of Agriculture. Probably no better drawings of these subjects have bern produced, and the privilege granted to use them is esteemed as a helpful favor of much ralue to the work. In this connection the author would especially express his gratitude to Dr. L. O. Howard, Chief of the Bureau of Entomology, to Dr. John R. Mohler, Chief of the Bureau of Animal Industry, to Dr. Herbert Osborn, to Dr. Howard Crawley, and to Dr. B. H. Ranson. Finally, thanks are due to Dr. W. H. Hoedt of Philaclelphia, for his skill and interest in preparing the photomicrographs and many of the drawings.

Philadelphia, Pa.

B. M. U. 


\title{
CONTENTS
}

\author{
PART I \\ PRELIMINARY CHAPTERS \\ THE EXTERNAL PARASITES
}

CHAPTER I

Origin of parasitism; Influences inhibiting organic multiplication; The struggle for existence; The sheltered mode of life; Its effect; Phases of the symbiotic relationship; Example of mutualism; Examples of commensalism; True parasitism; Adaptive and degenerative modifications of the parasite; Faculties of parasitic and predatory animals compared; Simplicity, primitive and degnerative; The Tunicata; Functions involved in adaptation to parasitism; The reproductive process in Melophagus ovinus; Development of the reproductive function in parasites; Parasitism of Gastrophilus intestinalis; Alternation of hosts in life cycle of parasites; The complicated cycle of the liver fluke; The tapeworm as an example of extreme parasitism; Deductions as to the systematic position of parasites through comparison with free-living forms.

\section{CHAPTER II}

Forms of Parasitism and Influence upon the Host ....................
Terms used in parasitology; Symbiosis; Mutualism; Commensalism; Helotism; Parasitism; Phytoparasites; Zoöparasites; Optional occasional parasites; Obligate occasional parasites; Determinate transitory parasites; Permanent parasites; Fixed parasites; Erratic parasites; Determinate erratic parasites; Monoxenous parasites; Heteroxenous parasites; Transmigration; Incidental or stray parasites; Ectoparasites; Entoparasites; Helminthes; Terms used in the designation of parasitic diseases; Predacious and parasitic animals; Factors governing injury to the host by parasites; General etiologic factors.

\section{CHAPTER III}

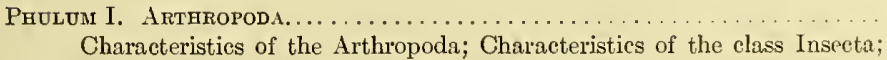
Inseet methods of reproduction; Duration of life of insects. 


\section{CHAPTER II}

Mosquitoes and Grats.

Charaeteristics of the order Diptera; Dipterous parasitism; Charactistics of the family Culicidæ; Range and prevalence of mosquitoes; Their breeding habits; Their pathologic importance; The transmitter of malaria; Methods of distinguishing between Anopheles and Culex; The transmitter of yellow fever; Characteristies and habits of the species Ades calopus; Effect of mosquitoes upon live stock; Mosquito control; Characteristics of the farnity Simuliidæ; The Southern buffalo gnat; Effect of its attack upon live stock; Control; Protection and treatment.

\section{CHAPTER}

The Flies.....

Charaeteristies of the family Tabanidx; Horse-flies; Gad-flies; Effect of their attack; Protection; Characteristics of the family Muscidæ; The house-fly; Habits of the house-fly and its retation to the transmission of disease; Its control; Protective measures; The horn fly; Its habits; Effect of its attack; I ts control; The tsetse flies; Charaeteristies of the genus Glossina; Distribution and habits of tsetse flies; Their relationship to trypanosomiasis; Investigations by Bruce and others; Tsetse fly eontrol; Characteristics of the family Hippoboscidæ; The "sheep tiek" or "louse fly;" Its effect; Treatment.

\section{CHAPTER VI}

The Difterous Lart:a. .......................

Myasis; The "screw worm fly;" Its habits; Effect of its attack; Protective ineasures; Treatment; The flesh flies; The blowfly; Its habits; Protective measures; Characteristics of the family (Estridæ; The horse bot flies; Gastrophilus intestinalis; Its habits and life history; Effect of the fly and larva upon horses; The red-tailed bot-fly; Its habits and effect; The chin fly; The ox bot or warble flies; Their life history; Their economic importance; The sheep bot fly; Its habits and life history; Fffect of the attack of the fly and its larva; Protection and treatment.

\section{CIIAPTER VII}

The Tleas. .

Charactcristics of the order Siphonaptera; The dog, cat, and human fleas; Differentiation of species; Life history; Relation of fleas to the transmission of infectious diseases; Treatment and control.

\section{CHAPTER VIII}

THE LICE

The sueking lice; Characteristies of the order Siphunculata; The biting lice; Characteristies of the order Mallophaga; Pediculosis of domestic ani- 
mals in general; Pediculosis of the horse; Pediculosis of cattle; Pediculosis of the sheep and goat; Pediculosis of the hog; Pediculosis of the dog and cat; Pediculosis of man; Control and treatment of pediculosis.

\section{CHAPTER IX}

Lice of Podltry; The Bedeug.

Prevalence and effect of poultry lice; Species infesting chickens; Species infesting turkeys; Species infesting ducks and geese; Species infesting swan; Species intesting pigeons; Control and treatment of poultry lice; Characteristies of the order Hemiptera; Characteristics of the family Cimicidæ; The common bedbug; Its habits and effect of its bite; The bedbug as a pest of poultry; Control.

\section{CHAPTER $\mathrm{X}$}

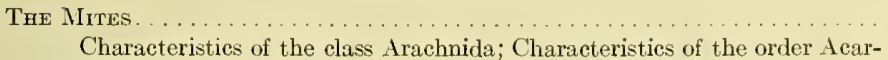
ina; Parasitism of the Acarina; Acariasis; Characteristies of the family Gamasidæ; The gamasid mites of poultry; Habits and effect of their attack; Control; Characteristics of the family Trombidiidx; The harvest mites, chiggers, or red bugs; Habits and effect of their attack; Treatment; The mange, scab, ol itch mites; Characteristics of the family Sarcoptidx; The genera Sarcoptes; Notoedres, Otodectes, Cnemidocoptes, Laminosioptes, Cytoleichus, Psoroptes, and Chorioptes; Their respective characteristics, hosts, and modes of attack; Characteristics of the family Demodecidx; Mange and scabies of the various domestic animals; Sarcoptic mange; Demodectic or follicular mange; Notoedric or head mange of the eat and rabbit; Otodectic or auricular mange; Psoroptic seabies; Auricular scabics of the rabbit; Chorioptic or leg seabies; Symptoms, development, lesions, diagnosis, and transmission of mange and seabies.

\section{CHAPTER XI}

Treatment of Mange and Scaímes.

General considerations; Treatment of sareoptic mange of the horse; Of the dog; Of the goat; Of the sheep; Of cattle; Treatment of notoedric mange of the eat and rabbit; Treatment of demodectic mange; Treatment of otodectic mange; Treatment of psoroptic scabies of the shcep; of eattle; Of the horse; Of the rabbit, Treatment of chorioptic scabies of the horse; Of eattle.

\section{CHAPTER III}

Mange of Poultri.....

The burrowing mite of poultry; Leg mange or "scaly leg"; Its course and trcatment; The depluming mite; The deep-seated acariases of birds; The family Cytoleichidæ; The conncetive tissue mite; The air passage mite. 


\section{CHAPTER XIII}

THE TICKS

Structure of ticks in general; Characteristies of the superfamily Ixodoidea; Characteristics of the family Argasidæ; The fowl tick; Its habits and effect upon the host; Control; The spinose car tick; Its habits and effect upon the host; Treatment; Cliaracteristics of the family Ixodidæ; Description of genera; Species found upon domestic animals in the United States; The Texas-fever or Southern cattle tick; Biological data established by the Zoölogical Division of the United States Bureau of Animal Industry; Life history of the Texas-fever tick; Its nonparasitic development; Its parasitic development; Loss occasioned by the Texas-fever tick; Progress made in its eradication; The orler Linguatulida; Linguatula rhinaria of the nasal cavitics of manmals.

\section{PART II}

THE INTERNAL PARASITES

\section{CHAPTER XIV}

Phyltar II. Platyhelminthes; The Flukes and Tapenoras

Classification of the parasitic worms; Characteristics of the Platyhelmintles; Characteristics of the class Trunatoda; The liver flukes; Their life history; Prevalenee of fascioliasis; Infection; Migration of flukes within the definitive host and pathogenesis; Fascioliasis of the sheep; Fascioliasis of eattle; Control and treatment; The blood fluke; Bilharziosis; Characteristics of the elass Cestoda; Characteristies of the family Tæniida; Life history of tapeworms; Their parasitism.

\section{CHAPTER TV}

TANIASI;

General consileration of the effect of tapeworms upon their hosts; Tapewornis of the horse; Tapeworms of eattle, sheep, and goats; Tapeworms of the log; Dog taperorms in relation to human infection: Tapeworms of the eat; Tapeworms of the rabbit; Characteristies of the family Diphyllobothriilic; Occurrence of species; Treatment of tæniasis of the dog; Prevention; Treatment of tæniasis of the elt; Treatment of tæniasis of sheep, goats, and cattle; Treatment of teniasis of the horse.

\section{CHAPTER XVI}

TAPETORMS OF CHICKENS

Characteristics of species; Investigations as to their relative oceurrence; Symptoms; Control; Treatment. 


\section{CHAPTER XVII}

The TaPeWorm LaRVE.

Pathologic importance; Forms and their characteristies, Cysticercosis or measles; Beef measles; Its occurrence; Degeneration and vitality of the cysts; Pork measles, Its occurrence; Degeneration and vitality of the cysts; Measles of the sheep; Cœnurosis or gid; Its occurrence; Its development; Its post-mortem appearance; Its symptoms; Control and treatment; Echinococcosis or hydatid disease; Structure of the echinococcus cyst; Its development; Post-mortem appearance in echinococcosis; Symptoms; Control.

\section{CHAPTER XVIII}

Phyldm III. Cegleluinthes; The Smooth and Segmented Roundworus . . 216

Characteristics of the Colhelminthes; Characteristics of the class Nemathelminthes; Characteristics of the ordcr Nematoda: Parasitism of the nematode worms in general; General consideratious as to treatment.

\section{CHAPTER XIX}

Nematoda; Family I. Ascaride; The Large Roundworms of the Intestine 229

Characteristics of the Ascaridæ; Investigations as to life history; Ascariasis; Ascarids of the horse; Occurrence of equine ascariasis; Its etiology, control, and treatment; Characteristics of the family Oxyuridæ; Oxyuriasis of equines; Ascarids of the dog and cat; Ascarids of the hog and sheep; Ascarids of the ox; The family Heterakidæ and heterakiasis of poultry.

\section{CHAPTER XX}

Nematoda; Family IV. Filaridd a; The Thread-Ltke Worms...........

Characteristics of the Filariidæ; Parasitism; Filaria of the horse; Their occurrence; Effect of filariasis upon equines; Filaria of sheep and cattle; Filaria of the dog; Hematic filariasis; Filaria of the hog; Filaria of poultry.

\section{CHAPTER XXI}

Nematoda; Family V. Strongyldie; Subfamiy I. Metastrongluine

Wornis of the Respiratory Tract.................... 255

Characteristics of the Strongylidæ; Parasitism; Strongylosis; Characteristics of the-Metastrongylinæ; Parasitism; Bronchial and pulmonary strongylosis of the sheep and goat; Its symptoms, course, and prognosis; Bronchial and pulmonary strongylosis of cattle; Its symptoms, course, and prognosis; Bronchial and pulmonary strongylosis of the pig; Its occurence and symptoms; Bronchial and pulmonary strongylosis of the horse; Cardiopulmonary strongylosis of the dog; Pulmonary strongylosis of the cat; Postmortem appearance in bronchial and pulmonary strongylosis; Development, etiology, control, and treatment of bronchial and pulmonary strongylosis. 


\section{CHAP'TER XXII}

PAGE

Nematoda; Subfamly II. Trichostrongyline; Worms of the Stomach

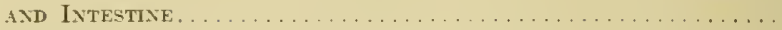

('haracteristics of the Trichostrongylinx; Parasitism; Gastro-intestinal strongylosis of the sheep and goat; Its occurrence; Its symptoms; Gastrointestinal strongylosis of cattle; Its oceurrenee; Its symptoms; Post-mortem appearance in gastro-intestinal strongylosis, Development, etiology, control, and treatment of gastro-intestinal strongylosis.

\section{CHAPTER XXIII}

Neniatoda; Subfamily III. Strongyun. Ixtestixes; Other Stroxgrles.

Characteristies of the Strongyline; Parasitism; Nodular strongylosis of the sheep and goat; Its occurrence; Its development; Its post-mortem appearance; Its symptoms; Treatment; Nodular strongylosis of eattle; Nodular st rongylosis of the hog; Strongylosis of the large intestine of the sheep and goat; Strongylosis of the intestines of the horse; Its development; Its symptoms; Its post-mortem appearanee; Intestinal strongylosis of the dog and eat; Other Strongylina; Traeheal strongylosis of chickens; The kidney worm of the hog; Family Lust rongylida and eustrongylosis.

\section{CHAPTER XXIY}

Nenatoda; Famlitil. Trichinelld ש.

("laracteristies of the Trichinctlide; The "whip-worms" of the large intestine; Trishinclla spiralis and trichinosis; Life history of Trichinclla spiralis; Intestinal trichinosis; Muscular triehinosis; Degeneration of the trichina cyst; Infeetion; Symptoms of intestinal and museular trichinosis in logs; Trichinosis in rats and miee; Prophylaxis.

\section{CIIAPTER XYV}

The Thor:-headed Worm; The Leeches .

Characteristics of the orler Acanthoeephala; The thorn-headed worm of the intestines of the hog; Its life history; Its oecurrenee; Its pathogenicity; Symptoms produred; Treatment; Characteristics of the class Annelida; Characteristies of the order Himulinea; The horse leech; The medicinal leech; Sources of infestation by leeches; Their effect upon the animal attacket; 'Treatment. 


\section{PART III}

\section{THE PATHOGENIC PROTOZOA}

\section{CHAPTER NXVI}

Phylum IV. Protozon

General consideration of the Protozoa; Characters differentiating Protozoa from Metazoa; Ameba, its main features for study; Parasitism of the Protozoa; Progress of research; Relationship of arthropods to infection with protozoal diseases; Evolution of pathogenicity in Protozoa; Methods of reproduction in free and parasitic forms; Life history of the malaria organisms; The schizogonic or asexual cycle; The sporogonic or sexual cycle; Classification of pathogenic species.

\section{CHAPTER XXVII}

The Protozoan Subgroups; Diseases Due to Protozoa.

Characteristies of the class Rhizopoda; Infeetious entero-hepatitis of turkeys; Amebic dysentery of man; Characteristics of the class Flagellata; Characteristics of the order Spirochetida; Spirochetosis of poultry; Characteristics of the order Trypanosomatida; Parasitism; Transmission of the infecting organisms; Nagana or "fly disease;" Surra, Mal de Caderas; Dourine; Trypanosoma americanum; Characteristics of the class Sporozoa; Characteristics of the order Coccidia; Coccidiosis; Eimeria stiedo; Coccidiosis of rabbits; Diplospora bigemina; Coccidiosis of dogs; Coccidium zurni; Red dysentery of eattlc; Eimeria avium; Coccidial enteritis of chicks; Characteristics of the order Henosporidia; Piroplasma bigeminum; Texas-fever of cattle; Its occurrence; Exposure and development; Its symptoms; The acute type; The chronic type; Prevention and treatment; Characteristics of the order Sarcosporidia; Sarcosporidiosis; Mode of infection.

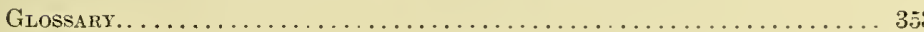

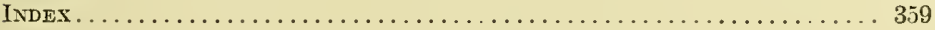





\section{LIST OF ILLUSTRATIONS}

FIG.

1. Diagram of an insect.

2. Diagram of interual parts of an insect.......... 16

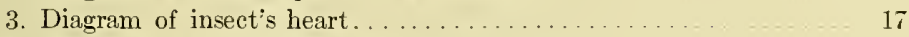

4. Mouth parts of a biting insect................ 1 T

5. Diagram showing tracheal system of an insect........... 18

6. Abrlomen of locust, showing spiracles................ is

7. Head of bee, showing compound eyes, ocelli, and antennæ. . . . 19

8. Metamorphosis of the house fly . . . . . . . . . . . . . 19

9. Diagram of segments of arthropod, showing leg muscles, etc.... 19

10. Eggs and larvæ, of Culex mosquito................. 24

11. Pupa, of Culex and Anopheles mosquitoes .............. 26

12. Culex pungens, male and female................... 27

13. Anopheles quadrimaculatus, male and female............ 2s

14. Position of Anopheles and Culeiv at rest............... 28

15. Breathing position of larva, of Anopheles and Culex . . . . . . 29

16. Eggs of Anopheles.......................... 30

17. The Southern buffalo gnat.................... 32

18. Larva of Southern buffalo gnat. . . . . . . . . . . . . . 33

19. Pupa of Southern buffalo gnat. . . . . . . . . . . . . 33

20. The black horsefly . . . . . . . . . . . . . . . . . . . . 36

21. The green-head fly . . . . . . . . . . . . . . . . . 36

22. The stable or stinging fly . . . . . . . . . . . . . . . . 39

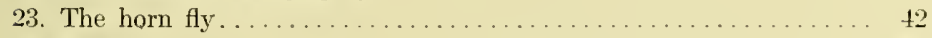

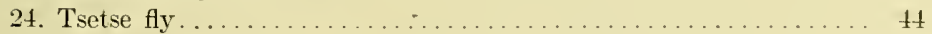

25. The "sheep tick." .......................... 4

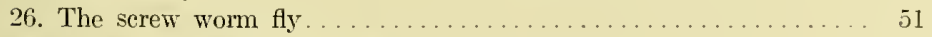

27. Metamorphosis of the flesh fly.................. 52

28. Horse botfly, showing eggs, larva, and adult.......... 54

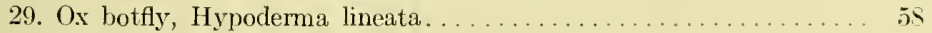

30. Ox botfly, Hypoderma bovis. . . . . . . . . . . . . . . . 59

31. Eggs of Hypoderma lineata . . . . . . . . . . . . . . . 59

32. Larval stages of Hypoderma lineata................ 61

33. The sheep botfly, showing larva, pupa, and adult......... 63

34. The $\log$ flea, anterior portion of body . . . . . . . . . . . 66

35. The human flea, anterior portion of hody . . . . . . . . . . 66

36. The $\log$ flea, showing development and mouth-parts. . . . . . . . 6 7

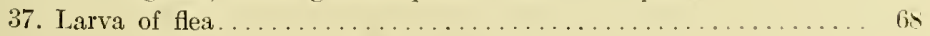

3S. Sucking louse of lorse, Hamatopinus asini............ 73 
FIG.

39. Biting lozse of horse, Trichodectes parumpilosus

40. rucking louse of cattle, Hæmatopinus eurysternus.

41. Sucking louse of calves, Linognathus (Hæinatopinus) vituli

42. Biting louse of cattle, Trichodectes scalaris

43. Sucking louse of sheep, Linognathus (Hæmatopinus) pedalis . $\quad 76$

44. Biting louse of shcep, Trichodectes sphærocephalus....... 77

45. Sucking louse of hog, Hæmatopinus suis............. is

46. Sucking louse of (log, Linognathus (Hrmatopinus) piliferus _ is

47. Biting louse of $\log$, Trichodectes latus. . . . . . . . . $\quad 79$

45. Louse of the cat, Trichodectes subrostratus ....... . . . . 79

49. Louse of chicken, Goniocotes gigas (G. abdominalis). $\$ 3$

50. Louse of chicken, Lipeurus caponis (L. variabilis) . . . . . . . . 83

51. Louse of chicken, Menopum trigonocephalum (Menopon pallidum). 83

52. Iouse of turkey, Goniodes stylifer ................. $\$ 5$

53. Louse of turkey, Lipeurus meleagridis (L. polytrapezius) . . . . . $\$ 5$

54. Louse of turkey, Menopum (Menopon) biseriatum. . . . . . . $\$ 5$

55. Louse of duck, Lipeuris anatis (L. squalidus) . . ... $\$ 5$

56. Louse of ducks and geese, Trinotum (Trinoton) luridum . . . . \$ $\$ 7$

57. Louse of swan, Plilopterus (Docophorus) cygni... . . . . . . $\$$

5.. Lonse of swan, Ornithonomus (Ornithobius) cygni _... S7

59. J.olse of pigeon, Goniocotes compar. . . . . . . . 87

60. Louse of pigenn, Goniodes damicomis _..... . . 87

61. Bedbug, adult female, mouth-parts ete.......... 91

62. Diagram of the anatomy of a spider ... . . . 95

63. Gamasid poultry mite, young and adult ... 98

(it. Mange mite of horse. . . . . . . 104

6.5. Mange mite burmw in human skin. . 105

6if. Colts affeeted with sarcoptic mange. 106

67. I.cg scal) mite of horse. $\quad 109$

(is. Scal, mite of sheep, female... 111

69. Scal mite of sheep, male. ... . 111

70. Follicular mange mite. ........ . 116

7l. Mange mite of eat and rabbit _ 118

72. Auricular seab mite of rabibit. 118

73. Portable dipping rat for sheep $\quad \ldots \ldots . \quad 127$

74. Nite of sealy leg of poultry, male and female 133

75. Foot of fowl affecterl with scaly leg. ........... 134

76. Capitulum of tick. . . . . . . . . . . . . . . 137

77. Capitulum, scutum, and fore leg of Texas fever tick _... 137

TS. Stignal plates of ticks Margaropus, Ixodes, and Dermacentor... 138

Ta. Photomicrograph of stigmal plate of Texas fever tick ......... 138

79. Fowl tick, alult and larva . . . . . . . . . . . . . . . . . 139

>0. Spinose eal tick, nymphal form.................. 141 


\section{LIST OF ILLLSTRATIONS}

FIG.

81. The castor-bean tick.

82. The American dog or wood tick

\$3. Linguatula rhinaria

8. Planarian worm.

85. Liver fluke, Fasciola hepatica.

S6. Reproductive organs of liver fluke

87. Fasciola hepatica, F. americanus, Dicrocelium lanceatum

88. Life history of liver fluke.

89. Blood fluke, male and female.

90. Segment of Trenia saginata, showing sexual organs......... 171

91. Tapeworms of the horses.................... 175

92. Tapeworm of cattle and sheep, Moniezia expansa . . . . 176

93. Fringed tapeworm of sheep, anterior segments. . . . . . 177

94. Tapeworm of $\operatorname{dog}$, Dipylidium caninum............... 180

95. Rostellum of Dipylidium 'caninum.................. 1 . 1 .

96. Egg packet and Cysticercoid of Dipylidium caninum . . 1 . 1 .

97. Tapeworm of $\log$; Tænia hydatigena. . . . . . . . . . . . . . . 180

98. Tapeworm of $\log$, Tænia pisiformis .................. 150

99. Tapeworm of $\operatorname{dog}$, Echinococcus granulosus. . . . . . . . 150

100. Rostellum of tapeworm of cat, Tænia tæniæformis. $18 t$

101. Diphyllobothrium Iatum........................ 186

102. Tapeworm of chicken, Choanotænia infundibuliformis.... . . . . 189

103. Scolex of Choanotænia infundibuliformis . . . . . . . . . . . . 190

104. Scolex of Davainea tetragona of chicken. ................. 190

105. Scolex of Davainea echinobothrida of chicken. . . . . . . . . 190

106. Tapeworm of man, Tænia saginata . . . . . . . . . . . . . . 196

107. Diagram of Cysticercus . . . . . . . . . . . . . . . . . . 195

108. Fragment of beef muscle, showing cysts of Cysticerus bovis. . . . . . . 195

109. Scoleces of Tænia solium, T. saginata, and Diphyllobothrium latum . . . 199

110. Eggs of Tænia saginata and T. solium................ 200

111. Mature segments of Trenia saginata aud T. solium. . . . . . . 200

112. Stages in tapeworm derelopment................. 201

113. Portions of adult gid tapeworm, Multiceps multiceps . . . . 205

114. Diagrammatic section of Multiceps (Cœnurus) erst. . . . . . . 206

115. Brain of lamb, showing furrows produced by young gid bladderworm. . 206

116. Gid bladderworm, showing immature tapeworm heads. ........206

117. Diagram of Echinococcus hydatid .................... 211

118. Fchinococeus granulosus, showing hydatid with brood capsules . . . . . 214

119. Transection of Ascaris equi................... 217

120. Posterior extremity of male nematode worm . . . . . . . . . 21s

121. Cephalic extremity of an ascarid worm ................ 229

122. Oxyuris equi. . . . . . . . . . . . . . . . . . . . . 236

123. Belascaris marginat a, showing head and male and female. . . . . 23s 
FIG.

124. Egg of Ascaris lumbricoides.

125. Ascaris lumbricoides, male and female

126. Hetcrakis perspicillum, male and female, and H. resicularis of poultry. 242

127. Setaria labiato-papillosa, male and female

125. Gongylonema scutata, anterior and posterior view:

129. Dirofilaria immitis, male and female

130. Lung worm of sheep and goat, Dictyocaulus filaria, male, female, and cggs

131. Lung worm of slicep, goat, and rabbit, Synthetocaulus rufescens, male and female

132. Lung wom of cattle, Dictyocaulus viviparous . . . . . . . . 259

133. Lung worm of jig, Metast rongylus apri, male and female . . . . . . . 260

134. Stomach worm of sheep, goat, and cattle, Hamonchus contortus, fenale

135. Hemonehus contortus, anterior portion of body . . . . . . 269

136. Hamonchus contortus, cnlarged posterior extremity of male . . . 269

137. Cooperia rurticei, male and female ................. 270

135. Cooperia curticei, cnlarged anterior portion _. . . . . 270

139. Ostertagia marshalli, male and female ......... 270

140. Trichostrongylus instalbilis, male and female $\quad .271$

141. Ostertagia ostertagi, male and female .......... . 273

142. Ostertagia ostertagi, posterior extremity of male enlarged . . . . . 273

143. Nematodirus filieollis, male and female and entarged anterior portion. . 274

14t. Cooperia oncophora, male and female. . . . . . . . . . . 274

14.5. Esophagostomum columbianmm, male and female ... .... 282

146. Esophagostomum columbianum, cnlarged anterior portion . . . . . 2\$2

147. Fsophagostomum columbianum, enlarged bursa of male. . . . . 283

14\$. (Esophagostomum venulosum, male and female... . . . . . 283

149. (Esophagostomum venulosum, enlarged anterior portion _... . 28.3

150. (Fsophagostomum venulosum, enlarged bursa of male _... 283

151. (Fsophagostomun ruliatum, male and femals . . . $2 \$ 6$

152. (Esophagostomum radiatum, enlarged anterior portion _.. 286

1.73. (Esophagostomum radiatum, enlarged bursa of male. . . . 286

154. Chabertia ovina, male and female .................. 287

15.5. Sitrongylus equinus, male and female................. 288

156. Hook-worm of dog and cat, Ankylostoma canina, male and female. 292

15\%. Bunostomm phlebotomm, male and female. . . . . . 293

15s. Tracheal wom of poultry, singamus trachealis, male and female. 294

159. Dioetophyme renale, male. _ . . . . . . . . . . . . . 297

160. Triehuris ovis, male and female..... ... . . 300

161. Trichuris ovis, egg _........ . . . . . 300

162. Trichinella spiralis, male and female... ... . . . 301

163. Trichincllat spiralis, eneysted larva in muscle. . . . . . 302 
FIG.

164. Trichinella spiralis, microphotograph of eyst.

301

165. The thom-headed worm, Gigantorhynchus hirudinaceus . $\quad 307$

166. Cephalic extremity of thorn-headed worm . . . . . . . . . . . 307

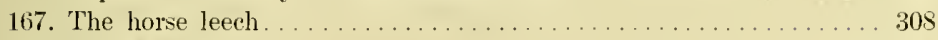

168. Ameba proteus. . . . . . . . . . . . . . . . . . . . . . . . . . . 312

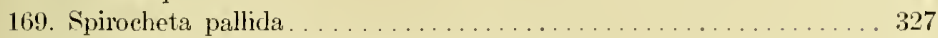

170. Hen suffering from acute spirochetosis................ 328

171. Piroplasma bigeminum. . . . . . . . . . . . . . . . . 348

172. Forms of Sarcosporidia, shown in infected muscle........... 351

PlaAtes.

PAGE

I. Texas fever tick, male and female, with details . . . . . . . . . 146

II. Texas fever tick, stages of engorgement and details . . . . . . . 147

III. Evolution of the parasite of kala-azar. . . . . . . . . . . . 317

IV. Life cycle of the malaria parasite . . . . . . . . . . . . . . 321

V. Various species of Trypanosoma . . . . . . . . . . . . . . . . 331

VI. Percheron stallion before and after development of dourine . . . . . 338

VII. Percheron mares, showing chronic dourine and last stage. . . . . . 340

VIII. Coceidian life eycle. . . . . . . . . . . . . . . . . . . . 344

\section{TABLES}

Classification of parasites of the class Insecta.............. 20

Life history of horse botfly, Gastrophilus equi ............. 5 5

Life history of sheep botfly, Estrus ovis. . . . . . . . . . . . . . . . 63

Classification of parasites of the elass Arachnida . . . . . . . . . . . 96

Summary on nonparasitic periods in development of Texas fever tick . . . 149

Sunmary on parasitic periods in derelopment of Texas fever tick. . . . 150

Life histories of $\operatorname{dog}$ tick and Texas ferer tick compared . . . . . . . . . 1 1

Classification of parasites of the phylum Platyhelminthes . . . . . . . 157

Life history of liver fluke, Fasciola hepatica . . . . . . . . . . . . . 163

Life history of beef tapeworm, Tæenia saginata . . . . . . . . . . . 172

The prineipal tapeworms, with their larve and hosts . . . . . . . . . 173

Synopsis of tapcwom larrx. . . . . . . . . . . . . . . . . . 194

Life history of the gid tapewom, Multiceps multiceps. . . . . . . . . 207

Life history of Echinococeus granulosus. . . . . . . . . . . . . . . . . 213

Classification of parasites of the phylum Colhelminthes. . . . . . . . 2222

Life history of Trichinella spiralis. . . . . . . . . . . . . . . . . . 303

Classification of parasites of the phylum Protozoa . . . . . . . . . . 322 

PARASITES AND PARASITOSIS OF THE DOMESTIC ANIMALS 



\title{
PARASITES AND PARASITOSIS OF THE DOMESTIC ANIMALS
}

\author{
PART I \\ PRELIMINARY CHAPTERS \\ THE EXTERNAL PARASITES
}

CHAPTER I

\section{INTRODUCTION}

The earth's vast laboratory of living matter includes a flora and fauna in which all of the highly diversified forms encounter conditions operating to restrict their multiplication and to govern the predominance of certain forms over others. These conditions are constituted, first, by topographic and climatic variations rendering certain localities more or less inhospitable to some organisms, while others may be uninfluenced or perhaps benefited. Second, there is the behavior of living things toward one another; this may be relatively harmonious or there may be an intense rivalry in which organisms encroach or prey one upon the other, the least fit for the strife being driven to less favorable habitats, progressively dwarfed, or ultimately becoming extinct. Though most of these inhibitive influences are not apparent to cursory observation, they are, nevertheless, numerous and varied as well as constant in their operation, constituting a prime factor in the evolution and specialization of organic forms.

There is, then, a perpetual struggle for existence, which may lead to the seeking of shelter from the conflict in a changed and often degenerate mode of life to which the organism becomes adaptively modified. Thus, through such influences, a terrestrial animal may be driven to an arboreal, or even an aquatic or semiaquatic, existence. A defenseless little member of the Insectivora burrows and becomes subterranean, while another finds protection in the nocturnal habit; others seek the shelter of caves or rock crevices, and we often find creatures, usually somewhat degenerate, in places which seem to us quitc unfavorable to their support. While in such cases the animal continues to lead a free and in- 
dependent, often solitary existence, on the other hand, a communion of life's interests may be established between two organisms which, it is sumised, is founded upon some nutual advantage in the strife. To such association the general term symbiosis has been applied and each of the organisms concerned is referred to as a symbiont. Though there is by no means a uniformity in the application of terms referring to the svmbiotic relationship, a usage is adopted here that secms best defined, and by which symbiosis is subdivided into the three categories, (1) mutualism, (2) commensalism, and (3) parasitism. In the first there is a reciprocal advantage derivel from the mion; in the second but one symbiont is benefited though the other suffers no harm, while in the third division one receives an advantage to the detriment of the animal or plant which it invarles. There is, however, no sharp line of demarcation between these three states of living together, and it may be difficult to determine in some cases whether one or both symbionts receives benefit from the mion, or whether one is or is not injured by it.

One of the more obvious examples of mutualism is the case of the hermit (rab) and the sea anemone. This crab selects a shell, as that of the whelk, for its habitation, from the opening of which it projects only its heal and claws. On the surface of the shell may often be found a sea anemone fastened near the opening with its mouth and tentacles in the vicinity of the crab's heacl. The anemone in this position not only in a measure serves to conceal the hermit crab from its encmies, but the creature that would prey upon the crab must first reckon with the dangerous stinging threads with which the tentacles of the anemone are arned. The anemone, in its turn, is benefited by being carried about by the crab and aided in this way in obtaining its food.

Such associations are not always of mutual advantage, and may be more in the nature of an invasion of one animal upon or within the hody of another, the invading animal alone deriving benefit, while the animal upon which the association is fored, though not benefiting, may in no way suffer from it. A familiar form of this living together (commensalions) is the little crab so commonly found in the shell of the oyster. The oyster is not harmed by its presence, but the crab is benefited by the protection which the shell affords. Another more curious cxample of such association is afforded anong the vertebrates by the species of Remora, or suck fishes, which have the first dorsal fin modified into a sucking disk on top of the head. By means of this disk it attaches itself to a shark or other large fish, and is thus carried about, detaching itself only to secure food. Its benefit from such association is in being carried to new feeding grounds without effort of its own, and in the shelter from its enenies which the body of the larger fish may afford. The host, on the other hand, camnot be benefited, nor does it seem to suffer by the presenee of its uninvited grest. 
Whether this relationship between different species is of reciprocal advantage or of benefit to but one, neither of the symbionts lives upon or at the expense of its co-symbiont, and neither has entirely renounced its independence. In true parasitism the invading animal lives upon the tissues of its host, deprives it of a portion of its nourishment; or is in other ways injurious to it. There are many examples of this form of symbiosis, and students of animal life are familiar with the conditions that seem always to attend it, such as the degenerative and adaptive modifications occurring in the parasite.

It is the common habit of many animals, however, to prey upon the bodies of other animals, and we should distinguish, so far as we may, between those which are predatory and those which are parasitic. The former are free and exercise their powers of sense and cunning in snaring or chasing their prey, while the latter, in fully acquired parasitism, live on or in the bodies of their victims, often burrowing into and consuming the body tissues, leading a lazy, beggarly existence in which all of the faculties of special sense and prowess, so highly developed in predatory animals, become degenerate and atrophied.

Parasitism is found throughout the range of animal life from the unicellular to the vertebrate, and, though a sharp distinction between predaceous and parasitic animals may not be made, in view of the degrading influence of the parasitic habit, the difference between the simplicity of degeneration and the simplicity of primitiveness should be clearly defined. In the development of a primitively simple animal the young stages are more simple than in the adult and it has only simple ancestors. In the degenerate animal, on the other hand, the ancestors are often more complex and the young stages are of a higher grade than the stage of the adult. The adoption of any mode of life which withdraws from the activities necessary to survival in a free existence seems to bring about this condition of degradation. Of this we have a remarkable example outside of the realm of parasitism in the Tunicata. These aberrant animals, in the stage of the free-swimming larva, have a chordal axis which in nearly all of the different species becomes entirely lost before they reach maturity. After passing the "tadpole" stage there follows an extreme specialization to the fixed habit which most tunicates retain throughout their adult life, becoming what are commonly known as sea squirts, mere attached, plant-like sacs, emitting a jet of. water when disturbed, and from which all chordate features have been entirely lost.

The degenerative changes which a parasite undergoes concern mostly the nervous system, the organs of locomotion, and those of nutrition, the nervous system becoming reduced to the most indispensable portion, while of the sense-organs nothing may be left except those of touch. The locomotor apparatus may become modified into claws or hooks for 
clasping the hairs of the host, or it may almost if not completely disappear and be replaced by such organs of fixation as sucking-disks. As the contents of the alimentary canal or tissue fluids of the host upon which the verminous parasite is nourished need scarcely any digestion, the digestive organs become simplified or may be quite lost, the absorbtion of nutriment in the latter case taking place entirely through the body integument, as in some of the worms which infest the intestines of man and other animals. The degree of chcadence will depend upon the degree of dependence upon the host. In this latter respect the parasitism may be optional, as in the ease of the mosquito, which may live upon the juices of plants but prefers a meal of warm blood, or it may be obligate, depending upon another for its means of subsistence, though such obligate parasites as the biting flies, fleas, and bedbugs may also live free and only occasionly visit their hosts, a form of parasitism which may be accompanicd by little modification of the adaptability to a free life.

In the event of the parasitc becoming progressively degraded into one which not only sccks its host for food, but has become dependent upon it for both its nutrition and place of abode, all of the above mentioned phenomena of adaptation become more conspicuous. There is furnished a very good example of such a transformation in the sheep tick (Melophagus ovinus), not a true tick, however, but a fly which, originally an occasional visitor, has, like the louse, taken permanent abode upon its host. No longer taking the aërial flight of its discarded free life, this fly lias become wingless, and, furthermore, is cnabled to pass its entire life cycle upon the body of the host animal by a remarkable method of reproduction involving the retention of the eggs in the oviducts until devclopment has passed through the larval stage. It is not until ready to pass into the stage of the pupa that the larvæ are extruded, the pupal casc then being attached to the individual wool fibers. From this case the young insect, on bccoming sufficiently devcloped, makes its escape and procceds to feed and grow, thus rounding out a complete parasitic cycle.

White the easy life of the parasitc tends to degeneration, the perpetuation of the species becomes more precarious, and the organs of reproduction undergo a marked development. If a host animal dies most of its parasites, especially those existing in the interior of its body, die with it, and, were it not that the eggs find lodgment in a new host, the parasitic species would in a short time become extinct. The transmission of but few of these eggs is successfully accomplished, and in compensation they must be produced in enormous numbers, well protected from the many elements of destruction which they encounter. The mode of reproduction is one of the principal factors deternining the conditions of parasitism, and, while the above modifications pertain more to those 
dwelling continuously upon or within the bodies of their hosts, we have in the Cstridæ, among the dipterous insects, a cycle involving internal parasitism during the larval stage, a familiar example being the common horse botfly (Gastrophilus intestinalis), the development of which is given on page 54. It is plain that a very small percentage of the eggs deposited by this fly can reach the horse's mouth, and that, having got thus far, many of the larvæ must be destroyed or pass entirely through the intestinal tract without having succeeded in becoming fixed to the mucous membrane. For this there seems to be compensation in the large number of eggs deposited by the persistent female.

While in some cases the complete life cycle of a parasite requires but one host, often, for reasons stated in the foregoing, two successive and generally specifically different hosts are required. A rather complicated example of the latter case is the life history of the common liver fluke (Fasciola hepatica), one of the flat worms infesting in its adult state the livers of Herbivora. It will be noted in referring to the cycle of this parasite, given in detail elsewhere (page 160), that it is a very hazardous one, and that its completion must depend upon the cooperation of numerous favorable conditions. The eggs, of which each individual fluke is capable of producing in the neighborhood of one hundred thousand, must reach the exterior amid surroundings favorable to their hatching. If hatched, the larva must escape its many aquatic enemies and within a few hours find a suitable snail host. Providing the snail is not eaten by a duck, or does not otherwise perish during this phase of the cycle, it issues from its host as the free-swimming cercaria, when it is again liable to fall prey to various small aquatic animals. Escaping this and becoming encysted, the chance of any herbivorous animal coming along and swallowing it is very small. The relation of the cnormous number of eggs, and the number of individuals which one egg may produce, to the survivai of the species amid conditions fraught with such dangers seems quite evident.

In general it may be said as to the propagation of parasites that their prodigious fecundity and the great vital resistance with which most of them are endowed enables species to survive and perpetuate their kind amid varied destroying influences which otherwise would bring about their extermination. The tapeworms inhabiting the intestines of man and other animals, afford another example of extreme parasitism accompanied by this remarkablc development of the reproductive function. Here is a creature so altered to its degenerate existence that it has become devoid of mouth and intestine, the body consisting of a scolex, usually referred to as the head, from which are give off segments which remain united until there is formed, as in Tania saginata of man, a band-shaped colony of from twelve hundred to thirtcen hundred or more, passing back from the worm's attachment to a length which may 
exceed twenty feet. After about the six hundredth, each segment is a mature and scxually complete individual, which later, as it is pushed on by new segments formed at the head, becomes filled with fecundated eggs. By the successive detachment of these "ripe" segments and their passage from the body of the host, it has becn estimated that Tonia saginata might throw off in a year as many as one hundred and fifty million eggs, of which but an infinitesimal number, as is quite evident, will reach the borly of their proper bovine host for larval development. Again, having bcen so fortunate, it is improbable that the larvæ will, while living, rach the intestines of the human host necessary for their further development into adult worms.

Here, then, is an animal well showing the degree of degeneration which may be reached in extreme parasitism; there are no organs of loeomotion, no organs of special sense, no organs of digestion, no organs of respiration, and none of true circulation. The body consists of a long band of commected segments, each, when mature, bisexually complete and in itself a sort of independent reproductive individual, the entire energy of the organism concentrated upon the function of reproduction that the perpetuation of the species may be insured amid the perils with which this process is beset.

In many forms promanently parasitic there is an early period of development in which organs of locomotion are distinctly present, but, as the mimal matures, these fail to develop or become lost. If it is assumed that this gradual loss of organs, change of structure, and protective transmission of the cmbryo to an intermediate host is clue to the parasitir life, it serms reasonable to conclude that all of the parasitic groups have been freived from free-living forms, and that, as parasitism becamc a nore fixed habit, such structural changes were in the course of time brought about as would make this mode of life obligatory. A review of the observed facts, then, in their biologic relationship, leads to the conclusion that symbiosis, of which parasitism is a form, has its causative basis in the struggle for existence, the symbiotic association in more or less neasure mitigating the hazarks to one or both symbionts. It further follows that, though some forms have undergone an extreme modification, through related contemporary free-living types, their true systematic position may be established. 


\section{Forms of Parasitism}

The student of parasitology will be greatly aided by an orderly and progressive pursuit of the subject, an elementary requisite to which is a broad conception of what is implied by the various terms used in the chapters which are to follow. Those below are not given with the recommendation that they be memorized as to the exact wording set forth in their definitions; more essential is such an understanding that examples can readily be picked out, a typical illustration always being in mind for application to the term at hand. With such a conception the student should be able to formulate his own definitions, and this will be of more advantage to him than accepting those set forth according to the conceptions of another.

Though some of the following terms have been treated of in foregoing introductory remarks, they are here included for more concise definition and to make the list inclusive.

Symbiosis is the more or less permanent living together of two plants, two animals, or an animal and a plant, the union being in a measure beneficial to both, or to one with or without harm to the other.

Symbiont,- one of two organisms partaking of symbiotic relationship.

Mutualism is a form of symbiosis in which both symbionts are in more or less measure benefited by the union.

Commensalism is that form of symbiosis in which but one symbiont is benefited, while its co-symbiont is neither benefited nor harmed by the union.

Helotism is a form of symbiosis in which one organism appears to enslave the other, enforcing it to labor in its behalf. The term is applied to such association in certain insects.

Parasitism is that form of symbiosis in which one symbiont, for purposes of procuring food, or food and shelter, visits briefly, or takes up its abode temporarily or permanently, upon or within the body of its co-symbiont which is harmed by the union. The symbiont receiving the advantage is known as the parasite, to which the one injured is the host.

Phytoparasites are parasites which belong with the regetable lingdom. 
Zoöparasites are parasites which belong with the animal kingdom.

Optional Occasional Parasites are those which only fleetingly visit their hosts to obtain nourishment, but are not dependent upon them for either nourishment or shelter. Example, mosquitoes.

Obligate Occasional Parasites are those which do not permanently live upon their hosts, but are dependent upon them for nourishment and to some extent for shelter. Examples, fleas, bedbugs.

Determinate Transitory Parasites are those in which the parasitism is limited to a definite phase or phases in their life history, during which time the parasitism is obligate and continuous. Examples, botflies, ticks.

Permanent Parasites are those in which the parasitism extends from the hatching of the egg to the stage of reproduction in the adult. Examples, lice, many entozoa.

Fixed Parasites are those which cannot pass spontaneously from one host to another. Examples, larvæ of botflies, Linguatula, helminthes.

Erratic Parasites are those which in their adult state may pass readily from one host to another of the same or different and widely separatel species. Examples, mosquitoes, biting flies, ticks, leeches.

Determinate Erratic Parasites are those which may pass from one host to another of the same species, or a species closely allied to the one ahandonerl. Examples, lice, psoric Acurina.

Monoxenous Parasites are (a) those the eggs of which are expelled by the host, the (mbryos, while still within the eggs, passing to a new host where hatching and development to the adult occurs. Example, Ascaris.

(b) The eggs having been hatehed, the larve are nourished in suitable conditions of moisture and temperature, but camnot undergo further development until they have reached the body of their host. Example, IIemonchus contortus.

Heteroxenous Parasites are (a) those which pass to their definitive host hy an intermerliate or transitory host, in which they cannot attain their complete development; consequently, a reciprocal transmission hetween these hosts is essential to the development and propagation of the paratite. Fxamples, tapeworms, Plasmodium of malaria.

(b) The eggs of the parasite are hatched in the body of the host, the enbryos invading the tissues of the same individual host and not attaining the adult state until they have reached a second host. Example, Trichinella spiralis.

Transmigration is a term applied to the passing of heteroxenous parasites from one host to another.

Incidental or Stray Parasites are those which under natural conditions are occasionally found in unusual hosts. Examples, Gigantorhyn- 
chus hirudinaceus (specific in pig, incidental in man); Fasciola hepatica (specific in Herbivora, incidental in man).

Ectoparasites (Epizoa) are those which are parasitic to the surface of the body, whether burrowing into the integument, living upon it, or only occasional visitors. Examples, scab mites, ticks, and other Acarina, lice, flies. All of the arthropodal parasites with scarcely an exception.

Endoparasites (Entozoa) are parasites which enter the body of their host, inhabiting its alimentary canal, blood, and other tissues. Examples, Linguatula, larvæ of the botflies, and almost all of the helminths.

Helminthes is a term under which are grouped all of the worms generally parasitic, with the exception of a small number in which the body is annulated. The group is not a natural zoölogical one and is used mostly in parasitology.

In terms used to designate parasitic diseases it is customary to apply the name of the genus, or other group name to which the parasite belongs, as the root, to which is added the suffix asis or osis. As for example:

Pediculosis, the condition produced by the presence of lice upon the skin; Acariasis, the condition produced by the presence upon the skin of mites and other Acarina; Filariasis, the condition produced by Filaria. And thus we have Ascariasis from Ascaris, Oxyuriasis from Oxyuris, Strongylosis from Strongylidæ, Trichinosis from Trichinella, Tæniasis from Tæniidæ, Fascioliasis from Fasciola, Helminthiasis from Helminthes, and Trypanosomiasis from Trypanosoma.

In view of the many factors to be considered, the formulation of exact and limiting interpretations of terms bearing upon kinds of parasitism is scarcely possible. It cannot be claimed for the above series, therefore, that it is entirely satisfactory as stated and defined. For our conceptions we must rely upon the behavior of the typical rather than the isolated or synthetic, and be content to regard any grouping based upon modes of parasitism as more convenient than exact. It is difficult to circumscribe parasitism; while we speak of the parasitic mode of life as a form of symbiosis, it may well be questioned whether such insects as mosquitoes and biting flies bear a true symbiotic relationship to their hosts; their fleeting visits certainly do not constitute the living together as usually implied by the term. Again, we may not be able to draw a distinct line between certain predaceous and certain parasitic forms. From the more general viewpoint, however, it may be repeated that all predaceous animals voluntarily, by the exercise of their powers of stealth and cunning, seize upon and aim to destroy their prey at once, feeding upon the body. There are parasites which use a degree of stealth in approaching their victims, as certain parasitic Diptera, though the invasion of the body of its victim by the parasite is more often passive than voluntary. While the parasite may appropriate a share of the 
nutriment of its host or feed upon its host's tissues, it is detrimental to the parasite's welfare to destroy its host. To destroy the body of the animal harboring it would mean the sacrifice of the parasite's means of subsistcnee as rell as in most cases its shelter. When the host animal ches its internal parasites die with it, and, if it were not for the previously occurring transmission of their offspring to new hosts, the species would rapidly perish. Serious disturbance $\mathrm{ol}^{\circ}$ death of the host due to its parasites is usually brought about by their presence in large numbers, in which case there is the operation of numerous pathogenie factors. I fatal termination may follow rapirly, but more often there are afebrite morbid phenonrena l'unning a prolonged course. In no case is the victim at once destroyed and wholly or in part devoured.

The parasite is always smaller and weaker than its host, and in many cases its influence upon the latter is not observable. It may be said in gencral that the degree of injury will depend upon the following principal factors:

\section{INFLUENCE LPON THE HOST}

1. The Number of Parasites Present. - $\mathrm{A}$ tapeworm or one or two ascaricls in the intestines may not produce a noticeable effect upon the host. If these parasites are numerous there may be serious disturbances in the host resulting from the deprivation of nutriment which has been appropriated by the infesting worms, from the toxins which they elaborate, or a more acute offect nay be brought about through obstruction of the bowel by large numbers of the parasites in mass.

2. Their Location.-An encystech larva of the beef or pork tapeworm in its usual location will do no observable harm to its host, but if it should lorlge in the eve or eentral nervous system it might give rise to selious rlisorders. As a rule, intestinal parasites are less harmful than those which invacke the bloor or respiratory tract, while of the external parasites, those which burrow into the integument are more injurious than those living upon the surface.

3. The Nature of their Food.-Any parasite which feeds upon the tisisues of its host is more harmful than one which merely appropriates a share of the katter's ingested nutriment. The blood-sucking worms, when present in considerable numbers, bring about serious depletive listurbances, while such worms as the arbult asearids, no'mishing mainly upon the residue of food materiak, are, in general, less harmful. Sucking lice, armect with piercing mouth parts, are more disturbing to the animal harboring them than the biting lice which feed upon cutaneous débris and the products of their irritation.

4. Their Movements. Serious pathologic conditions may be bought about by the migrations of parasites or their change from a usual to an unusual position. Muscular trichinosis, the collective 
effect of the movement of myriads of embryos of Trichinella spiralis, is a typical instance. An otherwise relatively harmless parasite may work its way into a duct, or, finding lodgment in an unusual organ, set up inflammatory changes and abscess formation. Again, by verminous wandering, fistulous communications may be established between contiguous organs normally possessing no direct connection.

5. Age of Host.- Young animals are predisposed to endoparasitic invasion. To forms which penetrate or are more or less migratory, the more tender tissues of the young offer less resistance than in older animals. Verminous bronchitis is a form of strongylosis observed almost exclusively in animals which are immature. The reduced vitality of old age invites the invasion of both external and internal parasites; there is not only a lessened ability to defend from attack, but reduced activities and secretions of the intestines, skin, and other organs decrease the capability of eliminating either ecto- or entozoa.

Such external parasites as mosquitoes, flies, ticks, and bedbugs are of greatest pathologic importance as disseminators of infectious diseases, acting either as direct carriers or as intermediate or definitive hosts of the infecting organism. Malaria, Texas fever, and forms of trypanosomiasis are among diseases which are known to be spread only by this means, while the possibilities as carriers of typhoid and other malignant infections engendered by the habits of the common house fly are well known.

That Helminthes elaborate materials toxic to their host has been demonstrated in experiments with the isolated poisons. It is obvious that, in cases of heavy infestation especially, this toxic effect must be considerably contributed to by the products of decomposition of dead worms.

Etiology:- So varied are the conditions that surround the propagation and existence of parasites that the consideration of the causes of parasitic diseases is best embodied in chapters devoted to their particular occurrence. However, certain circumstances favoring parasitism may be here briefly considered.

Crowded and unclean housing favors the propagation and spread of parasites of both man and domestic animals. For this reason lice and scab mites find their most favorable season in the winter months, when their transmission from animal to animal is facilitated and the reduced activities of the skin offer less resistance to their invasion. Pediculosis and the scab acariases are seldom seen, however, in stables that are well kept, or among animals where due attention is paid to cleanliness of the skin. The summer, on the other hand, is the season of attack by adult parasitic Diptera, and it is during the months at pasture that ticks most rapidly propagate and crawl upon their hosts.

In helminthiasis the influences of enviromment as an etiologic factor 
are more subordinate to the mode of development of the infecting species. Sheep grazing upon low, marshy land and in the vicinity of ponds are more exposed to infestation with flukes, because there are present conditions essential to the molluscan intermediate host in which the fluke at the stage of the miracidium must find lodgment. Infestation of the pig or the ox with the larve of the tapeworms of man is most likely to occur where untreated human excrement is used as a fertilizer, or where their food may otherwise be directly or indirectly contaminated with such material, while invasion of the human host with the adult worm only occurs after ingestion of the tissues of the larval host. The majority of ova of worms expelled by the host fail to find a new host, or meet with unfavorable conditions and are lost. Some, as those of ascarids, are very resistant and may find their proper host after months of exposure to destructive influences. Migration is facilitated to some extent where hatching takes place with the laying of the egg, as in the strongyles of the respiratory tract and in Trichinella.

While much remains to be determined as to the life histories of many of the intemal parasites, clinical experienec indicates that low and wet pasturage, with access to stagnant collections of water, is a strong etiologic factor in helminthiasis, either as harboring possible aquatic intermediate hosts of the worms, or as a vehicle which, directly or by drainage, spreads infestation by dissenination of their germs. 


\section{CHAPTER III}

\section{PHYLUM I. ARTHROPODA}

While there are advantages in arranging a description of parasites according to their location, as those of the skin, those of the intestines, those of the liver, those of the circulation, etc., the fact that so many in their life histories pass certain stages in different organs and different species of hosts makes such an arrangement somewhat confused. It seems better, therefore, to treat of the natural history of each parasite in the parasite's order, essentially including such anatomical and zoölogical migrations as may be involved, while at the same time considering its pathogenic influences in these varying locations.

Aside from the phytoparasites, which are not included in this work, the parasites infesting man and domestic animals are distributed among four grand divisions or phyla of the animal kingdom, which, in the order of their zoölogical grade, are Protozoa, Platyhelminthes, Coelhelminthes, and Arthropoda. The last named group contains most all of the external parasites and is the first to be considered in the pages to follow.

As a foundation for the scientific control of parasitism and for the recognition of adaptations to its various forms, at least an elementary knowledge of the structure and habits peculiar to the phylum and its subdivisions to which the parasite belongs is of essential importance. Only the more prominent structural features upon which the separation of the different groups and their subgroups is based will be given here. For more detailed study the student is referred to an advanced text-book in zoölogy.

The phylum Arthropoda includes such animals as the crayfish, crabs, lobsters, spiders, centipedes, and insects. The body is provided with a hard or leathery external chitinous skeleton divided into a number of segments demarcated externally by constrictions, each segment in the adult, or a certain number of the segments, bearing jointed appendages (Fig. 1). There are usually two or more body regions distinguished by a special modification of the constituant segments. In order that movements may take place between the segments of both the body proper and of the appendages, the cuticle at these points is thin and delicate (Fig. 9), forming joints which are protected by an overlapping of the heavier chitinous armor.

All arthropods periodically molt, the process consisting of the breaking and casting off of the chitinous cuticle after it has loosened from the 
underlying tissue and a new cuticle has been formed. While the cuticle is at first thin and soft, later it hecomes hard and unyielding, therefore the moltings are necessary for the accommodation of growth and occur periodically as long as this growth continues. Chitin, to which the firmmess of the cuticular exoskeleton is due, is an organic substance in which lime salts may be deposited, as occurs in the Crustacea. The skin is never ciliated, nor do ciliated cells occur in any other organs of the body.

The musculature (Fig. 9) consists of a large number of separate muscles passing from one segment to another and attached at their extremities to the imner sicle of the skin, their contraction bringing about movements of the segments of the boty and appendages one upon the other. They may be attached by so-called tendons, which consist of invaginations of the cuticle surrounded by a corresponding invagination of the epiclermis. The muscle fibers are striated and multinuclear.

The digestive tract (Fig. 2) passes directly, or with little flexion, through the body, the mouth being at the anterior end and usually rentral, the anus posterior. Aecessory organs, as salivary glands and liver, may or may not be present.

Of the circulatory system (Figs. 2 and 3 ) the most constant portion is the heart, which is usually tubular ant located dorsally. On each side of the organ are openings provided with valves through which the blood passes to he propelled forward. From the large arteries the blood may pass directly into blood sinuses, or it may course through capillaries and veins, though the vaseular system is never entirely closed. The blood is usually a colorless fluid with colorless anœboid corpuscles.

In aquatic forms (Crustacea) respiration is by gills, while in the airbreatlers it may be by trachea (Figs. 5 and 6), consisting of tubular ramifications from without to within the body, or by peculiar infolding molifications of the integument functioning as lungs. In some of the lower forms lespiratory organs are entirely alssent, the function in such cases lering cliffused over the cntire body surface.

In various spaces within the bodies of Arthropoda are frequently found fat hodies, a connective tissue the cells of which, richly laden with fat, serve as a store of nourishment. The fact that products of tissue metabolism, sucls as uric acid, have been found in the fat body, leads to the conclusion that it also acts as a place of storage for substances of excretion before their elimination hy the excretory organs, which latter greatly vary in the different groups. In insects and arachnids these organs are represented by the Malpighian tubes, long glandular canals which open into the posterior portion of the digestive tract.

The nervous system consists typically of a ventral chain of ganglia connected by a double longitudinal nerve cord. In well-developed segments the ganglia are large, and a pair of ganglia to each segment might 
be expected, as in the annelid worms. In the Arthropoda, however, there are differences due to fusion of the segments, in which case there is also fusion of their ganglia. Such fusion is usually accompanied by more or less shortening of the body, an example of which is afforded by the spiders and crabs where the whole ventral chain unites in a single ganglionic mass. From the most anterior of the ventral ganglia there spring two nerve cords which pass on either side of the esophagus to unite above it with the paired cerebral ganglion or brain, hying in the head. This ganglion remains distinct, its dorsal position preventing its fusion with ganglia of the ventral chain.

Of the sense organs the most highly developed are the eyes, which are compound (Fig. 6), or appear as simple ocelli. In many arthropods there are both of these forms, while others are provided only with ocelli, and in some arthropods eyes are absent. In the compound eyes the cuticle covering them is divided into hexagonal facets, the number of which varies with different groups from a dozen to two thousand or more, each of these areas corresponding to a small chitinous lens. The compound eyes are two in number, while the number of ocelli varies. The latter are very small and have their highest development in the spiders.

With rare exceptions the sexes are separate, and reproduction is generally by fertilized eggs, though parthenogenesis occurs, in some cases having a certain relationship to the life history. Usually the sexes can be readily distinguished by the difference in size and by various modifications of the appendages.

Of the subgroups of the phylum Arthropoda only those containing parasitic species of medical interest will be considered in this work. These are included in the two classes Insecta and Arachnida, which, with scarcely an exception, contain all of the external parasites. It is not correct, however, to say that the arthropodal parasites are exclusively external, as certain insects and arachnids pass a phase of their development within the bodies of their hosts.

\section{Class I. Insecta}

Arthropoda (p. 13).-In number of species the insects constitute the largest of all animal groups. The body is essentially segmented, and is divided into three regions,--head, thorax, and abdomen, which are distinctly marked off from each other (Fig. 1).

The head is usually freely movable at its junction with the thorax, and typically bears on each side a compound eye (Figs. 1 and 7 ), between which there may be a varying number of simple ocelli.

Arising from the head are a pair of antennie which consist of segments varying in size, shape, and number according to species. 
The mouth parts (Fig. 4) undergo great modification, though all may be referred to a common type. This is well presented in its primitive

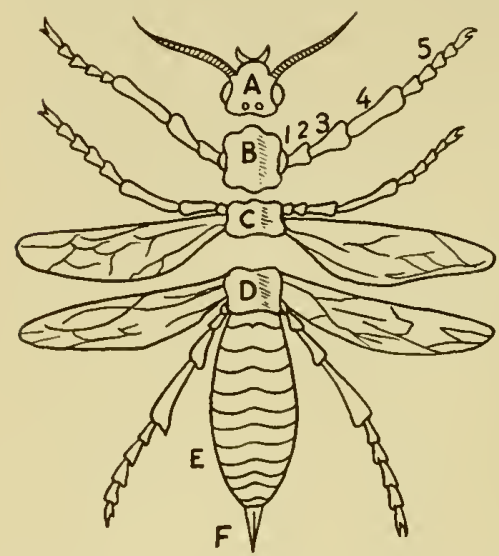

Frg. 1.-Diagram of an Inseet, with Head and Thoracic Segments Disarticulated: a, hcad, bearing compound eyes, simple ocelli, and antenne; b, prothorax; c, mesothorax; d, metathorax; e, abdomen; $f$, ovipositor. The pro-, meso-, and metathorax each bcar a pair of lcgs; the meso-and metathorax each a pair of wings. 1. Coxa; 2 , trochanter; 3 , femur; 4 , tibia; 5 , tarsus, terminating in a claw (after Orton, by Dodge; Copyright, 1894, by Harper \& Brothers). condition by the grasshopper, in which we have the labrum, or upper lip, represented by a broad unpaired plate situated in front of the mouth. Under the labium is a pair of strong jaws, the mandibles, each consisting of a single unsegmented piece with a cutting inner edge, the two having a lateral movement. Following the mandibles is the first pair of maxillæ which are prehensile and gustatory in function. These have a number of joints and bear curved and segmented palpi. The second pair of maxillæ are fused to form a single plate, - the labium, which is accessory in function to the first pair of maxillæ, and, like the latter, bear a pair of segmented palpi. The labium forms the posterior and the labrum the anterior boundary of the mouth.

The thorax (Fig. 1) has three segments, an anterior,- - the prothorax, a middle,- the mesothorax,

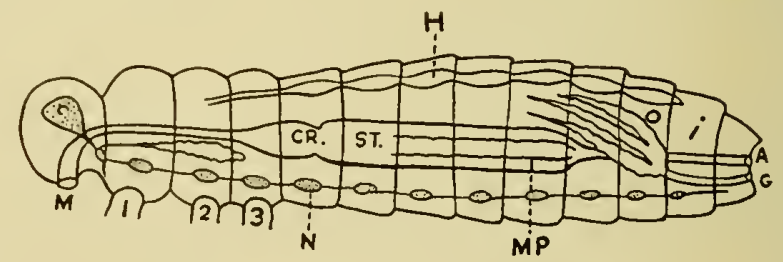

FIG. 2.-Diagram of the Principal Internal Anatomical Parts of an Insect: $m$, mouth; $c r$, crop; st, stomach; $i$, lower portion of intestine; $a$, anus; $h$, heart; $s$, salivary glands; $c$, cerebral ganglion; $n$, ventral ganglion; Mp, Malpighian tubules; $\mathrm{o}$, ovaries; $g$, genital aperature (after Boas, by Kirkaldy \& Pollard).

and a posterior,- the metathorax. The last two of these are usually somewhat fused. 


\section{ARTHROPODA}

There are three pairs of legs, each thoracic segment bearing one pair (Fig. 1). The leg is divided into five articulated parts,--coxa, trochanter, femur, tibia, and tarsus. The attachment to the body is by the short coxa, to which is joined the trochanter which is also short. Following the trochanter are two long segments,- the femur and tibia, the former considerably thicker than the latter and containing the muscles. The tarsus, or foot, follows the tibia, and consists of a number of short segments, the last bearing

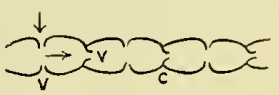

FIG. 3.-Diagram of Insect's Heart: c, constriction between two chambers; $v$, valves (after Boas, by Kirkhook-like structures, or claws.

Usually there are two pairs of wings arising dorsally from the meso-

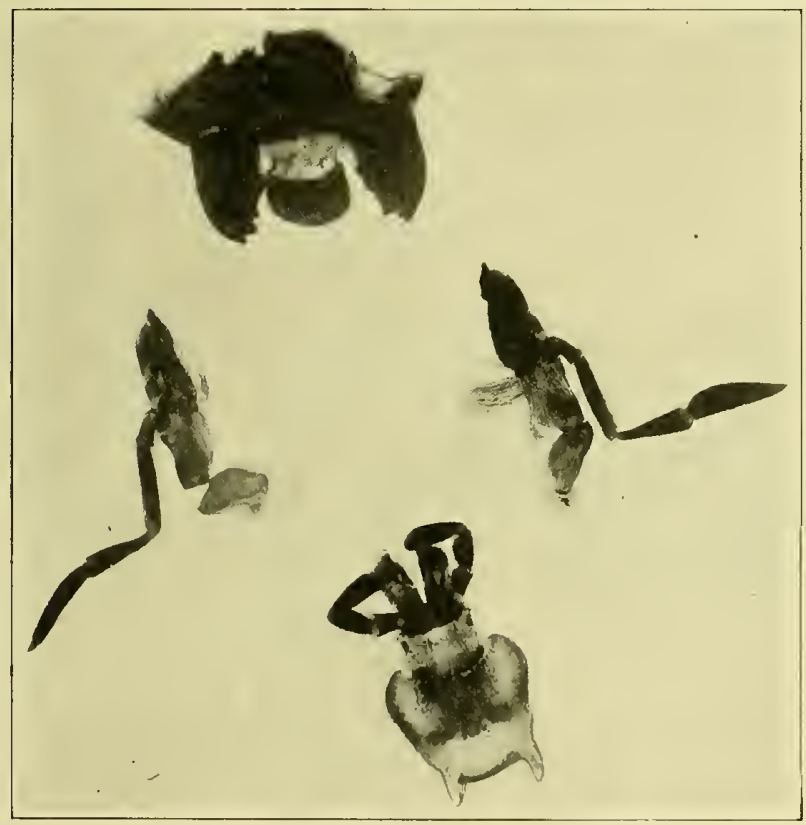

FIG. 4.-Mouth-parts of Locust, a biting insect: Labrum, or upper-lip, above, on each side of which are the mandibles, or upper pair of jaws. Labium, or under lip, with labial palpi below. Maxille, or lower pair of jaws, with maxillary palpi, to right and left (from photomicrograph of mounted spccimen, by Hoedt).

and metathorax (Fig. 1). They consist, when fully dereloped, of two closely apposed chitinous outgrowths, between which are extensions of 
the blood sinuses and trachex. Sometimes the anterior, sometimes the posterior pair is the larger, and both may be flexible and adapted for flight. In some insects (beetles) the anterior pair is modified to form

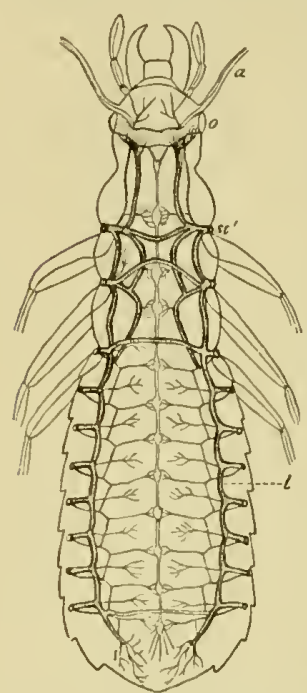

Fici. 5.-Diagram showing the chice trunks of the tracheal syistem of an insect (after Boas, by Kirkaldy of Pollari). wing-shields, or elytra, which are hard, but slightly flexible, structures serving to cover and protect the posterior wings during rest. some insects possess but one pair of wings (dipterous), while in ot hers wings are entirely absent (apterous).

The ablomen is segmented, the number of segments varying with different groups. Each segment consists of two cuticular plates (Fig. 6), the dorsal tergite and the ventral sternite, which are united laterally by a softer membrane, the pleurite. There are no abdominal limbs or limb-like appendages.

Respiration is by trachea (Fig. 5), a system of tubes containing air. These communicate with the outside by

the spiracles (Fig. (i), small symmetrically disposerl openings located laterally, one pair on the meso- and one pair on the metathorax and a pail on each of the abdominal segments

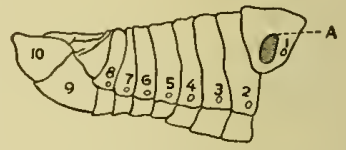

FIG . 6.-Abdomen of Locust, s howing Spiracles 1, 2, 3 , $4,5,6,7$ and $S$, one on each side of each of the abdominal segments: $A$, auditory sac (drawn iı part from Packard's Zoölogy).

exeept the most posterior. Just insicle of the spiracles the trachese are usually united ly longitudinal trunks from which are given off fine branches which ramify and anastomose within the body. Respiration is effected by abdominal movements of contraction and expansion.

Insects are mostly oviparous. In some the developed embryo is released from the egg while still within the borly of the parent, or this may oceur just as the egg is extruded. There are also pupiparous forms where the young pass from the borly of the female ready to enter the pupal stage in their development.

In order that the newly hatched larvæ may be supplied with nourishment, the eggs are generally deposited where suitable food is present. In many insects oviposition occurs by means of an ovipositor, a tubelike organ which is developed from the posterior abdominal segments and which may project free from the body or may be retracted into it. In the Hymenoptera the ovipositor may be modified to serve as a sting, 
a weapon of defense provided with poison glands. From its nature the sting is essentially only possessed by the females.

Some insects on leaving the egg develop directly to the adult stage, the larva in most cases differing from the adult principally in the absence of wings. In such cases there is a slight change of form with successive molts, the wings being ultimately acquired. Here the metamorphic process is not thorough, and is therefore referred to as incomplete metamorphosis. The majority of insects when hatched from the egg bear no resemblance to the adult, and there is no observable gradual approach to this form. The larva is characteristically worm-like and an active and voracious feeder, a number of molts occurring with the increase in size during this stage. There then intervenes between the larval and adult stages a period of pupation, during which the animal is quies-

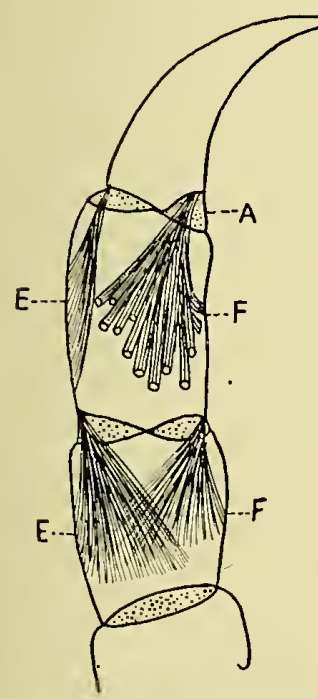

FIG. 9.-Diagram of terminal segments of arthropod leg, with muscles. a, articulation; f, flexors; c, extensors (after Boas, by Kirkaldy of Pollard).

cent and a series of changes occur in the body. At the

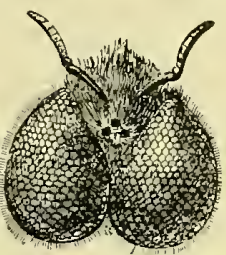

Fig. 7.-Head of the bee, showing compound eyes, the three ocelli, and the antennæ. - Magnified (after Orton, by Dodge; Copyright, 1894, by Harper \& Brothers). conclusion of these changes the pupal case splits and the imago emerges, which, with the unfolding of the appendages and hardening of the cuticle, has in all essentials developed into the complete sexual adult. In this form of development the changes are distinct, and the process is referred to as complete metamorphosis (Fig. 8).

The duration of life in insects, including the stages of the egg, larva, pupa, and adult, usually does not extend beyond a year. With quite a number it is much shorter than this, while with others it may be a matter of several years, an extreme example of larval longevity being

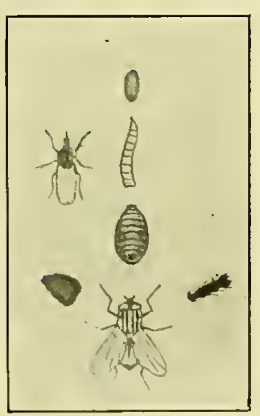

Fig. 8. - Metamorphosis of the House Fly, showing oval, larval, pupal, and adult stages. On the right is an enlargement of the foot; on the left, the foot pad, showing sticky, glandular hairs; on upper left, a tsetse fly (from photograph of drawing by author). 
afforded by the seventeen-year cicada. Most of the insect life is occupied by the larval stage, during which the greatest growth takes place. With a few exceptions, as honey bees and ants, the period of the adult is short, in some cases a few days or even hours. The life of the adult is devoted to the activities concemed in reproduction, and the insect usually dies when this is accomplished.

Of the class Insecta the five following orders contain parasites of medical importance:

Order I. Diptera-Flies, gnats, and mosquitoes.

Order II. Siphonaptera-Fleas.

Order III. Siphunculata-Sucking lice.

Order IV. Mallophaga-Biting lice.

Order V. Hemiptera-Bedbugs and allies.

\section{Classification of Parasites of the Class Insecta}

Phylum I. Arthropoda. P. 13.

Class A. Insecta. P. 15.

Order 1. Diptera. P. 23.

Fanily (a) Culicidx. Mosquitoes. P. 24.

Genus and species:

Culcx pungens. Pp. 25, 26.

Anopheles quadrimaculatus. P. 26.

A. punctipennis. P. 28 .

Ades calopus. P. 29.

Family (b) Simuliida. Buffalo gnats. P. 31.

Genus and Species:

Simulium peeuarum. Animals attacked, cquines and cattle. P. 32.

Fanily (c) Tabanille. Horseflics, gadflies. Animals attacked, equines, cattle. P. 35 .

Geuus and Species:

Tabanus atratus. P. 35.

T. lineola. P. 36 .

Family (d) Muscidie. House fly and allies. P. 37.

Genus and Specics:

Musca domestica. Injurious to man and domestic animals by irritation and eontamination. P. 37.

Stomoxys calcitrans. Animals attacked, equines and cattle. P. 39.

Lyperosia irritans. Animals attacked, cattle. P. 41.

Glossina palpalis. Animals attacked, man, and domestic and wild animals. P. 44.

G. morsitans. Animals attacked, same. P. 44.

C. longipalpis. Animals attacked, same. P. 44. 
Chrysomyia macellaria. Larvæ attack flesh and mucous surfaces of man and lower animals. P. 50.

Sarcophaga sarraceniæ. Larvæ attack fresh meat and wounds of animals. P. 52.

Calliphora vomitoria. Larvæ attack_fresh and decomposing meat and wounds. P. 52.

Family (e) Hippoboscidæ. P. 47.

Genus and Species:

Melophagus ovinus. Host, sheep. P. 47.

Family (f) CEstridæ. Botflies. P. 53.

Genus and Species:

Gastrophilus intestinalis. Host, equines. P. 53.

G. hemorrhoidalis. Host, equines. P. 57.

G. nasalis. Host, equines. P. 57.

Hypoderma lineata. Host, cattlc. P. 57.

H. bovis. Host, cattle. P. 58 .

Estrus ovis. Host, sheep. P. 62.

Order 2. Siphonaptera. P. 65.

Family (a) Pulicidæ. Fleas. P. 65.

Genus and Species:

Ctenocephalus canis. Host, dog. P. 65.

C. felis. Host, cat. P. 65.

Pulex irritans. Host, man. P. 65.

Order 3. Siphunculata. Sucking lice. P. 70.

Family (a) Pediculidæ. P. 70.

Genus and Species:

Hæmatopinus asini. Host, equines. P. 73.

H. eurysternus. Host, cattle. P. 74.

Linognathus vituli. Host, cattle. P. 74.

L. pedalis. Host, sheep. P. 76 .

L. stenopsis. Host, goat. P. 77.

Hæmatopinus suis. Host, hog. P. 77.

Linognathus piliferus. Host, dog. P. 78 .

Pediculus humanus. Host, man. P. 79.

P. eorporis. Host, man. P. 79.

Phthirius pubis. Host, man. P. 79.

Order 4. Mallophaga. Biting lice. P. 71.

Family (a) Philopteridæ. P. 71.

Genus and Species:

Trichodectes equi. Host, equines. P. 73.

T. pilosus. Host, equines. P. 73.

T. scalaris. Host, eattle. P. 75 .

T. sphærocephalus. Host, sheep. P. 76 .

T. climax. Host, goat. P. 77 . 
T. latus. Host, dog. P. TS.

T. subrostratus, Host, cat. P. 79.

Goniocotes gallinæ. Host, chicken. P. 82.

G. gigas. Host, chicken. P. 82.

Lipeurus caponis. Host, chicken. P. 83.

L. heterographus. Host, chicken. P. S3.

Goniodes stylifer. Host, turkey. P. 84 .

Lipeurus melcagridis. Host, turkey. P. 84 .

Philoptrus icterodes. Hosts, ducks and geese. P. 84.

Lipeurus anatis. Hosts, ducks and geese. P. 84.

Philoptcrus eygni. Host, swan. P. 86.

Ornithonomus eygni. Host, swan. P. 86.

Goniocotes compar. Host, pigeon. P. 86.

Coniodes damiconis. Host, pigeon. P. 86.

Lipeurus columbæ. Host, pigeon. P. 86.

Family (b) Liotheidæe. P. 71.

Genus and Species:

Menopum trigonocephalum. Host, chicken. P. 83.

11. biscriatum. Host, turkey. P. 83.

Trinotum luridum. Hosts, ducks and geese. P. 84.

T. lituratum. Hosts, ducks and geese. P. 86.

Order 5. Hemiptera. P. 89.

Family (a) Cimicidae. P. 90.

Genus and species:

Cimes lectularius. Hosts, man, poultry, etc. P. 90. 


\section{CHAPTER IN}

\section{MOSQUITOES AND GNATS}

Order I. Diptera.-Insecta (p. 15). The dipterous insects have only the anterior pair of wings developed, the posterior pair being represented by rudimentary structures called halteres, or balancers, which are supposed to function as organs of balance. In some parasitic forms (sheep "tick," bat fly) wings are entirely wanting.

The head, thorax, and abdomen are sharply defined. The mouth parts are adapted for sucking, the haustellum, or sucking tube, being formed by the labium and labrum, within which lie the mandibles and maxillæ, which may be modified into blade-like structures for piercing. With this structure the insect sucks the juices of plants or penetrates the skin of animals and feeds upon their blood. In the flies the antennæ are short, consisting of but three well-developed joints. The three thoracic segments are frequently fused, and the tarsi have five segments.

Metamorphosis is complete. The larva are apodal grubs, maggots, or wrigglers, the latter aquatic (mosquitoes).

Parasitism.-The dipterous group of insects includes a number of species varying in their grade of parasitism from optional occasional to obligate occasional and permanent. They are chiefly of importance from the medical viewpoint as carriers of bacterial and animal parasitic infection, investigations within recent years well establishing the fact that certain serious and often fatal diseases of man and domestic animals are spread by these insects either as essential hosts or as direct carriers of the infecting organism. As essential hosts a part of the development of the pathogenic organism must essentially be undergone in the insect. As direct carrier's they may inoculate directly into the blood with contaminated piercing or biting mouth parts, or they may simply transport disease germs upon their bodies and appendages, contaminating wounds, food, or any object upon which they may alight.

As blood-sucking pests and sources of torment in the habitations of man and in the fields and stables of his live stock, many of these twowinged insects are of very considerable economic as well as pathologic importance. In view of all that at the present time can be charged up against them, they are well worthy of the increasing attention they are receiving with a view to their more effectual control.

Of the families of the order Diptera containing parasitic species, six are here considered, as follows: 
Family I. Culicida-Mosquitoes.

Family II. Simuliidæ-Buffalo gnats.

Family III. Tabanidæ-IIorseflies.

Family IV. Muscidæ-House fly and allies.

Family I. Hippoboseida-Sheep "tick."

Family VI. Estridx-Botflies.

\section{Family I. Culicide; Mosquitoes}

Diptera (p. 23).-The mosquitoes are slender-bodied Diptera with narow wings which have a distinctive fringe of scale-like hair upon their margins, and in most cases also on each of the wing veins. In the female the proboscis is long, slender, and adapted for piercing. The
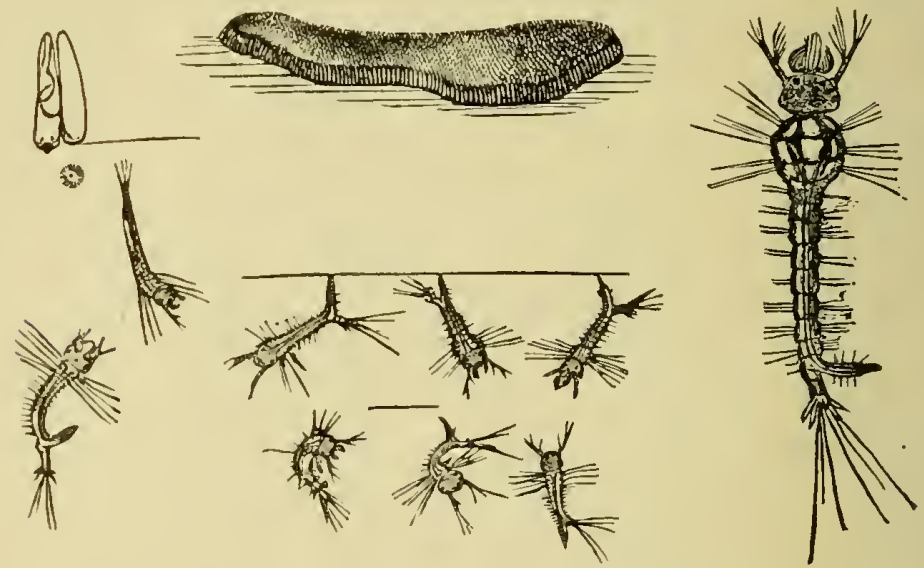

Fig. 10.-Egg-mass of Culex pungens, above; young larva, greatly enlarged, at right; young larve, less enlarged, below; enlarged eggs above at left (after Howard, Bul. No. 4, Bureau of Entomology, Dept. of Agr.).

males rlo not suck bloor, differing from the females in the absence of the piercing stylets and in the possession of plumose antennæ.

Mosquitoes have an adaptation to a very wicle range, flourishing equally as well in the frigid regions of the Alctic and Antalctic as in the humid heat of the tropics. Until comparatively recent years few species were known, but more intensive study, in view of their importance as carriers of disease and as pests of man, has brought the mosquito fauna of the world up to about one hundred genera including seven hundred species, of which there are about fifty known in the United States.

Breeding Habits.-In the larval stage all the known mosquitoes are aquatic, but such differences occur in their life histories and habits 
that no one species will serve as typical of the group. In observations conducted by L. O. Howard at Washington, D. C. (1900 Rept.), upon the species Culex pungens it was determined that the eggs were laid upon the water surface in masses of a variety of shapes, often described as boat-shaped because a common form is that of a pointed ellipse (Fig. 10). The number of eggs in each mass varied from two hundred to four hundred, all arranged perpendicularly and in longitudinal rows. The individual eggs are slender, somewhat pointed at the tip, and at the bottom broader and blunt, having a length of $0.7 \mathrm{~mm}$. and a diameter of $0.16 \mathrm{~mm}$. at the base.

It has been demonstrated that under the advantageous conditions of the warm summer months eggs may hatch in less than a day from the time they are deposited. The larvæ, issuing from the under side of the egg mass, are elongate, with head, thorax and abdomen distinct, the head bearing prominent antennæ each consisting of a single segment. About the mouth is a mass of prehensile filaments. The abdomen is segmented, and respiration is by tracheæ which open at the apex by means of the anal siphon. They appear to undergo four molts, and, under favorable conditions, may be transformed into pupæ in about seven days. Studied at a period when the larva is nearly full grown, it is seen to remain near the surface of the water with its respiratory tube at the exact surface and its mouth below receiving food which is directed to it by the rotary movements of the mouth filaments. Occasionly the larva descends below the surface, but, by a series of wrigglings, quickly returns. The return is only accomplished by considerable exertion, as, once below the surface, the tendency of the larva is to sink rather than to rise. If, therefore, for any reason it is unable to sufficiently exert itself to again reach the surface, it will perish. The efficacy of the film of oil spread upon the water may be thus explained; it not only prevents access to the air, but, by its deleterious effect, renders the larva unable to exert sufficient muscular force to recover the position necessary for respiration and buoyancy.

The transformation to the pupal stage, occurring under favorable conditions about the seventh day, is marked by a great enlargement of the thoracic segments (Fig. 11). Here the reverse of the just described physical phenomena obtains; the pupa is lighter than water, and, unlike the larva, effort is required to sink rather than to rise. It remains motionless at the surface, when disturbed descending to the bottom by violent wrigglings. As soon as these exertions cease it will again gradually rise. The differential structure of the pupa is noticeable in the inlargement of the thorax, and in that the air tubes no longer open at the abdominal apex, but through two ear-like processes on the thorax, the pupa remaining upright at the water's surface instead of head downward as in the larval stage. Since the adult insect emerges from its 
pupal case at the thorax, there is an apparent adaptability in this reversal of position.

The common house ol" "rain barrel" mosquito of the Northern T'nited States, Culex pungens (Fig. 12), breeds throughout the summer, broods developing wherever there may be standing water, as in pools, troughs, cans, discarded bottles, gutters, etc. The adults of this species may pass the winter in the shelter of darkened retreats, such as the ('ellars of houses, behind furniture, outbuildings, and wood piles, (merging from their hibernation in the spring to deposit their eggs. Many first spring broods in temperate climates hatch from eggs that have heen carried over the winter months, the eggs seeming to stand desiecation in dry locations to promptly hateh in pools left by the spring
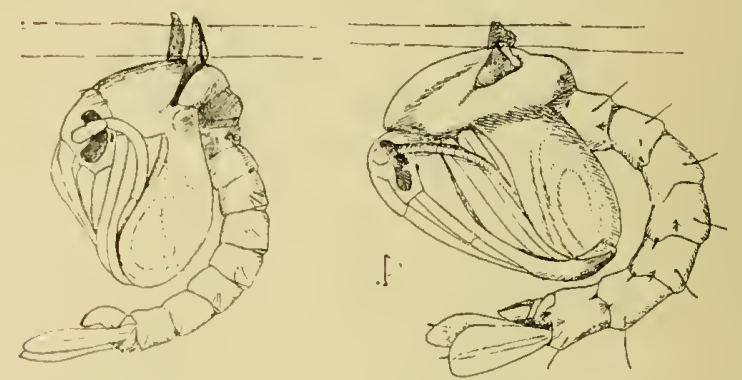

Fia. 11-Pupa of Culex pungens at left; pupa of Anopheles quadrimaculatus at right-greatly enlarged (after Howard, Bul. No. 25, Buresul of Entomology; Dept of Agr.).

rains, or even in water from melting snow during the warmer days of late winter.

In refutation of the assertion often made that mosquitoes cannot ovulate without a meal of warm blood, it has been demonstrated in experiments upon some of our common bloor-sucking species that females as woll as males can not only be kept alive for a long period when given access only to plants, but will, under such conditions, repeatedly breed.

Pathologic Importance.-While their preference for blood has made them of primary general interest as pests in the habitations of man, mosquitoes are of the greatest importance medically, not only as possible direct transmitters of disease, but as specific bearers of infection, bringing about such rliseases as malaria, yellow fever, and possibly filariasis. There have been many convincing demonstrations that malaria is transmitted exclusively by the bite of mosquitoes, only, however, by species belonging with the anopheles group, of which Anopheles quadri- 


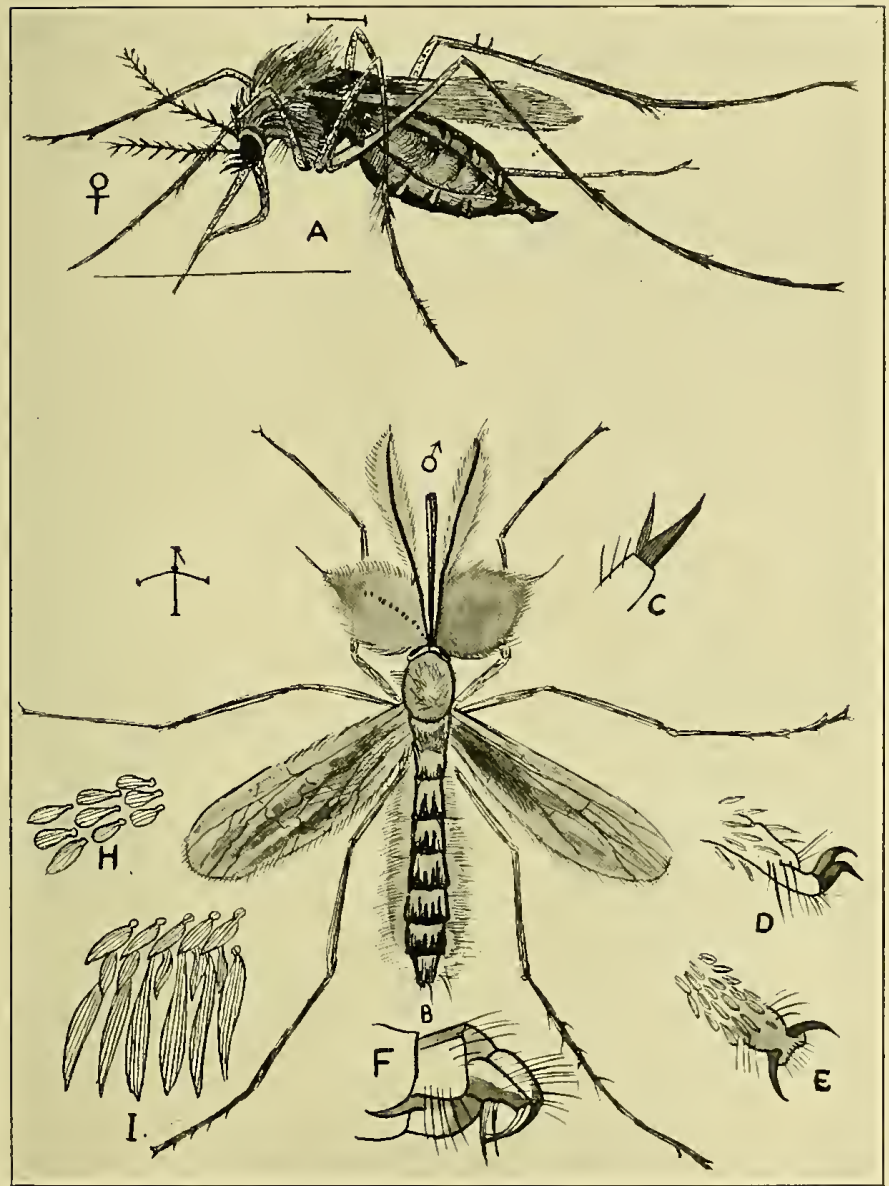

Fig. 12.-Culex pungens: a, female, from side; b, male, from above; c, front tarsus of same; d, middle tarsus; $e$, hind tarsus; f, genitalia of same, $i$, scales from hind border of wing: h, scales from disk of wing-enlarged (after Howard. Bull. No. 4, Bureau of Entomology, Dept. of Agr.). 
maculatus (Fig. 13) and A. punctipennis have been most often observed in the United States. While elaborate keys and tables are necessary even to the entomologist for more exact differentiation, it is not a difficult matter to decide whether a mosquito is or is not a transmitter of malaria,

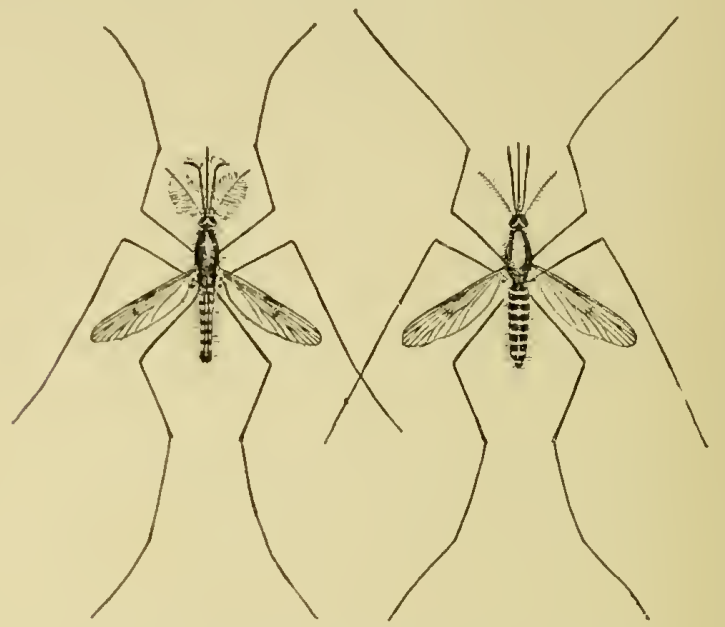

FIG. 13.-Anopheles quadrimaculatus: Adult: male at left, female at right-enlarged (after Howard, Bul. No. 25, Bureau of Entomology, Dept. of Agr.).

the two genera Culex and Anopheles being readily distinguished by the following more prominent characteristics:

The adult Culex, when at rest upon a wall, usualiy holds the body

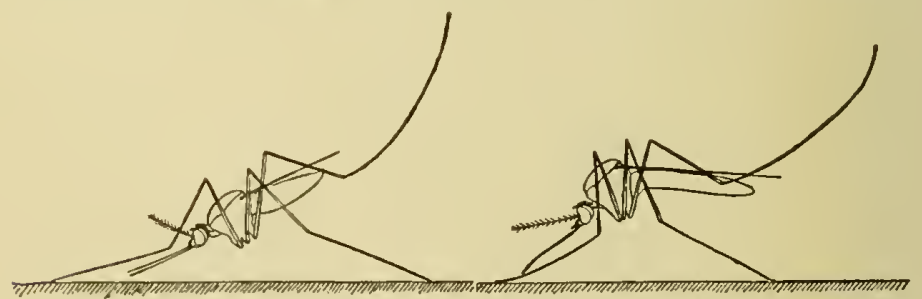

Fig. 14.- Anopheles at left, Culex at right-enlarged (after Howard, Bul. No. 25, Bureau of Entomology, Dept. of Agr.).

parallel with the wall, or with the abdomen slightly inclined toward it, the angle formed by the abdomen with the head and thorax giving a 
hunchback appearance. The proboscis projects forward but not sufficiently so as to be on a line with the axis of the body (Fig. 14). The palpi in the female are short, in the male usually long. The wings, as a rule, are without spots.

Adults of the anopheles group when thus at rest hold the body at an angle of about forty-five degrees with the wall's surface, the abdomen directed outward (Fig. 14). The proboscis projects forward on a line with the axis of the body. In both sexes the palpi are about as long as the proboscis. The wings are usually spotted.

The larva of Culex, when at the surface of the water, rests in an oblique or vertical position with the respiratory tube at the exact surface (Fig. 15).

The resting larva of Anopheles floats in a horizontal position just beneath the surface. There is no respiratory tube, the spiracles opening on the eighth abdominal segment which is applied to the surface (Fig. 15).

Eggs of Culex are deposited upon water in masses, the rafts of eggs often being more or less
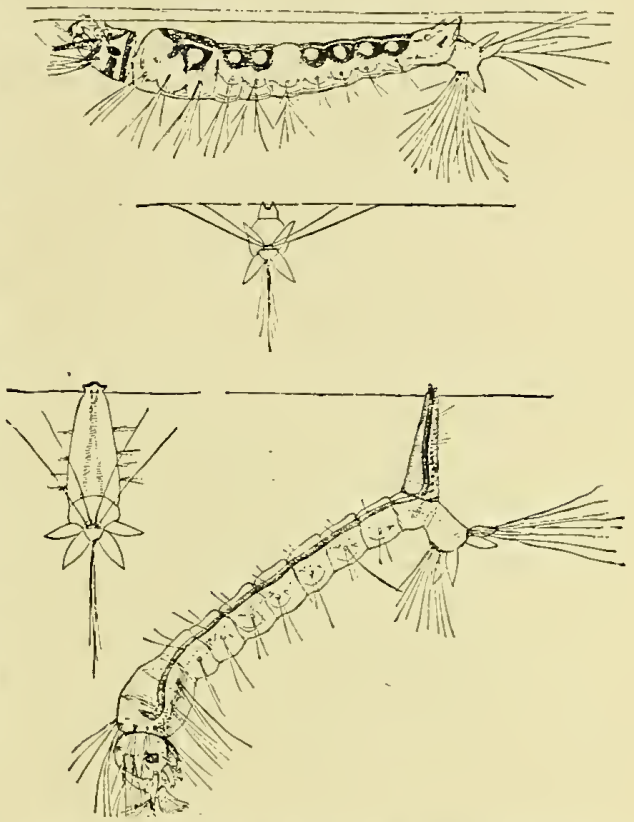

Fig. 15.-At top, half grown larra of Anopheles in breathing position, just beneath the surface film. At bottom, half grown larva of Culex in breathing position - greatly enlarged (after Howard, Bul. No. 25, Bureau of Entomology, Dept. of Agr.). boat-shaped (Fig. 10).

Anopheles lay their eggs upon water unmassed, the eggs floating singly by lateral expansions (Fig. 16).

The mosquito breeding in our Southern States which carries yellow fever from man to man, Edes calopus (Stegomya calopus, S. fasciata), is rather peculiarly marked. Upon each side of the thorax is a broad, silvery, curved line, between which there are two parallel median lines and a slender discontinuous line, the whole pattern presenting somewhat 
the shape of a lyre. At the base of each abdominal segment is a narrow, silvery hand, while on each side there is a silvery spot. At the base of each segment of the black legs there is a distinct whitc band.

Highly domestic, this species will breed in collections of water about and within the habitations of man, the larvæ often being found in small household water recptacles, such as flower pots, vases, etc. Of its habits acquired by long association with man, Howard thus speaks: "It approaches stealthily from behind, retreating upon the slightest alarm.
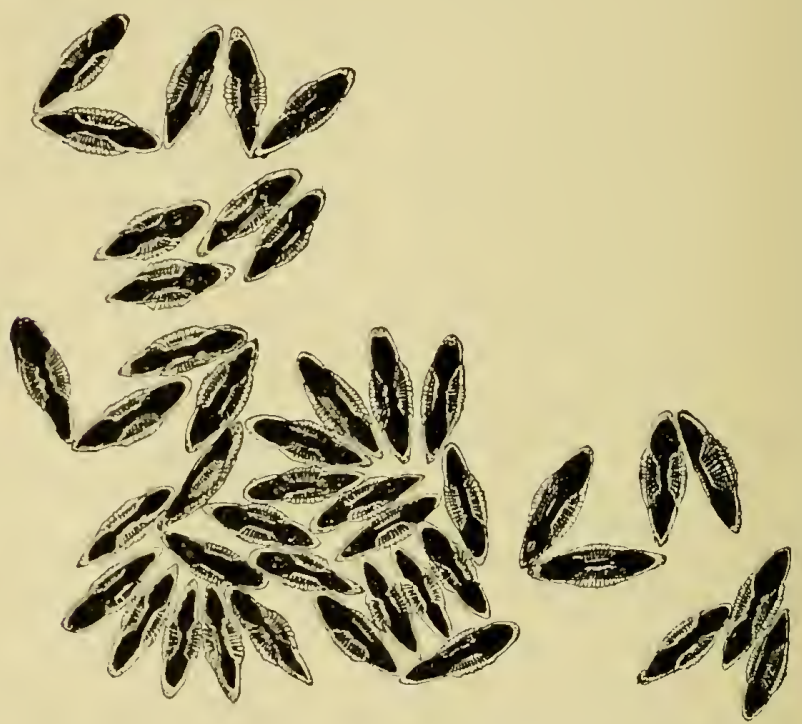

Fici. 16.-Cimoup of eges of Anopheles cuadrimatculatus as they appear resting naturally on the surface of the water-cnlarged (after Howard, Bul. No. 25, Burcsu of Entomolopy, Dept of Agr.).

The ankles and, when one is sitting at a table or desk, the under side of the hands and wrists ale favorable points of attack. It at tacks silently, whereas of her mosquitoes have a piping or humming note. The warning sound has doubtless been suppressed in the evolutionary process of its arlaptation to man. It is extremely wary. It hicles whenever it can, concealing itself in garments, working into the pockets and under the lapels of coats, and crawling up under the clothes to bite the legs. In houses it will hirle in dark comers, under picture moldings and behind the hearls of old-fashioned hedstearls. It will enter closets and hide in the folrls of gamments." 
Effect upon Live Stock.-That mosquitoes are a source of much annoyance and actual suffering to live stock can be attested to by stockmen. Horses and eattle pasturing upon low lands and amid vegetation where the insects abound are especially exposed to attack, the pests often hovering about them in clouds, while upon the bodies of the animals large numbers may he seen with abdomens engorged with the blood of their victims. Loss of condition and the falling off of productiveness in dairy herds must essentially follow this interference with their pasturage and comfort.

Control.-The most effectual preventive measures dealing with mosquitoes are those directed against the larvæ. The abolition of breeding places being of first importance, all receptacles for standing water, such as rain barrels, cans, vaults, gutters, etc., should be removed, covered, or otherwise made impossible to access and propagation of mosquitoes. Pools should be drained, or, if this is not feasible, may be treated with kerosene; or small fish, which feed upon the larvæ, may be introduced into the mosquito-breeding ponds. The quickest and most satisfactory way to destroy larvæ and pupæ is by the formation of the kerosene film upon the water's surface. The oil is best applied for this purpose as a spray, or, if but a small area is to be treated, it may be thrown upon the surface and the water then vigorously stirred. About one ounce of kerosene to fifteen square feet of water surface will be sufficient, and this application should be repeated at intervals of about three weeks.

Such measures are directed only against local species, and, essentially, there must be community action for it to be effective. Migratory forms, such as are bred in the marshes near our coasts, cannot thus be reached, their eradication constituting a problem demanding state control.

For indoor protection in mosquito-infested districts, screening is of course essential. In spite of the most thorough screening, however, mosquitoes will enter in various ways, as through opening doors and upon the clothing of persons passing in. As remedies against those which have gained access to houses various kinds of repellents are used. Burning pyrethrum powder will often rid a room of mosquitoes, a convenient method being to sprinkle the powder upon a heated shovel; or small cones may be molded from the dampened powder and, after drying, burned. Oil of pennyroyal or citronella applied to handkerchiefs or lightly touched to the hands and face, though objectionable to some, will usually insure a peaceful night against the pests.

\section{Family II. Simulidde}

Diptera (p. 23). The flies of this family are known as black flies, black gnats, or buffalo gnats, the latter name derived from their peculiar humpback appearance. They are dark colored, with short thick body. 
short eleven-segmented antennæ, no simgle eyes, broad wings, and stout legs. Only the females are provided with piereing mouth parts.

The larvæ, so far as known, are aquatic. The eggs are deposited in a compact layer upon some object, usually rock, near the surface of a flowing stream. Upon hatching the larva drop into the stream and live attached to sticks, stones, or other objects under the surface of swiftly running water. They may detaclr themselves and move about in a looping mamer similar to that of the measuring worm, or they may be carried by the current for considerable distances. Respiration is carried on ly gill-like processes.

\section{Simulium Pecuarum}

The Southern Buffalo Gnat (Fig. 17). Simuliidæ (p. 31). The adult female is nearly a quarter of an inch in length, the male somewhat

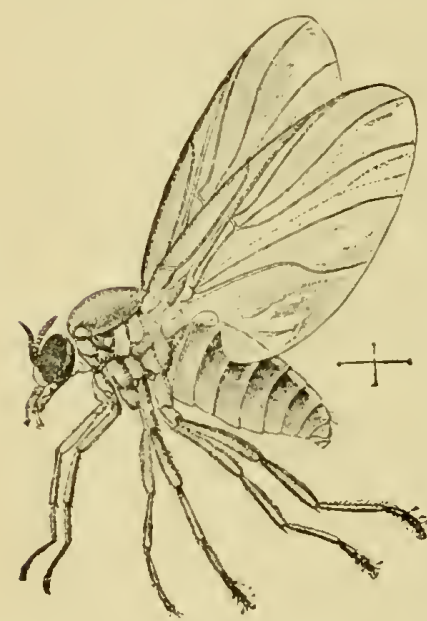

FIG. 17.-Simulium pecuarum, female -enlarged (after Osborn, Bul. No. 5, Bureau of Entomology, Dept. of Agr.). smaller. The color of the body is black, and it is covered with light brown hairs which are arranged upon the thorax in such a manner as to give a longitudiual striped appearance, the abdomen showing upon its dorsal side a broad grayish stripe widening out toward the abdominal apex. The male notably differs from the female in that the eyes are much larger and join each other in the middle line. The individual facets on the upper part of the eye are considerably larger than those of the female.

The larva (Fig. 18) agrees in general appearance with that of other species of Simulium. It is about three-eighths of an inch in length, twelve-segmented, somewhat constricted in the midclle, enlarging toward both ends. The posterior end is the larger and is somewhat clubshaped. In addition to the mouth, the head possesses two fan-shaped bodies which are prehensile in function. On the top of the last abdominal segment there are rows of hooklets, while in the vicinity of the rectum are organs of respiration consisting of three tentacles to which the large trachere lead.

The pupa (Fig. 19) has a peculiar tuft of respiratory filaments starting from each side of the thorax. The upper portion of the pupal case is open, exposing the hearl and permitting the respiratory filaments to 
have free access to the water. The pupa is firmly attached to sticks, leaves, or other submerged objects. On emerging from the pupal case the fly at once rises to the surface and, expanding its wings as it runs upon the water for a short distance, flies swiftly away.

Occurrence and Effect.-The buffalo gnat has been found in Alaska and throughout the Eastern United States, but appears in greatest numbers in the South, especially about the mouths of rivers and ereeks. During the worst years the whole of the Lower Mississippi Valley as far north as St. Louis may be invaded.

The attacks by swarms of this bloodthirsty and viciously active insect upon southern live stock is a source of serious injury and loss. Cattle and horses will manifest the presence of the swarms by frantie efforts to defend against the attack, cattle rushing wildly about and horses and mules trying to escape by running away. The most destructive raids of the fly usually occur in the months of March and April. They are exceedingly

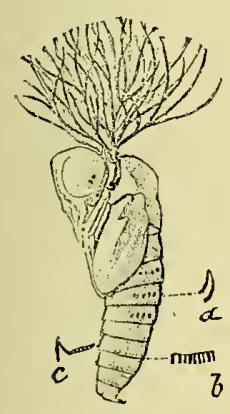

FIG. 19.-Simulium pecuarum, pupa-enlarged (after Osborn, Bul. No. 5, Bureau of Entomology, Dept. of Agr.). swift in their flight, darting at their victims in search of a suitable place to draw blood, and in their bite instilling a poison. Many animals die from exhaustion, combined with the toxic effects of the poison from the bites. Bronchitis and pneumonia, resulting from the inhalation of large numbers of the insects from which the exhausted animal becomes totally unable to defend itself, may also contribute to the conditions leading to its miserable death.

Control.- Outbreaks in heavily infested districts may be lessened in frequency and severity by the elearing out of logs and other débris in the beds of streams, thus reducing the number of objects for attachment of the larvæ. Unlike those of the mosquito, the larvæ of Simulium thrive best in swiftly running and well aërated water, therefore the removal of any submerged object causing shallow and swiftly moving water reduces the possibilities for breeding at this point.

Protection.-The black gnat dislikes smoke, therefore, as prevention against its attacks in fields and barnyards, the maintenance of smudges is of value. Other repellents, such as fish oil, oil of tar, or other oleaginous and resinous substances, either singly or in combination, are applied to the surface of the body, affording a measure of protection 
from attacking swarms. The most effectual protective measure is the sheltering of animals in a cool dark stable during the hours of the day when the swarms are most active.

Treatment.-Animals weakened by the bites may be given a diffusive stimulant and have the parts locally treated with a solution of bicarbonate of sorla or ammonia water. 


\section{CHAPTER V}

\section{THE FLIES}

Family III. Tabanidæ.-Diptera (p. 23). This family includes the so-called horseflies or gadflies. The head and eyes are large, the latter often of a brilliant color. The third segment of the antennæ has four to eight rings. The proboscis of the female is adapted for piercing the skin of animals. The males do not attack animals; their mouth parts are less powerful than those of the females and are adapted for feeding upon the juices of plants. The body has fine hairs; there are no bristles. The flight is strong and swift and is accompanied with a tormenting buzzing noise.

The eggs of Tabanidæ are deposited in masses upon vegetation growing in wet marshy ground. The larvæ are carnivorous and are aquatic or live in moist earth.

\section{Tabanus Atratus}

Tabanidæ (p. 35). This is the common large black horsefly, having a wide distribution in the United States. It is one of the larger species of the family, measuring an inch or more in length and having a body so uniformily black as to attract attention even when it is upon the wing (Fig. 20).

The eggs are deposited in masses, usually upon the stems of plants or grasses growing in the vicinity of water. In about seven to ten days there is hatched a large cylindrical larva which tapers to a point at both ends and has an integument that is somewhat transparent (Fig. 20, a). At this stage it lives mostly in moist earth into which it burrows actively, feeding mainly upon worms and the larvæ of other insects. While the period of larval life is long, in some observed cases lasting several months to a year, the stage of the pupa (Fig. 20, b) is short, the fly emerging from its case after a few days of pupation. It is probable that the broods are carried over the winter in the larval stage.

Effect.-The black horsefly is common throughout the summer months, attacking cattle and horses usually in the open sunny pasture, and inflicting with its long piercing mouth parts a painful wound. Fortunately it does not attack in swarms as does the buffalo gnat, nor does it instill with its bite as much poison. There is evidence of the sererity of its wound, however, in the drop of blood which wells up from the seat of puncture after the insect has left its victim. While there is little 
after-efiect from the bites of these flies they are a source of much torment to live stock, not only in the pain produced by their punctures, but in their peculiar buzzing, whieh often terrorizes nervous animals,

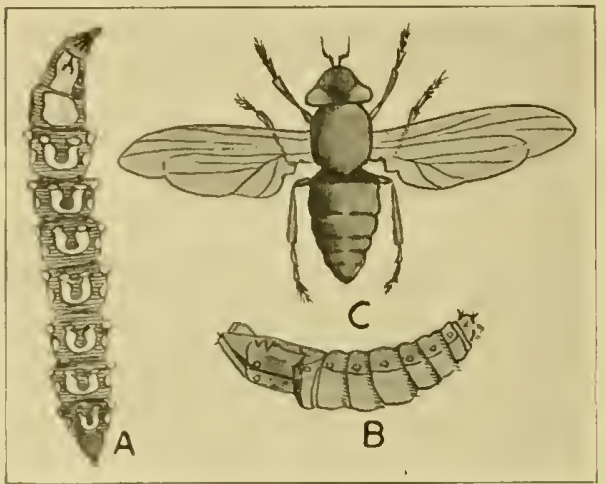

FIG. 20.-Tabanus atratus: a, larva; b, pupa; $c$, adult (after Osborn, from Riley; Bul. No. 5, Bureau of Entomology; 1)ept. of . Igr.). their frantie and heedless efforts to escape not infrequently resulting in injurr.

There can be no doubt that the Tabanidæe are coneerned in the transmission of celtain blood diseases of live stock. It is significant as to their possibilities as carriers of anthrax that their attack seems to be more commonly direeted against cattle than horses.

Protection. - Little can be done toward repelling the attacks of the flies. Horses at work are proteeted in a measure by covering them with nets. Where the flies are numerous and especially tormenting it is advisable to remove pasturing animals to a well-shaded retreat during the warmer and sunnier parts of the day.

\section{Tabanes Lineola}

Tabanicla (p. 35).-The Green-heact Horsefly (Fig. 21). This is the most widely distributerl species in North America. It is about fiveeighths of an inch in length. Eyes large and britliant green, abchonen brown, with a conspicuous grayish line ruming longitudinally on its dorsal side. It is from this marking that its specific name is derived, while the peculiar coloring of the eyes gives to it the common name "Green-head."

The oval, larval, and pupal stages are passed in moist places, and in other respects the life cycle from Packard, Bul. No.5, is similar to that of Tabanus atratus, though the Bureau of Entomology. larval period is probably not so long.

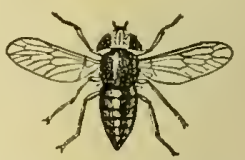

FLG, 21 - - Tabanus Dept. of Agr.).

The Green-heads appear in especially large numbers in marshy districts during the brightest and hottest days of the summer. They attack in greater numbers than the Black Horseflies, and, especially- 
during warm and sunny weather, their harassing bites cause much torture to horses and cattle. They do not fly in cloudy weather, and they perish with the frosts of early autumn.

\section{FAMILY IV. Muscide:}

Diptera (p. 23).-These flies are small to moderately large, with bodies thinly covered with hairs or bare. The bristles of antennæ are feathery. The abdomen is four-segmented and smooth except for bristles near the tip.

The larvæ are apodal maggots, feeding upon decaying animal or vegetable matter.

\section{Musca Domestica}

The common house fly (Fig. 8). Muscidæ (p. 37).-The mature insect is one-fourth to five-sixteenths of an inch in length; dorsal region of thorax grayish in color and bearing four longitudinal stripes; abdomen yellowish. The mouth parts are trumpet-shaped, adapted for sucking up liquids but not for piercing.

Life History.--In about ten days after emerging from the pupal case the female fly seeks suitable material upon which to deposit her eggs. This may be any decaying vegetable matter, though usually horse stable manure. About one hundred eggs are deposited at each laying, of which there are several at intervals of three to five days. In eight to twenty-four hours a white, footless larva is hatched. After five days to one week of feeding and and growing, during which period it undergoes two molts, the larva enters the pupal stage, the larval skin serving as its puparium. Before entering this stage the maggot may crawl away from its breeding place and burrow for a short distance into the adjacent ground, or find lodgment under a board, stone, or dried crust of manure. The stage of pupation lasts from five days to one week, and at its termination the adult fly emerges.

According to the longer periods given, the time required for development from the egg to the imago is fifteen days. This time, however, is greatly influenced by temperature, under the most favorable conditions of which the period for complete metamorphosis may be reduced to ten days; a fact always to be reckoned with in dealing with control of the fly through the regular and systematic removal of stable manure or other material which may serve as its breeding bed.

In the warm midsummer season adult flies may live for six to eight weeks, though it is probable that the average period will not exceed thirty days. They may survive the winter in a state of hibernation, seeking their retreats in the late fall months, and coming forth with the warm days of early spring to crawl upon the windows as they seek the warm sunlight or exit from houses. 
Habits and Relation to Disease.-While, so far as known, the house fly is not an essential host to pathogenic organisms of man and the mammalian domesticated animals, it is, by its structure and fithy habits of feeding, one of the most dangerous of disease-transmitting insects. Umniverous in habit, it will feed upon decaving vegetable and putrid animal matter, excrement, vomit, sputum, or other revoltingly filthy material. Direct from such sources of infection it may pass to the food upon our tables to which it is equally attracted, leaving a trail of contamination wherever it may drag its filthy parts.

From the viewpoint of the bacteriologist it would seem superfluous to discuss the house fly as a carrier of disease-producing bacteria. The form of its proboscis, habit of regurgitating its food, its six bristly feet (Fig. 8), each terminated by a sponge-like structure secreting a sticky substance, together with the vile material which it visits, make it both by structure and habit an ideal transmitter of such infectious diseases as typhoid fever, dysentery, cholera, glanders, anthrax, and ophthalmia. Furthermore, positive evidenee of the degree to which this insect is a carrier of bacteria has been well set forth by laboratory experiment.

Control.-As a widely disseminated menace to public health the house fly presents a problem that can only he successfully dealt with by community action. The measures taken should look to control rather than elimination, the latter, however desirable, being scarcely possible under present conditions. While it prefers horse manure, it is known that almost any fermenting material will serve as a breeding place, and it therefore follows that, in order to successfully combat this pest through its sources of propagation, all such material nust be systematically removed, screcned off. or so treated as to render it unsuitable for the development of the larvæ. Manure should be remored at least once a week, and if possible at once sprearl upon the fields. Kitchen garbage shoukl be likewise removed, and in the meantime kept in tightly closed receptackes. Access of flies to the vaults of outhouses can be prevented by their proper structure and sereening.

Protection. - As to measures of protection to the household against flies, there is little to be said that is not of common knowledge. The first of these to be mentioned is the thorough screening of doors and windows. Kitchens being especially attractive to flies, they should be doubly protected by screening the back porch, the screen doors at these locations being well fitting and made to withstand their frequent use. Flies that have gained entrance are best gotten rid of by hurning pyrethrum powder. A good method for the treatment of a room is to sprinkle the powder upon a hot shovel after first closing the doors and windows; if the kitchen, the powder may be sprinkled over the stove. It is hest applied at night, leaving the room tightly closed. In the morning the flies will be found lying ahout dead or stupefied, when they may be 
swept up and burned. The use of poisonous liquids set around in dishes has but little efficacy and for other reasons is not to be recommended. Sticky fly paper, to be most effectual, should be placed in parts of the room where there is most sunlight, as in the vicinity of windows.

In this connection it should be borne in mind that adult house flies and their allies seek the light, while their larvæ avoid it, characteristics referred to in the first case as light positive and in the second as light negative. This habit as to light is to be reckoned with and taken advantage of in measures looking to fly control.

\section{Stomoxys Calcitrans}

Stromoxys stabulans. Stable fly; stinging fly. Muscidæ (p. 37). About the size of the house fly. The color is brownish gray; proboscis black, slender, bent near its base, and extending forward from the head, fitted for piercing. The thorax bears four longitudinal stripes which may be more or less broken. The abdomen is stout, grayish, and spotted dorsally. The wings hyaline, and when at rest widely spread apart at the tips. The fly rests with its head well elevated and with wings sloping laterally downward and outward (Fig. 22).

The eggs are about one $\mathrm{mm}$. in length, curved on one side, on the opposite side straight and grooved. The larvæ resemble those of the house

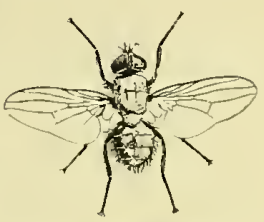

Fig. 22.-Stomoxys calcitrans, enlarged.

fly. They may be differentiated by the posterior stigmal plates, which in the larvæ of the house fly are large, irregularly oval, and close together, while in Stomoxys they are smaller, round or triangular, and much farther apart.

Life History.-The life-cycle of the stable fly is considerably longer than that of the house fly; like the latter it breeds in horse manure, but not to the same extent. Manure well mixed with straw is that most sought. Ideal for the deposition of its eggs are damp and fermenting collections of such material as cut grass, alfalfa, hay, grain, or piles of weeds. The eggs are deposited deep into the fermenting mass, and, under favorable conditions of temperature, will incubate in about three days. The larvæ are active feeders and complete their growth in from twelve to thirty days. As in related flies, the puparium is formed by the hardening of the last larval skin. The duration of the pupal stage will again vary according to weather, lasting from six to twenty days, or, if cool, it may be much longer. About twelve days may be taken as an average period. The time required for complete development may accordingly be set down as from twenty-five to thirty days under ordinarily favorable conditions. It is probable that the species is carried over the winter months in our Northern States in the larval and 
pupal stages. Development with the appearance of adult flies will occur in warm stables during this season.

Occurrence and Effect.- The stable fly is of workl-wide distribution, and is commonly mistaken for the house fly, the term "biting house fly" being often applied to it from its habit of entering our houses during damp, rainy weather and in the cooler days of early autumn. It may quickly be distinguished from the common house fly, however, by its elevated head when at rest, its protruding, bayonet-like proboscis, and its wings, which are widely spread apart at the tips.

Though commonly called the stable fly, Stomoxys is found in far less numbers about stables than is the house fly, and, as it will not visit such filth as does the latter, it is not such an offender against the cleanliness of dairy and other food products. Both sexes of Stomoxys, however, are vicious blood-suekers, and their bitc is especially a source of torture to thin-skimed, sensitive animals, Typically an out-of-door $\mathrm{fly}$, it is most likely to enter stables in the cooler days of late summer or early autumn when it will attack horses and cattle, attaching it self by preference upon the legs. Their sharp sting is manifested by the stamping, kicking, and general restlessness of the victims. The punctures are often followed by the formation of papules which may coalesce and lupture, leaving a sealy, more or less thiekcned skin with hairs scant, lusterless, and erect. To the dairy they are a source of loss in milk produetion through the worry and unrest eaused by their attacks.

Relation to Disease.-The posibilities of the stomoxys fly as a disseminator of infectious diseases have in recent vears received considerable attention. Its habit of visiting a number of hosts before becoming engorged with blood, together with its deep puncture, warrants us in charging against this speeies possibilities in the transmission of anthrax in eatte and glanders in horses. By some authors it is regarded as a carrier of the trypanosome (Trypanosoma evansi) which produces surra of horses. Of this, however, there is no conclusive experimental rvickence. As to the responsibility of the stable fly for the spread of infantile paralysis, it will he sufficient here to quote Riley and Johannsen, who, after reviewing the evidence, thus state their conchisions (1915): "The evidence at hand to date indicates that acute anterior poliomyeditis, or infantile paralysis, is transmitted by contact with infeeted persons. Ender certain conditions inscets may be agents in spreading the disease, but their rôle is a subordinate one."

Control.-Control measures eonsist in removing materials which afford favorable breeding places for the fly. Collections of moist and fermenting feed material, such as have been mentioned, should be removed and scattered in a layer sufficiently thin to insure thorough drying. It will then be unsuitable for the development of stomoxys larvas, as they require considerable moisture. Manure in which there is 
mixed considerable straw affords a favorable medium for the propagation of this fly, - a further reason for its systematic removal to be at once spread upon the fields, as stated in control measures for the house fly. It should be borne in mind, however, that stables are not predominant as breeding places of the fly under consideration, as is the case with the house fly. Stomoxys is attracted to stables because the animals from which it obtains its meal of blood are contained there. The favorite material for the deposition of its eggs is likely to be found elsewhere. These flies like the open, and districts far from stables may be overridden with them.

Protection.--Little can be done in the way of direct protection of live stock against the attacks of stable flies beyond thorough screening, the effectiveness of which is much lessened by the frequent opening of doors customary about stables. Means of keeping them out should be especially looked to in cloudy, damp weather, and in the cool mornings of early autumn, at which times they are most likely to seek the interior of stables and houses.

\section{LyPEROSIA IRRITANS}

Hcematobia serrata.-The horn fly (Fig. 23). Muscidæ (p. 37). About half as large as the house fly and like it in shape and color. The mouth parts are adapted for piercing and sucking blood, but differ from those of the stable fly in that the palpi are almost as long as the proboscis and are slightly spatulate.

The eggs (Fig. 23, a) are about $1.25 \mathrm{~mm}$. in length, irregularly oval, and reddish brown in color. They are deposited in the fresh dung of cattle, and, under favorable conditions of temperature, will hatch in about twenty-four hours.

Life History.-Newly hatched larvæ are about $2.5 \mathrm{~mm}$. in length, and pure white. When full grown they are about $7 \mathrm{~mm}$. in length and somewhat darker in color. The larvæ burrow into the dung and reach their full growth in about four days (Fig, 23, b). When ready to transform into the pupal stage the larvæ descend into the dryer parts of the dung, or for a short distance into the ground beneath it. The puparium (Fig. 23, c) is about $4.5 \mathrm{~mm}$. in length, irregularly ellipsoidal, and dark brown in color. The pupal stage occupies from five to ten days, therefore the time for full development from the deposition of the eggs will be, according to the above, from ten to fifteen days.

Occurrence and Habits.-The horn fly is an importation from Europe, making its first appearance in the vicinity of Philadelphia about the year 1886. It was first noticed as a pest to cattle in this country in 1887, from which time it has spread rapidly and at present is found in practically all parts of the United States and the greater part of Canada.

The popular name "horn fly" is derived from the habit peculiar to 
this speeies of elustering about the base of the horn, though this only oceurs when they are quite abundant. Their purpose in collecting here seems to be for rest in a location where they are not liable to be disturbed. There is a somewhat prevalent belief that the flies damage the horn by eating into it, depositing eggs, and developing maggots which may penetrate to deeper struetures, ete. This is a popular error for which there is no foundation, for, beyond " $\mathrm{fly}$ specking," it has not been observed that the flies do any injury to the horn.

Field study will show that this inseet assumes two characteristic positions. In the resting position, as they are found when upon the horns,
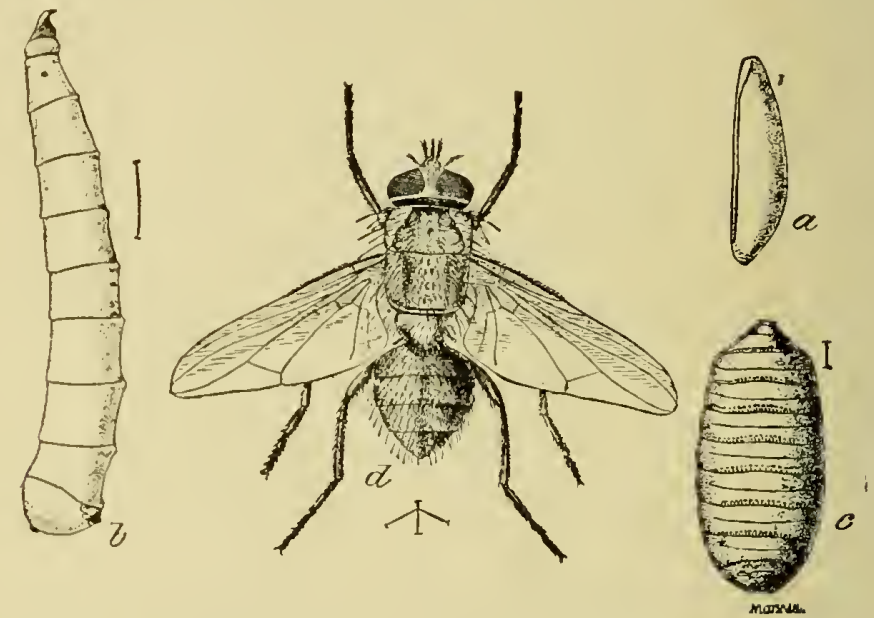

Fig. 23.- Lyperosia irrituns: a, egg; b, larva; c, puparium; $d$, adult in biting position-all enlarged (after Osborn, from Riley and Howard, Bul. No. 5, Bureau of Entomologs, lept. of Agr.).

the wings are held nearly flat down the back, overlapping at their bases and modrately diverging at their tips. The proboseis is extended forward, and the legs are not widely spread. When active and feeding, on the other hand, the wings are slightly elevated and held almost at right angles to the body, while the legs are spread. The proboscis is nearly perpendicular in position, and penetrates the skin of the animal attacked. To seeure this position it works its way to the skin, and is usually observed more or less eovered by the hairs. In damp, rainy weather they may be noticed as partieularly abundant beneath the hairs of the ventral surface of the body.

Effect. - Horn flies appear early in May and beeome most abundant in July and August. With the roming of cold weather they disappear, 
their full period depending upon season and latitude. During the time of their activity they are a veritable pest to cattle, causing interference with their grazing and disturbance of their rest, with consequent unthrift and serious loss in produetiveness. Horses do not escape their annoyance, but eattle seem to be the special object of their attack. Though the damage done is chiefly through their torment, the considerable amount of blood extracted from the animal by the large swarms which feed upon it must seriously contribute to the weakening effects. Further, as in all blood-sueking Diptera visiting cattle, we are justified in inferring that this fly may be a transmitter of infeetious blood diseases, such as anthrax, though as to this there has as yet been little if any investigation.

Control. - In control measures two lines of procedure should be followed, one looking to prevention of multiplication, the other directly protecting cattle from attack. Of these the former is most effective and involves such treatment of breeding places as will prevent larval development. As eggs are deposited in fresh dung, which must remain moist for the proper nourishment of the hatehed larvæ, any treatment of the droppings which will cause them to rapidly dry out will prevent or greatly inhibit larval development. Scattering or thinly spreading this manure, as may be done by a rake or by drawing brush across the fields, will accomplish this; the latter method, more economical in time and labor, is best adapted for large pasture areas. Hogs running with cattle will serve to scatter the manure to a large extent. The use of lime, which may be applied by simply throwing it over the droppings in the pasture, is very effective in destroying the larvæ. While piles of cow manure, especially those containing considerable straw, afford good breeding places for the stable fly, the horn fly will not seek this material to any great extent for the deposition of its eggs.

Protection.--For the direct protection of cattle a number of oleaginnous repellents are recommended. A mixture of fish oil and tar, equal parts, applied to the regions most attacked, is one in general use. Almost any oily or greasy substance is of value, though causing the animal to become somewhat unsightly from adhering collections of dust and dirt. Sprays of kelosene emulsion (page 48 ) may be used with advantage. though the effectiveness of such treatment is rery transient. The following mixture is recommended by the Kansas Experiment Station: resin (pulverized), one part; shaved soap, one part; water, one-half part; fish oil, one part; oil of tar, one part; kerosene, one part; water, three parts. The resin, soap, fish oil, and one-half part water are boiled together until the resin is dissolved, then the three parts water are added, and finally the kerosene and oil of tar. The mixture should be thoroughly stirred and boiled for fifteen minutes. This preparation when cool and applied as a spray will act as an effective repellent for twenty- 
four to forty-eight hours. It is necessary, therefore, to regularly repeat the application if the animals are to be continuously protected. Repelling agents are best applied in the evening when cattle are stabled or yarded.

\section{TSETSE Flies}

Genus Glossina.-Muscicle (p. 37). The tsetse flies (Fig. 24) are about the size of house flies, or may be somewhat larger. I The general color is light brown. When at rest the proboscis projects in front of the head. At the base of the proboscis is a bulbous enlargement, arista

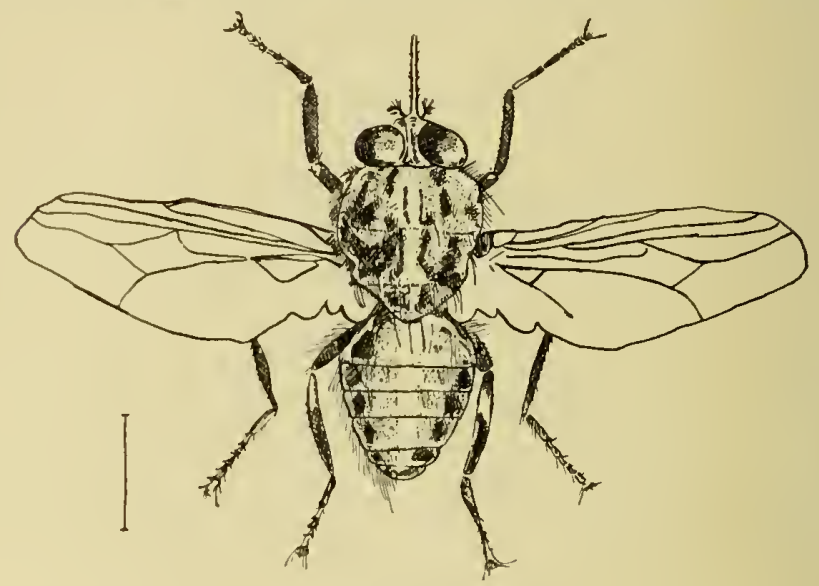

Fig. 24.-Tsetse fly.

phunose above. The resting wings are folded scissors-like over the back.

These flies are found only in certain areas in Africa.

Glossina Palpalis.-Glossina (p. 44). This species is 8 to $9 \mathrm{~mm}$. (5) 16 to 3/8 of an inch) in length. The color is brown dusted with gray. The antenna are black. All segments in the hind tarsi are black. The fourth and fifth segments of the fore tarsi are black. The halteres are white.

Glossina Morsitans.-Cilossina (p. 44). About the same size and eolor as $G$. palpalis. The antenna are dark. The first three segments of the hincl tarsi are vellow, the fourth and fifth segments black. The fourth and fifth segments of the first and second pairs of tarsi are black.

Glossina longipalpis is a species which in characteristies and distribution is almost identical with $G$. morsitans.

Breeding Habits and Habitat.--The Glossina deposit hatched larvie among roots of tropical regetation. When deposited the larva are well 
advanced and within a few hours enter upon the pupal stage which requires from six to eight weeks. Occurring only in Africa, they are most abundant in heavily wooded districts penetrated by water courses. Both sexes are blood-sucking, and it is in such locations that they are most likely to find the wild animals upon which they feed.

Relationship to Trypanosomiasis.-As transmitters of trypanosomiasis to man and domestic animals, tsetse flies may be regarded as the world's most dangerous insects. The first observation of trypanosomes in the blood of mammals was made by Lewis, who in 1877 described a trypanosome (Trypanosoma lewisi) of the blood of a rat. Three years later another trypanosome ( $T$. evansi) was studied as the cause of surra in horses. When Bruce in 1894 demonstrated the relationship between tsetse fly disease of horses in Africa, the cause of which was unknown, and nagana, trypanosomes received much more attention as to their pathogenic importance. The further investigations of Bruce as to the part played by the tsetse fly in the transmission of this disease are best given in his own account, from which the following is an excerpt:

"When it was once established that the two diseases were the same, experiments were made to find out how the animals became infected, whether the fly was the carrier or the mere concomitant of the low-lying, unhealthy district, and, if a carrier, if it was the only carrier of the disease from sick to healthy animals. Horses taken down into the fly country, and not allowed to feed or drink there, took the disease. Bundles of grass and supplies of water, brought from the most deadly parts of the fly country to the top of Ubombo and there used for fodder for healthy horses failed to convey the disease. Tsetse flies caught in the low country and kept in cages on top of the mountain, when fed on affected animals, were capable of giving rise to the disease in healthy animals up to fortyeight hours after feeding. Tsetse flies brought up from the low country and placed straight way upon healthy animals were also found to give rise to the disease. The flies were never found to retain the power of infection for more than forty-eight hours after they had fed upon a sick animal, so that if wild tsetse flies were brought up from the low country, kept without food for three days, and then fed on a healthy dog, they never gave rise to the diseasc. In this way it was proved that the tsetse fly, and it alone, was the carrier of nagana. Then the question arose as to where the tsetse flies obtained the trypanosomes. The flies lived among the wild animals, such as buffaloes, koodoos, and other species of antelopes, and naturally fed on them. It seemed that, in all probability, the reservoir of the disease was to be found in the wild animals. Therefore, all the different species of wild animals obtainable were examined both by the injection of their blood into healthy susceptible animals. and also by direct microscopic examination of the blood itself. In this way it was discovered that many of the wild animals harbored this 
trypanosome in their blool. The parasites were never numerous, so that it was only after a long search that they could be discovered by the microscope alone. The wild animals did not seem to be affected by the trypanosomes in any way; they showed no signs or symptoms of the disease, and it, therefore, appeared probable that the trypanosomes lived in their blood as harmless guests, just as the trypanosome of the rat lives in the blood of that animal.'

As Trypanosoma brucei is now known to be the organism causing the fatal nagana of horses and mules of Africa, so $T$. gambiense is known to be the cause of sleeping sickness of man. The relationship of the tsetse fly to human trypanosomiasis was shown in a way very similar to that by which Bruce reached his conchusions. While the tsetse species Glossina morkitans and $G$. longipalpis are especially concerned in the transmission of nagana, and $f$. palpalis likewise related to sleeping sickness, it has bcen shown by students in the field of protozoology that not only biting flies, but mosquitoes, lice, and leeches may carry trypanosomes from one vertebrate host to another.

Experiment has shown that the trypanosomes adhering to the proboseis of the biting fly after it has fect upon the blood of an infected animal rapidly lose their vitality, becoming sufficiently attenuated within forty-pight hours to be noninfective. The fly, therefore, can only inoculate medhanically, that is by the puncture of its soiled proboscis, within a few hours after it has become a carrier of the infecting organism. It is now known, however, that trypanosomes taken into the stomad of the fly with its meal of blood pass through a metamorphosis involving sexual forms, and that at the end of about twenty-eight days the fly may again become infective. At this time the parasites have reached the salivary glands and here they remain during the remainter of the life of the fly. How long such a fly may retain its power to infect is yet a question, though it has been found by the Sleeping sickness Commission to be at least three months. The duration of the life of the tsetse fly has only heen observed upon specimens in captivity, but it is probable that it is about four to six months.

Control.- Measures looking to the control of the breeding of the flies are limited practically to exchusion owing to the fact that the larval period is passed within the body of the female, hence offers no opportunity for attack through sources of larval food supply. The fact that tscetse flies seek the vicinity of water courses surrounded by wooded areas may be taken advantage of in excluding them from locations of settlement. With a view to this it has been recommended that clearings be made over an area of six hundred to eight hundred yards at some distance from streams of water, the water supply being obtained from wells. The difficulties presented, however, in the control of the fly are numerous and in many features seem unsurmountable. The ultimate 
solution of the problem probably lies in immunization against the tsetse fly diseases, as to which little progress has yet been made.

\section{Family V. Hrppoboscides}

Diptera (p. 23).-The body is flattened. Wings are present or absent. The wing veins are crowded toward the anterior margin. The head is sunk into an emargination of the thorax; the antennæ inserted in pits near mouth; mouth parts adapted for piercing and sucking blood. The legs are stout, terminated by strong claws. The abdomen is large and sacular with segments indistinct.

The Hippoboscidæ are pupiparous, the eggs being hatched and nearly the whole of the larval stage passed within the body of the parent. The larvæ are extruded only when nearly ready to transform into pupæ.

All are parasitic upon birds and mammals. Hippobosca equina is a winged species occurring upon the horse, and known in England as the forest fly.

\section{Melophagus Ovinus}

The sheep "tick."-Hippoboscidæ (p. 47). Three-sixteenths to onequarter of an inch in length. The color reddish or grayish brown. The wings and halteres are absent. The head is small and sunken into the thorax; abdomen large, sac-like, and covered with short spines (Fig. 25).

Life History.-Matured larvæ are extruded from the body of the female and at once enter upon their pupation, the reddish brown pupæ adhering to the wool fibers. The pupal stage occupies three to six weeks according to season and temperature, the shorter period occurring during the summer. At sexual maturity the deposition of pupæ begins, each female depositing from eight to ten. Probably the life of the tick will not exceed four to five months.

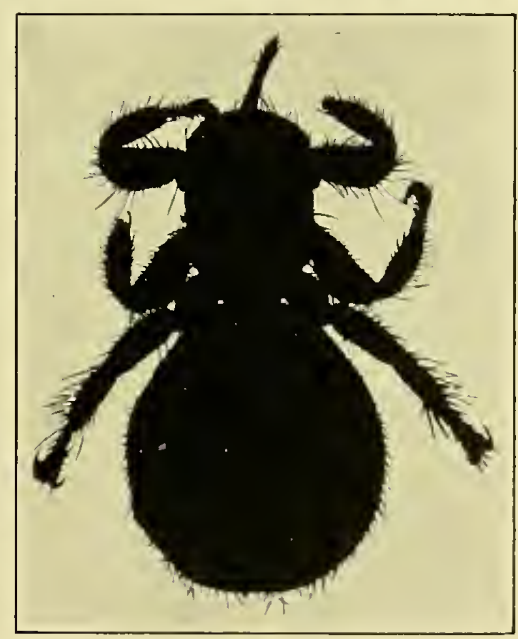

FIG. 25.- Melophagus ovinus (from photograph of mounted specimen, by Hoedt).

Occurrence.-The sheep tick is distributed over all parts of the world where sheep are kept. Its parasitism is continuous, the pupiparous 
habit of bringing forth its young adapting it to spend its whole life upon the host from which it never migrates unless to attach to another animal of the same species. It is probable that this migration occurs principally at the time of shearing when the ticks leave the sheared sheep and crawl upon the lambs. Off the host the ticks will not survive longer than a few days, probably all will be dead within a week.

Effect. - Itl breeds of sheep are alike subject to attack, the presence of the "tick," or "louse," as it is commonly called, and the injury which it eauses, being a matter of common knowledge to sheep breeders. Sheep are not materially affected by a few, but if in larger numbers, their presence will be manifesterl by rubbing, scratching, and biting at the fleree. Loss of flesh and general unthriftiness will oceur in barly infested animals. Where the ticks are prevalent lambs may be attacked by kare numbers at shearing time, in which condition many will die unkess promptly relieved.

Treatment.-In the winter months, when the long wool will not permit of other trotment, the ticks may be greatly reduced in number hy the use of pycthrum powder which shoukl be freely blown deep in to and upon the ficeec over all parts of the body. The most effectual treatnent is best applied after shearing and consists of the application by flipping or as a wash of such remedies as creolin, zenolium, lysol, or cresol, userl in two to three per eent. strength. Decoction of tobaceo, in strength of three to four per cent. is also used, but, to avoid danger of nicotine poisoning, should not be applied to all parts of the body at once. Foroseno (mulsion, which has a wide range of usefulness in the treatment of external parasites, is another of the numerous dips resorted to in this connection. The emulsion may be made either with milk or soap aceording to the following formula:

Milk cmulsion. - To one part milk atd two parts kerosene and churn by a foree pump or by other means of agitation. Dilute the resulting cinukion with eight to ten times its bulk of water.

Soap emulsion.--Dissolve one-half a pound of hard soap in one gallon of hot watel and, while still at near boiling point, add two gallons of kerosene. Enulsify by use of forer pump or other means of agitation. Dilute one part emulsion with eight or ten parts water.

These enulsions may be used in the proportions given as a spray, wash, or dip.

None of these dips will kill the pupre, and, therefore, keeping in mind the life history of the parasite, the treatment should be repeated in about twenty-four days. If the dipping has been done in the cooler weather of autumn, this interval should be accordingly prolonged.

As the movement of the ticks from the sheep to the lambs takes place principally at the time of shearing when the insects are removed from 
their host with the fleece, it is well at this time to keep the lambs at some distance from the stored wool. This precaution should be observed for at least a week from the time of shearing, at the termination of which period the ticks which have been removed with the wool will be dead. 


\section{CH.SPTER VI}

\section{DIPTEROUS IARVE}

Flesh flies, blowflies, botflies.-The larve of these files produce a form of parasitism to which the term myasis (also myiasis, and nyiosis) is applied. Tarious forms of myasis are recognized according to the location of the larve, as cutaneous, muscular, nasal, gastric, and intestinal. With certain spccies, as those of the family (Estridæ, or true botflies, the larval parasitism is obligate upon or within a living host animal, while the larve of the flesh and blowflics of the family Muscidr may attack either living or dead, usually decomposing, tissue.

\section{Chrysomyta Macellaria}

Compsomyia macellaria; Cochliomyia macellaria, Serew worn fly.Muscidie ( $) .37$ ). Three-eighths to half an inch in length; color bluish green with metallic reflections. There are three longitudinal black stripes upon the thorax. The head is reddish or yellowish brown; thorax and abdomen covered with stiff black hairs (Fig. 26).

The rggs are about $1 \mathrm{~mm}$. in length, white and cylindrical. They are deposited in masses of three hundred to four hundred upon dead and decaying flesh and upon wounds, sores, or within the nostrils or other natural mucous opcnings of man and lower animals. Hatching may oecur in from one to twelve hours from the time the eggs are deposited.

The larve are white, apodal, slender, and quite active. The head and segments are provided with spines which farilitate their burrowing into the living or putrefying flesh upon which they feed, a habit which gives to the mature insect its common name of screw worm fly. Under most favorable conditions the full larval growth is reached in three days, at which time they may be half an inch or more in length. When mature they leave the flesh upon which they have been feeding and bury themselves in the cartlo near by, in which location they enter upon pupation.

The pupre are 6 to $9 \mathrm{~mm}$. in lengtl, somewhat barrel-shaped, and dark brown in color. The pupal stage may last from six to twelve days.

Occurrence and Effect.- The serew worm fly is wiclely distributed, being found throughout North and South America. In the United states it is especially abumdant in the South, where it is responsible for the most serious cases of human myasis occurring in this country. It begins to attack in June, but has its greatest period of activity in the 
three months which follow. In its attacks upon man it usually deposits its eggs in the nostrils or mouth while the individual is sleeping. It is especially attracted if the parts are unclean, as from the discharge of nasal catarrh or collections of vomit about the lips. Persons in a drunken stupor are especially liable to attack. For the same reason open sores contaminated by collections of pus or blood are equally attractive to it.

The fly's greatest injury as a pest to domestic animals in the United States occurs in the Southwest, where cattle are the greatest sufferers from its ravages. In these animals the flies are attracted to wouncls of operations, such as dehorning, branding, castrating, etc., and to injuries such as may result from hooking or barbed wire. In fact any open wound or exposed mucous membrane, especially if soiled with an odorous discharge, is a favorite seat of attack.

Upon hatching, the larvæ at once proceed to attack the tissues and may rapidly produce a serious destruction and mutilation. They grow rapidly as they consume the tissues adjacent to them, and in locations, as parts of the limbs where there is little fleshy covering, the bones may be laid bare.

Protection.-As most of the fatal cases of myasis in man from this larged (after Osborn, from Francis, Bul. (ause are due to deposition of eggs No. 5, Bureau of Entomology, U. S. Dept. in the nostrils while the person is of Agr.).

sleeping, the first measure of precaution is to protect from attack by the use of netting. Those sleeping out of doors in infested regions are most exposed, but sleeping rooms should also be thoroughly screened. Open sores and wounds should of course be kept free from collecting discharge and covered with clean, dry dressing. The same precautions as to cleanliness of wounds and exposed mucous membranes applies to domestic animals. The vulvæ of cows recently fresh, especially if there has been a retention of the placenta, and the navels of calves offer favorite points for attack and should particularly be guarded.

Treatment.-Where sores and exposed mucous membranes have already become infested with worms a disinfecting wash, such as a one to three per cent, solution of carbolic acid, should be used. For injection into regions where the maggots have penetrated, the injection of carbolic acid or creolin in about five per cent. strength will destroy worms with which it comes in contact. Chloroform diluted to a strength of about 
twenty per cent. is also recommended for this purpose. An ordinary machinist's oiler affords a practical method of applying such agents. It has the advantage of deep application without waste of the material. For deeply infested wounds a final packing of oakum and oil of tar should be applied, and this should be covered by a protective dressing of tar and oakum as a prevention from further attack.

\section{Sarcophaga Sarracente}

A flesh fly--Museidie (p, 37). In markings somewhat similar to the house $\mathrm{fly}$, but considerably larger. The general color is light gray; eyes reddish brown. Body spiny.

The female deposits larvæ upon fresh meat, or in the wounds of living animals. Under farorable conditions the larval stage is completed in

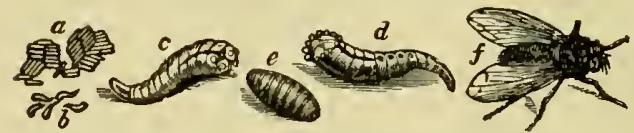

Fig. 27.-Metamorphosis of the flesh fly (Sarcophaga): a, eggs;b, young larve just hatehed; $c$, d, full-grown larva; e, pupa; f, imago (after Orton, by Dodge; Copyright, 1894, by Harper \& Brothers). about six days. The mature larvæ crawl to a convenient shelter where they undergo a pupation from which the arlults issue in from twolve to fourteen days (Fig. 27).

Protection. - The flesh flies are of world-wide distribution, and are of most importance as they affect fresh neats in the household or meats in storage. As a protection in such cases the flies should be screened off at some distance, as larvæ which have been deposited in the vicinity of meat will erawl to it, though it may not be accessible to the flies.

To prevent their attack upon wounds, the same general procedure may be adopted as recommended for the preceding species.

\section{Calliphora Vomitoria}

Blowfly.-Muscidx (p, 37), Somewhat larger than house fly; eyes brownish in color; abdomen bluish green with metalic luster and usually pollinose.

The eggs are oval, white in color, and are deposited upon decomposing animal and vegetable matter and in wounds of animals. Hatching may occur in from a few hours to one or two days, the shorter periods occuring in hot weather. After from three to nine days of feeding, the matured larræ seek the ground, become buried for a short distance, and in this location enter upon their stage of pupation. The time required for the entire life cycle, inclucling a prepupal period of several days, may be from two to five weeks, depending greatly upon temperature. Under ordinary conditions it would probably occupy about three weeks.

The blowfly agrees with the flesh fly in its habits, with the exception 
that it deposits eggs instead of living larvæ. After hatching the manner of attack and the effect upon infested meat and wounds is much the same and calls for the same treatment.

\section{Fanilly VI. Estrides}

Diptera (p. 23). Botflies, warble flies. The head is large, bearing two faceted eyes widely separated, antennæ short and sunken into pits in the front of the head. The mouth parts are rudimentary, most all of the flies living in the adult stage without food. The body is heavy and somewhat hairy. The coloration is usually inconspicuous.

The larvæ are thick and twelve-segmented, the first two segments not always distinctly separated. There is no demarcation into body regions, only a cephalic and anal end can be distinguished. The bodysegments are frequently provided with rows of spines. Buccal hooks may or may not be present. Tracheal openings are at the posterior extremity.

The larvæ are parasitic in the stomach and intestines, mucous membranes, subcutaneous connective tissue, nasal passages, and sinuses of facial bones of mammals; other parts are also invaded by their migrations. When completely developed the larvæ leave these locations in the host and pass to the ground where they enter the pupal stage.

The flies of the family Estridæ are of world-wide distribution.

Gastrophilus intestinalis (G. equi). Estridæ (p. 53). The horse botfly (Fig. 28, h). The body of the female is one-half to five-eighths of an inch in length and is very hairy. The head, thorax and abdomen are brown. The wings are transparent with dark spots, those near the center passing entirely across the wing transversely. The abdomen is rather long and tapers to a point. In the males, which are rarely seen, the abdomen is light brown or yellow, "and it is not tapering. In other respects the males closely resemble the females.

The larvæ (Fig. 28, c, d and g) when full grown are about threefourths of an inch in length. At the head extremity are two buccal hooks by which attachment is made to the gastric mucosa (Fig. 28, e). The body-segments are bordered by short spines (Fig. 28, d).

Habits. - Like other members of the (Fstridæ, the horse botfly at. maturity is extremely active, flying chiefly during the warmest and brightest days of the summer, and generally frequenting pastures in the vicinity of woods. It is the habit of the female to hover near thehorse with its long, pointed abdomen bent downward and forward. The fly then darts toward the horse, deposits its egg, retreats, and again hovers until ready to repeat the operation. The eggs (Fig. 28, a and b) are yellow in color, about one-sixteenth of an inch in length, and tapering toward the attached end, the free end being provided with an operculum which is set obliquely and gives to this end somewhat of an obliquely 
cut off appearance. 'They are generally deposited upon the hairs of the anterior parts of the body, as upon the forelegs, breast, shoulders, and under side of the body, regions which are most readily reached by the lips of the horse. It is not uncommon, however, for eggs to be attached to the sides of the neck, lower jaw, cheeks, mane, and other parts, the larve in such cases reaching the mouths of horses by their licking or nipping at each other,

Life History. - The eggs are deposited rapidly with their free ends down, and adhere to the hairs by a viscid substance which quickly dries
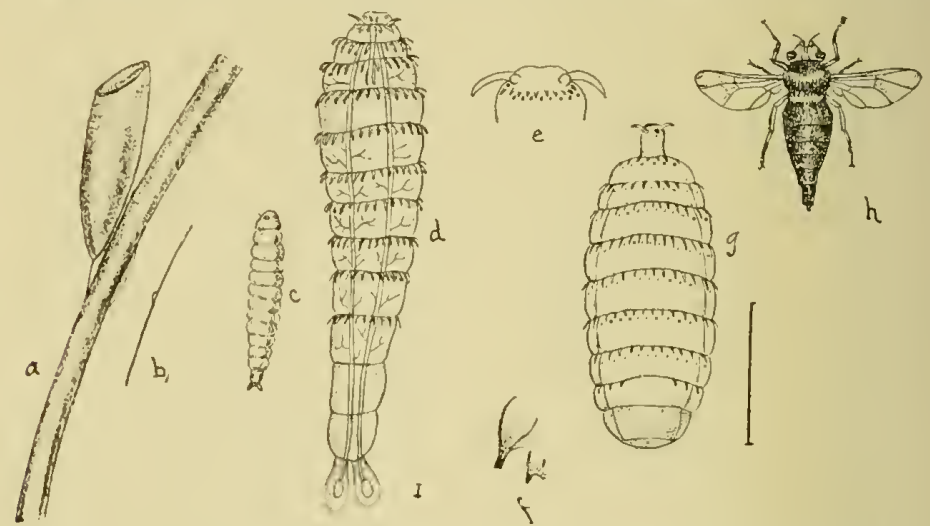

Frg. 2S-Gastrophilus intestinalis: a, egg-enlarged; b, egg-natural size; c, young larva; d, young larva much enlarged, showing spiny armature; e, oral hooks; $f$, body spines; $g$, full-grown larva-twice natural size; h, adult female (after Osborn, Bul. No. 5, Bureau of Entomology, ['. S. Dept. of Agr.).

and gives them a fim attachment. At this time they contain larra which have undergone a more or less advanced development.

Observations upon the botflies during recent years have been somewhat disturlbing to conclusions formerly held and apparently necessitate a certain revision of the life histories which have generally been given for them. According to the observations of Roubaud (1917) upon Gastrophilus intestinalis, the eggs of the fly do not open spontaneously, and the larve may not escape from thein for several weeks. The opening of the operculum and freeing of the larva probably occurs when the horse lubs an itching or irritated area with his nose or bites it with his teeth, the horse rarely licking itself. By experiments with bot larvæ on guinea-pigs Roubaud demonstrated that when the hatched larva is brought in contact with the buccal mucosa it at once burrows into this membrane and lies parallel to its surface. In two or three days it disappears, but he notes that one was seen traveling along the side of the 
tongue for nine days, during which time it grew to three times its first dimensions. Before leaving the buccal mucosa the larvæ probably undergo a molt and then proceed to the stomach. These observations undicate that the larvæ of the botfly escape from the eggs when the horse bites at his skin or rubs it with his lips, and that they burrow into the buccal mucosa where they undergo a degree of development before passing to the stomach.

Within the stomach cavity the larva fixes itself to the walls by its buccal hooks. Later the head becomes deeply inserted into an alveolus which is formed under the influence of the irritation to the mucosa. In this position the larva feeds upon the tissue juices and the products of the irritation which it sets up, becoming fully grown in about ten months. The period of larval development usually terminates from May to August, more especially in June, due to the fact that the deposition of the eggs occurs most actively in the month of August. At this time the larva becomes detached from the gastric mucosa, passes to the intestines, and with the intestinal contents leaves the body of its host.

The change into the pupal stage is made either in the horse manure or after the larra has burrowed for a short distance into the ground. At the termination of pupation, which lasts from four to six weeks, the matured fly creeps out, and, after fertilization by the male, proceeds to deposit ova for another generation.

Tabular Review of Life History of Gastrophilus Intestinalis 1. Adult Fly.-(August.)

2. Eggs.-Attached to hairs of horse (Aug. and Sept.); approximately 2 weeks.

3. Young Larvæ.- Upon or within mucosa of horse's mouth.

4. Larvæ (Bots),-Attached to wall of horse's stomach. Stages 3 and 4 approximately 10 months.

5. Pupæ.-Free (June); approximately 6 weeks.

6. Adult Fly.-(August.)

Effect.-The degree of injury due to the presence of the larvæ of this botfly will depend upon their number and location. That the stomach may be invaded by a considerable number of bots without apparent disturbance to this organ is probably due to the fact that they most commonly attach to the esophageal portion. this region of the horse's stomach haring a less important part in the function of digestion 
than that toward the pyloris. Where they occupy the glandular right half, especially if in large numbers, they interfere with the digestive secretion and its proper contact with the gastric contents. In exceptional cases they may be sufficiently numerous about the pyloris to form an obstruction to the passage of food material into the small intestine; or even the duodenum itself may be invaded. Under these latter conditions the larva bring about nutritive disturbances and may cause attacks of acute indigestion with its accompanying manifestations of pain. When we consider, however, the large number of horses essentially harboring the larva of the horse botfly, as indicated by the widespread prevalence of the insect, we must conclude that they are comparatively inoffensive, for in most cases there is an entire absence of any apparent disturbance and, with the execption of the voiding of the bots, nothing during the life of the animal which would lead to suspicion of their presence.

Treatment. - The larvæ of Castrophilus are so resistant that treatment having in view their destruction or expulsion has been generally unsatisfactory. Such agents as preparations of tar, benzine and turpentine, which are sometimes used for this purpose, add irritation to an alrcarly irritated gastric mucosa and, for this reason, in connection with their general ineffectiveness, the advisability of their use is questionable. Where the presence of the bots in sufficient numbers to cause disturbance to the health of the animal is suspected, gastric irritation may be allayed to some extent by feeding mucilaginous materials, such as flaxseed meal. Hay in such cases is best fed choppecl, and a substantial nutritive diet should be looked to as compensatory to the loss of nutriment.

A treatment recommended by Peroncito and Bosso (1894) consists in the administration of carbon bisulphide to adult horses in gelatin capsules, each containing 8 to 12 grams ( 2 to 3 drams). After fasting for twetve to twenty hours, the horse is given one capsule; after one hour a second capsule is given, and after another hour a third. As carbon bisulphicle is strongly irritant, care should be taken in the administration of the capsules that the cap does not become detached and that they do not become crusher in the mouth.

In so far as clinical observation can determine the presence of bots, or lead to the conclusion that a remedy has caused the expulsion of any considerable number of them in proportion to the infestation, this treatment is said to be generally satisfactory. It seems reasonable to concluck that an agent sufficiently active to cause the expulsion of these robust larvæ from their sccure attachment would have a severely irritant effect upon the gastric mucosa, though this membrane of the stomach appears to have a greater tolerance for such assaults than that of other regions of the alimentary tract. 


\section{Gastrophilus Hemorrhoidalis}

The red-tailed botfly.-Estridæ (p. 53). Somewhat smaller than G. intestinalis. Dark brown color, yellowish hairs upon the face; transverse black band upon thorax. The abdomen is covered with fine hairs which in the middle are dark and posteriorly orange-red. The wings are clear.

This species of horse botfly is found in common with $G$. intestinalis in North America and Europe.

The females attach their ova to the hairs of the horse, preferably those about the lips. The hatched larva cause an irritation which impels the horse to pass its tongue about its lips, thus carrying the parasite into the mouth. In other respects its life history is essentially the same as that of $G$. intestinalis. The larvæ differ from those of the latter in being somewhat smaller and in their dark-red color. There is also some difference in their habitat in that they attach usually to the pyloric portion of the stomach, and when fully developed pass on to the rectum where they remain for some time, assuming a green color before being voided.

Effect.-The presence of the larvæ of this fly in considerable numbers in the folds of the rectal mucous membrane may cause an annoying irritation, inducing violent efforts at defecation. Such cases, however, are extremely rare, and, as a rule, little or no evidence is given by the animal of their presence.

Gastrophilus nasalis.- Estridæ (p. 53). This species, commonly called the chin fly, is about $1 \mathrm{~cm} .(3 / \mathrm{s}$ of an inch) in length. The body is hairy and yellowish red in color. The wings are without spots.

Law describes the larvæ as "furnished with a row of spines on each ring from the second to the ninth on the dorsal surface, and as far as the tenth on the ventral. There is an unarmed part in the center of the eighth and ninth rings on the dorsal surface."

The fly deposits its eggs about the lips and nostrils. The larvæ attach to the mucosa of the upper part of the small intestine.

Fitch states (1918), as to New York State, that from examination of the larvæ it would seem that Gastrophilus nasalis is quite as frequent as $G$. intestinalis.

\section{Hypoderma Lineata and H. Bovis}

The ox botflies; warble flies (Fig. 29).-Estridæ (p. 53). Hypoderma lineata is about five-eights of an inch in length. The general color is black; body more or less covered with hairs. The front, sides, and back of the head, sides of thorax, and last segment of the abdomen are covered with long yellowish white hairs.

This fly is found in all parts of the United States, but more especially 
in the southern portion as far north as Illinois, Iowa, and Nebraska. It makes its appearanee in the spring or early summer and is at once attracted to cattle, depositing its eggs on the hairs, frequently upon those about the heel, a habit which gives to the fly its southwestern name "heel-fty,"

The entire length of the egr is $1 \mathrm{~mm}$. and its width $0.2 \mathrm{~mm}$. In color it is a vellowish white. The eggs are firmly attached to the hairs by

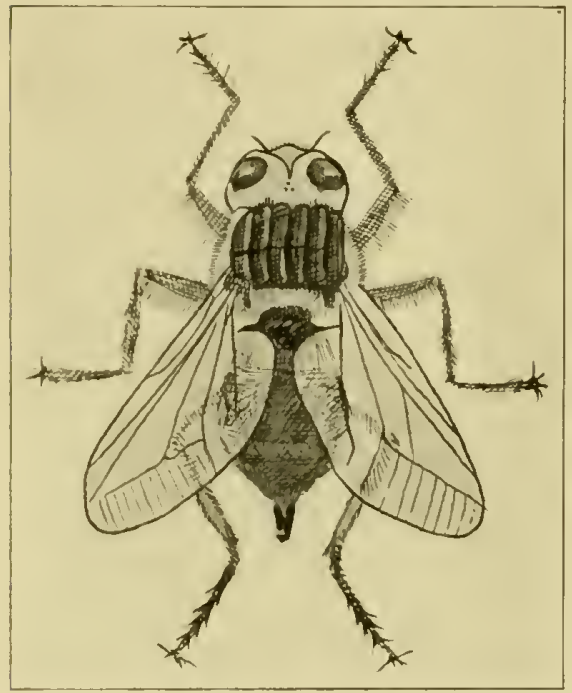

Fis. 29.-Hypoderma lineata (after Osborn, from Insert Life, Bul. No. 5, Bureau of Entomology, U. S. Dept. of . Igr.). The hairs from the base to the tip of the abdomen vary in color from white or yellow to black; orange red at posterior third. The legs are black, rellow at their terminations; wings somewhat biown.

As to the differentiation of the larve of these two species, Herms writes as follows: "The life history of the two species is very similar. The larve are different enough to distinguish them readily. The fully grown larva of $I I$. bovis is longer, 27 to $28 \mathrm{~mm}$., $H$. lineata about $25 \mathrm{~mm}$. The two species are distinguished on the basis of their spiny armature. In $H$. lineata each segment of the larva is provided with spines except the last, the ring upon which the stigmata are located, while in $H$. bovis all except the last two are almored."

Life History.-Dr. Cooper Curtice, from his researches in 1890 , 
concluded that the larve of Hypoderma lineata are taken into the mouths of cattle by licking the parts where the eggs are attached, the eggs under this influence hatching at once. From the mouth the larva, according to this investigator, is carried to the esophagus, the walls of which it penetrates. While lodged in the esophagus it molts, and the body becomes quite smooth. For a period of several months thereafter it wanders through the connective tissue beneath the skin or between muscles, and ultimately reaches a point beneath the skin of the back. Here the larva again molts and the spiny processes reappear upon its body. It now cuts a small opening through the skin, and places its

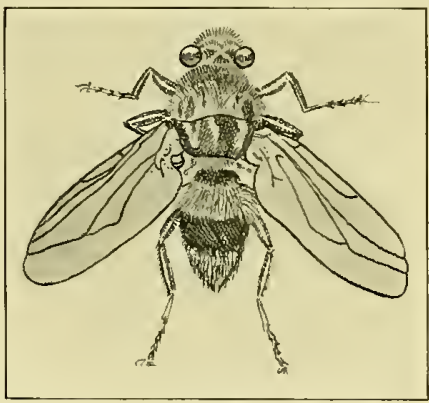

FIG. 30.-Hypoderma hovis (after Osborn, from Brauer, Bul. No. 5, Bureau of Entomology, U. S. Dept. of Agr.).

anal spiracle near this orifice in order to get air. In this location the larva lives upon the products of the inflammation which its presence sets up, such as bloody serous exudate and pus. It now develops rapidly and again molts, at which time the grub is fat, yellowish-white in color,
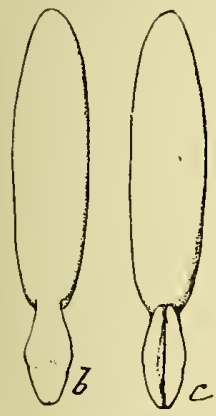

FIG. 31.-Eggs of Hypoderma lineata, showing clasplike processes-much enlarged (after Osborn, Bul. No. 5, Bureau of Entomology, U. S. Dept. of Agr.). Dept. of Agr.). as April 15th, but the usual laying period tured later than May 30th." Hypoderma bovis (Fig. 30) begins in the early part of June and continues up to the beginning of August. maturity of its larval period (Fig. 32, $\mathrm{g}$ and $\mathrm{i}$ ), which lasts about ten months, it works its way out of the orifice at the summit of the tumor and drops to the ground, into which it may burrow for a short distance. Here it enters upon the-pupal stage, the hardened larval skin becoming the protecting case for the pupa within. After about four to six weeks of pupation the adult fly escapes by pushing off the cap at the end of the pupal case.

Dr. Seymour Hadwen, in notes on "The Life History of Hypoderma bovis and H. lineatum" based on observations made at Agassiz, British Columbia (Journal of the American Veterinary Medical Association, June, 1917) summarizes as follows:

"Hypoderma lineatum lays its eggs as early" and an inch or more in length. Reaching the 
Between the last appearances of $H$. lineatum and the first of $H$. bovis there is usually a period of ten days when the cattle are immune from attack of either speeies, $H$. bovis frightens cattle much more than $H$. lineatum. The eggs take about a week to hatch; the larvæ bore through the skin in the coarser porous parts, taking several hours in the process; at this stage they are rather less than $1 \mathrm{~mm}$. long. The lesions resulting from this penetration are caused partly by bacterial invasion and partly by anaphylaetic reactions; those produced by $H$. lineatum being more severe. For the skin lesions I have proposed the name of hypodermal rash. At this point there is a hiatus in the life history as it is not positively known how the larvæ reach the esophagus, where they are subsequently found, most likely in the loose connective tissues under the skin up to the region of the throat and into the esophagus where the muscles bifurcate. Passing down the esophagus they follow the submueosa and are almost always found lying along the long axis of the canat. Whilst in the esophagus small edematous swellings are found surrounding the grubs, these are sterile and are anaphylactic in charaeter, the exurlate eontains large numbers of esinophilic leucocytes but 110 pus cells. The earliest record made at Agassiz was on August 15th, when a larva $3.4 \mathrm{~mm}$. was found and several slightly larger. According to Carpenter, continental observers have found them smaller than this. II. lineatum makes its appearanee in the backs of cattle about Decemleer 15 th and $I I$. bovis about a month later. The larvæ at this time have grown to about $1.5 \mathrm{~cm}$. and are of the same size in the neural canal and under the skin which they have just reached. At this age it is difficult to s'parate the larva of the two species, but Mr. F. C. Bishopp has, I believe, discovered good distinguishing marks between the species. The life histories overlap at this period making it difficult to follow the migration, but in the latter part of the season (the middle of March) the last larve to leave the gullet are at the pauneh end. They pass out uncler the pleura and go to the neural canal either up the crura of the diaphragm or up the posterior border of the ribs, entering the canal by the posterior foramen, from there they descend the canal under the dura mater, emerge again through the foramen and reach the back, forming the eharacteristic swellings commonly ealled warbles. The larve follow connective tissue exclusively and no larva have been discovered in muscular tissue. The mature larvæ leave the animals' backs from the early part of the year up to the first days of July. The periods for the two species have not been fully worked out, but judging from what records we have of the pupal period and the time of year the flies are about, $H$. lineatum begins to emerge in February and finishes about May 1st. $H$. bovis begins about May 1st and ends approximately on July 1st. The average pupal period for $H$. bovis is 32.5 days and for H. lineatum a little less. The duration of the life of the flies is short 


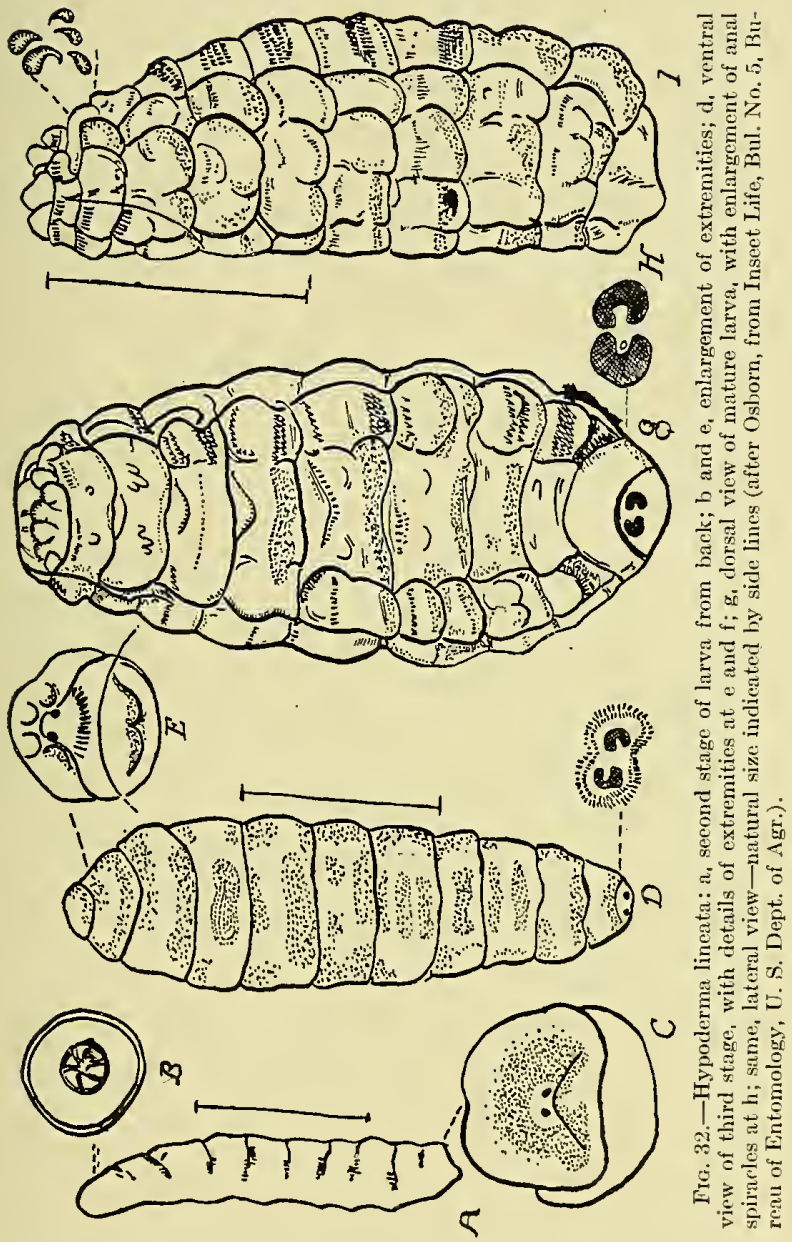


seeing that they cannot feed. This life history applies to Agassiz, British Columbia; doubtless in other countries variations will be noticed, but the period spent by the larve within the host must be of the same duration, secing that animals' temperatures are the same the world over."

Effect.-Cattle seem to be much annoyed by the attacks of these flies in clepositing their eggs, and in the endeavor to escape will of ten (nter mire holes or injure themselves in other ways. Probably the most important damage from the insect is that to hides, these being discomted from twenty-five to fifty per cent. aceording to the number of punctures by the grubs.

Treatment.-Treatment is best applied in the months of January and Febluary when the grubs have become sufficiently developed that the small tumors in which they are lodged may be felt by running the ham along the back of the animal. The application at this time of a little kerosene or mereurial ointment to the summit of the swelling will destroy the grub. By Mareh the tumors may be distinetly seen as prominent hmps upon the skin of the back. The orifice at the summit is now large enough to permit of the forcing out of the grub by careful pressure. Cirubs thus removed should be at once destroyed to prevent the possibility of their finding favorable conditions for development into the adult fly.

\section{Gstrus Ovis}

The sheep lotfly (Fig. 33, 1 and 2).-Estricle (p. 53). About onehalf an inch in length; yellowish-gray color; slightly hairy. The abdomen is spotted with white and yelow; posterior portion eovered with fine hairs. The wings are transparent.

Occurrence and Life History.-This species is of world-wide distribution, and is the most importunt insect pest with which sheepmen have to cleal. The flies make their appearance with the coming of warm weather from early June to July, like other (Estridae, flying on bright and warm days and eeasing their activities about the month of Oetober. Tho female, which is diffieult to observe owing to its small size and rapid flight, deposits living larva in the nostrils of the sheep. At this time the larva is rreany-white in eolor and about one-sixteenth of an inch in length (Fig. 33, 6). Later it becomes darker, and at maturity reaches a length of about three-quarters of an inch (Fig. 33, 4 and 5). Upon the cephalic segment there are two hooklets the points of which are curved downward and backward. With the aid of these the larva at once proceels to work its way upwarel through the nasal passages until it reaches the frontal sinuses where it attaches by its hookkets to the lining memhrane. Here it feeds upon mucus and serous exudate induced by the irritation of its plesence.

The larva remains in this location about ten months, at the end 
of which time, having reached its larval maturity, it detaches from the mucous membrane and passes to the nasal passages from which it is expelled by the violent sneezing which it excites in its host. Having reached the ground, it quickly buries itself, contracts within its smooth dark shell, and enters upon its pupal stage (Fig. 33, 3). After from four to six weeks of pupation the mature insect emerges.

Effect.-Both sheep and goats suffer from the attacks of this fly. Sheep are especially disturbed by it, and in their efforts to avoid its attack will toss the head, thrust the nose into the ground, or dash about in frenzy. The grubs cause much irritation to the sensitive membrane which lines the cavities of the head both by the hooklets with which they make their attachment and by the spines covering the ventral region. Furthermore, if numerous, and the mucus secreted is not sufficient for their nourishment, the grubs will feed upon the membrane itself. The disturbance to the host will be manifest according to the number of grubs present; if there are but few, there may be no more than a slight catarrhal discharge with occasional sneezing. In heavy infestation there is a profuse

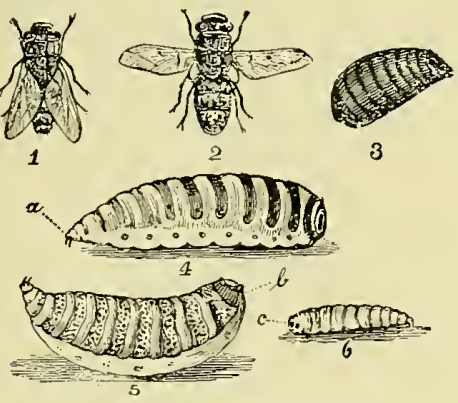

Fig. 33.-CEstrus ovis: 1 and 2, adult fly: 3 , pupa; 4, full-grown larva, dorsal view; 5 , same, ventral view; 6 , young larra. 1 and 2 natural size, the others enlarged (after Osborn, from Riley, Bul. No. 5. Bureau of Entomology, U. S. Dept. of Agr.). muco-purulent nasal discharge with frequent sneezing and tossing of the head, the respiratory passages in some cases becoming so filled as to bring the animal to the verge of suffocation. The appetite is lost, and emaciation and weakness may progress until there is inability to rise, death in such cases soon following.

\section{Tabular Review of Life History of Estrus Ovis}

1. Adult Fly.-(June to October.)

2. Hatched Embryos.-Deposited in nostrils of sheep.

3. Larvæ-Attached to lining nembrane of sinuses of sheep's head. Stages 2 and 3 approximately $101 / 2$ months.

4. Pupæ.-Free; approximately 6 weeks.

5. Adult Fly 
Treatment.-The location of the grubs and the tortuous extremity of the canals leading to such regions render the application of remedies looking to their dislodgment but partly effective at best. Benzene applied by lifting the head and pouring a teaspoonful into each nostril, has been recommended. As one side is treated the head should be held elevated and the nostril held shut for half a minute. The remedy is then likewise applied to the other side. In severe cases a few of the gruhs may be dislodged by a feather dipped in turpentine which is passed as far as possible up the nasal passage and rotated so as to apply it to as much of the surface as ean be reached. Valuable breeding animals showing severe infestation may be treated by trephining the sinuses.

Prevention.-To prevent the fly from depositing its larva the noses of the sheep may be smeared with tar. For the convenient application of this preventive remedy many flock owners use salt logs in their pastures. Into these logs two-inch holes are bored at intervals of about six inches in each of which a little salt is kept during the fly season. Two or three times a week tar is smeared with a brush around these lrotes in such mammer as to smear the noses of the sheep as they endearor to reach the salt. The logs should be of sufficient length to enable all the sheep to get to them. 


\section{CHAPTER VII}

\section{THE FLEAS}

Order II. Siphonaptera.-Insecta (p. 15). Members of this order have the body compressed laterally, and the color is usually dark brown. The head is small, generally bearing a single ocellus on each side, compound eyes are absent. The mouth parts are suctorial but differ from those of the order Diptera in that the true haustellum is lacking, the sucking structure consisting of the ventrally grooved labrum and the two mandibles, which form a half-open tube (Fig. 36, e and f). The maxillæ are sharp and serve to puncture the skin. The three thoracic segments are distinct, each bearing a pair of well-developed legs, the posterior pair being especially long, powerful, and adapted for leaping, which is the principal mode of progression.

Metamorphosis is complete. The larvæ are long, slender, without feet, and somewhat hairy. When mature the larva spins a cocoon and enters upon a distinct pupal stage. During this stage the pupa takes the form of the adult with the appendages enveloped in a hard pupal case. At no stage in the metamorphosis are there traces of the supposed ancestral wings. It is probable, however, that the fleas have descended from winged forms, and they are usually considered as being closely related to the Diptera.

There are many species of fleas, most of them inhabiting various wild birds and mammals. It will be sufficient here to consider the following three of the family Pulicidæ:

1. Ctenocephalus canis, the dog flea.

2. Ctenocephalus felis, the cat flea.

3. Pulex irritans, the human flca.

The two species of Ctenocephalus can easily be distinguished from Pulex by the presence in the former of comb-like spines on the lower margin of the head and on the hinder margin of the prothorax. These spines are dark colored, stout and closely placed (Figs. 34 and 35 ). The $\operatorname{dog}$ and cat flea have long been placed together under the one spccies Pulex serraticeps, but a later classification recognizes a specific difference based principally upon the form of the head. In Ctenocephalus canis the head, when seen from the side, is rounded in front and somewhat less than twice as long as high. The head of $C$. felis, seen from the side, is more acute angled in front and is long, being fully twice as long as high. The head of Pulex irritans, with its abscnce of spines, is 
more regularly rounded than that of the dog flea, and bears two bristles, one low, in the vicinity of the maxilla, the other below the eye.

Life History.- In their life history the fleas undergo a complete metamorphosis. The eggs are oval, $0.5 \mathrm{~mm}$. in length, and in eolor pearly white (Fig. 36, a). They are deposited loosely and unattached among the hairs of the host, dropping off readily during the movements of the animal. The period required for the eggs to incubate may be from one to four days or longer, depending much upon temperature.

The larvae are white, elongate, apodal, and have thirteen segments, each provicled with bristles (Fig. 37). They are very aetive and, avoiding the light in every way possible, seek such shelter as is afforded by crev-

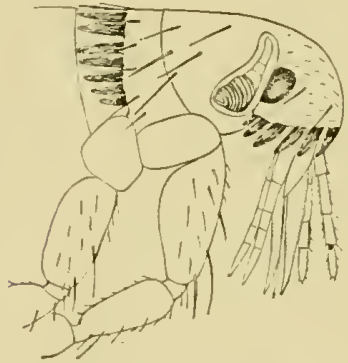

Fig. 34.-The dog flea, anterior portion of body (after Osborn, Bul. No. 5, Bureau of Entomology, I'. S. Dept. of Agr.).

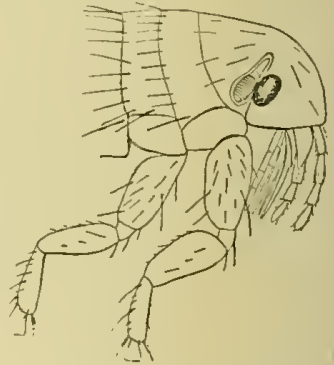

FIG. 35.-The human flea (Pulex irritans), anterior portion of body (after Osborn, Bul. No, 5, Bureau of Entomology, U. S. Dept, of Agr.).

ices in the floor, carpets, rubbish, or bedding of kennels, such material containing focal or other organic matter upon which they feed, being especially favorable for their development.

The length of the larval stage varies considerably under the influence of temperature. It may be from seven to thirty days, during which time there are two molts. Just before entering the pupal stage the larva spins a white silken cocoon within which the pupa (Fig. 36, c) is lodged (Fig. 36, b). Transformation to the fully developed imagoagain depencling upon temperature and moisture-will occupy from five to ten days. The time required for the development of the mature insept from the deposited egg is, therefore, from thirten to forty-four days, with twenty-eight days as probably a fair average under our ordinary elimatic conditions.

Habits and Relation to Disease.- Nearly all speeies of fleas have some one host upon which they prefor to live, but they will often live and thrive upon other animals. The human flea will infest dogs and 


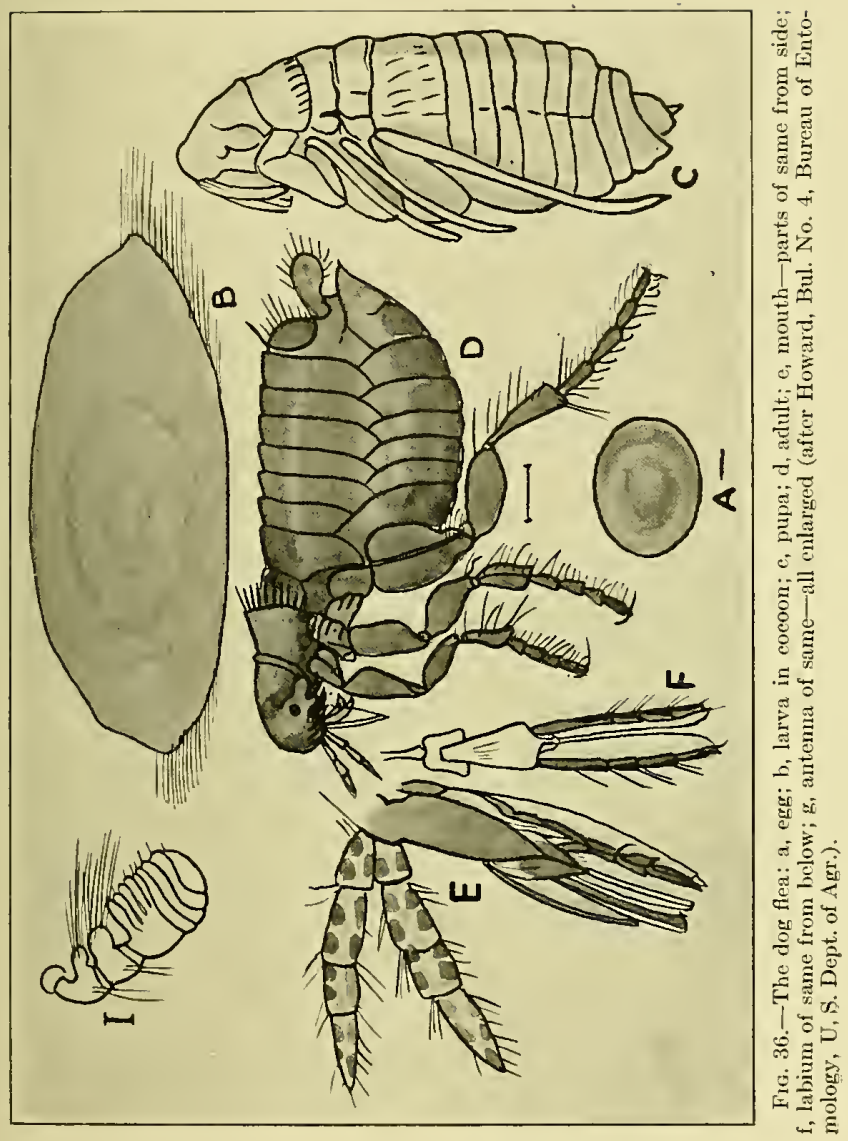


cats and may be found upon these animals in common with the species usually infesting them. As a pest of the household the human flea is more commonly found in Europe and the western part of the United States, while in the eastern United States houses may be rendered uninhabitable for a time by the presenee of the dog and cat flea.

Fleas are of importance as tormenting parasites of man and domestic animals, but of late have received greater attention in the field of medicinc as carriers of disease. It is known that bubonic plague, which during recent years has made its appearance on the Pacific and Gulf coasts of the United States, is transmitted by these insects. Tæniasis of the dog, due to the presence of Dipylidium caninum, may be conveyed to humans as well as to dogs through the intermediation of the $\operatorname{dog}$ flea, while a disease of infants known as kala azar, occurring in countries bordering on the Mediterranean, is thought to be transmitted by fleas.

Usual Hosts. - Our larger domestic animals, such as horses, cattle, and sheep, are rarely attacked by fleas. Hogs are somewhat less free from them, but, if occurring in these animals, the infestation is most always light and causes little disturbance. Dogs, cats, rabbits, fowls, and pigeons are especial ol)jects of attack. Young dogs and those chained up are more likely to be infested as they live anid conditions favorable to the breeding of the insects from the laying of the eggs to their full development, which is particularly favored by litter and wooklen floors. Unlike lice, fleas do not pass their

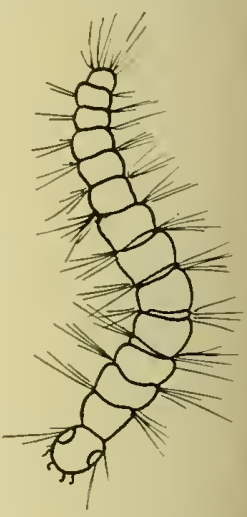

FIG. 37.-Pulex irritans, larva. entire cycle upon the host, nor are they limited to a particular species. The dog and cat flea will readily attack man, and in this country is more troublesome to him than the human Hea.

Vitality. - When fecding upon blood, which is the only food taken by the adults, fleas will live from several months to a year. Off a host the dog and cat flea will not survive longer than about two months, the length of life under such conditions being considerably shortened if the weather be hot and dry.

Treatment and Control.-Where habitations are infested by these insects it is of first importance as a measure of control that dogs, cats, and other domesticated animals kept about the premises receive treatment that will rid them of the parasites. The harboring animals may be dusted with Persian insect powder (pyrethrum), the remedy being applied liberally and driven well under the hair, preferably after the skin has been slightly moistened. This will not kill the fleas but will stupify them, in which condition they will drop off or may be combed 
from the hairs. It is well to place the animal while undergoing this treatment upon a large sheet of paper which may later be rolled up and burned with the collected fleas. In severe cases creolin or lysol solutions in two per cent. strength may be used. Quite effectual, but more expensive, is the preparation consisting of Peruvian balsan, ten parts; creolin, two parts; alcohol, one hundred parts which is recommended in the treatment for lice and scab mites upon small animals. In the treatment of cats, puppies, and chicks the powder is preferable to the last mentioned preparations.

Following treatment animals should not be permitted to re-enter their sleeping quarters until all litter has been removed and burned. In order that this cleaning up process may be effectual every detail must be looked to. Collections of dirt and dust between floor boards must be removed, as well as every particle of bedding or rubbish that may harbor a flea brood. After this preparation the quarter's should be thoroughly cleaned with hot, soapy water and, when dry, sprayed with kerosene or kerosene emulsion (formulæ, page 48 ) as an additional precaution. For kennels a bedding should be used which can be frequently replaced, as shavings or straw. Carpet or matting should never be used for this purpose.

Household Infestation.-In dealing with household infestation it is first necessary to exclude flea-bearing animals from the premises or destroy the adults which are producing the eggs upon these hosts. Flea larvæ find excellent conditions for development under tacked-down carpets or matting and in spaces between floor boards. The floor covering, whatever it may be, should be removed, bcaten, and thoroughly aired. The floors may then be swept and the dust, which contains many eggs and larvæ, collected and burned. Kerosene should then be applied with a mop in such-manner that it will penetrate all cracks and crevices in the floor and beneath the baseboards. Benzene is oftcn advised for this purpose, but, owing to the extreme danger of ignition, its use, excepting under the most careful supervision, is not to be recommended.

Following these eradicative measures the floor coverings may be replaced, but before doing so it is well, as an additional precaution, to sprinklc the floors with pyrethrum powder. This will work into the fabric and make the carpet or matting an unfavorable harbor for any liurve or adults which may have escaped the eradicative measures. Where the floors are oiled and rugs used instead of carpets or matting, the problem of getting rid and keeping rid of such an infestation is much lessened. 


\section{CHAPTER VIII}

\section{THE LICE}

There has been much disagreement among various authors as to the systematic arrangement of the lice. The classification given here, if fauly, will perhaps at least serve the purposes of this work until exacting systematists have better setted the matter.

Order III. Siphunculata.-Insecta (p. 15). The Sucking Lice.-The lice of the oreler siphunculata have the suctorial mouth parts at the anterior border of the head, the movalue proboscis being formed of the upper and lower lips (Fig. 38). Within this is the sucking-tube which is projected beyond its sheath and buried in the skin when used to aspirate blood. The ey's are two simple ocelli, one on each side. The antenna are short. The thorax is usually broader but shorter than the head, with indistinct division into three segments. The legs are short and thick, the tarsi teminating in a single claw. There are no wings. The abdomen is large and generally elliptical in outline. The last abdominal segment is roundert in the male with an opening for the penis. In the female this scgmont is noteherl and has two small teminal appendages. The frmale is from 1.5 to $5 \mathrm{~mm}$, in length, the male somewhat smaller.

Life History. - The metamorphosis is incomplete. The young, which leave the eggs by an opereulum, have the shape of the adults but do not acruire the adult color and consistency until after several molts.

The eggs as they are extruted from the female are glued fast to the hairs of the host by means of a viscid seretion. In this position they are commonly referret to as nits, which, wh the aicl of a hand glass, will be observed to have somewhat the shape of a barel with the attached end rounded and a blunt free extremity (Fig. 40, e).

Hatching occurs in from five to six clays, the young in general resembling the atults excepting in size. They become mature in about four weeks.

The sucking lice come into one family, the Pediculidie. All are pernament parasites, the entire life cycle being spent upon the host. All are limited to a specific host, and will only acciclentaly inhabit a host of a different species. Therefore if the host is known, the specifie identity of the parasite is reachily determined.

The characteristics of the species are here given under their respective host anmals. It may be said of the sucking lice in general that the head is inserted chectly on the thorax, their antemne are five-segmented; the 
segments of the abdomen number eight or nine, and their tarsi are terminated by a single claw.

\section{Order IV. Mallophaga}

The Biting Lice.-Insecta (p. 15). The members of the order of biting lice resemble the sucking lice in general form, but differ from them mainly in that they are much smaller and have the mouth parts adapted for biting and mastication. They may be at once distinguished by the head and mouth parts; the head is usually rounded, triangular, squared, or crescent-shaped, and is broader than the thorax (Fig. 39). Upon the under side of the head are located the mandibulate mouth pieces adapted for cutting and feeding upon epidermic scales, hairs, feathers, and other cutaneous products. The eyes are simple ocelli located back of the short antenna and are often indistinct. The thorax is generally narrow, the prothorax being distinct, the two posterior segments fused. The legs are adapted for either clasping or running; in the first case the tarsi terminate in a single claw (Philopteridæ), in the second the tarsi are long and terminate in two claws (Liotheidæ). Wings are absent. The abdomen is generally elliptical; it may be elongate, or short and broad, approaching a globular outline. Their relatively small size and hard, flattened bodies facilitate their movement among the hairs close to the body.

In their breeding habits and life history the Mallophaga agree with the preceding order.

Although the order has been variously subdivided, it will be sufficient here to place the biting lice according to their hosts in the two families Philopteridæ and Liotheidæ, the former including the biting lice of mammals and birds, the latter the lice of birds only.

Biting lice, like the suctorial, are limited to a specific host, which as a mule they do not voluntarily leave unless it is to crawl upon another host of the same species, in which case the migration is ordinarily accomplished when the bodies of the host animals are in contact. Under conditions of severe infestation among poultry some of the parasites miay pass to the roosts and nests and, by contact, even to the body of a llammalian host, but they will not survive such migrations for more than a few hours.

\section{Pediculosis of Domestic Maminals}

The condition commonly known as lousiness is medically referred to as pediculosis, a tem correctly applied whether the condition be due to thr presence of either the sucking or the biting species. The term phthiriasis should properly be restricted to infestation with the genus Phthirius in particular.

Lousiness is usually accompanied by an unthrifty condition, not 
necessarily resulting from, but rather predisposing to the attack, the reduction in the functional activity of the skin in such condition affording an inviting habitat for the parasites. Herbivorous animals which have been kept for a prolonged period upon dry feed, as during the winter months, are those most likely to be infested, lice rarely being found upon these animals after they have been turned upon more succulent food and the winter coat has been shed.

There is, in fact, little valid excuse for the presence of these parasites upon our domestic animals at any time. Infestation is usually the accompaniment of uncleanly, impoverished, and crowded conditions of stabling or yarding. Well houserl, well fed, and regularly groomed animals offer no attractions to lice, and animals so cared for will not have them. Excepting in accidental and transient incidents, their presence upon man or domesticated beast reflects upon man in either case.

Whether the degree of disconfort and injury to an animal due to the presence of lice upon its body is slight or serious in its consequences will depend upon the number present and the group to which they belong. The sucking lice, piereing the skin and feeding upon the blood and exudate, cause a much more intense pruritus than that occasioned by the biting lice which, in their habit of feeding upon surface epidernic products and débris, have more the nature of scavengers.

The presence of the lice, as well as their location, is indicated by the pruritus, hy their eggs or nits upon the hairs, and the débris of their molts. The irritation of the itching and rubbing, together with the loss of blood if suctorial lice are numerous, results in emaciation and general untlniftiness of an animal likely to have been in poor condition before becoming infested.

While the presence of lice may be unnistakably evident, it should be male quite sure that there is not also present a form of acariasis. Lice frequently invade animals suffering from scabies, and the pruritus, with the accompanying scaly and scabby condition of the skin, may be lue to scab mites, which, minute and deeply located, may be readily overlooked. The presence of these can only be determined with certainty hy examination of epidemic scrapings from beneatl the scabs. For their detection and examination the microscope is necessary. They are, however, often difficult to discover, and the material is best submittel to a laboratory for examination if such is available. More detailed methods of rliagnosis and treatment of this condition are given elsewhere under the discussion of the scab mites.

\section{Pediculosis of the Horse}

Hotses, mules, and asses harbor one species of sucking louse, Hamatopinus asini, and two species of biting lice, Trichodectes equi and $T$. pilosus. 
1. Hæmatopinus asini (H. macrocephalus).-Pediculidæ (p. 70). Head long and narrow; antennæ attached at lateral protuberances behind which are notches lodging the eyes. Anterior to this the hearl is more narrow with borders parallel, terminating in a blunt point. The thorax is much shorter than the head and widens posteriorly. The abdomen is oval, with stignata placed in the middle of lateral protuberances on the margins of segments. The general color is yellow, the thorax brownish. The female is 3 to $3.5 \mathrm{~mm}$., the male $2.5 \mathrm{~mm}$. in length (Fig. 38).

2. Trichodectes equi (T. parumpilosus). Philopteridæ (p. 71).-Head slightly longer than broad and semicircular in front of the antennæ which are set well back. The abdomen is oval

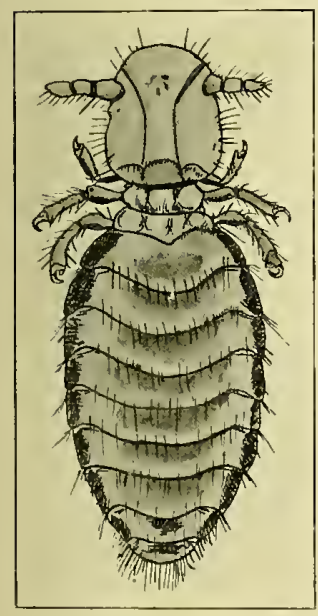

Fig. 39. - Trichodectes parumpilosus (after Osborn, Bul. No. 5, Bureau of Entomology, U.S. Dept. of Agr.). and bears eight transverse dark bands, each upon the anterior portion of a segment and tion of a segnient and asini (after Osborn, from middle line about half- Bureau of Entomology, U. middle line about halfway to the margin.

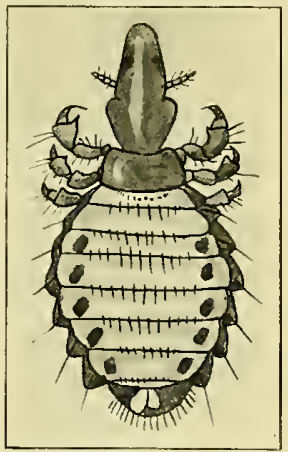

FIG. 3S. - Hrematopinus S. Dept. of Agr.). The general color of the abdomen is yellowish, the head, thorax, and legs chestnut (Fig. 39).

3. Trichodectes pilosus. Philopteridæ (p. 71).--Somewhat smaller than the preceding species. Head broader than long, rounded in front, and slightly widened at the temples. The antennæ are inserted well forward, almost on a line with the head's anterior border, in which respect it markedly differs from $T$. equi. The abdomen tapers posteriorly and has upon the middle of the first seven segments darkened spots, less conspicuous than the bands similarly located upon $T$. equi. The head, thorax, legs, and abdomen are hairy on both surfaces. The general color is yellow.

Pediculosis caused by suctorial lice upon the horse is usually located at the base of the mane and forelock, and at the root of the tail. The hairs about these parts are likely to be scant, broken, or the skin entirely denuded, due to the rubbing against anything within reach. During the act of rubbing the animal has a peculiar habit of protruding the upper lip, or, if in reach of another animal, will gently bite it. 
Biting lice are less common upon horses than suctorial. They are not often found on the upper parts of the body, more frequently occupving the regions of the neck, breast, and between the fore and hind legs. They cause less pruritus than the sucking lice, though the animals will frequently rub bare places at the regions infested. Both forms may coexist upon the same animal.

\section{Pedicllosis of the Ox}

Two species of suctorial lice inhabit the ox, Hamatopinus eurystermus, -the short-nosed ox louse, and Linognathus vituli, - the long-nosed ox louse. Of the biting species there is but one, Trichodectes scalaris.

1. Hæmatopinus eurysternus. Pediculidæ (p. 70).-Head relatively short and broad, rounded in front; thorax about twice as wide as long,
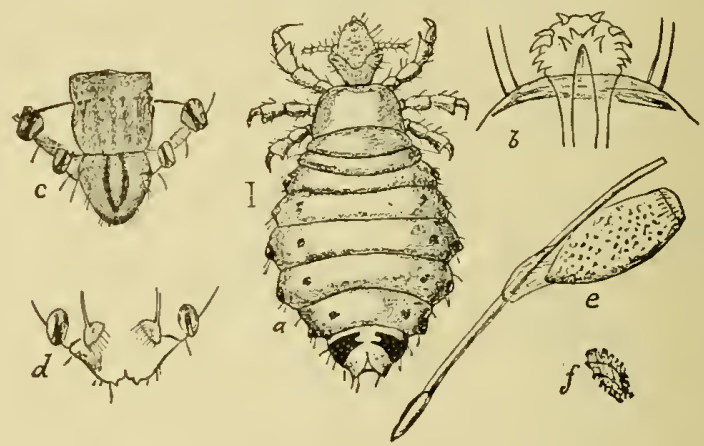

lici. 40.-Hamatopinus eurysternus: a, female; b, rostrum; $c$, ventral surface of the last segments of male; d, same of female; e, egg; $f$, surface of same greatly enlarged (after Osborn, Bul. No. 5, Bureau of Entomology: (. . S. Dept. of Agr.).

widest posteriorly. The abdomen is oval and much larger than that of the sucking louse of the horse. On the lateral margin of each abdominal segment is a slightly colored tubercle. In the female two black blotches are laterally located on the terminal segment. The general color is yellowish gray. The female is 2 to $3 \mathrm{~mm}$, the male $2 \mathrm{~mm}$. in length (Fig. 40).

2. Linognathus vituli (Hæmatopinus vituli). Pediculidæ (p. 70).somewhat smaller than the preceding. The head is long and narrow and somewhat sunken in the thorax, as in a notch. The thorax is about as broad as long. The abdomen, like the head, is long and narrow, giving to the entire insect a long and slender appearance. The general color is a deep chestnut. The female is 2.5 to $3 \mathrm{~mm}$., the male 2 to 2.5 inm. in length (Fig. 41). 
This species is found upon calves, though it will also,- - probably as frequently,-infest adults.

3. Trichodectes scalaris. Philopteridx (p. 71).-Head cone-shaped, rounded at the temples and in front, about as broad at the temples as long. The antennæ are inserted well back and are usually directed backward. The abdomen is not so tapering as in the biting louse of the horse, and the median spots are larger, forming bands which are quite distinct. The general color is white. It is somewhat smaller than the species infesting the horse (Fig. 42).

This is a very common and widely distributed specics, frequently found upon cattle in cohabitation with the sucking lice.

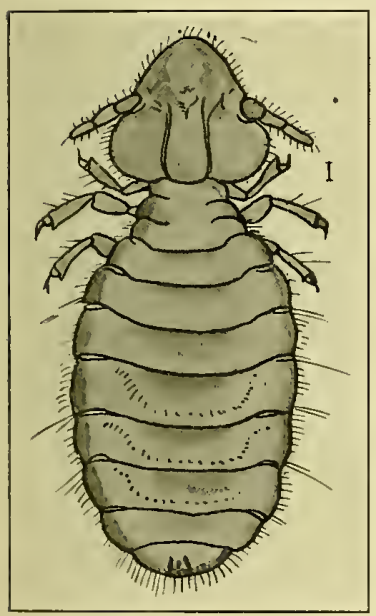

Fic. 42,-Trichodectes sealaris (after Osborn, Bul. No. 5, Bureau of Entomology, U., S. Dept. of Agr.).
Pecliculosis of the ox, caused by either the short or longnosed species, is most likely to be found about the ears,

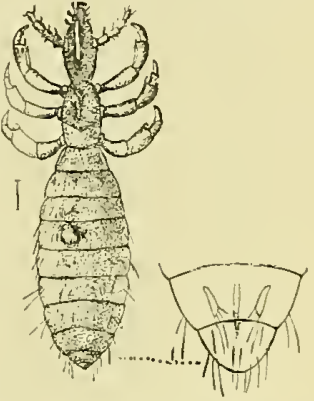

FIG. 41. - Hæmatopinus vituli- female, under surface of last segments of abdomen of same (after Osborn, Bul. No. 5, Bureau of Entomology, U. S. Dept. of Agr.).

base of the head, and along the dorsal line of the neck, back, and loins. The intense itching causes the animal to rub against any convenient object, and there is frequent licking of the parts which can be reached with the rough tongue. As a result of this rubbing large patches of skin may be entirely denuded of hair, and the skin itself in severe cases may become pustular and scabby.

Contrary to what has been observed in the horse, biting lice probably occur more frequently upon the ox than the sucking species, therefore lousiness of cattle is usually accompanied by less itching. As to their location the biting lice of cattle do not limit themselves, usually spreading to all parts of the body. They may frequentlybe observed crawling out upon the hairs and, when one is removed and examined with a hand glass, one or more hairs will often he found in the elutch of its claws. 


\section{Pediculosis of the Sheep}

This animal has one suctorial louse,-Linognathus pedalis, and one biting louse,-Trichorlectes sphorocephalus.

1. Linognathus pedalis (Hæmatopinus pedalis). Pediculidæ (p. 70). -Has the same general shape as the short-nosed ox louse, but is somewhat more slender. It is also much lighter in color, giving it a somewhat immature appearance (Fig. 43).

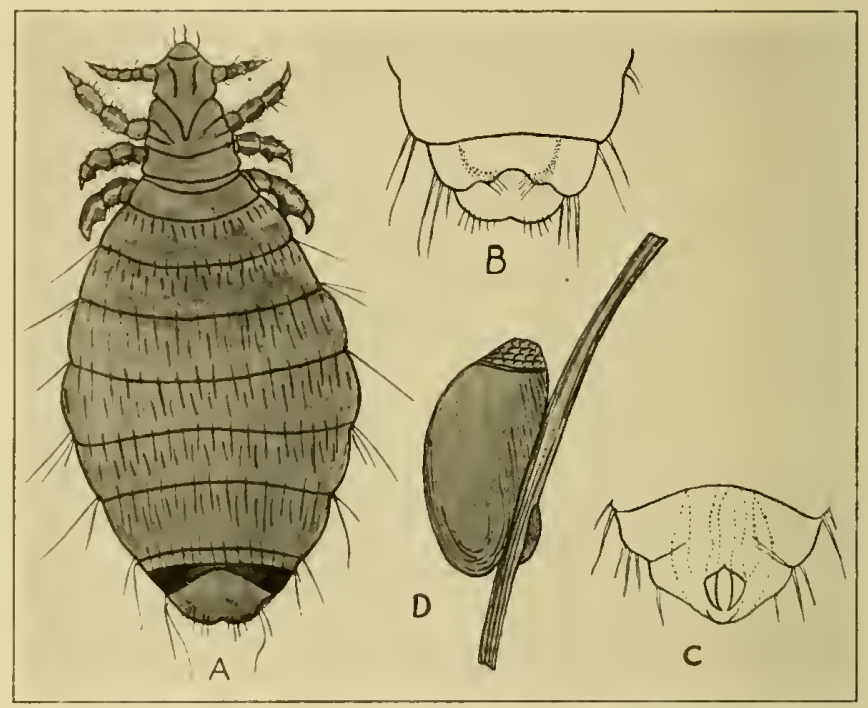

FIG. 43.-Hæmatopinus pedalis: $a$, adult female; $b$, ventral view of terminal segments of same; r, terminal segments of male; d, egg (after Osborn, Bul. No. 5, Bureau of Entomologry, U. S. Dept. of Agr.).

This species is rare. It is said to occur only where the hair is short upon the legs and fret, especially about the lew-claws. It is from this location that it gets its common name, "sheep-foot-louse."

2. Trichodectes sphærocephalus. Philopterida (p. 71).-Head broad as long, giving the rounded appearance from which the specific name is derived. The abdomen is elliptical, each segment having a median band which is somewhat rounded upon its anterior border. The general color is white (Fig. 44). Of rather rare occurrence.

The common so-called "louse" of sheep is not a truc louse, but the degenerate Hy Mclophagus ovinus, described elsewhere under the par- 
asites of the order Diptera. Pediculosis, properly so called, is seldom met with in sheep. While the sucking lice are localized to the lower parts of the legs, the biting lice lie deep in the wool, close to the body, seriously altering the fleece by cutting the fibers with their mandibles. Their location makes the condition rather a difficult one to contend with.

\section{Pediculosis of the Goat}

Goats have one suctorial species,-Linognathus stenopsis. The biting louse,-Trichodectes climax, is fairly com mon and is the only species of this genus upon goats that is well established.

1. Linognathus stenopsis (Hæmatopinus stenopsis). Pediculidæe (p. 70).- - Head long, narrow, and rounded in front; there are two lateral notches, below which are widened temples. From these the head narrows rapidly and becomes deeply fitted into the thorax. The thorax is widest posteriorly where it is somewhat concaved upon

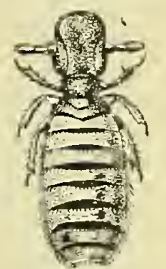

Fig. 44-Trichodectes sphærocephalus (after Osborn Bul. No. 5, Bureau of Entomology, U. S. Dept. of Agr.). the abdomen. The abdomen in outline is an elongated oval with stigmata near lateral margins of segments. The female is $2 \mathrm{~mm}$.; the male $1.5 \mathrm{~mm}$. in length.

2. Trichodectes climax. Philopteridæ (p. 71).-Head quadrangular in shape and broader than long. The abdomen is oval with median dark bands upon the segments. The head and thorax are reddish brown; the abdomen is pale yellow.

During the winter months especially, goats are apt to harbor lice in rather large numbers. As in other animals the sucking louse produces the greater irritation. The skin may become bare in places with numerous inflamed and ulcerated areas covered with crusts. In Angora goats especially, the biting louse causes a great depreciation from its habit of cutting the hairs with its mandibles.

\section{Pediculosis of the Hog}

Domesticated and wild hogs have one species of louse, Hamatopinus suis (H. urius). This is the largest known member of the suctorial group. The head is very long and narrow, cone-shaped, and rounded in front; just posterior to the attachments of the antennæ are horn-like protuberances, forming deep notches. The thorax is somewhat broader than long; dark, transverse bands may be noted upon the legs. The abdomen is oval in outline, with distinct segment borders; the stigmata are upon prominent lateral protuberances. The thorax is brownish red in color; the head and abdomen yellowish gray. The female is 5 mm.; the male $4 \mathrm{~mm}$. in length (Fig. 45 ).

This louse is a very active blood sucker, living upon hogs of any age 
or condition and everywhere where these animals are found. The intensity of the pruritus produced is proportionate to the parasite's size, the skin, as they increase in numbers, becoming covered with papules and scales. The constant itching and worry, which seems to

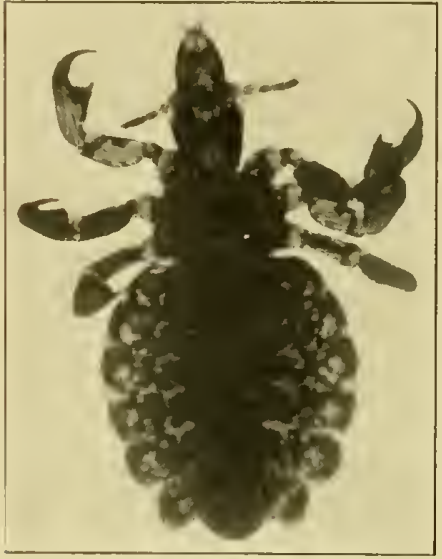

Fis. 45.- Hifmatopinus suis (from photograph of mounterl speeimen, by Hordt).

thorax anteriorly is but slightly wirler than the head; ablomen elongate oval in outline, the margins of the segments appearing somewhat rounder; st igmata marginal and distiuet. The general color is yellowish white. The female is 2 mm.; the male $1.5 \mathrm{~mm}$. in length (Fig. 46).

2. Trichodectes latus. Philoptericle (p. 71).Entire insect hroad and short; more than half as broarl as long. The hearl large, slightly rounded in front, and broader than long. The abdomen of the female is broad and somewhat globular in outline. The nedian abdominal bands or spots are alssent. The general color is bright yellow (Fig. 47).

Dogs do not seem to be as seriously affected as other animals by the presence of lice. The sucking louse is the more tormenting, and is usually found about the chin, under part of the neck, and breast, though, with the biting louse, it may be found on any part of the body. The biting species is most often found upon puppies.

The biting louse infesting dogs is particularly of medical interest in 
being a larval host of the common tapeworm of the dog, Dipylidium caninum, as is also the dog flea, Ctenocephalus canis. Infection of the louse by the larva (Cysticercus trichodectes) is readily brought about through ingestion of the eggs of the tapeworm which may have collected about the anus or in the litter of the kennel. This tapeworm is occasionally found to be present in the intestines of human beings, particularly children. It is quite conceivable how such infestation might occur in the fondling of lousy or flea-infested dogs, especially if the person's food be about at the same time to act as a vehicle for the insects containing the larva.

\section{Pediculosis of the Cat}

Trichodectes subrostratus, the only louse harbored by the cat, is about the same length as the biting louse

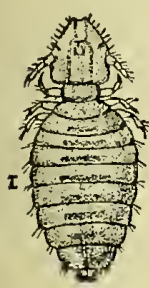

Fig. 48 .Trichodectes subrostratus (after Osborn, Bul. No. $5, \mathrm{Bu}$ reau of $\mathrm{En-}$ U. S. Dept. of Agr.). tomology,

of the $\operatorname{dog}(1$ to $1.3 \mathrm{~mm}$.), but is not so broad, and is distinguished by its pointed head, which is slightly longer than broad. The abdomen is oval, with median bands.

The head and thorax are bright yellow in color, the abdomen whitish (Fig. 48).

Lousiness is not often met with in the cat; when it does occur it is usually the accompaniment to a debilitated condition in young animals.

\section{Pediculosis of MaN}

Three species of pediculi infest man, Pediculus humanus ( $P$. capitis), the head louse, $P$. corporis $(P$. vestimenti), the body louse, and Phthirius pubis ( $P$. inguinalis) the pubic or so-called "crab-louse."

1. Pediculus humanis. Pediculidæ $(\mathrm{p}, 70)$.- - The head is somewhat cliamond-shaped, short, and about as broad as long. The abdomen has seven distinct segments, each bearing stigmata laterally placed. Color gray with darkened margins. The color is said to vary from light to dark according to the color of the skin or hair of the host. The female is 2.5 to $3 \mathrm{~mm}$.; the male about $2 \mathrm{~mm}$. in length.

2. Pediculus corporis. Pediculidx (p. 70).-Resembles preceding species, of which it is regarded by some authorities as merely a variety. It is slightly larger. The color is grayish-white. It lives upon the clothing of its host, crawling upon the body to feed.

3. Phthirius pubis. Pediculidæ (p. 70).-Distinctly differs in appearance from the two preceding. The head is short and thick, fitting 
into a broad concavity in the thorax. The thorax is broad and apparently fused with the abdomen, the two forming a somewhat heartshaped body with base anterior. The first pair of legs is much more slender than the second and third which are stout and terminated by powerful claws fitted for clasping the hairs. The female measures about $1.5 \mathrm{~mm}$; the male about $1 \mathrm{~mm}$. in length. It infests the hairs of the pubic region and of the armpits, rarely passing to other parts.

Of these three species Pediculus humanus is the most widely distributed.

\section{Pediculosis, Control and Treatment}

C'ontagion in pediculosis is due to the rapid succession of generations of lice, their passage from host to host being facilitated by close association, grooming utensils, blankets, harness, bedding, etc. It is possible for domestic animals of different species to infect each other. Such migrations, howcver, are usually of an accidental nature, and the parasites will not as a rule remain to multiply upon a host foreign to them.

Long hair, especially if combined with unclean conditions, predisposes to lousiness. If in addition there is debility, the etiologic factors become ideal. Plenty of nutritive food and a thorough cleaning up of animals and their surroundings are, therefore, essential to success, whatever metsures of eradication may be applied.

After the removal and burning of litter the stables, kennels, etc., may he treated with boiling water and afterward whitewashed or washed with a three to five per cent. creolin solution. For spraying interiors an emulsion of kerosene (formula, page 48), or the lime-sulphur preparation (page 125) may be used.

Clipping of long-haired animals, which may include the horse and ox, greatly simplifies their treatment. The Melophagus infesting sheep is removed with the fleece at time of shearing, the animal soon ridding itself of any which may have remained upon the skin.

Among the considerable number of insecticide agents used upon the bodies of infested animals but one or two of those most effectual and most commonly cmployed need be mentioned here. A decoction of tobacco, one ounce to the quart of water, as a local application answers well for all animals. In using this preparation the possibility of nicotine poisoning should be kept in mind. Large areas of the borly should not be dressed at the same time.

Horses may be treated with creolin two to three per cent., or kerosene emulsion. Brushes and combs, after having been disinfected by scalding, may have a little kerosene sprinkled upon them as they are used. Preparations of kerosene should not be applied to sweating animals or while they are exposed to hot sunshine. Friction with fatty substances, 
as linseed oil, will kill by asphyxia lice with which it comes in contact. This treatment is more effectual if kerosene be shaken up with the oil in the proportion of one of the former to two of the latter. A mixture of kerosene, sulphur, and lard, equal parts, is also quite useful for this purpose.

These treatments will apply to cattle as well as to horses. Where large numbers of cattle are affected resort must be had to spraying with kerosene emulsion or dipping. For the latter purpose ordinary sheep dip or a lime-and-sulphur preparation may be used.

The large sucking louse of the hog is found principally inside, behind, and in front of the ears, on the breast, and on the inner side of the elbows. For this animal the stronger preparations of the insecticides should be used, as creolin five per cent. or kerosene and oil equal parts. The kerosene, sulphur, and lard mixture is quite a suitable one for these animals. It is well also to treat their wallows with a three to five per cent. solution of creolin.

For dogs creolin in two per cent. strength is quite satisfactory. Longhaired dogs, especially if heavily infested, should be clipped before treatment. For small house animals, as toy dogs and cats, pyrethrum powder, applied to the moistened skin as for fleas, is most suitable.

Whatever insecticide is used it is well to apply vinegar in conjunction with it. This may be added to the fluid preparations in the proportion of about ten ounces to the quart, or it may be applied separately diluted with twice its quantity of water. The vinegar has a destructive action upon the eggs which may survive the ordinary remedies used to destroy the insects.

Sodium fluoride, which is recommended in the treatment of lice of poultry, all of which are biting lice, should also be effective for the biting lice of mammais, though experience with it up to the present time is not sufficient to have established its value in such cases. In its application it should be rubbed into the hair over all parts of the body. The treatment is only applicable to biting lice.

All measures used for the eradication of lice, whether in the quarters or upon the bodies of their hosts, should be repeated at least three times at intervals of eight to ten days. This is necessary to destroy the lice which may emerge from remaining eggs. 


\section{CHIPTER IX}

\section{LICE OF POULTRY. THE BEDBLG}

Birds under the usual conditions of domestication are especially prone to lousiness; there are, in fact, few fowls entirely free from them. Though, relative to their numbers, lice upon poultry probably do less harm than the blood-sucking ticks, their rapid multiplication, and the fact that they pass their entire cycle upon the borlies of their hosts, make it probable that any legree of infestation will become a destructive misance. The constant annoyance due to their crawling upon the skin and among the feathers, with the energy expender in the efforts to be rid of them, causes fowl to droop and become ready victims to other diseases commonly affecting poultry. Flesh and egg procluction, under such conditions, must essentially be retarded to a degree commensurate to the infestation.

Young (licks are especially apt to succumb. They give evidence of the prosenere of lice by drowsiness, refusal to eat, and an emaciated borly. The symptoms are generally accompanied by a loss of feathers, especially alout the head and lower part of the neck. Chickens hatched in an incubator should be free from them, and they will remain so unless placord witl a lousy hen or put in infested quarters.

The head and upper part of the neck afford a protective location for the lice, as they (ammot here be reached by the beak. They may, however, especially in older birds, be found upon all parts of the body.

The biting speries with which lirds are infested belong with either the Philopteridie or Liotheida, the former containing species harbored by both mammals and birls, the latter lice of birds only.

\section{LiCE OF CHICKENS}

The Philoptricla of chickens are Gonioentes gallina, (r. gigas, Lipeurus caponis, and $L$. heterographus.

1. (ioniocotes galliner (G. hologaster).-Head broad as long; anterior borker rounded; angular at temples. Ablomen sac-like in outline, having curved hands upon lateral borders of segments; transverse patches in double row. Gencral color dirty yellow. Female about $1 \mathrm{~mm}$. in lingth.

A rommon species.

2. Coniocotes gigas ( $G$. abdominalis).-Head rounded, circular in front. Thorax narrow. Abdomen large and but slightly longer than 
broad; each segment marked laterally by long tongue-shaped spots. The general color is yellowish. The female is 3 to $3.5 \mathrm{~mm}$. in length, a size exceptional in this genus (Fig. 49).

About as common as the preceding species.

3. Lipeurus caponis (L. variabilis). - In all members of this genus the body is elongated and narrow. Head longer than broad and rounded in front. Abdomen long and slender with black margins. Color yellowish white. Female about $2 \mathrm{~mm}$. in length (Fig. 50).

By its long and slender appearance this species can easily be distinguished from others infesting the chicken. It is not very common.

4. Lipeurus heterographus.-Head more narrow in front and body much stouter than in preceding species. Abdomen elongated oval in

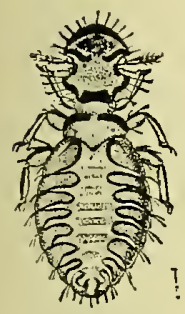

FIg. 49.-Goniocotes abdominalis (after Osborn, from Denny, Bul. No. 5, Bureau of Entomology, U. S. Dept. of Agl.).

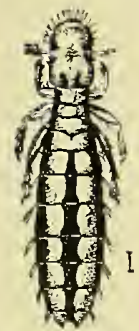

FIG. 50.-Lipeurus variabilis (after Osborn, from Denny, Bul. No. 5, Bureau of Entomology, U. S. Dept. of Agr.).

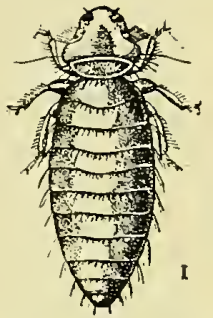

Fig. 51.-Menopon pallidum (after Osborn, from Denny, Bul. No. 5, Bureau of Entomology, U. S. Dept. of Agr.).

outline with median spots on each ring. General color pale yellow. Female $2 \mathrm{~mm}$. in length.

This species has not been often observed in this country. It is said to also occur upon certain species of pheasants.

Of the Liotheidx chickens are hosts to two species, Menopum trigonocephalum and $M$. biseriatum.

5. Menopum trigonocephalum (II. pallidum; Menopon pallidum).Head somewhat triangular, rounded in front and at the temples. Abdomen of female elongated oval in outline, in male longer and narrower. Legs stout and hairy. Color light yellow. Female about $1.5 \mathrm{~mm}$. in length (Fig. 51).

This is the most prevalent of all of the hen lice. It is an active rumuer and passes readily to other species of birds.

6. Menopum biseriatum (Menopon biseriatum). - Head somewhat crescent-shaped. Legs stout. Abdomen elongate. Has the same gen- 
eral color as $M$. trigonocephalum, but is larger. Female about $2.5 \mathrm{~mm}$. in length (Fig. 54).

Less common than preceding species. It attacks young ehicks, especially about the head and anus. It may also be found upon turkers and peafowl.

\section{Lice of TuRkers}

The Philopteridie of turkeys are Goniodes stylifer and Lipeurus meleagridis.

1. Goniodes stylifer.-Head broad as long, well rounded in front, with posterior angles projected backward into points which are terminated by strong bristles. Thorax angular and narrowed anteriorly. Legs slender and hairy. Abdomen broad, with tongue-shaped bands on the sides. Hairs are numerous and long on both surfaces. Color yellowish white. Female about $3 \mathrm{~mm}$. in length (Fig. 52).

This is a large species common upon turkeys everywhere.

2. Lipeurus meleagridis (L. polytrapezius).--Head longer than broad, rounded in front and at the temples. Thorax and abdomen narrow and clongate; last abdominal segment in female deeply notehed. Color pale yellow. Female about $2.8 \mathrm{~mm}$, in length (Fig. 53).

Also quite common.

The Menopum of the turkey is $M$. biseriatum (Fig. 54), referred to under the Liotheidie of chickens.

\section{Lice of DuCks AND Geese}

Of the Philopteridze ducks and geese harbor two speeies, Philopterus ieterodes and Lipeurus anatis.

1. Philopterus ieterodes (Doeophorus ieterodes).-Head longer than broad, rounded in front; lower portion expanded and rounded. Abdomen oval in outline, white in eenter, and with dark lateral bands. Color brownish red. Female $1 \mathrm{~mm}$, in length.

Of common occurrence.

2. Lipeurus anatis (L. squalidus).-Head longer than broad, coneshaped, rounded in front. Thorax and abdomen elongate with dark borders. On the abdomen the horder is broken into patehes eorresponding with the segments. General color light yellow. Female about $4 \mathrm{~mm}$. in length (Fig, 55).

Frequently found upon both domestic and wild ducks.

The Liotheidse of ducks and geese are Trinotum luridum and $T$. lituratum.

3. Trinotum luridum (Trinoton luridum).-Head as wide as long, somewhat triangular in shape, with rounded corners. Thorax longer than head. Abdomen long and narrow, with dark bands upon the 


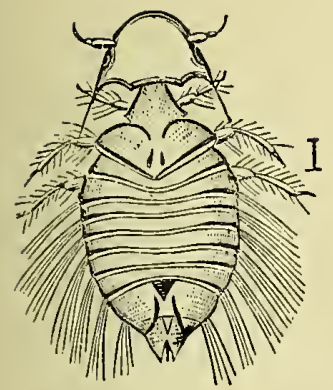

Frg. 52.-Goniodes stylifer (after Osborn, Bul. No. 5, Bureau of Entomology, U. [S Dept. of Agr.).

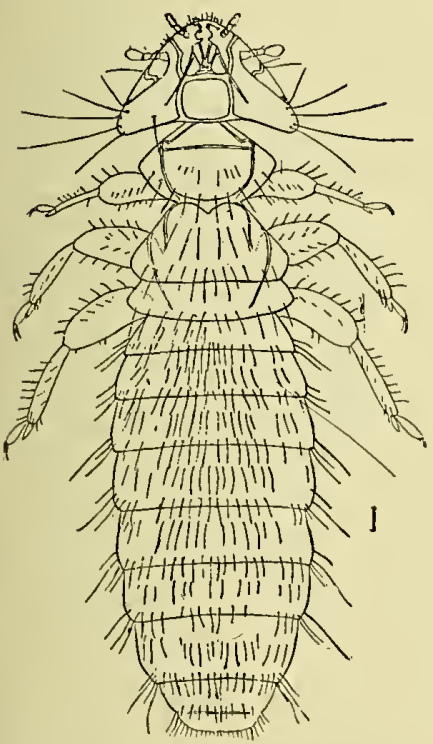

FIG. 54.-Menopon biseriatum (after Osborn, Bul. No. 5, Bureau of Entomology, U. S. Dept. of Agr.).

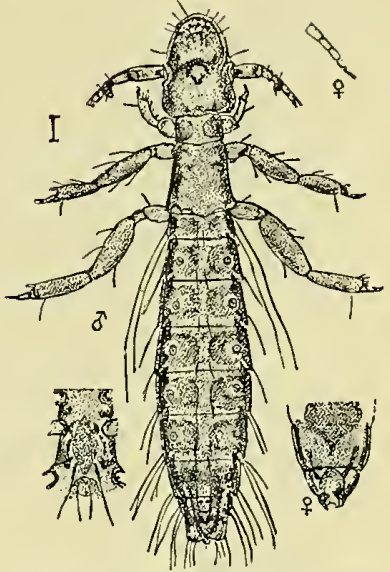

FIG. 53.-Lipeurus polytrapezius (after Osborn, from Piaget, Bul. No. 5, Bureau of Entomology, U. S. Dept. of Agr.).

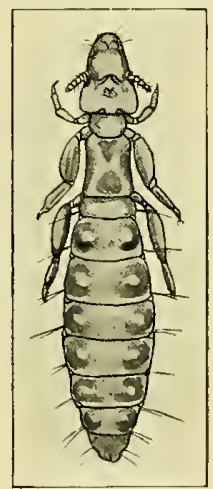

FIG. 55.-Lipeurus squalidus (after Osborn, Bul. No. 5, Burean of Entomology, U. S. Dept. of Agr.). 
segments. Entire insect long and narrow. General eolor grayish. Female 4 mm. in length (Fig. 56).

A common species.

4. Trinotum lituratum (Trinoton lituratum).- Shorter and smaller than the preceding species, with head, thorax, and abdomen relatively broader. Legs broad and stout. Abdominal segments bordered by darkened spots. Color white.

This speries occurs upon domestir gense.

\section{LICE OF SWAN}

Philopterus cygni and Ornithonomus cygni are species of Philopterida harbored by swan.

1. Philopterus cygni (Docophorus cygni).-Head about as broad as long, rounded in front. Thorax short and narrow. Abdomen saeular, white in center, darkened at sides. Head, thorax, and legs reddish brown. Fomale $1 \mathrm{~mm}$. in length (Fig. 57).

This is the "Little Red Swan Louse." It is quite rommon.

2. Ornithonomus cygni (Ornithobius bucephalus; O. cygni).-Head massive and nearly as broad as long. Thorax about the same length as head. Abdomen narrow oval, tapering toward apex; black points on outer margins of four of the abdominal segments. The body is transparent and mueh flattened. Gomeral polor white. Female $4 \mathrm{~mm}$. in length (Fig. 58).

Occurs in great abundanee on all speries of swan.

\section{Lic'E of Pigeons}

The more common Philoptridre of pigeons are froniocotcs compar, Goniodes damicornis, and Lipeurus columba.

1. Goniocotes compar.- Ifead large, nearly as broad as long, rounded in fromt. Thorax narrow. Abdomen broad oval. Color dirty yellow. Fenale about $1.3 \mathrm{~mm}$. in length (Fig. 59).

Found quite frequently.

2. Goniodes damicomis.--Head about as broad as long, rounded in front, angular behind. Legs stout. Abdomen broad and short. Color brown. Female 2 mm. in length (Fig. 60).

Not as conmon as preceding species.

3. Lipeurus columba (L. baculus).-Characterized by its extreme slendemess. Head long and narrow, as is also the thorax and abdomen. Upon the abdominal segments are brownish patches. Head and thorax brownish red in color; abdomen dusky. The female is $2 \mathrm{~mm}$. in length.

Occurs abundantly. 


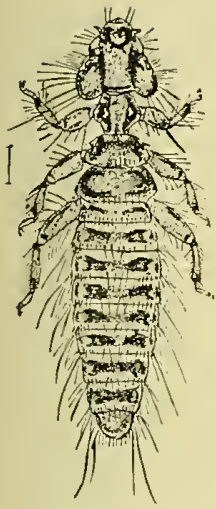

Frg. 56.-Trinoton luridum (after Osborn, Bul. No. 5 , Bureau of Entomology, U. S. Dept. of Agr.).

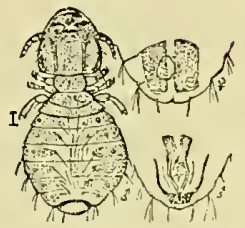

Frg. 57.-Docophorus eỹgni (after Osborn, Bul. No. 5, Bureau of Entomology, U. S. Dept. of Agr.).

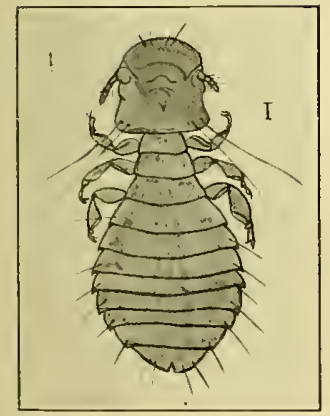

Fia. 59.-Goniocotes compar (aiter Osborn, Bul. No. 5, Bureau of Entomology, I. S. Dept. of Agr.).

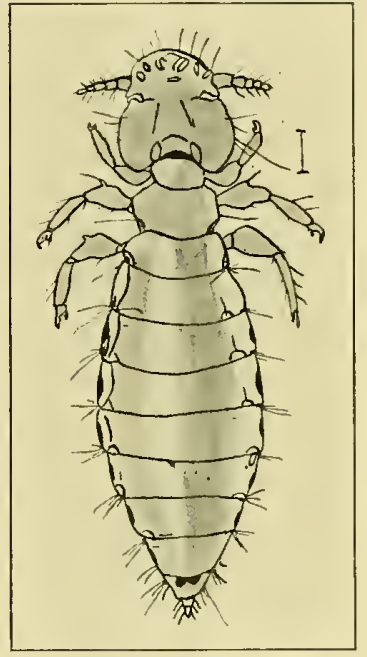

Fig. 58. - Onithobius eygni (after Osborn, Bul. No. 5, Bureau of Entomologs, C'. S. Dept. of Agr.).

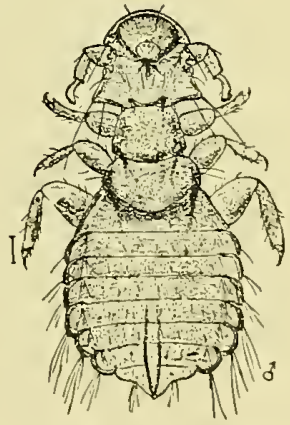

Frg. 60.-Goniodes damicornis (after Osborn, Bul. No. 5, Bureau of Entomologs, I. S. Dept. of Agr.). 


\section{Control and Treatment}

In dealing with lice of poultry we should first discriminate between the lice and the ticks, bearing in mind that the latter do not breed upon their hosts. According to whether they be one or the other the treatment will be modified somewhat, though certain measures of eradieation may be suitable for either. All speeies of lice, without a known exception, passing their transformation upon the host, there may be eonfidence in attacking them that there are no eggs and young developing in some out-of-the-way retreat, as in the case of ticks or bedbugs.

As a means of controlling bird liee the dust bath should receive first attention. The fine dust particles enter the spiracles of the insects, killing them by suffocation, therefore, of whatever material it may consist, the dust will be most effectual when fine and penetrating. Road dust is usually quite suitable; it will be the more effieient if powdered tobacco be added in the proportion of about one of tobacco to five of dust. Fine ashes, in which powdered sulphur is mixed, make an excellent dust wallow. A mixture of road and lime dust, with the addition of a cupful or two of sulphur, may be used with as good results. The clust baths should be in deep and roomy boxes placed where they will be sheltered from the rain.

As an insecticide for the individual treatment of badly infested birds, any oleaginous substance is effeetual. As with dust, the principle upon which its use is based is that of suffocation, the unctuous agent serving to plug the breathing pores of the insect. A mixture of lard and sulphur answers well for all birds. It should especially be applied at the throat, upper neck, bases of the wings, and at the base of the tail feathers. If a powder is used, as pyrethrum, the skin should be first moistened with soapy water or equal parts of glycerin and water and the powder then blown well under and through the feathers.

Investigations by the United States Bureau of Entomology with sodium fluoride have demonstrated that lice infesting poultry may be readily destroyed by the application of a small quantity of this powder. It may be used in the powdered form or as a dip. Applied by the former method, it should be sprinkled under the feathers of the neck, breast, back, tail, below the rent, and upon the under side of each wing as these are spread. If used as a dip, this may be prepared by adding one ounce of commercial sodium fluoride to the gallon of water. The solution should be made tepid and the entire body of the fowl, excepting the head, immersed in it. For the treatment of one hundred fowl, about one pound of the powder will be required.

As the lice are likely to be dislodged from their hosts to be harbored for a time about nests, loosts, ete., it is essential that the eradicative measures be also applied to the quarters of infested birds. The louse 
most commonly found upon the hen, Menopum trigonocephalum, is an especially active runner, readily passing to other species of birds or to any object with which the infested animal is in contact. It is said that horses kept in the vicinity of chicken houses harboring this louse are often seriously troubled by it.

In this connection the measures recommended for the eradication of the lice of mammals and poultry-infesting bedbugs will in general apply here. All nesting material and litter must, of course, be cleared out and burned or buried. A washing down with five per cent. creolin or carbolic acid solution should follow, the usual whitewashing in such cases adding to the probability of a complete destruction of the lice. The lime and sulphur mixture (page 125), applied as a spray to all parts of the interior, is penetrating and gives satisfactory results.

As a simple agent for the killing of lice or mites in the hen house and dovecot the cloud of lime dust is said to be of much value. In the application of this method the birds should be absent and the quarters closed. A few handfuls of finely powdered lime are then thrown against the roof and walls, producing a cloud of clust. This will settle upon the roosts, nest compartments, and floor, and into the crevices, destroying many of the exposed vermin. Afterward the place should be swept out and the sweepings buried, burned, or otherwise destroyed.

Fumigation is commonly resorted to, and may have value as a contributory measure. The sulphur fumigation, applied as recommended in the eradication of bedbugs, will serve here as well.

Observations made as to the length of time required for the hatching of the eggs, while not complete, indicate that for species of bird lice in general, five to six days are necessary at least. Therefore, in repeating treatments intended to kill individuals hatched from remaining eggs, there should be an intervening period of about ten days.

\section{Order V. Hemiptera}

Insecta (p. 15).-This group includes the cicadas, plant lice, and true bugs. The mouth parts are suctorial, the mandibles and maxillæ being modified into bristle-like structures for puncturing and extracting the juices of plants or the blood of animals. The labium is usually jointed and forms a sheath for the piercing bristles. There are usually four wings, some forms having the first pair thickened and leathery at the base, while only the tips are membranous and elastic. It is from this "half-winged" structure that the order derives its name. In some of the lower forms (bedbugs) wings are absent. A characteristic of the order is the presence of stink glands, which in the adult open ventrally on the metathorax. The secretion from these glands has a disgusting odor, probably originally of defensive service to the insect though in parasitic formis rather serving to reveal their presence and location. The meta- 
morphosis is incomplete, the immature insect resembling the adult except in the absence of wings.

\section{Fanlly C'micide}

Hemiptera (p. 89). Bedbug and allies.- The body is much flattened and is ovate in outline. The adults are reddish brown in color; young yellowish white. When full grown they are from one-sixth to onefifth of an inch in length. The mouth parts inclose long slender stylets (Fig. 61, d). Ocelli are ahsent. Wing-cover's rudimentary (Fig. 61, e).

\section{('IMEx Lectulatius}

Acanthia lectularia. The conmon bedbug. (Fig. 61).-Cimicidæ (p. 90). The body is covered with short hairs; rostrum short; third and fourth joints of antenne much thinner than first and second; second segment of antennx shorter than third.

The eggs are oval, pearly-white, and about a millimeter in length. The young leave the egg by a small opereulum at the end. The female deposits from one hundred to two hundred eggs in cracks, crevices, and seams of beds and hedding, beneath loose portions of wall-paper, baseboards, floor spares, and similar retreats.

Hatching occuls in about one week. Development from the nymphal to the adult stage will, under favorable conditions, occupy about six weeks. The time required for the development of adults from deposited eggs under such conditions may, therefore, be approximated at from seven to right weeks.

Habits and Effect of Bite. In their feeding halits bedbugs are nocturnal, hiding in their darkened retreats during the day and coming forth at night to erawl upon the legs, arms, neck, or other unprotected parts of their victims, where they will feed to repletion. After this engorgment the insects will retreat to their usual haunts to remain for several days, dnring which time the meal is digested:

The effect of the bite of the bedbug varies, depending upon the sus("eptibility of the one attacked. In some it produces marked irritation with more or less swelling; others may not be made aware of its presence. The inflammation experienced by sensitive persons scens to result mainly from the puncture of the skin. The biting organ is like that of other hempiterous inseets; there are four piercing filaments within the labim which is closely applied to the point of puncture as the blood is drawn up.

The degree to which the insect may injure other animals than man is somewhat obscure. Probably the same or closely allied species to those attacking man attack animals in the same manner. Chickens are es- 


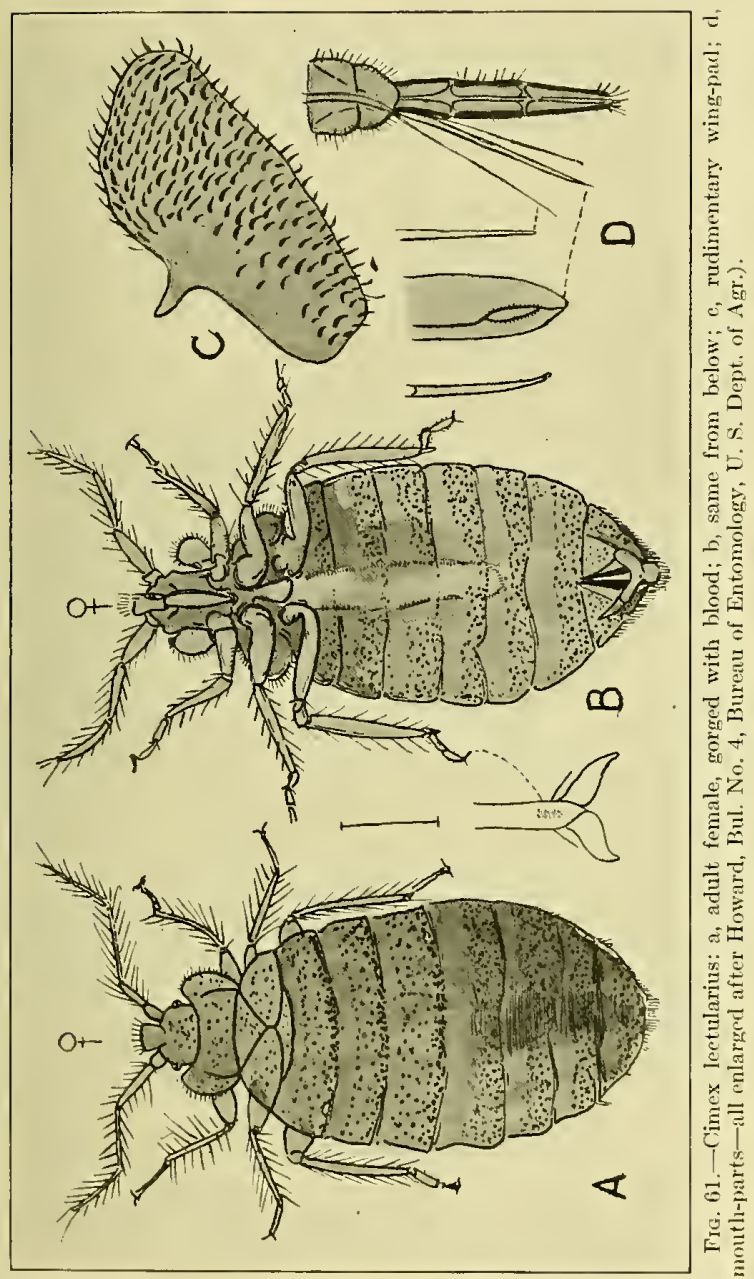


pecially likely to be their hosts, the usual quarters of poultry affording an ideal harbor for such pests.

Control.-Bedbugs may be easily carried upon elothing, therefore public conveyances and places where people of all sorts and conditions of living may congregate, afford a common means for their dissemination. They are highly prolific, and the introduction of a single eggbearing female may be sufficient to start a colony of bedbugs within a few montlis.

Eradication is made somewhat difficult by the parasite's habit of seeking hiding places during the day, therefore anything used for this purpose must be of such a nature that it will penetrate into cracks, crevices, joints of bedsteads, mattress seams, and all such places where the gregarious insects are in the habit of assembling and depositing their eggs. Powders, such as pyrethum, are of practically no value as they are not sufficiently penetrating. One of the best remedies is kerosene, applied with a feather, or, better, with an ordinary machine oiler. Benzene is as effectual and will volatilize more readily, but must be used with great caution against ignition. A solution of corrosive sublimate in alcohol may also be used with good results. Fumigation is of doubtful value, though flowers of sulphur, two pounds to each one thousand cubic feet of room space, has been recommended for this purpose. The sulphur should be placed in a heap in a pan, a depression made in the top, and a small quantity of alcohol poured into this to facilitate burning. The container should be placed in a larger pan and surrounded by water as a precaution against fire. During fumigation the room should, of course, be tightly closed. Fumigating with formalclelyde gas is as useless against bedbugs as it is against other insects.

Whatever remedy may be applied, thoroughness is essential to success. Beds and berlding should be inspected daily, and all places where the bugs may have found a hiding place repeatedly treated. 'There will be less difficulty if brass and iron bedsteads are used, the old-fashioned wooden bedsteads furnishing many retreats into which the bugs can force their flat, thin bodies.

In infested chicken houses the parasites usually secrete themselves around the ends of the roosts and in the nests. Their attack upon the chickens at night results in a loss of flesh with reduced egg production. In heavy infestation chickens will often die from emaciation and loss of blood. If the propagation of the bugs in the chicken houses is not checked, they may spread to nearby buildings to become a source of anmoyance to other live stock.

Control measures in such cases consist in thoroughly renovating the chicken house. Roosts in wooden fittings should be taken down, and all loose humber, useless boxes, straw, or other material affording hiding 
places removed and burned. Possible breeding places remaining should be sprayed with kerosene or kerosene emulsion (page 48). Scalding hot water or whitewash will destroy both the insects and the eggs. The kerosene application should be repeated at frequent intervals to insure the eradication of following generations. 


\section{CHAPTER I}

\section{THE MITES}

Class II. Arachnida. Arthropoda (p. 13).- The arachnids may at once be distinguished from the insects by the relationship of the body parts anct the number of ambulatory appendages, as to be described.

The regions of the body ale more or less fused, the head being eommonly fused with the thorax to form the pephalothorax (Fig. 62).

The abdomen is in some forms segmented (seorpions), in others unsemmented ancl separated from the thorax by a deep construction (true spiclers).

Sometimes the eephalothorax and abdomen are fused into one unsegmented body (ticks and mites).

In the ardult there are four pairs of locomotor appendages, usually seven-jointed, attached to the rephalothorax. There ale no wings.

Antemna are absent.

The mouth parts are paired chelieere and pedipalpi, the first in front of the mouth, the second to the sicle.

The chelicere are short, ensisting of two or three joints. The last joint may have a claw-like termination for piereing and introducing poison into prey (spicters), or it may be in the form of small ehelse (scorpions).

The pedipalpi are longer and more like the appendages for locomotion. The terminal segment may be strongly chelate (scorpions).

The eyes are locaterl anteriorly upon the cephalothorax and consist of a virying number of ocelli. The eyes are never emmound.

The skin is of a leathery consistency and is not so hard as in insects.

Respiration is either by trachese or by so-ealled book-lungs, the latter consisting of a series of invaginations of the skin elosely applied like the leaves of a book. Either one or both of these forms of respiratory organ may of'eur in at single individual.

IIost arachnids are oviparous. In aberrant forms, as Linguatulida and Aearina, eretain adult appendages are aequired after a molt.

The elass Arachnida inelucles the seorpions, spiclers, ticks, and mites.

The two parasitie orclers are Aearina, which includes the ticks and mites, and Linguatulida, eontaining the speeies Linguatula rhinaria.

1) rele I. Acarina. Ticks and Mites.-Arachnida (p. 9.4). These are small, frequently mierosepie, arachnicls in which there is generally no distinct demareation between the cephatothorax and abdomen, the body regions being massed into one. 
Due to parasitism, the mites have undergone considerable modification, the scab mites are without eyes or organs of respiration, and generally the tips of the feet are terminated by suckers or bristles.

In the larval stage, the Acarina have but three pairs of legs, the fourth pair appearing behind the third after a molt.

The mouth parts are modified into a beak-like structure for piercing and sucking.

The sexes are separate and reproduction is by eggs which are extruded from the genital pore situated, as in other Arachnida, anteriorly on the ventral surface of the abdomen. In the scab mites (Sarcoptidæ) the females are provided with a second genital opening, the copulating vagina,

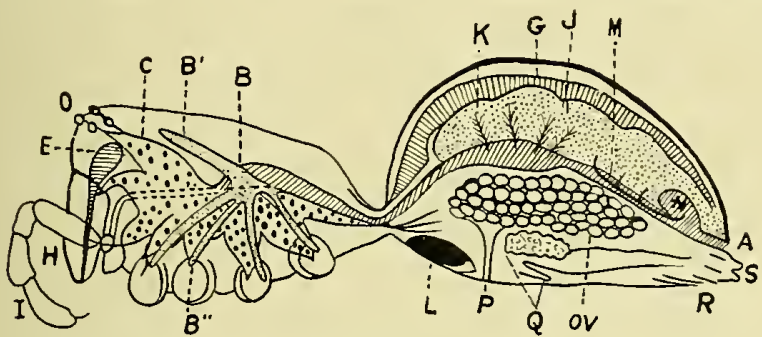

FIG. 62.-Diagram of the anatomy of a spider: $a$, anus; $b$, cecum of uesenteron; $b^{\prime}$, its anterior end; $b^{\prime \prime}$, branches of ceeum extending into legs; c, cerebral ganglion connected with ventral ganglionic mass; d, mesenteron; e, poison glands; $g$, heart; $h$, cheliceræ; $i$. pedipalpi; j. liver; $k$, hepatic duet; 1 , lung sac; $n$. Malpighian tubules; $n$, dilation of rectum into which Malpighian tubules open; o. eyes; ov, ovaries; p, female genital pore; $q$. large and small silk glands; $r$, opening of tracheal system; $\mathrm{s}$, spinnerettes (after Boas by Kirkaldy \& Pollard).

which is located posteriorly just in front of the anus. It is at this opening that spermatozoa are received during copulation, the anterior opening serving as the pore of the oviduct.

In their development the Acarina undergo a succession of stages. The larve are usually provided with but three pairs of legs (hexapodal), and have no definite sexual characters. After molting a fourth pair of legs appears, and the acarus cnters upon its nymphal stage. Following further molting the genital organs are acquired, and it has then reached the pubescent stage, or stage of sexual maturity. After copulation the female undergoes a further transformation, becoming an egg-bearing. or ovigerous female.

Parasitism.--The majority of the Acarina are parasitic, though, as to this habit, there is much diversity, some being semiparasitic, others essentially so and restricted to definite hosts.

The order contains a number of families of which the following are here consilered: 
Fanily I. Gamasidæ--Poultry mites.

Family II. Trombidiidæ.--Harvest mites or chiggers.

Family III. Sarcoptide.-Mange and scab mites.

Family IV. Demodecidæ.-Follicle mites.

Family V. Cytoleichidie.-Deep scated mites of birds.

Superfanily Ixorloidea.-The ticks.

Family I. Argasida. - The fowl tick and car tick.

Family II. Ixodidæ.-The cattle tick and other ticks.

Each of thesc contains species parasitic upon mammals or birls with the exception of the Demodecidie, which, so far as known, have only bcen found upon mammals.

The condition produced upon the host by the presence of parasitic Acarina is elcsignated medically as acariasis. Differing in their grade of parasitism, the numerous species bring about a varying degree of disturbanec to the skin which they inhabit. Accordingly there is distinguished sareoptic and psoroptic acariasis, the former produced by species which burrow and form subepidemic galleries in which they deposit their eggs, the latter by species living upon the skin's surface. The term mange is limited by most writers to acarises caused by species of the genus Sarcoptes and its near allics, or by Demodex, both living beneath the skin's surface, the last named in the hair follicles and sebaceous glands. The psoroptic form, in which there is deep scab formation, constitutes true scabies or scab, although these latter terms are frequently userl in a general sense relative to the condition produced by the mange and scab mites. Acari belonging with the families Gamasidx, Trombidiidre, and the superfamily Ixodoidea do not cause mange or scab.

\section{Classification of Parasites of the Clase Arachyida}

Class B. Arachnirla. P. 94.

Order I. Acarina. P. 94.

Family (a) Gamasidæ. P. 98.

Genus and Species:

Dermanyssus gallinæ. Host, poultry. P. 98.

Family (1) Trombichiidæ. P. 99.

Genus and Species:

Trombidium holosericeum. Larva attack man and lower animals. P. 100.

Family (e) Sarcoptidse. Mange and scab mites. P. 101.

Genus and speeies:

Sarcoptes scabiei var. Equi. Host, equines. P. 104.

S. scabiei var. Ovis. Host, sheep. P. 112.

S. scabiei var. Boris. Host, cattle. P. 114.

S. scahici var. Suis. Host, hog. P. 114. 
S. scabiei var. Canis. Host, dog. P. 115.

Notoedres cati var. Cati. Host, cat. P. 118.

N. cati var. Cuniculi. Host, rabbit. P. 118.

Psoroptes communis var. Equi. Host, equines. P. 108.

P. communis var. Ovis. Host, sheep. P. 109.

P. communis var. Bovis. Host, cattle. P. 113.

P. communis var. Cuniculi. Host, rabbit. P. 118.

Chorioptes communis var. Equi. Host, equines. P. 108.

C. communis var. Ovis. Host, sheep. P. 112.

C. communis var. Bovis. Host, cattle. P. 113.

Otodectes cynotis var. Canis. Host, dog. P. 117.

O. cynotis var. Cati. Host, cat. P. 117.

Cnemidocoptes mutans. Host, poultry. P. 132.

Cn. gallinæ. Host, poultry. P. 133.

Family (d) Demodecidæ. Follicular mange mites. P. 103.

Genus and Species:

Demodex folliculorum var. Ovis. Host, sheep. P. 112.

D. folliculorum var. Suis. Host, hog. P. 11 .

D. folliculorum var. Canis. Host, dog. P. 116.

Family (e) Cytoleichidae. P. 134.

Genus and Species:

Cytoleichus nudus. Host, poultry. P. 134.

Laminosioptes cysticola. Host, poultry. P. 134.

Superfamily Ixodoidea. Ticks. P. 139.

Family (a) Argasidæ. P. 139.

Genus and Species:

Argas miniatus. Host, poultry. P. 139.

Otobius megnini. Hosts, equines, cattle, etc. P. 140.

Family (b) Ixodidx. P. 141.

Genus and Species:

Ixodes ricinus. Hosts, cattle, equines, dog, etc. P. 143.

I. hexagonus. Hosts, cattle, dog, etc. P. 143.

Dermacentor variabilis. Hosts, cattle, dog, equines, etc. P. 143.

D. reticulatus. Hosts, cattle, equines, etc. P. 143.

Margaropus annulatus. Hosts, cattle, equines. P. 144.

Amblyomma anericanum. Hosts, cattle, dogs, equines, etc. P. 145.

Order 2. Linguatulida. P. 153.

Family (a) Linguatulidæ. P. 153.

Genus and Species:

Linguatula rhinaria. Host, dog. P. 153. 


\section{Famey I, Gamaside}

Acarina (p. 94).-The gamasid mites. The mouth parts are arranged for piercing and sucking, maxille fused into a tube, maxillary palps five-segmented and provided inwardly with secondary palps. The legs have six segments, the tarsi terminating by two hooklets. There are two stigmata located near the insertion of the posterior legs. The cephalothorax and aldomen are fused into one body. The integument is of a leatlery texture. Eyes are absent.

\section{Dermanissus Galline}

Poultry mite; clicken "tick" (Fig. 63). Gamasirla (p.'98).--Body somewhat egg-shaped with larger end posterior, slightly flattened from above to below. The lower half of the body is provided with short,

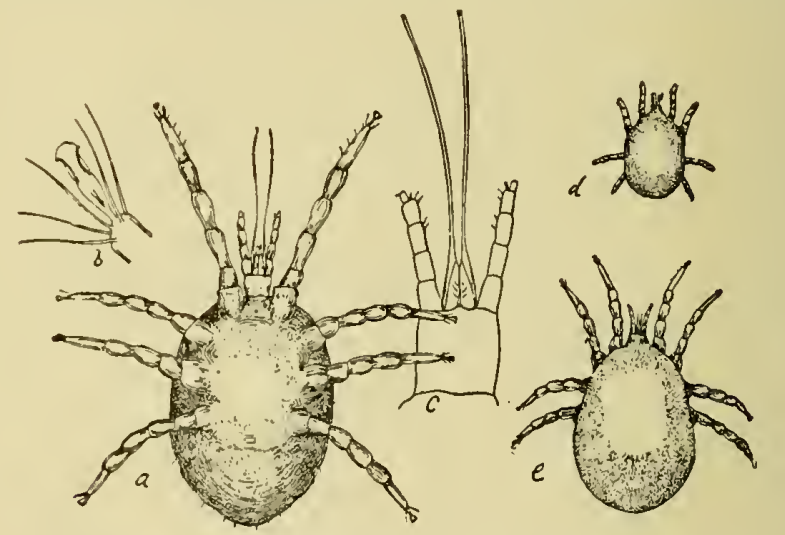

Fig. 63.-Dermanyssus gallinie: $a$, adult; b, tarsus; $c$, mouthparts; $d$ and $e$, young-all enlarged (after Osborn, Bull. No. 5, Bureau of Entomology, U. S. Dept. of Agr.).

well-separated bristles. The color is light gray with dark patches showing through the skin; when engorged with blood the color is a listinct red. The ovigerous fenale is rather less than $1 \mathrm{~mm}$. in length.

Occurrence and Habits. - The little poultry mite, found every where where clickens are kept, is one of the most persistent and injurious pests that the poultry raisel has to contend with. Remaining in darkened retreats about the henhous during the daytime, these acari come forth at night to swarm upon the fowls and suck their blood. Their attack, however, is not confined mitirely to the night, and hens may be driven 
from their nests by the activity of the pests which the warmth of their bodies creates.

The Dermanyssus does not limit itself to birds, but may attack mammals, including man, though these animals, being accidental hosts, the invasion is usually limited in its extent and duration. Horses kept in the vicinity of infested henhouses are likely to be tormented by the mites, the litter about stables so located affording a harbor to which they readily migrate.

The eggs are deposited in vast numbers in the daytime retreats. Under ordinary conditions about five days are required for the hatching of the hexapodal larvæ which do not wait for maturity to attack the chickens. They may, however, remain for months without a host upon which to satisfy their appetite for blood. Extremely prolific, they especially thrive upon filth, and large colonies may be found wherever such material has collected.

Effect.-Fowls suffer not only from the extreme irritation and annoyance of the attack, but additionally from the extraction of a considerable amount of blood. Prolonged infestation must essentially bring about a progressive emaciation and weakening which may end in death, young chicks especially being likely to succumb. In any event egg production is retarded, and the chickens, in their unthrifty condition, are unprofitable for marketing.

Control.-Cleanliness and plenty of sunlight are especially antagoistic to the Dermanyssus. The cleaning up measures set forth elsewhere for the eradication of the parasites of the henhouse need not be repeated here. Kerosene emulsion (page 48) is serviceable, but should only be applied after the entire interior has been stripped to the boards of everything movable and all crevices, joints, and roost insertions exposed. It is well to drench cracks and the ends of roosts with pure kerosene or scalding water. The ends of roosts, before being replaced, should be dipped in coal tar, and this spread along the roosts for about six or eight inches from their supports in such manner that the mites will be obliged to cross the tar before reaching the fowls. Pyrethrum powder, alone or mixed with lime dust, should be shaken through the fresh nesting material. The dust bath, as recommended in the treatment for lice, should always be accessible.

In order to insure continued freedom from the vermin it is necessary that the control measures be repeated at least three times at intervals of about ten days.

\section{Famrly II. TrombIDID.æ}

Harvest mites; chiggers, or red bugs. Acarina (p. 94).-The body is red in color and covered with bristles or fine hairs. The mandibles are chelate; palpi prominent. The legs have six to seven segments pro- 
vided with bristles or fine hairs, the tarsi terminating in two hooklets. Respiration is by trachere. There are two eycs, one located upon each side of the cephalothorax.

\section{Trombidium Holosericeum}

Trombidiidæ (p. 99).-Body red and nearly square; slightly narrower posteriorly where the terminal border is slightly concaved; body and legs covered with bristly hairs. Eycs pedunculated. About $1 \mathrm{~mm}$. in length.

Habits and Effect.-In the adult stage the Trombilium is freeliving, feeding upon the juices of plants and small insects. It is only parasitic in its larval condition, in which stage it will inhabit insects and attack warm-blooded animals as wcll. Living in the tall grass and upon the under side of the leaves of weeds, they are brushed off upon the hands or clotling of people and upon the bodics of animals as they pass through the regetation. They then proceed to burrow into the skin, setting up a most cxasperating itching with the formation of reddened patches often covering considerable areas. This phase of the mite's parasitism is peculiar in that it invariably perishes in the act of entering the skin. It is likely to be most troublesome during the late summer and autumn, the name Leptus autumnalis, under which the larval stage of the mite has been described, being derived from this fact.

Man is most often attacked about the lower parts of the legs and upon the hands. Among domestic animals, those which frequent locations densely covered with vegetation are the most likely to suffer. Hunting dogs especially are exposed, and on returning from the field will often exhibit symptoms of great itching about the face, paws, inner thighs, and belly, the parts most often attacked. Horses will be affected principally below the knees and hocks.

Treatment. - As the larval mitcs die upon entering the skin, the source of the irritation is soon eliminated and the intense itching will usually rapidly subside, leaving areas of epithelial exfoliation over the parts affected. Recently exposed animals will be relieved somewhat by frictions with a cloth sprinkled with benzene, or by the application of a mixture of equal parts of lime-water and linseed oil, or sulphur ointment may be used. Sponging with a solution of carbolic acid at about three per cent. strength in water to which a little glycerin has been added, will do much toward relieving the itching. Ammonia-water, or a solution of bicarbonate of soda are both of value for this purpose.

Persons working or passing through infested districts will, in considerable degree at least, be protected from attack by applying a mixture of kerosene and glycerin to the hands and ankles. 


\section{FAMILY III. SARCOPTIDE}

Mange, scab, or itch mites. Acarina (p. 94),--The body has the cephalothorax and abdomen fused; it is white or reddish in color. The cuticular surface is transversely striated and provided with bristles, sometimes with short dorsal spines. The mouth parts are beak-like, extending forward, and covered by the protruding labrum; cheliceræ scissors-like; maxillary palpi small and three-segmented. The legs are short and stout, have five segments, and are disposed in two groups of two pairs each, the anterior pairs, usually the larger and near the mouth parts, the posterior pairs near the abdomen. The tarsi commonly terminate in one or two hooklets; they may terminate in a long bristle or an ambulatory sucker, often upon a stalk which may be segmented. Respiratory organs are absent; respiration cutaneous. There are no eyes. All are scarcely visible without the aid of magnification.

There are frequently well-marked sexual differences. Males are considerably smaller than the females. In some males the fourth pair of legs is very small, and there may be plate-like copulatory suckers at the base of the abdomen with abdominal prolongations. As to the presence or absence of bristles or stalked suckers, the tarsi may terminate differently in the two sexes.

Development.-As already stated in the general reference to the Acarina, the Sarcoptidæ have three distinct stages in the development of the male, four in the female. After sexual maturity and fertilization of the female, the male usually dies. Following fertilization the female molts and enters upon her fourth or ovigerous stage,- the egg-bearing stage, recognizable by the presence of the genital pore upon the anterior ventral surface of the abdomen, through which the eggs are extruded.

The rapidity with which these acari breed is very great. It has been estimated that one female sarcopt will produce in a subepidermic gallery about fifteen individuals, from which, after ninety days, there may be $1,500,000$ descendants constituting the sixth generation.

The family includes a number of genera differing in their mode of attack and location upon the host. All are permanently parasitic. Of these, six, namely: Sarcoptes, Psoroptes, Chorioptes, Notoedres, Cnemidocoptes, and Otodectes are considered here. The characteristics and habits of the principal genera met with follow.

Sarcoptes (Fig. 64). Sarcoptidæ (p. 101).-The body is rounded or slightly oval; the mouth parts short and about as broad as long. Upon the dorsal surface of the body are a number of cone-like prominences and twenty spines, the latter short, thick, and grouped as follows: fourteen upon the abdomen, seren to the right and seven to the left side; six upon the cephalothorax, three to the right and three to the left. The legs are thick and conical, the posterior pair being nearly or quite 
concealed beneath the abdominal margin when the acarus is in chorsal view. In the female the first $t$ wo pairs of legs are terminated by stalked ambulatory suckers; the posterior pairs by bristles. In the male all of the legs are provided with stalked suckers but the third pair which terminates in bristles. The anus is located upon the posterior dorsal margin of the abdomen. Just anterior to this in the female is the copulating vagina (receptacuhm seminis). Upon the ventral side at the median anterior border of the abdomen of the ovigerous female is the genital pore. The males have no copulatory suckers or abdominal extensions.

The sarcoptes live upon man and practically all of the domestic mammals. In the latter animals they seek the parts of the body where the lrair is short, while in man their preference is for places where the skin is thin, as about the knuckles, between the fingers, and in the bend of the elbows and knees. A peculiarity of their attack is the habit in the fonale of eutting tumnels beneath the epidermis, in the botton of which she deposits her eggs (Fig. 65), a circumstance that renders this form of acariasis relatively difficult to cure.

The sarcoptes inhabiting the skin of various animals cannot be said to exhihit differences of specific importance. They may, therefore, be placer in a single species-Sarcoples scabiei-which may give rise to varietics according to host, as Sarcoptes scabiei, var. hominis of man, var. equi of the horse, and var. suis of swine, ete. The slight difference in these, as in other sarcopticlis, is mainly one of size.

Psoroptes (Fig.s. 68 and 69). Sarcoptidx (p. 101).-The body is oral, the mouth parts elongated and in the form of a cone. The legs of the anterior pairs are thick, the posterior pairs more slender; all four pairs extend heyond the margin of the body. In the female the first two pairs of leg: and the fourth pair are terminated by ambulatory suckers carried on long, three-segmented stalks, the third pair being terminated by bristles. The male has copulatory suckers serving for fixation to the fentale, and short posterior abdominal prolongations torminated by bristles. The first three pairs of legs are terminated by stalkerl suckers; the fourth pair is stunted.

Psoroptic scabies, the form produced by the members of this genus, is the most common and has been longest known. Unlike Sarcoptes, Psoroptes seck the parts of the body where the hair is long; they do not burrow beneath the epidermis, but attack the skin upon its surface, their punctures being followed by the formation of thick erusts. Under these they live in colonies which may coalesce and eventually cover areas of the body more or less circumseribed. Psoroptic seabies is most often observed upon animals with bodies covered wholly or in part by long hair, as the shcep, ox, and horse.

As with sareoptes, the difference in host inhahited by Psoroptes 
coincides with varieties which have unimportant and scarcely distinguishable differences. There is, therefore, but one species, Psoroptes communis, designated according to host as variety ovis of the sheep, var. bovis of the ox, var. equi of the horse, var, cuniculi of the rabbit, etc.

Chorioptes (Symbiotes; Dermatophagus) (Fig. 67). Sarcoptidæ (p. 101).-The body is oval. The mouth parts are about as broad as long and somewhat dome-shaped. The legs are long and visible beyond the sides of the body. The ambulatory suckers are large and carried on short, unsegmented stalks. In the female all of the legs are terminated by suckers excepting the third pair, these are terminated by bristles. The male has copulatory suckers and abdominal prolongations terminated by leaf-like processes. The fourth pair of legs is stunted; all of the legs are provided with suckers.

Chorioptic mites live, as do psoroptic, in colonies upon the skin where the hair is long and among the crusts which they form. There is one species, Chorioptes communis (Symbiotes communis, Chorioptes symbiotes, Dermatophagus communis). This infests the lower parts of the legs, especially of horses with long hairs upon the fetlocks, though in the ox this form of scabies generally has its seat at the base of the tail.

Cnemidocoptes (Sarcoptes). Sarcoptidæ (p. 101).-The body is rounded in outline. The mouth parts are short, broader than long, and rounded. In the female the legs are conical and very short; they are without suckers or bristles, terminating in two unequal hooklets. In the male the legs are somewhat longer and all four pairs are terminated by stalked suckers and bristles.

This genus contains a burrowing mite, Cnemidocoptes mutans (Fig. 74), which produces "scaly leg" in fowls; also a species known as the depluming mitè, Cnemidocoptes gallina, which attacks the skin of fowls near the insertion of the feathers.

Of the genera Notoedres (Fig. 71) and Otodectes, the former infests small mammals, and the latter lives in the external ear of the dog and cat.

\section{Family IT. Demodecidee}

Acarina (p. 94). Follicular mange mites (Fig. 70). These are very minute and worm-like. The body is distinctly divided into cephalothorax and abdomen, the latter elongated and transversely striated. The anus is on the anterior ventral border of the abdomen, probably serving in the female for both copulation and ovulation. The legs are three-segmented, short and stumpy. The mouth parts are suctorial. Respiration is cutaneous. There are no eyes. The length is about $0.3 \mathrm{~mm}$.

They undergo the same stages of development as other acari. 
There is but one species, Demodex folliculorum (Fig. 70), which inhabits the hair follicles and sebaceous glands of several mammalian species. Its size differs somewhat with its habitat, the difference in dimensions authorizing a division into varieties according to host.

\section{Scabies of THE Horse}

Horses, asses, and mules are affected with one form of mange and two of true scabies, as follows:

1. Sarcoptic mange, due to Sarcoptes scabiei var. equi.

2. Psoroptic scabies, due to Psoroptes communis var. equi.

3. Chorioptic scabies, due to Chorioptes communis var. equi.

Sarcoptic Mange of the Horse.- In the majority of cases acariasis of the horse is caused by Sarcoptes (Fig. 64). It begins most frequently
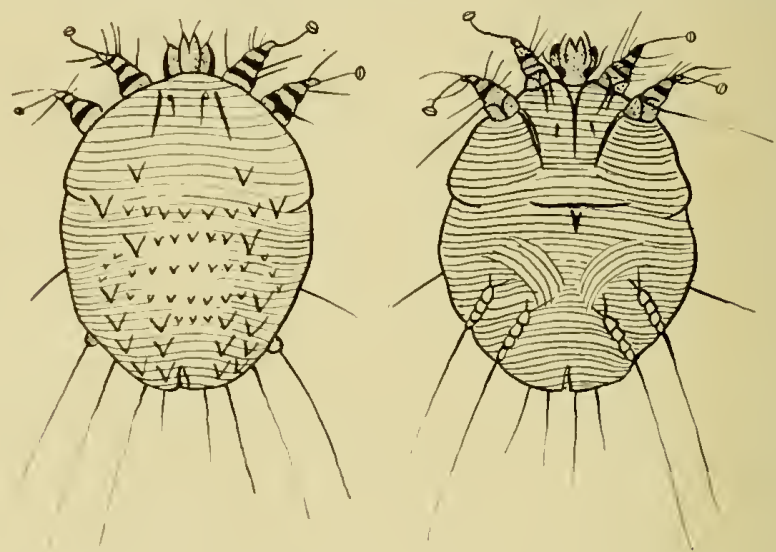

FIG. 64.-Sarcoptes spabiei var. equi, female; dorsal (left) and ventral (right) surface.

about the head, sides of the neck, or at the withers, extending, if neglected, over large areas of the body, involving in some cases even the lower parts of the legs. In its initial stage sarcoptic mange is somewhat slow in development, the small number of acari at the beginning not giving rise to symptoms readily observable. In from three to six weeks, however, the multiplication of the parasites has sufficiently progressed to clearly reveal the affection.

Symptoms.-The first symptom is itching, more or less intense, which the animal seeks to relieve by rubbing itself against anything available, or by biting affected parts of the body which it can reach. 
When groomed with the brush or currycomb it will manifest its pleasure by protrusion and movements of the upper lip, at the same time leaning toward the brush. This action is not peculiar to mange, however, as it may be observed in any itching skin affection of the horse. The pruritus seems to be greater at night and is always intensified by an increase in the warmth of the body, as by a warm stable or warm clothing. This is probably due to the greater activity of the parasites under such conditions.

Lesions.--The first changes in the skin will be the formation of small nodules, which may be felt by the hand as it is passed over the skin's surface. At these locations small crusts are formed about the tufts of matted hairs, which are casily removed, leaving a moist and reddened surface. From the nodules small papules develop, the epidermis being raised by the subepidermic serous effusion. These rupture, and the desquamated surface gradually dries, leaving a scaly formation upon the skin. With the extension of these lesions the hair falls out in patches, the affected areas becoming confluent and covered by dry

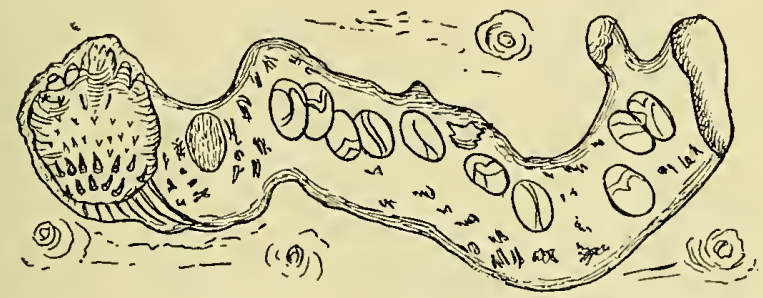

FIG. 65.-Burrow of sarcopt in human skin, with eggs and mite (after Osborn, from Furstenburg and Murry; Bureau of Entomology, U. S. Dept. of Agr.).

epidermic scales and thin crusts. Soon following upon this stage the skin thickens and forms into folds; especially over the parts where it is freely movable, as about the throat, neck and breast. When these folds are separated the skin between them is found to be in a raw and purulent condition, bleeding at the slight touch of an instrument or of the finger nail. In neglected cases the body may become almost entirely denuded of hair and the thickened skin covered everywhere with crusts, bleeding fissures, and ulcers, the animal presenting a most miserable appearance (Fig. 66). The alterations in the skin are not all directly brought about by the parasites, being contributed to by the violent rubbing of the animal in its efforts to relieve the itching. Excoriations with the formation of hemorrhagic exudations and ulcers are often an accompaniment from this cause.

Diagnosis and Development.-With these symptoms in their early 
or late stages, the diagnosis of sarcoptic mange may be nade positive by the recovery of the Sarcoptes. This should be looked for as soon as the presence of mange is suspected, as it is important to know with what form of the disease we have to deal. The nymphe and pubescent males and females live upon the hody surface and among the crusts over all affected parts. Immediately after they become impregnated the ovigerous females burrow galleries beneath the epidemis in which they deposit their eggs and live for a time with the young larva (Fig. 65). In man the course of the galleries is marked by fine red lines from 8 to $15 \mathrm{~mm}$. or more in length, but in the horse these cannot be seen owing to the thickness and pigmentation of the ppirteruis. The sarcopt is usually lodged at the extreme ond of the chamnel in the course of which her eggs

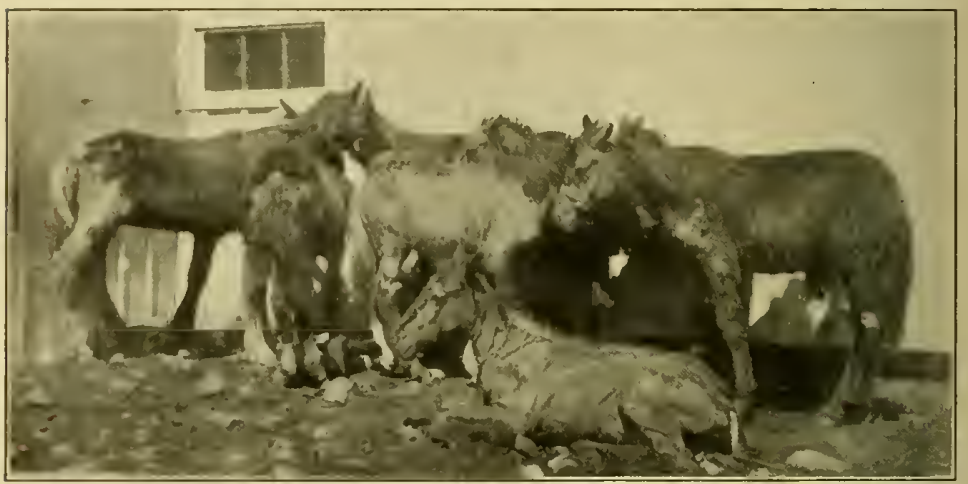

Frs. lifi.- Colts affected with advanced sarcoptic mange (from author's photograph).

are distributer. It has been estimated that approximately fifteen individuals will he produced in each of these subrpiclemic burrows, and that about fifteen days are recuired, under average eonditions, for their full development and the appearances of the next succeding generation. The larva issumg from the eggs live in the gallery for some time before finally making their exit along its course, while the parent female soon dies after ovulation is completed. Copulation takes place upon the skin beneath the crusts, the males dying after the performance of this function. As the males are also relatively less in number, it is the females which are more often met with.

To secure the parasite for examination the crusts should be removerl and skin scrapings taken iu such a manner as to include a portion of serous exudate with the epidermic scales. The material should be taken from a part showing evidences of recent attack, the mites being more likely to be fomm there than in the okder lesions. This material, to- 
gether with a few flakes from the deeper portion of the crust, may then be placed upon a glass and teased in glycerin. After having been sufficiently divided and spread by the needles, it is ready for examination under the low power of the microscope, or by a strong hand lens. It is oftcr necessary to thoroughly search several preparatious before finding the acarus. The material can be more easily teased and cleaned up if submitted for an hour or two to the action of a five to ten per cent. solution of caustic soda.

A method commonly used in the Laboratory of the Pennsylvania State Bureau of Animal Industry for the detection of scab acari is as follows: Cover the material with a ten per cent. solution of sodium hydrate and set aside for one or two hours. Heat to boiling and centrifuge for twenty minutes. The liquid is then carefully drawn off, water added, and the sediment shaken up. This is again centrifuged, water drawn off, and fresh water added in which the sediment is again washed and centrifuged. The sediment is then thinly spread upon slides and examined under low power. By this treatment the scabs and crusts are thoroughly disintegrated. Some of the mites may also be fragmental, but not to such an extent as to prevent recognition of the species.

Prognosis.-Owing to its great contagiousness and the difficulty in reaching the parasites, sarcoptic acariasis is the most serious of the three forms which may affect the horse. Early in its course the constantly tortured and unpresentable animal becomes unfit for work, and, when the disease is advanced, the skin lesions are accompanied by anæmia, emaciation, and a general debility that may terminate in death. $A s$ in other parasitic skin diseases, vigorous animals in good condition are more resistant and are more easily cured than those unthrifty or old and emaciated.

Transmission.--The transmission of mange from horse to horse or to asses and mules takes place by contact of individuals and by numerous ways in which the parasite can be transported, as by litter, grooming utensils, harness, clothing, or any object upon which the affected animal has rubbed. Its contagion is modified considerably in relation to the stage of the disease. Early in its course the acari have little tendency to leave their host, but after one or two generations, with the formation of the typical skin lesions, they emigrate readily, either directly or indirectly, from one animal to another.

Mange of the horse can be transmitted to man and, reciprocally, that of man to the horse, though such cases are rare. In either event the parasite does not find a favorable soil for its multiplication, and the inrasion is but transient, such affection as it produces usually yielding promptly to treatment or spontaneously disappearing in a few weeks. It is doubtful whether this mange can he communicated to other animals; 
varietics of the sarcopt accidentally conveyed from their natural to a foreign species of host meet with an unfavorable habitat and, if cutaneous manifestations follow, it may be assumed that they must in any case be slight and of relatively short duration.

Psoroptic Scabies of the Horse.-Psoroptic scabies generally appears about the regions of the longest hair, as at the base of the forelock, mane, and tail. It at once gives rise to pruritus, which is accompanied by rubbing and matting of the hairs as in mange, with which form it is somewhat similar as to its coursc and alterations. It spreads much more slowly, however, and rarely involves the whole surface of the body.

The psoropt does not burrow beneath the skin's surface as does the sareopt, therefore it can be more easily found. The methods recommended for securing the Sarcoptes will apply to the Psoroptes as well, though to obtain the latter it is not nccessary to go quite as deeply for the material. In this connection it should be borne in mind that two or all three forms of scabies may eoexist on the horse. It is advisable, therefore, in eertain cases to look for the mite in material obtained from various affected regions of the body, as from the base of the mane, forelock, or tail, from the cheeks and breast, and from the lower parts of the legs.

Lesions.- While the loeal alterations in psoroptic scabies are severe, the pruritus intense, and the scabs generally thicker than in the sarcoptic form, it is a less serious affection in that the mites do not burrow, and the lesions remain mueh longer loealized. More easily and promptly cured, it is not so frequently epizoötic, and it is not as likely to spread to other horses upon the same premises.

Transmission.-As to its transmissibility from the equine species to other animals, what has been said relative to this of the Sarcoptes applies also to the Psoroptes.

Chorioptic Scabies of the Horse.--This form of scabies begins on the extremities, most often the hind feet about the fetlocks and pasterns. From here it spreads to the hocks, or to the knees if from the fore fect, somctimes extending further, but rarely as far as the body. Like the psoroptes, these mites seck the parts covered by long hair, therefore horses with long fetloeks are pretlisposed to attack.

Symptoms.-The first symptom of the invasion is itching, which the horse numifests by stamping, kicking the side of the stall, efforts to bite the legs, or rubbing them one against the other. This irritation is especially noticeable upon the animal's return from work and at night in a warm stable. Its true cause is frequently overlooked in considering it a vicious habit.

Chorioptie scabies is slow in development, and is most troublesome in winter. This is probably due to the fact that the feet of horses at this 
time of the year are more exposed to mud and slush, bringing about a macerated and inflammatory condition of the skin that favors the multiplication of the mites.

Lesions. - Shortly after the invasion an abundant epidermic desquamation is noticed among the hairs and over the skin. Tufts of hair are easily pulled out, and patches appear where the skin is bare and smooth. Later crusts form over a thickened and exuding skin, which in the hollow of the pastern becomes fissured and bleeding.

Diagnosis.-In view of the special seat of chorioptic scabies, other parts not being involved, it is scarcely necessary to confirm its differentiation from other forms by the recovery of the mite. It is important, however, to know whether the case is truly one of scabies, and this diagnosis can only be established with certainty by finding the parasite. If present it will be easily found anong the deeper parts of the crusts and epidermic scales.

Prognosis and Transmission.-Foot scab is less infectious and is accompanied by less itching than the other forms. The prognosis is also more favorable, since, excepting in rare cases, the disease is confined to the lower parts of the legs and usually to the hind legs only. Again, unlike other scabies, it has little if any general effect upon the animal. It yields readily to suitable treatment, and it is not likely that horses receiving proper care as to cleanliness of the hair and skin will be attacked, even though exposed to the infection. Its transmission from animal to animal in the same stable is usually by bedding and grooming utensils in the hands of careless attendants.

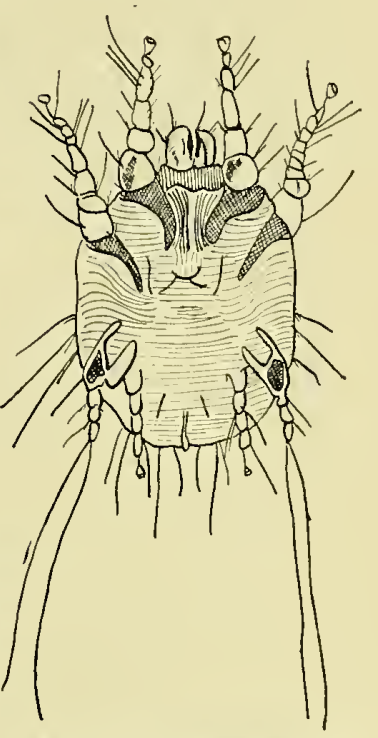

Fig. 67.-Chorioptes communis var. equi, female; ventral view:

\section{Scabies of the Sheep}

Sheep may be affected with the following forms of scabies, the first mentioned being by far the most important in this animal:

1. Psoroptic scabies, due to Psoroptes communis, var. ovis.

2. Sarcoptic mange, due to Sarcoptes scabiei, var. ovis.

3. Chorioptic scabies, due to Chorioptes communis, var. ovis.

4. Follicular mange due to Demodex folliculorum, var. ovis.

Psoroptic Scabies of Sheep.-Through its extensive prevalence 
among sheep, psoroptic scabies may be regarded, from an economic standpoint, as the most important of all scabies affecting live stock. That the disease has been known for many centuries is evident through references to it in early writings, including the Bible. The relationship of the mite to the disease, however, was not determined with certainty until the nineteenth century, during the first half of which the complete life cycle of the parasite was demonstrated. It was shown that mites, like larger animals, are the offspring of ancestors and are not of spontaneous origin or accidental occurrence. It was further proven by animal experimentation that the mites were not present as a result of the scab, as had been supposed by some, but that the scab resulted from the presence of the mites and could be produced in no other way.

The psoropt of sheep scab (Figs. 68 and 69) lives upon the surface of the body where it is most thickly covered with wool, as the back, sides, and shoulders. From their seat of invasion the colonies will spread and these areas may coalesce, involving large patches, though the regions of short wook, as the belly and front of the chest, are rarely attacked.

Symptoms and Lesions.-The first indications of the disease are rubbing and gnawing at the wool and general unrest caused by the itching. As the rhanges in the skin progress loosened tufts become raised over the surface of the fleece. These tags are soon rubbed or pulted away by the sheep, and the fleece over the affected parts becomes raggect and matted, the skin finally becoming more or less bare and showing at this stage a thickened, furrowed, and bleeding condition.

If the skin is examined before the sherling of the wool there will be seen small yollowish nodules and papular elevations of the epidermis. The latter with their serous exudate dry up, forming an accumulation of fatty yollowish scales upon the skin and among the deeper parts of the hairs. The papules are closer together as the punctures of the psoropt hecome more numerous. As they become confluent the skin thickens, and the drying exulate and papular débris form a massive yellowish (rust. This, as it increases layer by layer, envelopes and mats the wool, hifting the fibers from their follicles and raising large bunches ahove the surface of the fleece. These detached patches will soon fall away, the denuded skin showing a variation of lesions common to scabies. It will be thickened, cracked, and scabby, and there may be lere and there excoriations, with perhaps sloughing and ukcerated areas. The ac'ari forsake the more central and older lesions for the periphery of the denuded patch where they may be found in large numbers at the roots of the incrusted wool which in its turn will fall away. Due to lirect exposure to the atmosphere, old denuded or sheared areas dry out and become uniformly covered with a dry parchment-like crust beneath which the skin is thickened and fissured.

Course and Prognosis.-The course and termination of the disease 
will be influenced by age, condition, character of fleece, and the conditions under which the sheep are kept. Animals debilitated from age,

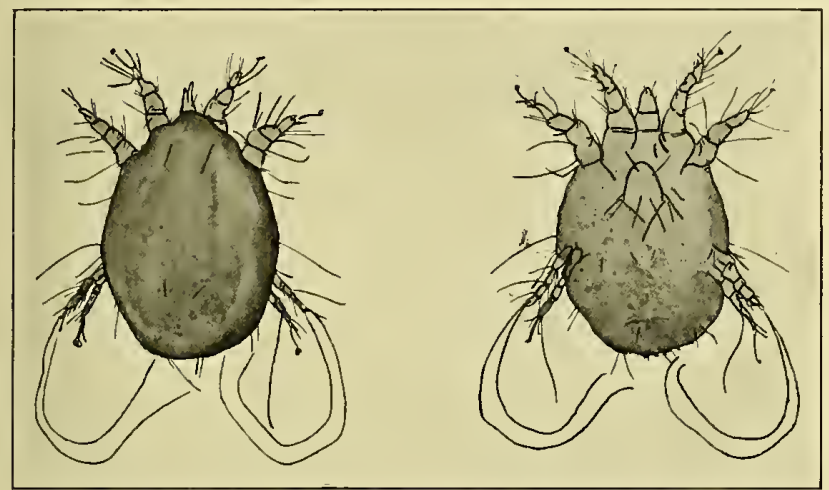

Fig. 68.-Psoroptes communis var. ovis, female; dorsal (left) and ventral (right) surface.

or other cause, offer little resistance, while lambs, due to the tenderness of their skin and their dense fleece, are apt to be attacked more severely. Sheep with a close wool, as the pure or grade merino, afford an ideal habitation for the rapid multiplication of the parasites. The contagion

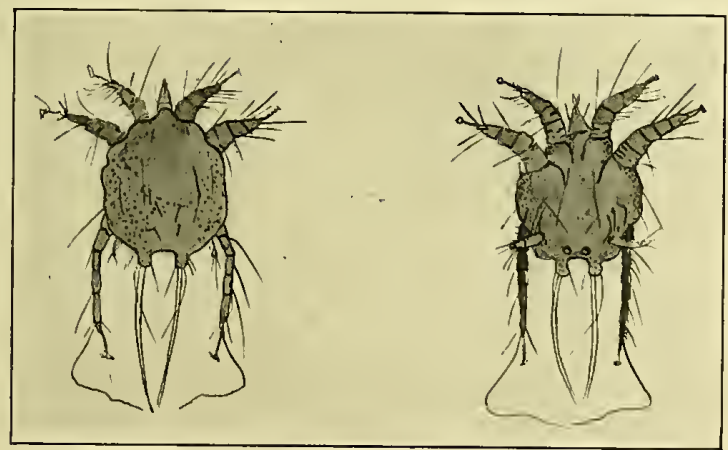

Fig. 69.-Psoroptes communis var. ovis, male; dorsal (left) and ventral (right) surface.

of any form of acariases in sheep is facilitated by their habit of living in flocks. The disease is, therefore, much more serious in winter when the animals are huddled together, especially making rapid progress if 
the quarters in which they are collected are damp and hot. In summer, after shearing and turning upon pasture, it rapidly subsides, in some cases even seeming to disappear.

Psoroptic scabies in sheep, if unchecked, will have a fatal termination. Death is preceded by denudation of the greater part of the body, emaciation, anæmia, and a progressive weakness. The course is often rapid in stabled sheep and those predisposed; within one or two months it may have spread over the greater part of the body, while, on the other hand, the disease may last in a more or less severe form for a year or more.

Transmission. - Sheep scab cannot he transmitted to other animals, nor can psoroptic scabies of other animals be transmitted to sheep.

Sarcoptic Mange of Sheep. - Sheep are rarely affected with this form. When it oceurs it can at once be distinguished from psoroptic scab by its location, which is exclusively upon parts of the body covered with short hair. It usually has its beginning about the upper lip or nostrils, extending from here to other parts of the face and to the eyelids and ears. In cases of long standing it may spread to the belly and inner sicles of the front and hind legs.

Prognosis. - The course of the disease with its typical skin alterations has already been described under Sarcoptic Mange of the horse. It is much less serious in sheep than in the horse; however, and if taken before it has spread extensively, yields easily to treatment.

Transmission. Sheep and goats transmit sarcoptic mange reciproeally. It has been reported as having been conveyed from these animals to man, but such cases, if ever occurring authentically, should be extremely rare.

Chorioptic Scabies of Sheep.-As in the horse, chorioptic scabies of the sheep begins in the hind fetlocks and pasterns where it is characterized by a redness of the skin and the presence of fine epidermic scales. There is considerable itching, causing the animals to stamp their feet and bite at the infected parts. Later yellowish crusts appear which thicken, and the skin becomes cracked and bleeding, especially about the folds of the pastern. Only rarely does the affection pass to the fore legs or upward to the udder in the ewe, or to the scrotum in the ram.

Prognosis and Transmission.-Again, as in the horse, the Chorioptes are not inclined to migrate, and the scabies they produce is but slightly contagious. It yields promptly to cleanliness and proper treatment, subsiding almost entirely when the flock is turned upon grass in the spring.

Follicular Mange of Sheep.-The follicular mite occasionally invades the eyelids of sheep. Few such cases have been recorded, however, and, in this country at least, follicular mange is of little importance to flock owners. 


\section{Scabies of the GoAT}

Goats may be affected by three forms of scabies,-sarcoptic, psoroptic, and-chorioptic. The first mentioned is the most frequently met with in these animals, having its seat, as in sheep, mainly about the face. The other forms are rarely met with in goats. Psoroptic scabies attacks the external ear, forming dark-colored, fungus-like scabs. Chorioptic scabies is said to have its beginning on the sides of the neck and withers and along the back.

\section{Scabies of Cattle}

Three forms of scabies affect cattle. These are as follows:

1. Psoroptic scabies, due to Psoroptes communis, var. bovis.

2. Chorioptic scabies, due to Chorioptes communis, var. bovis.

3. Sarcoptic mange, due to Sarcoptes scabiei, var. bovis.

Scabies is less frequent in cattle than in horses and sheep, in North America being most often met with in the range herds of the West and Northwest. In this country the psoroptic is probably the most frequent form.

Psoroptic Scabies of Cattle.--This usually has its beginning upon the sides of the neck and shoulders, at the base of the horns, or it may be at the root of the tail. From these points it usually advances along the back, passing to the sides, and in severe cases eventually involving the greater part of the body. In its symptoms, course, and skin alterations it is in all essential respects analogous to the same form of scabies in the horse. The pruritus is intense, the animal rubbing and scratching itself in every way possible, often causing bloody excoriations of the skin. As the disease advances an extreme cachexia sets in, and the anæmic and much weakened animal may die in a most miserable condition.

Such cases are most likely to occur about the close of the winter months, especially in cattle stabled or herded together in warm quarters. While upon grass, though the infection may remain, its symptoms subside, and in the falling away of the scabs with renewal of the coat, may even seem to have entirely disappeared.

Calves, yearlings, and two-year-olds suffer most, and it is among these that there is more likely to be a fatal temination.

Chorioptic Scabies of Cattle.-This form in cattle is commonly known as tail mange. It generally appears in the depressions at the base of the tail where as a rule it remains localized. If neglected it may spread to the loins, perineum, and inner surface of the thighs, or even over a considerable surface of the body, though such cases are rare. It is exceptional for mange to appear in the feet of cattle.

Its course is the usual one of chorioptic scabies. The it ching is mod- 
erate, and the skin becomes covered with fine, dry scales, later becoming denuded, fissured, and scabby.

It is but slightly eontagious and, except in eases of extreme neglect, has little tendency to spread upon the body. Where it seems to progress beyond the limits usual to the choriopt, it should be determined whether or not psoroptic scabies is coexisting with it-a condition which is quite possible. If this is suspected, material from several affected loeations should be examined for recognition of the infecting species.

Sarcoptic Mange of Cattle.-Mange of the ox clue to Sarcoptes need be no more than mentioned here. Probably in every case where it has occurred it has been by transmission from animals inore likely to harbor this species, as the horse or goat. In bovine animals the disease is usually of short duration, showing less tendency to spread and yielding more promptly to treatment than in the horse. It affects chiefly the skin about the eyes and cheeks and may extend to the sides of the neek.

\section{Mlaxge of the Hog}

Two kinds of mange affect the hog. These are as follows:

1. Sareoptie mange, lue to Sarcoptes scabiei var. suis.

2. Follieular nange, due to Demodex folliculorum var. suis.

Sarcoptic Mange of the Hog.-Sareoptic mange is considered to be the most eommon form in these animals. The infecting sarcopt is the largest variety of the speeies and may be seen with the unaided eye as a minute moving speek among the removed cutaneous débris.

Symptoms. - The presenee of the disease is first shown upon the skin about the eyes and ears, from which points it spreads to the back of the neck, withers, shoulders, and back, later, if unchecked, invading the greater surface of the body. The pruritus is extremely severe and is especially aggravated in animals subjected to the body heat of crowded pens. With the extersion of the itching nodules the bristles fall out, and the skin becomes wrinkled and eovered with brownish or dark gray erusts. Within the folds the skin presents the morbid changes usual to sareoptic mange; it is fissured and bleeding and there may be ulcerations.

Young pigs and those with a thick eurly growth of hair suffer the most. The condition retards development and fattening, and severe cases may leat to general debility and death.

Transmission.-Contagion is by contact of the animals with eaeh other, mesentially facilitated when crowded together in pens or lots. Because of the habit these animals have of rubbing their bodies, objeets upon whieh infected luggs have scratched are espeeially a source of transmission.

This mange of the hog may be transmitted to man and to the dog and 
possibly also to the horse, but the eruption produced in such cases disappears spontaneously in a few days.

Follicular Mange of the Hog.-Demodex being more difficult to recognize, its presence in the skin of pigs probably occurs more often than is generally supposed. The skin alterations which the follicular mites bring about in these animals is comparatively slight and, as a rule, are not such as to perceptibly interfere with general health or growth. The primary seat of invasion is usually the skin about the snout. The lesions may extend to the cheeks and even to the neck and chest, though such spreading of follicular mange in the pig is not often observed.

\section{Mange of the Dog}

There are three forms of canine mange, as follows:

1. Sarcoptic mange, due to Sarcoptes scabiei var. canis.

2. Follicular mange, due to Demodex folliculorum var. canis.

3. Auricular mange, due to Otodectes cynotis.

Sarcoptic Mange of the Dog.- Sarcoptic is considered the most common mange affecting the dog. Though it may first appear upon any part of the body, it generally begins about the muzzle, especially upon the bridge of the nose or, not infrequently, around the eyes, at the base of the ears, or upon the breast. As it spreads the ventral surface, axilla, and thighs become involved, the morbid process extending with such rapidity that by the end of a month it may cover the greater part of the body.

Symptoms, Course, and Lesions.-In its symptoms, course, and alterations sarcoptic mange of the dog is similar to that of the horse. It is first manifested upon thin and unpigmented skin by little red points which are soon converted into papules. These rapidly increase in number and, as they rupture and exude their serous contents, deposit a scaly accumulation upon the skin followed by the formation of yellowish gray crusts. As the disease progresses the denuded skin becomes thickened, wrinkled, and excoriated, the cheeks, neck, and breast especially exhibiting deep folds. The itching, always intense, is much aggravated by an increase in the body temperature, as may be brought about by rumning or warm quarters.

Where large areas of the body are involved in the disease, emaciation and general debility set in, the animal at times giving off an offensive, mouse-like odor. Finally, if the animal is neglected or treatment is unsuccessful, death will ensue by the end of two or three months from the beginning of the invasion.

Transmission.- The facts of contagion pertaining to sarcoptic mange of other animals apply to this disease of the dog as well. Young dogs and those debilitated are predisposed to infection, though dogs of any age or condition will support the sarcopt and readily develop the disease. 
Follicular Mange of the Dog.-Demodectic mange, or the so-called red mange of dogs, is of frequent and world-wide occurrence. The lanciform mites enter the orifice of the hair follicle where they multiply and occupy the follicle and sebaceous gland in large numbers, lying closely pressed together and ahmost invariably with the mouth parts directed toward the bottom of the follicle (Fig. 70). In this location they may be found in all stages of development, from eggs to sexually mature individuals and ovigerous females. As a result of this constant increase -there is a dilation of the hair follicle and gland, the pres-
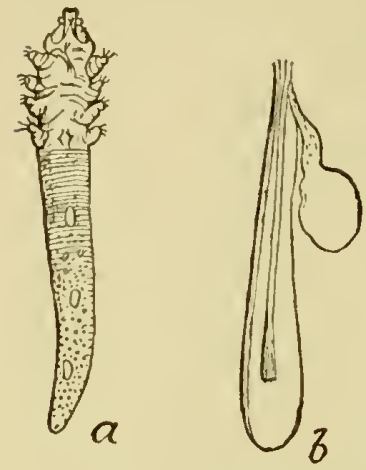

Fig. 70.-Demodex folliculorum: $a$, mite greatly enlarged; $b$, mites in hair follicle and sebaecous gland-enlarged (after Osborn, from Murry, Bul. No. 5 , Bureau of Entomology, U. s. Dept, of Agr.).

the formation of pustules and in some cases large abscesses.

Thougl follicular mange, owing to its resistance to treatment and general septic intoxication, frequently terminates in death, its course at the commenccment is very slow. In its early manifestations there are merely somewhat redclened areas, usually of the skin about the eyes, breast, elbows, or it may be at the toes. As the hairs fall away small papules are observed, and the affected patches become covered with fine, powder-like scales. The infection is extended by the mites abandoning the originally invaded follicles and entering the surrounding healthy ones, the spreading being aided somewhat by the rubbing and licking of the animal. As new parts are invaded the skin becomes decidedly red and, especially about the cheeks and breast, thickened; wrinkled, and crusty; the eyelids are swollen and covered at their borders by a purulent discharge. 
The disease finally becomes generalized, the skin everywhere exhibiting the lesions in their various stages, and, with it all, exhaling a disgusting odor. The pruritus increases, though it remains somewhat intermittent, and at no time is as severe as in sarcoptic mange. With the generalization of the malady its effect upon the whole animal organism is well established. The appetite is lost and emaciation advances, the subsequent marasmus leading to a fatal termination.

Transmission.-Due to the intra-cutaneous location of the parasites, follicular mange is not as contagious as other forms; furthermore a predisposition is necessary for its development, and this is found in young and short-haired animals. Adult dogs with healthy skins are rarely attacked.

Whether the dermatitis in follicular mange is primarily due to the presence of the Demodex may be questioned. The assumption that this mite is present in the hair follicles of all dogs needs the support of further investigation. Accepting it from clinical observation as a probability -and with the predisposing factors of other forms of acariasis in mind -there seems good reason to suppose that the mites, living, we may say, as commensals, find in erythematous and eczematous skins surroundings favoring their nutrition and more rapid multiplication, thus bringing about the secondary severe dermatitis of follicular mange, the pyodermatitis resulting from subsequent intra-follicular invasion by pyogenic organisms.

Auricular Mange of the Dog.-Otacariasis is of comparatively frequent occurrence in dogs, by reason of its contagiousness, being most often met with in hounds kept in packs. Symptoms of the presence of the mites are frequent scratching and flapping of the ears, which may be accompanied by whining and howling. Epileptiform seizures are not infrequently an accompaniment, these especially likely to occur when the animal is running. On examination the auditory canal is found to contain an adherent, soot-colored powder and a fetid wax which may be in sufficient abundance to produce deafness by obstruction of the canal and pressure upon the tympanum. An examination of this material under magnification will reveal the Otodectes in large numbers.

Prognosis.-Otacariasis yields readily to treatment, but if neglected may have serious consequences. The animal may die during an attack of convulsions or, if it survive, be rendered useless as a hunter.

\section{Mange of the Cat}

The cat may be affected with the two following forms of mange:

1. Notoedric mange, due to Notoedres cati var. cati.

2. Auricular mange, due to Otodectes cynotis. 
Notoedres cati, var. cati (Sarcoptes minor var. cali, Fig. 71), the dwarf sarcopt, is a small species having the body nearly spherical. The dorsal folds of the integument are circular. The anus is dorsal. There are six anterior dorsal spinules and but twelve

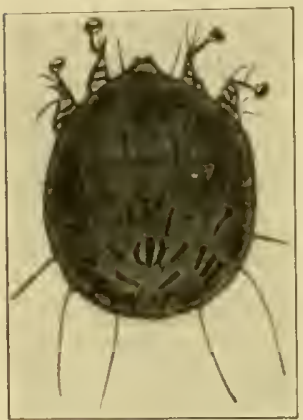

Fig. 71.-Genus Notoedres. posterior. The arrangement of the stalked suckers is the same as in Sarcoptes scabiei.

Course and Diagnosis.-Notoedric mange of the cat usually begins about the ears and upper part of the neck, extending over the forehead and then over the head generally. As a rule it remains limited to these regions, rarely passing to the body. The disease follows the usual course and alterations of sarcoptic mange, the eat giving evidence of the intense itching by frequently shaking the head and wiping it with its paws. In neglected cases animals may become much emaciated and may die in a few months.

Due to the wrinkled, papular, and crusty skin and its persistency of location upon the head, the diagnosis of this mange on the cat is not difficult. Its differentiation from other itching skin cliseases may be made certain by the discovery of the parasite, which is readily obtained in matcrial scraped from beneath the crusts.

Auricular Mange of the Cat.Auricular mange seldom occurs in the cat. It is caused by the same speciss of mite causing auricular mange of the dog and is similar in its symptoms and course.

\section{scabies of the Rabit}

Two species of scab inites afflict the rabbit, -Notoedres cati var. cuniculi and Psoroptes communis var. euniculi (Fig. 72), the latter caus-

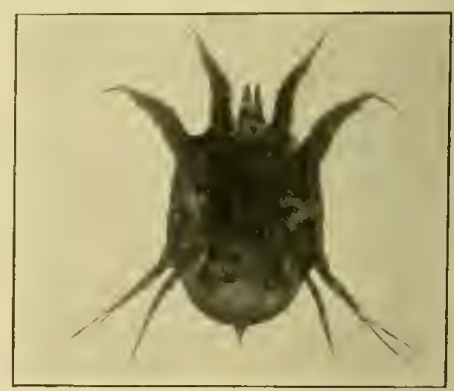

FIG. 72.-Psoroptes communis var. cuniculi (from photomicrograph of mounted specimen, by Hoedt). ing auricular scabies or psoroptic otacariasis.

In the rabbit notoedric mange most of ten has its beginning about the nose, from which it extends to the upper part and sides of the head where it remains localized. Its location, symptoms, and course are similar to those of the same form of mange in the cat.

Auricular scabies of the rabbit commences deep in the concha, gradually involving the skin of the entire inner side. Its presence is first 
indicated by the pruritus which the animal indicates by tossing its head and scratching the ears with the hind feet. If the deeper parts of the ear are examined early in the disease there will be found a yellowish, fetid matter in which many of the mites may be seen with the aid of a hand lens. At the end of a few months the greater part of the inner side of the ear becomes covered with a thick layer of scabs in which the Psoroptes are literally swarming. Usually they remain localized to the ear, rarely invading surrounding parts.

In prolonged cases of auricular scabies rabbits lose their appetites and become emaciated, diarrhea sets in, and the animals finally die in an advanced state of cachexia. 


\section{CHAPTER XI}

\section{TREATMENT OF MANGE AND SCABIES}

General Considerations.--Methods of treatment of scabies will vary according to the form of the disease to be dealt with and also according to the kind and number of animals to be treated. As a general rule the application of acaricides should be preceded by clipping the hair from either a part or the whole of the body, depending upon whether the affection is localized or general. The crusts slould then be softened and removed by washing with warm soapsuds and a stiff brush, after which the remedy chosen may be applied.

The whole process is to be repeated in ten to fourteen days in order to destroy mites from eggs which escaped the first treatment. It is important that there should be clean surroundings and, especially where emaciation is all accompaniment, an abundance of nutritious food. siarcoptic mange will require more energetic remedies than other forms where the mites live upon the surface and among the crusts of the skin.

Internal medication is of little or no value. A cure can only be reached by the destruction of the acari, accomplished by the local application of a suitable acaricide. In the use of such agents their irritant or possible toxic effects upon the animal treated are to be borne in mind. To avoid a sudden and general checking of the cutaneous functions, ointments and oleaginous materials are not to be spread over the entire body at one application, nor should the body be dressed over more than onefourth to one-half of its area with preparations containing carbolic acid, creosote, cresol, tobacco, or other such ingredients. Those containing mereury or arsenic, in addition to these limitations, should never be used upon animals such as cattle, dogs, and cats as these animals will lick the dressed parts.

Where large numbers of animals are affected in a flock or herd, individual treatment involving clipping, scrubbing, and the application of remedies by hand, is not practicable. In such cases a method of dipping must be resorted to. It is essential to the success of the treatment that thorough disinfection measures be applied to surroundings and to sucl portable paraphernalia as may serve as a means of reinfection. In this connection it should be borne in mind that the mites may live from two weeks to a month or more off a host, the longer periods usually amicl favorable conditions, such as warm stables and blankets. 
The treatments given below deal successively with the different forms of the disease and embody such modifications as may be required for the various domestic mammals.

\section{Treatment of Sarcoptic Mange}

Treatment of Sarcoptic Mange of the Horse.-Affected animals should be isolated in quarters where they will not be in contact with each other. Unless the disease is distinctly localized it is better to clip the hair from the entire body; its removal will often reveal the lesions over areas otherwise unsuspected. The clipping is not to be done in the stable or in a wind that will scatter the hairs about. All of the hairs should be carefully collected and burned.

The next procedure is the removal of the crusts in order that the remedy used may be applied directly to the skin. This is best accomplished by the use of soft soap well rubbed upon the scabby surface. A thick lather is then formed by the application of a limited quantity of warm water. This should be well worked into the crusts with a brush and allowed to remain for an hour. The softened crusts may then be removed with a brush or, better, a wooden scraper and warm soapy water, and the body finally rinsed with clear tepid water applied with a sponge. The scraping process should be done gently and in a manner that will add as little irritation as possible to an already inflamed skin. After the skin has become perfectly dry it is ready for the remedy which is to be applied with a view to the destruction of the parasites.

There are a number of such remedies in the use of which practitioners have had a varied experience. Creosote is among the most effectual. It may be used in any of the following combinations: (1) Creosote one part, oil sixteen to twenty parts; (2) creosote one part, oil of tar and soft soap of each ten parts; (3) creosote five parts, alcohol five parts, water twenty parts. With either of these not more than half of the body should be dressed at alternate periods of six days until the entire body has had two or three applications. It should be applied by rubbing.

Other remedies which have given satisfactory results are: (1) Lime and sulphur dip (Formula No. 1, page 125), two or three applications at intervals of one week; (2) creolin and soft soap, of each one part, alcohol eight parts. Rub upon one side of the body on alternate davs; after the body has had three applications rest three days and repeat; (3) decoction of tobacco five per cent. Apply over one-fourth to one-third of the body each day; repeat three or four times at intervals of one week.

Unctuous and oily preparations are to be preferred to the more fluid ones as they are more penetrating and, adhering to the skin, their action is prolonged. For this reason they are especially better suited for the treatment of sarcoptic mange. The lime and sulphur preparation is, 
Essentially, pens and yards must be cleaned up and all litter burned.

Treatment of Sarcoptic Mange of the Dog.-Dogs should be clipped and the skin covered with a thick lather. A good application for this purpose is green soap dissolved in an equal quantity of alcohol. Let this remain two to four hours, then remove the crusts with a brush and warm soapy water. Rinse and allow the skin to become dry. One of the following remedies may then be applied: (1) Creosote one part, oil fifteen to twenty parts; (2) creosote one part, green soap and alcohol of each eight parts; (3) sublimed sulphur two parts, potassium carbonate one part, lard eight parts (Helmerich's pomade); (4) creolin one part, alcohol fifteen parts; (5) Peruvian balsam two parts, creolin one part, alcohol twenty parts; (6) naphthalin two parts, vaseline eight parts, oil of thyme and oil of lavender of each one part.

The last named mixture is soothing to the skin, agreeable, and quite suitable for small house dogs. It is not to be depended upon, however, in old and generalized cases. To avoid a too generally irritant or toxic effect the acaricide should be applied to not more than one-fourth to one-third of the body each day. It should be applied freely and energetically and left on for three or four days. It may then be washed off with tepid soapy water. At the end of three or four days the application is to be repeated in the same manner, and again repeated until there is no further itching or formation of scabs. The animal should be prevented from licking by fitting it with a broad collar or by binding the mouth with tape.

Preparations of tar had better not be used upon dogs. Remedies containing carbolic acid, mercury, tobacco, and other poisons are also to be avoided, as any measure adopted to prevent licking is liable to be defeated by the dog and a serious poisoning result.

The usual precautions as to cleaning up of surroundings should of course be adopted here.

Treatment of Notoedric Mange of the Cat.-Cats rebel against and actually suffer from washing, therefore treatment of these animals is limited to the use of ointments. The hair should be clipped from the affected parts and a small amount of vaseline applied which may be removed in an hour or two by rubbing with dry bran and a cloth, removing in this operation as many of the crusts as possible.

The acaricide ointment best adapted to the cat is that of Helmerich, consisting of sublimed sulphur two parts, potassium carbonate one part, lard eight parts. The application of this is to be repeated at intervals of four to six days until scab formation and itching have ceased. It may be removed by rubbing in the manner already stated. Peruvian balsam is perhaps more effcetive, but in cats may cause severe cerebral disturbance followed by stupor and even death. If used at all it should be with extreme caution. 
Due to the usual location of notoedric mange of the cat upon the head, the dressing is inaccessible to licking, though the pads of the fect are likely to be applied to it and afterward licked. It is scarcely necessary to say that preparations containing tobacco, carbolic acid, and other poisons should be strictly avoided in the treatment of cats.

Treatment of Notoedric Mange of the Rabbit.-Remove the hair from the affected area and for a considerable margin around it, apply a lather of soft or green soap, allow to remain an hour or two, wash off, and repeat as neccssary to remove scals. When the parts have become dry, treat with the ointment of Helmerich as for mange of the cat.

Treatment of Sarcoptic Mange of the Goat.-Clip the hair and prepare the parts with soapy lather as directed for other animals. Treat with a sulphur ointment or a preparation of creosote, as creosote one part, oil fifteen parts. Repeat as previously directed.

Owing to the intractability of goats, dipping is attended with difficulties and, furthermore, is badly borne by these animals.

Treatment of Sarcoptic Mange of Sheep.-Remove crusts after softening with a lather of soft or green soap, dry, and apply (1) creosote one part, oil of tar and soft soap of each twenty parts; (2) sublimed sulphur one part, lard four parts, or (3) the ointment of Helmerich may be used. Repeat as directed for other animals.

Treatment of Sarcoptic Mange of Cattle.-After clipping and prepparation of the skin by removal of the crusts as has been repeatedly stated, apply the lime and sulphur mixture as given and prepared under scal of sheep, repeating three or four times at intervals of five days. (iood results may also be obtained by the use of sulphur in the form of an ointment, as one part of sulphur to four parts of hog's lard. Preparations containing such agents as creosote, lysol, or creolin are best limited to cases confined to the head and upper parts of the ncck, regions inaccessible to the tongue. They may be used in the following combinations: (1) Creosote one part, oil fifteen parts; (2) creosote one part, oil of tar and soft soap of each fifteen to twenty parts; (3) creolin and soft soap of each one part, alcohol eight parts; (4) lysol in five per cent. solution.

All of these are to be washed off with soapy water after three days and the treatment repeated as necessary.

\section{Treatment of Psoroptic Scabies}

Treatment of Psoroptic Scabies of the Sheep.-Proper hygienic conditions and an abundance of substantial nourishment will do much to protect sheep from the contagion of scab, but where it has made its appearance in a floek such measures are only to be relied upon as con- 
tributing to a rational treatment designed to rid the sheep of the disease by killing the parasites. The application by hand of either ointments, fluid preparations, or powders for this purpose is practically uscless. The acaricide chosen for the treatment of psoroptic scabies of sheep should be applied by dipping. It is better not to consume time, energy, and patience upon remedies which are not or cannot be used by this method.

Lime and Sulphur Dip.-Many formulæ for dips have been published, most of them containing lime, sulphur, tobacco, or arsenic as their base. The term "lime-and-sulphur dip" does not refer to an exact formula but includes a large number of formulæ containing the lime and sulphur in different proportions. While the ingrediants of a dip should be in such proportion as to make it a reliable parasiticide, it is essential that it should cause little or no harm to the sheep or fleece. The subject of dips has been carefully gone into by the United States Bureau of Animal Industry and the conclusion reached that probably the most effective dips are those containing sulphur and tobacco, and sulphur and lime of such strength that they are not injurious to the sheep and of minimum damage to the fleece. Among the formulæ for lime and sulphur dips mentioned by the Bureau are the following (Farmer's Bull. No. 159):

No. 1

Flowers of sulphur........... $24 \mathrm{lbs}$.

Unslaked lime............... 8 lbs.

Water..................... 100 gals.

No. 2

Flowers of sulphur........... $33 \mathrm{lbs}$.

Unslaked lime.............. 11 lbs.

Water.................... 100 gals.

For fresh scab, formula No. 1 will act as well as those with a greater amount of lime. In old cases with parchment-like scab a stronger dip, as formula No. 2, is to be preferred.

The following method of preparing the mixture is recommended by the Bureau:

"A. Take eight to eleven pounds of unslaked lime, place it in a mortor box, kettle, or pail of some kind, and add enough water to slake the lime and form a 'lime paste' or 'lime putty.'

"Many persons prefer to slake the lime to a powder, which is to be sifted and mixed with sifted sulphur. One pint of water will slake three pounds of lime, if the slaking is performed slowly and carefully. As a rule, however, it is neccssary to use more water. This method takes more time and requires more work than the one given above, and does 
not give any better results. If the boiled solution is allowed to settle, the ooze will be equally as safe.

"B. Sift into the lime paste three times as many pounds of Flowers of sulphur as used of lime, and stir the mixture well.

"Be sure to weigh both the lime and sulphur. Do not trust to measuring them in a bucket or guessing at the weight.

"C. Place the sulphur-lime paste in a kettle or boiler with about twenty-five to thirty gallons of boiling water, and boil the mixture for two hours at least, stirring the liquid and sediment. The boiling should be continued until the sulphur disappears, or almost disappears, from the surface, the solution is then of a chocolate or liver color. The longer the solution boils the more the sulphur is dissolved, and the less caustic the ooze becomes. Most writers advise boiling from thirty to forty minutes, but the Bureau obtains a much better ooze by boiling from two to three hours, adding water when necessary.

"D. Pour the mixture and sediment into a tul or barrel placed near the dipping vat anch proviched with a bung hole about four inches from the bottom, and allow ample time (two to three hours, or more if necessary) to settle.

"The use of some sort of a settling tank provided with a bung hole is an absolute necessity, unless the boiler is so arranged that it may be used both for boiling and settling. An ordinary kerosene oil barrel will answrer very well as a small settling tank. To insert a spigot about three to four inches from the bottom is an easy matter. Draining off the liguirl through a spigot has the great advantage over dipping it out, in that less commotion oc'urs in the liquid, which therefore remains frecer from sechiment.

"ls. When fully settled, draw off the clear liquicl into the dipping vat and and enough water to make 100 gallons. The secliment in the barrel may then be mixed with water and used as a disinfectant, but under no circumstances should it be used for dipping purposes."

There are a number of good proprietary dips upon the market which will bo found comvenient and effectual. No dip should be used, however, unless the ingredients and their exact proportion are known to the user. siecret formule put out by irresponsible parties should br avoided.

Dipping Vats.-Where but few sheep are to be treated the dipping arrangements may be quite simple. A tub or trough to which a draining platform is attached will serve the purpose. A small vat, suitable for dipping small flocks, may be constructed of wood or concrete. It should loe about nine inches wille at the bottom, four feet deep, and two feet six inches wide at the top. Its length will depend upon the number of sheep to he treated. A convenient length is nine feet at the top, the floor having a length of four feet. From one foot above one end of the floor an incline with ross cleats rises to the top end of the vat. From 
here the incline may lead to a dripping platform which may easily be improvised for the purpose. This should be so constructed and applied that the drip will flow back into the vat.

Plans for more elaborate dipping plants, suitable for large flocks, may be obtained from bulletins issued by the Bureau of Animal Industry, United States Department of Agriculture.

To obtain the best results sheep should be sheared before dipping, and the dip used at a temperature of $100^{\circ}$ to $110^{\circ} \mathrm{F}$. Keep each sheep submerged two minutes by the watch, forcing the head under at least once just before the animal comes out. The dips should be freshly

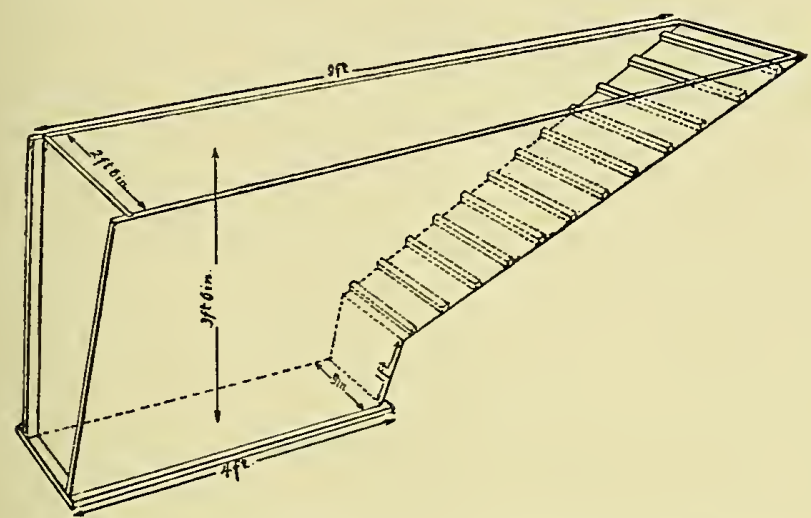

FIG. 73.-A small portable dipping vat for small flocks (from Bull. No. 21, Bureau of An. Ind., Dept. of Agr.).

prepared for each dipping; if permitted to stand for repeated treatment failures and possibly injurious effects may result.

Other Dips.--Tobaceo dips, used either with or without sulphur, are now much in use and give excellent results. Owing to the poisonous character of nicotine, the active principle of tobacco upon which these dips depend for their action, the exact nicotine content of the dip should be known before it is used. This, according to the Bureau of Animal Industry, should not exceed 0.07 of one per cent. Owing to the variation of the percentage of nicotine in different kinds of tobaceo and the added reason that tobacco dips are somewhat tedious and disagreeable to make, it is better to use a reliable tobacco extract, which may be obtained upon the market, and exactly follow the instructions given for the making of the dip.

Tobacco dip is not injurious to the wool, therefore it has an advantage for use upon sheep which may require treatment at a tine when they 
cannot be safely or profitably sheared. Its disadvantages are that it sometimes causes a setback in the sheep by sickening them, and that it also occasionally sickens persons who work with it, especially if they are not tobacco users.

Dips containing carbolic acid are easily made and rapid in their action, but soon evaporate from the lody, leaving the sheep unprotected from reirfection. Furthermore, in the strength at which it must be used as a reliable acaricide, it causes the sheep to receive a greater setback than they do with either the tobacco or lime and sulphur preparation.

After Treatment. - The dipping is to be repeated upon the entire flock in twelve to fourteen clays. Where it is necessary to place the sherp in the same pasture which they occupied before being dipped, sulphur should always be an ingredient of the dip. This remains upon the skin and wool and protects from reinfection during the period that the acari may remain infective. In any case it is better to place the flock after the second dipping in a pasture which they have not been upon for at least five weeks previous to their treatment.

Treatment of Psoroptic Scabies of Cattle.-As psoroptic scabies of the ox may become generalized or remain localized upon parts of the body easily reached by the tongue, mercurial preparations or those containing other poisons which may be licked off should not be employed. Where one or two animals are affected upon limited areas of the body, ointments of sulphur, such as flowers of sulphur one part, lard four parts, may be used with good results. The remedy should be preceded by the usual preparation of the skin. After three days it ean be washed off with soap and tepid water and the application repeated.

Is a convenient, safe, and effective remedy probably the lime and sulplur (lip will give better satisfaction than any other for the treatment of this form of scal, in the ox. It should be prepared with the proportion between lime and sulphur somewhat reduced, as by the following fornula:

$$
\begin{aligned}
& \text { Flowers of sulphur............ } 24 \text { lbs. } \\
& \text { Unslaked lime............... } 12 \text { lbs. } \\
& \text { Water.................... } 100 \text { gals. }
\end{aligned}
$$

Mix according to directions given under lime and sulphur formulæ for scab in sheep (page 125).

Where a small number of animals are to be treated the dip may be applied as a spray or with a brush, working it at the same time well into the scabs. In larger herds this method is not practical, and the animals must be treated by dipping. Even though few in the herd give evidence of the disease, it is safer to dip all, as it is probable that a number of the apparently healthy have become infected. 
Plants for dipping cattle range from the simple to the elaborate after various plans. Directions and cstimates for the construction of such plants, together with much other valuable detail as to dipping, may be obtained from the Bureau of Animal Industry, United States Department of Agriculturc, upon application for bulletins relating to the subject (Bull. No, 152).

The temperature of the dip when used should be from $102^{\circ}$ to $108^{\circ} \mathrm{F}$. Each animal should be kept in it two minutes and be completely submerged before coming out. The treatment is to be repeated in twelve to fourtecn days.

After dipping the precautions against reinfection, already referred to in connection with sheep scab, are to be observed.

Treatment of Psoroptic Scabies of the Horse.-The treatment of this scabies of the horse does not cliffer matcrially from that given for mange in the same animal. From the fact that the mites do not burrow and thus obtain a degree of protection from the acaricide, it is easier to control than the latter form.

The preliminary application of soap and water, as directed in the treatment of mange, should be followed here, after which the same general acaricide treatment may be employed. The lime and sulphur preparation is probably of more use for this form of scab in the horse than for the sarcoptic. It is prepared according to the formulæ given for scab in sheep (page 125), either formula No. 1 or formula No. 2 being uscd, according to the age and extent of the lesions. It can be applied as a spray or with a brush, being at the same time wcll worked into the scabs. The treatment should be repeated at intervals of eight to ten days until all indications of the presence of the mites have disappeared.

The precautions against reinfection, involving disinfection of harness, clothing, stalls, etc., as given under equine mange, are to be observed.

\section{Treatalent of Chorioptic Scabies}

Treatment of Chorioptic Scabies of the Horse.-Clip the hair from over the affected parts, usually from the hocks down. It is well in any case to treat the forc legs in the same manner as these may have been infected. A portion of the scales and crusts may be removed with a brush, after which the parts are to be rubbed with a lather of soft or green soap. Let this remain for an hour, then rinse with tepid water, scrape, and allow to dry.

The acaricides mentioned for the treatment of other forms of scabies in the horse will apply here as well. The fact that the affected area in chorioptic scabies is usually limited to the lower parts of the legs permits of the use of remedies which would not he safe for application over 
larger surfaces of the body. Strong tobaceo decoctions, benzene, or oil of turpentine may be used, the latter shaken up in an equal quantity of linseed oil. Equal parts of kerosene and linseed oil also give good results. Two or three applieations of the remedy applied several days apart usually suffiees to bring about a complete eure.

The usual preautions against remfection should be observed. The bedrling is to be bumed and utensils disinfeeted. Animals should have their legs regularly and earefully groomed, and attendants should be on the lookout for symptoms of a retum of the affection.

Treatment of Chorioptic Scabies of Cattle.-The eurative procedure for this scabies does not materially differ from that for bovine mange. As chorioptic scabies appears upon parts which may be reached by the tongue, preparations containing active poisons should be avoided. Probably an ointment of sulphur, as sulphur one part, lard four parts, or sulphur two parts, potassium carbonate one part, lard eight parts, is most suitable for such cases.

\section{Treatment of Follicular Mange}

Treatment of Follicular Mange of the Dog.-Owing to the intracutaneous location of the parasites, successful treatment of this mange is mack vory llifficult. The prospeets for eventual success will depend much upon patience ancl perseveranee. It is important that the general conclition of the animal be built up as mueh as possible by nutritious food and thoroughly sanitary surroundings. Such treatment as may be adoptrel must be prolonged and often repeated if carried out to effectiveness. The remedies given below for the destruction of the mites are among those which have been tried. The best that can be said for them is that they have sometimes given good results.

(1) Peruvian balsam 2 parts, ereolin 1 part, alcohol 20 parts. An objection to this remedy is its expense in view of the prolonged treatnont requiresl. (2) Creosote 1 part, olive oil 15 to 20 parts; (3) benzine 1 part, olive oil 4 parts; (4) creolin 1 part, green soap and alcohol of rarll 3 parts; (5) repeated applications over limited areas of tincture of iodine. (6) In the clinic for small anmals at the School of Veterinary Melicine, University of Pennsylvania, some encouraging results have been obtained from the use of ichthyol, prepared with lard or lanolin in the proportion of one to seven.

Fleming advises that the topieal treatment be accompanied by the internal administration of sulphur in frequent and large closes; the sulphur being exereted to some extent by the skin.

Treatment of Follicular Mange of Swine.-Treatment of this form of mange in the pig is rarely called for. If there are pereeptible indications of its presence a treatment as recommended for logs may be tried, 
though, due to the intractability and habits of pigs, there is probably even less prospect of a complete destruction of the mites. The presence of Demodex, however, is rarely recognized in pigs, and the effects it may produce are far less serious than in dogs.

\section{Treatment of Otacariasis of the Dog, Cat, and Rabbit}

Clean the ears of dogs and cats thoroughly and deeply with olive oil. It may be applied with a bit of cotton rolled upon a probe which should be rotated as it enters the deeper parts. Nocard's treatment, as stated by Neumann, is as follows: Naphthol 1 part, ether 3 parts, olive oil 10 parts. Inject into the external auditory canal each day. After injecting close the canal for ten to fifteen minutes with a pledget of cotton. This is to prevent the evaporation of the ether. The ether causes the remedy to penetrate the waxy lining of the canal which contains the parasites.

In the treatment of rabbits the scabs are first to be softened by a thick lather of soft or green soap which should be allowed to remain for an hour, rinsed, and repeated as may be necessary for deep crust formation. The deeper parts of the ear may then be cleaned with olive oil and cotton as directed for dogs and cats.

As an acaricide, the same treatment may be employed as recommended for otacariasis in dogs and cats, applying the remedy with a pledget of cotton over the whole inner surface of the concha as well as injecting it into the auditory canal. An ointment of sulphur, or a liniment composed of benzene and olive oil equal parts may also be used, either to be applied with a pledget of cotton rolled upon the end of a probe or stick.

It is a good precautionary measure to treat the ears of all rabbits which have been exposed, as there may be infections of a latent character which will later bring about another outbreak of the disease. 


\section{CHAPTER SII}

\section{MANGE OF POULTRY}

The acari-prockeing mange of fowls belong with the genus Cnemidocoptes, the characteristics of which are described on page 103 . There are two species, - C'n. mutans (formerly Sarcoptes mutans), which produces the condition known as sealy leg, and $\mathrm{Cn}$. gallince ( $\mathrm{Cn}$. lavis) which attacks the skin at the attachment of the feathers.

Mange of the Legs ("Scaly Leg").-The burrowing mite of leg mange most often attacks the fect and legs of chickens of the heavier breeds, as the Brahma, Dorking, and Cochin China, less frequently turkeys, pheasants, and pigeons.

The mites live under the epidermic scales from the tarsal joint downward, inchuling the upper part of the toes. In this location they deposit their regrs and multiply, the irritation of their presence soon being manifested by the formation of a white powdery matter which elevates the seales. Due to the exuded serum, this matter assumes a lardaceous nature, adhering to and soon covering the foot. Grachally rough crusts are fomed in the lower layers of which numerous mites may be found. The scabs adhere elosely to the skin, and, when removed, reveal an irritated and bleeding surface (Fig. 75).

The comse of the cliscase is slow, rumning several months to a year. There is a moderate pruritus which the fowl inclicates by restlessness ancl picking at the scabs with the beak. As the erusts increase there is a mechanical interference with flexion of the joints which makes cither moving about or stanching difficult. As a consequence the animal often squats fown with the legs extended and remains in this position with infrequent efforts to rise. In such severe cases arthritis is likely to appear, and one or even all of the toes may drop off. When the disease has advanced over several months we have the usual systemie accompaniment of prolonged mange; there is loss of appetite, eachexia, and stupor which is usually followed by death.

Treatment.-Treatment must hegin with sof tening of the scabs with soft soap, applied by hanch or by soaking in warm soapy water. They may then be removed by manipulation with the hancls or with a brush, care being taken in this operation to eause as little injury to the skin as possible. When the parts are cry, apply Pcruvian balsam, either alone or made up in the proportions of balsam 2 parts, creolin 1 part, alcohol 20 parts. The ointment of Helmerich, as recommended for scabies in 
other animals, is one of the best remedies for this scab. Others perhaps as effectual are (1) creosote 1 part, lard 20 parts; (2) benzene 1 part, olive oil 10 parts; (3) carbolized vaseline (5\%), or (4) an ointment of carbolic acid 1 part, lard 20 parts. The stronger acaricides should not be used upon young chicks. For these the ointment of Helmerich or Balsam of Peru are quite suitable. The application may be washed off and repeated as necessary.

To prevent contagion and reinfection, diseased fowls should be removed from the healthy and the quarters subjected to cleaning up and disinfection, especial attention being given to roosts and other places where the fowls are in the habit of perching.
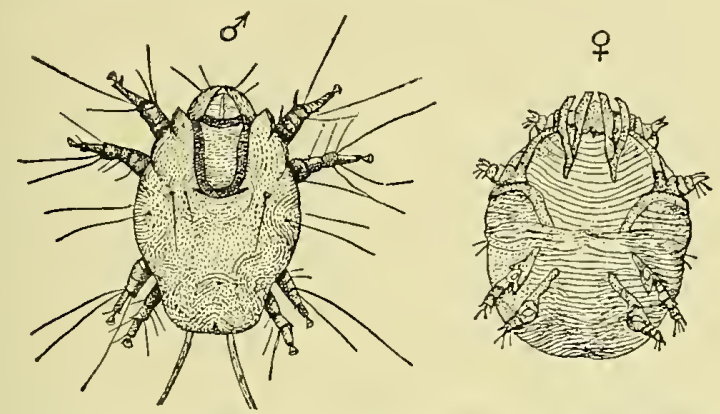

FIG. 74.-Cnemidocoptes mutans, male and female (after Osborn, Bull. No, 5, Bureau of Entomology, U. S. Dept. of Agr.).

Mange of the Body, or Depluming Mange.-The depluming mite, Cnemidocoptes galline, is closely related to the mite of foot mange and it may easily be mistaken for the same species where the two forms of mange coexist. The body form usually has its beginning on the back, near the insertion of the tail-featliers. Nore rarely the head and upper part of the neck are first attacked. From these regions it spreads to adjacent parts of the body.

The disease is accompanied by the production of an abundance of epidermic scales, iritation, and itching which impels the fow to pluck at the feathers. These easily drop out or are broken off, leaving a bald or partly denuded skin which is but little thickened and remains normally smooth and elastic.

The acaricide treatment employed may be the same as for foot mange. Where a number of birds are affected they may be treated by dipping for several successive days in a sulphur bath. The same precautions against contagion and reinfection are to be observed as for the leg form. In this comnection it is well to repeatedly disinfect the feet of roostcrs, 
as the disease is readily conveyed from the back of one hen to another in treacling.

\section{Family $Y$, Cytoleichide}

Acarina (p. 94).-This family contains two genera, Cytoleichus and Iaminosioptes, each with onc species causing a decp-seated acariasis in lirds.

Cytoleichus nudus. (ytoleichidæ (p. 134).-The body is rounded.

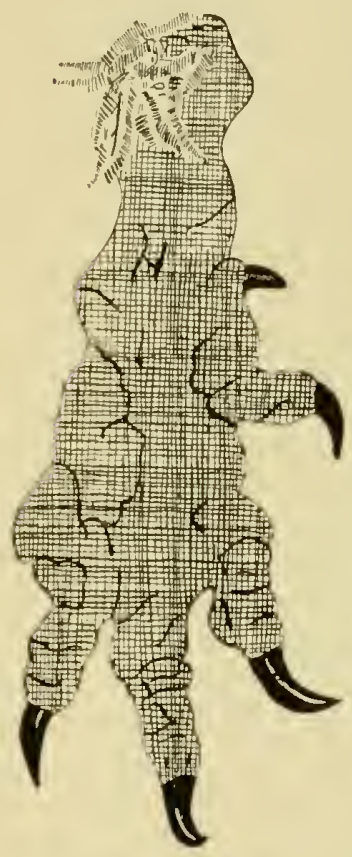

Fta. 75.-Foot of fowl affected with scaly leg. almost bald, and whitish in color. The mouth parts are conical. The legs have five articles and are strong and elongated; all terminate by a simple stalked sucker. The ovigerous female is 500 to 600 microns long by 350 to 400 microns broad. She may produce either larvæ ol cggs.

Colonies of these parasites live in the air passages and air saes of fowl.

Laminosioptes cysticola. Cytoleichidæ (p. 13.1). - The body is twice as long as broarl; color grayish. On the dorsal surface are several pairs of bristles, a long pair extending from the posterior extremity. The mouth parts and the two first pairs of legs are carried upon the anterior third of the body which is separated from the posterior portion by a transverse furrow. The legs are short, smooth, and provided with suckers, which are not permanent upon the anterior pair. The ovigerons female is 250 to 260 microns long by 100 to 110 microns broal.

Palasitic in subcutancous connective tissue of fowl.

The Cytoleichus spceics enter the respiratory passages and pass to the decper air chamnels, even to the air canals in the bones. From their relatively large size and whitish color they may be readily seen with the naked eye, usually in colonies of more or less number. Ordinarily these parasites do not cause sufficient disturbance to betray their presence during the life of their host. If in exceptionally large numbers they may cause attacks of coughing by irritation of the bronchial mucosa.

Laminosioptes cysticola lives in the subcutancous connective tissue. especially in regions where this is loose, as the neck, breast, sirles, and 
thigh. Where many are present they cause irritation with the formation of yellowish, oval nodules. These are about $0.5 \mathrm{~mm}$. by $1 \mathrm{~mm}$. in dimensions, and a large number of them may cover a small area. They are soft, granular or valcareous, and may contain the dead parasites. The health of the host does not appear to be affected by the lesions which these parasites produce. 


\section{CH.PPTER XIII}

\section{THE TICKS}

There has been consiclerable difference of opinion among various authors as to the systematic arrangement of the ticks. They have been brought into one family,-Ixodicke, in which two subfamilies are distinguished,-Argasine and Ixodina, and, again, these two subgroups have been considered as distinct families. The arrangement adopted here, which raises the ticks to the rank of a superfamily, is that of Banks (1894) and as followed by Salmon and Stiles (1901).

Structure of Ticks in General.-The proper study and differentiation of the ticks requires some knowledge of the external parts and an understanding of the technical terms which are used in reference to them. Confonning to the general characteristies of the oreler Acarina to which they brong, the ticks have a body in which the cephalothorax and abelomen are not demareated and this bears certain struetures possessing variations as to location and form which serve as defming characters for the various subgroups and species. The parts more commonly referred to with their trehnical names follow:

1. The ("apitulum (1…76) is the "head," "false head," or rostrum, as it is variously temel. It projects from the anterior extremity in the Ixodidae. In the Argasidar, exeept in the larval stage, it is upon the under surface of the anterior extremity. The structure consists of a number of parts, as follow:

(a) The Basis Capituli (Fig. 76,1$)$ ) is the hard base of the eapitulum; the basal ring or month shirlk.

(b) The IIypostome (Fig. 76, h) or "lalium" or "radula" of various authors is a needian ventral structure rising from the basis capituli and betring recurved tretl.

(e) The Chelicerc (Fig. 76, c), "mandibles," or "jaws" are paired clongate structures, one on rach side of the median line, lying dorsal to the hrpostome. Dorsal to these is the hood or sheath of the chelicera.

The hypostome, chelicere, and hood constitute the haustellum, or, as it is commonly called, the "boak," and it is these structures which penetrate the skin of the animal upon which the tick attaches.

(d) The Palpi (Fig. 76, p) are articulated structures, one on each sicle of the haustellum, and inserted antero-laterally upon the basis capituli.

2. The Scutum (1in. 77), or clorsal shield-present in the Ixodidx, 
absent in the Argasidæ-is a hard, plate-like struetwe located immediately posterior to the eapitulum. In the male it usually eovers the

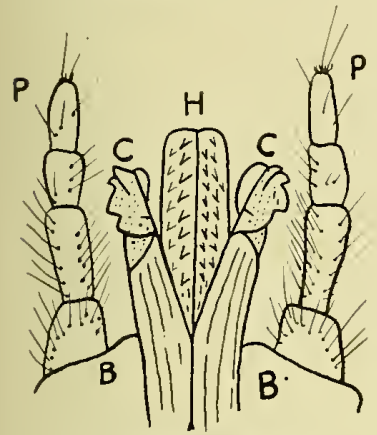

Fig. 76.-Capitulum (rostrum), of an argasid tick: $h$, hypostome; c, cheliceræ; p, palpi; b, basis capituli.

6. Ornamentation refers to enamel-like eoloration whieh may be present on the scutum, eapitulum, or other parts. Tieks upon whieh this coloration oecurs are referred to as ornate.

7. Venter.-This term refers to the whole ventral surface of the body.

8. The Spiracles (Figs. 78 and 78 , a) -also called stigmata, stigmal plates, and peritremes-are two respiratory organs situated ventro-laterally. In the Ixodidx they are situated posterior to the attaehment of the fourth pair of legs; in the Argasidx they are between the third and fourth pairs. The entire structure may be eonsidered as the stigmal plate or peritreme with an opening known as

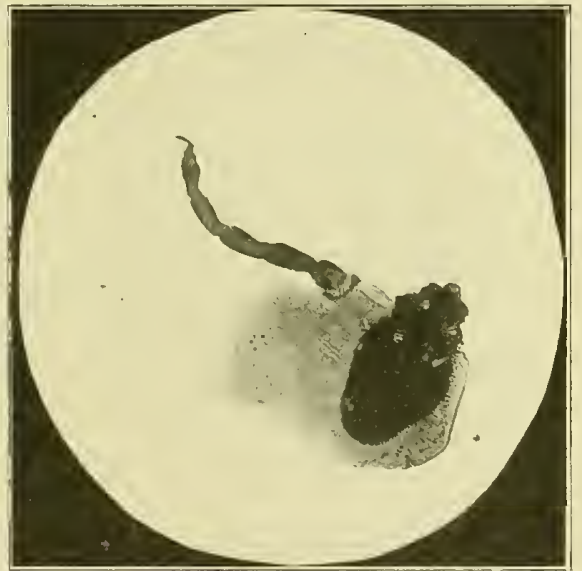

FIG. 77.-Capitulum (head), scutum (shicld), and foreleg of Margaropus annulatus (from photomicrograph of mounted specimen, by Hoedt).

the spiraele or stigmal aperture. The stigmal plates vary in form and 
structure in different species; they may be circular, oval, or commashaped.

9. The Genital Pore is a transverse ventro-median slit, situated ante-

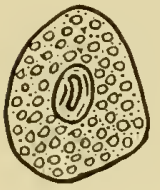

I
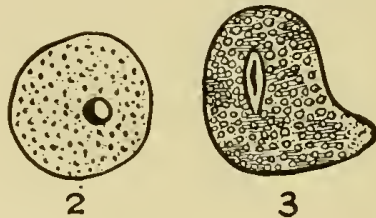

3

FIg. 78. - Stignal plates of ticks: 1, Margaropus: '2, Ixodes; 3 , Dermacentor.

They are present only in males of certain genera.

riorly between the attachments of the first three pairs of legs.

10. The Anus is in the ventro-median line, posterior to the attachment of the last pair of legs.

11. The Anal Shields are four elongate structures lateral to the anus.

12. Legs. - There are four pairs of legs in the adult males and females and in the numplss (octopod). In the larve there are three pairs (hex-

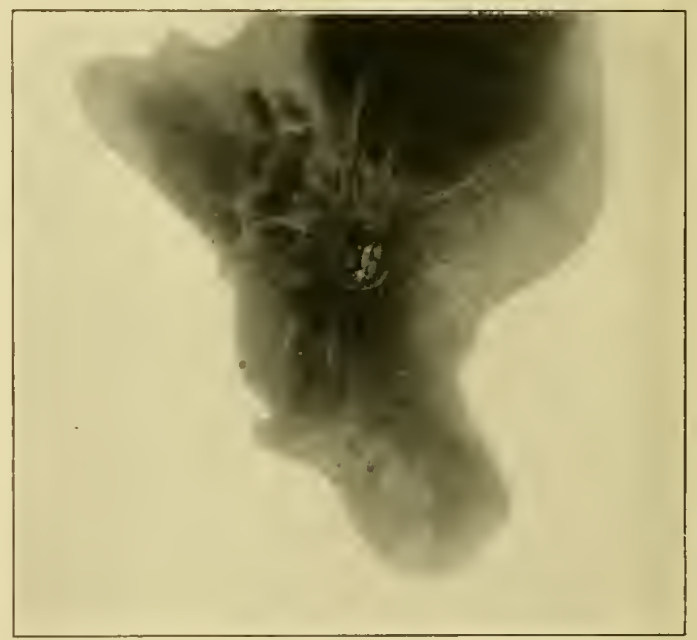

Fia. 78..-Stignal plate of Margaropus annulatus (photomicrograph of mounted specimen, by Hoedt).

apod). The pairs are numbered I to IV from before to behind. They are composed of six articles or segments which are united by articulations.

13. The Coxa or first article is an immovable portion which lies flat upon the boty and upon which the first movable article is articulated. 
14. Bifid Coxce bear two spurs and are deeply incised. When trenchant they have a knife-like margin.

Several stages are passed through in the development of the ticks. From the eggs are hatched the six-legged (hexapod) laver, often referred to as the "seed ticks" (Plate II, Fig. 6). These are very small but may be seen without the aid of magnification. The legs are relatively much longer than in the adults.

The nymph stage is reached after molting, when a fourth pair of legs appears posterior to the third pair (octopod).

The change from the nymphal to the adult stage is marked by another molting, and sexual maturity is reached.

After fertilization by the male, the female slowly enlarges and becomes the ovigerous or egg-eontaining female. Upon repletion she drops to the ground and proceeds to deposit her eggs.

Superfamily Characteristics. Acarina (p. 94).-The Ixodoidea are all blood-sucking parasites on animals. They have a movable capitulum consisting of a basal portion (basis capituli), protrusible serrate eheliceræ, a rigid serrate hypostome, and a pair of palps. The breathing apertures are situated posteriorly.

The superfamily Ixodoidea is divided into two families,-Argasidæ and Ixodidæ.

\section{Family I. Argaside}

Ixodoidea (p. 139).-The ticks belonging with this family have little sexual dimorphism as eompared with the Ixodidæ. The capitulum, instead of being terminal, oecupies in adults the ventral face of the
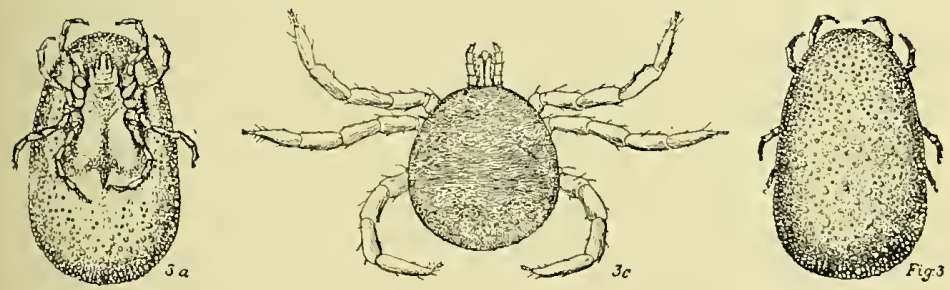

FIc. 79.-Argas miniatus: Fig. 3, dorsal view; 3a, ventral view; $3 c$, larva (after $\mathrm{O}_{\mathbf{s}}-$ born, from Marx, Bul. No. 5, Bureau of Entomology, U. S. Dept. of Agr.).

cephalothorax. The palps are leg-like, the articles very movable on each other. The scutum is absent. The coxa are unarmed; tarsi without ventral spurs.

The family has two genera,-Argas and Otobius.

1. Argas miniatus (A. americanus) (Fig. 79). The Fowl Tiek. Argasidae (p. 139).-The body is ovoid, flattened, with edges very thin. 
Depending on the stage of engorgment, the color varies from light reddish to dark brown. The eapitulum has four long hairs, all directed forward. The arlult females are about $8.5 \mathrm{~mm}$. (5/16 of an inch) in length. The males are slightly smaller, but are not easily distinguishable.

Occurrence and Habits.-Commonly called the "fowl tick" or "adobe tick," this species is widely distributed. It is a parasite of fowl in Europe, Asia, Africa, and Australia, in Mexico and the Southern United States. In its habits it is comparable to the bedbug, coming out to feed upon its host at night and retreating after engorgment to eracks, crevices, or other darkened hiding places to remain during the day. In these retrats the females deposit large, reddish brown eggs, usually several layings, in masses containing up to a hundred or more eggs in each. Herms (1915) gives the further life history as follows: "Hat ching takes place in from three to four weeks. The larve are six-legged and very active, attacking a host apparently as readily by day as by night. Once attached the larve feed for about five days, occasionally longer, remaining fimly attached during this time. At the end of this feeding perion the larve detach themselves and then erawl away from their host, hiding in some convenient crevice near by. The larvæ molt in about a work, when the fourth pair of legs appears and they are now in the first nymphal stage, appearing like miniature adults. Nocturnal feeding now takes place and in ten or twelve days another molt occurs and the second nymphal stage is reached. Again the tick attaches itself, being now able to engorge itself in about an hour; again after the expiration of something over a week a third molt takes place and the adult stage is leached. The alults are able to engorge themselves in from twenty to forty-five minutes."

Effect. - When attacking in large numbers these parasites extract large quantities of hlood and, furthermore, eause much irritation and unrest among the flock. As a result the animals become unthrifty, weak, and nonproductive.

Argas miniatus has been proven to be the earier of the spirochete (Spirocheta gallinarum) causing fowl spirochetosis or Brazilian septicenia of fowls (p. 327).

Control. For the eradication of this pest the same general methods nay be taken as reconmended for bedbugs of the hen house (p. 92). The ends of roosts should be repentedly covered with tar or wrapped in waste soaked with crude oil. Nesting and trash should be burned and the interior sprayed with kerosene. All woodwork about the buildings should be free from bark. as this affords a favorable hiding place for the ticks. It is well to repeat the treatment with kerosene at least once a month during the season that the ticks are active.

2. Otobius megnini (Ornithodorus megnini, Fig. 80). The Spinose 
Ear Tick, Argasidæ (p. 139).-The body is oval, broader anteriorly than posteriorly. The female is $5-6 \mathrm{~mm}$. (1/4 of an inch) in length and about $3 \mathrm{~mm}$. ( $1 / \mathrm{s}$ of an inch) in breadth. The nymphs are covered with numerous spines, a fact which has given to this species the common name "spinose ear tick."

Occurrence and Habits. - This tick occurs in the ears of horses of Mexico and the Southwestern States. Its attack is not confined to horses and mules; it also attacks the ears of cattle and occasionally other domestic animals and man. The larval ticks reach the head of the grazing host animal from weeds or other regetation upon which they have crawled immediately after hatching. Having gained entrance to the ear, they attach deeply in the folds where they feed for about five days. They then molt and, as nymphs with spinose bodies, continue to infest the ear and feed for several weeks. The nymphs then leave the host, again molt, and becoming unspined adults, the females are fertilized and soon begin depositing their eggs.

Effect.-In their attachment to the lining of the concha the spinose ticks cause much irritation which the animal indicates by shaking its head, or it may be

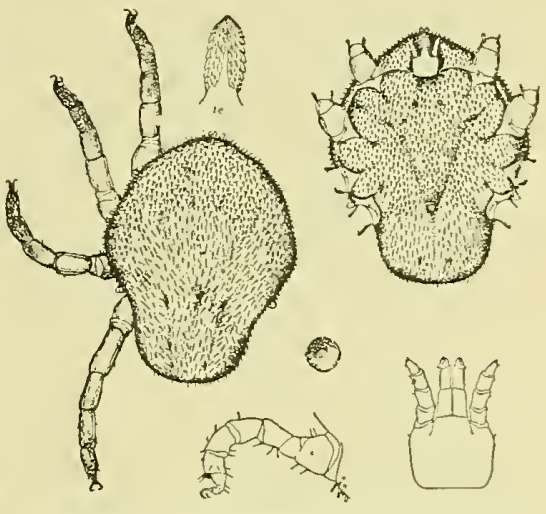

FIG. 80.-Otobius megnini: dorsal and ventral view of nymphal form, with details (after Osborn, from Marx, Bull. No. 5, Bureau of Entomology; U. S. Dept. of Agr.).

wrought up tọ a high degree of nervous excitement. The ticks are said to be responsible for much deafness among domestic animals, and, especially among young anima's, they are considered as a cause of serious illness and even death.

Treatment.- Good results have been obtained by flooding the ear with earbolized oil. This closes the breathing apertures of the ticks and causes them to release their attachment, after which they may be removed with a cotton swab or forceps and destroyed.

\section{FAMILY II, TxOdIDE}

Ixodoidea (p, 139).-The most prominent differential character by which these ticks may be distinguished from those of the family Argasidæ is the presence of a scutum, located immediately posterior to 
the capitulum, which is terminal and not upon the ventral face of the cephalothorax as in the Argaside. Sexual dimorphism is marked, the dorsal surface of the males being almost covered by the scutum. In the distented female the seutum appears as a smatl shield directly behind the capitulum. Only the females are capable of great distension. The spiracles are posterior to the fourth coxie. The eyes, if present, are situated laterally upon the scutum.

Nine genera have been described uncler the family Ixodidæ, as follows: lxodes, Hsemaphysalis, Demacentor, Rhipicentor, Rhipicephalus, Margaropus, Boöphilus, Hyałomma, and Amblyomma.

Four of the above,-Ixorles, Dermacentor, Margaropus, and Amblyomma,-contain species occurring upon cattle and other animals in the Inited States. The generic characteristics of these are given by Nuttall and Warburton (A Monograph of the Ixodoidea, 1911) as follows:

1. Ixodes.-Inornate, without eyes and without festoons; spiracles rouncl or oval; palps anc basis capituli of variable form; coxe either unamed, trenchant, spurred, or bificl; tarsi without spurs. Sexual dimorphism pronounced, especially with regard to the capitulum. In the male the vonter is covered by non-salient plates: one pregential, one median, one ana!, two adanal and two epimeral plates. Anal groove surrombling anus in front.

2. Dermacentor.- Csually ornate, with eyes and festoons; with short, broad or moderate palps and basis capituli rectangular dorsally. In some species coxre I to IV of the male increase progressively in size; in all species coxa IV is much the largest; the male, moreover, shows no ventral plates or shiekls. Coxa I bifid in both sexes. Anal groove contouring anus behind. Spiracles suboval or comma-shaped.

3. Margaropus.-Inornate, with eyes, but without festoons, with short pilps and eapitulum intermediate between that of Rhipicephalus and Boöplilus; highly chitinized; the unfed adults of large size. The female with very small scutum. Coxe conical, unarmed but for a small spine posteriorly on coxa I. The male with a median plate prolonged in two long spines projecting beyond and to either sicle of the anus; with coxie similar to those of the female; legs increasing progressively in size from pair I to $\mathrm{IV}$, the articles, especially of leg-pair IV, greatly swollen. When replete, the male shows a caudal protrusion. Anal groove obsolete. Fipiracles rounded or short oval in both sexes.

4. Amblyomma.-Cenerally ornate, with eyes and with festoons. With long palps; of which article II is especially long, basis capituli of variable form. The male without adanal shields, but small ventral plaques are occasionally present close to the festoons. Anal groove contouring anus behind. Spiracles subtriangular or comna-shaped.

six species are foumd upon cattle and other domestic animals in this 
country, the following brief descriptions of which are taken principally from those given by Mohler (Bull. No. 78, Bureau of Animal Industry, 1905; Farmers' Bull. No. 569, 1914). The parts described are those of the adult female.

1. Ixodes ricinus (Fig. 81). The Castor-bean Tick. Ixodes ( $p$. 142). - The body is ovoid in shape, narrower anteriorly than posteriorly; lead colored, with a diversity of yellowish red, brown, or gray. Festoons are absent. The mature female is three-eighths to seven-sixteenths of an inch in length. The legs are thin and dark brown in color. The capitulum and scutum are a shiny dark brown or chestnut brown; scutum pentagonal with prominent lateral borders. The palpi are well developed and extend outward upon each side.

This tick has been collected from sheep, goats, cattle, horses, deer, dogs, foxes, cats, rabbits, birds, and man. It is widely distributed in the United States.

2. Ixodes hexagonus. The Europeall Dog Tick. Ixodes (p. 142).-The body is oval in shape and of an ashy color; festoons absent. The legs are longer and more robust than those of the cattle tick. The capitulum and scutum are brownish red in color and similar to those of Ixodes ricinus in shape. The palpi are longer and more prominent than in the

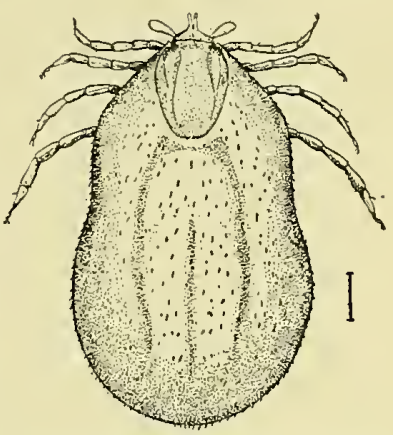

FIG. 81.--Ixodes ricinus--enlarged (after Osborn, Bull. No. 5, Bureau of Entomology, U.S. Dept. of Agr.). cattle tick and, like those of Ixodes ricinus, extend outward.

This species has been collected from dogs, cattle, sheep, foxes, rabbits, squirrels, gophers, cats, birds, man, and other hosts in the Eastern United States, but is less common in this country than the other species here described:

3. Dermacentor reticulatus (D. occidentalis). The Net Tick. Dermacentor (p. 142). - The body is oblong oval, five-eighths of an inch long, and of a deep brown or slate color. The legs are brown and of moderate length. There are eleven festoons about the posterior margin of the body which in the adult become shallow or effaced. The scutum has a silvery-white metallic rust extending along the two sides and posterior portion.

Found on man, cattle, horses, sheep, and deer. In this country it seems to be most common in the West, especially in California, Texas and New Mexico.

4. Dermacentor variabilis (D. electus, Fig. 82). The American Dog Tick or Wood Tick. Dermacentor (p. 142).-This tick resembles 
D. reticulatus so closely that a hand lens is necessary to distinguish between them. The body is oblong oval in shape and may measure as much as three-fifths of an inch in length. It can be distinguished from the Texas-ferer tick hy the capitulum and scutum which are longer and broacler. Extending anteriorly along each side of the scutum there are lines of yellowish white rust, separated by a central brownish area. There are eleven festoons on the posterior margin of the body, most distinet in the young female.

This tick has becn found on man, cattle, dogs, horses, and other animals, especially in the Eastern L'nited sitates.

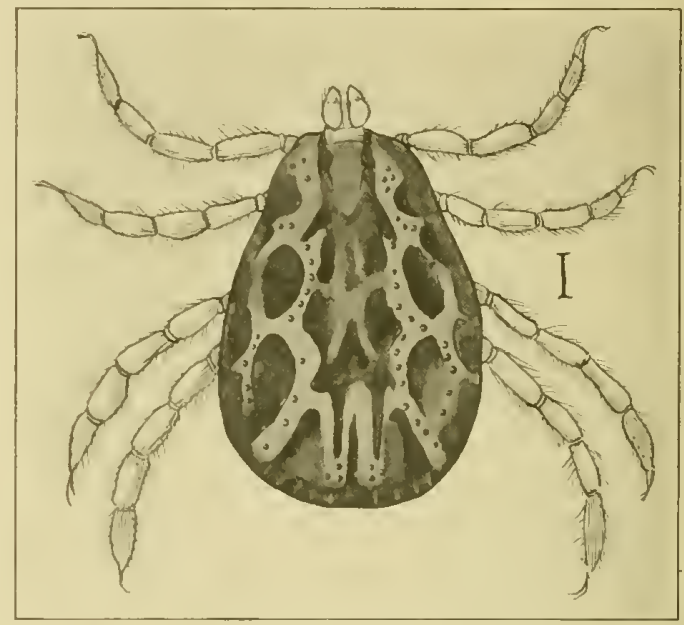

Fta. 62.-Dermaentor variabilis: male-enlarged (after Osborn, Bull. No. 5, Burcau of Entomology, U. S. Dept. of Agr.).

j). Margaropus annulatus (Boöphilus annulatus, B. bovis). The Texas-ferer or Cattle Tick. Margaropus (p. 142). - This tick may be distinguished from the other five by the small size and the color of the capituhum and scutum, the lateral borders of which are straighter and more parallel. These parts are short and relatively broad and in color redclish brown or chestnut brown. The body is oblong oval in shape and may reach a length of one-half an inch. The color may be dull rellow or olive brown. Often it is mottled with irregular areas of yellow and brown or streaked with wavy lines of these colors. Festoons arr absent. The legs are brown, moderately long, and very slender.

This tick is found principally on cattle, less frequently on horses, mules, and asses. 
6. Amblyomma americanum. The Lone Star Tick.-Amblyomma (p. 142).-The body is oval and in color yellowish gray or brown. When not distended, the body-surface is rough and puckered. Festoons are present. The scutum extends backward a short distance to form a triangle, at the apex of which is a white or yellowish spot, from which the tick derives its name "Lone Star." The mature female may reach a length of one-half an inch. The legs are long and thin.

This species has been found on cattle, dogs, horses, sheep, goats, hogs, and man. It is very widely distributed in the United States.

All of these ticks show longitudinal grooves upon the dorsal surface of the body which are most distinet a few days after the tick's repletion and removal from the host. These furrows vary considerably in different membcrs of the same species and, though some authors appear to attach importance to them, they can hardly be considered of much value as an aid in recognition. Color is also unreliable in the identification of genera and species, as this varies with the stages in the tick's development and may change variously in adult ticks of the same species.

The Texas-fever Tick.- Kilborne, of the Bureau of Animal Industry, proved conclusively by field experiments conducted in 1889 and 1890 that it is only through the bite of this tick that Texas-fever can be naturally transmitted. Economically, therefore, Margaropus annulatus (Plates I and II), the Texas-fever tick, is the most important for consideration. Other ticks not concerned in the transmission of Texasfever have been mentioned here as occurring upon cattle, all having the same successive stages in their development, namely, oval, larval, nymphal, and adult male and female. Before molting and transforming from one stage to the other these ticks fall from their host, after the transformation seeking a new host. That this is not true in the case of the Texas-fever tick was shown by Dr. Cooper Curtice, of the Bureau of Animal Industry, in 1891. He established the fundamental facts in the life history of this tick and showed that it remains upon its host from the time that it attaches as a larva until it drops to the ground replete and ready to deposit its eggs (Tables, p. 151). Careful observations by the Zoölogical Division of the Bureau have supplied valuable data relative to the biology of this tick, and much detailed information has been published by the Bureau pertaining to this and to tick control and eradication. In this connection, it may be of service to mention here the following titles, any of which can bc obtained upon application to the Superintenclent of Documents, Governmeut Printing Office, Washington, D. C.

Texas Fever, Mcthods for its Prevention, by John R. Mohler. Bull. No. 78 (1905).

Texas or Tick Fever and its Prevention, by John R. Mohler. Farmers' Bull. No. 258 (1906). 


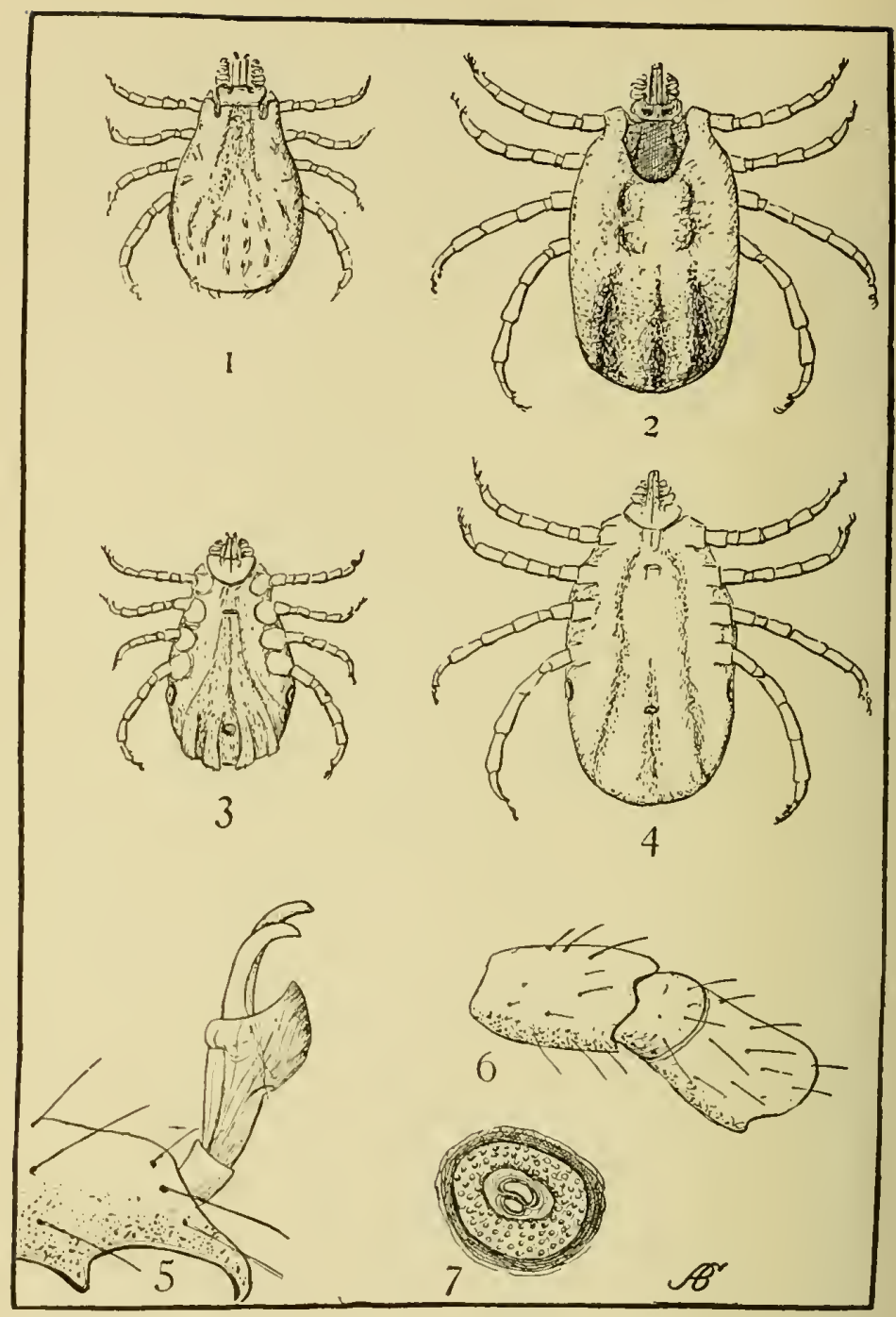

Plite I.-Margaropus annulatus: 1, Male, dorsal view; 2, Female, dorsal view; 3 , Male, ventral view; 4 , Female, ventral view; 5 , Claw and pulvillus; 6 , Lower surface of first, second, and third segment of leg; 7 . Stigmal plate. (After Osborn, from Curtice, Bull. No. 5, Bureau of Entomology, U. S. Dept. of Agr.). 


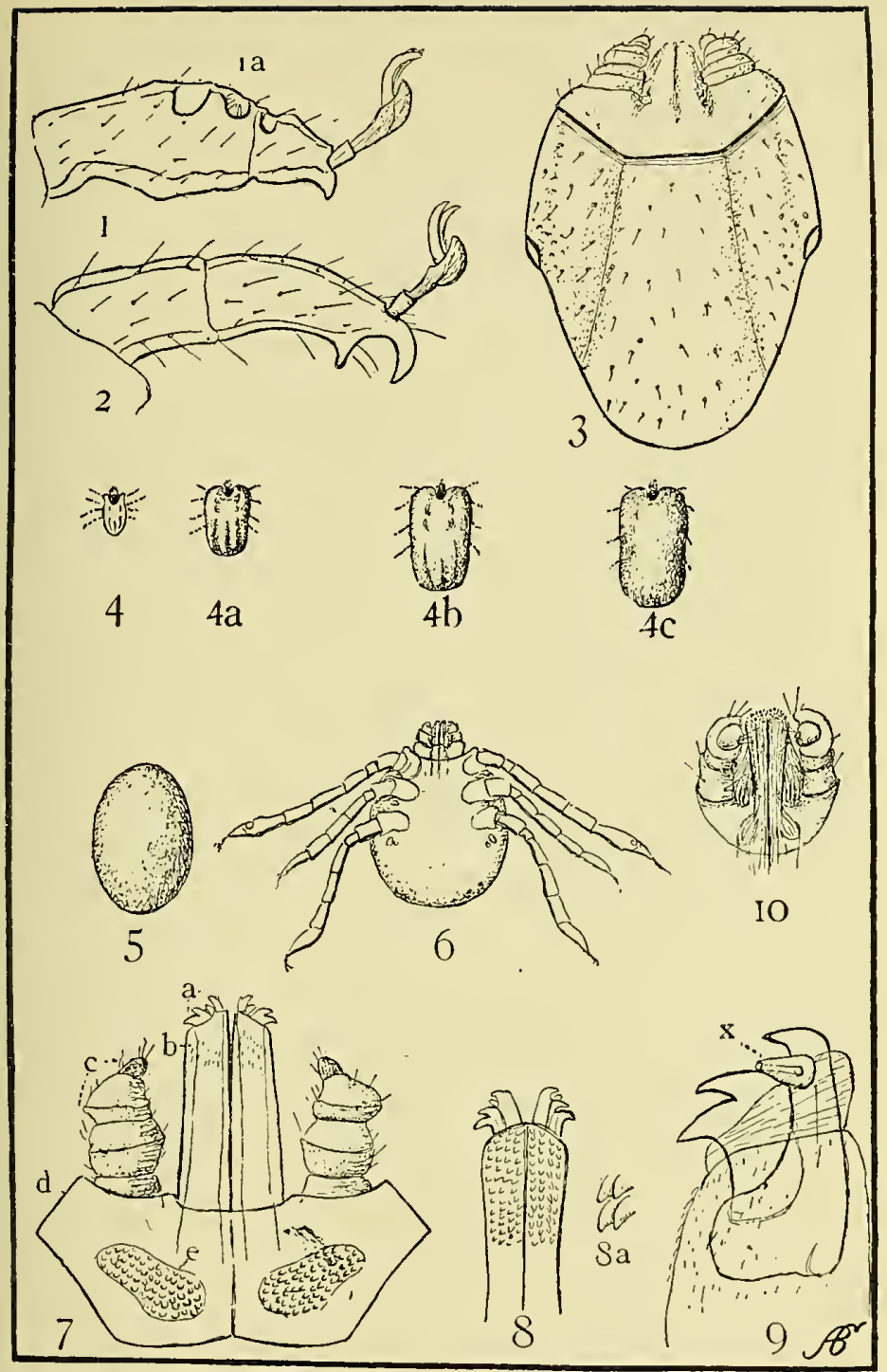

Plate II. -Margaropus anuulatus: I, Front foot, showing single spur; 1a, Supposed sense organs; 2, Hind foot, showing double spur; 3 , Head of female; $4,4 a, 4 b$, $4 c$, Female ticks, natural sizc, shown at diffelent stages of feeding; 5, Egg; 6, Larval or "seed" tick; 7 , Dorsal surface of the mouth parts of female-a, mandible; b, labrum; $c$, palpus; d, mouth ring; e, spots covered with papille; 8, Labium and mandibles; Sa, Papillze enlarged; 9. Mandible-X-Busk's organ, use unknown; 10, Mouth parts of young tick. (After Osborn, from Curtice; Bull. No. 5, Bureau of Entomology, U. S. Dept. of Ayr.). 
The Cattle Tick in its Relation to Southern Agrieulture, by August Mayrer. Farmers' Bull. No. 261 (1906).

Proceedings of a Conference of Federal and State Representatives to Consider Plans for the Eradieation of the Cattle Tiek. Bull. No. 97 (1907).

Methods of Eradicating Cattle Ticks, by Louis A. Kilein. Cir. No. $110(1907)$.

Studies on the Biology of the Texas-fever Tick, by H. W. Graybill. Bull. No. 130 (1911).

Methods of Exterminating the Texas-fever Tick, by H. W. Gravbill. Farmers' Bull. No. 498 (1912).

Progress and Prospects of Tick Eradication, by Cooper Curtice. Cir. No. 187 (1912).

Texas or Tiek Fever, by John R. Mohler. Fanners' Bull. No. 569 (1914).

Life History; the Nonparasitic Development.-The following data as to the life history of the Texas-fever tick is taken from Graybill (Stuclies on the Biology of the Texas-fever Tiek, 1911). The nonparasitic development is considered by this author under five periods, nancly, the preoviposition period, the oviposition period, the incubation period, the hatching period, and the longevity period of the lat vat.

The period of preoviposition extends from the time the fernale tick drops until she hegins to deposit her eggs. In a series of investigations carried out at Auburn, Ala., in 1907-8 it was observed that the average duration of this period ranged from three to forty-nine and three-tenths days, depending largely upon temperature, the shorter average period occurring in August, the longer in Decenber.

The average oriposition or egg-laying period for different months of the year ranged from eight and three-tenths clays for June to one hundred and twenty-seven and five-tenths days for November. The maximum periorl noted was one hundred and fifty-two days, observed in November, and the minimum three days, observed in June. The naximum number of eggs deposited by a female tick was 5105 , minimum $35 \%$, with an average ranging from 1811 to 4089.

The incubation period was found to range from nineteen days in the summer to one hundred and eighty days beginning in the fall. The conditions essential to development and hatching are moisture, such as supplied by sufficient atmospheric humidity to prevent eggs losing moisture by evaporation, and a favorable temperature.

The hatehing period is taken as the time required for all of the eggs to hatch after hatching begins, the eggs deposited by a female hatching approximately in the sequence in which they are laid. The average period was found to range from ten and six-tenths days for July to 
thirty-six days for October. The maximum period observed was fortynine days for October, the minimum four days for July.

The longevity period is stated to depend on individual vitality, humidity, and temperature. It was noted, especially in eggs laid during the winter, that some larvæ do not have sufficient vitality to disengage themselves from the eggshell and die partly inclosed within it; also that others die very soon after emerging. Cold, it is stated, prolongs longevity because of the fact that the tick remains quiescent with resulting conservation of body fluids and nourishment. The fact that the larvæ respond negatively to light is an additional factor promoting longevity. In places exposed to the sun they collect on the under side of leaves and other vegetation, thus protecting themselves from loss of body moisture through the direct heat of the sun. In observations made it was determined that the average maximum longevity for larvæ hatched from a number of lots of eggs in July was thirty-eight and six-tenths days. From eggs hatched in October the average maximum period was one hundred and sixty-seven and four-tenths days. The shortest period was four days for larvæ hatched in July, the longest two hundred and thirty-four days for larvæ hatched in October.

The following summary is given of the data on the nonparasitic period:

Total Time from Dropping of Female until all Resulting Larve are Dead

\begin{tabular}{|c|c|c|c|c|c|c|c|}
\hline $\begin{array}{c}\text { Date engorged } \\
\text { females were } \\
\text { collected }\end{array}$ & $\begin{array}{c}\text { Number } \\
\text { of engorged } \\
\text { females }\end{array}$ & $\mid \begin{array}{c}\text { Range of } \\
\text { entire- } \\
\text { time } \\
\text { periods }\end{array}$ & $\begin{array}{c}\text { Average } \\
\text { of } \\
\text { periods }\end{array}$ & $\begin{array}{c}\text { Date engorged } \\
\text { females were } \\
\text { collected }\end{array}$ & $\begin{array}{c}\text { Number } \\
\text { of engorged } \\
\text { females }\end{array} \mid$ & $\left|\begin{array}{c}\text { Range of } \\
\text { entire- } \\
\text { time } \\
\text { periods }\end{array}\right|$ & $\begin{array}{c}\text { Average } \\
\text { of } \\
\text { periods }\end{array}$ \\
\hline June 1,1907 & 7 & $\begin{array}{l}\text { Days } \\
79-100\end{array}$ & $\begin{array}{c}\text { Days } \\
86.9\end{array}$ & $\begin{array}{c}\text { Dec. 29,1907, } \\
\text { to } \\
\text { Jan. 1, } 1908\end{array}$ & 3 & $\begin{array}{c}\text { Days } \\
181-207\end{array}$ & $\begin{array}{l}\text { Days } \\
196.3\end{array}$ \\
\hline July 1,1907 & 7 & $82-112$ & 101 & $\begin{array}{l}\text { Jan. } 29 \text { to } \\
\text { Feb. 4, } 1908\end{array}$ & 7 & $156-189$ & 173.1 \\
\hline Aug. 1, 1907 & 7 & $172-221$ & 199.6 & $\begin{array}{c}\text { Feb. } 27 \text { to } 28 \\
1908\end{array}$ & 2 & $143-162$ & 152.1 \\
\hline Aug. 31,1907 & 6 & $230-272$ & 250.7 & $\begin{array}{l}\text { Mar. } 26 \text { to } \\
29,1908\end{array}$ & 9 & $144-161$ & 152.1 \\
\hline Oct. 1, 1907 & 7 & $276-288$ & 279.6 & $\begin{array}{l}\text { April 29, } \\
1908\end{array}$ & 14 & $122-173$ & 142.8 \\
\hline Nov. 1, 1907 & 7 & $200-253$ & 232.7 & & & & \\
\hline Nov. 30,1907 & 3 & $187-249$ & 217 & & & & \\
\hline
\end{tabular}

The Parasitic Development.-The parasitic development has three stages, the larval, the nymphal, and the adult. In the experiments car- 
ried on upon this portion of the tick's life history tick-frce animals were infested at nine different times from July, 1907, to May, 1908. It was found that the minimum larval period ranged from five to seven days; the minimum nymphal period of females, nine to eleven days; the adult period, from a minimum of five to a maximum of thirty-three days. The table which follows is given to show the range of the periods observed upon larvæ which were marked after they had become attached and then kept under observation from day to day.

Length of Period and Total Duration of Parasitic Development

\begin{tabular}{|c|c|c|c|c|c|}
\hline Date larre opplied & Sex & $\begin{array}{l}\text { Length } \\
\text { of larval } \\
\text { period }\end{array}$ & $\begin{array}{c}\text { Length } \\
\text { of nymphal } \\
\text { period }\end{array}$ & $\begin{array}{l}\text { Length } \\
\text { of adult } \\
\text { period }\end{array}$ & $\begin{array}{l}\text { Durotion } \\
\text { of porositic } \\
\text { period }\end{array}$ \\
\hline Feb. 29. . . . . . . & Females & $\begin{array}{l}\text { Days } \\
\text { S-9 }\end{array}$ & $\begin{array}{l}\text { Days } \\
10-15\end{array}$ & $\begin{array}{c}\text { Days } \\
5-13\end{array}$ & $\begin{array}{l}\text { Days } \\
25-34\end{array}$ \\
\hline Do ............. & Males & $7-9$ & $8-10$ & - & 一 \\
\hline Do. & $(?)$ & $7-14$ & - & - & - \\
\hline April $4 . \ldots \ldots \ldots \ldots$ & Females & 7 & $9-14$ & $4-9$ & $25-26$ \\
\hline Do . & Males & 7 & $8-12$ & 一 & 一 \\
\hline May $23 \ldots \ldots \ldots$ & Females & $6-7$ & $9-12$ & 6- 9 & $22-25$ \\
\hline Do $\ldots \ldots \ldots \ldots$ & Males & $5-8$ & $8-13$ & - & 一 \\
\hline
\end{tabular}

As to the importance of the foregoing data, Graybill says: "The duration of each of these stages and the duration of a single infestation upon cattle during different portions of the year are of great practical importance. Upon the duration of an infestation depends the time animals must be kept on tick-free fields in order to beconc frce from the ticks." 
Life Histories of the Dog Tick and Texas-Fever Tick Compared in Tabular Review (note italics)

DERMACENTOR VARIABILIS

Ovigerous Female.-Engorges upon host, drops to ground, and deposits eggs.

Eggs.-Deposited upon ground in mass.

Larvæ.-Bunched upon grass from which they reach first host.

First Molt, Larvæ to Nymphs.-Upon ground, after dropNymphs.-Crawl from grass upon second host.

Second Molt, Nymphs to Adults.-Upon ground, after dropping from second host.

Males and Females.-Crawl from grass upon third host; mate.

Ovigerous Females.-Engorge upon host.

Ovigerous Females.-Drop to ground and deposit eggs.

MARGAROPUS ANNULATUS

Ovigerous Female.-Engorges upon host, drops to ground, and deposits eggs.

Eggs.-Deposited upon ground in mass.

Larvæ.-Bunched upon grass from which they reach host.

First Molt, Larvæ to Nymphs.-Upon host.

Second Molt, Nymphs to Adults.

Males and Females.-Upon host; mate.

Ovigerous Females.-Engorge upon host.

Ovigerous Females.--Drop to ground and deposit eggs.

Loss Occasioned by Cattle Ticks.-According to estimates published in 1914, the main sources of loss occasioned by the cattle tick may be summarized as follows: 
The parasitic life of the ticks, together with the blood-destroying: properties of the protozoan parasites with which they inoculate their hosts, causes a loss of flesh and lack of development in southern cattle conservatively estimated at $\$ 23,250,000$.

The lower price which southern eattle from infested districts bring in northern stockyards averages at least $\$ 1.50$ per head. It is estimated that the loss upon animals marketed under these conditions, inchuding stock, beef, and dairy cattle, will sum up to $\$ 1,057,500$ annually.

The shrinkage in milk production of eattle infested with many ticks will average about one quart per day. Upon an estimate of 875,000 ticky dairy cattle out of more than $4,000,000$ dairy cattle below the quarantine line, the loss thus oceasioned, reckoned at three cents per quart, would amount to $\$ 26,250$ per day, or, counting three hundred milking days for pach cow to the year, $\$ 7,875,000$ annually.

The loss among nonimmume southern cattle in tick-free pastures through contracting Texas-fever when exposed to the tick has been estimated at $\$ 5,812,500$ per ammum.

The deaths from Texas-fever of pure-bred or high-grade cattle inported from the North for breeding purposes amount to about sixty per cent. among such eattle which have not been immunized by blood inoculations, and to about ten pel cent. among those which have had such immunization. Since these are usually expensive animals, the loss in such cases is of ten excessive.

Considering additional losses, direct or indirect, as published by the United States Department of Agriculture in 1914, it will be found that the TrXas-ferer tick is responsible for a loss of about $\$ 40,000,000$ annually, in ardition to which it is responsible for lowering the assets of the infersted country to the extent of $\$ 23,250,000$.

Progress in Eradication.-Methods of dipping and pasture rotation for the control of the cattle tick have been fully set forth in bulletins and circulars published by the ['nited States Department of Agriculture (Farmers' 13ull. No. 498). These are freely available to all interested in details of the subject which need not be repeated upon these pages.

Eradicative measures carried on by the Federal Government in coöperation with the states affected by the eattle tick have seen in progress since 1906. L'p to 1911 twenty per cent. of the infested area, mostly along the northern boundary, had been cleaned through this systematic coöperative mork. At the present time (1918), through the continuation of this work, fifty-two per cent. of the tick-infested area has been released from quarantine, and it is authoritatively predicted that five years hence the cattle tick will be entirely eradicated from the South. 


\section{Order II. Linguatulida}

Arachnida (p. 94).-The members of this group are arachnids which have become extremely altered in eonsequence of their parasitic mode of life. Due to their worm-like body and endoparasitic habits, they were formerly placed with the helminths.

The body is elongated, annulated, and somewhat flattened. The body regions are not defined from each other. With the exception of two pairs of articulated hooks surrounding the mouth, rcgarded by some as vestigial legs, the adult body is entirely without appendages (Fig. 83).

The mouth is anterior, and the intestine passes directly through the body, opening by the posterior anus.

There are no circulatory or respiratory organs. Respiration is by the general surface of the body.

The nervous system is reduced, consisting of the esophageal ring, which gives off filaments to the cephalothorax region. Eyes are absent.

The sexes are separate; the male much smaller than the female. From the eggs there hatches an ovoid embryo, constricted at its posterior extremity, and provided with two pairs of jointed legs. Anteriorly it has a perforating apparatus by means of which it bores through the intestinal wall of its host and reaches the liver, or other organ, in which it becomes encysted.

The adult Linguatula (L. rhinaria) infests the nasal cavities of mammals, usually the dog. The larvæ infest the visceral organs of herbivorous animals. 



\section{PART II}

\section{THE INTERNAL PARASITES}

\section{CHAPTER XIV}

\section{PHYLUM II. PLATYHELMINTHES. THE FLUKES AND TAPEWORMS}

With but few exceptions all of the metazoan internal parasites come into the old division Vermes, which brings together animals generally worm-like, though widely differing in many respects. Compared thus as a whole with animals usually rated below them in the zoölogical scale, worms are readily distinguished in possessing differentiated anterior and posterior extremities, the anterior directed toward their forward movement and involving a head which contains a ganglionic mass of nerve cells or, as it may be called, a rudimentary brain. Furthermore, the body is bilaterally similar, and there is a dorsal and ventral surface. The annulated worms, which include the higher representatives, differ from the Arthropoda mainly in the absence of articulated appendages to their body-segments, while the lack of a notoehord and gill-slits distinguishes them from certain lowly members of the Chordata. Beyond these few points there is little to be said as to the charaeteristics of the worms considered as a whole.

The including in a single phylum of all invertebrates generally elongate and without articulated appendages is systematically faulty in that it brings together animals with structural differences of grand division importanee, though agreeing in an external form generally worm-like. In most of the present-day systems of classification the worms are distributed into three, or at least two, phyla, the older class division Platyhelminthes, or flat worms, being given grand division distinction. Many authors also place the smooth-bodied Nemathelminthes and the annulated worms in separate phyla, while another division,- the Molluscoidea, has been created to dispose of the more or less related moss-like Polyzoa (Bryozoa) and the mollusc-like Brachiopoda. In objection to such arrangement is that groups poor in species, some of them mainly of parasitic interest, are placed on the same basis as such large and very important divisions as the chordates and arthropods, thus giving them an undue prominence in a general consideration of the animal lingdom. 
The classification adopted here places the smooth roundworms and the annulated worms together in the phylum Colhelminthes, an arrangement based upon the presence of a cœlom or body cavity, which is a structural feature clearly defining these worms from the Platyhelminthes and establishing a relationship between the smooth round and ammulated forms of primary importance.

The Platyhelminthes includes worms which are flattened dorsoventrally, the two surfaces uniting in more or less sharp margins. There is no borly cavity, the various organs being embedded in a mass of connective tissue and muscle fibers. The alimentary tract is a simple or bifurcated, sometimes branching, pouch having no anal opening (Fig. 85),

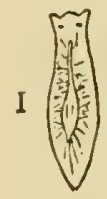

Fici. $4-1 .-$

Planarian worm (after Orton, by Doukge; Copyright, is 94 , by Harper \& lirothers).

the mouth serving as both inlet and vent. In some parasitic forms (tapewomns) alimentary organs are entirely wanting. A true circulatory sy'stem is absent. There is a series of excretory tubes which ramify throughout the body, usually opening to the outside near the posterior extremity. The nervous system consists of ganglia located above the esophagus, where this is present, and the lateral nerves which these give off. Most all are hermaphroditic, the sexual organs being distributed over a large portion of the body.

As is true of the worms in general, free living forms are found in fresh and salt water. They may often be revealed clinging to the under side of rocks (planaria, Fig. 84) and upon the moist soil, some of these specimens being nearly transparent. The largest members of the division are the tapeworms which may reach a length of thirty feet or more.

The phylum contains two parasitic classes, as follows:

Class I. Trematoda.-The flukes.

Class II. Cestorla.-The tapeworms.

\section{Class I. Trematoda}

Platylelminthes (p. 156).-All of the members of this group are parasitic, living either as ecto- or entoparasites. The body is usually leaf-like, often much like a pumpkin seed in form (Fig. 87), and is provided anteriorly with suckers by which attachment is made to the host. In most of those entoparasitic (Distomere) two suckers are present, one anterior and surrounding the mouth, and a second larger one just posterior to the mouth on the micl-ventral line. In the ectoparasitic species (Polystomex), which are usually parasitic upon the gills and skin of aquatic animals, the suckers are more numerous.

The alimentary tract leads by a short gullet to a bifurcation, forming two elongated blind sacs which may or may not give rise to lateral secondary pouches (Fig. 85). Eye spots occur in some of the ectoparasitie species and in the larve of the entoparasitic. 
Most of the Trematoda are hermaphroditic. At maturity the sexual organs reach a high degree of development adaptive to the mode of parasitism (Introduction, p. 5). The male sexual organs consist of tube-like testes, from which spermatic ducts take origin. These unite in a large seminal vesicle, the terminal portion of which is usually inclosed in a pouch. The ovary is also branching and tube-like. With the oviduct there unite ducts from the vitellaria or yolk-glands, this union being followed by the much convoluted uterus which receives the eggs and terminates by the side of the male sexual opening (Fig. 86).

The entoparasitic trematodes undergo a complicated life history, involving alternation of hosts and, within the intermediate host, multiplicative generations. A typical example of this cycle is given further on in reference to the species Fasciola hepatica.

Most of the trematode parasites of mammals live in the liver, producing the affection known as hepatic fascioliasis (distomiasis), or commonly as liver rot. Others invade the blood, lungs, and stomach, causing, accordingly, vascular, pulmonary, and gastric fascioliasis. The latter forms are rarely met with in the United States.

The species to be considered come under three families, as follows:

Family I. Fasciolidæ.-The common liver flukes.

Fanily II. Amphistomidæ.-Of the rumen.

Family III. Schistosomidæ.-The blood fluke.

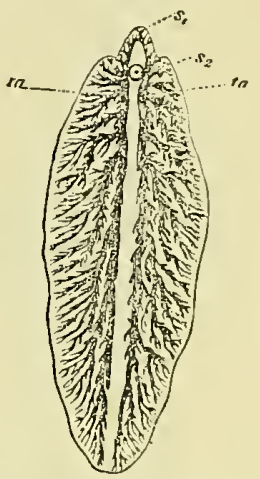

FIG. 85. - Sketch of Fasciola hepatica, showing bifureated and branching alimentary tract: s1, mouth and anterior sucker; s2, posterior sucker; t. a., alimentary traet, -enlarged (after Boas, by Kirkaldy and Pollard, from Thomas).

\section{Classification of Parasites of the Phylum Platyelainthes}

Phylum II. Platyhelminthes. P. 155.

Class A. Trematoda. Flukes. P. 156.

Order 1. Distomeæ. P. 156.

Family (a) Fasciolidæ. P. 160.

Genus and Species:

Fasciola hepatica. Hosts, sheep, cattle, etc. P. 160.

Dicrocoelium lanceatum. Hosts, same. P. 160.

Fasciola americanus. Hosts, same. P. 160.

Family (b) Schistosomidæe. P. 168.

Genus and Species:

Schistosoma bovis. Hosts, cattle, sheep. P. 168.

Family (c) Amphistomidæ. P. 167. 


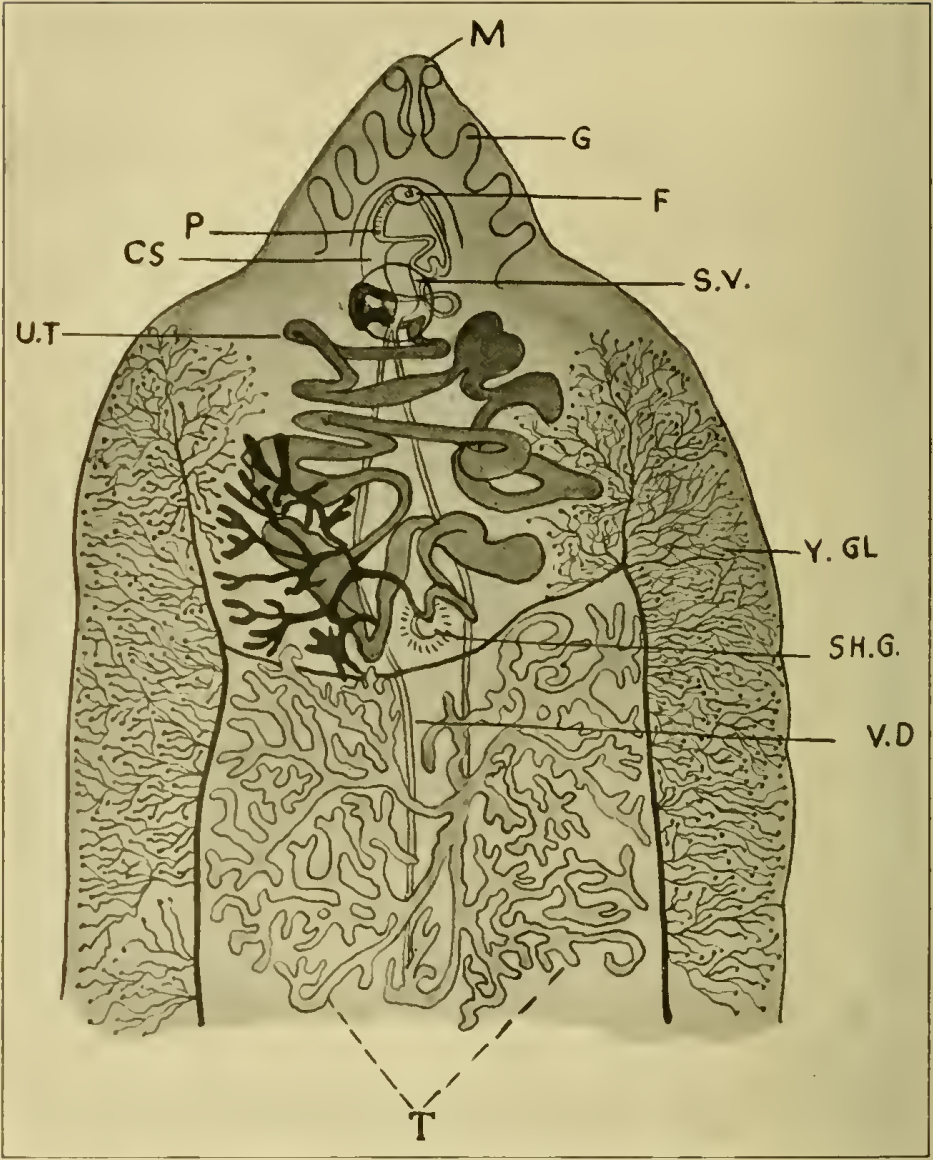

Frs. sh.- Reproduetive organs of liver fluke: $f$, female aperature; s. v., seminal vesicle; y. g. l., rliffuse yolk clauds; sh. g., shell gland; v. d., vas deferens; T., testes; ov, ovary (dark); ut, utorus; r. s., cirrus sar; p, penis; m, moutl, g, anterior lobes of gut (after Thumson, from simmm(r) 
Genus and Species:

Amphistomum cervi. Hosts, ruminants. P. 167.

Class B. Cestoda. Tapeworms. P. 169.

Order 1. Polyzoa.

Family (a) Tæniidæ. P. 170.

Genus and Species:

Anoplocephala perfoliata. Host, equines. P. 174.

A. mamillana. Host, equines. P. 175.

A. plicata. Host, equines. P. 175.

Moniezia expansa. Hosts, cattle, sheep, goats. P. 176.

M. alba. Hosts, same. P. 176.

M. planissima. Hosts, same. P. 176.

Thysanosoma actinioides. Host, sheep. P. 176.

Dipylidium caninum. Hosts, dog, cat, man. P. 178.

Larva, Cryptocystis trichodectes. Hosts, flea, louse. P. 178.

Tænia hydatigena. Host, dog. P. 178.

Larva, Cysticercus tenuicollis. Hosts, ruminants and hogs. P. 179.

T. pisiformis. Host, dog. P. 179.

Larva, Cysticercus pisiformis. Host, rabbit. P. 179.

T. ovis. Host, dog. P. 204.

Larva, Cysticercus ovis. Host, sheep. P. 203.

Multiceps multiceps. Host, dog. P. 179.

Larva, Multiceps multiceps. Host, Herbivora. P. 179.

M. serialis. Host, dog. P. 179.

Larva, Multiceps serialis. Hosts, rabbit and other rodents. P. 180.

M. gaigeri. Host, dog. P. 181.

Larva, Multiceps gaigeri. Host, ruminants. P. 181.

Echinococcus granulosus. Hosts, dog, cat. P. 181.

Larva, Echinococeus granulosus. Hosts, ruminants, hog, ete. P. 181.

Tænia tæniæformis. Host, cat. P. 184.

Larva, Cysticercus fasciolaris. Hosts, rat, mouse. P. 184.

Cittotænia denticulata. Host, chicken. P. 185.

Choanotænia infundibuliformis. Host, chicken. P. 189.

Larva, a cysticercoid. Host, house fly. P. 189.

Hymenolepis carioca. Host, chicken. P. 190.

Davainea tetragona. Host, chicken. P. 190.

D. cesticillus. Host, chicken. P. 190.

D. echinobothrida. Host, chicken. P. 191.

D. proglottina. Host, chicken. P. 191.

Larva, a crsticereoid. Host, snail. P. 191. 
Tania saginata. Host, man. P. 195.

Larva, Crsticereus bovis. Host, ox. P. 195.

T. solium. Host, man. P. 199.

Larva, Cysticercus cellulosa. Host, hog, ete. P. 199. Fanily (b) Diphyllobothriidae. P. 185.

Genus and species:

Diphyllobothrium latum. Hosts, man, dog, eat. P. 185. Larva, a plerocereoid. Host, fish. P. 185.

\section{Fanili I. Fasciolide}

1. Fasciola hepatica (Distomum hepaticum). The Liver Fluke (Fig. 87). Trematoda (p. 156). - The body is flattened, pale brown in color, oval in shape, and broadest in front, where it is terminated by a conical process bearing at its apex the oral sucker which surrounds the noutl. A larger ventral sucker is situated about $3 \mathrm{~mm}$. behind the oral. The cuticle is studded with minute spines directed baekward. The bifurcations of the alimcntary tract have ramifying branches. The vulva is situated beside the male opening or a little behind it.

I.ngth, 20-30 $\mathrm{mm}$. (3/t-1/4 inches); width, 10-13 $\mathrm{mm}$. (1/3-1/2 an incli).

The eggs are brown or greenish-yellow, provided with an opereulum at one encl. Thry are oval and 130-145 microns in length.

2. Dicrocolium lanceatum (Fasciola lanceolata). The Small Liver Fluke (1ig. 87). Trematoda (p. 156).--The body is slender and lancet-shaperl, mottled brown by contained ora. The integument is smooth and semi-transparent. The intestine has two nonramifying branches.

Length, 4-9 mm. (3/16-3/8 of an inch); width, $2.5 \mathrm{~mm}$. (1/8 of an inch).

The eggs are oval, brownish in color, 37-40 microns in length, and provicled witl an opereulum.

3. Fasciola magna (F. americana, Distomum americanum, D. magnum). The Large American Liver Fluke (Fig. S7). Trematoda (p. 156). Cimilar to $F$. hepatica, but larger, measuring $25-33 \mathrm{~mm}$. (1-1 1/2 inches) in length and $12-17$ mm. $(1 / 2-3 / 4)$ of an inch in width.

Life History of Fasciola hepatica.--The eggs leave the uterus before the beginning of embryonic development and pass to the outer world by way of the bile ducts and intestines. In heavy infestation enormous numbers may be passed by a single host animal, one mature fluke producing in the neighborhood of one hundred thousand eggs. 
After a period of embryonal development, which will only occur providing the eggs have reached water and suitable conditions of temperature, the larva escapes by the lifting of the operculum of the shell. It is then in the stage of the miracidium (Fig. 88, 2), an infusorian-like organism, ciliated, elongated, broader in front, and about 130 microns in length. During its free-swimming period it must meet with a suitable host within a few hours or it will perish. This host is a small snail, usually of the genus Limnæa ( $L$. humilis) into which the larva bores its way by a perforating rostruin at its anterior extremity.

If it escapes its aquatic enemies during this free stage and arrives at a suitable location within the snail, usually the pulmonary chamber, the larva loses its cilia and digestive tube and becomes transformed into a sporocyst (Fig. $88,3)$ - a sort of reproductive sac, ovoid in form and acquiring a length of about $0.5-0.7 \mathrm{~mm}$. The
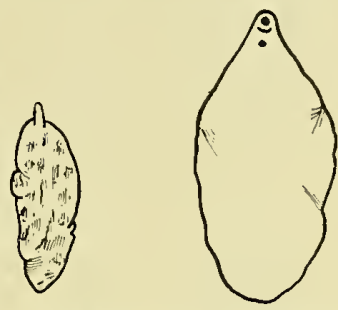

Fig. 87.-Left to right, Fasciola hepatica, F. americanus, Dicrocœlium lanceatum: natural size (drawn from author's specimens). cyst now becomes filled with germ-cells which are disposed in masses (morula) ordinarily five to eight in number.

The masses of germ-cells become transformed into so many redice (Fig. 88, 5 and 6) which may be seen in different stages within the cyst. The rediæ are cylindrical in form and have a simple intestine and pharynx with lips turned out like a sucker. When they have attained a certain stage of development the redix become actively motile, finally rupturing the maternal cyst and passing to another organ of the snail, usually the liver, in which location they grow to a length of $1.3-1.6 \mathrm{~mm}$. Within the body of the redia are germ-cells formed into six to ten cellular masses which are to be transformed into so many daughter rediæ, or directly into fifteen to twenty cercarice (Fig. 88, 7). Both daughter redix and cercarix leave the mother redia by a birth-opening located anteriorly.

The developed cercaria has an oral and ventral sucker, a muscular pharynx, and a bifurcated intestine which is as yet without lateral branches. It has a flat oval body about $0.28 \mathrm{~mm}$. in length, provided with a long actively vibratile tail. The cercariæ escape from the snail and swim about energetically in the water, eventually finding their wayto an aquatic plant or grass stalk. Here the tail is lost and the cystogenous cells of the body form a mucoid substance which serves both to encyst the cercarix and to attach them to the grass. The cysts may be observed upon the specimens of regetation as little white points about 
the size of an ordinary pin-head. An encysted cercaria will remain alive for an extended period as long as the grass upon which it is lodged is

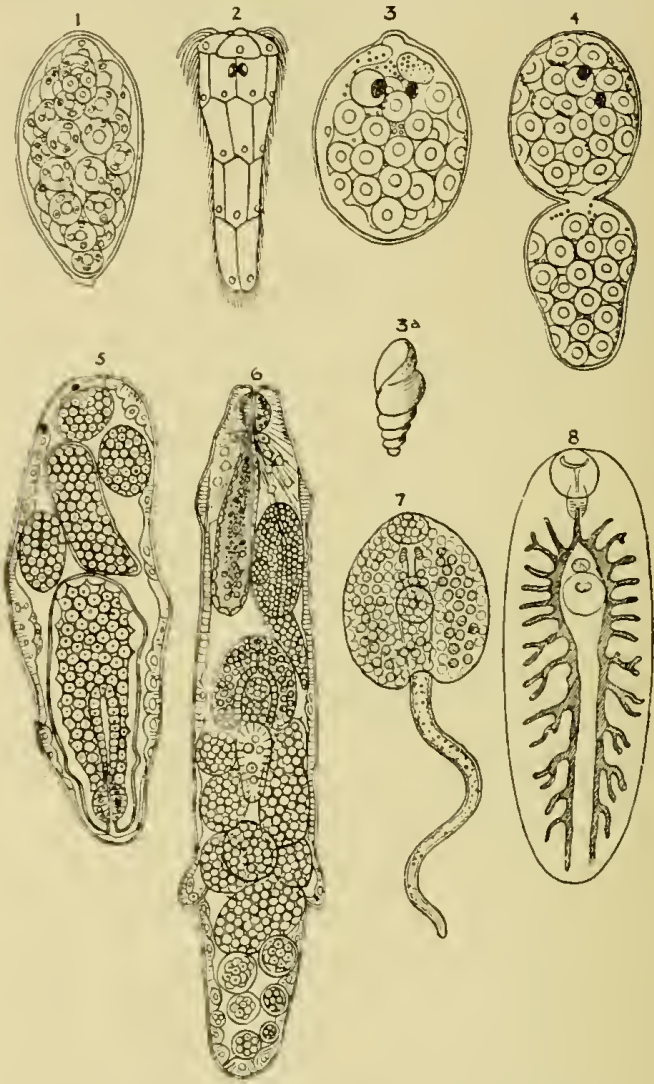

Fus. Ax.-Life history of liver fluke: 1 , egg containing developing embryo; 2 , free swinming miracidium; 3 , sporocyst; 3a, snail of the genus Limnsa; 4, division of sporocyst; 5 . sporocyst containing developing redic; 6 , redia with cercaria or more redia developing within it; 7 , cercaria; 8 , young fluke (after Thomson, from Thomas).

supplied with inoisture. Drought probably destroys it, though the length of time it may survive such conditions is undetermined.

When plants bearing these cysts are eaten by grazing animals the 
cysts, upon reaching the stomach, are dissolved, setting free the parasites which, passing to the intestine, enter the bile ducts and there become mature. After laying their eggs the majority of the flukes pass down the bile ducts to the intestine where, under the influence of the digestive juices, they shrivel and die.

The period of time occupied by the entire cycle is so influenced by climatic conditions that no definite estimate as to it can be given. As a rough approximation, twelve weeks may be given as about the time required under such favorable conditions as usually prevail during the summer season.

The life histories of Dicrocolium lanceatum and Fasciola magna are probably essentially similar to that of $F$. hepatica, but are as yet not definitely known.

\section{Tabular Review of Life History of Fasciola Hepatica}

Adult Fluke.-In bile duct of liver of ruminant.

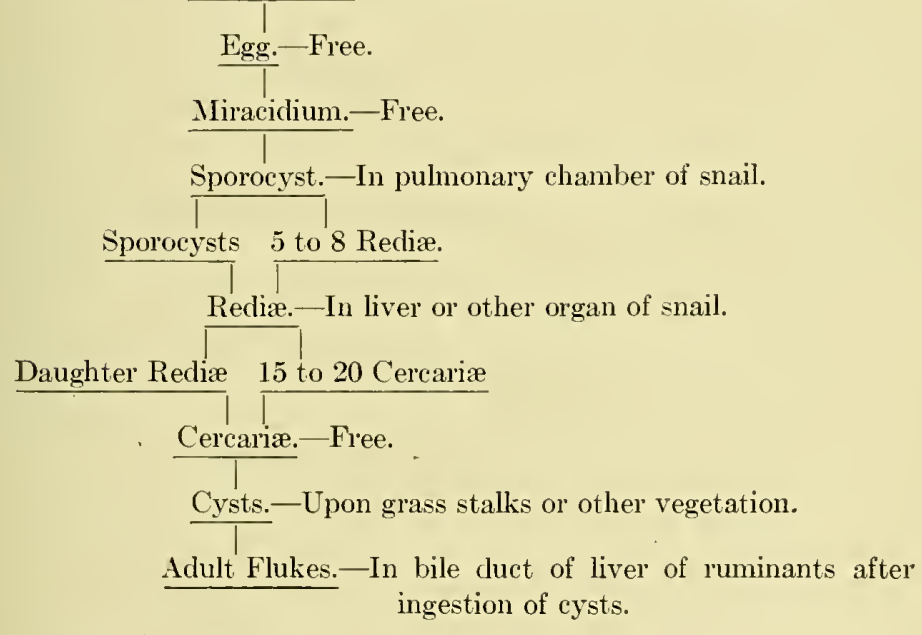

Prevalence.-The loss from hepatic fascioliasis in England was for a time in the neighborhood of three million head of sheep annually. It was principally for this reason that investigations were made by which the life history of the parasite was determined, and by which was revealed the essential alternation between the sheep and snail host. This pointed the way for measures of control consisting mainly in the elimination of snails by the drainage of pastures or in the limiting 
of the sheep to pastures free from standing water or overflow. Since the adoption of such preventive measures the loss from this source in England and other European countries has been greatly reduced.

While fascioliasis has not been as prevalent in the United States as in Europe, there are a sufficient number of cases to demonstrate the possibility of its becoming so unless such precautions are taken as are indicated by the life history of the fluke. Probably the freedom from such destructive prevalence has been largely due to the fact that in this country, more generally than in Europe, it is the practice to turn sheep upon higher and dryer pasturage.

The three species of flukes which have been mentioned infest the liver, therefore the hepatic form of fascioliasis is the most important. As would be concluded from the mode of infection, herbivorous animals are most often affected, those which crop the grass close to the ground, as sheep and goats, being for this reason especially susceptible. Horses, swine, Carnivora, and even man may be invaded incidentally by flukes, though in such cases they are rarely present in such numbers as to produce perceptible disturbance. The giant fluke (Fasciola magna) is most often found in the liver of deer or cattle in the Southwestern portion of the United States. It is supposed to be a species native to wild ruminants before the introduction into this country of those in domestication.

Infection.-While infestation of sheep most frequently occurs from the ingestion of plants upon which the encysted cercarix are attached, water contaminated with detached cercariæ may infect directly, or by vegetation over which it has washed. It is probable that many cases in cattle in the I'nited States result from the introduction of the flukes by the latter means. Cattle are not as close grazers as sheep, but they drink more frequently, often from shallow collections of water which may contain larva derived from the excrement of sheep or rabbits.

As many encysted cercariæ survive the frosts even of the late fall, the season during which infection may take place is somewhat extended, some investigators claiming that it may occur at any time of the year. IIowever, warmth being highly favorable to the development of the ova, it is essentially during the summer and early autumn that animals are most likely to become invaded. It is obvious that the most numerous and most severe cases would occur in seasons of copious rainfall, more elevated pastures at such times affording by their collections of water and overflow favorable conditions for the development of the parasites. The flukes may be introduced into lands previously free from them by new stock, or by wild herbivorous animals, such as deer and rabbits. After infestation has once taken place, it will, through successive infections, increase in degree the longer the pasture is used.

Migrations and Pathogenesis.-It is probable that the migration of the parasites from the small intestine into and along the bile ducts 
is accomplished by the extending forward of the parasite's anterior end, with alternate fixing of the oral and ventral sucker. The majority remain in the bile ducts, though some upon reaching the smaller ducts break through and pass into the liver tissue where they may excavate and destroy large areas. Such migrations may extend through Glisson's capsule to the serous covering of the organ and thus give rise to peritonitis in addition to the inflammation of the hepatic parenchyma. They do not essentially remain confined to the liver, but may pass through the capsule and serosa into the peritoneal cavity. Others may reach the ramification of the portal vein and set up an endophlebitis with accompanying thrombosis and embolism; or the hepatic veins may be involved and some flukes be carried by the blood current to the thoracic organs.

The destruction of liver tissue in hepatic fascioliasis is largely the result of direct irritation due to the spiny processes covering the parasites. During the first few weeks after being taken up by the host the flukes are small and do not cause a serious irritation. Later they set up an acute inflammatory condition of the bile ducts and liver tissue, the hepatitis remaining more or less localized or becoming generalized according to the number of parasites present and the extent of their migrations. In certain cases there is abscess formation, or hemorrhages may occur due to the breaking down of the walls of blood vessels. The inflammation running a chronic course is associated with connective tissue proliferation, causing a thickening of the walls of the ducts. Later this process extends to the interlobular connective tissue and brings about cirrhosis of the liver.

Flukes which have remained in the bile ducts pass back into the duodenum soon after the reproductive function has been accomplished. It is thought by certain investigators that the period of time which they remain in the ducts does not exceed nine to twelve months. Within the intestines they are much altered by the intestinal juices and pass from the host with the excrement.

\section{Fascioliasis of Sheep}

Symptoms and Course.-An animal harboring but few flukes will give no evidence of functional disturbance. This ean be readily demonstrated in sheep-slaughtering establishments where moderately infested livers have been repeatedly found in sheep in prinie condition. In heavier infestations a developing period of about three to six weeks intervenes between the taking up of the flukes and the appearance of symptoms.

In sheep usually the first symptom to be noticed is dullness, manifested by slowness of movement and an inclination to lag behind the 
flock. On examination of the visible mucosa (conjunctiva) and inner surface of the ears they will be found to be paler than usual, and there may already be edematous swelling of the eyelids and under the brisket. Notwithstanding the anrmia, the general physical condition of the animal may still be good; there is, in fact, a tendency to fatten, which may be explained physiologically in the increased assimilation of the fat-forming elcments of the food, brought about by the stimulation imparted by the flukes to the flow of bile.

This stage, however, is soon followed by a marked increase in dullness and a disinelination to take food. The animal ruminates slowly and irregulary, the fleece becomes dry and brittle, and in places may loosen and diop out; the skin and mucosæare whitish-yellow in color, the puffy conjunctiva forming a prominent ring about the cornea. Though the shecp may still be fat, weakness and disinclination to resist handling become more pronounced. With progressively diminished appetite, however, there is loss of flesh, and the edema of the dependent parts increases, involving the lower part of the neck, throat, and cheeks. The presence of ascites is erinced upon pereussion of the pendulous abdomen, and the respiration becomes labored and frequent.

With these symptoms, which gencrally appear about the third month after infestation, the disease is at its maximum, usually reached in the rarly minter months. The anæmia, elema, and cachexia have now becone mole pronouncel; in most of the advanced cases there is diarthea hy which large numbers of eggs may be distributed about. Finally, in a condition of extrence maciation and weakness, the animal dies.

Prognosis.- Most of the losses from fascioliasis of sheep are among the lambs. Older animals and those but moderately infested gradually recover with the passage of the flukes from the liver into the intestine, this usually occurring in the carly spring. With the disappearance of the relcmatous swellings and the return of the appetite, the animal resumes a good physical appearance and seems to completely recover. The liver lesions, however, will not entirely heal, and, impairing the function of the organ, will eventually have at deleterious effect upon the animal.

\section{Fascioliasis of Catthe:}

In cattle fascioliasis presents the same srumptons as in sheep. Due to the greater resistance of these animals, however, the effects are much less severe and may often pass umperceived. If the flukes are numerous there may be digestive disturbances manifested by loss of appetite, cliarrhea, and tympanites; very rarely there are edematous swellings in the dependent parts of the body. Fatalities from fascioliasis are rare among cattle. When they occur it is usualy among calves which have reached an advanced emaciation. 


\section{Family II. Amphistomide}

Amphistomum cervi (A. conicum) is a species belonging with this family not infrequently found in the rumen of domestic ruminants of this and other countries. Specimens collected in the Pennsylvania State Laboratory measure 6 to $7 \mathrm{~mm}$. (3/16 to $1 / 4$ of an inch) in length. The body is conical in form, thick, attenuated anteriorly, gradually enlarging posteriorly, the posterior end being obtuse and a little curved ventrally. The mouth is terminal and surrounded by a small sucker. At the thickened posterior extremity there is a second and much larger sucker. The color is white or reddish, darker at the attenuated anterior portion. Hermaphroditic; genital orifices ventral and median, situated in the anterior third of the body. Its development is not known.

This fluke is a parasite in the rumen of the ox and other domestic and wild ruminants. It fixes itself by means of its posterior sucker between the papilla of the rumen. Being very easily overlooked in its resemblance to the papillæ, it is quite probable that it is more prevalent than would appear from our present records.

The parasite has been considered as inoflensive to the health of the host animal.

\section{Control of Fascioliasis}

In sections where fascioliasis has appeared a prophylactic measure of first importance is the avoidance of pastures which are wet or contain collections of water affording habitation for snails. The following directions formulated by Thomas-as stated by Neumann-for limiting the ravages of fascioliasis are here quoted in part:

"a. Destroy the diseased sheep and bury them.

"b. Only put on dry pastures affected sheep intended for the butcher, as the fluke ova they evacuate cannot develop in the absence of humidity.

"c. As hares and rabbits-which are sometimes bearers of distomesmay infest pastures, they should not have access to those on which sheep graze. But this recommendation cannot well be carried out.

"d. Drain wet pastures, or, if this cannot be accomplished, dress them with salt or lime. The latter in solution- 0.75 per cent.-will destroy fluke embryos as well as the snails. With regard to salt, we are indebted to Perroncito for some precise notions as to its action. Ercolani had for a long time observed that water slightly impregnated with salt killed the cercarix, and in acting on these and on the encysted larva of the Limncea palustris, Perroncito found that in a 2 per cont. solution these parasites died in less than five minutes; in a 1 per cent. solution they rolled themselves up at the end of two to seven minutes, and perished after twenty to thirty-five minutes. The same happened in 0.64 per cent. solutions; and in those of 0.25 per cent. they were still 
alive after more than twenty hours. The period when salt or lime should be spread on the pastures should coincide with the time when the embryos of the distomes and the cercariæ abound-that is, June and July for the first, and August for the second."

If it is impracticable to keep sheep from land upon which conditions are favorable for the development of flukes, they should each be given in the morning daily two drams of salt mixed with feed. When possible, the salt may also be given in their drinking water in the proportion of 0.5 per cent. The salt is fatal to the ingested cercarix and tends to fortify the sheep by favoring digestion and assimilation.

Treatment. - No effective therapeutic agent for fascioliasis has as yet been found. Owing to the remote location of the parasites, it is hardly likely that anything could be given which would affect them.

\section{BiLhaRziosis}

This name has been given to a disease of cattle and sheep caused by the blood the Schistosoma bovis (Bitharzia bovis; $B$. crassa) of the family Schistosomidar.

In this trematode (Fig. 89) there is presented the peculiarity of separate sexes. The female, longer and much nar-

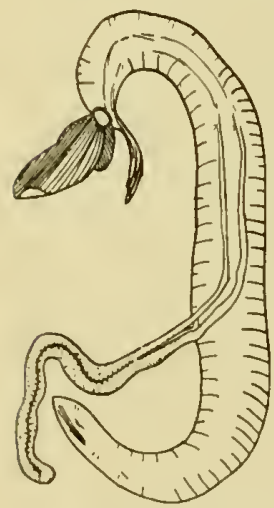

F19. 59 - - Schistosoma bovis, male and fomale, enlarged. rower than the male, is.filiform, $18-20 \mathrm{~mm}$. $(3 / 4$ of an inch) in length, and has a buccal and ventral sucker. The male is cylindrical, about $14 \mathrm{~mm}$. (1/2 an inch) in length, and has two suckers. It carries the female in a ventral furrow formed by the two sides of the body which are broad and leflected inward. Both male and female genital apertures are situated immediately behind the ventral sucker.

The eggs are elongate, and at one pole terminate in a pyriform point. They pass from the host with the fcces and urine, and, in the presence of water, set frce a ciliated cmlryo.

This parasite has been found in the portal and abdominal veins of cattlc of tropical and subtropical countries. The parasites themselves seem to do but little injury. 'The eggs, however, by their accumulation and sharp points, may rupturc the capillaries. If these are of the genito-urinary system, the chief symptom is a bloody urine. Where the cggs have accumulated in the capillaries of the bladder, they rupture these and, passing through the mucosa, fall into the cavity of the organ. The resulting cystitis is manifested by the hrmaturia and the 
pain which accompanies micturation. If the parasites are contained in the veins of the rectum, there are similar lesions in this organ; the feces may be stained with blood, and there is a condition somewhat resembling piles.

Diagnosis is best made by a microscopic examination of the urine to determine the presence of the eggs which may be readily recognized by their characteristic elongate shape and polar termination in a sharp point.

As the lesions are produced by the eggs, the severity of the symptoms will essentially depend upon the number of parasites present. In the majority of cases the infection is light and may give rise to no more than a slight chronic cystitis. In the more rare cases of severe infection death may ensue from rupture of the bladder or from uræmia accompanying an acute nephritis. A heavy intestinal infection may bring about an exhausting and fatal dysentery.

It is probable that infection has its source in contaminated drinking water. Therefore, where bilharziosis has marle its appearance, the water should, as a preventive measure, be filtered, or the cattle removed to an uncontaminated supply.

Treatment can only be applied to the relief of symptoms as they appear.

\section{Class II. Cestoda}

Platyhelminthes (p. 156).-An important character of the cestodes is that, as a result of their advanced parasitism, they have lost the last trace of an alimentary canal, and obtain their nourishment by absorption through their integument of the partly digested food of the host. Also markedly distinguishing them are the two developmental stages,-the bladder worm (Fig. 112, b and c) and the mature worm (Fig. 107) with its sexually developed segments, the first living usually in tissues, such as muscular, liver, nervous, and serous, of the intermediate host; the second in the alimentary tract of the definitive host. The adult is, in its general form, band-like, and consists of two parts,- the scolex (Fig. 109), which is generally referred to as the head, and a series of segments which are formed from the scolex asexually by longitudinal growth and transverse segmentation. It is due to this fact that an animal is not rid of its tapeworm so long as the head is retained in the intestine. As the segments are pushed on by the formation of younger segments at the scolex, they become progressively wider and longer, the width of the younger ones usually much exceeding their length, while the oldest, which are those most distant from the scolex, may become longer than wide. Each mature segment is hermaphroditic, the uterus usually containing a large number of eggs. In the Tæniidæ the genital pores (sexual openings) are on the margin or margins of the 
individual segments. In the Diphyllobothriiclæ they are on the flat ventral surface. The number of segments varies from three or four (Echinococcus gramulosus) to several thousand (Diphyllobothrium latum), a fact which gives to some species an enormous size. In the head is a crebral ganglion from which two principal nerves run backward, usually near the lateral margins of the segments. An excretory, or socalled water-raseular system, extends through the whole length of the worm by two principal trunks which may be connected by vessels ruming acloss the posterior margin of each segment, the system terminating at the hinder edge of the last.

Of the Cestoda, two families are to be described as containing species parasitic to domestic animals and man. These are as follows:

Family 1. Tamiida.

Family II. Diphyllobothriicke.

\section{FAMLY I. TENIIDE}

Cestoda (p. 169). - With rare exception, this family includes all of the tapeworms of rlomestic animals and man in the Enited States. Its nembers have the head fumished with four round or oval eup-like sucker's of muscular structure (Fig. 109), which, by their contraction, produce a vacuun affording a close attachment to the intestinal mucosa of the host. These suckers may suround a prominence,-the rostellum (Fig. 95), or in other cases a depression more or less marked. The rostellum may or may not be contractile, and may or may not be armed with hooks.

As a typical, though not constant, arangement of the reproductive organs, these of the species Trenia saginata, a tapeworm of man, are here lescriberl. Wach sexually mature segment (Fig. 90) of this worm has at its margin a protrucling genital pore, which, from segment to segment, is irrogularly upon alternate sides. This protuberance contains a cloaca-like cavity into which open the ras deferens and vagina, both of which extend laterally to the middle of the scgment. Here the vas doferens divides into a number of seminal ducts which are distributed through the supporting tissue and selve to cary the semen from the small spherical lestes which are located amost everywhere in the segment. As it approaches the lateral cloacal sac, the duct becomes convoluterl and much rlistended with the accumulated seminal fluid. In the vicinity of the cloaca it develops into a cirrus (penis) which is inclosed in a muscular sheath.

The vagina bends downward as it passes toward the center of the soment where it unites with the paired wing-like ovaries which are rather large organs consisting of branched tubules. In the posterior and midtle portion of the segment is a single organ, likewise of branched 
tubular structure,- the vitellarium or yolk-gland, the secretion from which surrounds the eggs in the cavity of the shell-gland, the latter a small body consisting of compactly arranged gland-cells and located just above the vitelline gland. From the shell-gland the eggs pass through a narrow duct into the uterus, a simple tubular organ ascending. directly in the middle of the segment and elosed at its distal end. The uterus becomes much distended from the accumulation of eggs and develops numerous lateral branches to which the other sexual organs gradually give place until little remains of them but vestiges of the vas deferens and vagina. The egg-engorged organ, with its lateral cecal pouches, may rupture, or the integument of the segment itself may give way, permitting the eggs to escape directly into the intestinal contents. As a rule these terminal or "ripe" segments are passed to the outside of the body of the host with the feces where, by their disintegration, the eggs are set free.

The eggs of cestodes are gtobular or more or less oval

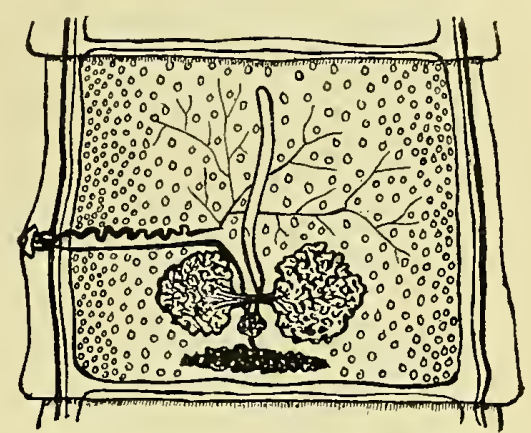

Fit. 90.-Segment of Tænia saginata, with sexual organs matured. Ovaries in lower portion to right and left; yolk gland in extreme lower portion; shell gland between yolk gland and ovaries; uterus, tubular organ extending upward; vagina, extending from glands to genital pore at left margin; testis, bodies distributed throughout segment; vas deferens, convoluted organ extending laterally to genital pore. Excretory ressel united by transverse commisures. Lateral longitudinal nerves shown by heavy lines.

in shape and are provided with shells of variable thickness (Figs. 96 and 110). Beneath the shell is a translucent yolk which surrounds an inner covering containing the onchosphere (hexacanth) or six-hooked embryo (Fig. 112, a). In some forms the eggs as found in the feces - often have the outer shell absent.

Life History. - Species of Tæniidæ in which the development is known undergo a complex series of metamorphic changes, involving larval and sexually mature parasitism in hosts of differing species. After the egg, either free or with the segment entire, has been ingested by a proper larval host, the shell and embryonic envelope are digested away by the gastric juices, and the onchosphere is freed (Fig. 112, a). At this stage the embryo is provided with three pairs of hooklets bywhich it penetrates the intestinal wall and, probably by blood and lymph currents, may be carried to certain parts of the body specificallyessential to its further derelopment. Thus passively lodged, it loses 
its hooklets and commonly becomes surrounded by a capsule formed by proliferation of the connective tissue of the host, though this does not occur in all of the larval forms.

At this stage the larva, which is now a mere vesicle containing more or less fluid and as yet without a head, is referred to as the acephalocyst (bladder-cyst), from which there may, in certain forms (echinococcus), levelop multiple daughter cysts (Fig. 117). By a process of budding from the germinal wall, the acephalocyst now develops a further stage, the cephalocyst (proscolex, Fig. 112, b and c), containing one (cysticercus, Fig. 107) or more (conurus, Fig. 114) heads which conform with the scolex of the adult worm except that the larval head is invaginated.

If the larva while still living at this stage is conveyed to the digestive canal of a suitable host for the adult worm, the head is evaginated from the vesicle (Fig. 112, c), becomes detached from it, and, passing to the intestine, fixes upon the mucosa by means of its suckers, to which attachment the crown of hooks contributes if this is present. By a process of budding, the scolex now proliferates a series of segments, each to becone bisexually complete (Fig. 90 ).

Sexual maturity of the segments marks the stage of the adult worm which, with its entire series, constitutes the chain, or, as it has been called by most writers, the strobila, a term which, with that of proglottid for segment, is discarded in this work.

\section{Tabular Review of Life History of Tffinia Saginata}

Arlult Tapeworm in intestine of man

Egg.-Expelled from intestine.

Hexacanth.-Freed from egg in digestive tract when ingested by ox.

Acephalocyst.-In striated muscle of ox.

Cephalocyst (Cristicereus), - Same.

Scolex--Attached to mucosa of intestine of man after ingestion of cephalocyst.

Adult Tapeworm in intestine of man.

Parasitism. - The tapeworms afford an example of extreme parasitism. So far as known, their existence is wholly dependent upon alternate cystic and adult hosts, their development exhibiting no freeliving stage. So advanced is their degeneracy that there is little of organization remaining excepting the procreative, and this has acquired 
a hyperdevelopment adaptive to the hazards encountered in the worm's life history.

The classification of the tapeworms has been somewhat more artificial than systematic in that it has not sufficiently taken into account mode of development, a factor which should furnish the basis for their true natural affinities. Their larvæ may, with reference to method of development, be placed in the five following forms: 1. Cysticercus (Fig. 107); 2. cxnurus (Fig. 114); 3. echinococcus (Fig. 117); 4. cysticercoid (Fig. 96); 5. plerocercoid (Fig. 112,-e). The first three are found in organs or serous cavities of Herbivora and Omnivora, oceasionaliy in Carnivora; the fourth lives mostly in invertebrates, and the fifth in the musculature of fishes. The more recent tendency in cestode nomenclature is to confine the generic name Tænia to those tapeworms which have a cysticercus stage in their life history.

The cystic forms enumerated above, with the conditions which certain of them produce in their hosts, are taken up further on in the consideration of the cestode lar'væ.

The accompanying tabular arrangement of the principal tapeworms considered in this work, with their adult and cystic hosts, is inserted for convenient reference. 


\section{CH.PTER AT}

\section{TENIASIS}

As to the effect of tapeworms upon their hosts, it nay be said in general that serious disturbances are most likely to be manifest when the worms are numerous, in which case the morbid effect is brought about by the operation of several factors. There may be a reduction or complete occlusion of the intestinal lumen with the usual inflammatory and toxic disturbances or displacements following interruption in the movement of the intestime's contents. While, as a general statement, invasion of the hile duet by tapeworms may be said to be rare, the fringed tapeworm of sherp (Thysanosoma actinioides) frequently enters this organ and therefore constitutes a more serious taniasis in thesc animals than that from the Moniezia species. Armed tapeworms, by the irritation from their hooks, will, essentially, sct up an inflammation of the mucosa proportionate to their number. Further, where the worms are mumcrous, their appropriation of nourishment contributes to the malnutrition of a eatarhal cnteritis. In heavy infestations the toxins elaborated by the worns undoubtedly play a considerable part in the general systemic effect.

The cystic forms of certain tapeworms have an important bearing upon the sanitary control of meat fool products. In our own country this is especially true of the eysticerci of the two tapeworms of man,Tonia saginata and $T$. solium, the eysts of the former being harbored in beef, those of the latter in pork. The presence of these cysts in the musches or other parts of the body constitutes the disease known as measles, to which affection the terms "measly beef" and "measly pork" have reference. While observed nost frequently in the animals mentionel, moasles may appear in sheep (C'ysticercus tenuicollis, C. ovis), and man is occasionally auto-infected by larve (Cysticercus cellulose) of Tania solium which he harbors.

\section{Cestodes of the Horse}

Threc speries of tapeworms oceur in the Equida. In all the cephalic armature and neck are absent, and all have a genital pole on the same sicle in each segment. Nothing is known of their larval forms.

1. Anoplocephala perfoliata (Tænia perfoliata). Fig. 91. Tæniiclæ (p. 170).-The hearl is large, rounded, and provided with well-developed 


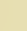




\begin{tabular}{|c|c|c|c|}
\hline ADULT & Hosts & ARMATURE & LA \\
\hline Anoplocephala perfoliata & Horse and ass & Unarmed & \\
\hline $\begin{array}{l}\text { Anoplocephala mamil- } \\
\text { lana }\end{array}$ & IIorse and ass & Unarmed & \\
\hline Anoplocephala plicata & Horse and ass & Unarmed & \\
\hline Moniezia expansa & $\begin{array}{l}\text { Cattle, sheep and } \\
\text { goats }\end{array}$ & Cnarmed & \\
\hline Moniezia alba & $\begin{array}{l}\text { Cattle, sheep and } \\
\text { goats }\end{array}$ & Unarmed & \\
\hline Moniezia planissima & $\begin{array}{l}\text { Cattle, sheep and } \\
\text { goats }\end{array}$ & $\overline{\text { Unamed }}$ & \\
\hline Thysanosoma actinioides & Sheep & Unarmed & \\
\hline Dipylidiun caninum & Dog, cat, man & Armed & $\begin{array}{c}\text { Cryptocys } \\
\text { dectes }\end{array}$ \\
\hline Tarnia hydatigena & Dog & Armed & Cysticeret $t$ \\
\hline T:Pnia pisiformis & Dog & Armed & Cysticerctp \\
\hline Multiceps multiceps & Dog & Armed & Multiceps \\
\hline Multieeps serialis & Dog & Armed & Multiceps \\
\hline Multiceps gaigeri & Dog & Armed. & Multiceps a \\
\hline Echinococcus gramulosus & Dog, cat & Armerl & $\begin{array}{l}\text { Eehinococ } 18 \\
\text { losus }\end{array}$ \\
\hline Tienia teniaformis & Cat & Armed & Cysticercl fs \\
\hline Cittotania denticulata & Rabbit & Unarmed & \\
\hline $\begin{array}{l}\text { Choanotwnia inf undibu- } \\
\text { liformis }\end{array}$ & C'hicken & Armed & A Cystice: \\
\hline Hymenolepis carioca & Chicken & Armed & \\
\hline Davainea tetragona & Chicken & Armed & \\
\hline Datvainea cesticillus & Chicken & Arned & \\
\hline Davaineat echinobothrida & Chicken & Armed & \\
\hline Davainea proglottina & Chicken & Armed & A Cystice? \\
\hline T:nia saginata & Man & Unarmed & Cysticerct b \\
\hline T:⿱nia solium & Man & Armed & Cysticerct \\
\hline Diphyllobothrium latum & Dog, eat, man & Unarmed & A pleroce: \\
\hline
\end{tabular}



suckers; it is prolonged behind by rounded flaps on the upper and lower side. The segments are very short, but wide, the width increasing toward the middle of the length of the body.

Length, $2.5-3 \mathrm{~cm}$. (1 inch); width, 3-15 mm. (1/8-5/8 of an inch).

The eggs, by mutual pressure, are polygonal. The shell, as in other Anoplocephalinæ, is prolonged by a pyriform point. They are $70-80$ microns in length.

It lives in the small intestine and cecum, more rarely in the colon.

2. Anoplocephala mamillana (Tænia mamillana). Fig. 91. Tæniidæ (p. 170).-The head is small, somewhat angular, and has a central lineal depression from before to behind. It is provided with oval suckers located upon the side. The segments are much wider than long, progressively increasing in width from the head. Their length increases toward the posterior extremity, the last segments being about half as long as broad.

Length. 1-5 cm. (3/8-2 inches); width, 4-6 $\mathrm{mm}$. ( $1 / 4$ of an inch).

The eggs are elongated and about 88 microns in length.

It infests the small intestine.

3. Anoplocephala plicata (Tænia plicata). Fig. 91. Tæniidæ (p. 170).-The head is rather large, broader than long, slightly concaved in the center. The four suckers are strong and are directed forward. The segments progressively increase in breadth and length to the posterior extremity.

Length, 8-12 cm. (3 1/8-4 3/4 inches); width, $8-20 \mathrm{~mm}$. (5/16-3/4 of an inch).

The eggs are polygonal or round and 50-60 microns in length.

It lives in the small intestine and has been found in the stomach.

Occurrence.- Horses rarely harbor tapeworms. They are said to be most often found in the horses of Russia and to some extent in Germany and other European countries. The most common species is Anoplocephala perfoliata, while of the other two mentioned, Anoplocephala plicata is the more rare.

Symptoms.- The presence of tapeworms in the intestines of the horse is seldom accompanied by perceivable symptoms. Those general to intestinal helminthiasis, as chronic digestive disturbances, with perhaps anæmia and general unthrift, may accompany the infestation 
though it can only be assumed that these symptoms are caused by tapeworms, even though the presence of the worms is made certain by the voiding of the segments.

\section{Cestodes of Cattle, Sheep, and Goats}

Cattle harbor thrce species of tapeworms. In all the heads are unarmed. Their larval forms are unknown.

The three species of tapeworms of cattle also occur in sheep and goats.

1. Moniezia expansa (Tænia expansa). Fig. 92. Tænïck (p. 170).

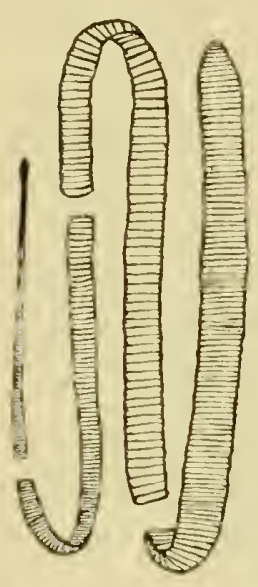

FIG. 92 - Moniezia expansa, portions of adult, reduced (after Railliet).

The head is small, generally pear-shaped. The suckers are slightly salient and slit-like. The anterior part of the chain is filiform. The first segments are very short, those which follow becoming longer, but alway's much broader than long. The broadest segments may reach a brcadth of $2 \mathrm{~cm}$. ( 3 t of an inch). The genital pores are double and located on the lateral margins of the segments.

The length varies considerably; it may be $15-30$ feet or more.

The eggs are globular or polygonal and are 50-90 microns in diaincter.

2. Moniezia alba (Tænia alba). Tæniidæ (p. 170). - The head is larger than that of the preceding species and is provided with large oval suckers. The neck is short and the segments are longer and narrower than in $M$. expansa; some may be slightly longer than broad. The width of the broadest segments is about $1 \mathrm{~cm}$. (3/s of an inch). There are two genital porcs in each segment.

Its maximum length is about eight fect.

The eggs are cuboidal and 48-58 microns in breadth.

3. Moniezia planissima. Tæniidx (p. 170),- The head is nearly squarc and has slightly elongated suckers. The segments are much brouder than long, the ripe ones having a width of $12-26 \mathrm{~mm}$. $(1 / 2-1$ inch). These segments are very thin and semitransparent. Each segincnt has two genital pores.

Length, 3-6 fcet.

The eggs arc about 63 microns in diameter.

Thysanosoma actinioides (Tænia fimbriata). Tæniidæ (p 170.).This is a species occurring in sheep, but has not been reported in other domesticated Herbirora. The head is without hooks or rostcllum. The 
segments are broader than long, having the uterus transverse and the genital pores double or irregularly alternate. The segments have long fringes on their posterior borders (Fig. 93).

Length, six inches or more.

Its larval form is unknown.

Occurrence and Symptoms.-All of these worms live in the small intestine. As nothing is yet known of their cystic forms, the mode of infection remains undetermined. Cattle are rarely disturbed in health by the presence of tapeworms. In exceptional cases there may be malnutrition and digestive disturbances accompanied by bloating. Again, it is difficult to with certainty assign these nonspecific conditions to the presence of tapeworms. As in all intestinal helminthiases, there is to be borne in mind the possibility of the worms passing to unusual locations, as the bile ducts, and of interference with the movement of the intestinal contents by massed worms.

Of the domesticated herbivorous animals, probably sheep most frequently harbor tapeworms. A species often found in those of the United States is Thysanosoma actinioides which, as is true of other species infesting sheep, is most prevalent among the flocks of the Western States. The worms may be found at any time of the year, though more

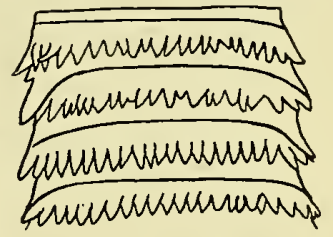

Fig. 93.-Thysanosoma actinioides, anterior segments,enlarged (after Railliet).

often during the season of grazing, a fact pointing to the probability that the encysted larvæ are taken up with the grass. Thysanosoma actinioides, when brought to certain parts of the Eastern United States, does not multiply. It may be assumed that this is attributable to absence of the proper intermediate host, whatever that may be. In parts of the west it constitutes a form of tæniasis much more severe than that from Moniezia. This is due mainly to their invasion of the bile duct, a habit which is cxceptional with other tapeworms, but with the fringed tapeworm it is the rule rather than the exception.

Lambs born in the winter and turned upon grass during the rains and moisture of spring are the more likely to suffer from tapeworm invasion. In such cases, or in heavy infestation, anæmia is indicated by paleness of the visible mucosæ, and this may be accompanied by loss of vivacity and more or less emaciation with arrest in development. Straining and ineffectual efforts at defecation, with prolonged elevation of the tail, are noticed, the feces later becoming unformed or even fluid and eontaining the segments.

Death may ensue in advanced emaciation and weakness, or before reaching this stage if the intestine becomes obstructed by the worms in mass or there arc other resulting complications. Such a course is 
rare in aged sheep. Where fatalities occur, they are usually among the grazing lambs.

\section{C'Estodes' OF THE DOG}

Of the tapeworms of the dog, nime are considered here, among which there is a wille variation as to frequency and importance. The first eight of the species to be mentioned belong with the family Truida; the ninth is referred to under the Diphyllobothriida. In all but the last the head is provided with the crown of hooks, and in all the life history is known.

1. Dipylidium caninum (Tænia cucumerina). Fig. 94, Tæniidæ (p. 170).-The heal is small and has a protractile rostellum surrounded by the four suckers (Fig. 95). There are three to four rows of small tholn-like hooks. The neck is slender, sueceeded at first by narrow trapezoidal segments. The nature segments are longer than wide and shaped somewhat like a cumber seed. They have a genital pore on cach lateral margin.

Length, 15-40 $\mathrm{cm}$. (6-16 inches).

Eggs globular, 43-50 microns in cliameter and grouped in snall capsules (Fig. 96).

The larva of this worn is a eysticereoid (Cryptocystis trichodectes) found in the boly-cavity of the biting louse of the $\log ,-$ Trichodectes latus (Fig. 96). Lice are not sufficiently prevalent upon dogs, however, to account for the frequent occurrence of this worm; in fact, later investigations have determined that the dog flea, Ctenocephalus canis, and the human flea, Pulex irritans, harbor its larva, and it is probable that the flea is its nore common host.

2. Dipylidium sexcoronatum. Tenirdie (p, 170),- - Hall and Wigdor (Jommal of the Anerican Veterinary Medical Association, June, 1918) refor to this tapeworm as follows: "Dipylidium sexcoronatum has been reported from (logs in the United States at Bethesda, Md., and Detroit, Mich., by Hall (1917). We find it fairly often here at Detroit and our impression is that it is as emmmon here as $D$. cominum. The strobila is much narrower than $D$. caminum. Some of the specimens with a narrow strobila appear to have only five rows of hooks and should be studied with a view to determining whether $D$. sexcoronatum has sometimes five rows of hooks, as well as six rows, or whether this material belongs to a new species."

3. Tænia hydatigena (T. marginata). Fig. 97. Tæniidæe (p. 170),The heal is small, but little broader than the neck. The hooks are large, $170220 \mathrm{microus} \mathrm{long}$, and mumber 30 -34. The mature segments are wider than long, the distal segments elongated. The gravid segments have a median longitudinal groove teminating in a noteh pos- 
teriorly. The number of segments is about 400. The gravid uterus has $5-10$ branches on each side.

Length, 1.5-2 meters (57-76 inches).

Eggs nearly spherical and 31-36 microns in diameter.

The larva is a eysticercus (Csyticercus tenuicollis) found in the peritoneum and, more rarely, in the pleura of ruminants and hogs. It has also been reported from rodents and inonkeys.

4. Tænia pisiformis (T. serrata). Fig. 98. Tænïidæ (p. 170).The head is small, but little broader than the neck. The hooks are large, 225-294 microns long and 34-38 in number. The segments are at first narrow and much shorter than broad; those mature are approximately square. The distal segments are elongated $(10-15 \mathrm{~mm}$. by 4-6 $\mathrm{mm}$.). The posterior margins of the segments project laterally, giving to the lateral margins of the chain a serrated appearance. The genital pores are prominent, and the uterus in gravid segments has 8-1.4 lateral branches on each side.

Length, 0.5-2 meters (19-76 inches).

Eggs oval, 36-40 microns long, 31-36 mierons wide.

The larva is a cysticercus (Cysticercus pisiformis) which develops in the mesentery and omentum of rabbits, and has been found in the mouse and beaver.

5. Multiceps multiceps (Tænia cœnurus). Fig. 113. Tænïdæ (p. 170).-The head is small and bears $22-30$ hooks. Larger hooks have a handle equal in length to that of the blade and wavy in outline. The segments of the middle portion of the ehain are approximately square. The distal segments are elongated $(8-12 \mathrm{~mm}$. long by $3-4 \mathrm{~mm}$. wide). The ripe segments are broader at their middle, narrowing toward their ends which gives them somewhat the appearance of a cucumber seed. The genital organs are well developed, $15-20 \mathrm{~cm}$. (6-8 inches) from the head, or toward the 125th segment. The genital pores are irregularly alternate. The uterus has 16-25 lateral branches on each side.

Length, 40-60 $\mathrm{cm}$. (16-231/2 inches).

Eggs nearly spherical and 31-36 microns in diameter.

The larva is a conurus (Multiceps multiceps; Conurus cerebralis) which develops in the ccrcbral cavity and, more rarely, in the spinal canal of herbivora, usually sheep (Figs. 114 and 116).

6. Multiceps serialis (Tænia serialis).-Tæniid:e (p. 170). The head is a little wider than the neck and bears 26-32 hooks. The small hooks have a short blunt handle; the larger hooks a wavy handle as long or a little longer than the blade. The scgments are similar to those of $M$. multiceps, the form of the uterus in gravid segments also being the same.

Length, $4-7+\mathrm{cm}$. (17-291/2 inches).

Eggs oval, 34 microns long, 27 mierons wide. 

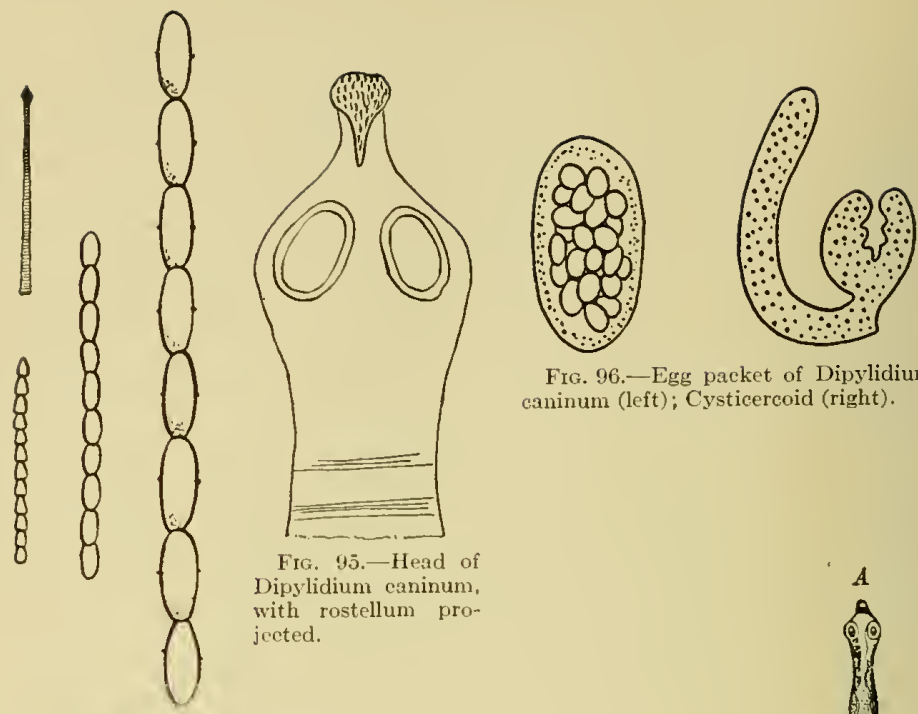

FIG. 96.-Egg packet of Dipylidium caninum (left); Cysticercoid (right).

Frg. 94.-Dipslidium caninum, portions of adult. natural size.
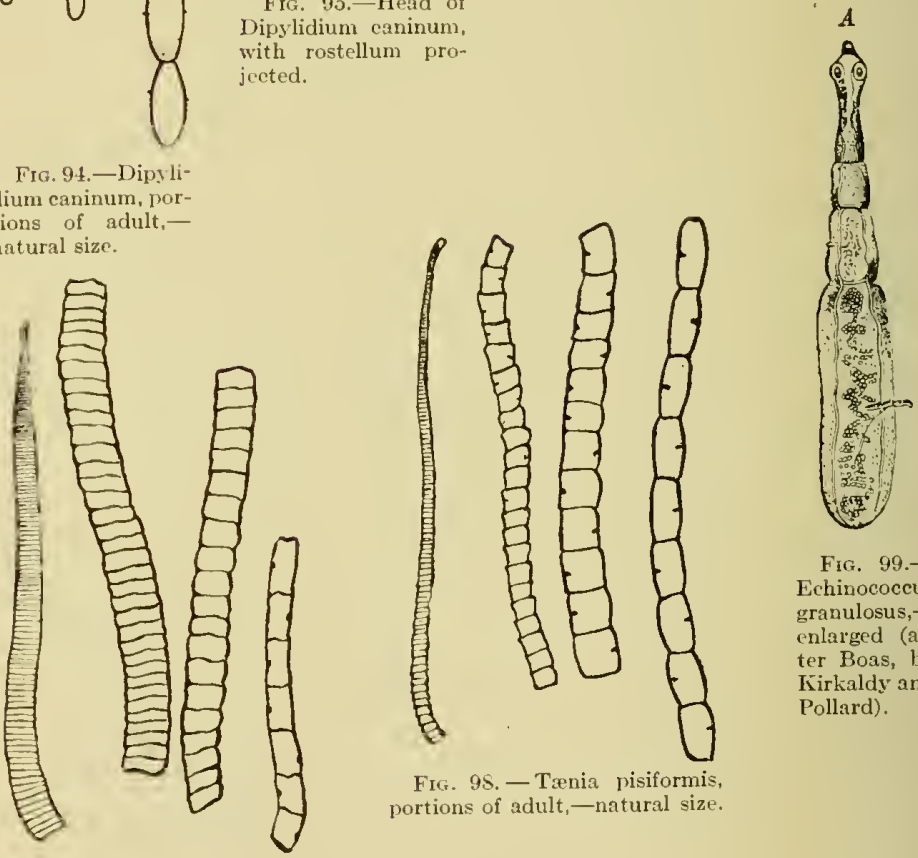

Dipylidium caninum, with rostellum projected.

Frg. 95. - Trenia pisiformis,

Fig. 99.Echinococcus gramulosus,enlarged (after Boas, by Kirkaldy and Pollard).

Frg, 97.-Tænia hydatigena, portions of adult.- natural size. 
The larva is a cœenurus (Multiceps serialis; Conurus serialis) found in the connective tissue of rabbits and other rodents.

7. Multiceps gaigeri. Tæniidæ (p. 170).-This is a species found in India and Ceylon, and described by Hall (Journal of the American Veterinary Medical Association, November, 1916), the larva of which develops in the central nervous system and also in the connective tissues and serous surfaces of ruminants. Thus in its cystic host this species combines the location of $M$. multiceps and $M$. serialis, the larva, as in that of the latter, forming an adventitious capsule.

The material for examination (Bureau of Animal Industry, Helminthological Collection) consisted of specimens of tapeworms from the $\log$ and the cœnurus from the goat. From his study of these, Hall (1916) regards this species as more closely related to the gid tapeworm, $M$. multiceps, than to $M$. serialis.

8. Echinococcus granulosus (Tænia echinococcus). Fig. 99. Tæniidæ (p. 170).--The chain is but $4-6 \mathrm{~mm}$. (3/16-1/4 of an inch) in length, and is composed of a head and three segments. The head is provided with 28-50 small hooks arranged in two rows. The first and second segments from the scolex are incompletely developed, but one segment at a time becoming gravid,- the third, when its length almost reaches that of the rest of the worm.

Eggs oval, 32-36 microns long, 25-26 microns broad.

The larva is an echinococcus (Echinococcus gramulosus; E. polymorphus) found in the internal organs, usually the liver and lungs, of ruminants and hogs, and also in man (Fig. 117).

Occurrence.-It follows from their habits that dogs should more frequently harbor intestinal parasites than other domestic animals. Probably over fifty per cent. are infested with varied species, frequently in considerable number. Of these, tapeworms predominate, several species of which often inhabit the intestine of a single individual.

The intermediate hosts of Dipylidium caninum-fleas and lice, the former ubiquitous in relation to canine existence,-would account for the greater frequency of this tapeworm than any other in dogs. Dogs which have access to butchers' offal are, in addition to this species, readily infected with Echinococcus granulosus, Tania hydatigena, and Multiceps multiceps, the cystic forms of which are harbored in organs of the principal meat-food animals, sheep, hogs, and cattle. Hunting dogs and those which roam afield are the most exposed to invasion with Tcenia pisiformis and Irulticeps serialis, these having their larval development in rabbits. In any case, young dogs are more susceptible to intestinal hehminthiasis than those which are older.

Symptoms.- Notwithstanding their frequent presence in large numbers, tapeworms seem, as a rule, to have little deleterious influence upon the health of dogs. As is true of intestinal worms in general, 
their accumulation may bring about obstruction with attendant displacenent and degenerative changes in the intestinal walls; and, again, there may be a serious and even fatal result from their unusual location. Such consequences of tæniasis are, however, exceptional in dogs. In general, the symptoms are those of chronic gastro-intestinal catarrh. The capricious appetite varies between extreme voraciousness and complete anorexia. Regardless of the anount of food consumed, there is a noticeable emaciation which may become well marked, young dogs especially becoming pot-bellied and stunterl in growth. More characteristic is restlessness, straining, and itching about the anus, the latter manifested by agitation of the tail and a peculiar squatting and dragging of the hind parts, sometimes referred to in the expressive, hut highly untechmical term, "rough-locking."

With increasing uneasiness, the development of intestinal pains, howling, and an inclination to bite, which is perhaps conjoined with a chull or wild expression, there are presented symptoms somewhat similar to those of rabies. In such cases convulsions may set in and the animal may dic during an attack, or it may gradually suceumb after sinking into a cataleptic condition.

Pathogenesis.-Necropsirs upon (logs which have suffered from treniasis generally show the worms lodged in the small intestine only. Probably as a result of post-mortem wandering, they may also be found in snall numbers in the large intestine or stomach. The inflammation of the mucosa is repecially extensive and of aggravated character in infestation with Echinococcus. This is a tapeworm of the dog which, though relatively very small, sets up the greatest irritation by reason of the vast number of incliviluals present, which, firmly implanted by their hooks, may completely cover the intestinal hining over large areas. Where obstruction occurs in teniasis, it is generally brought about by the presence of the larger tapeworms massed in coils. Dipylidium caninum, though smaller than some other species inhabiting the dog, is most likely to he found the offending agent in such conditions because of its prevalence and the presence of numerous individuals in the same host. The projecting rostellum of this species, sinking deep into the mucosi, is also a factor increasing its capabilities for damslge. Tenia hydatigena and $T$. pisiformis are much larger, but less common, while Multiceps multiceps and $M$. serialis have thus far been found nore commonly in European countries than in the Inited States.

Contributing to the systemic effects of tapeworm invasion, there is, as in other heminthiases, the operation of toxins elaborated by the worms. In cases of heary infestation this factor must he a considerahle one, espocially when combined with that of poisons derived from the deat and decomposing bodies of the parasites. 
Diagnosis. - The presence of tapeworms may in most cases be recognized by the passing of segments, or fragments of the chain, with the feces; occasionally these may also be expelled with vomited matter. Often the fragments may be arrested near or partly protrude from the anus, causing a pruritus in this region which the animal endeavors to relieve by rubbing the parts upon the ground.

Diagnosis may be assisted in doubtful cases by the administration of a laxative, in the operation of which detached portions of the chain will be expelled if present. Echinococcus, however, on account of its small size, is likely to escape observation in the ordinary means of examining fecal matter.

Dog Tapeworms in Relation to Human Infection.-Two species of tapeworms harbored by dogs-Echinoccocus granulosus and Dipylidium caninum-are especially of medical interest in that they may also infect man. The first mentioned produces in its larval development a condition known as hydatid disease, or echinococeosis, in man as well as in numerous lower animals.

The larval or, as it is called, the hydatid form of this tapeworm occurs usually in the liver, lungs and kidneys of these animals, and may produce from the original cyst numerous daughter cysts, the growth going on indefinitely and evolving bladders as large or even much larger than an orange (Fig. 117). Due to its pressure, necrotic degeneration of tissue, and also to secondary infection by bacteria, this growth gives rise to serious disturbances in the organ in which it is lodged. In man the condition is often fatal, less so in the lower animals, probably owing to the fact that their term of life is shorter, or they are likely to be slaughtered before sufficient time has elapsed for the full development of the slow-growing hydatid.

A more detailed reference to the echinococcus cyst is given further on in the special consideration of the cestode larvæ (p. 210).

The common tapeworm of the dog, Dipylidium caninum, may fincl adult hostage in the human initestine, According to Hall (Bull. 260, U. S. Dept. of Agriculture, 1915), seventy-six cases of this tapeworm in man, mostly children, have been reported, a number of these from the United States. It has been found in an adult thirty-eight years old, and it is stated that as many as two hundred and fifty-eight of these worms have been found in a single person.

Considering the privileges which are allowed dogs, it is quite apparent that a flea or louse containing the Cryptocystis might pass from the dog to the human mouth by the dog licking the face, or through the intermediation of food, especially sticky candy to which the insect readilyadhcres. Children give little attention to incidental contamination of their food, which is frequently partaken of in intimate proximity to their eanine companions, the dog often sharing in the feast-perhaps 
from the same plate. It follows that human infection with this tapeworm occurs more often among children than among adults.

As in trniasis of other animals, the presence of a few of these worms in man is not likely to occasion serious disturbance, though to the human conception, the presence of a tapeworm in the intestine is anything but a pleasant thing to contemplate. Where they are numerous, the irritation, possible obstruction, and other secondary conplications which may arise, make it, as in lower animals, a nore serious condition.

Prevention calls for restraint in the liberties of dogs, especially about children. Chilkren should not be permitted to handle vagrant and negleeted dogs. Those kept about the premises as pets should be obscrved for indications of the presence of tapeworms, and their bodies should be kept free from fleas and liee.

\section{Cestodes of the Cat}

Of the tapewoms harbored by cats, only the species Tania taniaformis is of importance as affecting their health. Others which have been found are: Dipylidium caninum, Echinococcus granulosus, and

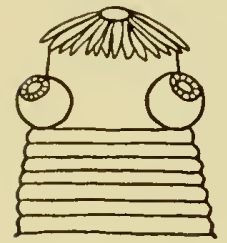

Fig. 100.- Head of Tenia tanimeformis, -enlarged (after Veumann). Diphyllobothrium latum, the first two described under the Tæniidx of the dog. These latter forms do not appear to eause disturbance to the animal.

Tænia tæniæformis ( $\boldsymbol{T}$. crassicollis). Tæniidæ (p. 170).- The head (Fig. 100) is rounded, has four prominent suckers and a strong rostellun provided with $26-52$ hooks. The neck is as wide as, or wider than, the head, and there is no intermediate constriction. The segments follow immediately from the head, increasing in size to a length of $8-10 \mathrm{~mm}$. $(5 / 16-3 / 8$ of an inch) and a width of 5-6 mm. (1/4 of an inch).

Length, 15-60 em. (6-231/2 inches).

\section{Egys globular, 31-37 microns in diameter.}

The larva is a cysticercus (Cysticercus fasciolaris) inhabiting the liver of rats and mice.

Occurrence and Symptoms.-This tapeworm is not uncommon in the eat, often infesting the small intestine in large numbers and seriously affecting the animal.

There is in the beginning a diminution of appetite which gradually passes to refusal to take any food whatever. Diarrhea, at first slight, later severe, is succeeded by constipation; there is salivation, and in some cases vision and hearing are seriously affected. Colic is a frequent accompaniment during the attacks of which the animal may rush about in a frantic manner, apparently heedless of or unable to see objects with which it may come in contaet. 
Finally, as a manifestation of the ncrvous disturbance, there are convulsions; there is much prostation and emaciation, and the animal dies, usually during or shortly after an epileptiform attack.

\section{Cestodes of Rabbits}

Tapeworm infection is said to frequently appear enzoötically among the wild hares of foreign countries. In domestic rabbits such infection is rare. The species here described is occasionally found. It is unarmed, and its life history is unknown.

Cittotænia denticulata (Moniezia denticulata). Tæniidæ (p. 170).The head is small, with flat suckers. The neck is as broad as the head. The larger segments may be $10 \mathrm{~mm}$. (3/8 of an inch) in width, always wider than long. The genital pores are on the posterior fourth of the border of the segment.

It may reach a length of $8 \mathrm{~cm}$. (3 inches).

There is little clinical experience with tæniasis of rabbits. In general, what has been said as to such infection in other animals will apply as well to them. Diagnosis can be made by finding the segments in the feces, or by destroying and examining one or two suspected animals.

\section{Family II. Diphyllobothridd.e}

The best known representative of this family is Diphyllobothrium latum (Dibothriocephalus latus, Bothriocephalus latus). The head is oblong or lanceolate, unarmed, and has two deep slit-like depressions, one dorsal, the other ventral, which serve as suckers (Fig. 109). The neck is not well demarcated from the first segments which are scarcely visible. The segments gradually increase in length and breadth; the largest are $4-5 \mathrm{~mm}$. long and may be $2 \mathrm{~cm}$. wide $(3 / 16 \mathrm{by} 3 / 4$ of an inch). The gravid segments become much narrower as their genital organs atrophy and the eggs are discharged, these being expelled in greater part before the separation of the segments from the chain. In sexually mature segments the rosette-shaped uterus may be seen in the middle line. The genital pores are special orifices for ovulation, located in the middle of the ventral surface of the segments (Fig. 101).

The length of the entire worm may be $2-7$ meters $(6-22$ feet). It may reach a length of 20 meters (Neumann). The segments may number 3,000 or more.

The eggs are oval, operculated, and 68-70 microns long. In the presence of water a ciliated embryo escapes from the egg by the lifting of the operculum and swims about until it enters the body of a freshwater fish, said to be especially the pike. In the muscles of this host it develops into the worm-like pleroccrcoid (Fig. 112, e). After the 
definitive host has eaten fish containing the living larve, the tapeworms drelop rapidy, becoming mature in about four weeks.

Occurrence.-This species is sometimes called the broad Russian

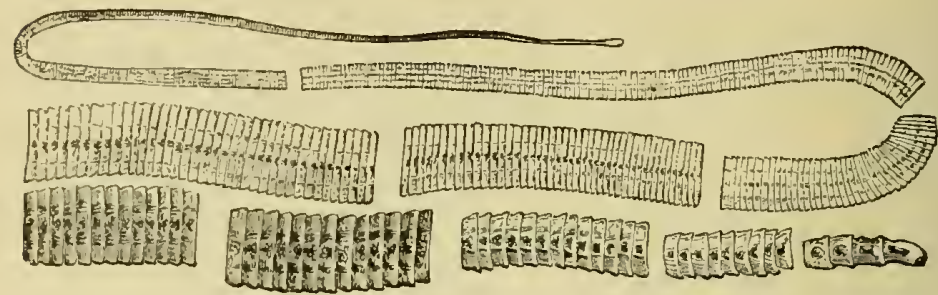

Fig. 101.--Sections of Diphyllobothrium latum,- - natural size (after Boas, by Kirkaldy and Pollard, from Leuckurt).

tapeworm. It infests man and fish-eating dogs in Russia, Switzerland, Japan, Finland. swolen, and other foreign countries. It is extremely rare in the United States, and is of little medical or economic importance hicre.

\section{Treatient of Texiasis}

Treatment of Tæniasis of the Dog.-Therapeutic measures for the expukion of tapeworms have two consecutive objects in view; first, the loringing about of a torpid condition or weakening of the worm; second, the expulsion of the entire worm from the host. The first is attained in part by depriving the parasite of its nomishment, and by the administration of a vernifuge which should sufficiently further weaken it to causo its dotachment from the mucosa; the second by a purgative which will expel the detached worm with the evacuations.

As preparatoly to the action of the vermifuge, all food should be kept from the animal for at least twenty-four hours immediatcly preceding its arministration; at the same time the cleaning out process will be considerably aided if a mild laxative is given. Some advocate a milk diet for sevoral dins, but in any case the fasting should he absolute for a periol of one day.

Of the vernifuge agents, those which have been found most reliable as truiafuges are: (1) male fern (aspiclium); (2) areca nut; (3) kusso; (4) kanala. Of these male fern is particularly sorviceable. Depending upon the weight and age of the aninal, the oleoresin of aspidium may be given to dogs in doses of fifteen minims to one dram. It can be advantageously combined with small doses of areca nut (one grain per pourd of body-weight), and conveniently administered in capsule. Aspiclium shoukl never be given with oil as this favors its absorption, and it is a local action which is sought. After three to four hours the 
dose may be repeated, and twelve hours after the first dose a purgative should be given.

The dog should be kept where its evacuations can be conveniently examined, and, if it is found that the head of the tapeworm has not been expelled, the treatment is to be repeated in a week to ten days. The expulsion of the worm may be aider somewhat by rectal injections of warm soapy water.

If areca nut is used uncombined, it may be given in doses of two grains for each pound of body-weight. It can be conveniently administered shaken up in a little milk. Areca nut in itself is laxative or purgative according to dosage. If purgation has not followed within a few hours after its administration, a full dose of castor oil should be given ten to twelve hours later.

Kusso has an advantage in being quite safe even in excessive doses. Small dogs take of the fluid extract one-half to one dram; large dogs, two to four drams. It can be given in milk and repeated three times at intervals of one hour. Vomiting, which sometimes follows the administration of kusso, may be prevented by previously giving a medicament having an anesthetic action upon the stomach.

Kamala is given to dogs in doses of one-half to two drams in honey or syrup. In cases where heavy infestation is suspected it should be repeated in eight hours. Kamala has some purgative action and may also nauseate; the latter effect can be corrected by the same means as for kusso.

Other teniafuges sometimes used are: (1) Pumpkin seeds, fed crushed and macerated or as an infusion, and (2) turpentine, one-half to one dram, given with the yolk of an egg and repeated until three doses have been administered twenty-four hours apart. Turpentine, however, on account of its irritant effect upon the kidneys, should be used with caution.

Whatever form of tæniafuge medication may be chosen, the chances of success will depend much upon a brisk purgative action following upon its operation. At best there is often failure to secure the head of the worm, in which event a repetition of the whole treatment is called for in the course of one to several weeks.

Prevention.-To prevent the spread of tæniasis, all expelled tapeworms and their fragments should be destroyed by burning. Dogs known to be infected had best be isolated and all of their excrement burned. Dogs which have their meat cooked, and those which are not allowed access to the viscera of slaughtered animals and rabbits, are not so likely to be infected, though such precautions will not protect them from the common species Dipylidium caninum, freedom from fleas and lice, and prevention from association with dogs less fortunate in this respect, being essential to avoidance of infection by this species. 
Treatment of Tæniasis of the Cat.-For tæniasis of the cat the same procedure may be followed and the same remedies used as for the dog. The dosage, however, should be reduced and proportioned according to the weight and age of the animal.

Prevention consists in restraining the animals from feeding upon rats and mice, the intemediate hosts of their most common tapeworm,-Tenia taniaformis.

Treatment of Tæniasis of Sheep and Goats.-For several days preceding treatment of these animals it is advisable to feed moderately upon green succulent food, avoiding bulk, as fodder and hay. Immediately before giving the vermifuge all food should be withield for a suffieient time to make the animals quite hungry. Powdered areca nut may then be given in one to two dram doses according to weight. It ean be administered mixed with bran or bran and chopped beets which the sheep, made ravenous by their preliminary fast, will eat greedily. Three hours afterward a purgative should be given and the evacuations of each individual kept under observation for the appearance of tapeworms.

Other vernifuges recommended are: (1) Oil of turpentine, one to two drans, given in one-half to one ounce of linseed, cottonseed, or olive oil, and (2) kaniala, forty-five grains to one and one-half drams in thin syrup or water, the dose to be repeated once at an interval of four hours.

Treatment of Tæniasis of Cattle.-Where treatment is inclicated for the expulsion of tapeworms of cattle the animals should be dietetically prepared as reconnended for sheep. As a vermifuge, tartar emetic is quite suitable fol these animals. It may be given in one and one-half to two and onc-half dran doses in gruel. Oil of turpentine, three ounces in a pint of linseed oil, makes a reliable remedy. Arsenic in daily ascending doxes for a period of fifteen days has also been recommended. The vermifuge treaturent should be followed by a purgative of glauber salts.

Treatment of Tæniasis of the Horse.-The existence of tapeworms in the horse generally remains unrecognized during life. The symptoms are those general to intestinal helminthiasis of horses, and the treatment is quite the same as that for ascariasis (p. 23t). The animal is to be renored from work, kept from hay, and fed only upon mashes. After at least twenty-four hours of such preparation, give two to four ounces of oil of turpentine, and one dram of oleoresin of aspiclium in a pint of linseel oil. Tartar enetic is also quite effectual. It should be given in two doses of three drans each at an interval of twelve hours. It may le mixed with a gruel of linseed meal. 


\section{CHAPTER XVI}

\section{TAPEWORMS OF CHICKENS}

Though tapewoms are comparatively frequent in chickens and other domestic fowl, they have not up to quite recent times been the subject of any considerable investigation in this country. In our literature upon the parasites in general, if not neglected entirely, but one or two species are as a rule described, and these generally in an incomplete manner.

With the exception of but one species, what is at present known as to the larval forms has been determined from studies upon poultry cestodes in foreign countries. Thus far in these investigations the life cycle of but one chicken tapeworm-Davainea proglottina-has been experimentally demonstrated, the only one among the six here described which has not been reported in this country. The remaining five have been found infesting chickens in various parts of the United States.

1. Choanotænia infundibuliformis (Drepanidotonia infundibuliformis) (Fig. 102) - The head (Fig. 103) is small, globular or conical, and bears a crown of 16-20 hooks. The suckers are prominent, may be projecting. The neck is very short. The first segments are short; those following are infundibuliform, with anterior border narrower than the posterior. The genital pores are irregularly alternate.

The length varies from $2-23 \mathrm{~cm} .(3 / 4-91 / 2$ inches).

Grassi and Rovelli, comparing cysticercoids which they had found in flies (Musca domestica) with the adult Choanotcria infundibuliformis, noted a structural agreement from which they inferred that the larvæ were the intermediate stage of this species. No experiments were carried on by these investigators, however, to demonstrate this connection.

Guberlet, of Oklahoma Agricultural and Mechanical Collegc, in a series of investigations upon chicken cestodes (19121914) seems to have conclusively demonstrated that the cysticercoid of Choanotenia infundibuliformis occurs in the common house fly. Briefly stated, his results were obtained by raising cysticercoids in the flies by feeding them on the

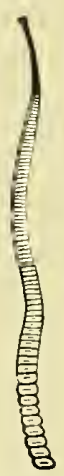

FIG. 102 . -Choanotænia infundibuliformis, nat. size. eggs of the tapeworm. These flies were fed to three of six chicks which had been removed from chance infection as soon as hatched. Three weeks after such feeding all of the chicks were killed, and two were found to be infested with Choanotenia infundibuliformis. The three birds used as a check on the experinent contained no worms. 
2. Hymenolepis carioca.-The head is piriform with retractile rostellum. It is unamed. The segments number about 500, all much wider than long; terminal segments measure $0.5-0.8 \mathrm{~mm}$. The genital pores are unilateral. The wom is very fragile and delicate.

Length, $3-8 \mathrm{~cm}$. (11/4-3 1/8 inches).

The life history is unknown.

3. Davainea tetragona (Tonia tetragona).-The head (Fig. 104) is sllull and tetragonal; rostellum armed with a crown of 100 hooks. The suckers are oval and arned with $8-10$ circlets of small hooklets. The short neck is followed by short trapezoid segments, those terminal

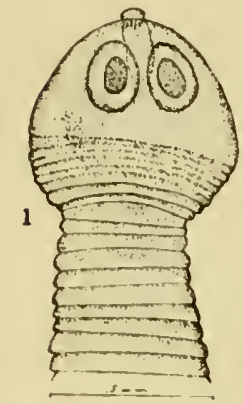

Fis, 103.--Choanotornia infundibuliforthis, scolex much contracted, enlarged (after Ciuberket, in "Trausactions of the Amerien Mieroseopical Socin $t^{\circ}$ ).

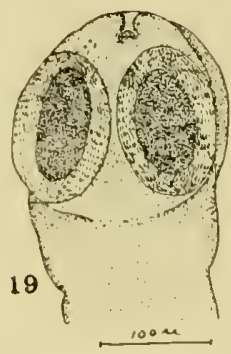

Fic. 104--Seolex of Davaimea tetragona,cnlarged (after Guberlet, in "Transactions of the American Microseopical society".)

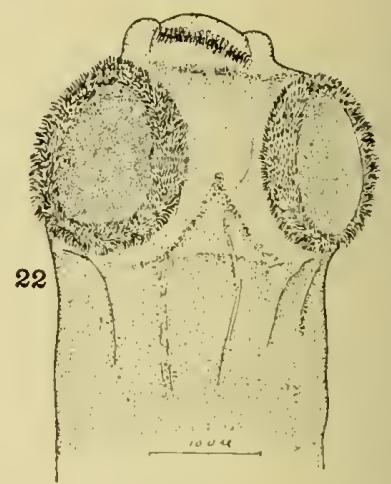

Fig. 105.-Scolex of Davainea echinobothrida, - enlarged (after Guberlet, in "Transactions of the American Microscopical Socicty".)

generally longer than wide. Their length varies between $1-4$ mm. The genital pores are milateral.

Tle k'ngth varies between $1-25 \mathrm{~cm}$. (3/8-10 inches).

Investigations of Piana point to certain little snails (Helix carthusianella and $I I$. maculosa) as the probable larval hosts of this species. .

4. Davainea cesticillus (Tenia ccsticillus).- The head is globular and has a rostcllum scurcely salient ol depressed. It is armed with a clouble crown of $400-500$ hooklets which are loosely attached. The suckers are small and unamed. There is no neck. The first segments are short and nuch wiler than the head; the last are about as long as broad. The genital pores are irregularly alternate.

Length, $1-4.5 \mathrm{~cm}$. (3/8-13/4 inches). By some authors it is said to attain a murh greater length (10-13 cm.). 
According to Grassi and Rovelli the intermediate host is a lepidoptelous or coleopterous insect.

5. Davainea echinobothrida (Tenia echinobothrida).-The small head (Fig. 105) presents an infundibulum provided with a double crown of about 200 hooks. The suckers are armed with $8-10$ circlets. There is no neck. The segments gradually increase in width, the largest being 1-4 mm. The genital pores are irregularly alternate.

Length, 5-25 cm. (2-91/2 inches).

Nothing is known of its larval development.

This species has a characteristic pathological effect in that the scolex, with its accessory armature about the suckers, bores through the intestinal mucosa, producing large nodules or ulcers. The condition in fowls is termed "nodular tæniasis" and is described by Moore (Bureau of Animal Industry, Cir. No. 3, 1895). The nodules are often mistaken for other diseases showing similar features.

6. Davainea proglottina (Trenia proglottina).-The head is quadrangular, slightly rounded. The rostellum is armed at its base with 80-95 hooks. The chain is composed of $2-5$ segments. The terminal and largest segments have a tendency to detach and develop separately in the intestine. These free segments may acquire a length exceeding that of the entire chain. The genital pores are irregularly alternate.

Length, 0.5-1.55 $\mathrm{mm}$.

Grassi and Rovelli have demonstrated that the larva of this species is a cysticercoid which inhabits several species of snail-Limax cinereus, L. agrestis, L. variegatus.

The species has not as yet been reported in this country.

Occurrence.-Guberlet, in a report of his investigations carried on in Nebraska (Journal of the American Veterinary Medical Association, May, 1916), sets forth some significant data as to the prevalence, in parts of the United States at least, of chicken cestode infection. During 1912-13 he examined sixty-eight birds collected mostly from Nebraska and Illinois. From this material he obtained 1,561 tapeworms, specifically distributed as follows: Davainea tetragona, 598; D. cesticillus, 582: Choanotania infundibuliformis, 176; Hymenolepsis carioca, 154; Davainea chinobothrida, 51 . The worms were present in numbers per host varying from 1-35. (The author is informed by Dr. Guberlet that he has since found as many as 115 in a single animal.) Most of the birds examined ranged in age from four to six months.

Symptoms.--As a rule it is only in moderate to heary infection that tapeworms bring about morbid conditions in fowl. In any case the symptoms are not well defined. They may vary in different individuals having an equal degree of infestation, age esperially having an influence, young birds being much more affected than adults and exhibiting the sinnptoms more definitely. The following are among the more usual: 
There is an abnormal desire for foor, in spite of which the heavilyinfested chickens emaciate and become anæmic, as manifested by paleness of the comb and wattles. The feathers become erect, ruffled, and dull, and the birds have a tendency to isolate themselves, often in drooping attitudes, or the constantly hungry creatures may seem never to be at ease, but are constantly running about, this probably accounting in part for the loss of flesh. In such aggravated cases there is often advanced emaciation, and, completely exhausted, the bircl may die.

Diagnosis. - A reliable diagnosis ean only be made by finding the segments in the feces, or by killing and examining one or two of the birds showing suspicious simptoms. When the latter method is adopted the intestine should be removed and slit open under water. After gentle stirring to remove the contents, it may be transferred to a basin of elean water, when the worms, if present, will usually be seen attached to the mucosa.

Control.-As in other forms of helminthiasis, control measures are most effectually applied to the parasites in their stage of larval development. Until more is known of the life histories of the chicken tapeworms little can be done in the way of prevention other than that based by analogy upon what has already been demonstrated. It is scarcely practical to keep poultry from eating such possible intermediate hosts as worms and inseets. Means may be taken, however, to restrict their access to fliss, snails, and the lower crustaceans of stagnant water, though such procaution cannot well be applied to birds rumning at large. A more feasible accessory measure is the prevention of the larve from raching the intermediate hosts by isolating the infected birds in screened quarters where their droppings may be colleeted and made sterile by buming or other means.

Treatment. - Vermifuges may be administered in the form of pills made up with hread. Probably the most suitable is areca nut which can be givon to adult chickens in doses of from ten to twenty grains according to weight. Young animals may take from three to five grains. After three days the treatment should be repeated. Other remedies userl are male fern, kamala, turpentine, and pumpkin seeds, the losage being proportionate to weight.

such a method of treatment has a disadvantage in that cach bird must he treated inclividually. Where the infection oecurs in large floeks the repeated handling of each bird involves such an amount of time and patience as to put it practically out of the question. Again we are indelsted to Guberlet for experiments which seem to point the way to a more practical method. Bearing upon this department of his work, his report is here quoted in part.

"Fifteen birds which showed symptoms of tapewom infection were placed in a eage which was insect-proof and were given the following 
treatment: $A$ gallon of a mixture of wheat and oats, to which was added a small tablespoonful of concentrated lye, was cooked slowly for about two hours and allowed to cool. The birds were fasted for about fifteen hours and were then given as much of the mixture as they would eat, with plenty of water. Twelve hours later one of the birds was killed and an examination of the small intestine was made. It was found that nearly all of the worms in the intestine were loose, the scolices being detached from the wall, and were also apparently dead. The rest of the birds were given a second dose twenty-four hours after the first. Many worms had passed with the droppings in from twenty-four to twenty-six hours after the first feeding. Most of the worms in these droppings were dead, but in all probability the embryos were still alive in the mature proglottids. Twelve hours after the second dose was given another bird was killed and it was found that only a few worms were left and all of these were detached and dead. The intestine was filled with a peculiar gray-colored, slimy substance composed mainly of mucus. Many entire worms and fragments were passed with the droppings during the period of feeding. The lye acted to some extent as a purgative.

"The birds were given normal diet again, and in a few days they showed no symptoms of infection. Eight days after the second dose had been given two more birds were killed and examinations made. One possessed a small fragment of a tapeworm and the other was entirely free,

"This remedy has been known to many poultry raisers for some time, but they have neglected to use it, mainly on account of the fact that heretofore no definite evidence has ever been presented concerning its actual working possibilities. It may not, and in all probability will not, remove all of the worms, but it does remore most of them so that they are not serious and can be controlled in the flock as a whole." 


\section{CHAPTER XYII}

\section{THE TAPEWORM LARV.E}

Certain tapeworms are to be considered as to their pathogenicity from two important points of view. They are not only parasites in their adult state in the intestimes of domestic carnivores and man, but, in the larval stage live as somatic parasites in animals used as food by man and it may be in man himself. Depending much upon their numbers and form of eyst, these cause no disturbance to their host, or, through their growth, pressure, and inaccessibility, may constitute a menace to health far more serious than that of the adult worms in the intestines.

Three forms of cestode larve are principally concerned in this connection,-cysticercus (Fig. 107), coenurus (Fig. 114), and echinococcus (Fig. 117). A brief synoptical arrangement of these, including the cysticercoid and plerocercoid, follows:

I. Larva having a caudal vesicle.

Cystic

A. Iarva of large size. Liquid in caudal vesicle abundant. Found in tissues and closed cavities of Herbivora and Omnivora, occasionally in Camivora.

1. Vesicke and head single, i. e., eyst monosomatic and monocephalic.

2. Vesicles multiple, each having a
Cysticercus
(Cysticercus pisiformis, larva of Tania pisiformis) single head, i. e, polysomatic and monocephalic.

3. Vesiches multiple, having many

Multiceps

(Multiceps multiceps, larva of $M$. multiceps) heads in each. i. e., polysomatic and polycephalic.

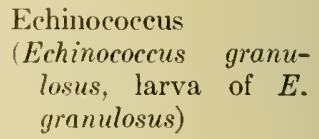


B. Larva small. Little or no liquid in caudal vesicle.

1. Larva firm, terminating in a taillike process.

\section{Cysticercoid \\ (Monocercus Davainece tetragone, larva of Davainea tetragona)}

\section{Cryptocystis \\ (Cryptocystis tricho- dectes, larva of Dipy- lidium caninum)}

II. Larva without caudal vesicle.

A. Larva worm-like. Found in muscles of fish.

\author{
Plerocercoid \\ (Larva of \\ Diphyllobothrium \\ latum)
}

\title{
Crsticercosis (Measles)
}

The presence of cysticerci in the connective tissue of muscles and other parts of the animal organism constitutes the condition commonly known as measles (cysticercosis). The disease is mainly of importance from the viewpoint of food sanitation, in view of the fact that measly beef or pork, imperfectly sterilized by cooking, when consumed by man, is likely to infect him with one or more tapeworms.

The cysticerci of medical interest are, in their order of frequency: Cysticercus bovis of the ox, the cystic form of Tania saginata of man, Cysticercus cellulose of the pig (also of the dog, cat, and occasionally man), the cystic form of Trenia solium of man, and Cysticercus tenuicollis of the sheep (occasionally of the ox and pig), the cystic form of Tania hydatigena of the dog.

For the development and structure of the cysticerci the reader is referred to the Life History of the Tændiiæ (p. 170).

\section{Measles of the $\mathrm{O} x$}

Tænia saginata (T. mediocanellata). Fig. 106. Tæniidæ (p. 170).This species, commonly known as the beef tapeworm, of which Cysticercus bovis is the larval form, lives exclusively in the intestine of man. The head (Fig. 109, B) is small, pear-shaped, and has four elliptical suckers which are frequently pigmented. There are no hooks, and in place of the rostellum there is a sucker-like depression. The neck is 
long and narrower than the head. The segments, which may number from one thousand to one thousand three hundred or more, are at first much wider than long. The complete development of the generative organs occurs at about the six hundredth segment, at which location the segments are about as long as broad. Segments containing the nrature embryos reach a length of $15-20 \mathrm{~mm}$. (5/ $-3 / 4$ of an inch) and a breadth of $5-7 \mathrm{~mm}$, (1/4-5/16 of an inch). The distal margin of each segment is somewhat swollen and surrounds the base of the following segment. The genital pores are irregularly alternate and protrude from the margins more and more markedly as the segments approach the distal cul of the chain. The median trunk of the gravid uterus has twenty to thirty-five dolicate lateral branches on each side, and these give off shorter secondary branches.

The length of the entire chain may be from 3 to 12 meters (9-38 feet), or it may reach a much greater length.

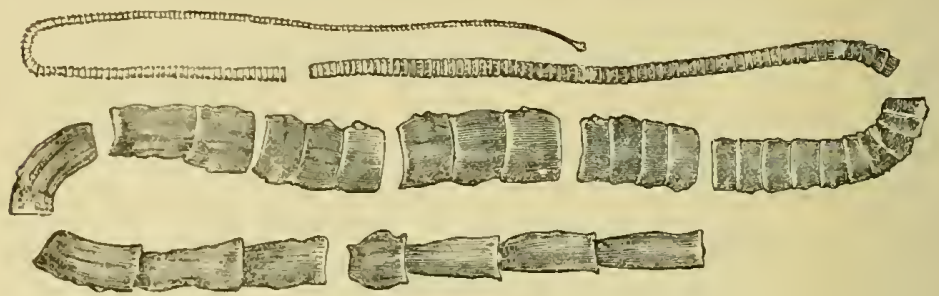

FIG. 106.-Trenia saginata, portions of adult,-natural size (after Boas, by Kirkaldy and Pollard, from Leuckart).

The rggs (Irig. 110) are more or less globular, the shell frequently carrying one or two filaments. As found in the feces, the eggs often have the outer shell absent.

Next to a small species-Hymenolepis nana-this is the most common tapeworm of man in the United states, and, in fact, with the exception of Diphyllobothrium latum in a few districts, is the most prevalent species infesting man in other parts of the workl. It is not found adult in other animals, and its cysticercus lives amost exclusively in the ox,

Occurrence of Beef Measles.-That the beef tapeworm and its cysts (Cysticcrcus bouts) are more commonly met with in the United States than the pork tapeworms is probably clue to the fact that beef is more often eaten rare in this country than is pork. Beef measles, therefore, is, in its relation to food sanitation, of the greater importance. Estimates made upon cattle slaughtered under Federal inspection indicate that nearly on' per cent, of all the cattle slaughtered in the United States 
are affected, which, in addition to the exposure of human beings to tapeworm infection, is a matter involving considerable economic loss in the condemnation of beef otherwise of perfectly good food value.

When it is considered that the gravid segments of the beef tapeworm each contain in the neighborhood of ten thousand eggs, and that eight to ten of these segments are usually passed by the human host each day, it is quite evident that, under certain not unusual conditions, the infected person could be responsible for the presence of the cysticerci in a large number of cattle. The chances for such transmission will be in relation to the location and habits of the carrier of the tapeworm. If it is his custom to defecate about stables or barnyards, the chance that some of the many thousands of voided embryos will reach their bovine hosts is obviously much increased. Where human excrement is used for soiling without its first having been made non-infective by special treatment, cysticercis infection among cattle and hogs is especially frequent.

Measles is more often found in young than in aged animals. This is probably explained by the fact that beef animals are usually slaughtered young and are more susceptible to infection during the first two years of their life when the tissues offer less resistance to the migration of the embryos. In aged animals the cysts are likely to be in a state of advanced degeneration or entirely absorbed.

Location and Appearance.-The cysticerci may be found in any organ, but are more especially to be looked for in the interfascicular connective tissue of striated muscle (Fig. 108). Of the muscles invaded, the first to be mentioned in order of frequency are those of mastication, chiefly the pterygoids and masseters; following these are the heart-which is probably as frequently infested as the masticatory musclesthe muscles of the neck, intercostals, and muscular portion of the diaphragm. In any case it is unusual to find the cysts numerous throughout the muscle, though cases occur of general invasion involving most of the organs of the body.

The size and appearance of the cysts vary in relation to their age and stage of development. Experimental infections have shown that in seventeen to twenty-five days they measure $24 \mathrm{~mm}$. (3/32-3/16 of an inch) in length and $1.5-3 \mathrm{~mm}$. (1/16-1/8 of an inch) in breadth. They are grayish white in color, the outer connective tissue envelope inclosing a fluid which surrounds the clear vesicle or bladder worm. This is $0.5-1.5 \mathrm{~mm}$. (1/32-1/16 of an inch) in diameter, and has at one point a yellowish white spot indicating the location of the invaginated scolex which will evaginate on pressure upon the vesicle.

Experiments by Hertwig have demonstrated that the cysts become fully developed in eighteen weeks after the occurrence of infestation. At this time he found the entire dimensions of the linger cysts to be 
7 by $4.5 \mathrm{~mm}$. (9/32 by $3 / 16$ of an inch), while those of the bladder were $6 \mathrm{by}+\mathrm{mm}$. $(1 / \mathrm{t}$ by $3 / 16$ of an inch $)$.

Degeneration.- - After a period of time, depending somewhat upon their location, the cysticerci undergo easeous degencration followed by caleareous infiltration. That these changes may set in early has been shown in the experiments of Hertwig, who found then four weeks after infestation. Commonly the degenerative changes do not oceur until full development is reached or fol some time after. The cystieerci most likcly to undergo early degeneration are those loeated in the heart, while those of the muscles of mastication probably survive the longest. If they are fonnd degenerated in the latter museles, therefore, it is not likely that eystieerei in other

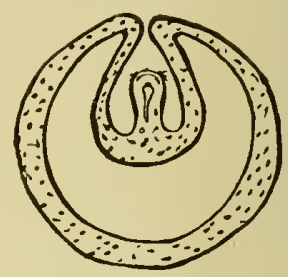

Fig. 107.-Diagram of Cysticercus. parts of the body will be living unless they are from a later infection.

The degenerated cysts may be recognized by their yellowish, or sometimes greenish eolor. They may be senisolid or quite gritty; pus may

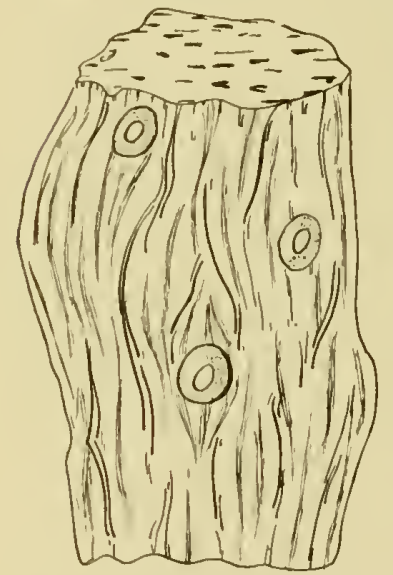

Fig. 10s.-Fragment of beef nuscle, showing eysts of Cysticereus bovis,-natural size (after NeveuLemaire, from Railliet). be present as a result of pyogenic organisms gathered by the embryos in their migrations. The caseation, however, may not always involve the parasite. In such eases the scolex is likely to be found just under the cyst wall with its usual eharacteristics retained, though the caudal bladder is apparently absent.

As eysts when dissceted away and exposed to the air tend to shrink by evaporation, their structure is more easily made out if they are kept moistened with a drop or two of water during the examination.

Vitality. - The cysts of beef measles naturally disintegrate at about three weeks after the death of the host, therefore meat kept in eold storage for this period will not be likely to contain living larve. In fresh beef all will be killed by the application of sufficient heat (60$70^{\circ} \mathrm{C} .=140-156 \mathrm{~F}$.) to cook the meat until its cut surface presents a uniform gray color throughout. Freezing for a number of days will destroy them, but this method has a disadvantage in that decomposition of the meat follows rapidly, making it neeessary that it be quiekly used. Based upon experiments by Ran- 
som relative to this method, Federal meat inspection regulations provide that beef eareasses showing a slight degree of infestation may be passed for food if held for six days at a temperature not exceeding $15^{\circ} \mathrm{F}$. $\left(-9.44^{\circ} \mathrm{C}\right.$. $)$, as an alternative to the requirement of retention for twentyone days.

Symptoms.-Symptoms in bovine measles are practically nil. There is rarely a history of chisturbance from the presence of the cysts, and it is extremely exceptional for the condition to be recognized before the animal is slaughtered.

\section{Measles of the Pig}

Tænia solium.-Tæniidæ (p, 170), This species, to which Cysticercus cellulosce gives rise, also lives in the human intestine and is commonly referred to as the pork or armed tapeworm. It is smaller than $T$. saginata. The head (Fig. 109, A) is globular and less than $1 \mathrm{~mm}$. in diam-

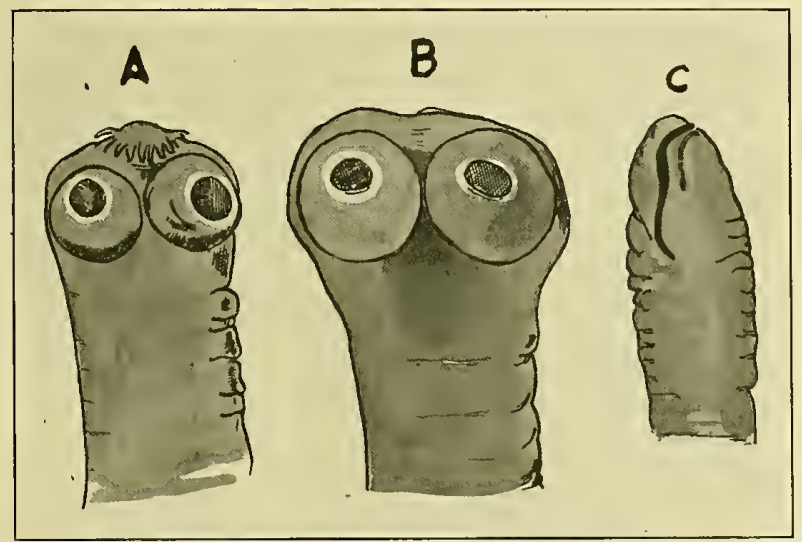

FIG. 109. - "Head" of Tænia solium (A), of T. saginata (B), and Diphyllobothrium latum (C). (After Boas, by Kirkaldy and Pollard).

eter; the rostellum is short and provided with a double crown of hooks. The neck is long and slender. The first segments are very short, gradually inercasing in length and breadth. At about one meter (39 inches) from the head they are as long as broad and have the generative organs fully developed. Toward the distal end of the chain they measure 10$12 \mathrm{~mm}$. (3/s-1/2 an inch) in length and $5-6 \mathrm{~mm}$. (1/4 of an inch) in brealth. The total number of segments is from 800 to 900 . The genital pores are more regularly alternate than in $T$. saginata. The median trunk of the gravid uterus has 7 to 12 tree-like lateral branches on each side. 
The entire length of the worm is $2-3$ meters (6-9 feet), though it may be longer.

The eggs (Fig. 110) are oval and provided with a very delicate shell. The shell surrounding the onchosphere is globular and thick.

This tapeworm is much more rare in the United States than is $T$. saginata. In general, its distribution may be said to correspond with that of the clomestic pig, correlated with the custom of eating the flesh of this animal raw or imperfectly cooked. The cysticercus not only infests the pig, but may find lodgment in man himself if the eggs from an adult worm infesting his intestine find their way to his stomach.

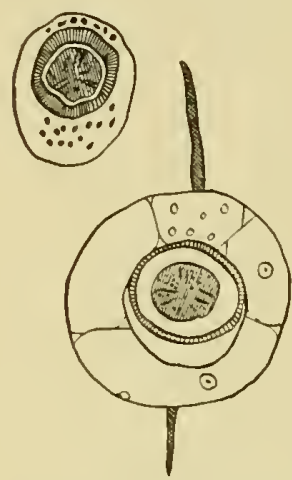

Fig. 110.-Eigg of Tania saginata, with outer shell and flaments; embryo, with embryonal shell, in center. Egg of T. solium (above), showiug embryo with embryonal shell.
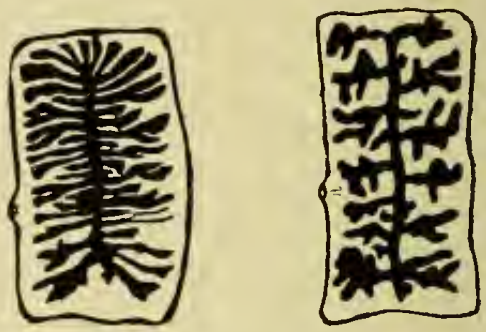

Fig. 111-Mature segnent of Tænia saginata (left) and $T$. solium (right), showing laterally branched uterus.

For this reason, with the added one that the larvie may become established in the central nervous system or ere, Trinia solium constitutes a much more serious infestation than does $T$. saginata.

A simple method for determining to which of these two species the infecting tapeworm belongs consists in elearing up a voicled segment, pressing it between two clean slicks, and observing the form of the gravid uterus as the specimen is held before a strong light. If the median trunk shows numerous dolicate lateral branches on each side (20-35) it indicates that the infection is with Tania saginata. If these branches are less numerous (7-12) and more robust, it may be concluded that the segment belongs to $T$. solium (Fig. 111).

If treatment has resulted in the expulsion of the entire worm, an exact differentiation can be make by examination of the head under low power magnification. The pork tapeworm will show the cephalic armature which in the beef tapeworm is absent.

Occurrence of Pork Measles.-While the larva of the unarmed tapeworm of man live only in cattle, those of the armed tapeworm may 
develop in almost any mammal to which they find access. The hog, however, is the most common host, and, from the point of view of public health, the most important.

As has been noted, the cysticereus of Tania solium (Cysticercus cellulosce) is a more dangerous parasite than that of $T$. saginata, as it may lodge in organs such as the brain or eye with serious consequences. Man can readily become a victim by auto-infection from his own armed tapeworm, the eggs of which may reach his stomach by way of the pyloris, or in being conveyed to the mouth by unclean fingers. By the latter means, moustache twirlers and nail biters are especially exposed.

Fortunately, the United States is favored by the rarity of the pork tapeworm and consequently its cysts. Pig measles is most prevalent in
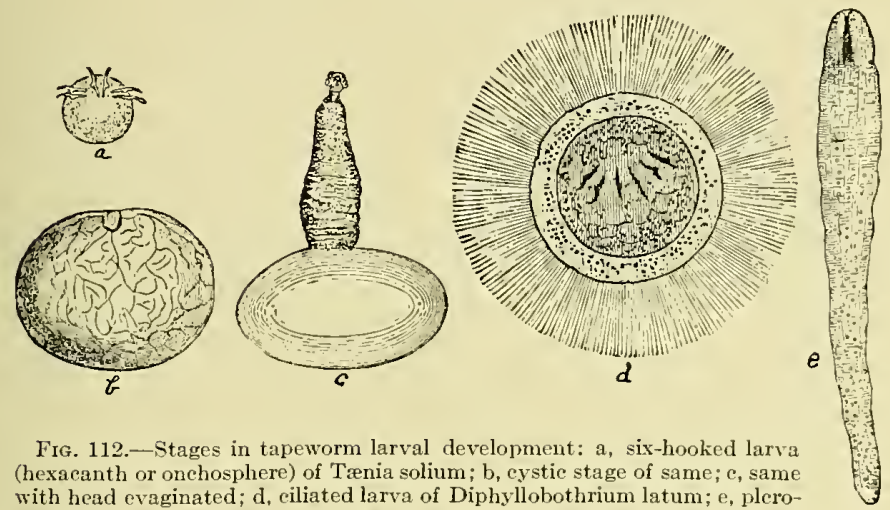

Frg. 112.-Stages in tapeworm larval development: a, six-hooked larva (hexacanth or onchosphere) of Tænia solium; b, cystic stage of same; c, same with head cvaginated; $d$, ciliated larva of Diphyllobothrium latum; e, plerocercoid of same-all cnlarged (after Boas, by Kirkaldy and Pollard, from Leuckart).

districts of foreign countries where bad hygienic conditions prevail: where pigs are kept near dwellings, and their flesh is eaten raw or imperfectly cooked, conjoined with the practice of depositing human excrement in the open or sprearling it upon the fields as fertilizer. In countries where sanitary control is of a more advanced standard the prevalence of the pork tapeworm has been greatly reduced.

Location and Appearance.--The muscles most of ten invaded by the cysts are those of the tongue, neck, and shoulder, then, in order of frequency, the intercostals, abdominal, psoas, the muscles of the thigh, and those of the posterior vertebral region. Organs less often infested are the liver, kidneys, heart, lungs, brain and eve.

While the eysts may be scattered and few in number, they are, on the other hand, sometimes present in certain locations in enormous numbers. Tuchenmeister in one case found one hundred and thirț- 
three in a piece of meat weighing seventecn grammes (260 gr.),--proportionately" eight thousand per kilogramme (2 lbs).

More delicate and transparent than those of beef measles, the cysts are elliptical in form, $615 \mathrm{~mm}$. long by $5-10 \mathrm{~mm}$. broad $(1 / t-5 / 8$ by $7 / 32-3 / 5$ of an inch). The wall enveloping the vesicle is a thin semitransparent connective tissue membrane which, in loose connection with the surrounding tissuc, when removed, leaves a reddened alvcolar pit. Pressure upon the caudal vesicle causes the evagination of the larval head which, on examination by low magnification, is seen to be tetragonal and to possess, in addition to the four suckers, a double crown of twenty-two to thirty hooks, - characters defining it as the larval heal of Tania solium.

At about twenty days from infestation the eyst shows as a delicate vesicle about the size of a pin head, with the rudimentary head indicated by a elourly point, and as yet without envoloping connective tissue membrane. At the age of one hundred and ten days all of the cysts are approxinately of cqual size; the scolex is developed and lies invaginated into the candial bladkler. When located in organs such as the lungs, liver, and splecrl, they often appear as grayish, caseous, calcareous, or purulent nolules somewhat resembling those of tubereulosis. Differentiation cun be made by eareful examination which will reveal the hooks and often the larval heads.

In some ('ases a diangsis can be male while the animal is still living by examination of the inferior surface of the tongue. If cysts are present in that organ, they will be near the base and at the sides of the frænum, where they may he seen as semi-transparent, round or oval vesicles protruding beneath the nucous membrane.

Degeneration. - Degeneration of the cysts may begin at any stage of their development, though those in the visceral organs are the first to molergo these changes. The process loegins with the connective tissue 'nvelop and later involves the scolex. The caseous eysts present a gray color, while those which have become calcified are white. In the oldor degenelated ersts the changes have advanced to transformation into small ralcareous bodies without fluid, constituting the "dry" morasles" as terued by the butcher. In such eases the larve are undoubtrolly dead.

Vitality. The eysticereus of pork measles is slightly more resistant to heat than is that of beef measles. Under post-mortem conditions it survives much longer. Ostritag found living larva in pork forty-two days after it had been slaughtered. Preservation in cold storage as for beef moasles, therefore, will not be effectual. All eysts will be rendered harnless if the pork is cooked until its cut surface presents a uniformly whitish color.

Symptoms. Ordinarily measles of the pig. as in the ox, presents 
no recognizable symptoms, and, unless the cysts can be seen beneath the visible mucous membranes, the condition is only observed postmortem. If the cysticerci become lodged in nerve centers, there may be such manifestations as circling movements, grinding of the teeth, or, possibly, convulsions and opisthotonos; symptoms which can no more than suggest measles as a possible cause.

\section{Measles of the Sheep}

Tania hydatigena, of which Cysticercus tenuicollis of the sheep is the larval form, has been described under Cestodes of the Dog (p. 178).

Occurrence.-Cysticercus tenuicollis has its development under serous membranes of the sheep principally, but it may also.appear in other ruminants and in the pig. Infestation is by food and water bearing ova which have been spread about by dogs harboring the adult worm.

Experiments have shown that the majority of the embryos reach the peritoneal cavity by way of the liver. Ten days after infestation tortuous hemorrhagic trails may be found upon the surface of this organ under the capsule of Glisson. These are produced by the migrations of the parasites, and are in close relation, usually at their extremities, with vesicles $0.5-3.5 \mathrm{~mm}$. in diameter. The head is fully developed about the fortieth day, and the vesicle reaches its full growth at about the seventh month, when it may have a diameter of $1.5-5 \mathrm{~cm}$. (5/8-2 inches), often about the size and form of a pigeon's egg.

These cysts ("water-balls") may be found in varying numbers, their size and location depending upon the age of the infestation. Their seat, especially in young animals, is usually beneath the serous capsule of the liver, though, particularly in old infestations, large bladders may be found in most any part of the peritoneal cavity.

As it relates to food sanitation, this cysticercus of sheep is of little importance. The location and size of the cysts render them easy of elimination from parts used as human food.

As a matter of control, it is obvious, in reference to the life history of the tapeworm, that offal containing such cysts should be inaccessible to dogs.

Symptoms. - Sheep measles can rarely be recognized until after the death of the animal.

Cysticercus ovis.-Muscular cysticercosis in sheep has been shown by investigations within the past few years to be more common than had been suspected. It has been determined by Ransom that the cysticercus is derived from a tapeworm having its adult development in the $\mathrm{log}$, and not to a tapeworm of man as had been supposed.

The following data in regard to this form of measles are quoted from Hall (Bulletin No. 260, U.S. Dept. of Agriculture): 
"Ransom's investigations showed that under careful inspection the percentage of afferted sheep in this country has amounted to two per cent. or more, and that approximately twenty thousand sheep carcasses were retained in 1912 in ahattoirs under Federal inspection on account of sheep measles due to this parasite.

"The bladder worm, Cysticercus ovis, in the meat of sheep is oval and ranges in size from about one-third of a eentimeter (one-eighth of an inch) to almost a entimeter (three-eighths of an inch) in length. Inside of this bladder there is a single tapeworm head, in which respect, as well as in size, this eystieereus differs from a hydatid or a conurus. Numerous eysts, however, may he scattered through the musculature, so that in their numbers there is a compensation, so to speak, for their small size and lack of multiplicity of heads. Inasmuch as the presence of these cysts calls for condemnation of a part or all of the infested carcass, according to the degree of the infestation, and the number of carcasses anounts to twenty thousand a year, this parasite has considerable ceonomic interest for this country, and never more than at the present time when the "high eost of living" is such a vital topic.

"When one of these cysticerei from mutton is ingested by a dog, the tapeworm head passes undigested to the dog's intestine and develops into a fairly large tapeworm, comparahle to the gid tapeworm. Similarly, this tapeworm, Tonia ovis, produces eggs which are passed out with the feres of the $\log$, and which are ingested by sheep as they graze over range or pasture or drink water contaminated by these feers.

"The parasite has been found in Europe, Africa, and New Zealand. It has been found thus far in scven States in this country. It appears to be partieularly prevalent in the West, a faet that is possibly related to earelesness on the part of the western sheepmen as regards disposal of careasses of sheep dying on the range."

Control.- Measures of prevention consist in restraining dogs from access to the flesh of affected sheep unless it is rendered non-infective by eooking. Homeless dogs should he destroyed, and others going about where their excrement may montaminate the food and water of sheep should be kept free from tapeworms as a precuation, not only against this, but other tapeworm larve infesting sheep.

\section{Cenctronis, Gid}

Gid, turnsick, or staggers are popular terms applied to a disease of the brain or spinal cord, caused ly the presence in these locations of the gril parasite. Multiceps multiceps (Comurus cerebralis), the conurus or latral stage of the tapeworm of the dog. Multiceps multiceps, Fig. 113 (p. 179). 
It is observed most often in sheep, more rarely in cattle, goats, and other ruminants. It has been reported in the horse.

Occurrence.-Gid is a common disease in Europe where it has been known for many years. The parasite has been observed in this country at least as early as 1901, though symptoms which were undoubtedly those of gid were authentically reported from our far western flocks during at least ten years preceding. In 1909 Taylor and Boynton found an outbreak in a flock of sheep about forty miles from Ithaca, New York. Necropsies in these cases revealed the presence of the gid parasites from which, by feeding to dogs, they claim to have raised the adult tapeworm. This is the first authentic instance of gid in the Eastern United States, and the first account of it was given by Dr. James I Law, of Cornell University, in a paper read before the New York State Veterinary Medical Society in the same year.

In view of the large number of sheep and dogs which have been brought to the United States from countries where gid prevails, it is somewhat remarkable that the disease has not been more often observed here. It is probable that numerous cases have occurred which have passed unrecognized and consequently unrecorded, the symptoms being ascribed to other causes. It is certain that it now has a foothold in this country, in view of which fact,

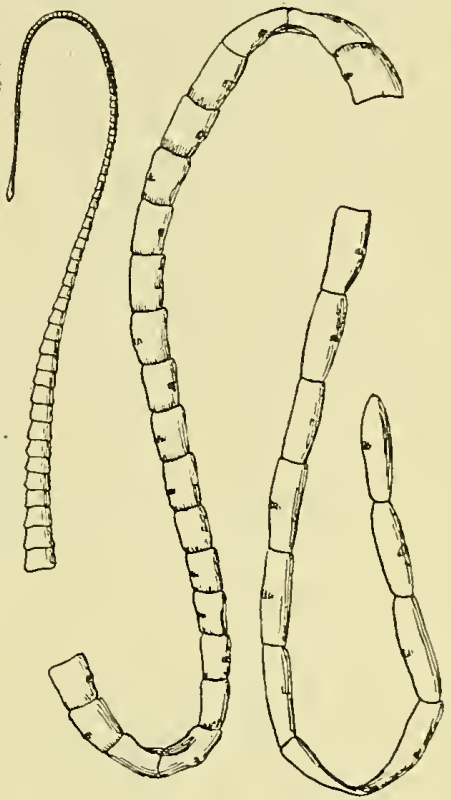

Frg. 113.-Portions of adult gid tapeworm (Multiceps multiceps), -natural size (after Ransom, from Railliet. Bull. No. 66, Bureau An. Ind., U. S. Dept. of Agr.).

and the further one that in other countries it is one of the most destructive parasitic diseases of sheep, veterinarians and sheep raisers should be on the lookout for it and take proper preventive precautions.

The Cœnurus.-The completely developed cœnurus (Figs. 114 and 116) consists of a membraneous vesicle which may vary in size from that of a hazelnut to that of a hen's egg. When located on the brain it tends to assume a spherical form; when on the cord, which is more rare, it becomes adaptively elongated. The wall is thin, translucent, and distended by a colorless fluid. On the surface of the resicle there are little 
white, irregularly grouped spots, each representing an invaginated larval tapeworm head. These vary in degree of development and in number from four hundred to five hundred, and herein lies an essential difference between conurus and cysticercus, the latter containing but one

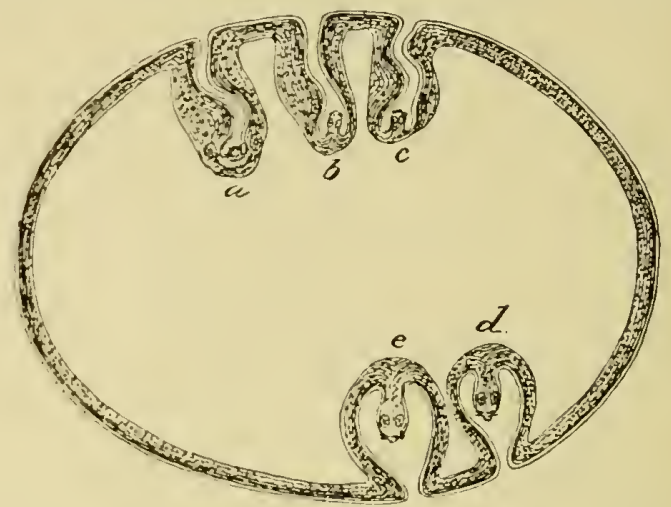

F1G. 114.-Diagrammatic section of Conurus: a, normal disposition of seolex; b, $c, d, e$, diagrammatic representation to show the liomology between cysticereus and conurus (after Ransom, from Railliet, Bull. No. 66, Bureau An. Ind., U. S. Dept. Agr.).

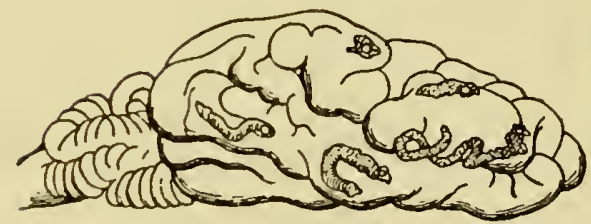

Fig. 115.- I3rain of lamb, showing the furrows proclueed by the migration of the young gid bladderworms, iaken at a time immediately following the period of invasion-i. e., from fourteen to thirty-eight days after infestation, - natural size (after Ransom, from Leuckart, Bull. No. 66, IBureau An. Ind., U. S. Dept. Agr.).

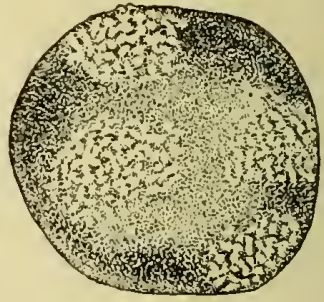

F16. 116.-Gid bladderworm showing immature tapeworm heads,-natural size (after Ransom, from Railliet, Bull. No. 66, Bureau An. Ind., U. S. Dept. Agr.).

head. In some cases the heads may be found evaginated to the surface of the resicle (Davaine), when the cerebral disturbance by pressure is contributed to by the direct irritation from the hooklets.

Development.-Animals susceptible to gid become infested by eggs of the tapeworm Multiceps multiceps which is harbored by dogs. The eggs and gravid segments, spread about as they are, will, in the presence 
of moisture and favorable temperature, retain their power to infect for several weeks. In dry locations and under the influence of a hot sun the period of their vitality is reduced, probably to a few days at most. Eggs, through the mediation of food and water, reaching the digestive juices of sheep and cattle have their shells dissolved, setting free the contained embryos which, on reaching the intestine, penetrate its walls by means of their hooklets. From here it is probable that they are passively carried to other parts of the body by the blood and lymph currents. With rare exception, only those embryos which reach the brain or spinal cord continue their development.

The central nervous system is reached by the embryos about the eighth day after the occurrence of infection, upon the arrival at which location they lose their hooklets and transform into small cysts. In the course of their burrowings along the surface of the brain they leave small sinuous tracks which may be found three to five weeks after infection, often marked by a yellowish purulent material (Fig. 115). At the termination of these furrows the young bladderworms become stationary, and their development proceeds.

In five to six weeks the cysts are about $1 \mathrm{~cm}$. (3/8 of an inch) in diameter and the heads have begun to appear, these attaining their full development in ten to thirteen weeks. The cysts continue to grow until they have reached a diameter of from 3 to $5 \mathrm{~cm}$. (13/16 to 2 inches), during which time new heads are in process of formation (Fig. 116). Heads in various stages of development, therefore, may be found in the same vesicle.

\section{Tabular Review of Life History of Multiceps Multiceps}

Adult Tapeworm in intestine of dog.

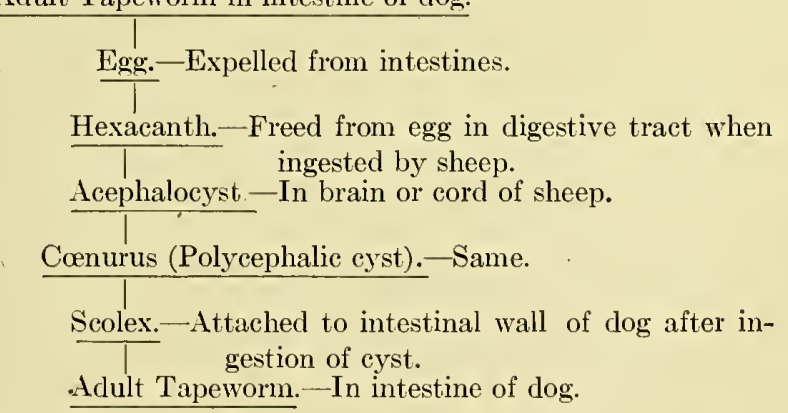

Post-mortem Appearance.-In chronic cases there are usually one or more cysts, rarely as many as six, though cases are recorded in which 
there were more than twice this number: The lesions produced will differ according to the development attained by the parasites at the time of the examination. Primarily the lesions are disseminated, and the small cysts may be found at various places upon the convex surface of the brain, surrounded by a yellowish exudate, granules, and calcareous particles, while, in the vicinity, there may be a small hemorrlagic area. In cases which have presented the characteristic symptoms of turnsickness, or girl properly so-called, but one large vesicle of alvancerl development is ordinarily found (Fig. 116). Such cysts are usually located upon the surface of the cerebral hemisphere, where, by their pressure, they produce an anxmia and softening of the cortical substance. In old cases with large cysts situated upon the hrain's surface the constant compression upon the roof of the cranium may, ly alsorption, bring ahout thinning of the bone to such a degree that it will yield to evon comparatively slight pressure of the fingers.

Wxeptionally, the conurus may be found free in an excess of fluid in a lateral vontricle, and, again rarely; exploration of the vertebral cant will reval a 'yst in the lumbar or cervical region, or it may be at the modulla oblongata. Such cysts are much elongated, and usually three is but one. At the cyst's location the medullary substance is atrophied and softened. Such museles as may be secondarily involved show the alterations of atrophy and cachexia.

Symptoms.- As may be inferred from the foregoing, the symptoms presented in conurosis will be conditional upon the age of the infection and the size attained hy the ersts, and also upon their location, the latter factor furnishing the two forms of the affection,--the cephalic, when located in the brain, and the medullary if in the vertebral canal.

If the parasites aro few in number, there will be no symptoms during the enrly stages, or they may be slight and unnoticed. If there is a heary invasion the corobal disturbances caused by the migrations of the parasites may he manifested as statel below. According to Moller, howerer, these primary simptoms are not observed in four-fifths of tlo cases.

Harly in the infostation there is dullness, somnolence, inappetence, and usually a rapill loss of flesh. Tisual disturbance is soon noticed, the animal colliding with objects which it is apparently unable to see. lixamination of the eycs at this time will show a congestion of the sclera; later there is strabismus with either convergence or divergence, and the pupils may be unequally dilated. There are concomitant troubles of motility, and, as the rlisease progresses, the animal frequently falls down or nua assume a lecumbent position for the entire day. If it becomes unable to rise, it is probable that death will soon follow:

When these early symptoms occur, they generally first appear ten to twenty days aftre infection and persist for a variable period of two 
to ten days. They then subside, and, during a following latent period of four to six months, it is only by close observation that anything abnormal about the animal can be detected. The ocular disturbances already referred to then appear; the head is held in a peculiar position, and the animal turns in circles or it may stagger and stumble about, repeatedly falling. The movements are made in an impulsive manner, with feet lifted high, and the turning may be to the right or to the left, usually toward the side on which the brain is compressed. Other movements than turning may be exhibited, and, in fact, their character will depend upon the part of the brain affected by the cyst.

These symptoms are not continuous, appearing several times during the day with intervals of comparative repose. In three to six weeks from their onset the animal passes into a state of complete paralysis and dies from exhaustion, or it may be in convulsions.

Such characteristic phenomena of gid are of the final stage, and are due to the pressure of the fully developed cœnurus upon the brain and, in part also, to direct irritation from the hooklets of the partly evaginated larval tapeworm heads. It is only at this stage that the turning movements appear, therefore the disease does not truly merit the name of gid or turnsickness until these manifestations are reached.

In gid of the spinal cord the parasite is usually located in the lumbar region. The chief symptom is a gradually increasing weakness and paralysis of the hind quarters (hydatic paraplegia). The bladder and rectum become involved and the animal becomes progressively weaker and emaciated. Death occurs in general debility and exhaustion after a course of one to three months.

The symptoms of gid in other animals are of the same general character as those in sheep.

Control.- Reviewing the knowledge possessed as to the etiology of gid, the measures to be followed for its eradication are suggested. Chance infection of dogs by the tapeworm should be removed by burning the heads harboring the cysts, or by cooking the affected brains if they are to be fed to these animals. Dogs kept in the vicinity of animals susceptible to gid should be given tæniafuge treatment every three months (p. 186). During the operation of this treatment they should be confined and the expelled worms, fragments, and feces collected and burned or deeply buried.

Gid is a further contribution to the accumulating reasons why uncared for and unnecessary dogs-numerically limitless in most communities - should be destroyed.

Treatment.--On account of the inaccessible location of the parasites. treatment, except by surgical means, is useless. The operative measure consists in trephining the cranial cavity and remoring the conurus, but this can only be advised as practical in the case of animals haring 
an especial value. Cold packs upon the head or continuous irrigation, accompanied by purgatives, have been recommended for the acute stage, but such treatment can be no more than palliative, and is scarcely practical unless under exceptional conditions.

In general, it is better, from considerations of economy, to slaughter animals upon the first evidence of gid.

\section{Echisococcosis}

Hydatid Disease.

Hydatid disease is caused by the presence of Echinococcus granulosus (E. polymorphus, E. multilocularis, etc.) or so-called hydatid, the eystic stage of the tapeworn of the dog,-Echinococcus granulosus (Tania echinococcus), elsewhere referred to under the cestodes of that animal (p. 181). It occurs in man and all of the domestic mammals, the hydatick usually located in the organs of the abdominal or thoracic cavity, most often the liver, though not infrequently the lungs, spleen, serous membranes, and other organs, several of which may be affected in the same animal. The clisease is as cosmopolitan as dogs and their parasites, therefore it is of world-wide prevalence.

The Echinococcus (Fig. 117). While the echinococeus is the largest of the tapeworn cysts, the dog tapeworm, of which it is the larral form, is but $5 \mathrm{~mm}$. (3/16 of an inch), or thereabouts, in length, and consists of a hearl and three segments. When uninfluencerl br pressure, the echinocoecus cyst is more or less spherical in shape and presents a complex structure, the parts of which may be set forth for study as follows:

1. An external cuticular membrane (hydatic membrane).

2. An internal germinal membrane.

3. The fhirl which distends the resicle.

4. The proligerous resicles, which contain the larval tapeworm heads.

5. The dinughter vesicles.

Furrounting the whole is a capsule formed from the connective tissue of the orym in which the structure is lodged.

1. The rutirular mombrane limits the echinococeus externally. It is whitish in color, concentrically laminated in structure, and in large vesicles may attain a thickness of $1 \mathrm{~mm}$.

2. The germinal membrane is much thinner than the eutieular, usually not excepding $20-25$ mierons in thickness. On its internal surface there appear groups of small papille, representing the beginning development of the proligerous resicies.

3. The hyrlatic fluid is colorless or yellowish and in reaction is neutral or slightly acirl. It may contain a number of substanees, mostly derived by endosmosis from the blood and lymph of the organ invaded.

4. The proligerous vecicles appear on the internal surface of the 
germinal membrane when the mother vesicle has developed to a sufficient size. At first papillary, each has a cavity that gradually enlarges, and the vesicles thus formed have an attachment to the germinal membrane by a short pedicle. Within each there develops a variable number-usually five to twenty or more - of little oval bodies. These are

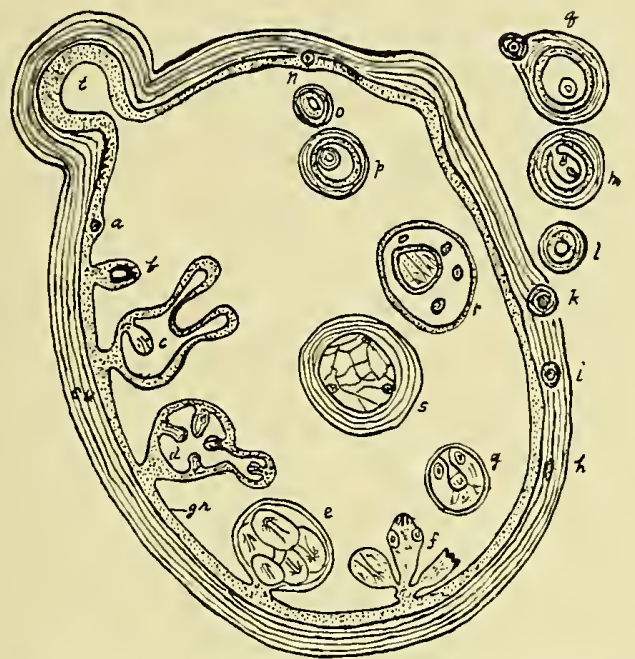

FIG. 117.-Diagram of Echinococeus hydatid: cu, thick cuticular membrane; gr, germinal membrane; a. b., development of proligerous vesicle; $c$, development of the heads according to Leuckart; d, development of heads according to Moniez; e, fully developed brood capsule with heads; f, brood capsule has ruptured and the heads hang into the lumen of the hydatid; $g$, liberated head floating in the hydatid; h, i, $k, l, m$, formation of secondary exogenous daughter cyst; $n, 0, p$, formation of endogenous cyst, after Kuhn and Davaine; q, daughter cyst with one endogenous and one exogenous grand-daughter eyst; r. s., formation of cndogenous daughter eysts, after Naunyn and Leuckart; r, at expense of head; s, from brood capsule; $t$, constricted portion of the mother cyst (copied from Osborn's "Economic Zoölogy," after R. Blanchard; Bureau An. Ind., U. S. Dept. Agr.)

the larval tapeworm heads. When completely formed the heads measure slightly more than $0.1 \mathrm{~mm}$. and show the suckers and double crown of hooks.

5. Daughter or secondary vesicles smilar in character to the mother vesicle have origin in the hydatic membrane which they distend and finally rupture, falling into or outside of the mother vesicle. In the first case they are termed endogenous vesicles, in the second exogenous 
resicles. The exogenous resicles are capable of implantation upon organs sonewliat remote from the primary vesicle. This oceurs more commonly in the pig and ruminants than in man.

The daughter vesieles may, in the same manner, give off granddaughter vesichs which, like the parent vesieles, may be endogenous or exogenous.

All of these vesicles develop proligerous vesicles and consequently the larvai tapewom heads, or they may remain sterile, in which case they are referred to as acephalocysts.

It will be noted from the foregoing that one onchosphere may rlevelop hundrefls of tapeworn heads.

The echinocoecus is usually considered as one species, though there is a form which has received the name of Echinococcus multilocularis (E. alveolaris), thought to be due to a tapeworm iffering slightly from E. granulosus. Its main distinguishing character is the size of the resicles, which floes not exeed that of the pea. They have a honeycomb arrangement, and are filled with a gelatinous material, the majority of the crsts remaining sterile. The mass of resieles may grow to the size of a child's head, and constitutes a rery fatal form of echinocoecosis. It liss been found in the ox and pig, but more frequently in man.

Development.- Embryos funding their way to the intestine with fook or water that has been contaminated with egg-eontaining excrement of dogs are probahly earrief to the liver by the portal system. Four weeks after infecting pigs, Lenekart found small white nodules about 1 mm. in liameter, each witl a eapsule derived from the hepatic connective tissue, and containing within it the globular eehinococcus. At about fire months the cysts were the size of a hazelnut, and cach containel a thick-walled whitish-colored vesicle,-the mother vesiele.

The development of the echinoeoceus is slow. It nuy remain simple and its growth he limited to increase in volume and thickening of the cuticular nembrane, in which case it may reach a diameter of $15 \mathrm{~cm}$. (6 inches). (innerally its size does not exeerl that of an orange, and its growth is attained lic the formation of secondary vesieles. Where these pass to the insidr of the mother vesicle this beeomes dilated in an irregular manner, influenced sonewhat by the eompression of the adjacent organs of the lost (Fig. 117).

As regarts the formation of the raughter vesieles, the proeess has usually been described as a normal one following the complete development of the lỵelatid. Déré, in a paper upon this subject (1917), states that every multivesicular eyst is one which has had its vitality menaced, and that the endogenous resicles are the result of a defense reaction. The simple cyst with its brood eapsules, accorching to this authority, represents the normal hyrdatid. 
Tabular Review of Life History of Echinococcus Granulosus Adult Tapeworm.- In intestine of dog.

Egg.--Expelled from intestines.

Embryo.-Released from egg in digestive tract after ingestion by pig, ruminant, or other mammal.

Mother Vesicle (Hydatid). - In liver or other organ of $\frac{\text { Daughter Vessicles }}{\text { Scoleces.-Attached to intestinal wall of dog }} \mid \begin{aligned} & \text { after ingestion of brood capsules con- } \\ & \text { taining larval heads. }\end{aligned}$ Adult Tapeworms.- In intestine of dog.

Regarding the longevity of the hydatids, such information as is possessed is furnished mainly by cases of hydatid disease occurring in man. A case is recorded of the persistence of an echinococcus cyst in a horse for seven years. Usually when found in lower animals it is in those slaughtered for food, and in most such cases the animals are not old enough for the hydatids to have reached their full development. It is probably for this reason that the disease is clinically unobserved or is much less serious in these animals than in man where the hydatid development remains uninterrupted.

The human evidence seems to indicate that the longevity of the cyst may be only limited by that of its host, for a case is recorded where it had existed for thirty-five years and another where the swelling had gradually spread over the face for forty-three years, and when operated upon had attained the size of a child's head.

Post-mortem Appearance.-Hepatic echinococcosis is accompanied by considerable alteration. When the cyst is large the liver becomes hypertrophied and its weight may be increased as much as ten times that of normal. The increase in volume may compress neighboring organs, hindering their function and displacing them. The diaphragm especially is crowded and pressed forward upon the lungs. The surface of the liver has protruding elevations of various size and number, and Glisson's capsule is noticeably thickened, perhaps forming adhesions with contiguous organs. Section of the organ reveals cavities of unequal size from which the hydatic liquid with contained vesicles flows out. The connective tissue capsules of the cysts will vary in thickness from 3 to $10 \mathrm{~mm}$. (1/16 to $3 / 8$ of an inch). These capsules are structurally 
somewhat eompact, and are generally little adherent to the wall of the hydatid.

Old hydatids may become considerably modified or completely destroyed. In such cases the walls are much thickened and show degenerative changes. The fluid diminishes and disappears with the contraction of the cavity, the degenerative material in the walls becomes more dense, there is calcareous infiltration, and, finally, the lydatid may be transformed into a. calcareous mass.

Symptoms. - The symptoms of hepatic echinococeosis in lower animals arc, as a rule, too vague for recognition of the specific affection;

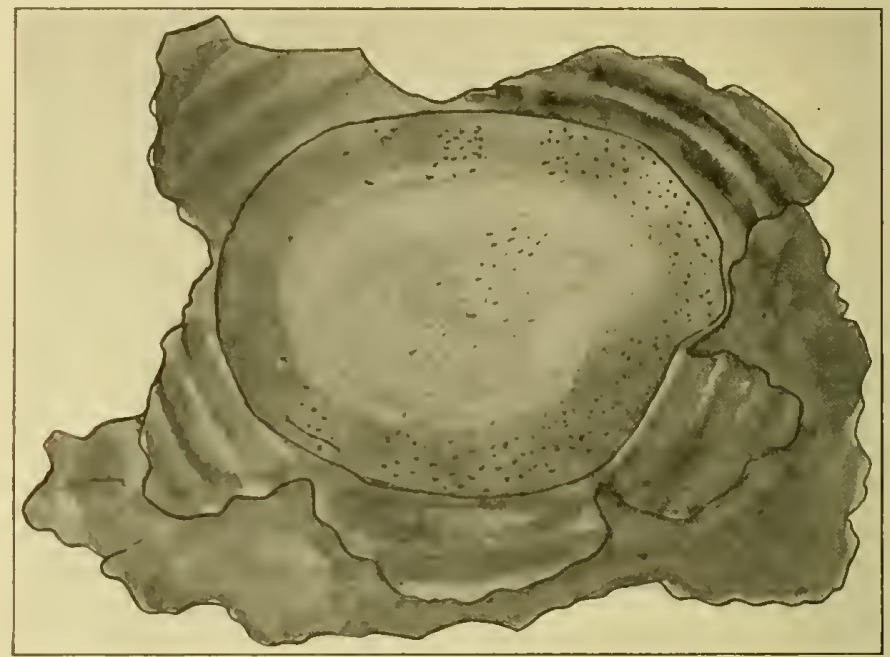

Fıg. 118.- Echinococcus gramulosus, with fibrous sac laid back, showing hydatid with brood capsules (after Leuckart).

it usually remains for post-mortem examination to establish the diagnosis. Pulmonary rehinocoecosis is generally accompanied by the hepatic form, and may cxhibit respiratory disturbances, as accelerated respiration and dyspnoea, - smptoms whieh may be entributed to by pressure of the enlarged liver upon the cliaphragm. In the region invaded by the hydaticl the vesieular murmur is lessened or wanting, while in parts nearby it is inereased. Percussion will generally definitely establish its location.

Hydatid disease rarely progresses to a fatal termination in lower animals,

Control.-As the tapeworm from which the echinococcus is.derived 
is harbored by the dog, rarely the cat, infection of man and domestic animals is by the dissemination of the eggs of this tapeworm with the excrement of its hosts. It follows that all hydatic viscera in slaughtering establishments or elsewhere should at once be destroyed by burning, thus preventing the larval tapeworm heads from reaching the intestines of dogs and cats. Where the disease has appeared it is a good precautionary measure, though often impractical, to administer tæniafuge treatment (p. 186) at repeated intervals to all dogs in the vicinity. During the treatment the animals should be confined where their fecal material can be carefully collected and burned. 


\section{CHIPTER XVIII}

\section{PHYLUM III. COELHELMINTHES}

\section{The FHooth AND SEguexted Rotrdworms}

The Collhelminthes are distinguished from all of the worms thus far considered by the presence of a colom, or body cavity located between the outer borly wall and the intestine. With the exception of the thornheaded worms, the digestive tract is complete, and there may or may not be a closed blood eirculation. Excretory vessels connect the cavity of the body with the outside. The body muscles are "epithelial muscle rells" developed from the outer epithelial wall of the colom. Subgroups exhibit distinct differences in the character of the colom. In the Ammelida, to which the earthworms belong, it is segmented, the segments (somites) corresponding to the annulations or ringing of the borly wall. In the Nemathelninthes, which includes most of the parasitic species, there is no segmentation of the body cavity or anmulation of the borly wall. In the Hirudinea, the ammulated group which contains the leeches, the colom is but slightly developed, and usually the ammulations outnumber the somites.

The phylum Corlhelminthes has the two classes named below for discussion in this work, the first containing all of the endoparasitic worms which remain to be considered, while of the second, only the leeches are of direct parasitic interest.

Class I. Nemathelminthes.-Body without external or internal segmentation.

Class II. Annelicla.-Borly with external and internal segmentation.

\section{Class I. Nemathelminthes}

Coelhelminthes (p. 216).-This group contains the roundworms, or so-called threadworms, though not all are filiform. There are both free and parasitic forms, examples of the former living under stones and in other moist places. The parasitic species are by far the more numerous and important.

The body is elongated, and, in being cylindrical, differs from that of the Platyhelminthes which is flat, while the absence of anmulations and segmentation distinguishes it from that of the Annelida.

The class inchudes two parasitic orders. The first contains the typical 
representatives of the class and, with the exception of the thorn-headed worms, all of the species of medical interest.

Order I. Nematoda.-Alimentary canal present.

Order II. Acanthocephala.-Thorn-headed. Alimentary canal absent.

\section{Order I. Nematoda}

Nemathelminthes (p. 216).-The order Nematoda includes numerous species having a wide distribution as parasites of animals and plants. The outer surface of the body is covered by a tough chitinous cuticle which is secreted by an underlying layer corresponding to the epithelium and derma. The cuticular surface may be plain, striated, or more or less mottled. Transverse section of the body wall shows four thickeningstwo median and two lateral-corresponding to the dorsal, ventral, and lateral lines which are disposed longitudinally. Within the lateral thickenings are contained the two excretory vessels which, in the vicinity of the head, unite by a transverse commissure reaching the exterior on the ventral surface. The muscles are a layer of

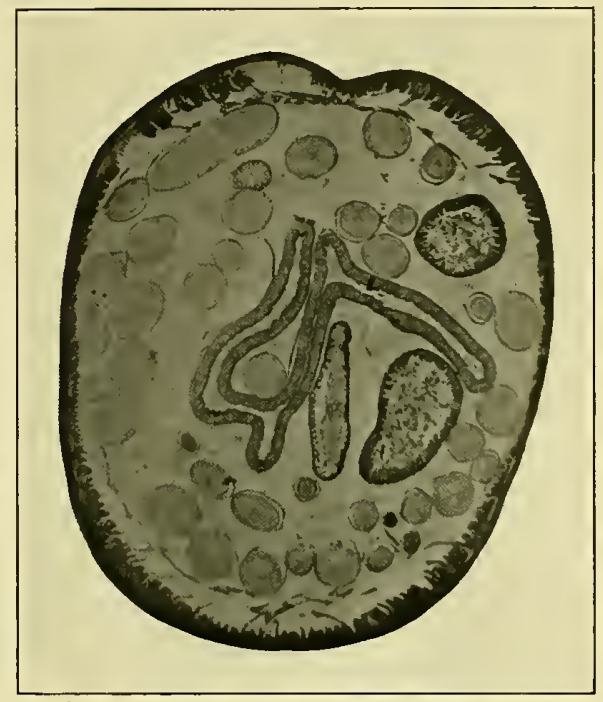

Frg. 119.-Transection of body of Ascaris equi (female), showing cuticular wall, muscle cells and protoplasmic processes extending into colom, transversely cut portions of ovary and uterus, and intestinal canal in center (from microphotograph by Hoedt). vesicular cells derived from the epithelium of the outer cœlomic wall. They are divided by the lateral and median lines into four fields, and so project into the colom as to occupy considerable of its space (Fig. 119).

The digestive system is simple and complete, beginning with the antcrior terminal mouth and ending in an anus which is ventral and close to the caudal extremity of the body. A muscular esophagus succeeds the mouth, soon expanding to form a bulbous sucking organ lined throughout with a cuticular layer. From this point to the 
anus the alimentary canal is usually a uniform tube with little or no flexion.

The nervous system consists of a nerve ring surrounding the esophagus, and of the nerves given off from this ring passing forward and back, the largest of which are in the dorsal and ventral lines. Along the course of these nerves there are ganglionic cells, but there is no massing to form true ganglia as oceurs in the Annelida.

The sexus are usually separate, hermaphroditic forms oceurring among frop-living species. In general, the fcmales attain a distinctly

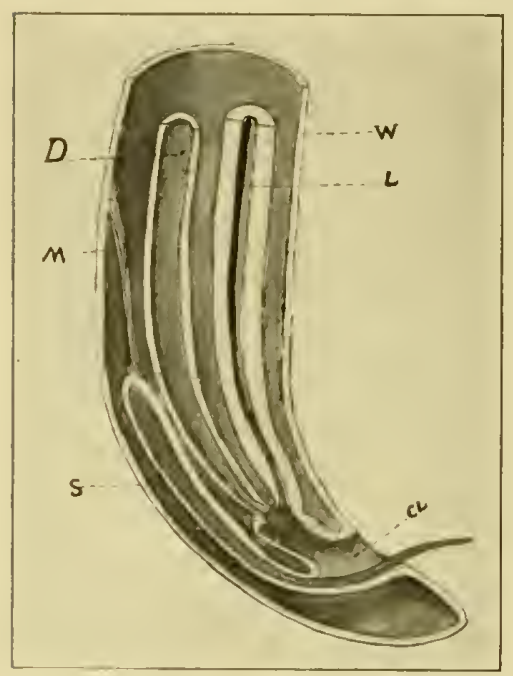

Fis. 120,-Posteriole extremity of male nematode: diagrammatic longitudiual section: cl, cloaca: d, intestium: II, retractor muscle of spicule; s, sheath of spicule: $w$, hocly-wall (after J3oas, by Kirkaldy and l'ollard). greater length and thickness of the borly than do the males, and in other respects thcy can easily be distinguished. The males ale usually provided with chitinous copulatory organs known as spicules. These are curved, spine-like structures which lie in a sheath close to the anus, and they can be protruded or retracterl through the cloacal opening (Fig. 120). They are usually two in number, but there may be but one. The character of the spicules often serves as a guide in the establishment of relationships of eertain groups. Surrounding the spicules there is, in some forms, a membraneous expansion which is referred to as the caudal lursa or pouch. This structure is best dereloped in the Strongylidxe, where its varied characteristies furnish an aid in the recognition of species. The bursa is a clasping organ userl in copulation, while the spicules serve to direct the course of the semen. In the female there is a special genital opening,-the rulva, located on the ventral anterior half of the body, or it may be toward the anus, it: position varying according to species. The cylindrical body is usually more or less distended with eggs, and frequently the egg-packed uteri can be distinctly seen uncler low magnification and transmitted light.

The internal reproductive systems of the male and female are much alike. In hoth they are long tubular organs, eoiled forward and back, 
and lying loosely in the cœlomic cavity. In the male this genital tract is always single, the finer part of the tube constituting the testis, the heavier remaining portion serving as a seminal vesicle and terminating in the duct. The ovaries and uteri are likewise continuous structures, the former being constituted by the finer portions, while the uteri are usually much distended (Fig. 119). In certain forms there is but one genital tube in the female, but in most all there are two which unite close to the external opening to form the vagina. There is no distinct vitellarium as in the flatworms, the ovary assuming the function of this gland.

The eggs are usually globular or ovoid in shape; as there is copulation, they are fertilized in the uterus. Following this the development may or may not take place while the eggs are retained.

As to the terms oviparous and ovoviviparous, frequently used in summarizing the characteristics of parasitic groups, it may be well to direct attention here to their correct application.

The term oviparous is properly applied to the oviposition of eggs which undergo incubation after they have been oviposited, or to the oviposition of eggs which have been incubated within the genital cavity of the female and at the time they are oviposited contain embryos more or less developed.

The word ovoviviparous is commonly used in reference to the oviposition of eggs containing embryos developed and ready to emerge at the time the eggs are extruded, as might be in the last-stated case. It is more correctly applied where the embryos, having been developed, escape from the eggs while these are still within the body of the female.

In other words, the escape of the embryos from the eggs occurs outside of the body of the parent in the oviparous method, within the parent body in the ovoviviparous.

The term viviparous, often applied in biology for ovoviviparous, has reference to the typical mammalian method of giving birth, where the egg is not concerned in this process, and there is consequently no hatching.

\section{Parasitisa of the Nematodes in General}

In most of the nematode parasites there is a post-embryonic free existence, the infection of the host being direct and necessary to the parasite's sexual maturity. A notable exception is furnished by Trichinella, where there is no period of free life, the transfer from host to host being accomplished by the ingestion of food containing the encrsted larvæ.

The degree of injury to their hosts by the nematodes varies considerably and is frequently not characteristic. In general, it may be said to depend upon the number of the parasites present, but the seriousness 
of their cffect does not depend upon this wholly. A relatively light invasion with forms which elaborate toxins possessing a high degree of toxicity may have a more deleterious influence upon the health of the animal than a heavier infestation with woms from which the eliminations are less toxic. Again independent of numbers, adult worms or their larva can, by their migrations, set up in their unusual locations serious inflammatory and degenerative changes which may be of an infective character due to the bacteria which they transport.

Intestinal worms which attach to the mucosa are far more capable of producing serious effects than those which live free in the intestinal contents. The former live upon the tissues of their host and cause at their attachment a wound through which infection may readily enter, while the latter obtain their nourishment from the partly digested alinentary material and do not directly lacerate the mucosa.

Location is a main pathogenic factor. This may be acciclental by active or passive migration, as in the case of adult or larval filaria, which seen capable of wandering to most any part of the bocky, or it may be specific, certain nematodes nomally infesting only the intestines, others the respiratory tract, while some occupy the blood vascular sytem in their larval state or both as larve and adults. Again, Trichinclla spiralis causes its most serious disturbance during the migration of the embryos through the musculature of its host. In general, it may be said that nematode invasion of the intestines is less serious than that of the respirat ory tract. The injurious effects from reminous parasitism of the blood are usually due to injury to the vascular walls, or, if the worns are numcrous and massed, to interference with the blood flow. Following upon this there may be the production of a thrombus and formation of emboli with the subsequent development of aneurism. While parasites in the blood in any case constitute a serious infection, the greater number of sperific conditions due to such parasitism are caused by blood-invading Protozoa.

The specific limitations as to host of the parasitic worms is probably much infucheed by the character of the nutriment with which they are supplied in each particular case. Certain hosts having no more than a class relationship may harbor intestinal worms of the same species, but are more likely to to so if there is a measure of similarity in the character of the hosts' almentation. This is exemplified in the distinctly ommivorous animals, man and the pig, each furnishing hostage for the intestinal worms Ascaris lumbricoides (A. suis) and Gigantorhynchus hirudinaceus, while, again, the carnivorous dog and cat both harbor Belascaris marginata and Ankylostoma canina.

Opportunity is also a factor. Animals of similar diet are alike exposed to infection by foor specific for or most likely to be contaminated with larve or eggs of certain species of parasites. Such parasitism as the 
invasion of the intestines of man by the thorn-headed worm of the pig (Gigantorhynchus hirudinaceus) is regarded as stray or accidental, but if the grub of the May beetle, the larval host of this worm, constituted a choice morsel of diet for man as it does for the pig, it is probable that the thorn-headed worm would much more frequently inhabit man's intestines.

Adaptive nodifications from a free to a parasitic life, and adaptations of the parasite to differing host environments, or to new locations taken up in the body of the same host, are best exemplified in the Protozoa. In the more complexly organized worms the faculty of adaptation is possessed in less degree; though undoubtedly the parasitic forms have without exception passed through at least the first of the gradations mentioned. The adult nematodes infesting the respiratory tract, as Dictyocaulus filaria of sheep, and those infesting the blood vascular system, as Dirofilaria immitis of the dog, have probably reached these regions from a primary parasitism in a less obscure part of the body, the adaptivity having become sufficiently fixed that the conditions supplied by the location later acquired are now specifically essential to their sexual development and reproduction.

Treatment in General.-Treatment in nematode helminthiasis has in view primarily the expulsion of the worms, and secondarily the building up of the general health of the animal. Anthelmintics act by destroying or in some way so affecting the worms that they are easily expelled from the body. An agent capable of killing the parasites may have a like effect upon the host if used without due precaution; in any event it is likely to be too drastic and cause an acute disturbance more serious than the subacute one which it is sought to remedy. In the casc of intestinal worms, remedics which reduce them to a sufficiently passive state that they may be readily swept out by the action of a purgative are to be preferred; and here the effect of the vermifuge upon the host, as compared with that of a true vermicide, is one of degree, and the tolerance of the patient is to be taken into consideration.

Essentially the success of vermifuge treatment will be influence $\mathrm{by}$ the location of the worms; only those in tubular organs in communication with the outside can be reached by such medication, while its action will be hanpered in the case of those which burrow into and attach upon the mucous liuing.

It has been said that it may be taken as an axiom in helminthology that each worm in the body develops from an egg or larva which has entered from without. Worms do not go on multiplying indefinitely with the production of new adult generations in the same host. The degree of the infestation, thereforc, depends primarily upon the degree of contamination of food or water taken in by the animal, and secondarily 
upon the susceptibility and farorable hostage offered by the individua? to the parasite.

It follows that preventive measures should be based upon the life history of the speeies to whieh sueh measures are applied. Where this is known and intelligently taken advantage of, the problem of the eradication of the parasites beeomes mueh easier of solution than it otherwise woukd be. For the same reason, more detailed referenee to control is reserved for application to particular cases in the pages to follow.

The nematorle parasites are to be ensidered under seven families having marked differenees as to parasitie habit and also as to degree of injury whieh they eause in their hosts. These are as follows:

Family I. Asearidx.

Family II. Oxyuridar.

Family III. Heterakidke.

Family IV. Filariidre.

Family V. Strongylidx.

Family VI. Iustrongylidae.

Family VII. Trichinellidæ.

Classificatuin of Parasites of the Phylum Celmelainthes

Phylum III. Coelhelminthes. P. 216.

Class A. Nemathelminthes. Smooth-bodied roundworms. P. 216.

Order 1. Nomatoda, P. 217.

Family (a) Asearide. P. 229.

(ienus and Speeies:

Ascaris equi. Host, equines. P. 233.

Belasearis marginata. Host, dog, cat. P. 237.

Toxasearis limbata. Host, dog. P. 238.

Asearis hunbricoides. Hosts, man, hog, sheep. P. 239.

A. vitulormu. Host, eattle. P. 241.

Family (h) Oxỵuride. Srat worns. P. 235.

Genus and species:

Oxyuris equi. Host, equines. P. 235.

Family (e) Heterakide. P. 242.

(ienus and Species:

Heterakis perspieillum. Host, poultry. P. 242.

H. vesieularis. Host, poultry. P. 242.

Family (d) Filariilce. P. 244.

Genus ancl speeic's:

Sotaria lathiato-papillosa. Host, equines. P. 244.

Hahronema megastoma. Host, equines. P. 245.

H. microstona. Host, equines. P. 246. 
Gongylonema scutata. Hosts, sheep, cattle. P. 247.

Filaria labiato-papillosa. Hosts, cattle, deer. P. 248.

Dirofilaria immitis. Host, dog. P. 248.

Spiroptera sanguinolenta. Host, dog. P. 250.

Arduenna stiongylina. Host; hog. P. 251.

Physocephalus sexalatus. Host, hog. P. 252.

Dispharagus spiralis. Host, poultry. P. 254.

D. hamulosus. Host, poultry. P. 254.

D. nasutus. Host, poultry. P. 254.

Tetrameres fissispina. Host, poultry. P. 254.

Family (e) Strongylidæ. P. 255.

Genus and Species:

Stephanurus dentatus. Host, hog. P. 295.

Subfamily (a) Metastrongylinæ Worms of the respiratory tract. P. 256.

Genus and Species:

Dictyocaulus filaria. Hosts, sheep, goat. P. 256.

Synthetocaulus rufescens. Hosts, sheep, goat. P. 257.

S. capillaris. Hosts, sheep, goat. P. 258.

Dictyocaulus viviparous. Host, cattle. P. 259.

Metastrongylus apri. Host, pig. P. 260.

M. brevivaginatus. Host, pig. P. 260.

Dictyocaulus arnfieldi. Host, equines. P. 261.

Hæmostrongylus vasorum. Host, dog. P. 261.

Synthetocaulus abstrusus. Host, cat: P. 262.

Subfamily (b) Trichostrongylinæ. Worms of the stomach and intestine. P. 268.

Genus and Species:

Hæmonchus contortus. Hosts, sheep, goat, cattle. P. 268.

Cooperia curticei. Hosts, sheep, goat. P. 268.

. Ostertagia marshalli. Host, sheep. P. 269.

Trichostrongylus instabilis. Hosts, sheep, goat. P. 271.

Ostertagia ostertagi. Host, cattle. P. 272.

Nematodirus filicollis. Hosts, cattle, sheep, goat. P. 273.

Cooperia oncophora. Hosts, cattle, sheep. P. 275.

Subfamily (c) Strongylinæ. Worms of the large and small intestines. P. 280.

Genus and Species:

Esophagostomum columbianum. Hosts, sheep, goat. P. 281.

E. venulosum. Hosts, sheep, goat. P. 282.

E. radiatum. Host, cattle. P. 285.

E. subulatum. Host, hog. P. 287.

Chabertia ovina. Host, sheep. P. 287. 


\section{P.ARASITES OF THE DOMESTIC ANIMIALS}

Strongylus equinus. Host, equines. P. 288.

St. edentatus. Host, equines. P. 289.

St. vulgaris. Host, equines. P. 289.

Cylicostomum tetracanthum. Host, equines. P. 289.

Ankylostoma canina. Hosts, dog, cat. P. 291.

Uncinaria stenocephala. Host, dog. P. 292.

Bunostomum trigonocephalum. Host, luminants. P. 293.

B. plebotomum. Host, eattle. P. 293.

Singamus trachealis. Host, fowl. P. 293.

Syn. bronchialis. Host, water fowl. P. 293.

Family (f) Eustrongylidxe. P. 296.

Genus and species:

Dioctophyme renale. Hosts, dog and other animals. P. 296. Family (g) Trichinellidx. P. 299.

Geins and species:

Trichuris ovis. Host, ruminants. P. 299.

T. crenatus. Host, hog. P. 299.

T. depressiusculus. Host, dog. P. 300.

Trichinellat spiralis. Hosts, hog, rat, mouse, and other mammals. P. 301.

Order 2. Acanthocephala. P. 306.

Family (a) Gigantorhynchidie. P. 306.

Cronus and Species:

( iigantorhynchus hirudinaceus. Host, hog, man. P. 306.

Class B. Annelicla. Anmulated worms. P. 307.

Order 1. Hirudinea. Leeches. P. 307.

Fanily (a) Gnatholulellidar. P. 308.

Cienus and Species:

Hiructo medicinalis. Medicinal leech. P. 309.

Hrmopis sanguisuga. Horse leech. P. 308.

With slight onissions, the following descriptions of superfamilies and their sublivisions are transcribed from a work upon the nematode parasites of small mammals br Maurice C. Hall (1916).

"Wsophagus consists of a chitinous tube which is embedded along the greater part of its length in a chain of single cells. The anterior portion of the body, occupied by the esophagus, usually very stender; the posterior portion, occupied by the intestine and reproductive organs, more or less swollen, or at least thicker than the anterior portion. Anus terminal or subterminal. Male with only one spicule or with no spicule. One testis. Female with one ovary. Vulva situated at the junction of the anterior and posterior portion of the body. Oviparous or ovoviviparous. In cligestive tract or adnexa or in urinary bladder as adults. Life history usually simple. Larra of at least one intestinal 
form penetrates to and encysts in the musculature of the host of the adult worm.

Superfamily Trichinelloidea Hall, 1916.

Type-family Trichinellidæ Stiles and Crane, 1910.

"Male without spicule. Female ovoviviparous; the spherical egg is surrounded with a delicate membrane and is without a true eggshell. Worms in the intestine of the host animal.

Subfamily Trichinellinæ Ransom, 1911.

Type-genus Trichinella Railliet, 1895.

"Male with one spicule, or, exceptionally, with only a copulatory" sheath. Eggs lemon-shaped, the apertures at each end closed with opercular plugs. Development, so far as known, direct and without intermediate host. Egg development often slow. Eggs with thick shell; do not hatch until swallowed by a suitable host.

Subfamily Trichurinæ, Ransom, 1911.

Type-genus Trichuris, Røderer, 1761.

"Mouth commonly provided with two or three prominent or inconspicuous lips which are often supplied with papillæ, but the mouth may be of variable shape and without lips. When three lips are present one is median and dorsal, the others are submedian and are approximated in the ventral line. Buccal capsule is not present. Males are provided with one or two spicules, rarely with none. Female with two ovaries, oviparous, rarely, as in Oxyuris vivipara, viviparous. As a rule development is direct and without intermediate host; exceptionally (as in ascarids of fish) there is an intermediate host.

Superfamily Ascaroidea, Railliet and Henry, 1915.

"Mouth with thrce prominent lips supplied with papillæ, the dorsal lip being median and the two other submedian and approximated in the ventral line, or with three main lips and three relatively prominent and inconspicuous intermediate lips (interlabia). Male usually with two spicules. Caudal extremity of female terminates conically and fairly abruptly.

Type-family Ascaridæ, Cobbold, 1864. Type-genus Ascaris, Linnæus, 1758.

"Mouth provided with two or three lips or without lips and of variable shape. Esophagus cylindrical or club-shaped, often followed bya distinct bulb. Males with a preanal sucker, which may be limited by a chitinous ring or a delicate cutaneous membrane, or formed by a simple longitudinal depression; this sucker is not present in Seuratum. Two spicules, one or both of which may tend to atrophy or show imperfect chitinization, and with accessory piece present or absent. Vulva near middle of body.

Family Heterakidæe, Railliet and Henry, 1914.

"Mouth with three well-defined lips; esophageal bulb present or 
absent; preanal sucker nearly circular and limited by a chitinous ring; spicules equal or inequal.

Subfanily Heterakinæ, Railliet and Henry, 1912.

Type-genus Heterakis, Dujardin, 1845.

"Mouth with simple, usually inconspicuous lips. Male usually with one spicule, at times reduced, imperfectly chitimized or absent. Caudal extremity of female much elongated and sublobate. Tulva anterior. Eggs characteristically flattened on one side.

Family Oxyuridx, Cobbold, 1864.

Subfanily Oxyurinæ, Hall, 1916.

Type-genus Oxyuris, Rulolphi, 1803.

"Males with a well-developed caudal bursa supported by rays; in forms near the outer limit of the superfamily the bursa is occasionally very small and the lays atypical, or the bursa may be lacking altogether. Fsophagus without posterior bulb. Mouth naked or with a buceal capsule ant six papilla, distinct or indistinct. Male usually with two spicules and female usually with two ovaries. Oviparous or viviparous. Superfamily Strongyloidea, Weinland, 1858.

"Buccal capsule present. Bursa highly developed, with a typical system of supporting rays consisting of one or two dorsal rays and two lateral ray systems of six rays each. Male with two spicules and female with two ovaries. Vulva at times anterior to the middle of the body, but usually posterior of the middle. Oviparous, eggs segmenting when laid. Development, so far as known, direct. Embryo rhabditiform. In rigestive, rarely in respiratory system.

Type-family Strongylidæ, Cobbold, 1864.

"Buccal capsule present. In digestive, occasionally in respiratory, system. Development direct, at times complex, involving cutaneous infection, nodular development or other embryonic or larval migration.

Subfanily Strongylinæ, Railliet, 1893.

Type-genus Strongylus, Nueller, 1780.

"Simple mouth without a buccal capsule. Parasitic only in the digestive systen. Development direct and simple, involving in all cases known only the possibility of infection by ingestion.

Family Trichostrongylidæ, Railliet, 1915.

"Borly straight or curverl, but not regularly coiled in a spiral. Females with two ovaries.

Subfamily Trichostrongylinæ, Leiper, 1908.

Type-genus Trichostrongylus, Looss, 1905.

"Buccal capsule present or absent. Bursa present or absent; when present, frequently atypical in structure and number of rays. Oviparous, with eggs in variable stages of segmentation when oviposited, or viviparous. Embryo not rhabditiform. Usually in respiratory and circulatory systems, rarely in digestive system. 
Family Metastrongylidæ, Leiper, 1908.

"Buceal capsule absent. Male with two equal spicules and femaie with two ovaries. Eggs in varying stages of development when oviposited. Embryo not rhabditiform. Parasitic in the respiratory and circulatory systems.

Subfamily Metastrongylinæ, Leiper, 1908. Type-genus Metastrongylus, Molin, 1861.

"Body usually very long and slender. Mouth with two lips or without lips and surrounded with circumoral papillæ. Esophagus slender, without posterior bulb. Anus subterminal. Male with a single spicule or with two unequal spicules. Tail provided with papillæ, usually curved spirally, and with bursal alæ present or absent. Female larger than male. Vulva present, or, less often, absent in gravid females; when present, usually anterior to the middle of the body or near the middle, rarely near posterior extremity. Oviparous, ovoviviparous, or viviparous. Development in many eases, perhaps in all, requires an intermediate host.

Superfamily Filarioidea, Weinland, 1858.

"Body long and filiform. Mouth without lips. Male with two spicules, usually quite dissimilar. Vulva near the anterior extremity of the body. Adults subcutaneous, in blood, or on serous surfaces.

Type-family Filariidæ, Claus, 1885.

"Vulva anterior, near mouth. Spicules quite dissimilar. Intermediate stages, so far as known, occur in blood-sucking arthropoda.

Subfamily Filariinæ, Stiles, 1907.

Type-genus Filaria, Mueller, 1787.

"Mouth with two lips; or without lips in forms where vulva is near posterior extremity of body. Male with posterior extremity of body commonly expanded and alate. Female with vulva usually in middle portion of body, exceptionally near posterior extremity.

Family Spiruridæ, Erly, 1885.

Type-genus Spirura, E. Blanchard, 1849.

"Body long and filiform. Anterior portion of body ornamented with cuticular bosses. In the median lines, immediately behind the mouth, are two semilunar depressions simulating suckers. The vulva is situated a short distance anterior of the anus.

Subfamily Gongyloneminæ, Hall, 1916.

Type-genus Gongylonema, Molin, 1857.

"Females with two uteri and with vulva in the middle portion of the body, not close to anterior or posterior extremities. Pharynx without cuticular rays or spirals.

Subfamily Spirurinæe, Railliet, 1915.

Type-genus Spirura, E. Blanchard, 1849.

"Mouth with two lips leading into a pharynx which is strengthened 
by cuticular ridges in the form of rings or spirals. Spicules unequal, the longer several times the length of the shorter. Four pairs of preanal papillæ. Eggs containing embryos when oviposited.

Subfamily Arduenninæ, Railliet and Henry, 1911. Trpe-genus Arduenna, Railliet and Henry, 1911. 


\section{CHAPTER XIX}

\section{NEMATODA. FAMILY I. ASCARID压}

\section{The Large Roundworms of the Intestine}

Nematoda (p. 217). The nematodes of this family have the body relatively thick (Fig. 125). The mouth is commonly provided with three lips which may be prominent or inconspicuous and often bear papillæ. When three lips are present one is dorsal, the other two submedian, touching on the ventral median line (Fig. 121). The males are somewhat smaller than the females and usually have the caudal extremity curved ventrally in the form of a hook. There may be one spicule or two. The females have two ovaries and they are oviparous. So far as known, development in all which are parasitic in warm-blooded animals is without intermediate host and infection is direct.

All of the ascarids live as parasites in the intestines of their hosts, though they may be found in other organs and in the body cavities reached by their migrations. They live free in the intestinal contents, obtaining their sustenance by absorption of the partly digested nutriment of their host through their simple alimentary tube.

Investigations as to Life History.-Investigations by Capt. F. H. Stewart (F. H. Stewart On the Life History of Ascaris lumbricoides, British Medical Journal, 1916, Vol. 2, No. 2896) have brought results of great importance bearing upon the life history of Ascaris lumbricoides and closely related forms. In these experiments Stewart found that if rats or mice were fed Ascaris eggs, the eggs hatched in the alinentary tract and the embryos migrated to the liver, spleen, and lungs. During these migrations they passed through certain

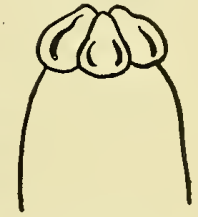

FIG. 121.-Dorsal view of cephalic extremity of ascarid, showing superior median and two ventrolateral lips. developmental changes, and many of them finally again reached the alimentary tract by way of the lungs, trachea, and esophagus. Within the alimentary tract they did not continue their development and were soon expelled with the feces, so that rats and mice surviving the pneumonia commonly caused by the invasion of the lungs became free of the parasites as early as the sixteenth day after infection.

From these findings Stewart concluded that in infection with Ascaris lumbricoides it is necessary in the life cycle for the eggs to be swallowed by rats or mice, and that the embryos hatching from the eggs undergo 
certuin migrations and changes of development, after which they may be carried in the feces or saliva of the rats or mice to food or other materials which may be ingested by human beings or pigs, thus ultimately reaching their final host.

This ronchusion is contrary to the opinion usually accepted that Ascaris infects man or the pig dircetly through the ingestion of the eggs of the parasite. In a preliminary note upon the life history of Ascaris lumbricoides and related forms Ransom and Foster, of the Zoölogical Division of the Bureau of Animal Industry, state that in a repetition of Sitewart's experinents in feeding rats and mice with Ascaris eggs they olstained results agreeing very closely with those which he hack recortrel, also that further investigations have shown that guinea pigs as well as rats and mice may be similarly infected by feeding Ascaris eggs: Theid negative or uncertain results from attempts to infect pigs with Ascaris by fording the eggs agreel with the experience of Stcwart and other investigators, nevertheless they did not fecl justified in aceepting these results as evilence against the hypothesis of a direct development without an intermediate host. They note that Epstein in carefully controlled exporiments with feeding eggs of Ascaris lumbricoides used rery youmg subjects and that the positive results which he obtained can scarcely be explainel upon any other assumption than that a direct development of the parasites ocenrerl following feeding of the eggs. The failures of others to infect adult human boings and the unsuccessful at as suggesting the possibility that age is an important factor influencing the susecptibility of human heings and pigs to infection with Ascaris. In support of this, and in agreenent with the migration of larva which oceurs in rats and nice, they (ite an instance of a pig about six weeks old which, dying from unknown e'auses, revealed on examination an Ascris larva in a fragment of lung and numerous immature ascarids in the intestine, the largest about two inches long.

In orker to test the possibility of infecting very young pigs these invertigators lued two young pigs from a sow which was found by fecal examination to be free from egg-producing ascarids. At the age of about two weckis one of these pigs was given a large number of Ascaris egge containing notile-vermiform rmbryos. One week after feceling the rges this pig died; the other pig continued in goot health. "Examination of the dead pig," the authors state, "revealed a pnemmonia, with nmorous petechial hemorrhages in the lung tissue. Nunrerous ascuricl larve, varying in length from 0.7 to $1.2 \mathrm{~mm}$. in length, were found in the lungs, trachea, and pharynx; none in the liver, spleen, esophagus, small intestine, or large intestine." As to conclusions the authors are further quoted as follows:

"Stewart's rery important discoveries concerning the behavior of 
Ascaris larvæ in rats and mice, the various contributions of other investigators toward the solution of the problem of the life history of Ascaris lumbricoides and related parasites, and our own experiences, appear to justify certain conclusions, some of which in anticipation of a more extended statement in a future paper, may be briefly given as follows:

"The development of Ascaris lumbricoides and closely related forms is direct, and no intermediate host is required.

"The eggs, when swallowed, hatch out in the alimentary tract; the embryos, however, do not at once settle down in the intestine, but migrate to various other organs, including the liver, spleen, and lungs.

"Within a week, in the case of the pig Ascaris, the migrating larvæ may be found in the lungs and have meanwhile undergone considerable development and growth.

"From the lungs the larva migrate up the trachea and into the esophagus by way of the pharynx, and this migration up the trachea may already become established in pigs, as well as in artificially infected rats and mice, as early as a week after infection.

"Upon reaching the alimentary tract a second time after their passage through the lungs, the larvæ, if in a suitable host, presumably settle down in the intestine and complete their development to maturity; if in an unsuitable host, such as rats and mice, they soon pass out of the body in the feces.

"Heavy invasions of the lungs by the larve of Ascaris produce a serious pneumonia which is frequently fatal in rats and mice and apparently caused the death of a young pig one week after it had been fed with numerous Ascarid eggs.

"It is not improbable that ascarids are frequently responsible for lung troubles in children, pigs, and other young animals. The fact that the larve invade the lungs as well as other organs beyond the alimentary tract and can cause a serious or even fatal pneumonia indicates that these parasites are endowed with greater capacity for harm than has heretofore been supposed.

"Age is a highly important factor in determining susceptibility to infection with Ascaris, and susceptibility to infection greatly decreases as the host animal becomes older. This, of course, is in harmony with the well-known fact that it is particularly children and young pigs among which infestation with Ascaris is common, and that Ascaris is relatively of tare occurrence in adult human beings and in old hogs."

\section{ASCARIASIS}

Ascariasis occurs most frequently in young animals, those matured rarely harboring the worms in such numbers as to bring about symptoms 
by which the condition can be recognized. Where there is a heavy infestation they cause injury by their irritation to the intestinal mucosa. In such cases they may become massed and constitute an obstruction to the intestinal lumen sufficient to cause stasis of the contents and degenerative changes in the intestinal walls.

The ascarids are active worms, and have a tendency to wander to unusual locations; one or two may find lodgment in accessory organs of the intestincs by way of their ducts and, by the consequent continuous irritation, bring about results of a serious nature. Verminous fistulae may be thus cstablished, or there may be abscess formation with discharge of pus into the peritoncal cavity, followed by peritonitis. In dogs and cats especially, the worms when numerous often pass to the stomach in considerable numbers, setting up more or less gastric disturbance and consequent voniting, the expelled material generally containing from one to scveral worms.

Certain foreign investigators, having demonstrated the presence of blood in ascarids, have concluded from this that these worms are blood suckers. Hatl, in an article upon the parasites of the dog in Michigan (Journal of the Anerican Veterinary Medical Association, June, 1917), states that an ascariel which he collected from the feces of a dog showed a pronounced red color in the intestine, evidently due to blood. As post-mortem examination of the $\log$ the same day revealed a severe hemorrhagic enteritis, lic concludes that this was cvidently the explanation for the blood in the intestine of the ascarid. The conditions found in this casc suggest the possibility of similar conditions in cases regarded as evidence that these worms arc blood suckers, - a conclusion that certainly has no support in the structure of the ascarid's mouth.

There secms reason to doubt that ascarids feed upon epithelial cells, as stater by some authors. Their simple intestinal tube is restrictively modified to the primary function of absorption of nutriment already madc in a certain state of solution by the digestive juices of the host, and it is unlikely that such digestive powcrs as are retained by the parasites would be adapted to a diet of epithelial cells. In view of the fact that frec epithelial eclls and their débris are contained in the alimentary entents of the host, it follows that such material would be ingested along with the alimentary matter by the worms and would be found in their intestinal contents.

Aside from the mechanical injury caused by the ascarids, there are to be considered the effeets of toxic products elaborated by their bodies. These may be practically nil or considerable according to the character and degree of the infestation. The loss of condition in heavy invasions can probably be attributed to the systemic effect of these poisons comhined with that of the catarrhal enteritis. It seems reasonable to conclucle that the deprivation of nutriment, which has been appropriated 
by the horde of parasites in the alimentary canal, is also a morbid factor. Manifestations of the toxemia are often of a nervous character; there is hyperreflex irritability, and convulsions are a not infrequent accompaniment.

In general, it may be said of the ascarids that, while they often inhabit the intestines without perceptible indications of their invasion other than their occasional expulsion with the feces, their presence constitutes a condition calling for treatment. They should be expelled by the administration of a vernifuge, in most cases followed by a purgative, and their bodies collected and burned. Not only should the treatment be carried out for considerations pertaining to the health of the host, but to prevent the spreading about of the worms with their eggs and embryos to infest other animals.

\section{ASCARIDE OF THE HORSE}

One species of ascarid inhabits the intestine of the horse, ass, and mule.

Ascaris equi (A. megalocephala, A. equorum). Ascaridæ (p. 229).This is the largest species of the family. The body is yellowish white, about the thickness of a lead pencil, and somewhat rigid. The head is distinct and bears three lips. The caudal extremity of the male is bordered laterally by two small membranous wings, and ventrally on each side there are 80-100 papillæ. The female is considerably longer and thicker than the male. The vulva is situated toward the anterior quarter of the body.

Length of female: 15-30 cm. (6-12 inches), or it may be somewhat longer.

Eggs globular, 90-100 microns in diameter.

The species is found only in Equidæ, and lives in the small intestine, occasionally found in other organs by migration.

Occurrence and Symptoms. - The large ascarid is very common in the small intestinc of the horse. Unless numerous, they do not, as a rule, perceptibly affect the health of their host, often the only evidence of their presence being the voiding of one or more of the worms with the feces. Young animals do not bear the parasitism so well, and in moderate to heavy infestations are likely to manifest serious disturbances of a local and systemic character.

As a result of the irritation to the mucosa there is a chronic intestinal catarrh, and this may be accompanied by a diarrhea which is persistent, or alternating with a hard dry feces covered with slimy mucous material. Colic is a not infrequent symptom, and there may be intervals of more or less tympany. The worms, when massed in large numbers, are capable of bringing about an obstruction with all that follows such a condition, possibly involving intussusception and eren rupture. 
Young animals, as a result of aggravated ascariasis, lose condition and there is arrest in their development. Due largely to the accumulation of gas, they are likely to become more or less pot-bellied, the activity of the skin is reduced, and the coat takes on a dry, harsh, and erect appearance. The alertness and inclination to play, natural to foals and young holses, is lost, and the animals may stand about looking more or less dejected.

Nervous disturbances are occasionally exhibited by vertigo or, rarely, by epileptiform or tetanic symptoms. They may be due to reflex irritation or to toxic products from the bodies of living worns, to which is adcled toxins from the bodies of morms which are dead and decomposing.

Etiology.--Infection occurs by the introduction of eggs and embryos into the alinentary canal with food and water. Development takes place after the eggs have left the body of the host and is favored by factors of wamtl and moisture, such as is supplied by moist earth and a temperature of about $37^{\circ} \mathrm{C} .\left(98^{\circ} \mathrm{F}\right.$.). While segmentation will not procerel under low temperature conditions, the eggs will retain their fertility in unfarorable surrounchings for a comparatively long period and will (levelop) upon reaching a favorable enviromment. Enbryos within the eggs appear to possess considerable resistance, since they lave locen of server to retain their vitality in dried horse manure for six months. It is probable that infection is by eggs, and that few enbryos arre reaserl until the intestinal contents of the equine host is reacherel.

Control. - Comsidering the persistent vitality of the eggs and embryos, it is rspecially important as a prophylactic measure that as many as possible of the expelled worms be collected and burned. If they are permiterl to find their way to the manure pile or to be seattered about, some of the myrials of eggs contained in their bodies will meet with conditions favorable to their development and infect other horses. l'reaution shoukl be taken that the drinking water for horses cloes not leceive contamination from collected manule, and that it be as pure and free frour surfice drainage as possible.

Treatment. Treatment should be precerled by the withholding of all bulky foor for twenty-four to forty-eight hours. During this time the aminial shoukl be at rest and may bo given bran mashes, to which a moterate anount of grain may be added cluring the first twenty-four hours if the preparation is to be for the longer period.

While the prelininary fasting of the host for a day or two probably will not sufficiently "starve" the parasites to be of any value as an aid in their expukion, it permits the removal of the bulky portion of the intestinal contents and prepares for a diffuse action of the anthehnintic which ot herwise would not be possible. 
Following the period of fasting, give two to four ounces of oil of turpentine and one dram of oleoresin of aspidium, in a pint of linseed oil. If necessary, follow twelve hours later with an additional pint or two of linseed oil.

Tartar emetic in two to three dram doses, repeated once at an interval of twelve hours, is also an effectual expellant. This is best administered with linseed meal which may be stirred into a small bran mash.

These doses are for aged horses of average size, and are to be modified according to age and somewhat as to weight.

The vermifuge is in most cases to be followed twelve to twenty-four hours later by a purge, preferably oleaginous, but this should not be given if there is diarrhea, and may not be necessary if the animals are upon grass.

Sulphate of iron and arsenic are remedies which have also been recommended. If arsenic is used, it should be given in the form of powdered arsenous acid in increasing doses for about two weeks.

Family II. Oxyuridæ. Nematoda (p. 217).-This family is considered by many authors as belonging with the Ascaridæ. Conspicuous characteristics of the group are the curved anterior portion of the body and the elongated and attenuated caudal extremity of the female. The males usually have but one spicule, and this may be reduced and inperfectly developed. The vulva of the female is anterior.

Oxyuris equi (O. curvula, O. mastigodes). Oxyuridæ (p. 235).The body is generally white, somewhat thickened, and curved. The mouth is provided with three lips. The male is much smaller than the female, and has an obtuse caudal extremity which bears several papillæ, the largest of which sustains a caudal bursa. There is but one spicule and this is straight and slender. In the female the anterior portion of the body is thickened and curved, while the posterior portion is attenuated to a point. The vulva is about $8-10 \mathrm{~mm}$. (3/8 of an inch) from the mouth. The body may have its posterior attenuated portion of variable length (Fig. 122); in some individuals this is very much prolonged and filamentous. This difference has led some authors to describe two species of Oxyuris of the horse- $O$. curvula and $O$, mastigodes, the latter including those with the extended caudal extremity: Railliet has demonstrated that forms exist possessing all intermediate gradations between those with very short and those with very long tail extremities, and that there is not, therefore, a difference of true specific character.

Length of female, $4-15 \mathrm{~cm}$. ( $15 / 8-6$ inches); male, about $1 \mathrm{~cm}$. (3/8 of an inch).

Eggs oval and operculated; 85-95 microns long, 40-15 microns wide.

The species inhabits all of the large intestine of the horse, ass. and mule. 
Occurrence.-Oxyuris equi is a common inhabitant of the large intestine of the horse. The condition produced by these worms is usually referred to as oxyuriasis, and they are commonly known as seat-womns or pin-worms. Often they are observed projecting from the margin of the anus to which they adhere while depositing their eggs. By means of a sticky substance the eggs attach about the skin of the anus and perineum and develop embryos within two to three days. Later the sulsstance by which they are fixed to the skin dries and the eggs drop

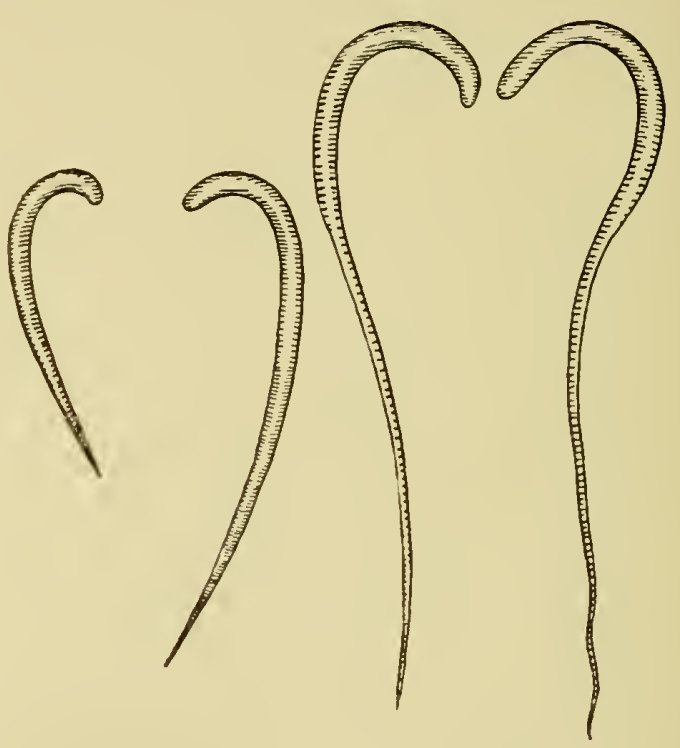

FIG. 122.-Oxyuris equi, showing varying lengths of posterior attenuated portion.

to the ground where, through seattered manure, they contaminate the pasturage, or, if the animal is in the stable, the feed may be contaminated in the same manner.

The equs are provided at one end with a sort of operculum which, on reaching the stomach, is digested away. The released embryos are then carried with the alimentary material to the large intestine where they reach maturity.

Effect. The offense of the oxyurids is mainly one of unsightliness. They produce itching about the anus which may become intense, causing the animal to rul, the parts and thus bring about a denudation of the 
tail and skin. The tail is frequently agitated, and annoying habits of "switching" and "line-hugging" may have origin from this source.

In aggravated cases there may be loss of flesh due to the constant irritation to which the animal is subjected. The anus becomes swollen, flacid, and, on defecation, the mucous membrane is noticed to be a deep red.

The condition is readily diagnosed in observing the protruding or expelled worms. The sticky yellowish-colored deposit about the anus and perineum, together with denudation of the skin and base of the tail by rubbing, indicates the presence of the worms.

Treatment.-Treatment is mainly per rectum. Previous to the administration of vermifuge enemata the bowel should be emptied by an injection of glycerin and water or of warm soapy water. As an expellant, either of the following may be used: (1) Infusion of quassia, one to two quarts; (2) infusion of tobacco, one ounce to one quart of water; (3) vinegar in soapy water; (4) one quart of a one per cent. solution of lysol; (5) one to two ounces of oil of turpentime shaken up in a quart of lime water and linseed oil; (6) mercurial ointment repeatedly applied to the borders of the anal orifice is also of service. The injections are best given through a rubber siphon.

As developing worms from ingested eggs may be in the intestines too far forward to be acted upon by the enemata, it. is well to supplement this treatment with the administration of a vermifuge as recommended for the large ascarids of the small intestine.

Treatment is to be repeated at intervals of four to six days until indications of the presence of the worms have disappeared.

The adhering deposit about the rectum and perineum should be regularly removed and so disposed of that the contained eggs cannot reinfect.

\section{Ascaride of the Dog and Cat}

One species of ascarid is common in the dog and cat, although some authors recognize two-Belascaris marginata of the dog, and B. mystax of the cat. Other than being a little smaller, the ascarid of the cat scarcely differs from that of the $\mathrm{dog}$, and at the present time the majority of helminthologists consider the difference as one of variety only.

A much less common species infesting dogs in this country is Toxascaris limbata.

Belascaris marginata (Ascaris marginata, A. mystax, Belascaris mystax, B. cati). Ascaridæ (p. 229).-The body is white, or reddish white. The head is usually curved and is provided on each side with a membranous wing, giving the appearance of an arrow-head (Fig. 123). On the curved tail of the male there are two small membranous lateral wings and twenty-six papillie on each side. The rulva of the 
female is situated toward the anterior quarter of the body. The tail is obtuse.

Length of female, $9-14 \mathrm{~cm}$. (3 1/2-5 1/2 inches); male, 5-10 cm. (2-4 inches).

Eggs globular, $75-80$ microns in diameter.

Infests the small intestine.
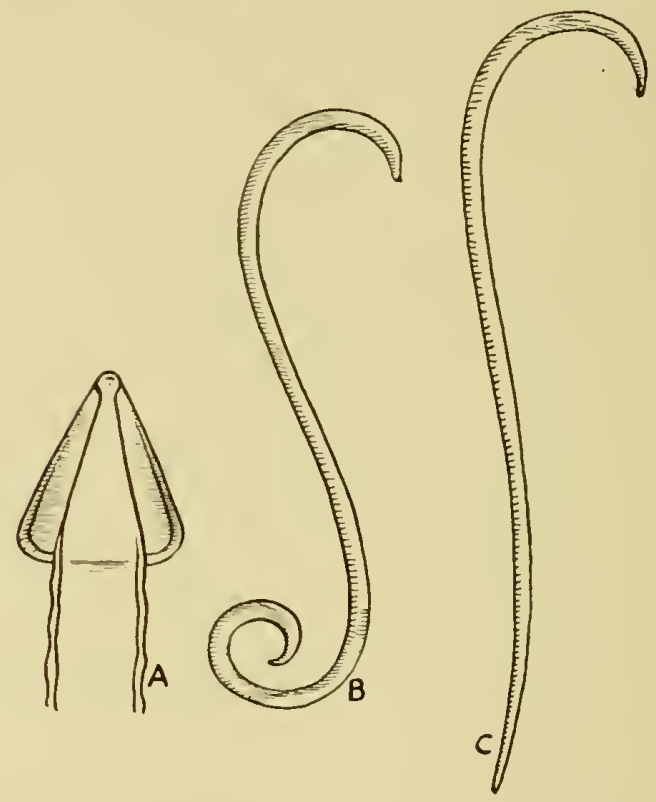

Fici. 123.-1Belasearis marginata: 1 , head, enlarged; $B$, mitle; C, fomale, natural size.

Toxascaris limbata (Toxascaris marginata). Ascaridæe (p. 229).The boly is firm and whitish or pale red in color. The cephalic wings are long, narrow, and somewhat lanceolate. The spicules of the male are not quite equal.

I.'mgth of fomale, 6.5-10 em. (2 $1 / 2+$ inches); male, $4-6 \mathrm{~cm}$. ( $11 / 2-$ 238 inclics).

The eggs are 75 to 85 microns in dianeter.

Parasitic in the intestines of the dog.

Occurrence in the Dog.-Belascaris marginata is most often found in young dogs of three to four months. It is probable that about thirty per cent. of all puppies harbor the worms in nore or less numbers in 
their small intestine. They frequently enter the stomach and cause vomiting, the expelled material often containing several worms. Otherwise the symptoms are much like those caused by the presence of tapeworms. There is emaciation, enlarged abdomen, and irregular appetite. There may be diarrhea or constipation, and, finally, epileptiform or rabiform seizures. By massing in the small intestine, they may induce invagination and fatal obstruction to the alimentary matter.

Necropsies upon dogs which have died from ascariasis reveal the lesions of an intense hemorrhagic enteritis, with tumified mucosa, showing small ulcerative points and involvement of the submucous tunics.

Treatment.-(1) Powdered areca nut, two grains to each pound of body-iveight, may be given shaken up in a little milk. (2) Santonin is one of the most frequently used remedies. The dosage should be carefully graded, giving one-eighth of a grain per pound of body-rieight, the dose in no case to exceed three grains. It may be administered suspended in milk or combined with one-fourth to two grains of calomel, made into a pill. (3) Fifteen minims to one dram of oleoresin of aspidium, singly or combined with a grain of areca nut, per pound of bodyweight, may be given in capsule. (4) Benzene, in fifteen drop to one dram doses in oil, has been recommended.

The anthelmintic should be administered in the morning after a twelve hours' fast. If the bowels are not already freely active, it is well to follow the remedy a few hours later with a purgative of castor oil or syrup of buckthorn. Care should be taken in the administration of these drugs to toy puppies. Santonin, especially, should not be given until they are at least eight weeks old; under that age, a simple laxative will often bring away quite a number of the worms.

If vomiting occurs after giving the medicine, allow an interval of $t$ wo or three days before repeating; then precede by a stomach sedative of bismuth or a small dose of cocaine.

Occurrence in the Cat.-Ascariasis of the cat does not sufficiently differ from that of the dog to merit a special description. As in the dog, the worms are more likely to infest young animals, though cats seem to bear the invasion better.

Remedies recommended for the dog will serve as well for the cat, though the peculiar intolerance of these animals should be taken into consideration in the selection and dosage. (1) Cusso, fifteen to thirty grains, is relatively safe, but is likely to cause vomiting. (2) Oleoresin of aspidium, minims fifteen to twenty, may be given in mills.

\section{Ascaride of the Hog aNd Sheep}

Ascaris lumbricoides (A. suis, A. suum, A. ovis). Fig. 125. Asearidx (p. 229).-The head has three strong lips, the lateral sides of 


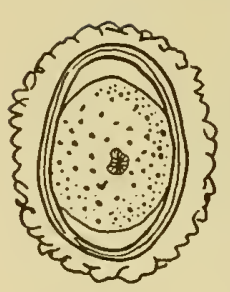
Ascaris lumbricoides, with shcll and albuminous envelopr (copied from Braun's "Animal Parasites of Man").

bugs, oval, 60-75 microns long by 40-5s microns wide. The shell is mammillated.

In its adult state this worm lives in the intestines of the hog and sheep, and also of man.

The ascarid of the hog and sheep and that of man so elosely rescmble each other that a number of authors now consider then as one spceies; others distinguish a specific differenee, claiming that the ascarid of the pig differs from the human ascarid in being thinner, having the longitudinal strixe closer, spieules less sharp, and ova smaller. It would seem, however, that such slight differences should be regarded as of no more than varietal importance.

Heary invasions of these worms in the intestines of logs bring about the conditions such as have already been described in aggravated intestinal helminthiasis. In young pigs especially, there is general unthrift, and maciation may become quite advaneed. There is usually a eough, and this is likely to be aceompanied by occasional romiting. The pig shows a peculial restlessness, wandering about without apparent motive and emitting cries indicative of colicky pains. The lumen of the intestines may be obstructed by the

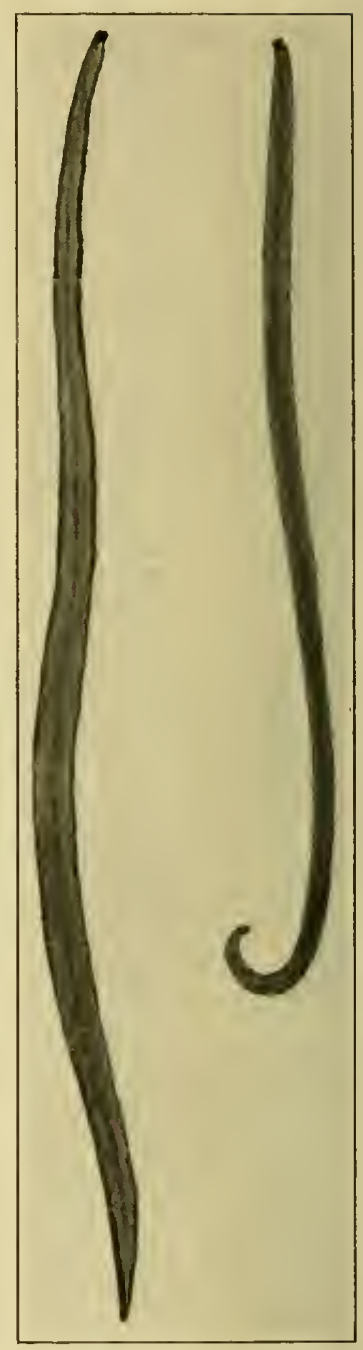

Fig. 125. - Asearis lumbricoides, male at right, female at left, natural size. 
worms in mass with the usual sequence of localized inflammatory changes.

Invasion of the bile cluct of pigs with these ascarids is of frequent occurrence and may often bring about a fatal result. Autopsies at the Pennsylvania State Laboratories upon pigs dead from this parasitism have in some cases revealed the common bile duct literally packed and occluded with the worms.

Treatment.-Treatment is mainly prophylactic. Thorough eleaning up, burning of litter, and a liberal application of disinfectants is essential, and the source of water supply and drainage should be looked to. Infested pigs should be isolated and precautions taken against reinfection.

Medicine is best administered in milk, or other semi-fluid media, fed to the pigs as a whole, the dosing of individual pigs being a somewhat discouraging task. It is better to separate the pigs for this purpose into groups of not more than ten of nearly equal size, otherwisc the largest and most aggressive. will get more than their portion.

As a vermifuge, pulverized areca nut may be used, the close being approximately one grain to each pound of body-weight. This should be followed by a purgative, preferably saline, the dose graded according to size of pigs, and administered as above. Benzene, in one to three dram doses mixed with the food, has been recommended as effective.

When individual treatment of young pigs is resorted to, one to five grains of calomel, given in milk and followed by castor oil, will in many cases be sufficient to dislodge the worms. For older pigs it is better to follow the calomel with a saline evacuant.

Ascariasis of Sheep.-Ascarids are rarely found in sheep. In the Bureau of Animal Industry Collection there are specimens of ascarids obtained from sheep at Blairsville, Pa., Broolings, South Dakota, and Bethesda, MId. (Bulletin 127, 1911.)

\section{ASCARIDE OF THE Ox}

Ascaris vitulorum. Ascaridæ (p. 229). - The head is small and has three lips which are somewhat enlarged at the base. The body is white or may be reddish white. The caudal extremity of the male has two rows of papillæ, $10-15$ in each; these are lateral and pre-anal. The vulva of the female is situated toward the anterior sixth of the body.

Length of female, $22-30 \mathrm{~cm}$. (8 1/2-113/4 inches); male, 15-20 cm. (6$73 / 4$ inches).

Eggs, 75-80 microns in diameter.

Lives in the intestine of calves; rare in adult cattle.

This worm is most frequently met with in parts of Southem Europe, where it is found in rather large numbers in the small intestine of calves slaughtered for veal. 


\section{Heterakiasls of Chickens}

Family III. Heterakidæ. Nematoda (p. 217).-This family, like the Oxyuridee, is placed by some authors with the Ascaridæ. The type-genus is Heterakis, of which two species infesting chickens are to be described.

1. Heterakis perspicillum (H. inflexa). Fig. 126. Heterakick (p. 242).- The mouth has three lips of mequal size, the dorsal lip the largest. The boly is yellowish white. The caudal extremity of the

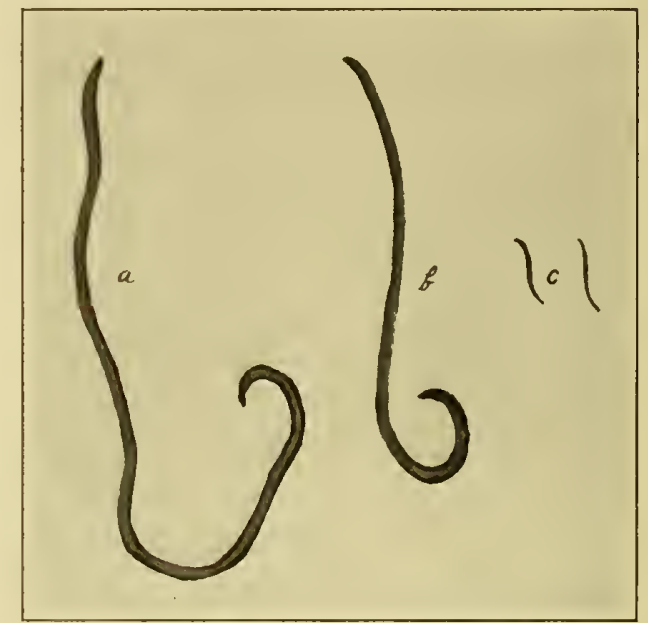

Fis, 126. Heterakis perspicillum: a, fomale; b, male; c, Irterakis vesieularis. All natural size.

male torminates obliquely, and is provided on each side with a membranous wing and ten papillate. The two spicules are nearly equal. On the rentral surface anterior to the anus there is a rounded sucker. The cauclal rextremity of the fomale is straight, conical, and teminates in a point. The vulva is locater in the anterior part of the body.

Length of female, 6-12 cm. (2 1/2- \$3/8 inches); malc, $3-8 \mathrm{~cm}$. (1 1/4$31 / 8$ inches).

Fugs, elliptical, 75-80 microns in length by $45-50$ microns in width.

The sprecies is rommon in the small intestine of the chirken, turkey, and guinea fowl.

2. Heterakis vesicularis (H. papillosa). Fig. 126. Heterakidæ (1) 242).-The mouth has three small lips of erpual size. The body is 
white and attenuated at its two extremities. The caudal extremity of the male is straight, with lateral wings, and twelve papillie. The spicules are unequal. The caudal extremity of the female is very slender. The vulva is posterior to the middle of the body.

Length of female, $10-15 \mathrm{~mm}$. (3/8-5/8 of an inch); male, $7-13 \mathrm{~mm}$. (5/16- $1 / 2$ inch $)$.

Eggs, elliptical, 63-71 microns in length by 38-48 microns in width.

This species-much smaller than the preceding-is also common, and lives in the cecum of the chicken, turkey, guinea fowl, pheasant, pea-fowl, duck, and goose.

Symptoms.-Heterakiasis of chickens is usually caused by Heterakis perspicillum. In general, the presence of the worms is indicated by dullness and an indisposition to move about. Though the appetite may be preserved, there is more or less emaciation, the feathers become erect and lusterless, and the wings droop. If the condition is aggravated the symptoms progress, diarrhea sets in, the appetite dwindles, the comb becomes pale, and the creature, with eyes half closed, remains huddled up and unmovable until death comes to its relief.

In such cases necropsy will reveal the lesions of a subacute enteritis, and frequently the presence of numerous tapeworms as well as roundworms.

Intestinal helminthiasis in fowls is often an accompaniment to diseases presenting somewhat similar symptoms, therefore care should be taken that a coincidence does not mislead, and that such causes of high mortality as fowl-cholera be not overlooked.

Treatment.--Sick birds should be isolated in clean bright quarters and their droppings frequently removed and destroyed. As medicinal treatment, probably areca nut is most effectual. This may be given to full-grown birds in doses of eighteen to twenty-four grains, administered in bolus made up with linseed meal or bread. Calomel, one to two grains, given in the same manner, has also been recommended.

Essentially, thorough cleaning up and disinfection are necessary to the successful eradication of the parasites. 


\section{CHAPTER XY}

\section{NEMATODA. FAMILY IV. FILARIID.E}

\section{The Thread-Like WorMS}

Nematoda (p. 217). - The nematodes of this family have the body long and filiform (Figs. 127 and 129). The shape of the mouth varies; it may be provicked with lips or it may be surrounded with papillæ. The esophagus is slender, without posterior bulb. The males may have one spicule or two unequal spieules, and the tail is generally spirally rolled. The females have two ovaries; vulva usually anterior to the middle of the body. The embryonal development is usually within the borky of the female.

Parasitism.--The filarice live as parasites chiefly in serous eavities of the body, blood and lymph channels, and in the submueous and subcutaneous eonneetive tissues. They may be found in most any part of the body, but do not commonly inhabit the lumen of the alimentary canal.

The parasitism of the filarix prorluces a condition in their hosts known as filariasis.

\section{Filarild.e of the Horse}

1. Setaria labiato-papillosa (Filaria equina). Fig. 127. Filariidæ (p. 21.1).--Tlie body is long, white, filifom, and attenuated at both ends. The integument has fine transverse striations. The mouth is small, cireular, and provicled with a ehitinous ring, the border of which is divided by four salient papillat. Outside of this on each side are two small papilla in the form of small spines. The tail of the male is rolled up spirally and presents on each side four preanal and four or five postanal papillx. There are two spicules. The tail of the female is slightly spiral and is terminated by a papilla. The vulva is situated near the anterior extremity.

Length of female, $9-12 \mathrm{~cm}$. (3 $1 / 2-43 / 4$ inches); male, $6-8 \mathrm{~cm}$. (2 $3 / 8-31 / 8$ inches).

Newly hatched embryos are about 280 mierons long by 7 mierons in breadth. The embryonie development is within the body of the female.

Occurrence.-This species is most often met with in the peritoneal cavity-more rarely in the pleural eavity of the horse, ass, and mule. The worms are espeeially fitted for migrations by their slender and attenuated bodies, and, from their location in serous cavities, may pass 
to the subperitoneal and subpleural connective tissues or to the muscular septa, scrotum, or other parts of the body. The small filarix occasionally found in the anterior chamber of the eye are considered by most authors to belong to this species.

Effect.- Unless present in exceptionally large numbers, these worms do not produce serious disturbance. Their presence in the eye may cause inflammation with bulging and opacity of the cornea for the relief of which operative measures must be resorted to.

Nothing definite is known as to the evolution of this nematode; the fact that the embryos have been observed in the blood of the horse, points to the probability that they pass to the body of a bloodsucking insect.

2. Habronema megastoma (Spiroptera megastoma). Filariidæ (p. 244).-This is a small nematode with whitish colored body attenuated at the extremities. The cephalic portion is separated from the remainder of the body by a constriction, and is provided witl four chitinous lips. The mouth is continued by an infundibuliform pharynx. The caudal extremity of the male is rolled and bears two lateral wings, each sustained by four preanal and one postanal papillæ. There are two spicules. The tail of the female is straight and obtuse; vulva situated toward anterior third of the body.

Length of female, $10-13 \mathrm{~mm}$. (3/8 of an inch); male, $7-10 \mathrm{~mm}$. (1/4-3/8 of an inch).

Eggs, elongate, 33 microns long by 8 microus in breadth. Development and hatching are within the body of the female (ovoviviparous). The liberated embryos measure 600-700 microns in length.

The life history is not known.

This species infests the submucosa of the stomach of the horse. They are usually in the right sac, and their presence may be recognized by oval or rounded prominences varying in size from that of a hazel nut

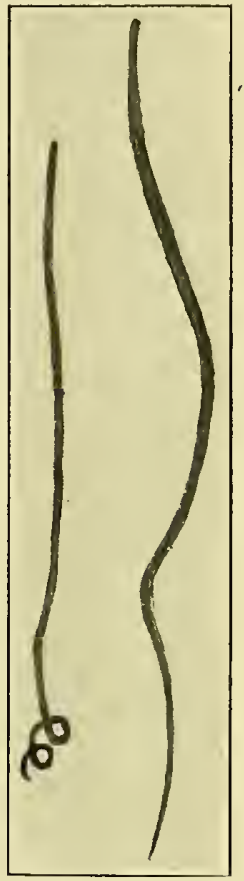

FIG. 127.-Setaria labiato-papillosa,male at left, female at right. to that of a walnut. The mucous membrane covering the tumors is unaltered with the exception of a number of perforations at the summits which communicate with the contained cavities. Within these cavities are lodged the worms which, on pressure upon the tumor, are extruded together with a purulent matter.

It is probable that the worms reach their submucous lodgment as embryos by way of the gastric crypts, the irritation of their presence 
setting up proliferative changes with the formation of promincnces. Outwardly the tumors are limited by the museular layers of the stomach, the conneetive tissue involved being that of the submueosa. In old tumors the walls become of a dense fibrous eharacter, taking somewhat the eonsistency of cartikge. In these no worms may be found, or there may be a few of their disintegrated bodies contained in a small amount of purulent material.

Eksentially the presence of such parasites can only le revealcd postmortem. The tumors are not as a rule numerous, and do not secin to cause any serious disturbance.

The manner of infestation by the worms is not known, nor is it known whether they multiply within the tumors.

3. Habronema microstoma (Spiroptera microstoma). Filariida (p. 214). 'This speeies is larger than the preceding and may also be distinguished from it by the absence of the eonstriction behind the cephatic extrenity. The mouth presents a notch on each side, and there are two lateral lips. The tail of the malc is rolled spirally, has two lateral wings, and a varying number of papillie. There are two spicules. The vulva of the fomale is situated noar the antrrior third of the body.

Lenutl of female, 12-27 mun. (1/2-1 inch); male, $10-20 \mathrm{~mm}$. $(3 / 8-3 / 4$ of an incli).

The ('gas are (longate and truncater at their extremities. They are 45-49 microns long by 16 microns wide. Development and hatehing are within the boly of the fenale (ovoviviparous). The herated embryos measure 90-9s microns in length.

The life history is not known.

Occurrence. Post-morten inspcetion of the interior of the horse's stomath will oc"asionally reval the prescnee of these worms in such quantity as to calus an undulating movement of the eontents of the organ, clue to their active motion. While most of the worms are free, many may be found with their heads inserted in the gastric crypts of the right sac. More or less inflammatory disturbanee of the mucosa mav thus bo set un), in some ("ases involving ulceration.

is in the cise of the procerling species, infestation with these worms ean ouly he revaled when they are brought to light after the death of the host. Where a chronie gastrie disturhance is suspected to be due to parasites of the stomach, one or two ounces of oil of turpentine may be given in two or threr pints of linsered oil.

\section{Filaridde of Sheep and Cattle}

1. Gongylonema scutata (Spiroptera scutata). Fig. 128. Filariidæe (p. 244).- The hody is long and filiform, white or yellowish white, striated transversely, and slightly attenuated toward the extremities. 
The mouth has two lateral and four smallel submedian papillæ. On the anterior 1 to $3 \mathrm{~mm}$. of the body are rounded or oval cuticular tubercles arranged more or less regularly in rows. The tail of the male is rolled up and has two asymmetrical wings and two spicules. The vulva of the female is situated in front of the anus.

Length of female, $8-14 \mathrm{~cm}$. (3 1/8-5 1/2 inches); male, $3-5 \mathrm{~cm}$. (1 1/4 2 inches).

The cggs arc oval. Embryonal development is within the borly of the fomale.

Occurrence.-This is a common species found in a large percentage
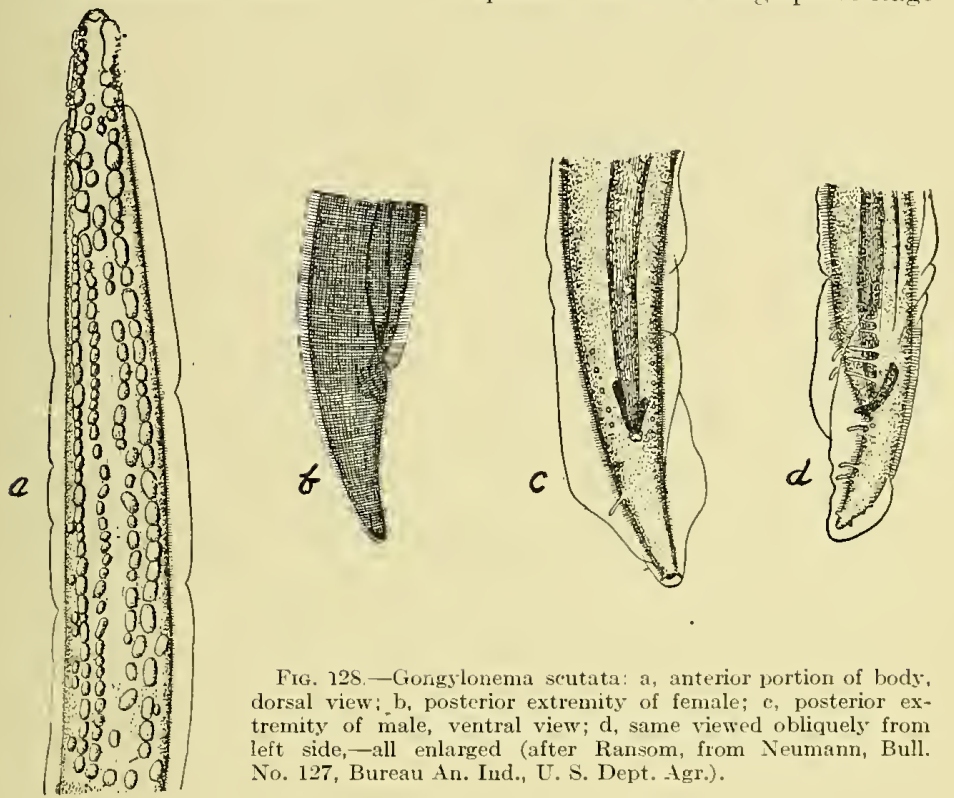

FIG. 128-Gongylonema scutata: a, anterior portion of body, dorsal view; b, posterior extremity of female; $c$, posterior extremity of male, ventral view; d, same viewed obliquely from left side,-all enlarged (after Ransom, from Neumann, Bull. No. 127, Bureau An. Ind., U. S. Dept. Agr.).

of shecp and cattle slaughtered in the abattoirs of this country and Europe. It has also been obscrved in the horse and in the moutl and pharynx of pigs. It inhabits the mucosa of the esophagus, usually in the thoracic portion where it is lodged just beneath the epithelium. Its body runs parallel to the long axis of the organ and is disposed in a spiral manner, giving somewhat the appearance of the wool-fiber of a merino sheep.

Therc is no apparent effect upon the health of animals harboring this worm. Its only economic importance seems to be in rendering the esophagus undesirable for use in meat food products. 
Experiments by Ransom and Hall have shown that dung beetles and croton bugs fed upon the eggs of Gongylonema scutata become infested with an encysted larval stage of the parasite. Evidence is thus furnished that the mammalian hosts of the worm become infested as a result of swallowing insects bearing the cncysted larvæ.

2. Filaria labiato-papillosa (F. cervina). Filariidæ (p. 244). -This species resembles Setaria labiato-papillosa of the horse, but differs from it in the absence of transverse striations of the integument and in the caudal papilla of the female, which form a terminal chuster of small blunt points, anterior to which are two thick conical papillæ.

Length of female, $6-12 \mathrm{~cm}$. (2 3/8 $13 / 4$ inches); male, $4-6 \mathrm{~cm}$. (1 1/2-2 3/8 inches).

Development and hatehing is within the body of the female (ovoviviparous). The freed embryos are 140-230 microns in length.

This nematode of the ox and decr is found almost exclusively in the peritoneal carity. It does not appear to have any effect upon the health of its hosts. A roorm occasionally found in the eye of the ox is considered as belonging with this species.

\section{Filariide of the Dog}

1. Dirofilaria immitis (Filaria immitis). Fig. 129. Filariidæ (p. 244).-The borly is white, long, decidedly thread-like, with ends having an obtuse appearance. The mouth is small and surrounded by six indistinct papillix. The posterior extremity of the male is stender, rolled spirally, and bears two small lateral wings. There are two spicules. The posterior extremity of the female is obtuse.

The female is 25 to $30 \mathrm{~cm}$. in length and about $1 \mathrm{~mm}$. in diameter (9 $3 / 4$ inches by $1 / 32$ of an inch). The length of the male is $12-18 \mathrm{~cm}$. (4 $3 / 4-7$ inches).

The enbryos are developed and hatehed in the body of the female (oroviviparous). As they enter the circulation they measure 285295 microns in length and have a diameter of about 5 microns. The anterior cxtremity is obtuse, the posterior extremity attenuated and slencter.

Occurrence.--Hematic filariasis of dogs, produced by this species, has been most frequently met with in China and Japan, about fifty per cent. of all dogs in the latter country, it is estimated, being affected. It occurs also in other countries, including North America.

The usual seat of invasion is the blood-vascular system, particularly the right rentricle of the heart, the pulmonary arteries being more rarely involved. Not infrequently mature filariæ are found in the subcutaneous connective tissue. In the heart and large arteries the worms may be found in a tangled mass containing hundreds so interlaced as to make it difficult to extricate single individuals. 
Pathogenesis. - The disturbances caused by the presence of the mature filarix are principally mechanical. Depending upon their number, they more or less interfere with the circulation, in some cases forming a thrombus which may give rise to emboli in the branches of the pulmonary artery. In such eases necrotic areas in the lungs with abscess formation may result.

The larvæ, probably by their toxic products, bring about anæmia with a leucocytosis which, depending upon the number of the parasites present, may be more or less pronounced. As a result of the invasion of the heart, local manifestations of endocarditis are to be looked for. The heart's action is variously disturbed, leacing to dropsical conditions accompanied by cough and dyspnoea. Nephritis and convulsions may develop as a later complication. If the condition terminates in death, it is usually from paralysis of the heart or a general weakness followed by complete paralysis.

Diagnosis.-The parasites may be present without causing observable manifestations, while, on the other hand, no line of clinical symptoms can with certainty be attributed to such invasion. A more precise diagnosis can usually be made by microscopic examination of the blood for demonstration of the presence of the larvæ. Under low magnification, a drop of infected blood placed between a slide and a coverslip will reveal fine worm-like larvæ in snake-like, movements between the corpuscles. It is claimed by most investigators that they appear in greatest numbers in the peripheral

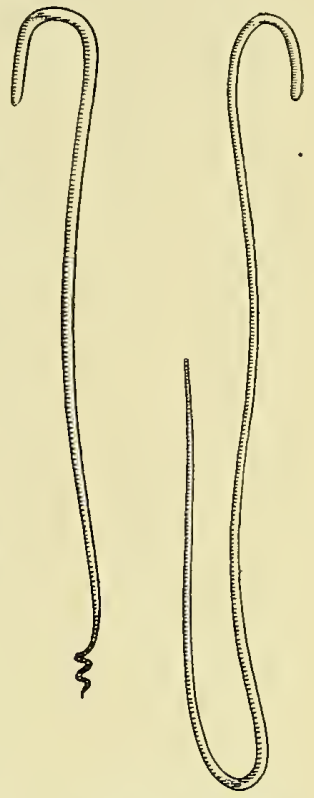

FIG. 129.-Dirofilaria immitis; male at left, female at right, - natural size (after Railliet). circulation during the night, and, therefore, that blood for such examination is best drawn during these hours.

Infection.- - The manner of natural infection with this parasite has not yet been satisfactorily determined. Manson concluded from his investigations that the larvæ of Filaria bancrofti ( $F$. sanguinis hominis) a blood parasite of man resembling the species under consideration-pass into the digestive tract of a mosquito (Culex) when it sucks the blood of an affected person. Later the mosquito, after depositing its eggs upon the water, dies, the body disintegrates, and the larval filariæ are liberated, man becoming infected by drinking the water thus contaminated. It has been held that Dirofilaria immitis has a similar derelopment. 
According to Noe, some of the larve are taken with the infected blood into the bodies of blood-sucking insects. From the intestine they migrate to the Malpighian tubes where they undergo a certain degree of development. In about twelve days from the time they entered the borly of the insect they pass through the walls of the Malpighian tubes and entrr the mouth parts. If the piereing organ of the insect is broken during the act of sucking blood, the animal beeomes infected, and the harve are earried with the blood or lynuph to the heart where they at tain sexual maturity.

Grassi demonst rated ly his investigations that nearly all of the larva of the filaria of man lie in the intestines of mosquitoes, and that the fog filaria camnot live in other parasitie insects harbored by dogs. He concluckel, therefore, that the larva from affected anmals reach the water rirectly.

The prevalence of the lisease in low marshy localities points to the transmission of henutic filariasis through contaminated water. The kure from affocted animals may leach the water with the excrenent, the urine, or, occasionally, with blood from wounds. In such ease infection nay be direct or after the larve have undergone a further development in an intermediate small crustacenn, as eyclops, the parasites gaining rentrance to the mammalian host by way of the alimentary canal and from here reaching the blood streani to be carried by the venous bloor to the light healt.

Treatment.-Therapeutie measures in this form of filariasis, especially where there is promonneel disturbance of nutrition and circulation, is unsutisfatory. Nutritions foot and the avoidanes of exertion, conjoined with the arhinistration of heart stimulants and prevention, so far ats possible, of roinfortion, may bring results if the parasites are not ton mumerous or the disturbances oceasioned by them are not too far advinechl.

2. Spiroptera sanguinolenta (Filaria sanguinolenta). Filariidæ (p. 24.). - The most prominent charaeteristic of this wolm is its bloodref color. The tail of the make is obtuse, spiral, and has two lateral wings. There are two spicules. The tail of the female is obtuse and slightly eurverl. The rulva is situated 2 to $3 \mathrm{~mm}$. behind the mouth.

Length of female, $6-8 \mathrm{~cm}$. (2 3/8-3 1 / 8 inches); male, $3-5 \mathrm{~cm}$. (1 $1 / 4$ 2 inches).

The rges are thick-shelled, elliptical, and about 30 mierons long by 12 microns in width.

Occurrence and Pathogenesis. - This nematode of the dog is usually found lolget in tumors of the esophagus and stomach, though it is oecasionally met with in large blood vessels, the hungs, and in lymph nodes. The tumors vary in size from that of a hazel mut to that of a pigeon's egg, and usually but few are present. They lie beneath the 
mucosa, which is unaltered with the exception of an opening at the tumor's summit. Outwardly, they are limited by the muscular coat.

Upon incision of the hardened tissue of the tumor it is found to contain cavities which, on pressure, yield a purulent fluid with which are extruded the parasites. A varying number of worms may be found coiled up in these chambers, generally from two or three up to twenty.

Symptoms and Course.-The most characteristic symptom of the presence of this worm is persistent vomiting. A fatal termination may be brought about from inanition resulting from the repeated vomiting, or the gastric tumors may rupture upon the peritoneum and cause a fatal peritonitis.

Development.-Railliet has demonstrated that the eggs retain their shells in their passage through the intestines of the dog and reach the outside with the excrement. Researches of Grassi have shown that the embryos then pass into the body of a cockroach, probably by its feeding upon the egg-containing excrement of infected dogs. In the body-cavity of this insect he found large cysts containing larval nematodes agreeing in color with this species. The cysts were fed to dogs which, after two weeks, showed on necropsy the young parasites already embedded in the mucosa of the esophagus. Natural infection of dogs probably occurs by their eating the roaches containing these cysts.

Treatment.-In the absence of precise symptoms indicating the presence of these worms, the diagnosis in practically all cases being made post-mortem, there is little to be said as to the treatment of the affection. Bismuth or small doses of cocaine may be given as palliative treatment for the relief of the recurrent vomiting.

\section{Filárilde of the Hog}

1. Arduenna strongylina (Spiroptera strongylina). Filariidæ (p. 244), - The body is subcylindrical and of ten curved ina semicircle. The anterior portion is attenuated, the posterior somewhat broader. The cuticle is densely striated transversely. The mouth has two lateral lips, each with three lobes leading into a small buceal capsule which is followed by a cylindrical pharynx marked with cuticular ridges forming a series of spirals. The caudal end of the male is curved, has two unequal wings, and five pairs of stalked papillæ asymmetrically arranged. The spicules are long and very unequal. The vulva of the female is slightlyanterior to the middle of the body.

Length of female, 16-22 mm. (5/8-7/s of an inch); male, 10-15 mm. $(3 / 8-5 / 8$ of an inch).

The eggs are oval, 34-39 microns long by 20 microns wide. They have thick shells and contain well-developed embryos at the time of oviposition. 
The species is parasitic in the stomach and small intestine of the hog.

2. Physocephalus sexalatus (Spiroptera sexalata). Filariid: ( $p$. 214).--The body is subcylindrical and slightly tapering anteriorly. The head is made distinct by a cuticular inflation extending to the posterior end of the pharynx. The mouth has two three-lobed lips; each lobe having a rounded papilla and leading into a small buccal capsule. The cylindrical pharynx has a spiral band which usually breaks up into separate rings in the middle of its course and again becomes spiral toward the posterior end. The body of the male is nearly uniform in diameter. The caudal extremity is twisted spirally and has narrow membranous wings which are symmetrical. There are eight pairs of papillæ, of which four pairs are preanal and stalked, the postanal papillæ small, with short stalks, and close to the tail. The spicules are very unequal. The body of the female is thickest near the anus, terminating abruptly in a blunt point furnished with a small conical tip. The vulva is posterior to the middle of the body.

I.ength of female, $13-19 \mathrm{~mm}$. (1/2-3/4 of an inch). In the region dilectly anterior to the anus the width is $333-450$ microns. The male is (j-9 nmm. (3/16-11/32 of an inch) in length.

The eggs are oval, $3 \pm$ by 15 microns, slightly flattened at the poles, and thick-shelled. They contain well-developed embryos at the time of oviposition.

The species is parasitic in the stomach and small intestine of the hog.

In neither of these two species is the life history known. The thickness of the rgg-shell indicates that the embryos are not released until this is acted upon by the gastric juice of the host, and, therefore, that development occurs without an intermediate host.

In a report upon his investigations of these worms published in 1912, loster, of the \%oölogical Division of the Bureau of Animal Industry, grives the following summary:

"T'wo species of roundworms belonging to the family Filariidæ, of particular interest to hehminthologists and veterinarians on account of their wide distribution and frequency of occurrence in American swine and the possibility that they may cause scrious injury to their host, are given special consideration in this paper.

"One of these species, identified as Spiroptera strongylina, has recently been placed in a new genus, Arduenna, of which it is the type, and several crrors regarding the anatomy of this parasite have been corrected. Another species, Arduenna dentata, has been found in China associated with Arduenna strongylina, and, although not yet reported in Imelican swine, is mentioned in this connection, as further investigation may leveal its presence in this country.

"Arduenna strongylina is much more common in American swine than it is said to be in European swine, and has been found abundantly in 
the slaughterhouses of St. Louis, Chicago, South Omaha, and Kansas City, and has also been collected at Benning, D. C., and Bethesda, MId.

"Specimens of hogs' stomachs received from Chicago showed the worms deeply fastened in the submucosa or embedded in necrotic tissue near which were dcep ulcers. The condition suggested infcction with Bacillus necrophorus, the inoculation with which might easily result from the burrowing of the worms; however, owing to the sterile condition of the specimens received, this could not be satisfactorily demonstrated. A similar diseased condition of the stomachs of hogs in Europe is attributed by Von Rátz to infeetion with Arduenna strongylina. Under the circumstances the worm should be regarded with grave suspicion, and general prophylactic measures for the prevention of the spread of the infection are suggested.

"Commonly associated with Arduenna strongylina in this country is another worm, identified as Physocephalus sexalatus, first described by Molin from specimens from the peceary (Dicotyles labiatus) from Brazil; also found by him associated with Arduenna strongylina from the wild boar in Germany. It is also reported by Von Listow (who apparently mistook this species for Arduenna strongylina) and Piana, from Europe, and by Railliet and Henry from Madagascar and Indo-China, in the former case associated with a severe gastritis. Seurat (1912) has recently reported this species from the ass and dromedary in Algeria, but his statements would seem to require confirmation.

"According to the writers' experience, Physocephalus sexalatus is almost as widely distributed as Arduenna strongylina, since out of eight lots of specimens of the latter species, specimens of Physocephalus sexalatus were found in all but one. In a mixed infection, however, it has never been found as abundantly as Arduenna strongylina. This worm has apparently the same habit of injuring the mucosa as has Arduenna strongylina, as both species were found in the same necrotic tissue in a hog's stomach. It must therefore be considered only less dangerous because it is less abundant, and should be subject to the same treatment suggested for infestation with Arduenna strongylina."

Control.-As that part of the parasite's life history external to the host is not known, no more than general preventive measures can be recommended. The author quoted above suggests the following:

"1. Hogs suffering from loss of appetite or failing to fatten under proper food and hygiene should be examined for evidence of infection by killing one or two and looking in the stomach for worms; or, where practicable, the feces of the entirc herd may be examined microscopically.

"2. Those swine found infested with stomach worms should be isolated from noninfected or presumably noninfected swine in clean pens, and the dung removed daily and mixed with quicklime or disposed of by carting it to places to which hogs do not have access. 
"3. The noninfected swine should not be allowed to remain in the sanc pens formerly occupied by the infested animals, but should have clean quarters. The old pens should be thoroughly disinfected with lime after removing the dung and burning over the ground where feasible."

Treatment. - Treatment in such infection is.mainly prophylactic. As a medieinal remely, probably benzine is one of the best. It may be given in two to four dran doses in nilk, administered as recommended in the treatment for ascarids. Areca nut, one grain per pound of bodyweight, may be given in the same manner.

\section{Filaridde of Chichens}

Of the filaria harhored by poultry, four species may be mentioned here. As to the first three at least, there is little of record in this country.

1. Dispharagus spiralis. Filariidx (p. 244).--The body is generally rolled spirally. Thros are three papillw around the mouth. The tail of the male is spiral and is provided with wings. There is but one spicule. The fonle is $9 \mathrm{~mm}$. (3/8 of an inch) and the male is $7 \mathrm{~mm}$. (5) 16 of an inch) in length.

This species lives in the wall of the esophagus and intestines of poultry.

2. Dispharagus hamulosus. Filariida (p. 244).-The body has eight denticulated longitudinal wings. The fomale is $16-25 \mathrm{~mm}$. (5/81 inch) and the male is $14 \mathrm{~mm}$. (9/16 of an inch) in length.

This worm has been found in Brazil and in Italy. It is parasitic in the gizzard of fowls.

3. Dispharagus nasutus. Filariida (p. 244).-The body is slightly attemater at its extremities. There are two long teminal papilla on each sicle of the mouth, from which two flexuous wings have their beginning. These pass to a clistance of $0.6 \mathrm{~mm}$, then curve forwald. The make is filiform, with cauclal extremity spiral. There are two unequal spicules. 'The vulva of the female is in the anterior portion of the boly. The fentale is 59 mm. (3/16-3 8 of an inch) and the male is 5 mmi. in longth.

It inhal)its the gizaard of fowls.

1. Tetrameres fissispina (Tropisurus fissispinus). Filariidx (p. 244). -This surcics is characterized by a marked sexual dimorphism. The mule is white, slender, 3-6 mm. (1/8-1/4 of an inch) in length, and bears upon the nedian and lateral lines spines foming four longitudinal series. The body of the female is sulgglobular, $2 \mathrm{~mm}$. in length by $1-2 \mathrm{~mm}$. (in width; redelish in eolor; tail short and eonieal.

The species is found in the proventrieulus of the domestic duek where it inhabits submucous crsts and may set up a scrious inflammation of these parts. It is said to be quite common in parts of New York State, and it is probablo that it exists in other localities. 


\section{CH.APTER XXI}

\section{NEMATODA. FAMILY V. STRONGYLIDE, SUBFAMILY I. METASTRONGYLINE}

\section{Worms of the Respiratory Tract}

Nematoda (p. 217).-The most prominent character by which this family may be recognized is the caudal bursa of the male which is usually well developed. The body is elongate, cylindrical, and in some cases filiform. A buceal capsule may be present or absent and may be armed with teeth in its interior. The esophagus is more or less enlarged posteriorly. The males have a more or less well-developed caudal bursa, usually divided into lateral lobes, each supported by ray-like chitinous thickenings. There are two equal or unequal spicules. The vulva of the female may be posterior or anterior to the middle of the body, usually posterior, in some cases near the anus.

Parasitism. - While these worms in their adult form mostly infest the lumen of the alimentary and respiratory tracts, other organs may be primarily or secondarily involved. The subserous larval phase of intestinal invasion by the genus (Esophagostomum and the vascular larvæ of Strongylus vulgaris may be mentioned in this connection, while other organs are not uncommonly invaded by migration. The term strongylosis is a general one which has been applied to any helminthiasis produced by strongyles. It is more precisely used when qualified by terms indicating the seat of invasion, as gastric, intestinal, bronchial, vascular, or renal strongylosis.

Being responsible for some of the most depletive and fatal forms of parasitism, the strongyl worms have especially demanded study and investigation; this has established important advances in knowledge as to their pathogenicity, though much remains to be revealed as to their life histories and consequently as to effectual means for their control. In general it may be said that low marshy pasturage and wet seasons favor infestation with strongyles, which would indicate that the ova and embryos of some forms at least are spread by water, and that contaminated water and herbage are the vehicles by which the parasites reach their hosts.

As in other parasitic invasions, age and physical condition have a decided influence in predisposition to strongylosis. Young ruminating animals are especially susceptible to the broncho-pulmonary form, while in all animals which may be affected both youtl and senility farol. 
intestinal infestation. Again, the general rule applies that resistance is always reduced in animals in low physical condition, while, essentially, crowding and general unsanitary conditions favor the transmission and spread of the parasites.

Of the Strongylidae three subfamilies may be distinguished, viz:

Subfamily I. Metastrongylina.

Subfamily II. Trichostrongylinæ.

Subfamily III. Strongylinæ.

\section{Subfamli I. Metastrongyline}

Strongylidx (p. 255).-This subgroup comprises the strongyles parasitic in the respiratory system and some in the eirculatory system. The buccal capsule is absent or very slightly developed. The bursa of the male is frequently atypical in structure and number of rays. There are two equal spicules. The eggs are in varying stages of development when deposited.

The life history is as yet unknown. It is probable that infection is without intermediate host. Romanovitch and Slavine (1914) found that eggs of Dictyocaulus filaria when placed in water formed embryos. Two noltings followed, the cuticle being retained and encapsulating the larve, and these when fed to sheep produced infection with the adult worms. This would indicate direct development and infection by the worms of this group.

Bronchinal and Puluonary Strongylosis of the Sheep and Goat

Three speciess of Metastrongyline invade the respiratory tract of the sheep and goat; a fourth,-Metastrongylus apri-described under broncho-pneumonia of the hog, is exceptionally found in the sheep.

1. Dictyocaulus filaria (Strongylus filaria). Fig. 130. Metastrongyline (p. 256).-The body is white, filiforn, slightly tapering at posterior extremity. The anterior extremity is obtuse, without wings; mouth circular and without papillæ. The bursa of the male is notehed in front; spicules short, thick, brown in color, and provided with membranous wings. The caudal extremity of the female is straight and conical; rulra somewhat posterior to the middle of the body.

Length of female, $5-10 \mathrm{~cm}$. (2-t inches); male, $3-8 \mathrm{~cm}$. (1 1/8-3 1/8 inches).

The eggs are oval, 112135 microns in length by 52-67 microns in breadth. They contain dereloped embryos which are liberated in the bronchi as the eggs are deposited.

The embryos are 540 microns long by 20 microns in dianeter, tapering to a blunt point behind. 
The worm is parasitic in the respiratory organs of the sheep, goat, camel, and deer.

2. Synthetocaulus rufescens (Strongylus rufescens). Fig. 131. Metastrongylinæ (p. 256).-The body is thin and hair-like, brownish red in color. The mouth has three papilliform lips. The bursa of the male is notched in front and has two small lateral indentations. The spicules are striped transversely and rounded at their ends. The posterior extremity of the female terminates in a blunt point; vulva immediately in front of the anus at the base of a small pre-anal elevation.
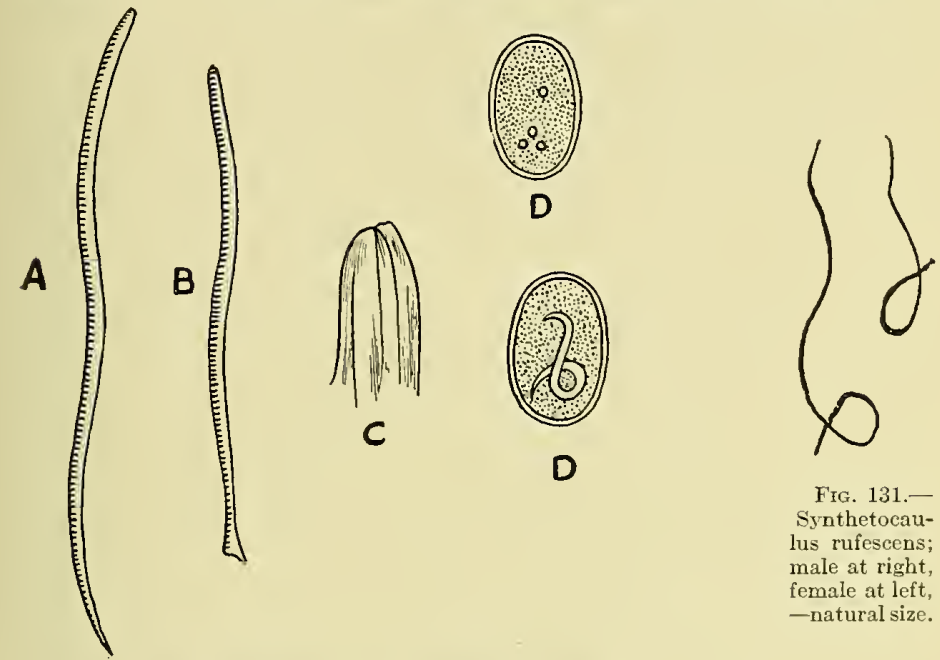

Fig. 131. Synthetocaulus rufescens; male at right, fermale at left, -natural size.

Fig. 130.-Dictyocaulus filaria: a, female; b, male, natural size; e, anterior extremity; d, eggs,- - enlarged.

Length of female, 25-35 mm. (5/8-1 3/8 inches); male, 18-28 mm. ( $3 / 4-11 / 2$ inches).

The eggs are oval, 75-120 microns in length by $45-82$ microns in breadth. Segmentation has advanced at the time they are deposited, after which the embryos develop rapidly and are liberated in the pulmonary alveoli. From the alveoli they pass to the bronchi and trachea from whence they are expelled to the outside where they have a strong vitality and are capable of resisting desiccation for a long time.

As found in the trachea and larger bronchi, the embryos measure $300-100$ microns in length by $16-18$ microns in breadth.

The worm is parasitic in the respiratory organs of the sheep, goat, and rabbit. 
3. Synthetocaulus capillaris (Strongylus capillaris). Metastrongyline (p. 256).--This worm like the preceding is thin and brownish in color, The mouth has six papilke and the caudal extremity is pointed. The caudal extremity of the male is curled spirally; bursa small and supported by seven ribs; spicules dentate. The vulva of the female is just in front of the anus.

Length of female, $20-22 \mathrm{~mm}$. ( $7 / 8$ of an inch); nale, $14 \mathrm{~mm}$. (9/16 of an ineh).

The eggs are brownish in rolor. The embryos develop after the eggs are depositerl and are liberated in the pumonary atveoli and bronchi. After depositing the eggs the adult worms invade the lung tissue where they die and become encapsulated.

The wom is parasitic in the respiratory organs of the sheep and goat.

Bronchial and pulmonary strongylosis of sheep and goats is due to the presence of these worms together with their eggs and larva in the air passages and alveoli. The affection is usually a broncho-pneumonia, though the symptoms presented will be somewhat subordinate to the infeeting spereics. If the infeetion is with Dictyocaulus filaria, or this dominates a pulmonary species coexisting in the same animal, the bronchial stmptoms will be the more prominent. On the other hand, in an abundant infestation with Synthetocaulus mescens the pumonary simptoms are likely to predominate.

Symptoms.- Bronchial strongylosis of sheep and goats is usually due to the presenee of adults of the speeies Dictyocaulus filaria in the larger air passages, and in most all cases the pulmonary form is associated with it. In general, the symptoms are those of a bronchial catarrh. There is a short dry cough which at first is at long intervals. Iater this is more frequent and may become paroxysmal and accompanied by distressing attacks of dyspnoea. The bronchial secretion expelled through the mouth and nostrils is frequently lumpy and usually, though not always, contains the worms with their eggs and embryos, the latter fomd by examination of the material with the microscope. It first the hiveliness and appetite of the animal are retained and there is no apprecialle loss of flesh. If the number of the parasites remains small there will continue to be little or no manifestation of their presence. Relative to the degree of infestation, the symptoms may pass through the gradations above given to extreme difficulty in respiration, emaciation, pallor, and edema of the larynx, muzzle, and eychids, the brisket and other dependent parts of the body in some cases also becoming edematous. Finally, in extreme weakness, the animal is unable to get upon its feet and, in a condition of complete prostration, succumbs.

Symptoms occasioned by the presence of strongyles in the pulmonary air spaces and alveoli are in themselves less prominent than those of verninous bronchitis. Attentive percussion over the thorax may reveal 
dullness in cireumseribed areas, but as a rule it shows nothing abnormal. Usually symptoms are only observed upon the appearance of cachexia and weakness following the development of purulent areas in the lung tissue, this finally bringing about the death of the animal.

Course and Prognosis.- The duration of broncho-pulmonary strongylosis varies according to the number of parasites present and the toleration of the affected animal. In the majority of unfavorable cases the disease will run a course of two, three, or four months. In the very young this period may be much shortened, the animal succumbing in a few days from the first obscrvation of symptoms. Strong adult animals, on the other hand, are likely, unless there is reinfection, to gradually recover during a course of six to eight months. In any case where the symptoms are well marked a fatal termination is to be looked for.

For Post-mortem Appearance, Development and Etiology, Control, and Treatment, refer to pp. 262-265.

\section{Bronchial and Pulmonary Strongylosis of Cattle}

Dictyocaulus viviparous (Strongylus micrurus). Fig. 132. Metastrongylinæ (p. 256).-The body is long, slender, and attenuated at both extremities. The head is rounded and without wings; mouth circular and nude. The bursa of the male is small, without lobes, and is supported by five ribs. There are two short and strong spicules. The tail of the female terminates in a sharp point; vulva near the posterior sixth of the body.

Length of female, $6-8 \mathrm{~cm} .(23 / 8-31 / 8$ inches); male, $3.5-4 \mathrm{~cm}$. (1 $3 / 8-15 / 8$ inches).

The eggs are oval, 85 microns in length by $35 \mathrm{mi}-$ crons in breadth. Embryos are developed within the body of the female and are liberated at the time the eggs are deposited.

The liberated embryos are 256 microns long by 25 microns in thickness. They pass from the bronchi to the trachea from which they are expelled to the exterior.

Symptoms.- In light infestations no symptoms may be observed save an occasional cough. When the parasites are mole numerous the cough becomes molc frequent and sonorous, and, in the further course, paroxysmal, the animal extending the head, protruding the tongue, and frcely salivating during the attacks.

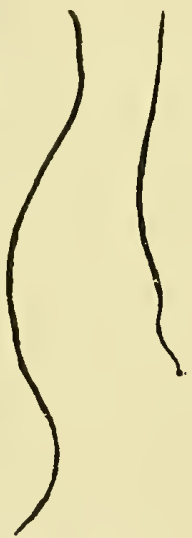

FIG. 132. - Dictyocaulus viviparous; male at right, female at left, natural size. The paroxysms are accompanied by dyspnoea and suffocation, with beating flanks, quickened pulse, and injected conjunctira. In serere 
cases with violent attacks occurring several times a day, the gasping aninal may fall prostrated and die from asphyxiation.

The mucus expelled by the coughing is frequently streaked with blood and contains the worms which are often collected in masses. It is to these masses obstructing the large bronchi that the suffocation is due.

Course and Prognosis. - What has been said as to influences governing the duration and intensity of the malady in sheep will, in general, apply to cattle also. The prognosis, especially in calves, is usually unfavorable. Death is generally brought about in three to six months by asphyxia or extreme cachexia and exhaustion.

For Post-mortem Appearance, Development and Etiology, Control, and Treatment, refer to pp. 262-265.

\section{Bronchial ayd Puluoxart Stroxgrlosis of the Pig}

Two strongyles are met with in the respiratory tract of the hog.

1. Metastrongylus apri (Strongylus apri; St. paradoxus). Fig. 133. Metastrongylinæ (p. 256).-The body is white or brown. The mouth has six lips. The bursa of the male is bilobate, each lobe

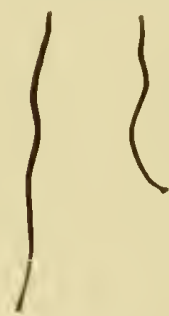

Fig. 133.Metastrongylus spri; male at right, fenale at left, - natural size. sustained by five ribs. The spicules are slender and very long, measuring about $+\mathrm{mm}$. (3/16 of an inch) and each terminated in a barb. The tail of the female terminates by a short hook-like process. The vulva is on a slight eminence immediately in fron of the anus.

Length of female, $2-5 \mathrm{~cm}$. ( $3 / 4-2$ inches); male, 1.2-2 cm. (1/2-3/4 of an inch).

The eggs are oval, $5 \overline{7}-100$ microns in length by $39-72$ microns in breadth. They contain developed embryos at the time they are deposited and these are liberated in the bronchi.

The embryos at the time of their liberation measure 220-250 microns in length and 10-12 microns in thickness.

The $\pi 01 \mathrm{~m}$ is parasitic in the respiratory tract of domestic and wild hogs, occasionally of sheep.

2. Metastrongylus brevivaginatus. Metastrongylinie (p. 256).-This species has for a long time been confounded with the preceding under the name of Strongylus paradoxus. It differs from it in the shape of the bursa and in the spicules which are short, each terminating in two barbs.

The worm is parasitic in the respiratory tract of domestic hogs.

Occurrence and Symptoms. - While the presence of strongyles in the bronchi of pigs has been known for a long time, it is not as frequently observed in these animals as in sheep and calves. Heary infestations 
with Metastrongylus apri sometimes occur with high mortality among pigs. Such cases take a course similar to that in sheep and calves. In the milder cases there may be disturbances of nutrition and occasional cough, though usually in light invasions nothing is observed to cause suspicion of the presence of the worms which are only revealed on examination of the respiratory passages after slaughtering.

For Post-mortem Appearance, Development and Etiology, Control, and Treatment, refer to pp. 262-265.

\section{Bronchial and Pulionary Strongylosis of the Horse}

Dictyocaulus arnfieldi (Strongylus arnfieldi).-Metastrongylinæ (p. 256).- The body is white and filiform and the mouth is nude. The bursa of the male is short, with faint lobulation. The spicules are slightly arched, 200-240 microns in length, and have a net-like marking. The tail of the female is short, slightly curved, and terminates in a blunt point. The vulva is situated somewhat posterior to the middle of the body and is not prominent.

Length of female, $4.3-5.51 \mathrm{~cm}$. (1 11/16-2 3/16 inches); male, 2.8$3.6 \mathrm{~cm}$. (1 1/8-1 7/16 inches).

The eggs are oval and measure $80-100$ microns in length by $50-60$ microns in breadth. They contain cleveloped embryos at the time they are deposited, and these are liberated in the respiratory passages of the host.

The liberated embryos measure $400-490$ microns in length and have a thickness of 14-18 microns.

The worm is parasitic in the bronchi of the horse and ass.

Bronchial strongylosis of equines seldom occurs. Clinically it is manifested by symptoms similar to those of rerminous bronchitis in other animals.

For Post-mortem Appearance, Development and Etiology, Control, and Treatment, refer to pp. 262-265.

\section{Cardio-Pulmonary Stroxgylosis of the Dog}

Hæmostrongylus vasorum (Strongylus vasorum). Metastrongylinæ (p. 256).-The body is filiform, whitish or reddish in color, and has longitudinal striations. The mouth is nude. The bursa of the male has two lobes, each sustained by four ribs. The vulva of the female is situated in front of the anus.

Length of female, 18-21 mm. (3/4-13/16 of an inch); male, 14-18 mm. $(9 / 16-3 / 4$ of an inch).

The eggs are oval and measure $70-80$ microns in length by $40-50$ microns in breadth. Segmentation occurs after they are deposited. 
When freed from the eggs the embryos measure 300 -360 microns in length by 13 mierons in thickness.

The worm lives in the right heart and ramifieations of the pulmonary artery of the dog.

Cardio-pulmonary strongylosis of the dog is due to the presenee of these parasites, together with their eggs and embryos, in the right ventriele of the heart and small ramifieations of the pulmonary al'tery.

Symptoms.-Fymptoms in this form of strongylosis of the dog are obscure, and generally the disease is not recognized until post-mortem examination of the animal. Respiratory disturbances occur in some eases, and there may be the development of ascites. The attacks of respiratory difficulty may disappear after a few days, or they may lead to asplyzia and the death of the animal.

For Post-mortem appcarance, refer to page 263.

\section{Pellionary śtrongrlosis of the Cat}

Synthetocaulus abstrusus (Strongylus pusillus). Metastrongylinæ (p. 256i).-The body is filiform and the mouth is without papillæ. The bursa of the male is short and slightly festooned. The spicules are slender, long and leeured. The eaudal extremity of the female terminates in a blunt point; vulva immediately in front of the amus.

Tength of fenale, about $10 \mathrm{~mm}$. (3/8 of an inch); male about $5 \mathrm{~mm}$. (3/16 of an inch).

The eggs are oval or subglolular, 60-85 mierons in length by 35-80 microns in breadth. Segmentation occurs after they are deposited.

The liberated cmlnyos are $370-450$ mierons in length by $16-18$ microns in dianeter.

The worm is parasitie in the lungs of the eat.

Symptoms.- Verminous pnemmonia of eats produced by the ova and embryos of this worn not infequently oecurs without symptoms by which it may be recognized. On the other hand, the animals may have a froquent cough accompanier by vomiting. Where emaciation and diarrhea follow upon such symptoms, death will usually result after a course of two to three month:.

\section{Post-Mortem Appearance in Bronchial and Pelmonary S'TRONGYLOSIS}

Animals which have dice as a result of strongyles in the respiratory passages will, upon neeropsy; show an abundant eolleetion of mueoid and mucopurulent matcrial in the bronchial tubes which is frequently streaked with blood and contains the adult wolms, ova, and embryos. 
The worms may be in masses sufficient to obstruct the medium-sized or larger bronchi which in places may present sac-like dilations containing bundles of worms together with more or less purulent mucus. The mucosa of the heavily infested bronchi is cclematous and may show hemorrhagic streaks. In the vicinity of bronchial dilations especially there is proliferation of connective tissue, the air-containing tissue being compressed and obliterated and at the pcriphery sometimes showing localized pleuritic adhesions.

In pneumonia due to the presence of strongyles three forms have been distinguished, viz: 1. A lobar pneumonia due to the presence of the adult worms in the ramifications of the bronchi. 2. A diffuse pneumonia due to ova and embryos which invade the pulmonary tissue in large numbers. 3. A nodular or pseudo-tuberculous pneumonia due to the accumulation of eggs and embryos in circumscribed parts of the lungs. The last is the most common form and is characterized by the presence of small, hard, grayish yellow centers from the size of a millet secd to that of a pea which may be more or less confluent. Most of these nodules are found toward the periphery of the lungs, particularly at the margins and just beneath the pleura. Generally they adhere closely to the surrounding tissue, varying in color from yellow, grayish yellow, reddish brown, violet, or black according to their age and the character of the inflammatory process. All of the centers become cascous and finally undergo calcareous infiltration.

In addition to the bronchial and pulmonary lesions there are presented in severe cases the evidences characteristic of anæmia and cachexia, involving subcutaneous edema and serous exudate in the cavities of the body.

Dogs which have suffered from cardio-pulmonary strongylosis will, on necropsy, reveal adult worms (Hcemostrongylus vasorum) in the right heart and branches of the pulmonary artery. The lungs at the bases of their lobes show circumscribed granular areas in which the tissue is gray, compact, and heavicr than water. The granules are hardly the size of a pin's head, semi-transparent, and give a roughened aspect to the surface. About the eggs and embryos lodged in the small arterioles there are found small pseudo-follicles which, on histological examination, will cxhibit three zones,-(1) a central consisting of a giant cell containing a segmented egg or embryo; (2) a middle of epithelial cells; and (3) a peripheral consisting of embryonal tissue elements disposed circularly. Larger nodules may be found, usually in close relationship to a clot in a branch of the pulmonary artery in the vicinity of which there is an accumulation of adult strongyles.

Development and Etiology.-The lungworms deposit their eggs in the respiratory passages of their host and the freed embryos are either expelled dircetly with the bronehial secretion or, passing to the pharynx, 
are swallowed and reach the outside with the feces. Further than this little is known as to their life history. The larvæ do not appear to pass through any stages of development in the bronchi of their host, the first phases of their existence probably requiring that they he expelled from the animal.

Having reached the outside, if the larvæ encounter sufficient warmth and moisture, they molt and this is later followed by a sccond molting after which they retain their coverings and in this condition may lesist desiccation for a long time. It is probable that the larvæ find their way to a host with the wet grass and, especially in the case of sheep, with collections of water upon the pastures which the animals drink. The view as to direct development and infection is supported by the investigations of Romanovitch and Slavine (p. 256), and it seems probable that in all cases of bronchial and pulmonary strongylosis the infection is direct. Some authors, however (Cobbold, Leuckart), believe that a portion of the larval stage is lived in an invertebrate host, as an earthwoln, larval insect, or molluse.

The larve are usually taken up by the host animals in the spring, though it is probable that infection nay occur at any time cluring the pasture scason. That infection cannot occur directly from animal to animal has been demonstrated by Leuckart, Herms and Freeborn and others who were not successful in bringing it about by the introduction into the respiratory passages and stomach of bronchial mucus containing numerous enbryos.

The course of the larval worms in reaching the bronchi after natural infection by way of the rligestive organs has not been demonstrated. Based upon the function of rumination and the peculiar susceptibility of ruminating animak, the invasion of the air passages has been attributed to the regurgitation of contaminated food, the worms passing from the pharynx to the larynx and trachea. But this hypothesis seens to have no more than plausibility in its support, and certainly cannot well apply to the ease of the non-ruminating hog.

Control.- In districts where bronchial and pulmonary strongylosis prevails, low, marshy and wet pastures or parts of pastures should not be accessible to susceptible animals. Drainage and a liberal covering of the ground with lime plosphates will do much to destroy the larve. Bearing in mind that roung animals are more susceptible to attack than older ones, it is arlvisable where the disease prevails to give them feed and water each day before they are turned upon pasture. This will in a measure prevent them from going to pools and marshy places for water where they are likely to linger and graze unless their night's fast has been previously somewhat broken. Where hogs and cattle are concerned the pens, stables and drinking places should be repeatedly eleaner and disinfected. Sputum, feces and bedding are not to be placed 
with manure to be spread upon the fields, but should be collected and burned as should also the infected respiratory organs of slaughtered animals.

Treatment.--Treatment with a view to attacking the worms by way of the digestive tract with remedies supposed to act by their excretion through the lungs can at most be but mildly successful. Administered in this way, a sufficient quantity of the anthelmintic to be effectual would probably include the host in its destructive effect.

Fumigation with various substances has been recommended and widely practiced. This procedure has more to recommend it than the first mentioned in that the remedy reaches the worms directly, having such a deleterious action upon them that they are more readily expelled in the coughing induced by the irritant smoke and vapors. Again an objection to the method is the intensity of application required for its success, this demanding that the animals be subjected to the fumes until they are dangerously close to asphyxiation.

Where the fumigation treatment is resorted to it should be carried out in a tightly closed building to acconmodate not more than fifty lambs at a time. Among the various substances which have been used to generate the fumes are tar, creolin, asafetida, horns, hoofparings, hair and the vapor of heated oil of turpentine. The intensity and duration of the treatment should be governed by the size and vigor of the animals and according as they become accustomed to it. At first it should not be applied for more than a few minutes each day; later two or three treatments of ten or more minutes duration each may be given daily. During the fumigation the animals should be closely watched for evidences of asphyxiation.

Of agents for creating the fumes, tar, sulphur and turpentine may be mentioned as probably among the best. These may be placed upon hot coals contained in a pot suspended by a chain from the ceiling in such manner that it will be just beyond the reach of the animals' heads. The fumes should fill the entire enclosure and can be maintained by adding more of the ingredients as required.

A more successful method of treatment is by tracheal injections of liquids which will kill the worms or reduce their vitality to a sufficient degree that they may be easily expelled. This procedure is especially to be recommended for calres and is equally effectual for lambs, though where flocks of considerable size are involved, it is not so practicable.

The measure of success attaincd by such treatment will depend largely upon the degree to which the worms and their larve have penetrated to the decper parts of the respiratory organs. The solutions used must reach their destination by gravity, aided somerhat by the currents of inspired air, so that ultimately they will probably pass no further than 
to the anterior portions of the lungs, the more deeply lodged parasites remaining unaffeeted. Furthermore, where an air passage is oceluded by a mucus plug and mass of worms, the remedy will not pass beyond the obstruction and, therefore, cannot reach the further ramifications of the passage.

Probably aqueous solutions for intratracheal injection have an advantage in more readily becoming diffused. Oily preparations do not penetrate so deeply nor do they mix with the mucus. On the other hand, it is to be said in their favor that they are not so readily absorbed as aqueous solutions and remain in the air passages longer. The use of both aqueous and oily mixt ures eonjointly might well be recommended.

Among the numerous formula for intratracheal injection the following may le mentioned; (1) Iodine two parts, iodide of potassium ten parts, distilled water one hundred parts. Mix and make into an emulsion with equal parts of oil of turpentine and olive oil. Give one to two drams to each sheep; ealves three to four drams. Two injections with an interval of two days nuy be sufficient. (2) One per cent. aqueous solution of carbolic acid. Silcep one to one and a half drams, calves three to five drams. Inject once daily for several sucessive days. (3) Creolin five parts, oil of tupentine and olive oil of each fifty parts. Sheep one to one and a lialf clrams, calves three and a half to five drams. Inject once daily for thees suecrsive days. (4) Creosote twenty parts, oil of amygclala one lumcherl parts. Calves one to one and a half drams. Injeet onee daily for four days.

The intratracheal injections should be made slowly with a curved neelle of large ealiber or with a curved trochar. Previous to the operation the wool slould he shaved or closely elipped from the region. The nerllo shoukl enter between the tracheal rings, preferably after a small incision has been made in the skin.

Baser] on experiments which they carried on for over one year (1914), involving about two liundred and fifty animals, Herms and Freeborn concluder thit chloroform arlministered nasally is, under proper conditions, a valuable method of treatment. The chloroform is introduced first into one nostril, then into the other, with an all glass syringe or medicine clropper in doses sufficient to nearly anxsthetize the animal, or, in other work, until it beeomes "groggy." The dosage required for this will depend upon the animal's suseeptibility, and therefore cannot lo exactly given. It is stated as rarying from twenty-three to forty-six drops for angora goats, and from sixty to one hundred and sixty-five drops for ealves, one-half the quantity in each nostril. The treatment is to he repeated at five or six day intervals until recovery, which, under good eonditions of food and shelter, should not require more than three injections. Experiments by the investigators mentioned have shown that, while the worms were not lilled immediately, death and disin- 
tegration of most of them occurs a few hours after the administration of the chloroform when large numbers are expelled in coughing.

Whatever procedure may be adopted in the treatment of bronchial and pulmonary strongylosis, or if treatment is not attempted, it is highly important that the animals receive plenty of nourishing food and that they be well sheltered against cold and wet weather. 


\title{
CHAPTER IXII
}

\section{NEMATODA. SUBFAMILY II. TRICHOSTRONGYLINE}

\author{
Worms of the Stomach AND Intestine
}

Strongylidx (p. 255).-These strongyles are parasitic only in the alimentary canal. The mouth is simple and without a buccal capsule (Fig. 135). The body is generally straight or it may be somewhat curved. The eggs are generally segmented at the time they are deposited. Development is direct, and infection, so far as known, is only by ingestion.

\section{Gastro-Intestinal Śtrongrlosis of the Sheep and Goat}

1. Hæmonchus contortus (Strongylus contortus). Fig. 134. Trichostrongylinx (p. 268).- The body is filiform, attenuated at the extremities, and red or white in color. The integument is striated transversely. Noar the anterior extremity there are two lateral toothlike papillse directed backward. The bursa of the male has two long lobes and a small lobe accessory to the right (Fig. 136); there are two spicules. The tail of the female is acutely pointed; anterior extremity more gradually attenuated; vulva toward posterior fifth of the body.

Length of female, $18-30 \mathrm{~mm}$. (11/16-1 3/16 inches); male, $10-20 \mathrm{~mm}$. $(3,5-3 / 4$ of an incli).

The eggs are rlongated oval and measure 70-95 microns long by 43-5t microns wide. According to Railliet they contain developed embryos at the time of reposition. Hatching probably takes place in water, the embryo at the time of its release measuring $300-400$ microns in length by $17-21$ microns in breadth. Infection is probably by drinking water and contaminated pasturage bearing the larve.

The worn is parasitic in the abomasum and duodenum of sheep, goats, and cattle.

2. Cooperia curticei (Strongylus ventricosus; St. curticei). Fig. 137. Trichostrongylinx (p. 268).-The anterior end of the body is usually coiled spirally. The cuticle at the region of the head is striated transversely; cuticle of remainder of the body exhibits fourteen to sixteen longitudinal lines. The mouth is small and not well defined. The bursa of the male has two lateral lobes and a small median lobe. The spieules are short. The rulva of the female is elose to the posterior end of the body. Tail slender and acutely pointed. 


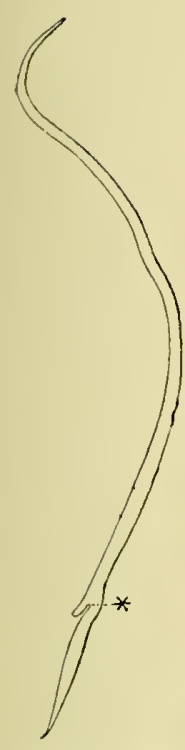

Fig. 134.-

Hæmonchus contortus, female.

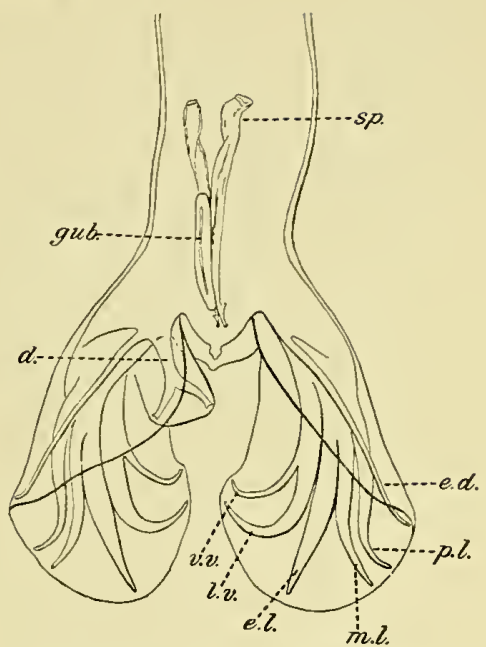

Fig. 136.-Hæmonchus contortus,-enlarged, Posterior extremity of male, dorsal view; $d$. dorsal ray supporting the asymmetrically situated dorsal lobe of bursa; e. d., externodorsal ray; e. 1., externo-lateral ray; gub., gubernaculum; l. v., latero-ventral ray; m. 1., medio-lateral ray; p. l., postero-lateral ray; sp., spicule; v. v., ventro-ventral ray (after Ransom, Bull. No. 127, Bureau An. Ind., U. S. Dept. Agr.). Fig. 135.-Hxmon- Length of female, about $6 \mathrm{~mm} .(1 / 4$
hus contortus, an- of an inch); male about $5 \mathrm{~mm} .(3 / 16$ *Vulva. x5. (Af- chus contortus, anNo. 127, Bu. body,-enlarged: c. of an inch).

An. Ind., 'U. S. p., cervical papilla; The eggs are oval, 63-70 microns in Dept. Agr.). cs., esophagus; int., length by $30-32$ microns in width, segintestine; n. r., nerve mented at time of deposition.

Bull. No. 127 , Bu. The worm is parasitic in the small An. Ind., U. S. Dept. intestine, more rarely the abomasum, Agr.).

of the sheep and goat.

3. Ostertagia marshalli. Fig. 139. Trichostrongylinæ (p. 268).The mouth is small and surrounded by six indistinct papillæ. The cuticle has twenty-five to thirty-five longitudinal ridges appearing as lines. Cervical papillæ 340-415 microns from anterior end of the body. The bursa of the male is bilobate; spicules short and similar, yellowish brown in color. The tail of the femalc is slender, gradually tapering, and rounded at the tip. The vulva is a transverse slit located near the tail extremity. 

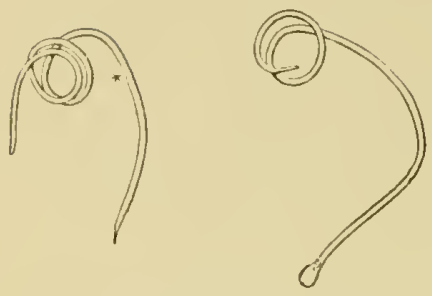

FIG, 137.-Cooperia curticei; male at right, female at left. *Vulva. x15. (After Ransom, Bull. No. 127, Burea • An. Ind., U. S. Dept. Agr.).
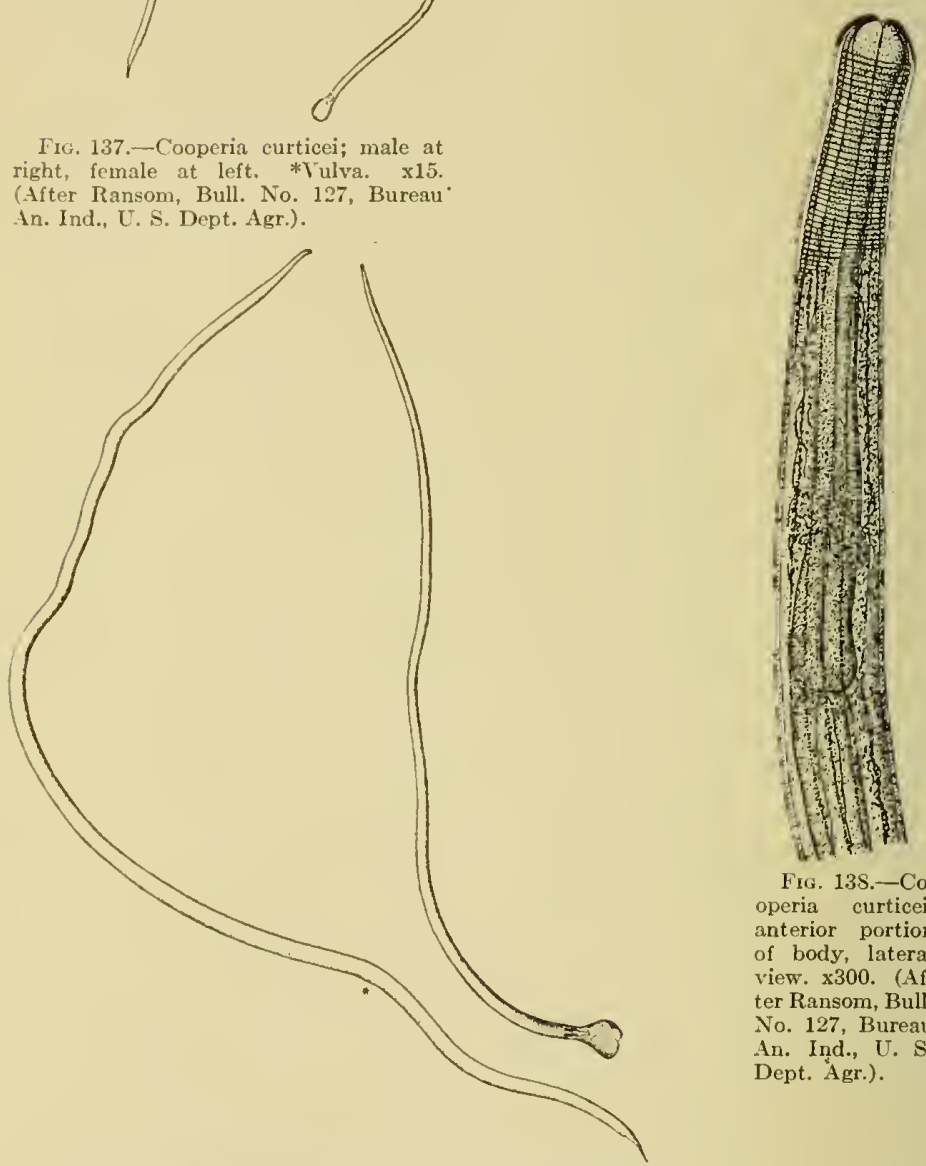

Fig. 138.--Cooperia curticei, anterior portion of body, lateral view. $\mathrm{x} 300$. (After Ransom, Bull. No. 127, Bureau An. Ind., U. S. Dept. Agr.).

FIG. 139.-Ostertagia marshalli; male at right, female at left, enlarged (after Ransom, Bull. No. 127, Bureau An. Ind., L. S. Dept. Agr.). 
Length of female, $12-20 \mathrm{~mm}$. (1/2-3/4 of an inch); male, $10-13 \mathrm{~mm}$. (3/8-1/2 an inch).

The eggs are oval, 160-200 microns in length by $75-100$ microns in breadth.

The worm is parasitic in the abomasum, rarely the small intestine, of the sheep. It was first collected by Dr. H. T. Marshall and Prof.

V. K. Chestnut in Montana.

4. Trichostrongylus instabilis (Strongylus colubriformis; St. instabilis). Fig. 140. Trichostrongylinæ (p. 268).-The body is small, slender, gradually attenuated forward from posterior fifth; color reddish. Cuticle transversely striated; longitudinal lines and cervical papillæ absent. The bursa of the male is large and laterally lobed; spicules short, spatulate, and appearing as though twisted. The body of the female is but slightly thinner toward the anus; behind the anus it suddenly narrows to form a sharp tail; vulva near middle of posterior half of the body.

Length of female, $5-6 \mathrm{~mm}$. (1/4 of an inch); male, $4-5 \mathrm{~mm}$. (3/16 of an inch).

The eggs are oval, $73-76$ microns in length by $40-43$ microns in breadth.

The worm is parasitic in the duodenum of sheep and goats of North Africa, Europe, Japan, and United States. In Egypt it has been observed in man.

Other species which may be found in sheep and goats are Nematodirus filicollis and Cooperia oncophora which are referred to under gastro-intestinal strongylosis of cattle.

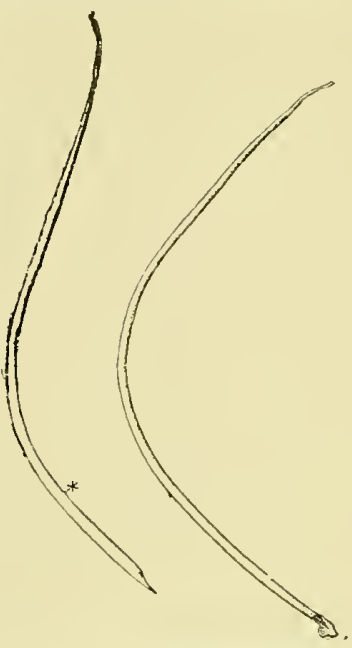

FIG. 110.-Trichostrongylus instabilis; male at right, female at left.-* Vulva. x15. (After Ransom, Bull. No. 127, Bureau An. Ind., U. S. Dept. Agr.).

Occurrence.-Gastro-intestinal strongylosis of sheep and goats is generally caused by the presence of Homonchus contortus which may be in association with one or more other species. This stomach worm is recognized as one of the most serious of the numerous pests with which the sheep raiser has to contend. Animals of all ages become infected, but the most serious effects are observed in lambs and kids. Occurring mostly in wet marshy districts and in seasons of frequent rain - conditions favorable to the propagation of the lung as well as the gastric worms-the affection is frequently associated with the respiratory form of strongylosis.

In the United States the stomach worm of sheep, goats, and cattle 
is espccially prevalent in the Mississippi Valley, in the region of rivers tributary to the Mississippi, and in the Gulf States. In parts of the Middle West and South the parasite has been such a source of discouragement as to cause the sheep industry to be almost completcly abandoned.

Pathogenesis. - Taken up as larvæ with ingested plants or drinking water, the worms attack the mucosa of the fourth stomach and feed upon the blood of their host. The degree of disturbance which they cause will be proportionate to their number. Heavy infestations are accompanied by disorders of digestion and lead through loss of blood to anemia, dropsy, and cmaciation, the general morbid effect being contributed to by the toxins claborated by the parasites.

Symptoms. - The symptoms are those of a pernicious anæmia. The infected animal becomes dull and spiritless and there is arrested development. The appetite is diminished and depraved, and the animal frequently secks water to quench an intense thirst. The anæmia is revealed in the paleness of the skin and visible mucous membranes and in the edematous swellings in dependent parts of the body, often under the lower jaw. Later in the course of the disease a diarrea appears with watery dark discharge of putrid odor. In some cases the toxic disturbances may he manifested by convulsions or paralysis. Finally, after a course of scveral months, the animal dies in a state of extreme emaciation and weakness.

The cause of these symptoms of a progressive anæmia can often be no more tlian suspected, and, where the condition prevails in flocks, a more certain cliagnosis may be made by killing an affected animal and examining the fourth stomach.

For Post-mortem Appearance, Development, Control, and Treatment, refer to pp. $275-279$.

\section{Gastro-Intestinal Strongylosis of Cattle}

Sereral species of strongyles may occur in the abomasum of cattle. Of these the most important are Homonchus contortus, described under gastro-intestinal strongylosis of sheep, and the encysted stomach worm, Ostertagia ostertagi.

1. Ostertagia ostertagi (Strongylus ostertagi). Fig. 111. Trichostrongylina (p. 268). - The hody is filiform with attenuated extremities. The mouth is small and surrounded by six indistinct papillæ; cervical papilla present. The cuticle has 25 to 35 longitudinal lines or ridges. The bursa of the male is comparatively small and has two lateral lobes united by a small median lobe (Fig. 142). The spicules are short, each having two slender barbed processes coming off from the inner side in the posterior half. The vulva of the fomale is a transverse slit covered 


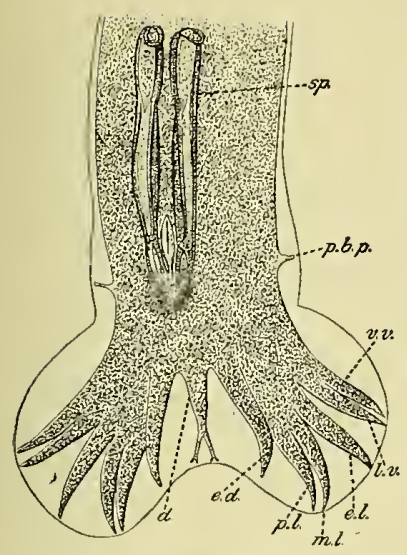

FIG. 142.-Ostertagia ostertagi. Posterior extremity of rnale with bursa spread out: d, dorsal ray; e. d., externo-dorsal ray; p. l., posterolateral ray; m. l., medio-lateral ray; e. l., externo-lateral ray; 1. v., lateroventral ray; v. v., ventro-ventral ray; p. b. p., pre-bursal papilla; sp., spicules. x150. (After Ransom, from Railliet, Bull. No. 127, Bureau An. Ind., U. S. Dept. Agr.).

by a prominent cuticular flap; it is located close to the caudal extremity of the body. The tail tapers gradually and ends in a slender tip.

Length of female, $8-10 \mathrm{~mm}$. (5/16-3/8 of an inch); male, $7-8 \mathrm{~mm}$. (1/4-5/16 of an inch.)

The eggs are oval, $65-80$ microns in length by $30-40$ microns in breadth.

The worm is parasitic in the wall and eavity of the abomasum of cattle.

2. Nemàtodirus filicollis (Strongylus filicollis). Fig. 143. Trichostrongylinæ (p. 268). - This is a white hair-like worm, very thin in front, thicker behind. The cuticle has eighteen longitudinal ridges. The bursa of the male is bilobate; there are two very long and slender spicules united by a membrane posteriorly which forms a spatulate enlargement at the tip. The vulva of the female is a transverse slit located about one-thind of the length of the body from the eaudal extremity. At this location the body has its maximum thickness which is suddenly reduced 


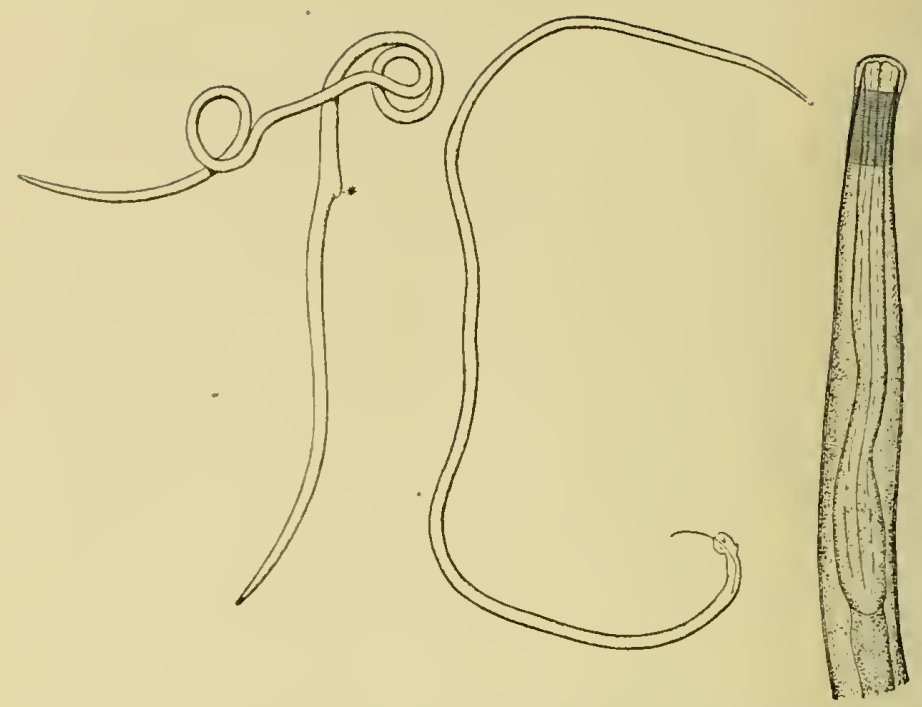

Fig. 143.-Nematodirus filieollis; male in eenter, female at left. *Vulva. x15. At right, enlarged anterior portion of body. (After Ransom, Bull. No. 127, Bureau An. Ind., [C. S. Dept. Agr.).

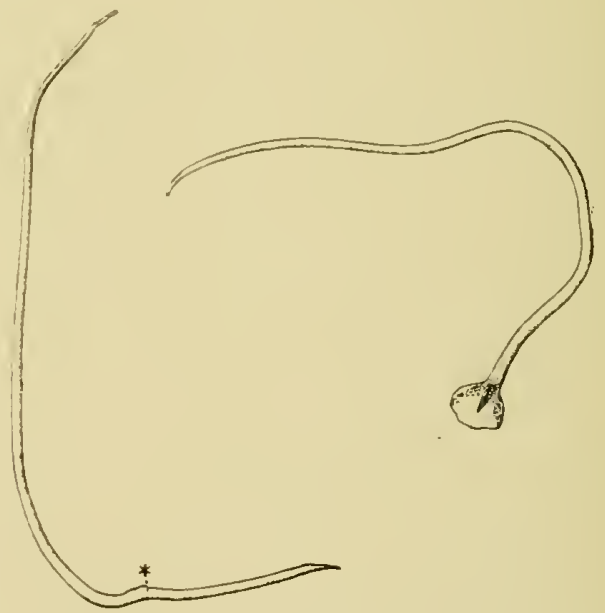

FIG. 14.-Cooperia oncophora; male at right, female at left. * Vulva. $x 15$. (After Ransom, Bull. No. 127, Bureau An. Ind., U. S. Dept. Agr.). 
just behind the vulva. The tip of the tail is truncate and bears a short bristle-like process.

Length of female, $10-24 \mathrm{~mm}$, (3/8-15/16 of an inch); male, $8-13 \mathrm{~mm}$. (5/16-1/2 of an inch).

The eggs are elongated oval, $110-113$ microns in length by $64-70$ microns in breadth; segmented at time of deposition. The further development is not known.

The worm is parasitic in the small intestine of cattle, sheep, and goats.

3. Cooperia oncophora (Strongylus oncophora). Fig. 144. Trichostrongylinæ $(p, 268)$. - The head is rounded, without well-marked papil$l æ ;$ mouth cavity small and not well defined. The cuticle in the region of the head is transversely striated; cuticle of remainder of body with 1416 longitudinal lines or ridges; cervical papillæ absent. The bursa of the male, when spread, is large and has two lateral lobes and a small median lobe; border of median lobe incised. The spicules are short and of comparatively simple structure. The vulva of the female is in the posterior fourth of the body. At the region of the vulva the body is much enlarged. The tail is slender with rounded tip; terminal portion of tail marked with annular striations.

Length of female, $6-8 \mathrm{~mm}$. (5/16 of an inch); male about the same.

The eggs are oval, $60-80$ microns in length by 30 microns in width.

Inhabits the small intestine of cattle and sheep.

Occurrence and Symptoms.- Hæmonchus contortus is frequently found in the abomasum of cattle. When the infestation is heavy, which usually occurs in young pastured animals, they bring about the symptoms of a pernicious anæmia as described in the infestation of sheep. The cattle become infected by grazing upon pastures which are contaminated by the droppings of infected sheep, goats, or other infested cattle.

The symptoms caused by the presence of Ostertagia ostertagi, or the encysted st.tomach worm, are similar to those produced by Homonchus contortus. It lives in small cysts in the mucosa of the abomasum and is also found free in the contents of this organ. When numerous, they cause a catarrhal condition and disturbances of digestion.

For Post-mortem Appearance, Development, Etiology, Control, and Treatment refer to pp. 275-279.

\section{Gastro-Intestinal Strongylosis. Post-Mortem Appearance}

Examination of the contents of the abomasum and duodenum from an animal which has been heavily infested with stomach strongyles will reveal undulating movements of the fluid produced by the active wriggling about of the worms. Large numbers will also be found deeply adhering to the mucosa which will show the lesions of a subacute or chronic eatarrh. Further than this, the pernicious anæmia is evidenced 
in the paleness of the body tissues, edematous swellings, exudate into the serous cavities, and cachexia.

Where Ostertagia ostertagi are present in the abomasum of cattle they will be found both free in the stomach contents and embedded in the subepithelial tissue of the mucosa in small round cysts about the size of a pin-head or slightly larger. When numerous, the same lessions are shown as in the attack upon the mucosa of a heavy invasion with Hamonchus contortus.

\section{Gastro-Intestinal Strrongrlonis. Developaent and Etiology}

The ergs of Homonchus contortus passed in the feces of the host will hatch in a variable time according to the conditions of temperature and moisture. Whon these are favorable it nay occul in a few hours, while, under more adrerse conditions, it may take several days or weeks. Dryness or a freezing temperature kills the embryos and newly hatched larve in a short tine. Upon hatching the larva feeds upon the fecal matter with which it is surrounded. Later it becomes enveloped by a chitinous sheath, in this condition probably receiving nourishment from foor material stored within its borly. At this stage the larva can survive freezing and drying for long periods and is motile at temperatures above $40^{\circ} \mathrm{F}$, becolning more active with increase in temperature. Where there is sufficient moisture, as from dew or rain, it crawls upon a blade of grass or other regetation and gradually makes its way to a position well removed from the ground. In this position it is taken up by the grazing ruminant host and, reaching the abomasum, becomes mature in two to four weeks. If the eggs or newly hatched larva are ingested ther apparenty do not undergo further development. It seems, thereforc, that only the ensheathed larva are infective.

Control.- - Is stated in the foregoing, moisture favors the development of the embryos, while dryness kills them at their early stages. High pasture ground, therefore, with good natural drainage greatly reduees the chances of the larve reaching the infective stage. Furthermore, larva which have become infective are more motile in the presence of moisture such as is supplied by the heary dews and fogs occurring over low land; crawhing, then, out upon the wet blades of grass, the worms are more likely to be taken up by the grazing animals.

If the temperature remains constantly at about $95^{\circ} \mathrm{F}$. the infective larval stage is reached in three to four days after the eggs have passed from the body of the host. At $70^{\circ} \mathrm{F}$. one to two weelis are required, while three to four weeks are necessary at about $50^{\circ} \mathrm{F}$. At temperatures below $40^{\circ} \mathrm{F}$. the eggs are dormant and the larve rcmain inactive. Under the usual climatic conditions of the northern part of the United States, therefore, there is little possibility of new infection from placing in- 
fected and noninfected aninials together in clean fields from the first of November until March.

During the warmer months the best means of controlling the parasite seems to be by the rotation of pastures, keeping each pasture free from sheep and cattle for at least a year, by which time the larvæ will be dead. As to this method Ransom (U. S. B. A. I., Cir. No. 102) suggests the following: "Infested and noninfested sheep which have been kept together in clean fields from November to March or later, according to weather, if moved then to another clean field may remain there nearly the entire month of April before there is danger of infection. From the first of May on through the summer the pastures become infectious much more quickly after infested sheep are placed upon them, and during May it would be necessary to move the sheep at the end of every two weeks, in June at the end of every ten days, and in July and August at the end of each week, in order to prevent the noninfected sheep from becoming infected from the worms present in the rest of the flock. After the first of September the period may again be lengthened:"

The difficulties and inconveniences of this method consist in the number of small pastures and subdivisions of pastures which it requires; furthermore, it imposes limitations upon the size of the flock. It is, however, probably the most effective system thus far devised for the eradication of this parasite.

Where it can be conveniently practiced, it is a good precautionary measure to burn over the pastures in the early spring or fall. This will destroy most of the eggs and larvæ which are lodged upon the grass or upon the ground.

Treatment.-Experiences recorded with the use of drugs for the expulsion of stomach worms are somewhat varied. The success attained by such treatment has not equaled expectations based upon experiments made with the agents upon worms outside of the body of a host. It is probable that this is mainly due to the fact that drugs administered to ruminants by the mouth do not pass directly to the abomasum, but must first mix with the ingesta of the rumen and reticulum, passing from the latter by way of the omasum to the abomasum and intestine. Hence, before reaching the worms the drug become sufficiently diluted or mixed with the bulky ingesta to greatly reduce its effectiveness. Treatment for the expulsion of Homonchus contortus gives better promise for success than that for the smaller stomach strongyles, as Ostertagia ostertagi, owing to the protected position of the latter within the mucosa.

Animals which are to be treated should be taken up in the afternoon of the day previous to treatment and all food withheld from them for eighteen to twenty-two hours. The remedy should be given the following morning either with a long-necked bottle or, better, with a drenching tube consisting of about three feet of one-half inch rubber tubing with 
a fumnel inserted at one end and a four to six inch piece of metal tubing inserted in the other end, the metal tube to be placed in the animal's mouth between the molar teeth. The funnel may be held by an assistant or fastened to a post while receiving the liquid, the flow of which may be controlled by pinching the rubber tube near the insertion of the metal piece. The dosage for each sheep should be earefully measured according to age, and care taken to lower the hearl at once upon entrance of the liquid into the larynx, this of ten a result of holding the head too high and indicated by coughing.

Among the remedies used for the expulsion of stomach worms may be mentioned (1) copper sulfate, (2) gasoline, and (3) coal-tar creosote. An objection to the last named is its variable composition, the substance not infrequently sold under the name of coal-tar creosote being quite unreliable for the purpose here considered. Copper sulfate has received high recommendation and is extensively used in the sheep flocks of South Africa. It may be prepared and given as follows:

Dissolve $1 / 4$ of a pound (avoirdupois) of clear blue crystals of copper sulfate in one pint of boiling water, having first crushed the crystals in a mortar to a fine powder. In making the solution use a porcelain or enamel-ware vessel as the bluestone will corrode most metals. Add to this solution cnough cold water to make it up to three gallons, using non-metallic receptacles. This will make an approximate one per cent. solution, and, allowing for waste, will be enough for the treatment of about one hundred adult sheep.

The closage is to be graded according to age as follows:

Lambs 3 months to 1 year old. . . . .5 drams to $11 / 2 \mathrm{oz}$. (20-50 cc.).

Sheep over 1 year old.........2 to $3 \mathrm{oz}$. (64 to $96 \mathrm{cc}$.).

Calves.................... 3 to 4 oz. (96 to 128 ce.).

Yearling cattle. ..........6 oz. (192 cc.).

The animals should receive no water at any time during the day they are dosed.

Where the stomach worm exists in a flock, it has been suggested as a control measure to give 50 cc. of a one per cent. solution of copper sulfate every month or so except during the winter in climates where the winter is freezing.

Gasoline has afforded a convenient remedy, but, for reasons whieh need not be gone into here, the commercial gasoline of the present time is unsuitable for this purpose. Under such conditions only the official purified gasoline (benzinum purificatum, U. S. P.) should be used. At best, however, gasoline is probably less satisfactory for the purpose than copper sulfate; furthermore, to be effectual, the gasoline treatment must be repeated upon three consecutive days.

In the preparation for the administration of gasoline withhold water 
as well as feed. The following morning give the gasoline in milk, linseed oil, or flaxseed tea, mixing the dose for each animal according to age as follows:

Lambs..............2 drams ( 8 ce.).

Sheep . . . . . . . . . . 4 drams (16 ce.).

Calves............ 4 drams (16 ce.).

Yearling cattle....... oz. (32 ec.).

Three hours later allow feed and water. At night again confine the animals without feed and water. The next morning give the second dose, the third morning the third dose, the treatment before and after dosing being the same in each case. Gasoline should not be given in water, nor should it be given soon after the animals have taken water.

Coal-tar creosote may be given in solution of one per cent. strength. The solution is made by shaking together one ounce of coal-tar creosote and ninety-nine ounces ( 6 pints and 3 ounces) of water. The doses of this as recommended by Stiles are as follows:

Lambs 4 to 12 months old............2 to 4 ounces

Yearling sheep and above............. 3 to 5 ounces

Calves 3 to 8 months old............. 5 to 10 ounces

Yearling steers................... 1 pint

Two-year-olds and above.............. quart

If a good quality of coal-tar creosote is used, good results may be obtained from a single dose of this one per cent. solution.

Other remedies, such as lysol and arsenic, have been recommended by various authors, but probably the nost effectual will come within those which have been particularly mentioned.

The treatment should be administered to the entire herd, since animals which may be but lightly infested will remain a source of reinfection to others.

The general condition of the animals should be built up and maintained by a generous supply of nourishing food and they should receire a plentiful supply of salt. 


\section{CHAPTER XXIII}

\section{NEMIATODA. SUBFAMILY III. STRONGILINA}

\section{Worms of the Large and Small Intestines; Other Strongyles}

These worms are parasitic in the digestive tract, rarely in the respiratory organs. The buccal capsule is present. The bursa of the male is well developed and has one or two dorsal rays and two lateral ray systems of six rays each. There are two spicules. The vulva of the female is usually posterior to the middle of the body, but may be anterior to the middle. There are two ovaries.

The eggs are segniented at the time they are deposited. The embryos are rhabditiform. The development, so far as known, is direct. In some forms the development is complex, involving a nodular phasc or larval migration.

Based mainly upon the formation of the bursal rays and the location of the rulva, the Strongylina have been grouped by Railliet and Henry into five tribes, as follows:

Tribe I. Esophagostomer

Tribe II. Strongylere (Ankylostomeæ)

Tribe III. Bunostomeæ

Tribe IV. Cylicostomex

Tribe $V$. Syngamex

I. Esophagostomeæ. Strongylinæ (p. 2S0).-The bursa of the male has two lateral lobes united by a smaller median lobe. In each lateral lobe there are six rays. The ray of the median lobe divides into two main branches, each of which again divides into two. The vulva of the female is situated a short distance in front of the anus; uteri divergent. The tribe includes three gencra, as follows:

Genus I. Esophagostomum

Genus II. Chabertia (Sclerostomum)

Genus III. Agriostomum

II. Strongyleæ. Strongylinæ (p. 2S0).-The ventral and lateroventral rays of the lateral bursal lobes are close together and parallel. The medio-lateral and postero-lateral rays are not close together and parallel. The dorsal ray ends in tridigitate terminations. The vulva of the female is situated in the posterior third of the body; uteri divergent. The tribe includes four gencra, as follows:

Genus I. Strongylus

Genus II. Ankylostoma

Genus III. Uncinaria

Genus IV. Characostomum 
III. Bunostomeæ. Strongylinæ (p. 280).-The ventral and lateroventral rays of the bursal lobes are close together and parallel. The medio-lateral and postero-lateral rays are not close together and are not parallel. The dorsal ray ends in a bifurcation. The vulva of the female is situated in the middle of the body or a little anterior to the middle; uteri divergent. The tribe includes four genera, as follows:

Genus I. Bunostomum

Genus II. Gaigeria

Genus III. Bathmostomum

Genus IV. Grammocephalus

IV. Cylicostomeæ. Strongylinæ (p. 280).-The ventral and lateroventral rays of the bursal lobes are close together and parallel. The medio-lateral and postero-lateral rays are not close together and parallel. The dorsal and externo-dorsal rays originate separately. The vulva of the female is situated close to the anus; uteri convergent. The tribe includes four genera, as follows:

Genus I. Cylicostomum

Genus II. Esophagodontus

Genus III. Gyalocephalus

Genus IV. Triodontophorus

V. Syngameæ. Strongylinæ (p. 280). - The bursa is obliquely truncated. The anterior and middle rays are cleft, the posterior tridigitate. The vulva of the female is situated in the anterior quarter of the body; uteri divergent. The tribe includes one genus-Syngamus.

\section{Nodular Stroxgylosis of the Sheep and Goat. Esophagosto- MIASIS}

1. Esophagostomum columbianum. Fig. 145. Strongylinæ (p. 280). - The thickness of the body is nearly uniform over its greater portion; attenuated toward ends. The anterior portion is usually curved in the form of a hook. The cuticle surrounding the mouth is inflated to form a collar which has almost the shape of a hemisphere. Six circum-oral papillæ penetrate this mouth collar. In front of the middle of the esophagus there is a transverse groove with accompanying cuticular fold extending around the body to the lateral lines. There are two cervical papillæ in front of the middle of the esophagus. Posterior to the cervical groove are two lateral membranes which extend well back along the lateral lines. The bursa of the male has two lateral lobes united by a small median lobe. The spicules are 750-850 microns in length, slender and pointed. The vulva of the female is naked, transversely elongated, and situated a short distance in front of the anus.

The length of the female is $14-18 \mathrm{~mm}$. (9/16-11/16 of an inch); male, $12-15 \mathrm{~mm}$. (1/2-19/32 of an inch). 

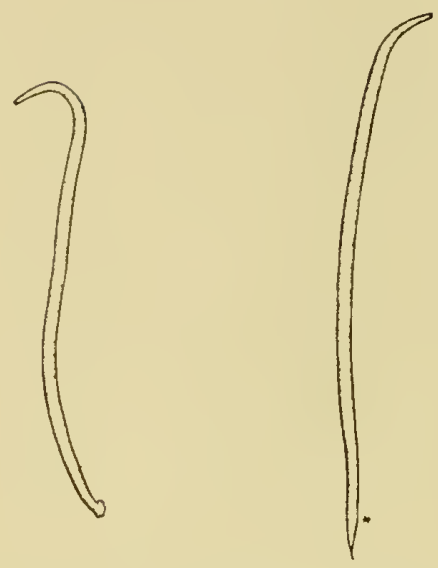

FIG. 145.-CEsophagostomum columbianum; male at left, female at right. *Vulva. x5. (After Ransom, Bull. No. 127, Burcau An. Ind., U. S. Dept. Agr.).

The eggs are oval, $65-75$ microns in length by $40-15$ nicrons in breadth. Segmentation occurs while they are within the uterus.

The freed embryos measure $230 \mathrm{mi}-$ crons in length.

Parasitic in the large intestine of the Bull. No. 127, Bureau An. Ind., sheep and goat.

2. Esophagostomum venulosum. Fig. 148. Strongylinæ (p. 280). -The thickness of the body is nearly uniform over its greater portion, attenuated toward ends. The anterior end is usually straight. The height of the cuticular collar about the mouth is about one-third of its diameter. The cuticle of the neck is inflated between the mouth collar and the cervical groove. The lateral membranes extend well back but are very narrow. The bursa of the male has two lateral lobes united by a small median lobe. The spicules are 1.1-1.5 mm. long. The vulva of the female is naked and located just in front of the anus. From a short distance in front of the vulva the body tapers, terminating in a sharply pointed tip.

The female is $15-24 \mathrm{~mm}$. (23/32-15/16 of an inch) in length; male, $12-16 \mathrm{~mm}$. (15/32-5/8 of an inch).

The eggs are oval, 90 microns in length by 55 microns in breadth. 


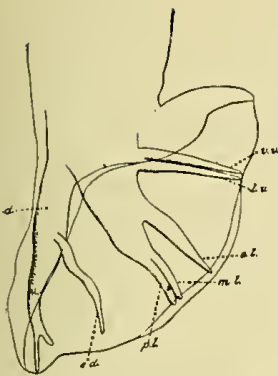

FIG. 147.-Cisophagostomum columbianum. Enlarged bursa of male viewed from right side: $d$, dorsal ray; e. l., externo-lateral ray; l. v., latero-ventral ray; m. l., medio-lateral ray; p. l., postero-lateral ray; v. v., ventro-ventral ray. (After Ransom, Bull. No. 127, Bureau An. Ind., U. S. Dept. Agr.).

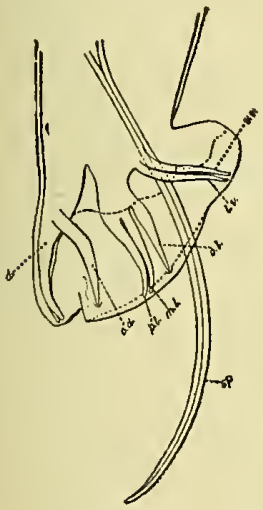

FIG. 150.
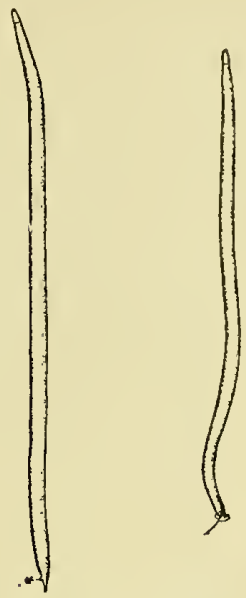

Fig. 148.-Esophagostomum venulosum; male at right, female at left. *Vulva. x5. (After Ransom, Bull. No. 127, Bureau An. Ind., U. S. Dept. Agr.).

Fig. 150.-- Esophagostomum venulosum. Enlarged bursa of male viewed from right side: d., dorsal ray; e. d., externo-dorsal ray; e. l., externo-lateral ray; $m$. l., medio-lateral ray; p. 1., postero-lateral ray; sp., spicules; v. v., ventro-ventral ray. (After Ransom, Bull. No. 127. Bureau An. Ind., U. S. Dept. Agr.).

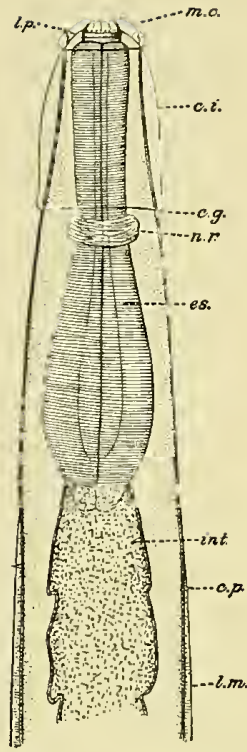

FIg. 149.-CEsophagostomum venulosum. Anterior portion of body - enlarged, ventral view: e. g., cervical groove; c.. i, cervical inflation; c. p., cervical papilla; es., esophagus; int., intestine; 1 . m., lateral membrane; 1. p., lateral circumoral papilla; m. c., mouth collar; n. r., nerve ring. (After Ransom, Bull. No. 127 , Bureau An. Ind., U. S. Dept. Agr.)

Parasitic in the large intestine, more rarely in the small intestine, of the sheep and goat. The species has been collected in Europe and in the United States. It is much less common in this country than Esophagostomum columbianum.

Occurrence and Development.-Nodular disease of the intestines of sheep caused by Esophagosotomum columbianum is common in the 
United States. The nodules are due to the larva which live embedded in the connective tissue of the submocosa, to which they at once penetrate after being taken up by the host. According to Marmotel, after six to seven months of development in this location, they pass to the intestinal lumen where they become sexually mature and the female, after copulation, deposits her eggs. The eggs pass from the host animal with the feces and promptly hatch if they meet with favorable conditions of heat and moisture. The further development outside of a host is not knomn.

Natural infection probably takes place by food and water from wet marshy pastures. If it occurs during August and September the larvæ will pass from the nodules into the intestinal lumen during March and April, here attaining maturity and copulating in July and August.

Post-mortem Appearance. - The nodules are most commonly found in the wall of the cecum and colon, but they may occur in the small intestine and at times on the liver and other abdominal organs. They may be isolated, but are frequently massed in hundreds and thousands. In size they vary from that of a pinhead to that of a pea, or they may be consilerably larger. Their color varies from blackish in the smaller ones to grarish white in the larger. The connective tissue capsule of the norlule is thick, and, as the nodule increases in size, it becomes filled with a greenish cheesy or purulent material, later becoming calcareous. Only the younger nodules contain the larve.

Symptoms. - Light infestations, with the presence of a few nodules, are not, as a rule, accompanied by perceptible symptoms, the condition in such cases being observed only after slaughtering. Relative to their degree, heavier invasions may be accompanied by diarrhea without a considerable loss of condition, or the diarrhea nay be uncontrollable and accompanied by progressive emaciation and anæmia. Such cases usually terminate fatally after a course of two or three months, the animal suceumbing in a state of coma. The effect of the invasion will depend considerably upon the age and vitality of the animals infested.

Importance.- The fact that many slaughtered sheep that were apparently perfectly healthy show these nodules tends to lead to the impression that they are of little importance and has perhaps caused them to be overlooked as a primary cause of death. Cases of nodular disease submitted to the laboratory of the Pennsylvania Bureau of Animal Industry indicate that the disease may assume an enzoötic character of severe type occasioning numerous losses. Usually where there is high mortality there is heavy infestation with large areas of massed nodules, though there are several factors which render this unnecessary to a fatal termination. Lighter invasions may have this result when by morms with a relatively high degree of virulence; when the invaded animal has a low degree of resistance, or when other worms are present to contribute to the morbid effect. Furthermore, these 
worms may infect the blood and lymph with organisms which cause other diseases through acting as direct carricrs in penetrating the intestinal wall, or by the wounds which they create affording portals of entrance. In such cases a comparatively slight infestation with Esophagostomum would be sufficient for what might prove a fatal secondary effect.

Treatment.-No effective curative treatment is known. Preventive measures consist in keeping the sheep from low wet areas. Where the disease is prevalent, lambs may be protected from serious infestation by placing them in a dry uncontaminated lot and feeding and watering them from racks and troughs sufficiently elevated that the contents cannot be soiled by droppings from the nursing ewes.

\section{Nodular Strongylosis of Cattle. Esophagostomiasis}

Esophagostomum radiatum (Æ. inflatum). Fig. 151. Strongylinæ (p. 280).- The thickness of the body is nearly uniform over its greater portion; attenuated toward ends. The anterior portion is usually curved in the form of a hook. The cuticular inflation about the mouth (mouth collar) is disk-like, its height a little more than onefourth of its diamcter. The mouth capsule is bordered by a circle of numerous small triangular denticles. The cervical groove and fold are well developed and the cuticle between it and the mouth collar is inflated. This inflation has a slight constriction at about one-third of the distance from the cervical groove to the mouth collar. The lateral membranes begin at the cervical groove and extend well back along the body; near their beginning are two cervical papillæ. The bursa of the male has two lateral lobes united by a small median lobe; spicules $700-$ 800 microns in length. The vulva of the female is transversely elongated upon an eminence located just in front of the anus. From the vulva the body rapidly tapers, terminating in a tip which is usually somewhat bent in a ventral direction.

The female is $16-20 \mathrm{~mm}$. (5/s-3/4 of an inch) in length; male, $11-16$ $\mathrm{mm} .(9 / 16-5 / 8$ of an inch).

The eggs arc oval, 75-80 microns in length by $38-43$ microns in breadth. Their segmentation occurs within the body of the female.

Parasitic in the small and large intestines of cattle.

While the nodular larval stage of Esophagostomum columbianum of sheep is usually found in the large intestine, that of Esophagostomum radiatum of cattle is often found in the small intestine, the nodules usually occurring in the terminal portion with involvement of the region of the ileo-cecal valve and the cecum.

In other respects. what has becn said as to nodular disease of sheep will, in its esscntials, apply to that of cattle. 


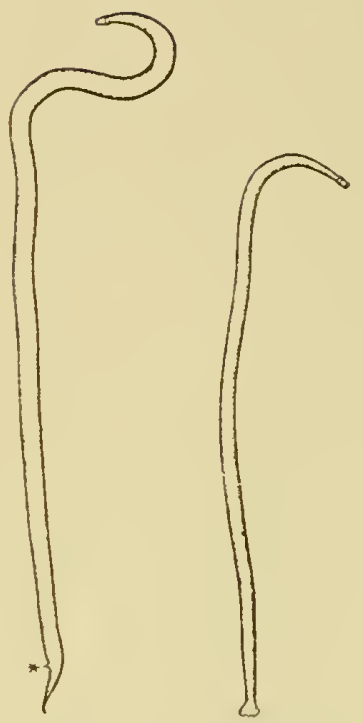

Fig. 151. - Esophagostomum radiatum; malc at right, female at left. *Tulva. x5. (After Ransom, Bull. No.127, Bureau All. Ind., U. s. Dept. Agr.).

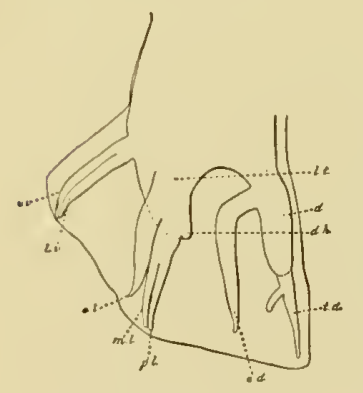

Fit. 153.

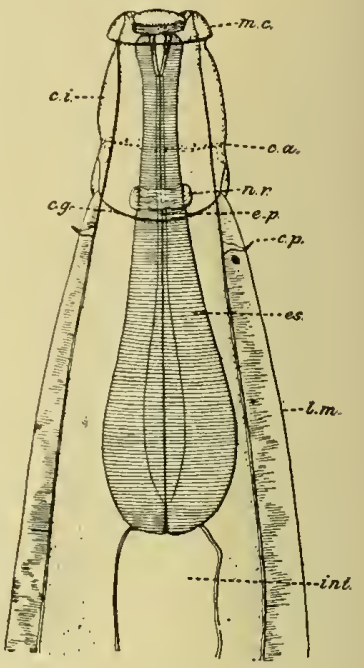

FIG. 152. - Esophagostomum radiatum. Enlarged anterior portion of body, ventral view: c. a., annular groove surrounding cervical inflation of cuticle; c. g., cervical groove; c. i., cervical inflation; c. p., cervical papilla; e. p., excretory pore; es., esophagus; int., intestine; l. m., lateral membrane; m. c., mouth collar; n. r., nerve ring. (After Ransom, Bull. No. 127, Bureau An. Ind., U. S. Dept, Agr.).

Fig. 153.- Esophagostomum radiatum. Enlarged bursa of male, vicwed from left side: d., dorsal ray; d. h., dorsal projection of trunk of lateral rays at base of postero-lateral ray; e. d., externo-dorsal ray; e. l., externo-lateral ray; 1 . t., trunk of lateral rays; $1 . v$., latero-ventral ray; m. l., medio-lateral ray; p. l., posterolateral ray; $t$. d., terminal branch of dorsal ray; v. v., ventro-ventral ray. (After Ransom, Bull. No 127, Bureau An. Ind., U. S. Dept. Agr.). 
Nodular Strongylosis of the Hog. Esophagostomiasis

Esophagostomum subulatum (CE. dentatum). Strongylinæ (p. 280). - The body is straight and attenuated at both extremities. The circular mouth is surrounded by a horny ring furnished with a crown of converging bristles. Upon a cutaneous ridge surrounding the crown of bristles are six papillæ. There are no lateral membranes. The bursa of the male has two lateral lobes united by a small median lobe; spicules slender. The vulva of the female is just in front of the anus and is surrounded by a prominent ring.

The female is $12-15 \mathrm{~mm}$. (1/2-9/16 of an inch) in length; male, 8-12 $\mathrm{mm}$. (5/16-1/2 an inch).

The eggs are oval, 60-80 microns in length by 35-45 microns in breadth.

This species is found in submucous nodules and in the lumen of the large intestine of the hog. Considerable numbers may be present without causing serious disturbance. If the infestation is unusually heavy-especially if associated with the thomheaded worm-there may be diarrhea, loss of appetite, and general unthrift. Such cases may be given treatment as recommended for other roundworms of the intestines of the hog.

STRONGYLOSis OF the LARGE INTESTINE OF THE SHEEP AND Goat

\section{Chabertia ovina (Sclero-} stomum hypostomum). Fig. 154. Strongylinæ (p. 280).The body is almost uniform in thickness. The head is slightly globular and is obliquely truncater anteriorly,
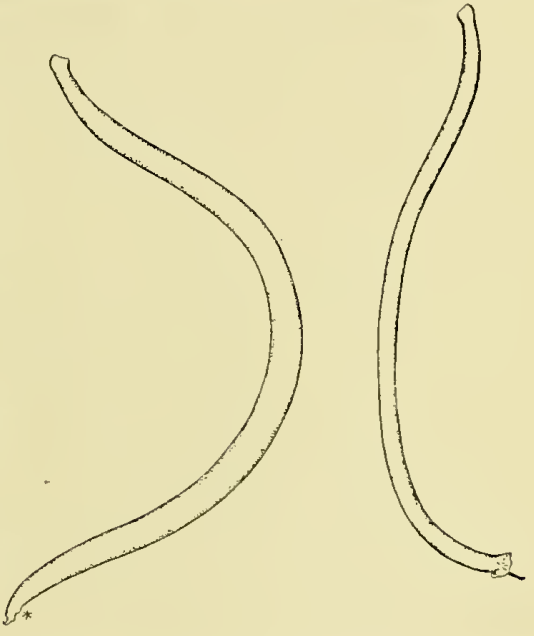

FIG. 154.-Chabertia orina; male at right, female at left. *Vulva. x5. (After Ransom, Bull. No. 127, Bureau An. Ind., U. S. Dept. Agr.). the mouth facing antero-ventrally. The buccal capsule is large; border of mouth armed with a double crown of small triangular denticles. Located ventrally, just in front of the excretory pore, is a short transver'se cervical groove. The bursa of the male is short and has an obliquely cut-off appearance; spicules long and slender. The vulva of the female 
is situated a little in front of the anus. From in front of the vulva the body gradually attenuates, the tail terminating behind the anus in a sharply pointed tip which is bent dorsally.

The female is $17-20 \mathrm{~nm}$. (11/16-3/4 of an inch) in length; male, 13$14 \mathrm{~mm}$. (1/2 an inch).

The eggs are oval, $90-100$ microns in length by 50 microns in brearth. They are segmented within the body of the female. The eggs have similar eharacters to those of other selerostomes, and it is probable that the evolution external to a host is the same.

Occurrence. - Strongylosis of the large intestine of sheep due to this species is probably more prevalent in Europe than in the United States. In referenee to the speeies, Hutyra and Marek state that it is often found in the colon of sheep, goats, and deer, inducing in some cases intestinal hemorthage and diarthea followed by anæmia and emaciation which may cause considerable loss among the young animals.

Neveu-Lemaire speaks of strongrlosis of the large intestine of sheep as at times ravaging certain flocks in the form of an epizoötic.

Ransom, in United States Bureau of Animal Industry, Bulletin No. 127 (1911), refers to Chaberlia ouna as follows: "This species appears to be comparatively harmless. Its food consists of the vegetable material in the contents of the large intestine. The buccal capsule is commonly found filled with such material.".

S'trongylosis of the INTentixes of the Horse. Sclerostomiasis

1. Strongylus equinus (St. armatus; Sclerostomum equinum). Fig. 15\%. Ntrongylinæ (p. 280).-The body is straight, rigid, and finely

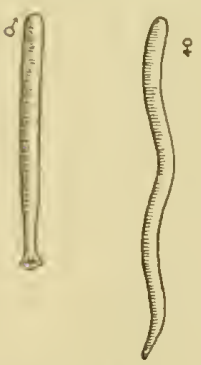

Iig. 15.5- Strongylus equinus; male at right, female at left, - natural size (drawn from specimens). striated transversely; color gray or grayish brown, or it may be shaded with red according to the amount ; of ingested blood. The mouth is distended by several rhitinous rings the innemost of which are provided with an ilnature of fine teeth, while the outermost hare six papillse. The buceal capsule has three teeth at its base. The bursa of the male has two lateral lobes between which is a smaller median lobe; spicules long and slender. The vulva of the female is located near the posterior third of the bory. The tail is obtuse.

The length of the female varies from $20-55 \mathrm{~mm} .(3 / 4$ to 2316 inches); that of the male from 18 to $35 \mathrm{~mm}$. (11 16 to $13 / 8$ inches).

The eggs are oval, 92 microns in length by $54 \mathrm{mi}-$ crons in breadth. Segmentation commences at the time of their deposition. The hatched embryos measure $340-500$ mierons in length. 
2. Strongylus edentatus (Sclerostomum edentatum). Strongylinæ (p. 280).--The head is globular. The buccal capsule is goblet-like, and teeth are absent. The bursa of the male is similar to that of Strongylus equinus. The vulva of the female is near the posterior third of the body. The female is $33-36 \mathrm{~mm}$. (1 $5 / 16-17 / 16$ inches) in length; male, $23-$ $25 \mathrm{~mm}$. (7/8-1 inch).

The eggs are oval and in dimensions about as in Strongylus equinus. As adults these worms are parasitic in the cecum and colon of the horse; as larvæ in the abdominal and thoracic organs.

3. Strongylus vulgaris (Sclerostomum vulgare). Strongylinæ (p. 280). - The buccal capsule is shallow and has a single tooth at its base, prominent projections causing the tooth to appear as two. The bursa of the male has three lobes, the median one overlapped by the two lateral. The vulva of the female is near the posterior third of the body.

The female is $24 \mathrm{~mm}$. (15/16 of an inch) in length; male, $15 \mathrm{~mm}$. $(5 / 8$ of an inch).

The eggs are as in the preceding species.

Parasitic as adults in the cecum and colon and in immature stages in the mesenteric blood vessels of the horse.

4. Cylicostomum tetracanthum (Sclerostomum tetracanthum). Strongylinæ (p. 280).-A white or reddish white worm, attenuated anteriorly, the mouth surrounded by a cuticular fold. The buccal capsule is armed with a crown of triangular teeth. The vulva of the female is just anterior to the anus.

The femalc is $10-18 \mathrm{~mm}$. (3/8-11/16 of an inch) in length; male, $8-$ $12 \mathrm{~mm}$. (5/16-1/2 an inch).

The eggs are oval, 100 microns in length by 47 microns in breadth.

Parasitic in the cecum and colon of the horse.

Development.-The worms causing sclerostomiasis of the horse were formerly grouped under the name Strongylus armatus. According to Looss (1902) it is the immature stages of the species Strongylus vulgaris (Looss, 1900) which are concerned in the production of verminous aneurysms in the mesenteric arteries of the horse. MI. Nereu-Lemaire (Parasitologie des Animaux Domestiques, 1912) describes the worm responsible for these lesions under the name Strongylus equinus.

This worm when mature lives in the cecum and colon where it firmly attaches to the mucosa by its buccal armature. In its agamous state it is found in submucous cysts of thesc organs and in aneurysms of the mesenteric artery. According to the investigations of Railliet the eggs, which are deposited in the cecum and colon and expelled with the feces, may develop in a few days if they meet with moisture at a temperature of $12^{\circ}$ to $25^{\circ} \mathrm{C}$. $\left(53^{\circ}\right.$ to $77^{\circ} \mathrm{F}$.). The hatched embryos, if they continue amid favorable conditions, grow, molt, and acquire a great vitality, It is at this stage that they are ingested by the equine host with the drink- 
ing water or perhaps with green forage. Reaching the intestines, they penetrate the mucosa from which probably the majority of them reach the circulatory system where they become lodged in the visceral arteries, as the trunk of the great mesenteric. After a variable time in this location they again enter the blood stream and, reaching the cecum, necome encysted in the submocosa where their development proceeds. Within the cyst they possess a buceal capsule and a caudal bursa, but the generative organs are not as yet developed.

linaly they pass to the lumen of the bowel where they attach to the nuccosa and acruire all the characters of the adult. Copulation then takes place, the rgas are depositerl, and a new generation repeats the cycle.

Symptoms. - The symptoms brought about by the presenee of these worms- a condition generally known under the name of sclerost omiasisare not characterist ic and vary according to the location of the parasites. The prosenes of the adults upon the mucosa of the cecum, even in considerable numbers, rarely causes serious disturbance, diarrhea and occasional attacks of colic resulting in exceptional cases.

Felerostomiasis profuced by the larva is of a much more serious nature. Their most frepuent location in this state is in the large arteries where they bring about the formation of verminous aneurysms, usually at the origin of the great mesenteric. Fragments of the clot within the aneurysu may be carried by the blood to form emboli in the arterial ramifications leading to the intestines, that portion of the intestine supplinl by an artery in which an embolus is lodged being deprived of its norinal supply of blood. As a lesult there is suspension of secretion and peristaltic movenents in this section, the walls of a portion of which freme dark and tumified with the presence of hemrorrhagic infaret. One or nure portions of the intestine may be thus affected, the arrested contents fromenting and producing an abundance of gas, while in the hothly portions of the intestines there are abnormally energetic contractions which cause a severe enteralgia and may lead to invagination, displacenent, and even rupture. The rupture may be of the paralyzed intestine, or it may be of the stomach or diaphragm, brought about by the ac'mmulation of gas generated from the stagnated and fermenting intestinal contents, the violent movements of the animal often contributing tromard this termination.

Post-mortem Appearance.-The arlult worms are fixed to the murosa, usually that of the ceemu, where they nourish from the blood of their host and produce at their point of attachment a small dark promincnee. Immature worms nay be found in submueous nodules of the cecum, or of both the cecum and colon. These nodules vary in size from that of a pinhead to that of a hazelnut and contain a small quantity of pus or sero-purulent material in which the worm, if present, is rolled up. The worms escape from the nodules by a central orifice to the lumen of 
the intestine where they attach and are sexually mature, the sexes of ten being found coupled in this location. Before their intranodular existence the larval worms live in the blood-vascular system, having gained this location through the intestinal wall immediately after their ingestion. It is at this stage that they produce the aneurysms as found in the visceral trunks of the posterior aorta. These aneurysms are usually sonewhat elongate, with tunica media much thickened, and with fibrim deposit upon the intima, on which a number of reddish tinted strongyls are likely to be fixed. The aneurysm may, however, be entirely free from worms, in which case they have probably passed with the bloodcurrent to the intestinal wall.

Where death has occurred from thrombo-embolic colic due to verminous aneurysm, the most prominent alterations found are those which have already been described in reference to this complication. The intestines are usually much distended by gas, or, if rupture has occurred, this, with more or less intestinal contents, will be in the abdominal cavity. Extensive darkly discolored areas are usually observed in the intestinal walls, and there are likely to be evidences of degeneration if the course of the attack has beell sufficiently prolonged. Owing to the great engorgment of the mesenteric vessels, it is often difficult, without the most searching examination, to discover the location of the embolus. Rarely the immediate cause of death may be found to have been due to rupture of the aneurysm and internal hemorrhage.

Treatment.-For the strongyles in the intestine the same treatment may be employed as has been recommended for the ascarids, though, owing to the firm attachment of the former to the mucosa, their expulsion is difficult. Oil of turpentine has been recommended as particularly valuable. It may be given in two to four ounce doses in oil.

In prophylaxis clean water is a main factor. This should be filtered or quite pure and free from drainage contamination.

\section{Strongylosis of the Intestine of the Dog and Cat. ANKYLostomiasis}

1. Ankylostoma canina (Dochmius trigonocephalus; Uncinaria trigonocephala; U. canina). Fig. 156. Strongylinæ (p. 280).-The body is whitish in color and slender; slightly enlarged at the anterior extremity. On the ventral surface of the buccal capsule are two chitinous plates. each having three recurving teeth. The bursa of the male is three-lobed, two large lateral and a small median. There are two long and slender spicules. The vulva of the female is situated near the posterior third of the body.

The female is $10-20 \mathrm{~mm}$. (3/8-34 of an inch) in length; male, 9-12 mm. (11/32-1/2 an inchs). 
The eggs are oval, 74-84 microns in length by 48-54 microns in breadth.

Parasitic in the small intestine of the dog and cat.

2. Uncinaria stenocephala (Dochmius stenocephalus; Ankylostomum stenocephalum). Strongyline (p. 280).- The body is very slender, and the anterior extremity is much narrower than in the pre-

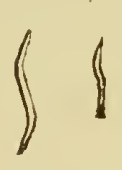

FIG. 156Ankylostoma canina, male at right, female at left (drawn from specimens). ceding species, being somewhat attenuated. The buccal capsule is conical and has two pairs of small teeth on the ventral side. The bursa of the male is similar to that of the preceding species. The vulva of the female is situated near the posterior third of the body.

The female is $8-10 \mathrm{~mm}$. (5/16-3/8 of an inch) in length; male, 6-8 mm. (1/4-5/16 of an inch).

The eggs are oval, 63-76 microns in length by $32-38$ microns in breadth.

Parasitic in the small intestine of the dog. There is no authentic report of its occurrence in this country.

Occurrence and Development.-Ankylostomiasis (dochmiasis; uncinariasis) is a severe affection of dogs caused by the presence of Ankylostoma canina. The condition is analogous to ankylostomiasis or hookworm disease of man, caused by the spccies Ankylostoma duodenale.

The worms fix themselves to the mucosa of the small intestine where they extract blood. Hunting dogs confined in kennels are those which most often suffer, especially if their quartcrs are damp. Cats are not often affected.

The development of the parasite is rapid. The eggs are segmented within the body of the female and, when expelled to moist earth, develop embryos in three to six days. These become encysted and, probably through the medium of contaminated water, reach the intestine of the dog where they mature.

Post-morten Appearance.-Necropsies upon dogs which have died in the advanced stages of ankylostomiasis show the alterations of anxmia and cachexia. The mucosa of the small intestine is thickencd and marked by numerous hemorrhagic areas. Small ulcerations are present as a result of the irritation from the attachment of the womm, and the intestinal contents may be hemorrhagic.

Symptoms.-The symptoms are those of anrmia, debility, and emaciation. There is depression and indifference, and hunting dogs lose their zest. The skin becomes dry and scaly and the coat harsh and lusterless. The legs swell intermittently at first, later the edema is greater in extent and becomes permanent. There is a muco-purulent discharge from the nostrils and this may be streaked with blood. Later there may be attacks of nasal hemorrhage. There is at first constipation, later a dysenteric diarhea. Emaciation and general debility progress, 
and the symptoms are finally terminated by death in a state of coma or it may be in convulsions.

Treatment. - As the disease usually attacks hunting packs in kennels, and there is constant reinfection, treatment is, as a rule, not successful. It is most important that care be exercised as to cleanliness of the kennel. Where possible, the sick should be removed to other quarters. Water and food should be given from buckets or troughs which are thoroughly flushed out after each meal, and the yards should be kept free from pools and mud. As medicinal treatment, the usual vermifuges recommended for dogs may be tried.

Other Strongylinæ.-Two other strongylines occasionally found in sheep and cattle may be mentioned.

1. Bunostomum trigonocephalum (Uncinaria cernua; Dochmius cernuus). Strongylinæ (p. 280).--Yellowish or reddish in color; cuticle transversely striated. The buccal capsule has a long dorsal tooth projecting forward. The mouth is surrounded by six papillæ; cephalic extremity curved dorsally. The vulva of the female is near the middle of the body.

The female is $20-28 \mathrm{~mm}$. (3/4-1 $1 / 8$ inch) in length; male, $15-18 \mathrm{~mm}$. $(5 / 8-11 / 16$ of an inch).

Parasitic in the small intestine of ruminants, particularly sheep and goats.

2. Bunostomum phlebotomum (Uncinaria radiata; Dochmius radiatus). Fig. 157. Strongylinæ (p. 280). - Dark in color. The dorsal buceal tooth is short; two rentral buceal teeth and two subventral buccal teeth or lancets. The cephalic extremity is curved.
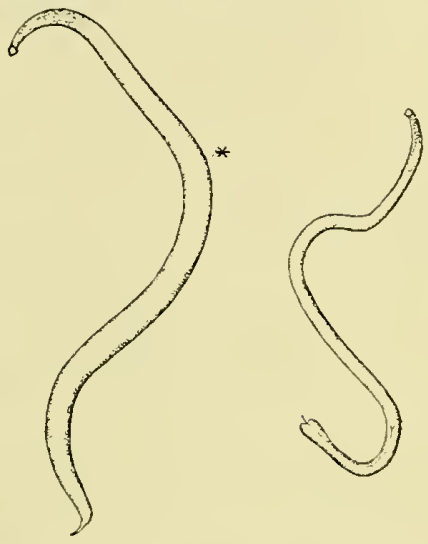

FIG. 157.-Bunostomum phlebotomum; male at right, female at left. *Vulva. x5. (After Ransom, Buil. No. 127, Bureau An. Ind., U. S. Dept. Agr.).

The female is $24-28 \mathrm{~mm}$. (15/16-1 1/s inch) in length; male, 10-16 mm. (3/8-5/8 of àn inch).

Parasitic in the small intestine of cattle.

\section{Tracheal Strongylosis of Chickens. Strgamosis}

Two species of strongylines invade the trachea and bronchi of forl,Syngamus trachealis and Syn. bronchialis. The last named is somewhat the larger and inhabits the air passages of water fowl. 
Syngamus. Strongylinæ (p. 280).-Members of this genus have a slender body of reddish color. The mouth is surrounded by a strong chitinous capsule. The female is much larger than the male and is usually found with the male firmly attached at the vulva which is situated near the anterior quarter of the body. This permanent coupling gives to the pair a forked appearance from which the worm has deriverl its common nams of "forked worm" (Fig. 158). The attachment of male and female is less constant with the species Syn. bronchialis.

The female of syngamus trachealis is 5-20 $\mathrm{mm}$. $(3 / 16-3 / 4)$ of an inch in length; male, 2-6 mm. (1/16-1/4 of an inch).

The eggs are elliptical, measuring 85 microns in length by 50 microns in breadth. In the uterus of the fomale they undergo a variable degree

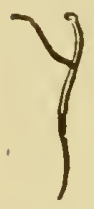

Fig. 15is. Gingumus trachealis; male (at tacherl at left) anct female). of derelopment, containing when freed al segmented mass or a sereloped embryo. The egge are not laid hut escape from the hody by its rupture, which ordinarily occurs from decomposition, though, according to Railliet, eggs contained in the vagina may pass through the rulva and from under the hursa of the male to the outside.

Occurrence and Development.- The condition produced in fow hy syngami is commonly known in England and the Inited States as gapes. It is widely prevalent, practically all of our domestio birds and many wild birds, espccially those in captivity, suffering from it.

I peculiar fouture in the evolution of syngamus trachealis is the fact alrady noted that, due to the covering of the vulva by the promanent attachment of the male, the eggs cannot be "xtruder and are only liberated by the rupture or disintegration of the mothel worm. This may oceur within the air passages or after the worm has been expelled. If the eggs meet with water or moist earth thr embryos develop and are liatched in seren to forty days according to temperature. Birks may become infested by ingesting eggs or embryos, often by eating the worms expelled by infested members of the flock. From the digestive tract the larve migrate to the air passages where they mature.

Lesions. - The worms are generally found covered with mucus and in wreatest number near the division of the trachea into bronchi. The mrucosa, to which they are firmly fixed by their buccal capsule, exhibits at each point of attachment a small purulent tumor, or there may have developed an abscess sufficiently large to obstruct the trachea. The number of coupled worms present may he three or four or twenty to thirty, the smaller numbers being quite sufficient to cause death by asphyxiation, though this will be influenced somewhat by age and the dianeter of the trachea.

Symptoms.- Young birds suffer most from synganosis, those in 
good condition being equally susceptible with others. A typical symptom of the affection is a peculiar stretching of the neck accompanied by a yawn-like opening of the beak from which novement the disease derives its name "gapes," The birds repeatedly shake their heads, sneeze, and expel tenacious masses of mucus which may contain one or more pairs of the worms. The appetite, at first voracious, diminishes, and the birds become dull and inactive with feathers erect and lusterless.

Emaciation progresses, the mouth is filled with frothy saliva, respiration becomes increasingly difficult, and the animal dies from exhaustion, or it may be from asphyxia before such advanced symptoms are reached. Recovery is rare in young birds. Older ones sometimes survive if the infestation is light.

Treatment. - A method of treatment commonly practiced is to strip a feather of its barbules to within a short distance of its tip and inserting this into the trachea with a rotary movement, attempt to detach and elevate the worms. Only such worms as are not firmly fixed to the mucosa are removed by this process and, in view of the danger of its causing suffocation, it is a questionable procedure unless as an urgent palliative measure.

$A$ better treatment is to give with the food certain substances of strong odor eliminated in the respiratory passages and having a deleterious effect upon the parasites. As such agents garlic and asafetida have been employed with success. According to Neumann, Mégnin has had good results with a mixture of equal parts of asafetida and powdered gentian root incorporated in a cake and given in the proportion of eight grains per bird each day.

Another method recommended is the injection into the trachea of about fifteen drops of a five to eight per cent. solution of salicylic acid. The injection should be made slowly with a small syringe and canula.

Fumigations with such agents as sulphurous acid or tobacco smoke, resorted to by some, involve such risk of accident from suffocation as to make their use unadvisable.

As prevention, affected birds and those apparently healthy should be removed to clean and separate quarters and the infested yards cleaned and sprinkled with a one to one thousand solution of sulphuric acid. The bodies of dead birds are to be buried deeply or burned. Food and water should be fresh, given from elean utensils, and not permitted to stand ahout. As an aid in prevention the addition of fifteen grains of salicylate of soda to the quart of drinking water has been recommended.

The Kidvey Worm of the Hog

Stephanurus dentatus. Strongylidæ (p. 255).-This worm is at present of somewhat uncertain position in the elassification of the 
strongyles. The body is thick, cylindrical, and has a mottled appearance, due to the intestine and reproductive organs showing through the semi-transparent integument. Both extrenities are somewhat blunted; the mouth terminal with six small teeth. The bursa of the male is formed of five tongue-like parts united by a membrane; there is but one spicule. The obtuse caudal extremity of the female is curved; rulva near the middle of the body.

The length of the female is $30-10 \mathrm{~mm}$. (1 3/16-1 9/16 inch); male, 22-30 mm. ( $7 / 8-13 / 16$ inch).

Parasitic in fat surrounding abdominal viscera, especially that of the sublumbar region in the vicinity of the kidneys.

The kidney-worm is found in hogs of the United States-especially those of the South - and in south America, the species being first discovered in Brazil. Its presence may cause the formation of eysts up to the size of a pigeon's egg in the adlipose tissue, these on incision usually revealing one or two of the worms and a small amount of pus. Rarely the worms penetrate the capsule of the kidney or enter the suprarenals. Indurated fistulous tracts, liver lesions, and peritoneal effusion have been observed as a result of the presence of these parasites, though it may be said of them that they rarely cause perceptible disturbance unless in unusual locations in the abdominal eavity.

Due to their location, treatment can be of no value.

\section{FAMHLY VI. ELSTRONGYLIDE}

\section{EustrongrLosis}

This is a condition produced by a giant nematode,-Dioctophyme renale (I). visceralis; Eustrongylus visceralis; Eu. gigas), which is sometimes met with in the kidney and peritoneal cavity of dogs and other domestic animals. It has also been reported in man.

Dioctophyme renale (Nenatoda, p. 217) is of somewhat uncertain position anong the nematodes. It has been commonly placed with the family strongylicks, but it does not conform to all of the characteristics of this fanily. Neveu-Lennaire deseribes the genus Eustrongylus under the separate family Eustrongylidir.

The worn is the largest of all the nematodes, the female attaining a length of one meter ( 39 inches) and a thickness of a centimeter (3/s of an inch); the males a length of forty centimeters (15 inches). The borly is bloorl-red in color, somewhat thinner toward the anterior extremity than postriorly. The bursa of the male is collar-like, entire, and without rays. Within its base is located the anus. There is a single slender spicule (Fig. 159). The tail of the female is obtuse. There is a singte ovary; vulva near the mouth. 
The eggs are $64-68$ microns in length by $40-44$ microns in width. They are brownish in color and have numerous round depressions on their surface. They develop in a moist medium.

The embryos are tapering at the extremities and about 240 microns in length by 40 microns in brearth. They have a great vitality and may survive within the eggs for a year or more.

Attempts at direct infection have been unsuccessful. An intermediate host is evidently required, and the fact that the worm is found parasitic in the seal and otter points to the probability that it lives a portion of its life in a fish.

The eustrongyle is much more frequent in Carnivora, especially the dog, than in other animals, but it is rarely met with. In the Journal of the American Veterinary Medical Association, June, 1917, Hall states that from Riley's and his own record of cases reported it appears that this worm has been found at least forty or fifty times in the United States. How and in what form it finds its way into the body of its host is not known. It is most frequently found in the pelvis of the kidney where it grows to an enormous size, producing a purulent inflammation from which destruction of the renal tissue follows. Eventually the kidney becomes a mere thick-walled cyst containing a bloody purulent material within which the worm is coiled up. But one kidney is invaded, usually by a single worm, though in rare cases two have been found in the kidney pelvis. The uninfesterl kidney is usually found to have undergone a compensatory hypertrophy. The worm has been met with in other parts of the urinary organs, as in a part or the whole of the ureter and in the bladder. Where it is found outside of the urinary organs, as in the peritoneal cavity, it is probable that it did not reach such location until after primary development in the urinary passages.

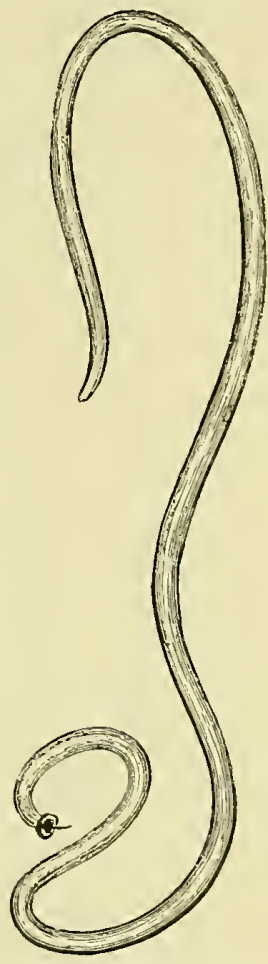

FIG. 159.-Dioetophyme renale; male,natural size (after Railliet).

Symptoms.-The symptoms are not characteristic and in some cases may not be observed. Horses and cattle especially are said to show little disturbance from the presence of the worm, while dogs, on the other hand, suffer severe pain, are restless, and sometimes exhibit a lateral curvature of the vertehral column, the coneavity correspondingto the affected side. Nicturation may be painful and with effort, and 
the urine may be purulent and bloody. An exact diagnosis can only be made in the living animal by fincling the characteristic eggs of the eustrongyle in the urine.

In view of the location and size of the worm, treatment is impracticable. 


\section{CHIPTER XIIT}

\section{NEMATODA. FAMILY VII. TRICHINELLIDE}

\section{Nematoda (p, 217).}

The nematodes of this family have a very slender and elongated anterior portion of the body, containing only the esophagus. The posterior portion is more or less enlarged and is occupied by the intestine and reproductive organs. The mouth is rounded and nude. The anus is terminal or nearly so. The males have a single testis and but one spicule or the spicule may be absent. The females have a single ovary. The vulva is located at the junction of the smaller with the larger portion of the body. They are oviparous (Trichuris) or ovoviviparous (Trichinella).

The worms of this group to be described come under two genera, Trichuris and Trichinella. Of these but one species,-Trichinella spiralis, is of pathologic importance.

Trichuris ovis (Trichocephalus affinis). Fig. 160. Trichinelliclæ (p. 299).--The esophageal portion of the body is very long and slender; the posterior portion, containing the reproductive organs, much thicker. The head is sometimes provided with two transparent wing-like enlargements. The posterior extremity is more or less blunt and rounded. The body is transversely striated. The posterior portion of the body of the male is rolled dorsally in a spiral. The spicule is very long, measuring $5-7 \mathrm{~mm}$. ( $7 / 32-9 / 32$ of an inch) and terminating in a sharp point.

The female is 50-70 $\mathrm{mm}$. (2-2 34 inches) in length, the esophageal portion constituting about tro-thirds of the total length. The male is $50-80 \mathrm{~mm}$. (2-3 1/s inches) in length, the esophageal portion in the same proportion to the total length as in the female.

The eggs are lemon-shaped, $70-80$ microns long, and have an opereular plug at each end. Development is direct.

This species is a common parasite in the large intestine of ruminants. particularly the sheep and goat. Leuckart has denonstrated that it develops directly from the egg without intermediate host and without a free living stage. When the eggs are taken into the intestine of the ruminant host the embryos are freed and attain their achult development in about sixteen days. They are usually found attached firmly to the mucosa, but apparently cause little if any trouble.

Trichuris crenatus (Trichocephalus crenatus). Trichinellidie ( $p$. 299). - The esophageal portion of the body is very slender, the posterior 

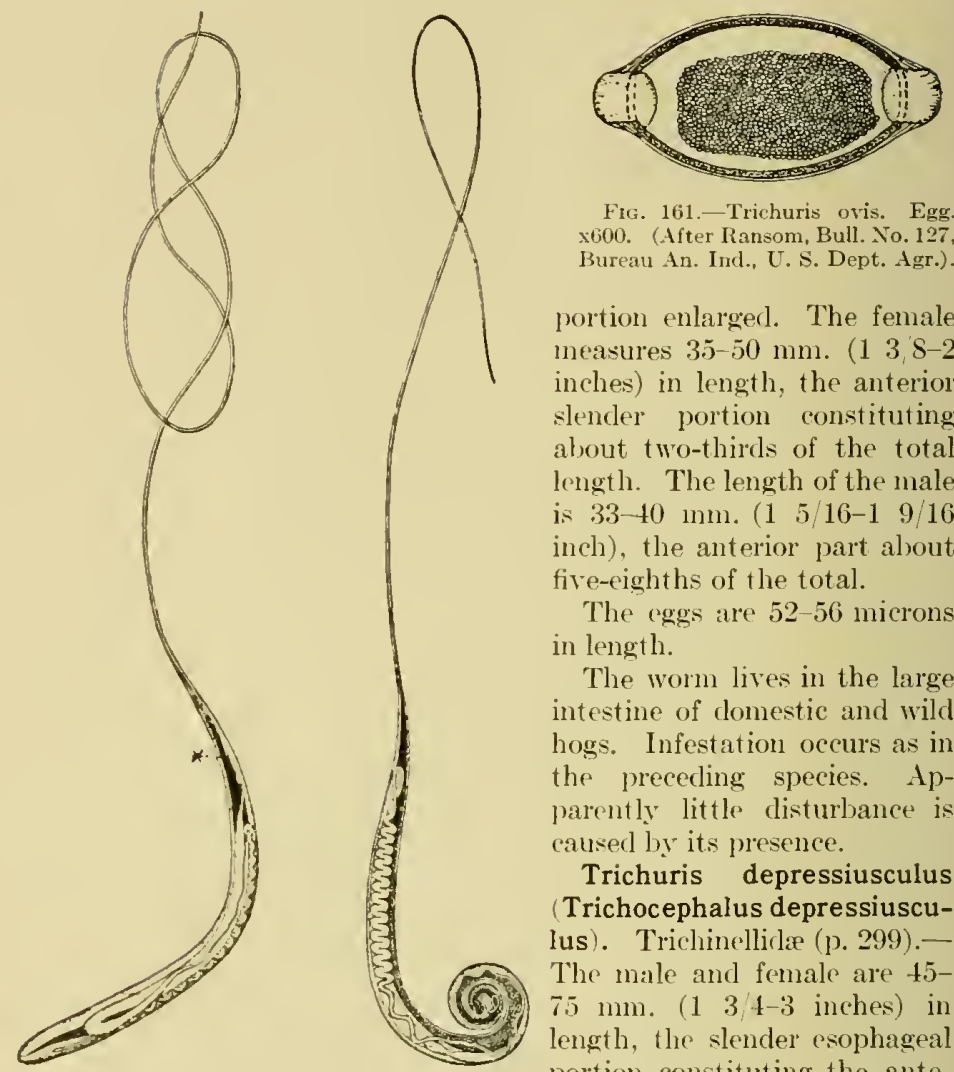

Fig. 161.-Trichuris ovis. Egg. x600. (After Ransom, Bull. No. 127, Bureau An. Ind., U. S. Dept. Agr.).

portion enlargerl. The female ineasures $35-50 \mathrm{~mm}$. (1 $3, \mathrm{~S}-2$ inches) in length, the anteriol slender portion constituting about two-thirds of the total length. The length of the male is $33-40 \mathrm{~mm}$. ( $15 / 16-19 / 16$ inch), the anterior part about five-eighths of the total.

The eggs are 52-56 microns in length.

The worm lives in the large intestine of domestic and wild hogs. Infestation occurs as in the preceding species. Apparently little disturbance is caused by its presence.

Trichuris depressiusculus (Trichocephalus depressiuscuIus). Trichinellick (p. 299).The male and female are $45-$ $75 \mathrm{~mm}$. (1 3/4-3 inches) in length, the slender esophageal portion constituting the ante-

Fis. $160 .-$ Trichuris ovis; male at right, female rior three-quarters. The speat left. *Vulva. xi. (After Ransom, from Curtice, Bull. No. 127, Bureau An. Ind., L.S. Dipet. . Igr.). cies resembles Trichuris ovis of ruminants and $T r$. dispar of man. The spicule of the male may reach the length of $10 \mathrm{~mm}$. ( $3 \mathrm{~s}$ of an inch) and teminates in a sharp point.

The (xges are $70-80$ microns in length. The development is similar to that of the preceding species.

This parasite inhahits the large intestine, usually the cecum, of the (log. Eggs taken up by dogs release their embryos within the digestive tract where they attain full development. The woms are often found 
in the cecum of dogs suffering from ankylostomiasis, but have an insignificant secondary part to Ankylostoma canina as a cause of this affection.

\section{Trichinosis}

Trichinella spiralis (Trichina spiralis). Fig. 162. Trichinellida (p. 299). $-A$ very small worm with body somewhat thicker posteriorly, but without abruptly demarcated filamentous anterior as in the Trichurinæ. The mouth is round and unarmed. The esophageal portion extends to about onehalf of the length of the body, the esophagus embedded in a chain of single cells. The portion of the body posterior to the esophageal contains the intestine which ends in a terminal anus. The single testis of the male originates posteriorly and extends forward to the esophagus where it turns back and becomes the seminal vesicle which terminates at the anal aperture. The cloaca thus formed has on each side of its opening two projections which serve to clasp the female, the cloaca being extruded in copulation. There is no spicule. The single ovary of the female begins posteriorly and, extending forward for a short distance, becomes the uterus. The vulva is about one-fifth of the length of the body from the anterior end.

The female is $3-4 \mathrm{~mm}$. (1/8-5/32 of an inch) in length; male, $1.4-1.6 \mathrm{~mm}$. (1/16 of an inch).

The embryos are developed within the uterus and are hatched there by breaking through the delicate nembrane surrounding the egg. From the uterus and vagina they pass from the body of the mother worm through the vulva. The hatched embryos are 100-160 microns long by 9 microns thick, the anterior end somerwhat thicker than the posterior.

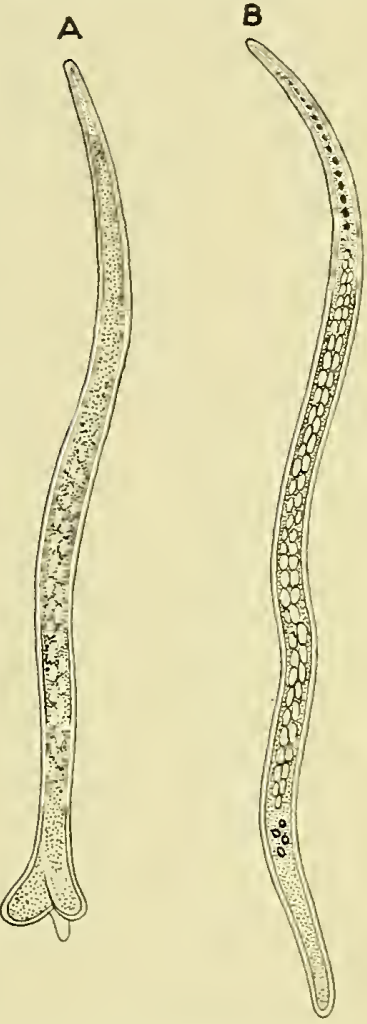

Frg. 162.--Trichinella spiralis; male at left, female at right,much enlarged.

Parasitic as adults in the small intestine and as larræ in the musculature of hogs, rats, mice, and other mammals, including man. 
Life History. When flesh containing encapsulated living trichinze is taken into the stomach of a suitable animal, the capsule is digested and they are liberated within eighteen to twenty-four hours. The larve then enter the snall intestine and are sexually mature in two to five clays. The females with the males are pressed into the crypts of Lieberkühn where, a week to ten days after the infection, the female leposits living cmlnyos. There is at first an equal number of males and females in the intestine; later the males gradually disappear, so that ten to fourteen days after infection almost all of the worms will be females. These live five to eight weeks, a single female, according to Icuckint, drpositing not less than fifteen hundred embryos; accolding to Braun, the number may reach ten thousand.

Fron Lieberkühn's ghands the embryos penetrate the mucosa and, reaching the lymphatics, are probably carried to the blood by way of the thoracic duct. With the blood they are distributed to various parts

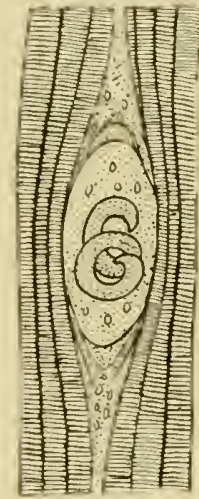

Fis. 1fi3. - Trirhinellat spiralis. Encystod larva in muscle (after Leuckart). of the body, passively in greater part, though it is probable that their ultimate lodgment is influenced sonewhat by their activity. Embryos deposited by capillary blook in striated muscle with sarcolemna are anid conditions farorable to their further development. From the eapillaries the trichina force their way through the sarcolemma and into the plasma of the muscle-fiber, where, at first actively motile, they pass to a state of rest and proceed to develop into the larval stage at which, if ingested, they may infect otleer animals.

In about three weks after the oceurence of the infection the larve in their muscular location have attained a length of eight-tenths to one millimeter. and their growth is completer. At this time they are usually curved in the form of a sickle, later becoming coiled spirally (Fig. 163), from which characteristic they derive their specific name, though they may be found in various looped and curved forms. The anterior portion of the larva is now the thinner; the posterior thicker and rounded at its extrenity.

As al result of this invasion the nuscle-fibers undergo certain changes; the transverse striation is lost, there is degeneration of the sarcoplasm, and the mucke increase in number and size, each becoming surrounded by a granular mass. The irritation to the surrounding tissues caused ly the presence of the parasites results in the formation of cysts which rnclose the trichinse and are fully developed at the end of the third month. The long axis of the eapsule is parallel to that of the musclefiber. The capsules are usually oval in shape and more or less drawn 
out at the poles, giving them somewhat the shape of a lemon. Their dimensions vary with the thickness of their walls. In general, they are about four-tenths of a millimeter in length by twenty-five onehundredths of a millimeter in breadth, but their length may be from three-tenths to eight-tenths of a millimeter and their breadth from two-tenths to four-tenths of a millimeter. After the formation of the cysts they are of ten made more recognizable to the unaided eye by the deposition of fat cells immediately around their poles. Within each cyst there is usually one, more rarely two or more, larvæ.

\section{Tabular Review of Life Histort of Trichinella Spiralis}

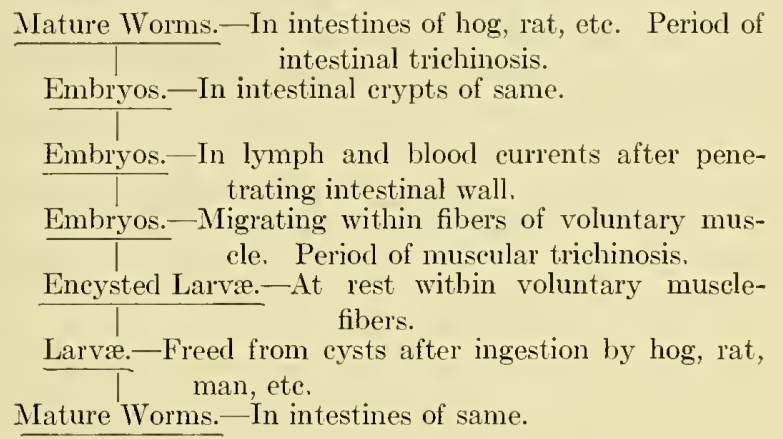

Degeneration.-After a varying perior of time the trichina cyst undergoes fatty and calcareous degeneration. In the first there appear within the cyst cells small fat granules which rapidly increase in number and are soon set frec to invade the whole of the cyst. Later there is a deposition of carbonate and phosphate of lime, the calcification involving the capsule and the tissues of the trichina, though the latter often escapes the process, and perfectly intact trichinæ may be found in cysts entirely calcified and opaque.

Calcification of the capsule begins about the seventh month after infection and is completed in from fifteen to eighteen months, though exceptions give to these periods but a gencral application. Ostertag states that completely calcified trichina capsules were found in two hogs nine and twelve months old, and, according to the same author, Dammann reported a case in which after cleven rears the trichina capsules were not completely calcificd and contained trichina still capable of producing experimental trichinosis,

Location.-Encysted trichinæ are found in striated muscle in which the fibers have a sareolemma. They are not found in the musele- 
fibers of the heart. Certain muscles are peculiarly liable to invasion by the parasites, and these in the order of frequency may be listed as follows,-pillars of the diaphragm, muscles of the larynx and tongue, abdominal and intercostal nuuscles, psoas muscles, and muscles of the back. They are usually found in greatest number toward the extremities of the muscles in the neighborhood of tendons, a fact probably to be accounted for in the arrest offered by these locations to their migrations.

The number of eysts which an infested individual may harbor is capahle of reaching an enormously high figure. Neumann states that Leuckart has eounted between twelve hundred and fifteen hundred in a

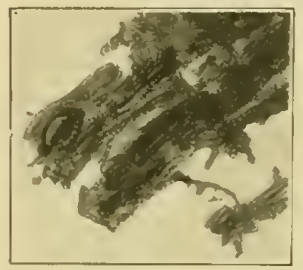

Fig. $164 .-$ Trichinella spiralis. Cyst in human muscle (from microphotograph by Hoedt). gram (15.43 grains) of musele, while Fielder, according to the same author, estimated the number found in the body of a young woman as ninet $r$-four inillion.

Occurrence.-Adult trichina are only found in the intestines, especially the upper part of the small intestine, of mammals and birds which have recently eaten fesh containing the encysted larve. In fishes and other cold-blooded vertcbrates the trichina cysts are not acted upon by the digestive canal and they pass through without ehange. Of the animals conmonly used for human food only the hog harbors muscle trichine hy natural infeetion, and triehinosis of man is usually atcouired by cating the trichinosed flesh of this animal. Rats are peculiarly susceptible to trichina, and probably one of the most frequent sources of the infection of hogs is by eating trichinous rats. Transmission to herbivorous anmals, as cattle, sheep, and horses, is difficult. After experimental feerling of fiesh containing the cysts to these animals there: is wsully a development of intestinal trichina but no muscle trichinie. Intestinal trichine have been experimentally developed in birds, lut birls do not harbor the eneysted larva.

Only encysted living larve are capable of producing trichinosis in their suitable hosts. Ingested larve which are unprotected by a eyst are destroyed in the stomaeh by the direct action of the gastrie juice.

Symptoms in Hogs. - Symptoms of trichinosis by natural infection are rarely observed in hogs, though where a considerable quantity of the ersts have been ingested it is probable that such symptoms follow, their true cause being unreeognized. Feeding experiments have shown that after massive infestation intestinal trichinosis is manifested by the third to the eighth day. There is then depression, loss of appetite, grinding of the teeth, and a disposition to remain crouched in the bedding or to stand about with back arched and abdomen retraeted. 
A persistent diarrhea follows which is at first lumpy, then watery and of bad odor. With these symptoms there may also be those of colic. In general the symptoms are those of an entero-peritonitis and they continue over several weeks during which time the animal may die.

In from one to two wecks the larvæ are penetrating the muscular tissue, and muscular trichinosis has set in. The anumal now lies upon its side, or, if it moves about, it is in a stiff, halting, and painful manner. The respiration is superficial, the voice husky, and chewing and swallowing difficult.

With the coming to rest and encapsulation of the larvæ the animals, in most cases, gradually recover. Where there has been exceptionally heavy infestation edema may appear in various parts of the body; such a development is usually followed by death.

Prophylaxis.-Most all cases of infection of man with trichina are from eating trichinosed pork, the swine usually becoming infected by eating the trichinous flesh of other swine or that of affected rats and mice. Knowing these facts, prevention is made relatively simple. Places where hogs are kept should be freed from rats, and the flesh of animals subject to muscular trichinosis should not be fed to hogs unless it has been thoroughly cooked. According to Leuckart, trichinæ are killed at a temperature between $62^{\circ}$ and $70^{\circ} \mathrm{C}$. $\left(143^{\circ}-158^{\circ} \mathrm{F}.\right)$. These degrees of heat must be continued sufficiently to penetrate the entire piece of meat, a white or light gray cut surface indicating that the cooking has been sufficient.

Treatment. - Treatment is ineffectual. In the case of such an extremely rare occurrence as the early diagnosis of intestinal trichinosis, the administration of anthelmintics followed by purgatives might be of some value, but the deep location of the mature worms in the crypts of the mucosa affords them a high degree of protection against such agents. 


\section{CHAPTER XXY}

\section{THE THORN-HEADED WORN. THE LEECHES}

Order II. Acanthocephala. Nemathelminthes (p. 216).-Essential differences separating this order from the Nematoda are the absence of a digestive tube and the possession of a protractile rostrum provided with hooks. The body cavity contains a fluid in whieh are the sexual organs. The sexes are separate.

One speeies is of suffieient pathologic importance for consideration. This is the large intestinal roundworm of the hog, Gigantorhynchus himedinaceus of the family Gigantorhynchida, more eommonly described under the name Echinorhynchus gigas.

Gigantorhynchus hirudinaceus (Echinorhynchus gigas). Fig. 165. Acantlocephala (p. 306).- The body is white, eyhondrical, transversely wrinkled, and often expanded at several points. The rostrum is almost globular, retraetile, and has five or six rows of baekward-curving hooks (Fig. 166). The eaudal extremity is somewhat tapering. The males are smaller and thimer than the females and have a bell-shaped eaudal bursa. The eaudal extrenity of the female is rounded.

The female is $20-35 \mathrm{~cm}$. ( $8-13$ inches) in length by $4-9 \mathrm{~mm}$. $(5 / 32$ 1132 of an inch) in brearth. The male is $6-10 \mathrm{~cm}$. (2 38-4 inches) in length and in lreadth $3-5 \mathrm{~mm}$. (1 8-7/32 of an inch).

The eggs are oblong, measuring $87-100$ mierons. When developed they are surounded by three envelops. The embryos are formed within the borly of the female.

The adult worm is parasitic in the small intestine of the hog; exceptionally it oecurs in man. The larva lives encysted in the white arub of the May-beetle and probably some other invertebrates.

The eggs of Cigantorhynehus, diseharged to the ground with the feces of the hog and eaten by the larva of the May-beetle, are hatehed in the digestive canal, and the embryos, by burrowing through the intestinal wall, find their way into the hody-eavity where they become cneysted. In this state they may continue to live through the larval and pupal stages and even after the maturity of the insect. If the hog rats the May-beetle in any of these stages eontaining the eyst, the cyst wall is digested away and the freed larval worm attaches by its eephalic hooks to the intestinal mucosa where it attains full development.

Occurrence, Pathogenesis and Symptoms. - The giant intestinal wom of the hog is quite common in the United States, especially so in 
the southern portion. The implantation of the worms upon the intestinal wall by means of their hooked rostrum causes limited inflammatory areas of red or yellowish color. The tumifaction of the wall causes the serosa to be pushed out in the form of nodules which may be of yellowish color and somewhat tubercular in appearance. Exceptionally it has been observed that the parasite has bored through the walls of the intestine and given rise to a purulent peritonitis.

As applies to helminthiasis in general, the disturbances which these worms produce will be in proportion to their number. Pain may be evidenced by continual grunting and restlessness, and there is the general derangement of digestion and the unthrift usual to heavy invasion of the intestines by worms. Young pigs suffer most and, in these particularly, there may be muscular twitchings and epileptiform seizures, such symptoms usually being followed by death.

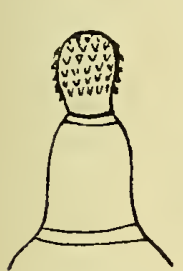

FIG. 166. -

Armed cephalie extremity of $\mathrm{Gi}$ gantorhynchus hirudinaceus, $\rightarrow$ enlarged.

Treatment.-Due to the firm attachment of the worms, little or nothing can be accomplished by treatment. If this is attempted,

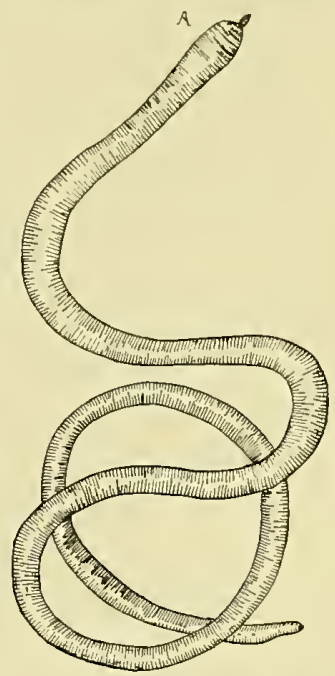

Fig. 165.-Gigantorhynchus hirudinaceus, - natural size (drawn from specimen). the same remedies may be used as recommended for the ascarids (p. 241).

\section{Class II. AnNelida}

Collhelminthes (p. 216).-The annulated worms differ from those of the class Nemathelminthes in haring a segmented body eavity with corresponding ringing or annulation of the body wall. The earthworm is usually taken for type study of the group.

Order Hirudinea. Annelida (p. 307).-This order includes the leeches which differ in many respects from typieal annelids. The body is flattened dorso-ventrally and lacks the appendages for locomotion (setæ) characteristic of other forms. Locomotion is accomplished by two suckers, one at the posterior end, used only for locomotion and attachment, the other surrounding the mouth, used for locomotion and attachment and also for sucking the food. In moving from place to place the head end is thrust forward and attached by the sucker. The hind sucker is then released and brought close to the anterior sucker 
by a looping up of the body, the anterior sucker being again advanced and the process repeated. They can also swim freely by snake-likc morements in the water. The body surface is transversely striated, giving the appearance of a large number of segments. The striations, howerel, are in 'xeess of the true segmentation representing the somites, the primitive segment rings being divided by secondary striations. The alimentary canal has a number of paired sac-like protuberances varying in number according to species. When the lecch gorges iiself these sacular pockets are filled with blood upon which the animal may live for some time before again feeding. The body cavity is reduced by the connective tissue and musculature to a number of tubular sinuses.

The leeches are hermaphroditic and copulate reciprocally (cross fertilization). As in the earthworns, certain of the somites at the time of reproduction derelop into a clitellum which secretes porous cocoons in which the eggs are deposited.

The leeches to be considered come under one family, the Gnathobdellirk, which have the pharynx provicled with three senicircular chitinous

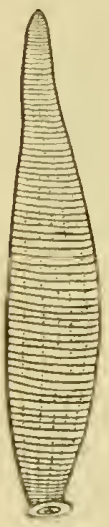

FIG. 167.-Hremopis sanguisugga. Oral sucker of same at right. plates or jaws, each armed on its free edge with numerous teeth. The Rhynchobdellidx are without jaws. This family contains species which attack fishes and invertebrates and occasionally water fowl.

1. Hæmopis sanguisuga. The horse leech. (Fig. 167). Hirudinea (p. 307).-Dorsally this leech is greenish brown or sometimes reddish in color; ventrally dark gray, reddish gray, or black. (ienerally the body has four to six longitudinat rows of closely set dark points which may be somewhat indistinct. The body is widest in the midhle, grarhully narrowing anteriorly, and is composed of ninety-five to ninety-seren segments. It is rounded rorsally; flattened ventrally, soft, viscid, and capable of great extension and retraction. The olat sucker is shightly concave, having at its center the mouth which is in the form of a three-rayed star (Fig. 167). Wach of these ray-like shits permits the passage of a jaw, the teeth of which wound the mucous membrane and thus enable the leech to suck blood while it holds on by means of the oral sucker. There are ten inclistinct eyes located anteriorly on the dorsal surface. The rulva is a transverse slit located five rings behind the male orifice, or between the twonty-ninth and thirtieth rings.

In fecundation two individuals come together by their ventral sur- 
faces in opposite directions, each having the part of male and female. After the cross fertilization is accomplished there forms around the part of the body where the sexual organs are located a clitellum which is a sort of girdle secreting the capsules with which the eggs become surrounded. The leeches then bury themselves in damp ground where the eggs are deposited and incubation proceeds, this process occupying about twenty-eight days.

2. Hirudo medicinalis. The medicinal leech. Hirudinca (p. 307).This species is a little smaller than the horse leech. The dorsal surface is darker than the ventral and is usually marked with six longitudinal reddish stripes. The ventral surface is usually olive green and may be more or less spotted.

This leech was once extensively employed in medical practice for the abstraction of blood.

All of the domesticated animals and man are attacked by Hæmopis, probably the horse most frequently. The leeches live in ponds and springs where the animals are likely to drink and are conveyed to the mouth with the water. Those taken up are usually the young ones, these keeping near the surface of the water, while the adults usually lie in the mud at the bottom. Having thus gained access to the mucous membranes, they fix upon the lips, cheeks, pharynx, or other parts of the mouth. They may enter the nasal cavities through the nostrils direct, or they may attach to the eyelids. While holding fast in these positions by their oral and caudal suckers, the leeches lacerate the mucous membrane with their cutting jaws and become gorged with blood. They then detach and pass from their host, or they may attach to another part of the mucous membrane and renew their feeding.

The effect of the infestation will depend upon the number of leeches present, and this is extremely variable. It is estimated that a single leech when engorged will hold about eight cubic centimeters (two drams) of blood. The host suffers an additional loss from the fact that there is considerable hemorrhage from the wounds after the engorged leeches have become detached. Heavy invasions, therefore, are capable of bringing about considerable depletion with evidences of anæmia, as paleness of visible mucous membranes, edemas, and emaciation. A fatal asphyxia may develop from edema of the pharynx which may be contributed to by the mechanical obstruction offered by the leeches in this location.

Treatment.- Where exploration of the mouth or nasal passages reveals the presence of leeches, those which are accessible may be removed by forceps or with the hand wrapped in a towel. Vinegar, or a strong solution of common salt repeatedly applied with a view to causing them to release their hold, is recommended by some, but the effectiveness of such treatment can only apply to the leeches with which the liquid 
comes in contact, many of which may be so far back in the passages as not to be reached.

A method which is probably better than the syringe in the application of this treatment consists in firmly attaching a small sponge to the end of a probe, such as a piece of rigid rubber tubing. The sponge is saturated with salt solution and, preferably with the use of a mouth speculum, passed back over the soft palate and pharyn. In the same manner it may be applied deeply into the nasal passages, the tube being inserted slowly and with a rotary movement. 


\section{PART III}

\section{THE PATHOGENIC PROTOZOA}

\section{CHAPTER XXYI}

\section{PHYLUM IV. PROTOZOA}

This division includes the most primitive organisms belonging to the animal kingdom. While some can be detected by sharp eyes as tiny swimming specks, most all are so small that they can only be seen with the aid of the microscope. The individual animal is constituted by a single cell, which, with a difference in development, characteristically distinguishes the Protozoa from other animal groups. In most cases they live independently of each other, but not rarely a number are associated in colonies. Each individual in such a colony is, as a rule, physiologically complete, that is, performing within itself all of the functions necessary to its life and reproduction. The colonization, however, tends to a degree of differentiation and interdependence, and in certain cases there are morphological and physiological differences anong the individuals so grouped, these usually being related primarily to the functions of nutrition and reproduction.

The protozoan colony may be said to differ from the metazoan in that each cell of the colony represents an animal which may live unassociated with other cells, while in the metazoan the individual is comprised by the aggregation of cells among which there is a morphological differentiation corresponding to special functions which are distributed among adaptively specialized cell-groups; the body-cells are not capable of free existence and they can only live as integral parts of the metazoan. The Protozoa being single-celled animals, there is a further fundamental difference in their development, since it essentially follows that there is no formation of germ layers as occurs in all Netazoa. The division or budding of the protozoan cell results directly in a new generation and not in the development of germinal tissue layers, though the new cells may remain aggregated to form a colony.

While the Protozoa are referred to as the most simple representatives of the animal kingdom, they present, nevertheless, considerable differences in form and modification of the cytoplasm, the functions of motion, alimentation, excretion, and reproduction being perforned by a 
much greater specialization in some than in others. While a nucleus is not easily demonstrable in certain of the Protozoa, most have one or more distinct muclei, in this, as in other respects, possessing the essential parts of a typical cell.

Ameba.- I simple representative of the Protozoa is the Ameba (Fig. 168) which may be found in most any still water, most readily in the ooze upon the bottom or adhering to leaves or other submerged

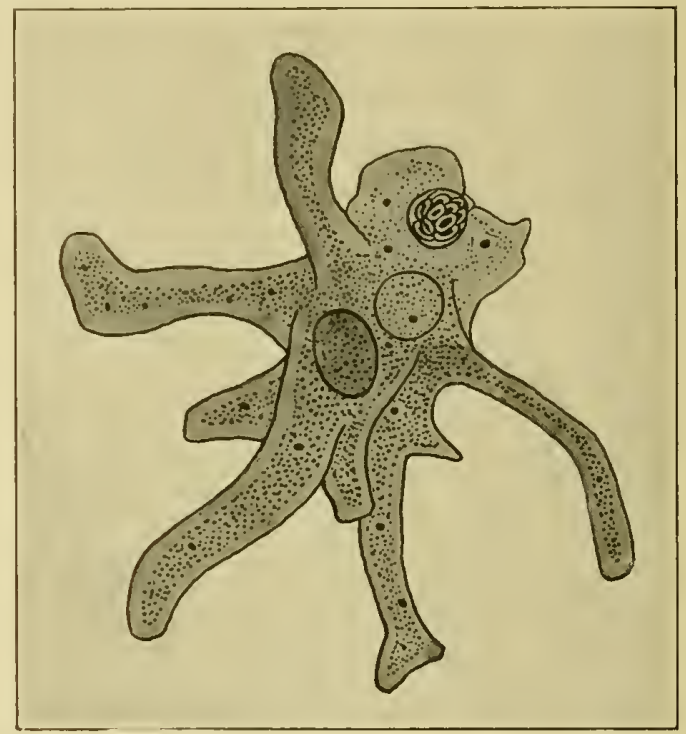

Fig. 16is.-. Ineba proteus (after Crawley, from Doflein; Cir. Xin. 194, Burestu . In. Ind., L'. \&. Dept. Agr.).

objects. Fearch of such material under the low power of the microscope will reveal this organism as a mimite protoplasmic particle which slowly changes its shape and location by a peculiar flowing and extension of the cytoplasm at one or nore points, forming irregular, often finger-like, projections, - the pseudoporlia. These may be withdrawn or the whole substance of the animal may appear to flow into one of the projections; by this manner of locomotion it mav slowly pass out of the microscopic field. Close study of the organisun will reveal two distinct regions, an outer hyaline,- the ectoplasm (ectosarc), and a central more granular and less transparent part,-the endoplasin (endosarc). Within the latter may be seen the food vacuoles which are rounded or oval, of varying 
size, and inclose granules of food material. At intervals clear globules may be seen to gradually form within the eytoplasm and then suddenly contract and disappear. These are the contractile vacuoles which on contracting empty their fluid contents to the exterior. They are rudimentary cell organs for the elimination of injurious substances and differ from the food vacuoles in having a definite place in the cell as well as in their approximately constant number. Young amebr usually have within the endoplasm a single nucleus but they may early become multinucleate. All of the vital functions appear to be under the control of the nucleus; experimental removal of the nuclei has shown that Protozoa thus treated cannot properly perform their functions and soon perish.

In feeding the ameba merely flows around the object which it is to use as food; becoming thus inclosed in the cytoplasm the nutritive elements are digested and assimilated. Circulation is limited to the streaming movements of the cytoplasm, and respiration is carried on by absorption of oxygen from the surrounding water.

Reproduction in ameba is by fission or budding. Before division of the cell changes occur in the nucleus involving a separation of the nuclear parts with the formation of two distinct nuclei. These separate and during the process the cell constricts, finally dividing completely with each part inclosing one of the new nuclei. In some cases the cell becomes spherical and secretes a protecting membraue around itself before division; the outer membrane becomes hard and adapted to resist drying and extremes of temperature, the organism assuming in this condition a resting or encysted stage. Encysted individuals usually divide into more than two; there may be four, eight, or even hundreds of small amebæ resulting from the reproductive process. In nultinucleate forms it frequently happens that the division is into as manyparts as there are nuclei.

\section{Parasitisi of the Protozon}

In 1881 Laveran, a physician in the French army, distinctively directed attention to the Protozoa as a cause of disease in animals by his discovery that the cause of malaria in man is a protozoan which, entering the red blood cells, destroys them and in this way causes the anæmia characteristic of the disease. Later it was demonstrated that this malarial organism is transmitted by a mosquito and that this is the only way that the disease can be acquired. This discovery served to indicate lines of research looking to insects and other arthropods as essential carricrs of other forms of pathogenic Protozoa, in which field much has already been accomplished,

Theobald Smith, in 1892, found that Texas ferer of cattle is caused 
by a protozoan which, though not iclentical with it, is allied to the malarial parasite, and, like it, enters and destroys the red blood cells. In this case the infecting organism has been found to be conveyed from animal to animal by a certain species of tick (Margaropus annulatus, p. 144), and it is now known that the presence of the tick is essential to such transmission.

Trypanosomes were first stucher in mammalian blook by Lewis in 1877, who observel them in the blood of a rat. Three years later Trypanosoma evansi was studied as the cause of surra, a disease of horses of Asiatic countries, the transmitting agent of which is thought to be a blood sucking fly (Tabanus, p. 332).

Bruce, in 1894, demonstrated that a trypanosome (Trypanosoma brucci) Was the specific organism easing the fatal magana or tsetse fly disease of horses and other domestic animals of Africa. He showed conclusively that blood-sucking invertebrates, mainly the tsetse flies ( rlosina, p. 44), are responsible for its transmission from the blood of wilt inmune to the hlood of susceptible clomesticaterl animals.

'The relationship of the tsetse fly to human trypanosomiasis was shown in much the sane way as that followed in the researches of Bruce. African slecping sickness of man was originally confined to the West Coast; it has spread eastward and is now a serious menace to the developnemt of Central Africa. In 1902 the infecting organism of this fatal liscase was disenvered to be a trypanosome (Trypanosoma gambiense) carrich from lost to host mainly by a tsetse fly. Stuchents of protozoö]ogy have since shown that mosquitoes, lice, and leeches may eary trypanosones, anct that picreing flies, therefore, may not alone be responsible for the spreat of the diseases which are caused by these Protozon.

The instances above cited will serve to direct attention to the importance of the Protozoa from the viewpoint of their pathogenicity both in its ceonomic relation and as regards discase in man. ITp to the present fimo the Protozod as clisease-producing organisms have not receiver the atlention in the United states that has been given them by invesligators in Africa and Europe. This is probably due to the fact that. though this country is not free from pathogenic trypanosomes, it has thus far escapert the ravages of the trypanosomiases of Africa, Asia, and fouth America, to which countries sleeping sickness, kala-azar (leishmaniasis), nagana, surra, and mal de carleras have to the present time confined their plague. A shight acquaintance with the subject, however, is sufficient to dispel a fecling of security based upon the rroneons impression that these diseases are restricted to tropical countrics or that their spread depends upon the presence of a certain kink of fly. It has aheady been noted that the African trypanosoniases may not depend wholly upon the tsetse flies for their existence and 
spread; surra and mal de eaderas eertainly do not, as these are diseases of Asia and South America respeetively, and tsetse flies are not found in either of these eountries. There is, in faet, no reason to doubt that any blood-sucking fly can transmit trypanosomes from the blood of one host to that of another. In view of this the horse and stable flies, so eommon in North Ameriea, would, in the presenee of trypanosomiasis, amply supply the means for its spread.

In reeent years important advanees have been made in the study of the rôle of arthropods in the spread of disease. Common knowledge as to its powers for earrying bacterial infeetion has eondemned the fly to the swat, but it is as essential hosts, and not as purely meehanieal earriers, that these invertebrates furnish the greatest field for researeh. Mueh has already been aeeomplished in working out the life histories of the parasites of inseets and tieks, ineluding parasites whieh have no apparent eonneetion with diseases of higher animals, for these, potentially at least, may not be so harmless to higher animals as may at first appear. Change of habitat, as from one part of the body to another in the same host, or from a host of one speeies to that of another, frequently leads to great alteration in the mode of life of an organism whieh, relatively harmless in the inseet, may in the vertebrate evolute into more harmful parasitism with the development of pathogenieity. The newer a parasite is to the animal harboring it, the less it is in harmony with its environment. Protozoa whieh produce acute forms of disease have less adaptation to their environment than those produeing a chronic type of malady. This diseord between parasite and host is manifested by aeute disturbanees whieh may result in the death of the infeeted aninal. Sueh parasitic diseases of a ehronie eourse are usually eorrelated with a greater degree of adaptation of the parasite to its host and also with acquired resisting powers of the host to the speeific aetion of the parasite.

The seale of evolution through the saprophytie, parasitie, and pathogenie is thus exhibited by eertain groups. The Spiroehetida, long, delieate Protozoa with a corkserew-formed body, may be found as inhabitants of the body-eavities, of normal mueous surfaees, of inflamed mueous surfaees, as parasites whieh have penetrated the tissue, and as blood parasites. This series is suffieient to show how parasitism may evolute by various gradations from harmless eommensalism to distinet parasitism and pathogenieity. When the habit of living in inflamed or ulcerated tissues is reached the power of penetrating healthy tissues soon follows which, with the multiplieation of the spiroehetes in sueh situations, eauses destruetion of invaded tissue and loeal disturbanees. The products of this tissue destruetion, together with those eoming from the dead bodies of the parasites, form toxins whieh, getting into the blood, produce the general toxemie symptoms. The final stage of 
malignant parasitism is reached when the spirochetes acquire the habit of living in the blood. In this case it is evident that, exeept under celtain conditions of contaet, the transfer from host to host cannot be direet, but that the intervention of an intermediate host is neessary. This must be a blood-sucking invertebrate, and, in certain known cases of spirochetosis of clomestic animals, has been found to be a tick, as the tick Argas miniatus, the carrier of Spirocheta gallinarum which causes a spirochetosis in fowls, and the cattle tick Boophilus decoloratus, the intermediate host of Spirocheta theileri, the cause of a disease among South Imerican cattle.

The malaria parasites afford study in the evolution of pathogenicity of other Protozoa. These organisms inchicate in theil morphology and levelopment that they are closely allied to the Coccichia, which are protozoan coll parasites attacking and entring tissue cells, especially epithelium, of arthropods and vertebrates. There is little doubt that the malaria parasites were originally Coccidia of insects that, with change of habitat, developed increased pathogenieity toward the new lost.

Granting this, we have, then, in the malaria parasites an example of the "yolution of disease in the past, while disease in the making is eridenced to-day more esperially in the ease of certain parasitic flag(allates of the genus Herpetomonas.

The introduction of herpetomads into vertelorates by the latter swallowing infected insects, or by the way of wounds of the skin, has been shown to result in pathogenic effects in the vertebrate host. A sories of experiments extenrling over some six vears (Fantham and l'orter', Jourual of Parasitology, June, 1916) have shown that certain herpetomarls normally parasitic in insects, when introrluced into vercobrates will produce a condition resembling kala-azar, an infectious discrise of nuan common in eertain regions of India, China, and countries hordoring on the Mediteranean, eaused by the herpetonad Leishmania (Herpetomonas) donouni. The symptoms developed and the morphology of the parasite found in the vertelonte host show that here at least are examples of kala-azar in process of evolution.

Plate III.-Evoletion of the Parasite of Kala-Azar. Figs. 1 to 5 . Parasites of kila-izar. 1. Is lated parasites of different forms in the spleen and liver. 2. Division forms from liver and bone marrow. 3. Mononuclear spleen cells containing the parasites. 4. Groups of palasites. 5. Phagocytosis of a parasite by a polynuclear leucocyte. Figs. ti to 15. Parasites from cultures. 6. First changes in the parasites. The protoplasm has increased in bulk and the nucleus lias becone larger. 7. Further increase in size. Vacuolization of the protoplasm. 8. Division of the enlarged parasite. 9. Evolution of the flagella. 10. Small piriform parasite showing flagellum. 11. Further development and division of the parasite. 12. Flagellated trypanosome-like form. 13, 14. Flagellated firms lividing by a splitting-off of a portion of the protoplasm. 15. Narrow flagellated parasites which have arisen by the type of division shown in Figs. 13 and 14. (After Crawley, from Mense's "Handluch," after Leishman, Cir. No. 194, Bu. An. Ind., U. S. Dept. (Inr.). 


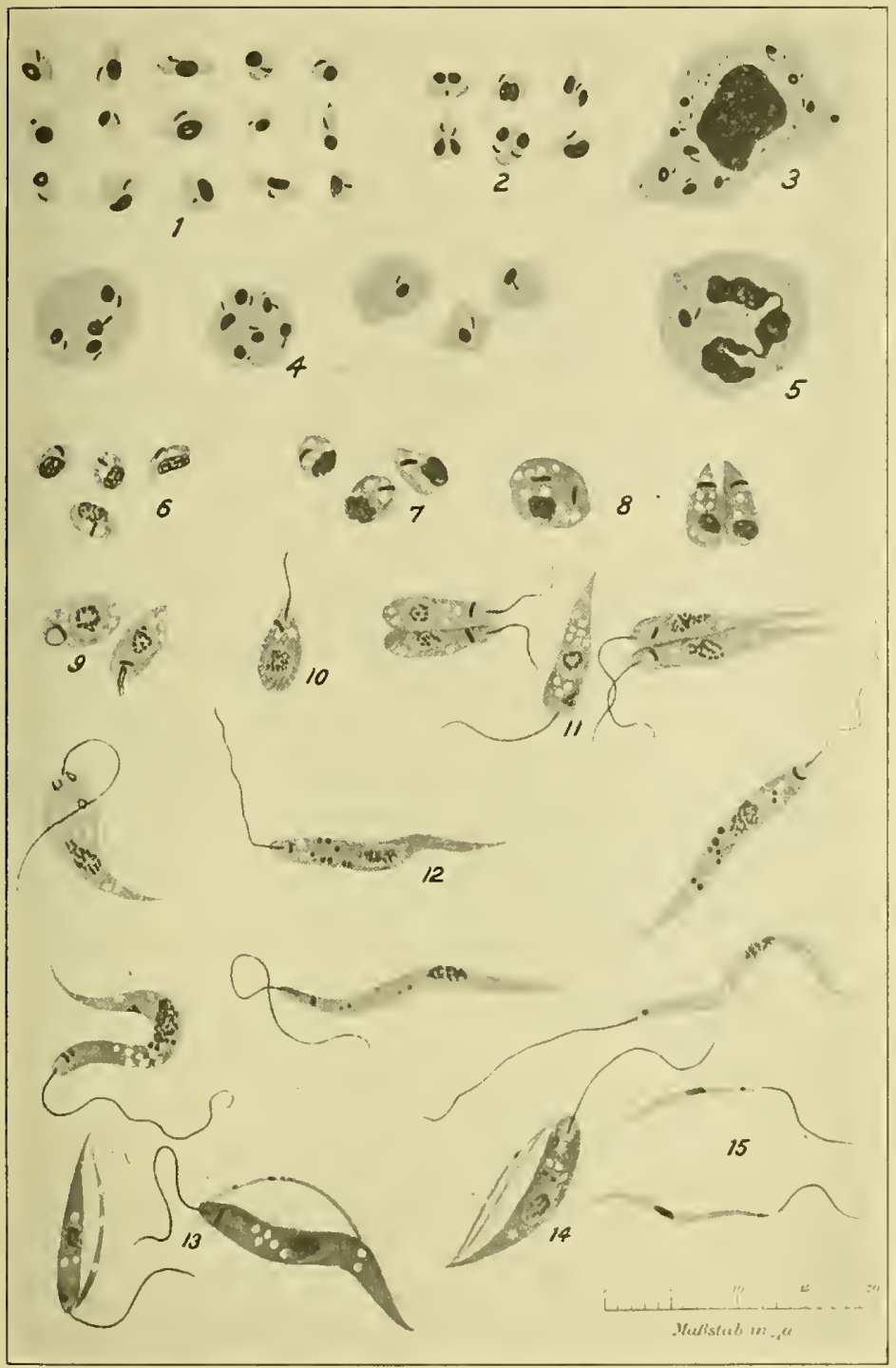


A brief review of these ronchusions, drawn from the results of experimental research, will be sufficient to direct attention, not only to the powers which insects have as carriers of disease, but to their potential powers in the making of disease as well.

Methods of Reproduction. - Sexual and asexual methods of reprocluction atternate in free forms of Protozoa, but the asexual method is usually liniter to simple division or budding. Parasitic forms, on the other hand, have acquired a more prolific means of multiplication, the simple division and bulding being replaced by asexual spore formation as exemplified among the Sporozoa. In the parasitic Protozoa, therefore, two kinds of spores may be present, the one occurring asexually during the regetative life in the host and giving rise to auto-infection in the same host, the other sexual, ocurring at the end of the vegetative life of the parasite, preparing its germs to withstand the unfavorable conclitions of an external rnviromment, and giving rise to infection of new hosts.

The asexual methol of multiplication, taking place during the vegetative life in the host, is termed schizogony or schizogenesis, while the term sporogony or sporogenesis has been given to reproduction by the sexuml mothod. The first is sometimes referred to as the multiplicative, the seconcl as the propagative cycle.

Life History of the Malaria Organisms. - With a view to an elemontal conception of these reproductive and infective processes in the sporozoa, the life history of the organisms producing malaria in man afforrls a clear examplo for stuely.

Malaria was the first of the human cliseases in which it was proved that a protozoan is the clirect cause, and by 1901 the disease was as theroughly understoon as perhaps any other due to a germ. The malaria parasites belong with the genus Plasmodimn, so naned from their early supposed resemblance to some of the plasmodia-forming fungi. They are usually considered under three forms with which three well-marked types of malaria are ascoriated. These may be briefly summarized as follows:

1. Plasmodium vinax.-Cause of tertian fever; parosysms occur every forty-right hours; incubation prion about two weeks. Temperate climates, also in tropies and subtropics.

2. Plasmodium falciparum (P. proecox). - Cause of estivo-autumnal f(rer; paroxysus every twenty-four hours; incubation period usually from ten to twolve days. Tropies and subtropies.

3. Plasmodium matarice-Cause of quartan fever; paroxysms every seventy-two hours; ineubation period about three weeks. Tropies and subtropics.

Two distinct erces are involved in the life history of the malaria organisms. The first takes place in the blood of the human patient and 
is known as the asexual or schizogonic cycle, during which the plasmodia multiply by the asexual method or schizogony. The second occurs in the body of a mosquito and is the sexual or sporogonic cycle, involving reproduction by the sexual method or sporogony. A third phase is to be recognized during which the female gametocytes sporulate without fertilization. This is referred to as the parthenogenetic cycle. It is passed within the body of the human host and explains the recurrence of malaria after more or less prolonged periods of latency.

The Schizogonic or Asexual Cycle.-The asexual cycle begins with the infection of the human blood with the sporozoites by the bite of a mosquito of the genus Anopheles (p. 26). The sporozoite is spindleshaped and on entering the blood at once penetrates a red corpuscle where it takes a ring-like form, referred to as the signet ring stage, Living at the expense of the corpuscle, the organism grows rapidly until it more or less fills the corpuscle. At this stage it is known as the schizont, which is the period of its ameboid movement and highest vegetative activity. As the schizont matures its nucleus breaks up into a number of daughter nuclei, each becoming surrounded by a spherical portion of protoplasm to form a small reproductive element.-the merozoite, or asexually formed spore. Finally the corpuscle is broken down and the swarm of merozoites is liberated in the blood-plasma. Coming from the same original broorl, the parasites all sporulate and become liberated in the blood at the same time; this results in the constantly increasing number of merozoites being liberated at stated intervals with corresponding intervals of paroxysm in the host. The general toxic effect upon the malaria patient is contributed to by the accumulated waste products of the parasite's metabolism which pass into the plasma with the liberation of the merozoites. Each liberated merozoite now enters another corpuscle, and the asexual cycle is repeated in from twentyfour to seventy-two hours according to the species of the infecting organism.

This process of multiplication may continue for an indefinite time or, by analogy with other parasitic Protozoa, until the vitality is exhausted. Asexual merozoites are greatly in the majority, but certain of them are potentially sexual and require a longer time to fully develop into males and females when they are known as male and female gametocytes. 'Up to this time they are still intracorpuscular and, in the estivo-autumnal or pernicious type of fever, appear as large crescents. The female crescent (macrogametocyte) has numerous pigment granules collected in the center; the male (microgametocyte) is the mother cell of the male reproductive elements (microgametes). The nucleus of the male cell divides into a number of daughter nuclei which migrate to the periphery and become the nuclei of the flagelliform microgametes. These bodies are constantly in the blood after the first few paroxysms. 
If the blood is now drawn by an anopheline mosquito further changes take place.

The Sporogonic or Sexual Cycle.-In the intestine of the mosquito the female gametocyte undergoes certain nuclear changes preparatory to fertilization; the cell becomes rounded or oval in form, and is now known as the macrogamete. From the male gametocyte there are extruded from three to six flagelliform filaments corresponding in number to the peripherally disposed daughter nuclei. These filaments detach from the mother cell to become the actively motile microgametes, which are analogous to the spermatozoa of higher animals. Thus the flagellated parent body may be referred to as a mierogametoblast producing the male sexual elements or microgametes.

Fertilization of the macrogamete is brought about by its penetration by one of the microgametes. The fertilized macrogamete now becomes the oökinete or zygote, in which stage it passes by a vermiform movement into and through the epithelium of the mosquitoe's mid-intestine and comes to rest just beneath the outer lining membrane. Here it rapiclly grows, the nucleus divides, and by the third to the fifth day it has formerl a cyst in which there are many nuclei, each to become the nucleus of a mimute borly,- the sporoblast. The sporoblasts, by division, form a number of germs, - the sporozoites, spindle-shaped, nucleated borlies which are mature after a period of ten to fourteen days in the body of the mosquito. On reaching maturity, the sporozoites are liberated into the body eavity of the insect where they are carried about by the body fluids, collecting eventually in the salivary glands. From here they pass to the piercing proboscis from which, with the next bite of the mosquito, many may pass into the blood of another human vietim to begin the asexulal eycle.

Plate IV:- Life Crcle of the Malaria Parante. 1. Free sporozoite, either in salivary glands of the mosquito or in blood of man. 2. Penetration of the sporozoite into a red blood corpuscle. 3 to 6 . Growth of trophozoite. 7,8 . Division of trophozoite which brings about destruction of the blood corpuscle and the release of the merozoites in the blood stream. The frep merozoites then enter new blood corpuscles, and this cyele may he repeated many times. Finally, however, the sexual cycle is initiated as follows: 9 a to 12a. Growth and differentiation of female cell. 9b to 12b. Growth and differentiation of male cell. 13a, 13b. The male and female rells are swallowed by a mosquito. 14a. Maturation of fcmale cell. $1 \mathrm{tb}$. Formation of microgametes. 15b. Free nicrogamete. 16. Fertilization. 17. Ookinete. 18, 19.20. The ökinete attacks and penetrates a cell of the intestine of the mosquito, and passes completely through the epithelium, eoming to rest in the peri-intestinal tissue. (There is not, in life, the reduction in size indicated by the figure.) 21 to 25 . Stages in the devclopment of the cyst and formation of the sporozoites. 26. Migration of the sporozoites. 27. Sporozoites in the salivary glands of the mosquito. 13e to $17 \mathrm{c}$. These figures portray the cycle which is supposed to account for eases where malaria is latent for a longer or shorter period. Ordinarily, unless removed by a mosquito, the differentiated male and female eells (12a and $12 \mathrm{~b})$ die, but under certain eonditions the latter may continue to live in the blood, to give rise to a renewal of the disease. (After (rawley, from Mense's "Handbuch," after Grassi and Schaudinn, Cir. No. 194, Bu. In. Ind., I. ,. Dept. Agr.). 


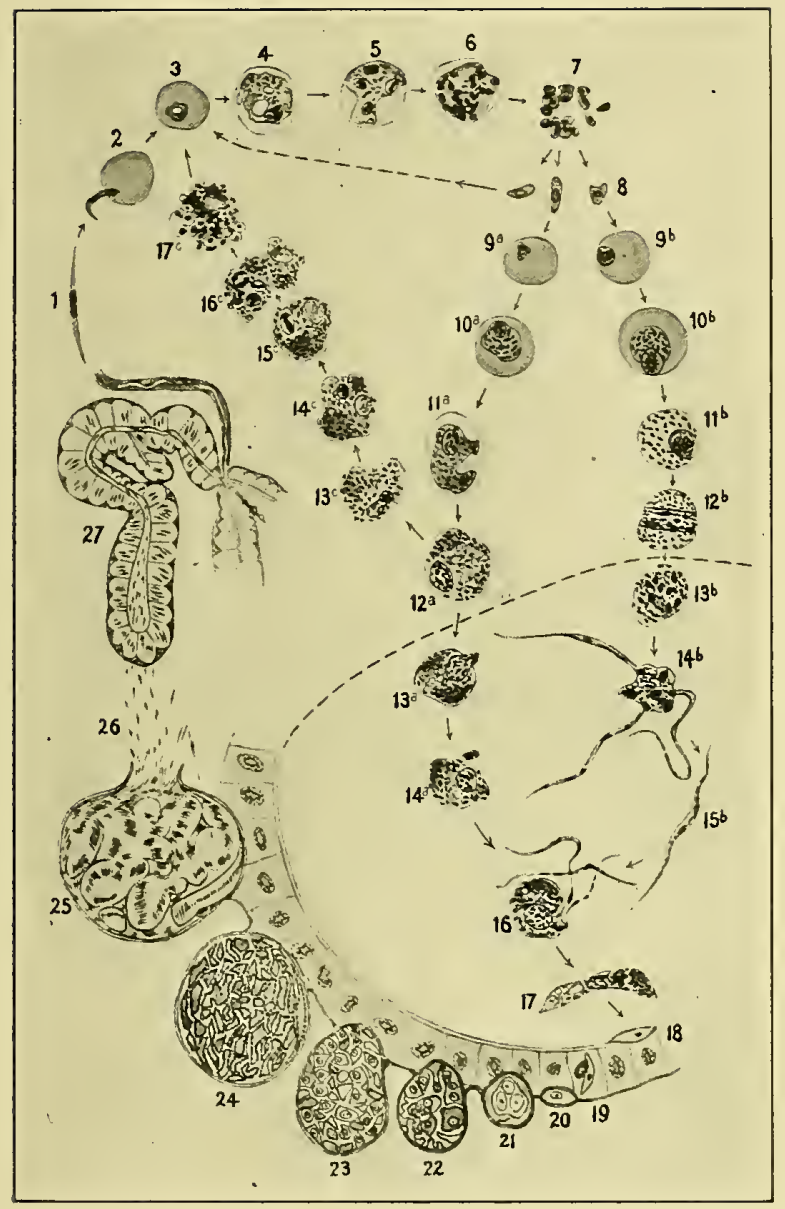


In the parthenogenetic phase, whieh oecurs in the human host, the female gametocyte sporulates without fertilization. After months of latency these spores nua pass into the blood current and enter the corpuscles, bringing about a recurrence of malaria after its apparent cure.

It should be noted in the sexual cycle that the formation of the sporolblasts is similar to the formation of corresponding reproductive centers of the Coccilia, which pass a portion of their cycle external to a host and which are elsewhere referred to (p. 337). The sporoblasts of the plasmolia, howerer, differ from those of the Coccidia in having no protecting numbrane or capusle, in the absenee of which protection, the sporozoites are unfitted for existenee outside the body of a host animal.

Classification.-- Aecording to their mode of life, Calkins divides the parasitic Protozoa into the following groups. The arrangement is not a llatural one and is merely for descriptive purposes:

1. Enterozoie.-Living in the lumen of the digestive tract.

2. Colozoic-Iiving in the colomic cavities of the body.

3. Cytozoic.-Living throughout the vegetative period as intracellular paraisites.

4. Caryozoic- - Passing into the cell to find lodgment in the cell nucleis.

5. Henatozoic--living in the blood plasma.

In some eases the parasite may pass through a number of these modes of life. Thus the plasmodia of malaria are hematozoic in the blood current, eytozoje in the blood corpuseles, enterozoie in the digestive tract of the mosquito, and colozoic when they pass as sporozoites into the body eavity of this insect.

In the arrangement of the classification of the Protozoa which follows, only those grolips eontaining speeies of parasitic importance are given.

\section{Clasisification of Parasites of the Phylta Protozoa}

Phylum 1V. Protozoa. P. 311.

Class A. Rlizopoda. P. 324.

Order 1. Lobosa. P. 324.

Crenus and species:

Amelna meleagridis. Host, turker. P. 32.5.

Entaneba histolytica. Host, main. P. 326.

E. coli. Host, man. P. 326.

Class 13. Flagellata. P. 326.

Order 1. Spirorhetida. P. 327.

Genus and speeies:

spirocheta gallinarm. Host, fowl. P. 327.

Orler 2. Trypanosomatida. P. 328. 


\section{PROTOZOA}

Genus and Species:

Trypanosoma theileri. Host, eattle. P. 329.

T. brucei. Hosts, equines, cattle, ete. P. 330 .

T. evansi. Hosts, equines, camel. P. 332.

T. equinum. Host, equines. P. 332.

T. equiperdum. Host, equines. P. 333.

T. americanum. Host, cattle. P. 336.

Trypanoplasma. P. 329.

Class C. Sporozoa. P. 336.

Order 1. Coccidia. P. 337.

Genus and Species:

Eimeria stiedæ. Host, rabbit. P. 342.

Diplospora bigemina. Host, dog. P. $3+2$.

Coccidium zurni. Host, cattle. P. 343.

Eimeria avium. Host, chicken. P. 345.

Order 2. Hemosporidia. P. 347.

Genus and Species:

Piroplasma bigeminum. Hosts, cattle, tick. P. 347.

Plasmodium vivax. Hosts, man, mosquito. P. 318.

Pl. falciparum. Hosts, man, mosquito. P. 31 s.

Pl. malariæ. Hosts, man, mosquito. P. 318.

Order 3. Sarcosporidia. P. 350 .

Genus and Species:

Sarcocystis miescheriana. Host, pig. P. 351.

S. tenella. Host, sheep. P. 351 .

S. blanchardi. Host, cattle. P. 351 .

S. bertrami. Host, equines. P. 351. 


\section{CHAPTER XXVII}

\section{THE PROTOZOAN SLBGROUPS. DISEASES DUE TO PROTOZOA}

\section{Class I. Rhizopoda. Protozoa (p. 311).}

The Protozoa of this group lack permanent structures for locomotion and nourishment, these functions being performed by the undifferentiated protoplasm. For this reason they are considered to be the lowest in position of the Protozoa. The class name-Rhizopoda-has reference to the extension of the cytoplasm in root-like processes or feet,the pseudopodia or false feet. It is in this manner that the animal flows ovel and engulfs its food, the movements serving for locomotion as well. This type of locomotion is known as ameboid, it having been first accurately studied in the Ameba. It differs from that of higher Protozoa in that it is not accomplished by constant cell organs, as cilia and flagella. A pseudopodium is formed when the cytoplasm streams to a point of the body, the process extending more or less beyond the general body surface; the body may then be drawn after it or appear to flow into it, the protrusion disappearing and new pseudopodia being formed at other points. By repetition of this process a slow change in the position of the organism occurs, and if particles of nourishment are encountered in such wandering they are engulfed by the cytoplasm within which they become surrounded by a certain amount of liquid, presumably of a digestive nature, to form the food vacuole.

The form of the pseudopodia varies, and this serves as a factor in the separation of the rhizopods into different groups. In the Ameba (Fig. 168) they are thick and finger-like, while in certain other forms they are of such delicacy as to appear like fine threads.

Reproduction in Rhizopoda may be accompanied with the formation of flagellate spores, the ameboid method of motility being exchanged for that of the flagellated Protozoa. In this stage the body becomes oval and the flagellum develops at the end containing the nucleus, where it persists during the spore stage.

The parasitic Rhizopoda belong with the order Lobosa which is the only one considered here. The characteristics of this group have been sufficiently referred to in the description of the type genus Ameba (p. 312). There are but few parasitic species known, and these are included in the two genera Ameba and Entameba. 


\section{Infectious Entero-Hepatitis of Turieys}

This disease-commonly known as blackhear-has been attributed to an organism found by Theobald Smith in the necrotic liver of affected turkeys and named by him Ameba meleagridis. That this is an ameba, however, has been questioned. Certain other investigators consider the organism described by Smith as a form in the development of intestinal Coccidia, the acceptance of which conclusion would place the disease among the coccidioses.

The term "blackhead" has been used to designate a number of diseases of fowls, among which, in addition to entero-hepatitis, are cholera, helminthiasis, intestinal coccidiosis, and, in general, any disease which may be accompanied by dark discoloration of the comb and wattles.

Symptoms.- It has been shown that entero-hepatitis can be transmitted directly from diseased to healthy turkeys, natural infection probably taking place through food and water contaminated with the droppings from the affected animals. At the expiration of the incubation period, which is usually within one month, the disease is initiated by loss of appetite and a drooping listlessness which is soon followed by diarrhea, the fluid discharge being yellowish in color and of exceedingly offensive odor. Weakness and emaciation have already set in, and the comb and wattles show the blackish discoloration from which the disease takes its name,--blackhead.

Death usually occurs after a course of from five to eight days. The mortality is highest in young animals, among which it is estimated to be eighty to nimety per cent. Adults are more likely to recover, though usually only after a long period of emaciation during which there may be a relapse.

Post-mortem Appearance.-The changes observed on necropsy are those of necrotic degeneration of the cecal mucosa and liver. The walls of the ceca are thickened, the mucous membrane ulcerated and covered with fibrous menbranes and exfoliating necrotic tissue. The liver is much enlarged and shows on its surface numerous yellowish areas with the centers softened. These areas may be quite small or up to $15 \mathrm{~mm}$. (5/8 of an inch) or more in diameter. Other portions of the digestive tract are not affected.

Examination in hanging drop of emulsified tissue of the cecal mucosa and the necrotic foci of the liver will reveal the amebre. The organisms found in the liver occur as rounded or oval cells measuring 6-14 microns and having a comparatively small nucleus. Sinith concluded from his investigations that the parasites were not intracellular but lived in the tissue spaces. In the liver they are thought to occupy the spaces of the necrosed and disappearing liver cells. 
Control.-The sick animals should be at once separated from those which are apparently not infected and the pens and runs subjected to thorough cleaning up and disinfection as recommended in other forms of poultry parasitism. It is important that the yards be kept dry and that the droppings be promptly removed and so disposed of that they cannot be a source of reinfection.

Treatment is of little value. As palliative, intestinal antiseptics, as eucalyptus or listerine, may be tried.

Amebic Dysentery in Man. - This is a disease occurring in tropical and subtropical, and at times in temperate regions, the cause of which is regarded by pathologists to be an aneba,-Entamba histolytica. Artificial production of amebic dysentery has been brought about in dogs and cats by rectal introduction of hmman feces containing the amebæ. It has been shown in such cases that the parasites invade the glandular crypts of the intestinal mucosa from which they penetrate to the submucosa and give rise to a hemorrhagic enteritis. In its further course the affection is accompanied by thickening and destructive ulceration of the mucosa.

The diagnosis of amebic dyscntery is by demonstration of the amebre in the stools. They may be differentiated from Entameba coli, an intestinal species which is considered to be a harmless commensal, by their definite and relatively firm ectoplasm which gives a rigid character to the pseudoporlia, cnabling the parasites to force their way between the epithelium of the crypts and into the more deeply lying tissues. The nucleus of $E$. histolytica varies in shape and position with the activities of the crtoplasm; it has little chromatin, and no nuclear membrane is apparent. The nucleus of $E$. coli is usually spherical and shows little change in position.

\section{Class II. Flagellata (MIastigophora)}

Protozoa (p. 311).

As has been stated, there are certain forms among the Rhizopoda in which the pseudopodia disappear from time to time to be replaced by one or more flagella; in other cases there may even be permanent flagella contributing to the pseudopodia in their function of loemotion and prehension. Such flagellate rhizopods are transitional to the Flagellata and serve to prevent the drawing of a sharp line of demareation between the two groups based upon the possession of flagella. In general it may be said of the Flagellata that they are permanently flagellate, the flagella serving for locomotion and feeding. They exhibit a great diversity of form which is to a large extent correlated with the number and location of the flagella. A degree of complexity is exhibited by some freeliving forms in the possession of a mouth and cytopharynx, but all par- 
asitic forms, and most of those which are free-living, obtain their nourishment by absorbtion through the general surface of the body.

The parasitic flagellates come within two orders,-Spirochetida and Trypanosomatida.

\section{Order I. Spirochetida}

Flagellata (p. 326).

The spirochetes are of somewhat uncertain position because of incomplete knowledge of their flagella and life history. They multiply by longitudinal division, or it may be by transverse division as do bacteria, and many writers have placed them with the latter organisms. They range from one to two hundred microns in length, and the body is filamentous and spiral in form (Fig. 169). Delicate flagella may be present at one or both ends. Nuclei cannot be distinctly demonstrated: the nuclear material is probably distributed as granules throughout the protoplasm as in bacteria. Motility is exhibited by rotatory movements, and the progression may be in either direction.

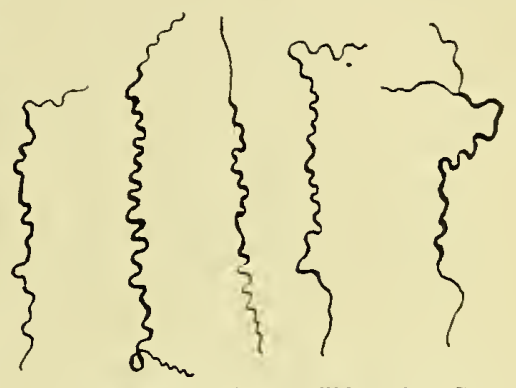

FIG. 169.-Spirocheta pallida (after Crawley, from Doflein, after Schaudinn, Cir. No. 194; Bu. An. Ind., C. S. Dept. Agr.).

Excepting in poultry, the spirochetes are not, so far as known, seriously pathogenic in the domestic animals. The extreme pathogenicity of certain spirochetes in man, however, indicates the disease-producing possibilities of the group and rates it, potentially at least, as a dangerous one to all higher animals.

\section{Sipirochetosis of Fom"Ls}

This disease was first described by Marehoux and Salimbeni who, working in Brazil, noted that special varieties were more susceptible and suffered more severely from the attack than common forls. The condition was originally termed forl septicemia, or Brazilian septicemia of fowls, and is now considered to be due to the presence of the spirochete Spirocheta gallinarum (S. marchouxi) which lives in the blood, is 15-20 microns in length, and is carried from host to host by the tick Atrgas minialus.

The investigators above mentioned distinguish an acute and chronic form of the disease, the former characterized hy emaciation, drooping. 
diarrhea, and anmmia. Toward the end weakness has so far advanced that the affected birds are completely helpless and lie with their heads upon the ground. Those which survive are said to be immune to further attack. The spiroochete sometimes penetrates the red blood cells; it has also been found in the eggs and in the embryonal epithelium of the chick.

It is not known with certainty that the disease exists in this country. It is not unlikely, however, that some of the as yet obscure diseases

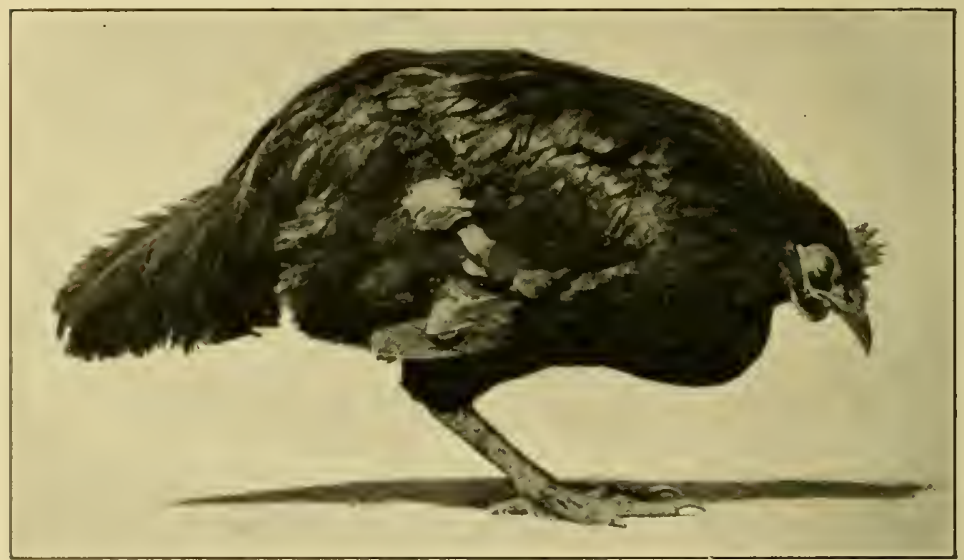

Fig. 170.-Hen suffering from acute spirochetosis (after Crawley, from Balfour, Cir. No. 194, Bu. An. Ind., U. S. Dept. Agr.).

of poultry may be found to be due to menbers of the spirochete group, - a sufficient reason for mentioning the Brazilian spirochetosis here.

\section{Order II. Trypanosomatida}

Flagellata (p. 326).

A number of classifications have been proposed for these organisms, salmon and Styles placing then in the order Monadida (Moore, 1906). Calkins (1909) classifies them as follows: Subphylum Mastigophora; class, Zoönastigophora; subclass, Lissoflagellata; order, Trypanosomatida; typical genera, Trypanosoma and Trypanoplasma. The same author thus describes the order in tabulation: "Organisms of elongate, usually pointed form, and of parasitic mode of life; with one or two flagella arising from a special "motor" nucleus, and with an undulating membrane provided with myonemes ruming from the kinetonucleus to the extremity of the cell; one of the flagella is attached to the edge 
of this membrane throughout its length, and may terminate with the membrane or be continued beyond the body as a free lash."

All species of the genus Trypanosoma show a general morphologic similarity. In general they may be said to measure from $15-45$ microns in length, including the flagellum, and 1-5 microns in thickness. As typical of the group, T. theileri, living exclusively in the blood of cattle, may be taken for brief description. The body is spindle-shaped, more or less serpentine, and pointed at the ends, from one of which there projects a vibratile flagellum. The flagellum is continued as a marginal cord toward the opposite end of the body where it takes origin in a minute granule (blepharoplast). In close relation to this granule is a deeply staining body which, because of its connection with the motile elements of the cell, has been designated the kinetonucleus. Arising from the kinetonucleus, the flagellum passes along the body on the border of a delicate protoplasmic membrane -the undulating membrane-toward its free extremity. Centrally located is the trophonucleus, the nucleus concerned with the vegetative processes of the cell. This is clearly defined and usually has the chromatin in the form of granules of definite number. The endoplasm is granular and may appear vacuolated. Reproduction in the blood of the vertebrate host is by longitudinal division following division of the blepharoplast, kinetonucleus, and trophonucleus. In some cases the daughter cells remain together for a longer or shorter time in a sort of rosette formation.

The members of the genus Trypanoplasma (Cryptobia) have two flagella. They are mostly parasitic in fishes; so far as known there are no species which attack higher animals.

Transmission.-The Trypanosoma are parasites of the blood, lymph, or cerebrospinal fluid of vertebrates, and, with one known exception, their transfer is accomplished by the intervention of an intermediate carrier which is either essential and indirect, or mechanical and direct. In the former case a blood-sucking fly becomes infected by feeding upon the blood of an animal harboring the trypanosomes. In the body of the fly the trypanosomes undergo certain changes, probably of a revitalizing nature, and for a period of time the fly remains noninfective. When this period has elapsed the trypanosomes within the fly resume their ability to infect any host whose blood is reached by the piercing mouth parts of the fly. Furthermore, such flies remain infective for an indefinite period, probably for the remainder of their lives.

By the direct or mechanical method of transfer the fly, after having bitten an infected animal, very shortly afterward visits a healthy one and may inoculate it directly with its contaminated proboscis. If the fly draws the blood of a sick animal and then successively risits two 
healthy ones, the second of the latter will not usually contract the disease. This is due to the fact that the proboscis of the fly, charged with the trypanosomes from the blood of the sick animal, becomes cleaned of the organisms in biting the first of the healthy ones. Any biting arthropod may transmit by the direct method; the ability to infect is usually limited to a few hours from the time of biting an infected animal, though under experimental observation it has been retained for a considerably longer time (see Glossina, p. 44).

\section{NAGANA}

The fundamintal work upon this disease was carried on in Zululand by Bruce who, in 1895, discovered that nagana, or the so-called tsetse fly cliscase, was caused by a trypanosome which, after its discoverer, has been named Trypanosoma brucei.

"Nagana, or fly disease," Bruce writes, "is a specific disease which occurs in the horse, mule, donkey, ox, dog, cat, and many other animals, and raries in cluration from a few days or weeks to many months. It is invariably fatal in the horse, donkey, and dog, but a small percentage of cattle recover. It is characterized by fever, infiltration of coagulable lympl into the subcutaneous tissue of the neck, abdomen, or extremities, giving rise to swelling in these regions, by a more or less rapid destruction of the red bloorl corpuscles, extreme emaciation, often bhindness, and the constant occurrence in the blood of an infusorial parasite."

Nagana is a Zulu worl which, according to Brucc, refers to the state of depression and weakness characteristic of the discase.

Nagana exists, particularly in low and humid regions, throughout Africa with the exception of Tunis, Algeria, and Moroceo, and most of the country south of the Tropic of Capricom. The disease is supposed to be transmitted mainly the by the tsetse fly Glossina morsitans, though other species probably play an equal part in this respect. Etiologic reference to nagana has already been made in the review of the work of Bruce under the sulject of Glossina (p. 4t) and need not be repeated here.

Plate V.-Yaziod - Species of Trypanosoma. 1. Trypanosoma lewisi, of the rat. 2. Trypanosoma lewisi, multiplieation rosette. 3. Trypanosoma lewisi, small form resulting from the disintegration of a rosette. 4. Trypanosoma brueei, of nagana. 5. Trypanosoma equinum, of eaderas. 6. Trypanosoma gambiense, of sleeping siekness. 7. Trypanosoma gambiense, undergoing division. S. Trypanosoma theileri, a harmless trypanosome of eattle. 9. Trypanosoma transvaliense, a variation of $T$, theileri. 10. Trypanosoma atium, a bird trypanosome. 11. Trypanosoma damonix, of a tortoise, 12. Trypanosoma solex, of the flat fish. 13. Trypanosoma granulosim, of the eel. 14. Trypanosoma rajæ, of the skate. 15. Trypanosoma rotatorium, of frogs. 16. Cryptobia borreli, of the red-eye (a fish). (After Crawley, from Laveran and Mesnil; Cir. No. 194, Bu. An. Ind., I. S. Dept. Agr.) 


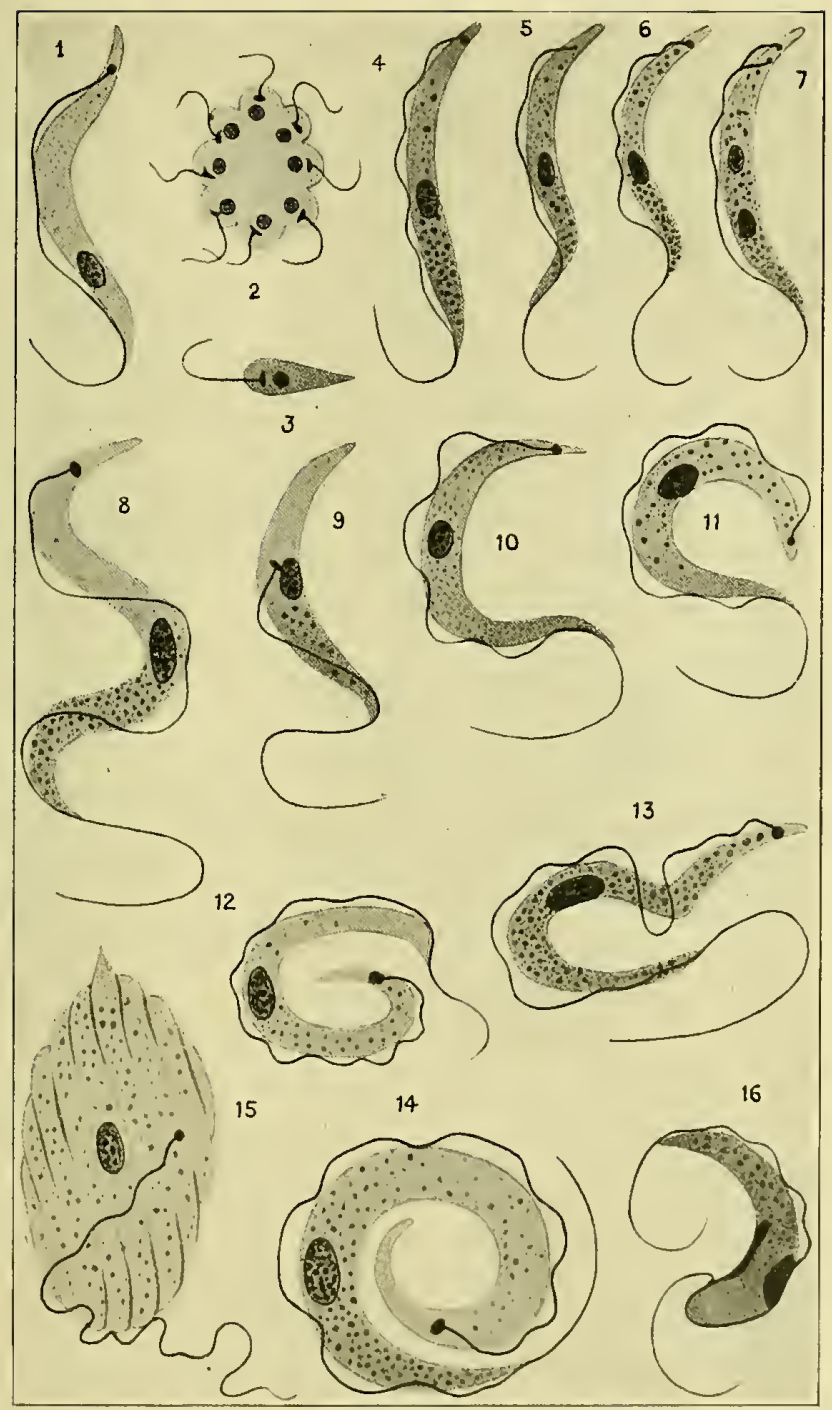




\section{Surra}

This name has becn given to a discase of horses, camels, and dogs of Asia caused by Trypanosoma evansi, which in 1850 ivas found by Evans in the blood of affected horses. Surra occurs in Southern Asia, the East Indies, the Philippines, Korea, Australia, and among the dromedaries in Northern Africa where it is known under the name of mbori.

Symptoms.-In its constant and progressive anæmia and cachexia the disease closely resembles nagana. At its outset there is a rise of temperature which in some cases may be followed by an urticarial eruption. Edema appears under the skin of the belly and limbs, and the eyelids become puffy with conjunctiva congested. The appetite is usually retained, but in spite of this there is loss of flesh and strength. Later the appetite is lost, there is great weakness, and the wasted and enfeebled animal may fall and be unable to again get upon its feet.

Course.--Horses invariably die in from one to several months after the onset of the disease, though in some cases death may occur suddenly in the early stages. In camels the disease runs a much longer course. Cattle, though they may harbor the parasites in their blood, generally resist the disease.

Infection.-A specific carrier of the organism causing surra is not known. Tsetse flies are not found in Asia, but it has been determined that the stable fly (Stomoxys calcitrans) and the horsefly (Tabanus striatus) of Asiatic countries can transmit the disease by their bite. It is believed by some that the horsefly is the principal carrier. So far as known the flies carry the disease from animal to animal directly by means of contaninated mouth parts, and are unable to infect for more than one or two days after having drawn the blood of an infected animal.

\section{Mal De Caderas}

Mal de caderas (discase of the hip) is a trypanosomiasis oceurring in horses throughout the greater part of South America, eaused by Trypanosoma equinum, which was discovered by Elmassian in the blood of horses in Argentina in 1901. The occurrence of the disease by natural infection is almost exelusively anong horses and mules, the former of which are the more susceptible. A number of other mammals may be successfully inoeulated, among them the hog, rabbit, guinea pig, rat, and mouse.

Symptoms.-Following a statement that, owing to its great ravages in certain parts of South America, eattle have to be used for riding purposes, Laveran and Mesnil (Trypanosomes and Trypanosomiases, English edition) describe the symptons of the disease as follows:

"The first sign of the disease in horses is wasting, which rapidly pro- 
gresses in spite of a good appetite. The temperature is often raised to $104^{\circ}$ to $105.8^{\circ} \mathrm{F}$. After a varible time it is noticed that the hind quarters are weak, and that the animal drags its legs, the hoofs grazing the ground. These symptons increase and become characteristic, so that when the animal is made $t$ ) walk it staggers along, the hind quarters swaying from side to side. On account of this sympton the name mal de caderas, or disease of the hind quarters, has been given to the disease. There comes a time when the animal is unable to stand; if in the stable, it leans up against a wall or seeks other support; if in the open, it staggers and falls. After thus falling to the ground an animal may still live for several days if it be fed; otherwise the inevitably fatal end is hastened by inanition."

Infection.--The mode of natural infection is not as yet known. The observed fact that horses separated from affected animals only by a fence remain healthy in spite of the presence of piercing flies, would indicate that these insects are not the transmitters. Until something definite is established as to the transmitting agent, no certain preventive measures can be adopted.

\section{Dourine}

Dourine is an infectious disease of the horse and ass affecting primarily the genital tract. It is due to Trypanosoma equiperdum, transmitted from animal to animal in the act of copulation. The disease is variously named "maladie du coit," "el dourine," or " dourine," according to the country in which it is found, dourine, which is from the Arabic for "unclean," being the term most commonly employed for it in the United States. It is supposed to have been introduced into Continental Europe early in the nineteenth century by horses imported for breeding, especially those from the Orient where the disease has long existed.

In the United States dourine first appeared in Illinois where it was recognized by Dr. W. L. Williams in 1886 . The source of the infection was found to be imported Percheron stallion, and it had been disseminated for some time before the true nature of the malady became known. By the application of rigid preventive measures, the disease was eradicated from Illinois in 1888, but it had been carried by a stallion to Nebraska, where an investigation of an outbreak in 1892 by an inspector of the Bureau of Animal Industry revealed that upward of two hundred mares and stallions in the northwestern part of that state were affected with the discase. Measures taken by the federal authorities brought this outbreak under control for a time, but a few years later the infection again appeared in the same part of the statc. In 1901 there was an outbreak in the Pine Ridge and Rosebud Indian Reservations of South Dakota, and in 1903 the discase was reported in Van Buren Counțy, Iowa. It was again found in Taylor County , Iowa, in 1911. Thus dour- 
ine has appcared at various times within certain limits in the United States.

Infection.-Dourine is a peculiar trypanosomiasis in that there is no intermediate carrier of the trypanosome specifically. responsible for it. Like the spirochete of human syphilis, it is inoculable by contact, the infection usually occurring during the act of copulation, though reported cases of the disease in geldings and in mares which have never had the stallion would indicate that its transmission is not entirely by copulation. It nay be artificially transmitted to horses and to other susceptible animals, as dogs and rabbits, by inoculation with blood from animals affected. Sexual intercourse is, however, by far the most common means of natural infection, the trypanosome reaching the blood by penetrating the intact mucosa of the genital tract.

Symptoms.--The symptoms of dourine as given by John R. Mohler (Bureau of Animal Industry, Bulletin No. 142, 1911) are, with some omissions, here quoted.

"There are many variations in the symptoms of dourine, and this is particularly true of the clisease as it occurs in this country. Two distinct stages may be noted which vary somewhat from those described in textbooks, but probably no more than could be expected when differences of climatic conditions and methods of handling are taken into consideration.

"The first stage chiefly concerns the sexual organs, and therefore liffers somewhat in the malc and fcmale. In the second stage symptoms indicating an affection of the nervous system are more prominent and are not reprurlent on the sex of the animal.

"Following a variable period of incubation of from eight days to two months, there is seen in the stallion an irritation and swelling about the penis first noticed in the glans. This swelling extends throughout the organ, and the penis may be continually protruded and frequent erections noticed. The edematous swelling also involves the groin, with enlargement of the aljacent inguinal glands, and extends forward along the abdomen. In a few days small vesicles or blisters appear on the penis, which break, discharging a yellowish serous fluid and leaving irrogular raw ulcers. Where primary ulcers are in proximity to each other therc is a marked disposition to coalesce, a large raw surface with irrcgular border resulting. The ulcerative process may form a wound extending almost cntirely around the penis. The ulcers show a tendency to heal rapidly, leaving white cicatrices which are permanent. In some cases the urinary meatus is very red and swollen, and according to some observers, espccially European, more or less thick catarrhal exudate is discharged from its oriface. This condition, however, has been rarely seen in cases in this country, a more or less continuous dripping from the urcthra of a yellowish serous-like discharge alone being present. 
The stallion retains his full genetic instinct and becomes very amorous when brought in the vicinity of mares. If allowed access to mares in season, service is often impossible, due to the fact that a complete erection of the penis does not occur. The testicles may be involved and tender to pressure, and abscess formation may occur with sloughing.

"In the mare the first symptoms may be so slight as not to be noticed by the owner. The disease being the result of copulation, begins with swelling and inflammation of the vulva and vagina. The labia are continually everted, exposing the clitoris, which is constantly in a state of erection. There will also be a muco-purulent discharge like that coming from the penis of the male, which may be slight or profuse in quantity. The mare will switch the tail, appear uneasy, and urinate frequently. Shortly papules and vesicles appear on the external vulva, as well as on the mucosa of the vulva and vagina. These vesicles soon rupture, but before doing so the contents undergo a change from a transparent to a purulent fluid. The rupture of these pustules is the initial stage in the formation of deep, angry.ulcers. These ulcers show a tendency to heal rapidly, but invariably leave a cicatrix. On the dark skin of the external vulva the scars will always be white. This depigmentation is permanent.

"Sometimes, especially in the mare, the above-described lesions tend to disappear gradually, and in case the mare is not served again the disease may remain in abeyance for months or a year. The apparent recovery, however, is not permanent, and any excessive work or excitement may set up the disease anew. In case an affected mare conceives, she is liable to abort at any time during her term of pregnancy. When the fetus is carried to full term, it occasionally is a weak or imperfectly developed foal, but in this country many fine colts have been born to affected mares.

"The nervous or constitutional disturbances of the second stage may not come on for months or even a year after the appearance of the local lesions, and are similar in both male and female. They consist of a general nervous disorder with staggering, swaying gait, especially in the hind linbs. The animal becomes extremely emaciated, particularly in the hind quarters, and the abdomen assumes a "tucked-up" appearance. The first indication of paralysis will be noted in traveling, when the animal fails to pick up one of the lind feet as frecly as the other. There is a tendency to drag the foot partially. This condition may shift from one hind foot to the other, or both may become affected simultaneously. Twitching of the superficial muscles has been noticed in several instances. Urticarial eruptions or plaques nay break out over various parts of the body, and there may be noticed pruritus of the skin, which causes the animal to rub itself frequently. The tentperature of the animal seldom goes above $101^{\circ}$ or $102^{\circ} \mathrm{F}$. When the 
paralysis of the hind limbs starts to appear, it usually progresses rapidly, the horse gocs down, is unable to rise, and dies in a short time from nervous exhaustion."

Control.-As dourine is transmitted and spread only by copulation, its eradication is a less difficult problem than in trypanosomiases which may be carried by flies. So little benefit is to be derived from medicinal treatment that in this country, where the disease has appeared only in restricted arcas, it is not advisable. While cure may be possible, an apparcntly cured animal may carry the trypanosomes for months in the sexual organs, and relapses are likely to occur. In areas where the discase appears measures of eradication must be based upon the prevention of infected animals from breeding.

To confine the losses to the minimum, therefore, the prompt castration of affected stallions and the destruction of diseased mares is essential. Spaying of such mares is not a sufficient precaution from the fact that they may be sold and an attempt madc to breed them, thus infecting the stallion and through this source sprcading the disease. Restrictions in the movement of horses in infected districts and frequent reinspection arc further state and federal measures for confining an outbreak so far as possible to its original limits.

Trypanosoma americanum.- This trypanosome is found in cultures of blood from healthy American eattlc. It deserves mention here on account of its common occurrence, though it appears to be harmless. A report by Crawley upon his extended study of this organism will be found in Burcau of Animal Industry Bulletin No. 145 (1912).

\section{Class III. Sporozon}

Protozoa (p, 311). - The Sporozoa are all parasitic. Though without motilc organs, they are capable of moving from place to place, in some eases by mcans of pscudopodia. Reproduction is mainly by spore formation, either asexual or sexual. There are a number of forms, however, in which simple reproduction occurs, and the group comprises organisms with life histories as yet not fully known. The Sporozoa, therefore, is a division to be regarded as provisional, containing at present organisms which when their lifc histories are fully made out may be more accurately placed with other divisions of the Protozoa.

Based upon the belief that the Sporozoa are polyphyletic; that is that all have not the same ancestral history, they have been placed in two divisions,-Telosporidia and Neosporidia, the former regarded as descended from the flagellates, the latter from the rhizopods. Of the Telosporidia but two orders are to be considered here,-Cocidia and Hemosporidia. The Neosporidia has one order,-Sarcosporidia, containing parasites of domestic animals. 


\section{Order I. Coccidia}

Sporozoa (p. 336).--The Coccidia are cytozoic or cell-infesting parasites, attacking epithelium of invertebrate and vertebrate animals. Reproduction is by schizogony and by sporogony, the asexual and sexual generations alternating in the life cycle. In species parasitic to domestic animals the fertilized cell produces sporoblasts covered by a sporocyst membrane.

Life History.-The life cycle is similar to that of the malaria organisms except that no arthropod intermediate host is required for the sexual reproduction. Infection with Coccidia is with the encysted stage (oöcyst) by way of the mouth. Hence the parasites are almost exclusively found in the epithelium of the alimentry caulal and organs connected with it. Reaching the stomach and duodenum, the oöcyst is acted upon by the digestive juices and the sporozoites contained in the cyst are liberated. These enter the epithelial cells of the mucosa. Within the cells they lose their spindle form and enter the stage of the trophozoite in which they grow to a size depending somewhat upon that of the invaded cell. By the process of schizogony the trophozoite divides into a number of small protoplasmic masses which are the merozoites or asexually formed spores. These invade other cells and in the same manner grow into another generation of merozoites. By many repetitions of this cycle a large number of cells are invaded and destroyed, and the death of the host animal may follow as a result. After a number of asexual cycles some of the merozoites do not grow and divide into another generation of merozoites, but develop into stages which begin the sporogonous or sexual cycle. In this proeess the female trophozoite instead of dividing develops into an egg or macrogamete. The male trophozoite, by division, forms minute male reproductive elements or microgametes. By their motility the microgametes reach and fertilize the macrogametes which, becoming surrounded by a resistant membrane, arrive at the stage of the oöcrst. Within the oöcyst a number of spores may be formed, each inclosed in a protecting membrane and constituting a sporocyst. By clivision each sporocyst forms two or more sporozoites, and thus the sexual cycle is completed. Where the parasites are in the epithelium of the alimentary tract or its conmunicating organs, the oöcysts pass to the exterior with the feces. In other cases it may be that they can only reach the outside after the death and disintegration of the host.

The effect of coecidiosis upon the animal is brought about by the extensive destruction of cells resulting from the repeated production of merozoites by schizoguy. This progressive reproduction and cell destruction would in every case result in the death of the animal were it not that the number of sehizogonous generations is limited. The cell 


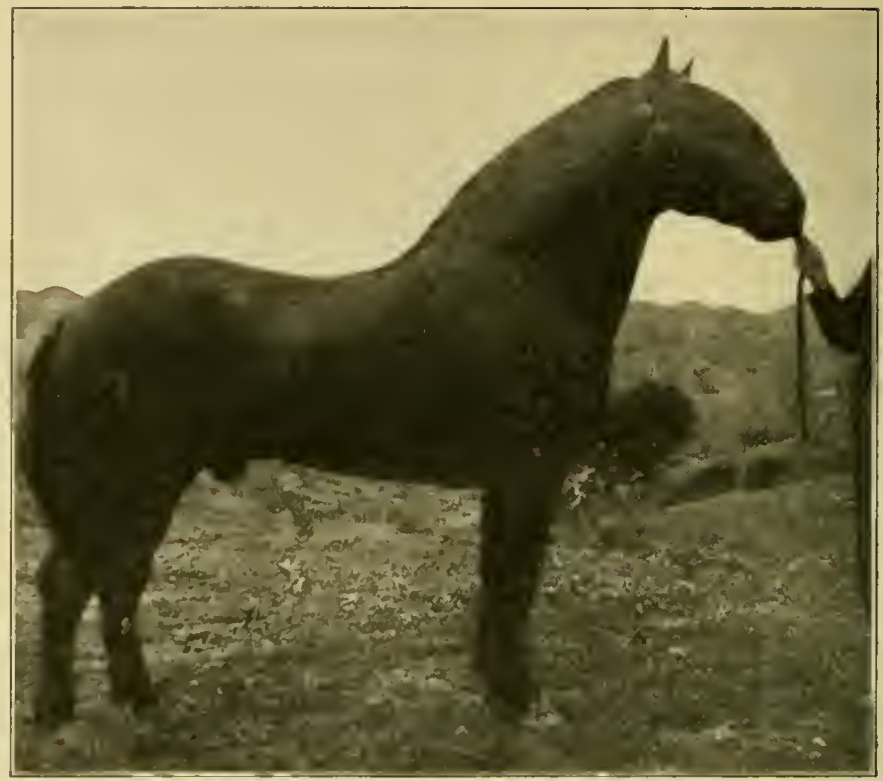

Plite VI, Fig. 1.

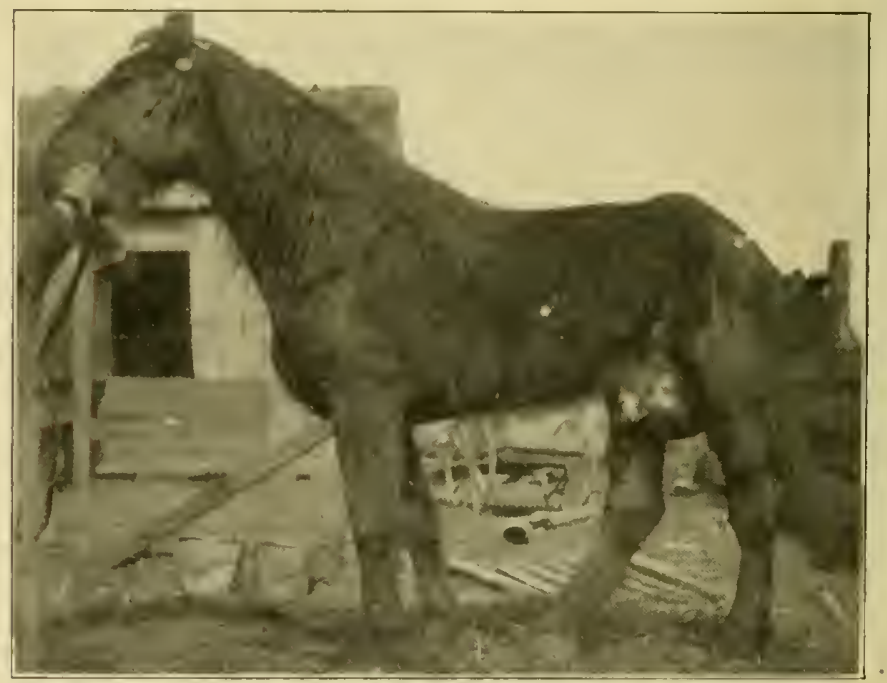

Plate VI, Fig. 2. 
Plate. VI.-Frg. 1.-Percheron stallion, showing condition at the time of purehase. Fig. 2. Same stallion after dourine had developed. Spots on side and croup give location of plaques. (After Mohler, Bul. No. 142, Bu. An. Ind., U. S. Dep Agr.). 


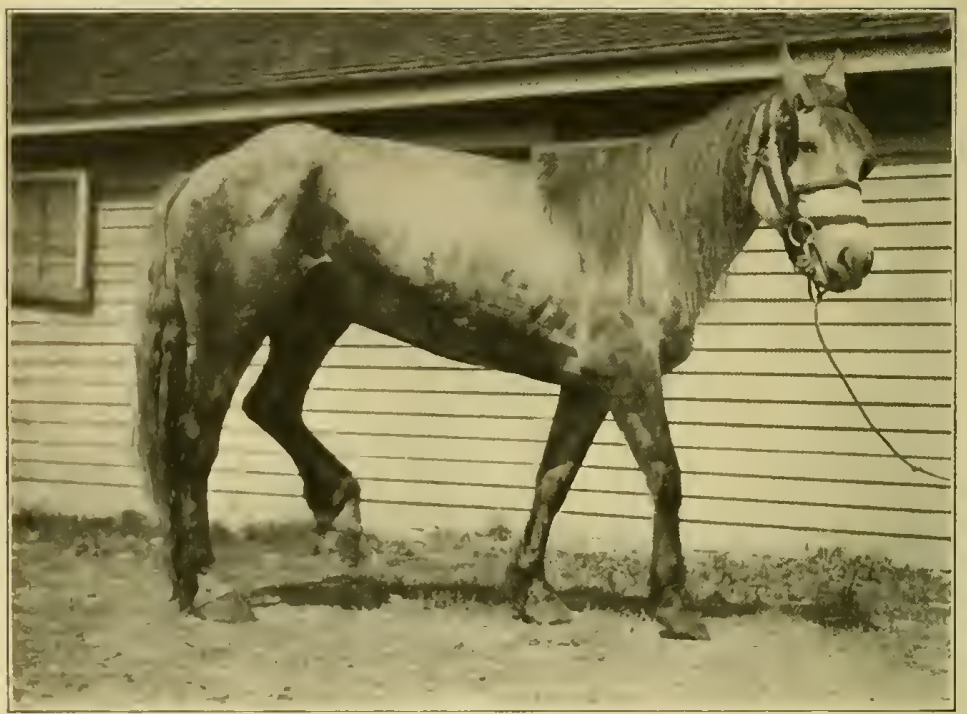

I'late Vill, Fili. 1.

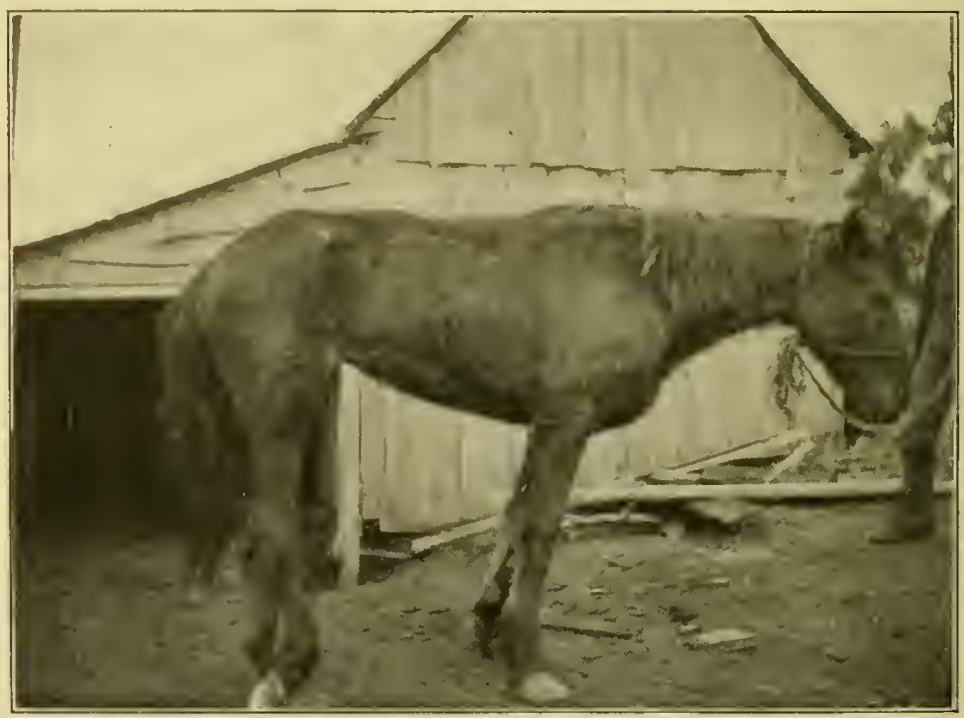

Plate Vil, Fig. 2 
Plate VII.-Frg. 1.-Percheron mare, showing chronic dourine. Observe the "tucked up" abdomen and emaciation, the mare having lost over 700 pounds in the previous four months. FIG. 2.- A mare in the last stage of dourine. Notice the position of the off hind foot and the straightened hock joints. (After Mohler, Bul. No. 142, Bu. An. Ind., U. S. Dept. Agr.). 
destruction ceases with the beginning of the sporogonous cycle, and, if the acute stage of the disease is survived, the animal tends to recover, the destroyed cells being replaced more or less completely by newly formed ones. Thus it may be said that the disease is self-limiting.

Eimeria stiedæ.-Coccidia (p. 337).-This coccidian, also known as Coccidium oviforme and $C$. cuniculi, is the species commonly found in the liver of domestic rabbits. Most frequently it attacks the epithelium of the bile ducts where it causes destruction of cells and pathologic changes in the liver by which the secretion of bile is reduced. The condition affects rabbits seriously and deaths occur as a result of it.

Eimeria stieda is considered by some authors as a cause of coccidiosis in man.

Diplospora bigemina (Isospora bigemina). Coceidia (p. 337). - In a report upon their mork with this coccidian Hall and Wigdor (Journal of the American Veterinary Medical Association, April, 1918) state that in two hundred dogs examined at Detroit, Michigan, it was found in fifteen, or slightly over seven per cent. From this finding they suggest that the parasite may be more common in American dogs than our present lack of information would inclicate.

In reference to the pathogenesis of Diplospora bigemina, these authors may be further quoted from the same article as follows:

"As regards the pathological significance of $D$. bigemina, we have but little information. but the following notes may serve some purpose: Dog No. 130 presented a clinical picture of distemper and died of pneumonia, probably due in part to distemper and partly to an accident in drenching. The small intestine showed diffuse hemorhagic points, most pronounced in the ileum, especially the lower ileum near the valve. Scrapings of the mucosa showed the coccidia to be most abundant in the ileum, less so in the jejunum and least so in the duodenum. These findings of increasing numbers of coccidia with increasing severity of lesions may be correlated, but in the absence of sections indicating the relation of the coccidia to the hemorrhage, we do not care to hazard a definite opinion. Dog No. 173 showed numerous fine petechiæ in the intestinal mucosa, and these were especally numerous in the Peyer's patches, giving these a uniformly dark appearance. No sections were inade and this dog had shown no oöcysts in the feces for forty-five days. Dog No. 127 showed innumerable pinpoint petechiæ in the ileum, but it would be unsafe to draw conclusions based on this one dog, as the animal figured in other experiments. The intestine of $\log$ No. 223 was macroscopically nolmal except for the presence of hook-worm petechiæ. In view of the fact that coccidia are destructive to epithelial tissue and that some species fairly closely related to $D$. bigemina are known to be lighly pathological, it would seem reasonable to suppose that $D$. bigemina might be distinctly pathological at times, though the apparent 
grood health and lack of post-mortem lesions in other dogs makes it certain that it often does no visible damage."

Coccidium zurni. Coccidia (p. 337).--Red dysentery of cattle is attributed to this coccidian. The disease occurs in Europe, generally among young animals as an enzoötic. The attack of the parasites upon the cells of the intestinal mucosa causes extensive hemorrhage, the red diarrhea resulting from the mixture of the blood with the feces. Mild cases, particularly in adult animals, may soon recover. Severe cases, occurring particularly in young animals, may run a hyperacute course and terminate fatally within two days, or an acute course of five to ten days may precede this termination.

In the report of the Committee on Medicine and Surgery submitted at the meeting of the Pennsylvania State Veterinary Medical Association, held in January, 1918, Dr. W. J. Lentz, of the University of Pennsylvania, called attention to cases of intestinal coccidiosis of cattle which had come under his observation in the State of Delaware. His report as published in the Journal of the American Veterinary Medical Association for November, 1918, follows:

"Was asked to consult with a veterinarian on an interesting condition in a herd of grade Holsteins. Owner had lost four or five heifers over a period of about two weeks, ranging in age from six months to eighteen months. All presented similar symptoms. There was first noticed a serous, fetid, black diarrhea. Fever was rarely in evidence at any time. The diarrhea after a few days changed to mucus, with the passage of blood clots with the mucus and feces from time to time. Straining was very marked. Appetite somewhat impaired but, nevertheless, partook of some food, but finally, in about six to eight days, became very dull, refused food, emaciated rapidly, rectum became relaxed, temperature subnormal, pulse hardly perceptible, and these symptoms of collapse were soon followed by death. On arrival at the farm found six to eight calves and one adult cow presenting some of the symptoms mentioned, and, inasnuch as one was about to die, it was destroyed and posted. Lesions were confined to the large intestine. No apparent pathological change in any other organ. The mucous membrane of the large intestine, which was almost empty, was red brown in color, soft and spongy, and everywhere coated with a bloody mucus. The back of the knife, after the intestine was slit open, was passed over the mucous surface and the bloody mucus scraped off, when it was noticed that large supcrficial ulcers, white in color, and about the size of one's palm. were present throughout the whole extent of the large intestine from the cecum to the anus. Some of the mucous patches were scraped of and collected in a bottle, also some of the blood and feces. On microscopic examination, coccidia were detecterl. I diagnosis of "intestiul coceidiosis," or "red dysentery," was therefore made. Treatment 


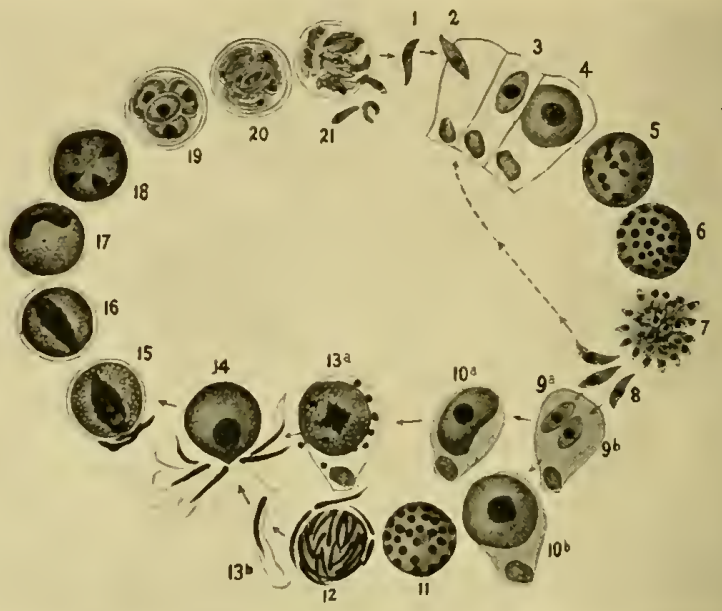

Plate VIII, Fig, 1.

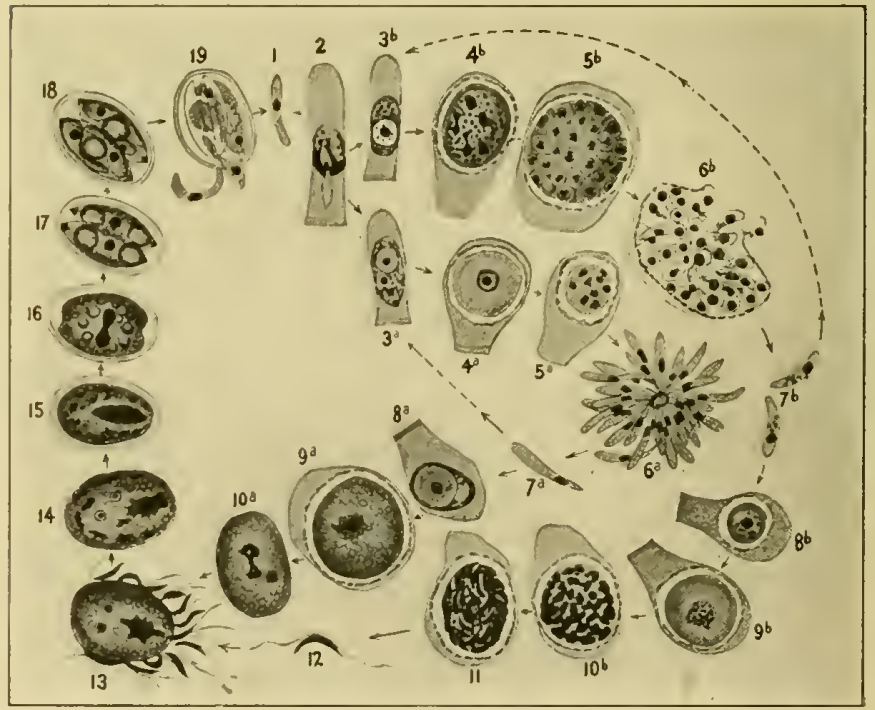

Plate VIII, Fig. 2. 
Plate VIII.-Coccinian Life Cycle.-Fig. 1. 1. Sporozoite released in intestine of host. 2. Penetration of sporozoite into epithelial cell. 3, 4. Growth of sporozoite into trophozoite. 5, 6, 7. Schizogonous cycle. Nuclear division, followed by division of entire trophozoite into a large number of merozoites. 8. Free merozoites, which for an indeterminate number of generations merely repeat the schizogonous cycle, behaving precisely as do the sporozoites. Eventually, however, the sporogonous cycle is initiated, which proceeds as follows: $9 \mathrm{a}$. Undifferentiated female cell. 9b. Undifferentiated male cell. 10a. Differentiated female cell. $10 \mathrm{~b}$. Differentiated male cell. 11, 12. Formation of the microgametes, one male cell producing many microgametes. 13a. Macrogamete. One female cell produces but one macrogamete. 13b. Ripe microgamete. 14. Fertilization. 15, 16, 17. The zygote. 18. Beginning of spore formation. 19. Completion of spore formation. 20. Formation of the sporozoites within the spores. 21. Release of the sporozoites in the intestine of the host. FIG. 2.- Introduced for comparison with the more typical cycle shown in Fig. 1. Here the parasite penetrates and comes to rest in the nucleus instead of the cytoplasm, and there is sexual differentiation in the schizogonous cycle as well as in sporogony. (After Crawley, from Mense's "Handbuch," after Schaudinn, Cir. No. 194, Bu. An. Ind., U. S. Dept. Agr.).

suggested: Pearson's creolin well diluted with milk or water, also large doses of camphorated tincture of opium, and rectal injections, using garden hose and funnel, of a two per cent. creolin solution, alternating night and morning with a one per cent. alum solution. A week later received word that all were doing nicely and no deaths."

In Europe outbreaks of red dysentery similar to that of cattle have occurred in sheep.

\section{Coccidial Exteritis of Chicks}

The use of the name "white diarrhea" for this coccidiosis tends to its confusion with bacillary white diarrhea, which is a fatal septicemia of chicks caused by Bacterium pullorum. Coccidial enteritis or coccidiosis of chicks is caused by Eimeria avium (Coccidium tenellum), which attacks the epithelium of the intestinal mucosa, usually that of the ceca. Occationally the infection is found in other organs. The disease is usually seen in chicks from two to ten weeks old.

Symptoms.--The symptoms are merely suggestive of coccidiosis as they do not materially differ from those of some other diseases of poultry. The affected chicks droop and are inclined to stand about by themselves with eyes closed and feathers ruffled. In most all cases there is a diarrhea with whitish-colored discharge which stains and mats the feathers below the vent; a bloody diarrhea gives evidence of coccidial infection. If the discharge is examined under the microscope large numbers of circular or slightly oval oöcysts may be found. Death usually occurs after a course of three to four days.

Post-morten Appearance.-Post-mortem examination reveals the ceca much enlarged. Their contents may be normal or they may be packed with a yellowish white or bloody semiliquid material. The conclusion that the chicks are not infected with cocciclia should not be made from the absence of enlarged ceca, as occasionally there is no 
enlargement of these organs nor abnormal appearance of their contents. Not infrequently the enteritis involves the entirc length of the intestines. For a positive diagnosis microscopical examination of the intestinal contents or of the sectioned intestinal wall is necessary. Spreads of scrapings from the cecal mucosa examined uncler the microscope will reveal epithelial cells much distended by the deveiopment of the parasites within them. It is as a result of this invasion that the cells finally break down and separate from the underlying stroma to become a part of the pasty catarihal exudate which characterizes the fecal discharge.

Infection.- Though the fatalities are usually among the young chicks, the coccidian which causes the discase may be found in chickens of all ages and it may be sprearl from this source. Infection is by food and ingested soil or water contaminated by droppings which contain the cysts. It has been demonstrated that the cysts may remain infective for a year or more, therefore chickens may become infected if allowed access to yards where those harboring the parasites were kept the year previous.

Control.- There are no drugs which have been found to be of value in treating the clisease, therefore control is the essential consideration in contending with it. Morse states (Bureau of Animal Industry Circular No. 128, 1908) that this must begin with the eggs used for hatching. "These," he writes, "should be thoroughly and antiseptically cleaned by wiping in ninety-five per cent, alcohol. If artificial incubation is used (and in this method lies the great hope of success), the incubator, if used before, should, previous to receiving the eggs, be carefully washed with antiseptic solutions and exposed to the sun. The egg tray should be scalded or flamed. The floor of the mursery should be movable, so that it may be taken out and sterilized, and if made of burlap the old piece should be torn off and a new piece mounted on the sterilized frame. The same precautions shou'd be used with the brooders. The soil to which the chicks have access should be well covered with lime, dug up, and exposed to the drying effects of the sun and air. If natural incubation is practiced the hen for a week or two before being set should be treated with one-quarter to one-half grain doses of sulphate of iron daily, with occasionally an active purgative, such as calomel, one grain, or castor oil, one-half teaspoonful containing five to ten drops of turpentiue. The eggs, cleansed as directed above, should be placer in a perfectly fresh llest, which may be sprinkled from time to time with a little lime. After hatching, the hen with her chicks should be placed upon ground that has been thoroughly sterilized, as described above, and at least every fer durs moved to fresh ground which has been treated in the same way and from which all chickens have been debarred."

Further preventive measures are the removal of visibly sick chicks 
from the flock, either keeping them isolated or killing and burning them. It is better to put all of the chickens on new ground if possible, otherwise the ground should be covered with lime and spaded so that it may be exposed to the drying effect of the sum and air. All litter and nesting should be burned and a thorough cleaning up of the quarters followed by the application of a strong disinfectant solution. After drying, the floors may be protected from recontamination somewhat by covering them with shavings, chopped bedding, or other absorbant material, which is to be cleaned up and burned daily. Boards should be placed beneath the roosts to receive the droppings for convenient daily removal, Contamination of feeding and drinking vessels can in a measure be prevented by elevating them somewhat from the ground. They should at all times be kept clcan; daily treatment with scalding water or flaming followed by exposure to the sun will do much to eliminate the source of the infection.

\section{Order II. Hemosporidia}

Sporozoa (p. 336). - The Hemosporidia are Sporozoa which dwell in the blood where they invade the corpuscles, hence are cytozoic. Flagellated stages appear in their life history, and many protozoölogists suspect that the entire group has been evolved from the flagellated Protozoa. Comparing the life history of the malaria organisms (p. 318) with that of the Coccidia (p. 337) a distinct difference will be noted in the method of infection, the hemosporidian, as is true of others of the group, being transmitted from the blood of one animal to that of another by means of a known intermediate host, while the Coccidia infect directly, usually by food or water bearing the cysts. In diseases caused, by Hemosporidia, the infection, due to the activities of the intermediate host, is more widely disseminated, and large numbers of animals may be seriously and fatally attacked. As blood parasites, therefore, the Hemosporidia may be rated with the trypanosomes in pathologic importance.

\section{Texas Fever}

Tick fever, Splenic fever.

Smith and Kilbourne in 1893 found small parasites in the red blood corpuscles of cattle suffering with Texas fever. Due to their frequent occurrence in pairs, they were given the specific name bigeminum, and the genus was named Pyrosoma. The later generic name Piroplasma was derived from their often assuming a pear-like form, and the name now generally used for the hemosporidian enusing Texas ferer is Piroplasma bigeminum (Fig, 171).

The medium by which the organism is transmitted is the cattle tick Margaropus anmulatus, which crawls upon its host as a larva, attaches, 
and here undergoes its complete development. (Ref. Margaropus annulatus, Life History, p. 148.) For a number of days following her fertilization the female tick engorges with the blood of her host and then drops to the ground where a few days later she deposits her eggs and, having completed her cycle, soon dies. The parasites contained in the

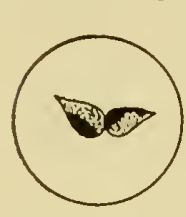

FIG. 171.-

Piroplasma bigeninum (after Crawley, from Doflein, Cir. No. 194. Bu. An. Ind. C.... Dept, Agr.) blood upon which the tick has fed reach the eggs and are present in the larval ticks when these are hatched. Thus the larvie have the power to infect any susceptible animal to which they attach.

In the first stage of development after gaining the circulation the piroplasma is within the red corpuscle as a single body near the corpuscle's margin. Later it divides into two bodies which remain slightly connected by a small filament. A single corpuscle may contain as many as four or even six parasites. The doubled bodies enlarge, assuming a spindle-shaped and later a pearshaped appearance. Finally, as a result of this invasion, the corpuscles break down, and the parasites become frec bodlies in the plasma. That a multiplicative stage occurs within the bovine host is evidenced from the fact that inoculation of susceptiblc eattle with a small quantity of virulent blood will produce the diseasc with the development of myriads of the parasites in the blood of the inoculated animals.

Occurrence. - Numerous attempts have been made to produce Texas fever in other species of animals by inoculating them with infected blood from cattlc. That all of these experiments have proved negative indicates that the clisease is one purely bovine. All bovine animals that have never becn exposed are susceptible, and in all cases natural infection with the protozoan causing the clisease is due to puncture by the cattle tick.

The disease exists in European and Asiatic countries, Africa, Australia, and the Philippine Islands. It was probably introduced into the United States by cattle brought over by the early Spanish settlers. The terms "Texas fever" and "southern cattle fever" are misleading to some in giving the impression that the discase is confined to the Southern States. Southern cattle carrying the infecting organism in their blood, though themselves possessing degrees of immunity to Texas fever, disseminate it through ticks from their bodies among eattle in the North or among those of the South which are susceptible to the clisease in a virulent form.

Exposure and Development.--The period from exposure to tick infested pastures or pens to the appearance of the disease depends upon the time which elapses from the dropping of the female ticks from the southern cattle to the hatching of the larva from their eggs, and this 
will be influenced by climatic conditions. If the larval ticks are already present and at once attach to the exposed animals symptoms of the fever may develop ten to twelve days later. Where the susceptible animals are placed upon pastures, in pens, or other places inmediately after these have been infected with ticks from southern cattle, a period must intervene covering egg-laying and hatching of the larvæ before the northern animals become inoculated. In summer this period may occupy from twenty to forty days; in cooler weather it takes longer for the eggs to hatch, and under such conditions sixty days or longer may be required before the infective generation of ticks appears. Thus, depending upon season and temperature, the disease may appear in twelve days to two or three months after exposure (see life history of Texas fever tick, page 148).

Symptoms.- Two distinct types of Texas fever are presented, -an acute fatal and a chronic form, from the latter of which the animals usually recover. Whether the fatal or the milder type appears will depend upon season and the susceptibilty of the animals. When northern cattle and those raised in tick-free districts in the South are attacked in the hot weather of summer, the acute form occurs. If the susceptible animals are affected in the latter part of autumn the milder chronic symptoms appear, and it is by this type of the disease that partly immune southern cattle are affected at any season, the fatal form rarely attacking these animals.

The Acute Type.--In this form of the disease the onset of the symptoms is rapid. The animal is depressed and stands or lies down apart from the herd, there is loss of appetite and rumination ceases. The temperature rises within twenty-four to forty-eight hours to $107^{\circ}$ or $108^{\circ} \mathrm{F}$., the fever accompanied by increase in the rate of pulse and respiration. During the early stages of the disease there is constipation which is generally followed by diarrhea. The hemoglobin released by the disintegration of the corpuscles causes a blood-stained urine (hemoglobinurea), from which symptom is derived the name "red water," sometimes given to the disease. Cerebral disturbances, exhibited by staggering, disorder's of vision, or delirium, may appear in some cases. A conclusive diagnosis may be made upon finding the parasites within the corpuscles by microscopic examination of the blood.

A fatal termination is usually reached within three or four days. If recovery occurs, it is much prolonged, due to the time required for the generation of new corpuscular elements to replace those destroyed.

The Chronic Type.-The difference in the symptoms of the chronic type of the disease from those of the acute is one of degree. Further, there is a seasonal difference, the milder chronic form usually" appearing in the late fall and early winter, the acute in the hot summer months. The temperature does rot go as high, remaining at about $103^{\circ} \mathrm{F}$. and 
not exceeding $105^{\circ} \mathrm{F}$. The anrmic condition is indicated by the paleness of the visible mucosa, and the extended course brings about great emaciation. In these cases hemoglobin is not usually passed with the urine, hence hemoglobinurea or "rerl water," typical of the acute form, is absent.

Death rarely occurs in this type of the disease, though, due to its prolonged course and the excessive loss of flesh, much loss is sustained in the productive valuation of the animal.

Prevention and Treatment.-Prevention is by measures dealing with the cattle tick Margaropus annulatus, which is the specific carrier and transmitter of the protozoan causing the disease. As study of the life history of this tick has shown that it will not mature except upon a bovine or equine host, it follows that it can be exterminated from infested premises by kerping cattle and horses off of such premises until the larval ticks, unable to find a host, have perished. With this purpose in riew, systems of pasture rotation have been devised additional to mothods directed toward the destruction of ticks on the cattle (Ref. Margaropus ammulatus, p. 145).

Melical treatment of animals sick with Texas fever has not proved satisfactory. In the milder type of cases the constipation may be relieved somewhat by Epsom salts. Repeated doses of digitalis during the excessive anfmia and the administration of tonics, such as gentian and nux vomica, during the stage of convalescence, have been recominended as beneficial. The recovering animal should have free access to pure water and a generous supply of nutritious food.

\section{Order III. Sarcosporidia}

Sporozoa (p, 336).-The Sarcosporidia are parasites in striated muscle cells of vertebrates. Sporulation takes place during the development of the trophozoite which becomes surrounded by a protective envelope.

These muscle parasites are found in man, in domestic and wild birds, and are common in domestic mammals. The muscles more commonly invaded are those of the upper part of the esophagus, larynx, the body wall, the diaphragm, and the psoas muscles.

Development. - Irithin the muscle fiber the parasite first appears as a minute body in which stage it is known as Miescher's tube. As the young trophozoite levelops it becomes multinuclear and surrounded by a nembrane, while groups of spores form in the center of the protoplasmic body. With the continuation of the spore formation the cyst enlarges, causing such distension of the muscle fiber as to result in its rupture, releasing the cyst which ultimately bursts, the spores thus becoming scattered to infest new muscle cells. By repetitions of this 
auto-infective process the entire skeletal musculature may become affected. More or less destruction of muscle tissue is thus brought about which necessarily is relatively injurious to the host; furthermore, the effect is contributed to by the extremely toxic nature of the parasites themselves.

Importance of Sarcosporidiosis and Mode of Infection.- Hosts showing high incidence of infection with Sarcosporidia among domestic animals are pigs, sheep, cattle, and horses, the infecting species in each case being Sarcocystis miescheriana occurring in pigs, S. tenella in sheep,
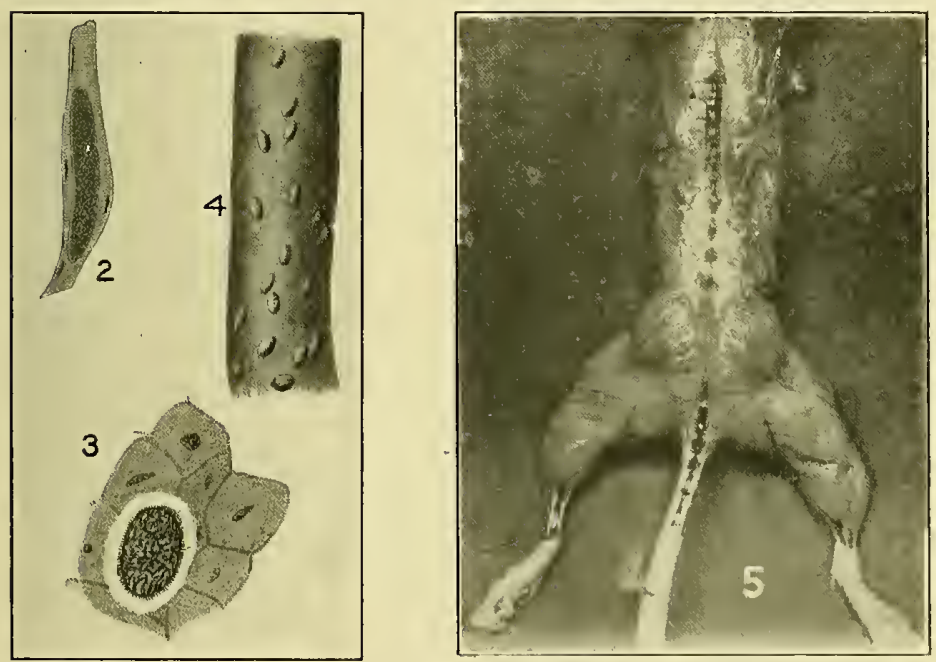

Fig. 172.-Various forms of Sarcosporidia.-2. Sarcocystis blanchardi. Longidtudinal section of an infected muscle witl young individual (after Crawley, from Doflein, from VanEecke, Cir. No. 194, Bu. An. Ind., U. S. Dept. Agr.). 3. Sareocystis tenella in a Purkinjc cell of the heart of a sheep (after Crawley, from Doflem, from Schneidemuhl, Cir. No. 194, Bu. An. Ind., U. S. Dept. Agr.). 4. Sarcoeystis tenella in the wall of the csophagus of a sheep (after Crawley, from Doflein, from Schncidemuhl, Cir. No. 194, Bu. An. Ind. U. S. Dept. Agr.). 5. Sareocystis muris in museles of mouse (after Crawley, Cir. No. 194, Bu. An. Ind, U, S. Dept. Agr ).

S. blanchardi in cattle, and S. bertrami in horses. In these animals the infection has been considered as of little pathologic importance; the sarcosporidiosis is apparently never fatal, and it is rare to find an animal visibly affected. This conclusion, however, may be modified somewhat by further study of the parasite, warranted by its prevalence, toxicity, and possibly greater pathologie import than at present supposed. Up to the present time little has been brought to light as to the life his- 
tory of the Sarcosporidia or as to the mode by which they infect. They are known to be fatal to mice, and it has been found that when mice are fed upon the flesh of other mice containing Sarcosporidia they become infected. Hence the conclusion follows that natural transmission occurs in these animals through their habit of nibbling at their dead; but this method of transfer can hardly be considered in the case of sheep, cattle, and horses, and the mode of infection in these animals remains a problem.

In an article upon the Sarcosporidia encountered in Panama (Journal of Parasitology, March, 1915), Darling suggests that these muscle parasites of vertebrates are aberrant forms of the Neosporidia of invertebrates, and points to the facility with which herbivora may ingast Neosporidia with leaves and other vegetation bearing infected invertebrates and their droppings. "Is it not possible," Darling writes, "that Sarcosporidia may be sidetracked varieties of some of the Neosporidia of invertebrates which have invaded the musculature of a hospitable though by no means definitive host and are unable to continuc further their life cycle and escape from a compromising and aberrant position?" The high incidence of infection among sheep, cattle, horses, and swine is evidence favoring this explanation. 


\section{GLOSSARY}

Aberrant. In botany and zoölogy, differing in some of its characters from the group in which it is placed.

Acari. Arthropods of the order Acarina; mites and ticks.

Acaricide. A medicinal agent used to destroy acari.

Agamous. In zoölogy, having no distinguishable sexual organs.

Amorphous. Without definite form; shapeless.

Ambulatory. Formed or adapted for walking.

Ametabolic. Pertaining to insects and other animals which do not undergo a metamorphosis.

Anorexia. Loss or absence of appetite.

Antenna. A segmented process on the head of insects, myriapods, and crustaceans.

Anthelmintic. A medicinal agent used to destroy or expel worms from the intestinal tract.

Apodal. Without feet.

Apterous. Without wings.

Aquatic. Growing in or frequenting water.

Arboreal. Attached to or frequenting trees.

Arista. A tactile filament at the end of the antenna of an insect.

Article. A segment or part of the body connected by a joint with another segment or part.

Asexual. Having no sex.

Basis capituli. Basal portion of the capitulum or head of a tick.

Bitid. Cleft or divided into two parts.

Bisexual. Having the organs of both sexes in one individual.

Buccal. Pertaining to the cheeks or mouth cavity.

Budding. A method of reproduction by which a protuberance from the parent organism develops into a new organism.

Bursa. A sac or sac-like cavity.

Capitulum. The head of a tick.

Caryozoic. Pertaining to parasites which live in the cell nucleus.

Catalepsy. Suspension of sensibility and voluntary motion.

Caudal. Pertaining to the tail.

Cephalic. Pertaining to the head.

Cephalothorax. The fused head and thorax of arachnids.

Chelæ. Pincer-like terminations of certain of the limbs of crustaceans and arachnids.

Chelate. Terminated by chelæ.

Chitin. The horny substance forming the harder part of the integument of insects and other arthropods.

Cilia. Hair-like processes, as of a cell, capable of vibratory movement.

Cœlom. The body-cavity, as distinguished from the intestinal eavity; the periaxial, perivisceral, or perienteric space.

Cœlozoic. Pertaining to parasites which live in the cœlomic cavities of the body: 
Coxa. The hip or hip joint. In insects and other arthropods the first segment of the leg from the body, articulating with the second segment or trochanter.

Cystogenous. Producing or bcaring cells.

Cytozoic. Pertaining to parasites which live within the cell cytoplasm.

Dentate. Having a toothed margin or tooth-like projections.

Denticulate. Having very small tooth-like projections.

Dimorphism. The property of assuming or of existing under two distinct forms.

Dipterous. Having two wings; belonging to the insect order Diptera.

Dorsum. The dorsal surface or back of an animal.

Ecdysis. The proeess of casting the skin; molting.

Elytra. The fore-wings of beetles, serving to cover the hind wings.

Enterozoic. Pertaining to parasites which live in the lumen of the digestive tract.

Epimeron. One of the side-pieces in the segment of an arthropod animal.

Facet. A smooth, flat, cireumscribed surface.

Fauna. The aggregate of the animals of a given region or gcological pcriod.

Femur. The thigh bone. The third segment of the leg of an insect, articulating proximally with the trochanter and distally with the tibia.

Filiform. Thread-like.

Fission. Reproduetion by division of the body into two parts, each of which becomes a complete organism.

Flagellum. A whip-like appendage or process of a cell.

Flora. The aggregate of the native plants of a given region or pcriod.

Gamete. A sexual cell or germ cell.

Gametocyte. An adult parasite, as in the plasmodium of malaria, when in its reproductive form.

Granular. Consisting of grains or granules.

Gregarious. Inclined to gather together, as to live in flocks or herds.

Habitat. The natural abode of an animal or plant.

Halteres. The rudinentary hind wings of Diptera; balancers.

Haustellum. A proboseis adapted to take food by suction, as in many insects.

Hematozoic. Pertaining to parasites which live in the blood.

Hemelytra. The partially thiekened anterior wings of certain insects.

Hermaphroditism. The union of the two sexes in the same individual.

Hexacanth. The six-hooked tapeworm embryo; the onchosphere.

Hexapod. A six-footed animal; a true inseet.

Hyaline. A glassy or transparent substance or surface.

Imago. The final or adult stage of insects.

Infundibuliform. Having the form of a funnel.

Labium. In inseets, the lower lip, former by the second pair of maxillee.

Labrum. In insects, the uppor lip.

Lobe. A somerhat rounded projection or division of an organ or part.

Macrogamete. The large female gamete or gern cell.

Macrogametocyte. The female gametocyte.

Mandibles. In arthropods, the anterior pair of mouth parts which form biting jaws.

Marine. Living in the sea.

Maxillæ. In arthroporls, paired appendages behind the mandibles, usually serving as accessory jaws.

Merozoites. Asexually formed spores of the malaria parasite. 
Mesothorax. The middle segment of the thorax of an insect.

Metabolism. The processes concerned in the building up of protoplasm and its destruction.

Metamere. One of a series of segments composing the body, as in many worms and in arthropods.

Metamorphosis. Change of form or structure, as in the larval, pupal, and imago stages of an insect's development.

Metaphyta. Plants consisting of many cells; all plants above the Protophyta.

Metathorax. The posterior segment of the thorax of an insect.

Metazoa. Animals which, in an embryonic condition, possess at least two distinct germinal layers; all animals above the Protozoa.

Microgamete. The male germ cell consisting of a detached flagelliform process of a microgametocyte.

Microgametocyte. The parent male cell.

Micron. One thousandth of a millimeter; a unit of microscopic measure.

Molting. The shedding of the hair, feathers, or outer layer of the skin, which are replaced by new growth.

Morphology. The seience of the outer form and internal structure of animals and plants.

Myasis. A disease caused by the presence of the larvæ of flies in or on the body.

Myiasis. Same as myasis.

Myiosis. Same as myasis.

Ocellus. A small simple eye of many invertebrates.

Octopod. Having eight feet, as in adult arachnids.

Onchosphere. The tapeworm embryo; the hexacanth.

Oökinete. Same as zygote.

Oöspore. Same as zygote.

Operculum. A lid-like process or part.

Ovum. An egg cell or egg.

Ovigerous. Egg bearing.

Oviparous. Producing eggs that hatch after they have passed from the body of the parent.

Oviposition. 'The laying of eggs, especially applied to insects and arachnids.

Ovipositor. A specialized organ, as in certain insects, for depositing eggs.

Ovoviviparous. Producing eggs that have a well developed shell or covering, as in oviparous amimals, but which incubate within the body of the parent.

Ovulation. The formation of eggs in the ovary; the discharge of the egg or eggs from the ovary.

Palpi. Appendages, usually organs of touch or taste, attached to the mouth parts of insects and other arthropods.

Papilla. A small nipple-like or pimple-like projection.

Parasiticide. A remedy that destroys parasites.

Parthenogenesis. The production of individuals from ova without fertilization by the male element.

Pedipalpi. Leg-like or pincer-like appendages of arachnids, located on cacl side of the moutl.

Phylogenic. Pertaining to the ancestral history of an animal or plant.

Phytozoön. A colony of animals resembling a plant. 
Plasmodium. A mass of protoplasm formed by the union of two or more amebiform bodies or individuals.

Plumose. Feathery; plume-like.

Pollenose. Bearing a powdery or pollen-like substance.

Predacious. Living by preying on other animals.

Prehensile. Adapted for grasping.

Proboscis. The tubular process of the head, especially of insects and arachnids, adapted for sucking or piercing.

Proglottid. The segment of a tapeworm.

Prothorax. The anterior segment of the thorax of an insect.

Protophyta. The division of unicellular plants.

Protozoa. The phylum consisting of the unicellular animals.

Pruritus. An intense degree of itching.

Pseudopodia. Processes of the protoplasm of a cell which may be protruded or retracted, as for locomotion or for taking food.

Pubescent. Arrived at puberty, or the earlicst age at which the reproductive function can be performed.

Puparium. The case in which an insect is enelosed between its larval stage and the state of full development or imago.

Pupiparous. Pertaining to insects in which the young are born ready to become pupx, as in the sheep tick.

Quiescent. At rest.

Rostellum. A small beak or hook-like process.

Rostrum. A beak-like process or appendage.

Saprophyte. Any vegetable organism living on dead or decaying organic matter.

Schizogenesis. Reproduction by fission.

Schizogony. Same as schizogenesis.

Schizont. A malaria parasite of the asexual generation.

Scolex. The head of a tapeworm, either in the larval or adult stage.

Scutum. The dorsal shield or plate, present in eertain ticks.

Serrate. Notehed or toothed on the edge.

Somatic. Pertaining to the body as a whole.

Somite. One of the longitudinal segments into which the body of annehid worms, arthropods, and vertebrates is divided.

Spiracle. A breathing orifice, as in the tracheal openings of insects.

Spore. A germ or seed of one of the lower animals or plants.

Sporocyst. A case or eyst containing many spores.

Sporogenesis. Reproduction by means of spores.

Sporogony. Same as sporogenesis.

Sporozoite. One of the young active spores of a sporozoan produced by division of the passive spores contained in the sporocyst.

Sporulation. Spore formation.

Stigmata. Small spots or marks; usually applied to the respiratory openings of insects; spiracles.

Strobila. An adult tapeworm.

Suctorial. Adapted for sucking.

Tarsus. In inseets, the small segments forming the distal termination of the leg and articulating with the tibia. 
Tergum. In zoölogy, the back.

Terrestrial. Of or inhabiting the land or ground in distinction from trees, water, etc.

Tibia. In insects, the fourth segment of the leg, articulating proximally with the femur and distally with the tarsi.

Tracheæ. The air-conveying tubules forming the respiratory system of insects and other arthropods.

Trenchant. Sharp; cutting.

Trochanter. In insects, the seeond segment of the leg, articulating proximally with the coxa and distally with the femur.

Vacuole. A cavity or vesicle in cell protoplasm.

Vermicide. A substance which kills worms; a drug to kill parasitic worms of the intestines.

Vermifuge. A medicine that expels worms from the bodies of animals.

Verminous. Infested with worms, or eaused by worms, as verminous diseases.

Viviparous. Producing living young by true birth, as in mammals, and not by hatching from eggs, as in oviparous and ovoviviparous animals; often applied to the bringing forth of young which have been hatched from eggs within the body of the parent.

Zoöphyte. Same as phytozoa.

$Z$ ygote. The encysted stage of certain sporozoans after fertilization by a sperm cell and before division into spores. 



\section{INDEX}

A

Acanthia lectularia, 90

Acanthocephala, 217, 224, 306

Acariasis, 96

Acarina, 94

parasitism of, 95

Ades calopus, 29

Agriostomum, 280

Amblyomma, 142

americanum, 145

Ameba, 312, 324

budding, 313

ectoplasm, 312

encystation, 313

endoplasm, 312

fission, 313

method of feeding, 313,324

morphologic characteristics, 312

motility, 312, 324

nucleus, 313

pseudopodia; 312, 324

reproduction, 313,324

respiration, 313

streaming of eytoplasm, 312,313 , 324

vacuoles, 312,313

Ameba meleagridis, 325

Amebic dysentery, 326

in $\operatorname{man}, 326$

American dog tick, 143

Amphistomidxe, 157, 167

Amphistomum cervi, 167

Ankylostoma, 280

canina, 291

duodenale, 292

Ankylostomex, 280

Ankylostomiasis, 291

Ankylostomum stenoccphalum, 292
Annelida, 224, 307

Anopheles, 26, 320

maculipennis, 26

punctipennis, 28

quadrimaculatus, 26

Anoplocephala mamillana, 175

perfoliata, 174

plicata, 175

Anthelminties, use and action of, 221

Apterous insects, 18

Arachnida, 94

classification of, 96

Arduenna, 22S

strongylina, 251

Arduenninæ, 228

Argasidæ, 97, 139

Argas americanus, 139, 327

miniatus, 139,327

Arthropoda, The, 13

circulatory system, 14

digestive system, 14

excretory organs, 14

musculature, 14

nervous system, 14

reproduction, 15

respiratory system, 14

sense organs, 15

structure in general, 13

Arthropoda as transmitters of infectious discases, 313,315

Arthropoda, parasitic subgroups of 15

Ascariasis, 229, 231

importance of treatment, 233

location of worms, 229, 232

occurrence, 231

pathogenic influences, 232 
Ascariasis of the eat, 237 occurrence, 239

treatment, 239

Ascariasis of the dog, 237 occurrence, 238 post-mortem appearance, 239 treatment, 239

Ascariasis of the hog, 239 effect, 240 treatment, 241

Ascariasis of the horse, : 33 control, 234 ctiology, 234 occurrence, 233 symptoms, 233 treatment, 234

Ascariasis of the ox, 241

Ascariasis of the sheep, 241

Ascaride, 222, 229 parasitism of, 229, 231

Ascaris, 225, 229

equi, 233 equorum, 233 lumbricoides, 229, 239 nuarginata, 237 megalocephala, 233 mystax, 237, 239 ovis, 229,239 suis, 229, 239 suum, 229, 239 vitulorum, 241

Ascaroidca, 225

Auricular mange of the cat, 118 Auricular scabies of the rabbit, 118

\section{B}

Bacillary white dianhea of chicks, 345

Bacterium pullorum, 345

Bathmostomum, 281

Bedbug, The 8,90 as a pest of poultry, 90 control, 92 effect of bite, 90 habits, 90

reproduction and devclopment, 90

Beef measles, 174, 194, 195

degeneration of cyst, 198

deve'opment, 197

federal regulations in regard to, 199 influence of temperature, $19 \mathrm{~S}$

location and appearance, 197

method of infection, 197

occurence, 196

vitality of larvæ, 198

Beef and pork tapeworm, methods of differentiation, 200

Beef tapeworm, 170, 195

Belascaris marginata, 237 mystax, 237, 239 cati, 237,239

Bilharzia bovis, 168 crassa, $16 \mathrm{~s}$

Bilharziosis, 168

Black gnat, 31

Blackhead of turkeys, 325

Black horse fly, 35 as a transmitter of disease, 36 effect, 35

life history, 35 protection from, 36

Bloorl fluke, 168

Blow fly, 50, 52 effect, 53 reproduction and development, 52 Blucbottle fly, 52

Body louse, 79

Body mange of poultry, 132

Boophilus, 142 annulatus, $144,145,314,347$ bovis, $144,145,314,347$ decoloratus, 316

Bot flies, 53

Bot, horse, j, 53, 57

Bothriocephalus latus, 185

Brachiopoda, 155

Bronchial and pulmonary strongylosis of cattle, 259 
control, 264

course, 260

development, 263

etiology, 263

post-mortem appearance, 262

prognosis, 260

symptoms, 259

symptoms, duration of, 260

treatment, 265

Bronchial and pulmonary strongylosis of the horse, 261

occurrence, 261

symptoms, 261

Bronchial and pulmonary strongylosis of the pig, 260

occurrence, 260

symptonis, 260

Bronchial and pulmonary strongylosis, post-mortem appearance, 262

control, 264

development, 263

etiology, 263

treatment, 265

Bronchial and pulmonary strongylosis of the sheep and goat, 256 control, 264

course, 259

development, 263

etiology, 263

post-mortem appearance, 262

prognosis, 259

symptoms, 258

treatment, 265

Buffalo gnat, 31,32

control, 33

effect, 33

life history, 32

occurrence, 32

protection from, 33

treatment, 34

Brazilian septicemia of fowl, 327

Bruce, investigations of, $45,315,330$

Bryozoa, 155

Bunostomex, 281
Bunostomum trigonocephalum, 293 phlebotomum, 293

C

Calliphora vomitoria, 52

Cardiac filariasis of the $\mathrm{dog}, 248$

Cardio-pulmonary strongylosis of the dog, 261

post-mortem appearance, 263

symptoms, 262

Castor-bean tick, 143

Cattle tick, 144, 145, 314, 347

Cestoda, 159, 169

Chabertia ovina, 287

Chiggers, 96, 99

Chloroform as treatment for lung worms, 266

Choanotænia infundibuliformis, 189

Chorioptes, 103

parasitism, 103

species, 103

Chorioptes communis, 103

var, bovis, 113

var. equi, 108

var. ovis, 112

Chorioptic scabies of cattle, 113

course, 113

location, 113

treatment, 120,130

Chorioptic scabies of the horse, 108

course, 108

diagnosis, 109

lesions, 109

prognosis, 109

symptoms, 108

transmission, 109

treatment, 120,129

Chorioptic scabies of the sheep, 112

course, 112

prognosis, 112

symptoms, 112

transmission, 112

Chrysomyia macellaria, 50 
Cimex lectularius, 90

Cimicida, 22, 90

Cittotænia denticulata, 18.5

Classification of the Arachnida, 96

Classification of the phylum Coelhelminthes, 222

Classification of Insects, 20

Classification of the phylum Platyhelminthes, $15 \%$

Classification of the plylum Protozon, 322

Cnemidocoptes, 103. 132 specics of, 10.3, 132

Cnemidocoptes gallinæ, 103, 133

inutans, 103, 132

Coccidia, 322, 323, 337

infection, $33 \bar{\imath}$

life eycle, $322,33 \pi$

parasitism, 337

pathogenicity, 337

reproduction, 337

Coecidial enteritis of chicks, 345

control, $3+6$

diagnosis, 345

differentiation from hacillary white diarrhea, 345

infection, $3+6$

post-mortem appearance, 345

symptoms, 345

Coccicliosis of the dog, 342

investigations by Hall and Wiglor, 342

Coccidiosis of eattle, 343

of chicks, 34.5

of the $\log , 345$

of man, 342

of the rabbit, 34 ?

Coccidium cuniculi, 342

oviforme, 342

tenellum, 34.5

zurni, 343

Cochliomyia macellaria, 50

Collhelminthes, 216

classification of, $155,216,22$ ?
Cœlon, 216

Conurosis, 204

Coenurus, 173, 194, 204, 205

Colic, thrombo-embolic, 2SS, 290

Commensalism, 2, 7 . example of, 2,7

Compsomyia macellaria, 50

Connective tissue mite of poultry, 134

Cooperia curticei, 268 oncophora, 275

Cryptobia, 329

Cryptocystis, 178,195

Ctenocephalus canis, 65,79 felis, 65

Culex and Anopheles, differentiation, 28

Culex pungens, 26, $2 \mathrm{~s}$

Culicidæ, 20, 24

Cylicostomeæ, 281

Cylicostomum, $2 \triangleleft 1$

Cysticercoid, 173, 178, 195

Cysticercosis, 174, 195

Cysticercus, 173, 174, 194, 195

bovis, $174,195,197$

cellulosæ, 17t, 195, 199, 202

ovis, 203

tenuicollis, 174, 179, 195, 203

trichodectes, $79,178,183$

Cytoleichiclæ, 134

Cytoleichus nudus, 134

D

Davainea cesticillus, 190, 191

echinobothrida, 191

proglottina, $1 \mathrm{~S} 9$

tetragona, 190, 191

Degeneration, parasitic, 3,4

Demodecidx, 96, 97, 103

Demodectic mange, 96, 104

of the dog, 116

of the hog, 115

of the sheep, 112 
Demodex folliculorum, 104

var. canis, 104, 116

var. ovis, 104, 112

var. suis, 104, 115

Depluming mange of poultry, 133

Depluming mite, 101, 133

Dermacentor, 142

electus, 143

occidentalis, $1+3$

reticulatus, 143

variabilis, 143

Dibothriocephalus latus, 185

Dibothrium latum, 185

Dicrocœlium lanceatum, 160, 163

Dictyocaulus arnfieldi, 261

filaria, 221, 256

viviparous, 259

Dioctophyme renale, 296

- visceralis, 296

Diphyllobothriasis, 185 occurrence, 186

Diphyllobothriidæ, 160, 185

Diphyllobothrium latum, 185

Diplospora bigemina, 342

Dipping vats, 126

Dips, 48, 120, 125

Diptera, 18, 20 parasitic families of, 23 parasitism of, 23

Dipterous insects, 18,23

Dipylidium caninum, $68,79,178,181$, 183

Dirofilaria immitis, 221,248

Dispharagus hamulosus, 254 nasutus, 254 spiralis, 254

Distomex, 156, 157

Distomiasis, $157,163,16.5$

of cattle, 166

of the shcep, 165

Distomum americanum, 160

hepaticum, 160

lanceolatum, 160

magnum, 160
Dochmiasis, 291, 292

Dochmius cernuus, 293

radiatus, 293

stenocephalus, 292

trigonocephalus, 291

Docophorus cygni, 86 icterodes, 84

Dourine, 333

control, 336

federal control of outbreaks, 333

infection, 333, 334

stages in, 334

symptoms, 334

Drepanidotænia infundibuliformis, 189

Dysentery of cattle, $3+3$

\section{E}

Earthworm, 216

Ecdysis, 13

Echinococcosis, 183, 210

Echinococcus, 173, 181, 183, 194, 210 alveolaris, 212

granulosus, 181, 183, 18t, 194, 210

multilocularis, 210, 212

polymorphus, 181, 183, 210

Echinorhynchus gigas, 306

Ectozoa, 9

Eimeria avium, 345

stiedæ, 342

El dourine, 333

Endoparasites, 9

Entameba, 326

coli, 326

histolytica, 326

Entero-hepatitis of turkeys, 325

Entozoa, 9

Erratic parasites, $\&$

Esophageal and gastric filariasis of the dog, 250

course, 251

development, 251

occurrence, 250

pathogenesis, 250 
symptoms, 251

treatment, 251

Esophageal filariasis of cattle, 246

of the dog, 250

of the shcep, 246

of the horse, 247

European dog tick, 143

Eustrongylidæ, 224, 296

Eustrongylosis, 296

occurrence, 296

symptoms, 297

treatment, 298

Eustrongylus gigas, 296

visceralis, 296

Exoparasites, 9

\section{F}

Fasciola americama, 160, 163

hepatica, 5, 160

lanceolata, 160, 163

magna, 160, 163

Fasciola hepatica, life history of, 5, 160

Fasciola lanccolata, life history of, 163

Fasciola magna, life history of, 163

Fascioliasis, 157, 163, 165

Fascioliasis of cattle, 166 control, 167

symptoms, 166

treatment, 168

Fascioliasis of the sheep, 165

control, 167

course, 165

prognosis, 166

symptoms, 165

treatment, 168

Fasciolidae, 157, 160

Filaria, 227

bancrofti, 249

cervina, 248

equina, 244

inmitis, 248

labiato-papillosa, 248

sanguinis hominis, 249

sanguinolenta, 250
Filariæ of cattle, 246

of the $\log , 248$

of the hog, 251

of the horse, 244

of poultry, 254

of the sheep, 246

Filariasis of cattle, 246

effect, 247,248

occurrence, 247,248

Filariasis of the deer, $24 \mathrm{~s}$

Filariasis of the $\operatorname{dog}, 248$

diagnosis, 249, 251

occurrence, 248,250

pathogenesis, 249, 250

theories as to infection, 249

treatment, 250, 251

Filariasis of the $\log , 247,251$

control, 253

occurrence, 252

treatment, 254

Filariasis of the horse, 244

effect, 245,246

occurrence, $244,245,246$

treatment, 246

Filariasis of poultry, 254

Filariasis of the sheep, 246

effect, 247

occurrence, 247

Filariidæ, 222, 244

parasitism of, 244

Filarioidea, 227

Fixed parasites, $s$

Flagellata, 322, 326

Fleas, 65

as carriers of disease, 66

control, 68

habits, 66

household infestation, 69

reproduction and development, 65,66

species, differential characters of, 65

treatment, 68

usual hosts, 66

vitality, $6 \mathrm{~s}$ 
Flesh flies, 50, 52

protection from, 52

reproduction and development, 52

Flies, 11, 23, 35

Fluke, liver, 5, 156, 160, 163

Fly, house, 11, 37, 189

Follicular mange of the dog, 116

course, 116

symptoms, 116

transmission, 117

treatment, 130

Follicular mange of the hog, 115

occurrence, 115

treatment, 130

Follicular mange mite, 103

Follicular mange of the sheep, 112 location, 112 prevalence, 112

Forked worm of fowl, 293

Fowl septicemia, 327, 345

Fowl tick, 139

control, 140

development, 140

effect, 140

habits, 140

occurrence, 140

Fumigation treatment in verminous bronchitis, and pneumonia, 265

\section{G}

Gaigeria, $2 \$ 1$

Gamasidæ, 96, 98

Gamasid mites, 96, 9s

Gastric filariasis of the dog, 250

Gastric filariasis of the horse, 245, 246

Gastric and intestinal filariasis of the hog, 251,252

Gastro-intestinal strongylosis of cattle, 272

control, 276

development, 276

etiology, 276

occurrence, 275 pasture rotation, 277

post-mortem appearance, 275

symptoms, 275

treatment, 277

Gastro-intestinal strongylosis of the goat, $26 \mathrm{~S}$

Gastro-intestinal strongylosis of the sheep, 268

control, 276

development, 276

etiology, 276

occurrence, 271

pasture rotation, 277

pathogenesis, 272

post-mortem appearance, 275

symptoms, 272

treatment, 277

Gastrophilus equi, 5, 53

hemorrhoidalis, 57

intestinalis, 5,53

Gid of cattle, 205, 209

Gid of the sheep, 204

the cœnurus, 205

control, 209

development, 206

occurrence, 205

post-mortem appearance, 207

symptoms, $20 \mathrm{~S}$

treatment, 209

Gigantorhynchus hirudinaceus, 306

Glossary, 353

Glossina, 44, 314

longipalpis, 44, 46

morsitans, 44, 46, 330

palpalis, $\mathbf{4 4}, 46$

Gnat, buffalo, 31, 32

Gnathobdellidæ, 224, 30s

Gnats, 31

Gongylonema, 227

scutata, 246

Gongyloneminie, 227

Goniocotes abdominalis, $S 2$ compar, $\mathrm{S} 6$

gallinx, 8 ? 
gigas, 52

hologaster, $\$ 2$

Goniodes damicornis, 36

stylifer, 4

Grammocephalus, 2\$1

Green-head fly, 36

Gyalocephalus, 2s1

\section{II}

Habronema megastoma, 245 . microstoma, 246

IIxmaphysalis, 142

Hrematolia serrata, 41

Hrmatopinus asini, 73

curysternus, it

macrocephalus, 73

suis, 77

urius, 77

IIxmonchus contortus, 265

IIæmopis sunguisuga, 30.

IIarvest mites, 99

(effect, 100

habits, 100

protection from, 100

treatne'nt, 100

Heel fly, is

Helminthes, 9

Helotism, 7

Hematic filariasis of the $\log , 24 \mathrm{~s}$

(liagnosis, 249

occurrence, 248

pathogenesis, 249

theories as to infection, 249

treatment, 250

Hematic filariasis of 1111,249

Hemiptera, 22, $\$ 9$

Hemosporidia, 323, 347

difference in $m$ de of infection from

Coccidia, 337, 347

relationship to other groups, 336 , 347

relative pathologic importance, 347

Hepatic coccicliosis of rabbits, 342
Herpetomads, 316

cxperiments with, 316

Herpetomonas donovani, 316

Heterakiasis of poultry, 242

symptoms, 243

treatment, 243

Hetcrakidæ, 222, 242

Heterakinæ, 226

Heterakis, 226

inflexa, 242

papillosa, 242

perspicillum, 242

vesicularis, 242

Hcteroxcnous parasites, $\mathrm{s}$

Hippoboscidæ, 21, 47

Hirudinca, 224, 307

Hirudo medicinalis, 309

Hook worm, 291, 292

Horn fly, 41

control, 43

effect, 42

habits, 41

life history, $\$ 1$

occurrences, 41

protection from, 43

Horse bot flies, 5, 5.3

effect of bots, 55

habits, 53

life history, 54

treatment, 56

Horse leech, $30 \mathrm{~s}$

cffect, 309

mode of infestation, 309

oceurrence, 309

treatment, 309

House $f y, 11,37,159$

as a transmitter of infectious diseases, 11, 3s, 189

control, 38

habits, 38

life history, 37

longevity, 37

protection from, 3s

Hyalomma, 142 
Hydatid disease, 173, 181, 183, 194, 210 control, 214

development, 212

the echinococcus, 210

longevity of cyst, 213

occurrence, 210

post-mortem appearance, 213

symptoms, 214

Hymenolepis carioca, 190, 191

Hymenoptera, 18

Hypoderma bovis, 58

lineata, 57

\section{I}

Imago, The, 19

Incidental parasites, 8

Infectious entero-hepatitis of turkeys, 325

control, 326

course, 325

infection, 325

post-mortem appearance, 325

symptoms, 325

treatment, 326

Insecta, 15

classification of, 20

Insects, 15

developinent, $1 \mathrm{~S}$

duration of life, 19

growth, 19

larve, 18

metamorphosis, $1 \mathrm{~s}$

mouth parts, 16

parasitic subgroups, 20

reproduction, 18

structure, 15

Internal parasites, 155

Intestinal strongylosis of the cat, 291 of cattle, 272,285

of the $\operatorname{dog}, 291$

of the goat, $268,281,287$

of the hog, 287

of the horse, $25 s$

of the shcep, 268, 281, 257
Intratracheal injections, 265

Introduction, 1

Isospora bigenina, 342

Itch mites, 101

Ixodes, 142

hexagonus, 143

ricinus, 143

Ixodidæ, 96, 97, 136, 141

Ixodoidea, 96, 97, 136, 139

K

Kala-azar, 316

Kerosene emulsions, 48

Kerosene in mosquito control, 25, 31

Kidney worm of the dog, 296

Kidney worm of the hog, 295

L

Laminosioptes cysticola, 134

Larvæ, dipterous, 50

Larræ, insect, 18

Leeches, 216, 307

Leg mange of poultry, 132

Leishmania donovani, 316

Leptus antumnalis, 100

Lice, 70

biting, 71

sucking, 70

Lice of poultry, 82

control, ss

occurrence, $\$ 2$

treatment, ss

Life, degeneracy in mode of, 1

Life history of beef tapeworm, tabular review, 172

Life histories of dog tick and Texas fever tick compared, 151

Life history of Echinococcus granulosus, tabular review, 213

Life listory of gil tapeworm, tabular review, $20 \overline{7}$ 
Life history of horse botfly, tabular review, 55

Life history of liver fluke, tabular revicw, 163

Life history of sheep botfly, tabular review, 63

Life history of Trichinella spiralis, tabular review, 303

Lime and sulphur dips, 122, 125 method of preparing, 125

Linguatula rhinaria, 94, 153

Lin:uatulida, 153

Linguatulidæ, 97

Linognathus pedalis, 76 piliferus, $7 \mathrm{~s}$

stenopsis, 7

vituli, 74

Liotheidse, 22, 71

Lipcurus anatis, 84

baculus, $\$ 6$

caponis, 83

columbæ, 86

heterographus, 83

meleagridis, $\$ 4$

polytrapezius, $\$ 1$

squalidus, $S 4$

variabilis, $\$ 3$

Lissoflagellata, 325

Liver flukes, 5, 156, 160

infection, 160,164

life history, 5, 160

losses from, 162

migrations and pathogenesis, 164

prevalence, 162

prevalence in United States, 164

Lobosa, 322, 324

Lone star tick, 145

Lousiness, 71

Lung worms, 256

control, 264

development, 256,263

method of infection with, 256, 263

Lyperosia irritans, 41

Maladie du coit, 333

Malaria, 26, $31 \mathrm{~s}$

Malaria, latent, 322

Malaria organisms, the asexual cycle, 318,319

the gametocytes, 319

liberation of the merozoites, 319

the macrogametocyte, 319

the merozoites, 319

the microgametes, 319

the microgametocyte, 319

relation of liberation of merozoites

to chill, 319

repeating of cycle, 319

the schizont, 319

the signet ring stagc, 319

the sporozoites, 319,320

Malaria organisms, life history, 318

Malaria organisms, the parthenogenetic phase of, 322

Malaria organisms, the sexual cycle, 320

fertilization of the macrogamete, 320

formation of eyst, 320

formation of macrogamete, 320

formation of the microgametes, 320

formation of the sporoblasts, 320

formation of the sporozoites, 320

liberation of the sporozites, 320

the microgametoblast, 320

migration of oökinete, 320

the oökinete or zygote, 320

passage of sporozoites to salivary glands of mosquito, 320

relationship of anopheline mosquito

to, $26,313,319,320$

Mal de caderas, 332

infection, 333

occurrence, 332

symptoms, 332 
Mallophaga, 21, 71

Mange, 96, 101, 102, 103, 104, 112, $113,114,115,116,117,118$ cnemidocoptic, 132 follicular, 102, 112, 115, 116 notoedric, 118 sarcoptic, 102, 104, 112, 114, 121

Mange of the body of poultry, 133

course, 133

symptoms, 133

treatment, 133

Mange of the cat, 117

course, 118

diagnosis, 118

treatment, 120, 123

Mange of cattle, 114 treatment, 120, 124

Mange of the dog, 115, 116

course, 115,116

lesions, 115,116

symptoms, 115, 116

transmission, 115, 117

treatment, 120, 123, 130

Mange of the goat, 113

treatment, 120, 124

Mange of the hog, 114, 115

symptoms, 114, 115

transmissions, 114 .

treatment, 120, 122, 130

Mange of the horse, 104

control, 122

development, 105

diagnosis, 105

lesions, 105

prognosis, 107

symptoms, 104

transmission, 107

treatment, 120, 121

Mange of the legs of poultry, 132

course, 132

symptoms, 132

treatment, 132

Mange mites, 96, 103, 132, 13 t
Mange of poultry, 132, 134

Mange of the rabbit, 118

treatment, 120, 124

Mange and scab mites, 96, 101, 102, $103,117,132,134$

development, 101, 103

reproduction, 101, 103

Mange of the sheep, 112

treatment, 120, 124

Margaropus, 142, 145

annulatus, 144, 145, 314, 347

Mastigophora, 322, 326

Measles, 174, 194, 195

of man, 174, 194, 195

of the $\mathrm{ox}, 174,195$

of the pig, 17t, 195

of the sheep, 174, 195

Medicinal leech, 309

Melophagus ovinus, $4,47,76$

Menopon biseriatum, 83

pallidum, 83

Menopum biseriatum, 83

pallidum, 83

trigonocephalum, 83

Metamorphosis, insect, 19

complete, 19

incomplete, 19

Metastrongylidæ, 227

Metastrongylinæ, 223, 256

life history, 256, 263

Metastrongylus, 227

Metazoa, 311

Miescher's tube, 350

Mites, 94

Molluseoidea, 155

Molting, 13

Moniezia alba, 176

denticulata, 185

expansa, 176

planissima, 176

Monoxenous parasites, $s$

Mosquitoes, 11, 24

brecding habits, 24

control, 31 
Culex and Anopheles, difterentiation, 28

development, 25

effect upon live stock, 31

larvie, 24

pathologic importance, 26

protection against, 31

рuрæ, 25

range, 24

relationslip) to filariasis, 26

relationship to malaria, $26,313,320$

relationship to yellow fever, 26,29

Multiceps gaigeri, 1s1

multiecps, 179, 194, 204, 206, 207

serialis, 179

Musea rlomestica, 11, 37, 189

vomitoria, 52

Museilla, 20, 37

Mutualism, 2, 7,

example of, 2,7

Mrasis, 50

\section{N}

Nigana, 4.5, 314, 330

etiology, 45, 314, 330

investigations by Bruce, 45, 314, 330

occurrence, 330

Nemathelminthes, $155,216,222$

Nematoda, 217, 222,

Nematode worms, parasitism in general, 219

adaptability to ehanged environment, 221

factors influeneing injury to host, 220

host limitations, 220

infection, 219, 220

treatment in general, 221

Nematodirus filicollis, 273

Neosporidia, 336, 350

Net tick, 143

Nodular discase, 28]
Nodular strongylosis of cattle, 285

of the goat, 281

of the hog, 287

Nodular strongylosis of the sheep, 281

development, $2 \$ 3$

importance, 284

occurrence, 283

post-mortem appearance, $28 t$

symptoms, 284

treatment, 285

Notoedres, 101, 117

var. cati, 117,118

var. cuniculi, 118

parasitism of, 103

Notoedric mange, treatment of, 120 , 123,124

O

Obligate parasites, 8

()cular filariasis of the horse, 245

of the $0 x, 248$

(Esophagostomeæ, 280

(Esophagostomiasis of eattle, 285

of the goat, 281

of the hog, 287

of the sheep, 281

(Esophagostomum, 255, 280

columbianum, 281

dentatum, 287

inflatum, 25.5

radiatum, 285

subulatum, 287

venulosum, 282

(Fstridæ, 21, 53

Estrus ovis, 62

Optional parasites, 8

Organic multiplication, influences restricting, 1

Ornithobius bucephalus, 86

Ornithodorus megnini, 140

Ornithonomus eygni, 86

Ostertagia marshalli, 269 ostertagi, 272 
Otacariasis of the cat, 118

occurrence, 118

treatment, 131

Otacariasis of the $\operatorname{dog}, 117$

occurrence, 117

prognosis, 117

symptoms, 117

treatment, 131

Otacariasis of the rabbit, 118

course, 118

symptoms, 119

treatment, 131

Otobius megnini, 159

Otodectes, 101, 103, 115, 117 parasitism, 103

Otodectes cynotis, 115, 117

Oviparous, application of the term, 219

Oviposition, 18, 219

Ovipositor, 18

Ovoviviparous, application of the term, 219

Ox bot flies, 57

effect of bots, 62

life history, 58

occurrence, 57

treatment, 62

Ox warbles, 53,57

Oxyuriasis, 236

effect, 236

oceurrence, 236

treatment, 237

Oxyuridæ, 222, 235

O. yurinæ, 226

Oxyuris, 226

curvula, 235

equi, 235

mastigodes, 235

$\mathrm{P}$

Parasites, alternation of hosts in, j, 8

Parasites, detemninate transitory, 8 determinate erratic, 8

erratic, 8 fixed, $s$

heteroxenous, 8

incidental, 8

monoxenous, 8

optional oceasional, 8

permanent, 8

stray, 8

Parasites, development of pathogenicity in, 315

Parasites, external, 9

internal, 9

Parasites, factors influencing injury by, 10,315

age of host, 11

location, 10,315

movements, 10

nature of food, 10

number present, 10

Parasites, influence upon host, 10, 315

Parasites, systematic position of, 6

Parasitic diseases, terms used in, 9

Parasitism, 2, 3, 7, 315

adaptation to, $3,4,315$

degeneration in, 3,4

factors leading to, $1,6,315$

forms of, 7

functions involved in adaptation to, 3

range of, 3

reproductive function in, 4

Parasitism, evolution of, 315

Parthenogenesis, 15, 322

Pathogenic Protozoa, 311, 324

arthropods as carriers of, 23,315

Pediculidx, 21, 70

Pediculosis of the cat, 79

control, 80

oceurrence, 79

treatment, si

Pediculosis of eattle, it

control, so

indieations of, 75

location, ij

treatment, is 
Pediculosis of the dog, 78

control, 80

effect, 78

location, 78

treatment, 81

Pediculosis of the goat, 77

control, 80

effect, 77

occurrence, 77

treatment, 80

Pediculosis of the hog, 77

control, 80

effect, 77

occurrence, 77

trcatment, 81

Pediculosis of the horse, 72

control, 80

indications of, 73

location, 73

treatment, 80

Pediculosis of nammals, 71

complications, 71

effect, 72

indications of, 72

predisposing factors, 71

treatment, 80

Pediculosis of man, 79

Pediculosis of poultry, 82

control, ss

dust bath in, 85

effect, 82

indications of, 82

occurrence, 82

parts attacked, 82

sodium fluoride in treatment of, 88

treatment, ss

Pediculosis of the sheep, 76

control, 80

occurrence, 77

treatment, 80

Pediculosis, control :and treatment, 80

Pediculus capitis, 79

corporis, 79 humanus, 79

vestimenti, 79

Permanent parasites, 8

Pharyngeal filariasis of the hog, 247

Philopteridæ, 21, 71

Philopterus cygni, 86 icterodes, 84

Phthiriasis, 71, 79

Phthirius inguinalis, 79 pubis, 79

Physocephalus sexalatus, 252, 253

Phytoparasites, 7

Piroplasma bigeminum, 313,347

Plasmodium, 313, 318

falciparum, 318

malariæ, $31 \mathrm{~s}$

præcox, 318

vivax, 318

Platyhelminthes, 155, 157

classification of, 155,157

Plerocercoid, 173, 195

Polystomeæ, 156

Polyzoa, 155, 159

Pork measles, 174, 195, 199

degeneration of cyst, 202

development, 202

diagnosis, 202

influence of temperature upon larvæ, 202

locati n and appearance of cysts, 201

method of infection, 201

occurrence, 200

symptoms, 202

vitality of larvæ, 202

Pork tapeworm, 195, 199

Poultry mite, $9 \mathrm{~s}$

control, 9

development, 99

effect, 99

luabits, $9 \mathrm{~S}$

occurrence, 95

reproduction, 99

Predaceous animals, 3,9 


\section{Protozoa, 311}

caryozoic, 322

colozoic, 322

colonization of, 311

cytozoic, 322

differentiation from Metazoa, 311 enterozoic, 322

hematozoic, 322

investigations as to pathogenicity, 313,315

investigations as to pathogenicity in the United States, 314

natural classification of, 322

parasitism, 313

pathogenicity, 313, 315

pathogenic classificarion of, 322

specialization in, 311

Protozoa, classification of, 322

Protozoa, methods of reproduction in, $313,31 \mathrm{~s}, 32 \bar{\tau}, 329,336,33 \bar{\top}$ asexual method, $318,319,337$ multiplicative cycle, $318,319,337$ propagative cycle, $318,320,337$. sexual method, $318,320,337$ sporulation, $318,319,320,336,337$

Pseudopodia, 312, 324

Psoroptes, 101, 102

parasitism, 102

species of, 103

rarieties, 103

Psoroptes communis, 103

var. bovis, 103, 113

var. cuniculi, 103, 11

rar. equi, 103, 10s

ral. ovis, 103, 109

Psoroptic seabies of eattle, 113

course, 113

symptoms, 113

treatment, 120, 12s

Psoroptic scabics of the goat, 113

Psoroptic scabies of the horse, $10 \mathrm{~s}$ lesions, 10s

transmission, 10s

treatment, 120,129
Psoroptic scabies of the rabbit, 118

course, 118

symptoms, 119

treatment, 120, 131

Psoroptic scabies of the sheep, 109 after-treatment, $12 \mathrm{~S}$

course, 110

historical, 110

lesions, 110

prognosis, 110

symptoms, 110

treatment, 120, 124

Pubic louse, 79

Pulex irritans, 65 serraticeps, 65

Pulicidæe, 21, 65

Pulmonary strongylosis of the cat, 262 symptoms, 262

Pupation, 19

Prrosoma bigeminum, 313

$\mathrm{R}$

Red bugs, 99

Red dysentery of cattle, 343

Ped mange of the dog, 104, 116

Red-tailed bot fly, $\overline{5}$

Remora, 2

Reproduction, oviparous, 1S, 219

ororiparous, 18, 219

pupiparus, 4, 15

viviparous, 18,219

Respiratory mite of fowl, 134

Rhipicentor, 142

Rhipicephalus, $1 \pm 2$

Rhizopoda, 322, 324

reproduction in, 324

Rhynchobdellidæe, 30s

Sarcocystis bertrami, 351

blanchardi, 351

miescheriana. 331

tenella, 351 
Sarcophaga sarracenix, 52

sarcoptes, 101

parasitism, 102

species of, 102

varieties, 102

sarcoptes minor var. cati, 118

minor var. cuniculi, 118

mutans, 132

Sarcoptes scabiei, 102

var. bovis, 114

var. canis, 115

var. equi, 104

var. ovis, 112

var, suis, 114

sacroptic mange, 101, 102

of cattle, $11 t$

of the $(\log , 115$

of the goat, 113

of the hog, 114

of the horse, 104

of the shcep, 112

Sareoptida ${ }^{2}, 96,101$

Sarcosporiclia, $323,336,350$

development, 350

muscles commonly invaded, 350

parasitism, 350

pathologic importance, 351

theory as to source and mode of infection, 351

toxicity, 351

Aarcosporidiosis, 350

mode of infection, 352

Sarcosporidiosis of cattle, 351

of the horse, 351

of mice, 352

of the pig, 351

of the sheep, 351

Scabies, 96

Scab mites, 94, 96

Acaly leg of poultry, 132

Achistosoma bovis, $16 \mathrm{~s}$

s̈chistosomidae, 157

Sehizogony, 318, 319, 337

sclerostomiasis, 288
Sclerostomum edentatum, 289

equinum, $2 \mathrm{sS}$

hypostomum, 2S7

tetracanthum, 289

rulgare, 289

Scorpion, 94

Serew worm fly, 50

development, 50

effect, 50

occurrence, 50

protection from, 51

reproduction, 50

treatment, 51

Sea anemone and hermit crab, mutualism of, 2

Septicenia of chicks, 345

Setaria labiato-papillosa, 244

Sheep bot fly, 62

effect of bots, 63

life history, 62

occurlence, 62

prevention, 64

treatment, 64

Sheep measles, 17t, 195, 203

Sheep measles, muscular, 203

control, 204

derivation, 203

development, 204

economic importance, 204

occurrence, 203

Sheep measles, visceral, 203

control, 203

development, 203

method of infection, 203

occurrence, 203

relation to food sanitation, 203

symptoms, 203

Sheep staggers, 204

Sheep "tick," 4,47

control, $4 \mathrm{~S}$

effect, $4 \mathrm{~S}$

life history, $t, 47$

occurrence, 47

treatment, 48 
Simplicity, primitive and degenerative, 3

Simuliidæ, 20, 31

Simulium pecuarum, 32

Siphonaptera, 21, 65

Siphunculata, 21, 70

Sleeping sickness, 46, 314

Southern cattle fever, $145,313,347$

Southern eattle tick, 144, 145, 347

Spider, 94

Spinose ear tick, 140

development, 141

effect, 141

habits, 141

occurrence, 141

Spirocheta gallinarum, 327

marchouxi, 327

theileri, 316

Spirochetida, 315, 322, 327

as blood parasites, 315,316

evolution of pathogenicity in, 315

pathogenicity, 315,327

transmission, 316

Spirochetosis, 315,327

of fowl, 327

Spiroptera megastoma, 245

microstoma, 246

sanguinolenta, 250

scutata, 246

sexalata, 252

strongylina, 251

Spirura, 227

Spiruridæ, 227

Spirulin:e, 227

Splenic ferer of cattle, 145, 313, 347

Sporogony, 318, 320, 337

Sporozoa, 323, 336

relationship to other forms, 336 reproduction in, 315, 322, 336, 337

Stable fly, 39, 332

control, 40

effect, 40

life history, 39

occurrence, 40 protection from, 41

relation to infectious diseases, 40 332

Staggers of sheep, 204

Stegomya calopus, 29

fasciata, 29

Stephanurus dentatus, 295

Sting, insect, 18

Stomach worms, pasture rotation in eradication of, 277

Stomach worms of cattle, 272

of the goat, 268

of the sheep, $26 \mathrm{~s}$

Stomoxys calcitrans, 39, 315, 332

Stray parasites, $\mathrm{S}$

Strongyleæ, 280

Strongyles of the respiratory system, 255,256

Strongylidæ, 223, 255

parasitism of, 255

Strongylinæ, 223, 280

Strongyloidea, 226

Strongylosis, 2ృj

bronchial, 256

gastric, 268

intestinal, 268, 280

pulmonary, 256

renal, 295, 296

vascular, 259

Strongylosis, bronchial and pulmonary

of cattle, 259

of the goat, 256

of the horse, 261

of the pig, 260

of the shcep, 256

Strongylosis of the intestincs of the cat, 291

Strongylosis of the intestines of the dog, 291

development, 292

oceurrence, 292

post-mortem appearance, 292

symptoms, 292

treatment, 293 
Strongylosis of the intestines of the horse, $28 s$

development, 289

post-mortem appearance, 290

symptoms, 290

treatment, 291

Strongylosis of the large intestine of the goat, 287

Strongylosis of the large intestine of the sheep, $2 \times 7$ occurrence, $2 \mathrm{ss}$

Strongylosis, pulmonary of the dog, 261

of the cat, 262

Strongylosis, tracheal, of poultry, 293

Strongylus, 226, 25.

amatus, $2 \mathrm{Si}$

amfieldi, 261

capillaris, $22 \mathrm{~s}$

colubrifornis, 271

contortus, $26 \mathrm{~s}$

curticei, $26 \mathrm{~s}$

edcntatus, 2\!!

equinus, $25 \mathrm{~s}$

filaria, 256

filicollis, 273

instabilis, 271

micrurus, 259

oncophora, 275

ostertagi, $2 \pi 2$

paradoxus, 260

pusillus, 262

rufescens, 257

vasorum, 261

ventricosus, $26 \mathrm{~s}$

rulgaris, $255,2 \times 9$

Strongyl worms, importance of, 255 infestation, conditions favoring, 255

Struggle for existence, 1

Subcutaneous mite of fowl, 134

Summaries on development of Texas fever tick, 149,150

Surra, 314, 315, 332

course, 332 flies as carriers of, $314,315,332$ infection, 332

occurrence, 332

symptoms, 332

Symbiosis, 2, 7

phases of, 2

Symbiotes, 103

communis, 103

Syngamex, 281

Syngamosis, 293

Syngamus, 281, 294

bronchialis, 293, 294

trachealis, 293, 294

Synopsis of tapeworm larvæ, 194

Synthetocaulus abstrusus, 262

capillaris, $25 \mathrm{~s}$

rufescens, 257

\section{$\mathrm{T}$}

Tabanidæ, 20, 35, 332

Tabanus atratus, 35

lineola, 36

striatus, 332

Table of principal tapeworms and larræ, 173

Tænia, 173

Tænia alba, 176

cesticillus, 190

cœnurus, 179

crassicollis, $1 \mathrm{S4}$

cucumerina, 178

echinobothrida, 191

echinococcus, 1s1, 210

expansa, 176

fimbriata, $174,176,175$

liydatigena, 178, 195, 203

mamillana, 175

marginata, $17 \mathrm{~s}$

mediocanellata, 195

ovis, 204

perfoliata, 174

plicata, 175

proglottina. 191 
saginata, 170, 174, 195

serialis, 179

serrata, 179

solium, 174, 195

tæniæformis, 184

tetragona, 190

Tæniasis, 172, 174

prevention, 187

treatment in general, 186

Tæniidæ, 20, 159, 170

life history of, 169, 171

Tail scab of cattle, 113

Tapeworm larvæ, 173, 174, 194 synopsis of, 194

Tapewolms, 5, 169 classification of, 159,173

cystic forms, 173, 194

degeneration of, 5, 172

parasitism of, 5,172

Tapeworms of the cat, 184

occurrence, 184

symptoms, 184

treatment, 188

Tapeworms of cattle, 176

occurrence, 177

symptons, 177

treatment, $18 \mathrm{~S}$

Tapeworms of chickens, 189

control, 192

diagnosis, 192

investigations as to, 159

occurrence, 1S9, 191

symptoms, 191

treatment, 192

Tapeworms of the dog, $17 \mathrm{~S}$

diagnosis, 183

occurrence, 181

pathogenesis, 182

prevention, 187

relation to human infection, 183

symptoms, 181

treatment, 186

Taperoims of the horse, 174

occurrence, 175 symptoms, 175

treatment, 188

Tapeworms of the rabbit, 185

diagnosis, 185

occurrence, 185

Tapeworms of the sheep, 176

occurrence, 177

symptoms, 177

treatment, 188

Telosporidia, 336

Tetrameres fissispina, 254

Texas fever, 11, 145, 313, 347

acute type, 349

chronic type, 349

development of the piroplasma, 348

distribution, 348

infecting organism of, 347

influence of climate upon, 349

occurrence, 348

period from exposure to development, 348

prevention, 350

relationship of the tick to transmission, $145,314,347$

symptoms, 349

treatment, 350

Texas fever tick, $11,144,145,314,347$

losses occasioned by, 151

progress in eradication of, 152

publications relative to, 145

Texas fever tick, life histoly of, 148, 347

adult period, 150

hatching period, 148

incubation period, 148

larval period, 150

longevity period, 149

nonparasitic development, $14 \mathrm{~S}$

nymphal period, 150

oviposition period, 148

parasitic development, 149

preoviposition period, 148

summary of nonparasitic periods, 149

summary of parasitic periods, 150 
Thorn-headed worm, 306

Thorn-headed womn of the hog, 30.3

life history, 306

oceurrence, 306

pathogenesis, 306

simptoms, 306

treatment, $30 \bar{\tau}$

Thỵsanosoma actinioides, $17 t, 176$, 177

Tick fever, $365,145,313,347$

Ticks, 136

classification of, 130

stages in derelopment of, 139,145

structure of, 136

Tick, Texas ferer, 14t, 145, 31t, 347

Toxascaris limbata, $23 \mathrm{~s}$ marginata, 23s

Toxins, parasitic, $11,174,220$

Tracheal injections, 26.5

Tracheal strongy losis of fowl, 293 de velopment, 294

lesions, 294

occurrenee, 294

prevention, 29.5

symptoms, 294

treatment, 295

Transmigration, s

Trematoda, 156, 157

Trichina spiralis, 220, 299, 301

Trichinella, 225

Trichinella spiralis, 220, 299, 301 degeneration of cyst of, 303 development of eyst of, 302

life history, 302

location of eysts of, 303

migration, 220,302

Trichinellidse, 224, 299

Trichinellinæ, 225

Trichinelloidea, 225

Trichinosis, 220, 301

intestinal, 302

method of infection, 302, 304

museular, 302 oecurrence, 301,304

prophylaxis, 305

symptoms in the hog, 304

treatment, 305

Trichinosis in man, 304

Trichocephalus affinis, 299

crenatus, 299

depressiuseulus, 300

Trichodectes climax, 77

equi, 73

latus, is

parumpilosus, 73

pilosus, 73

scalaris, 75

sphærocephalus, 76

subrostratus, 79

Triehostrongylidx, 226

Trichostrongylinæ, 223, 265

Trichostrongylus, 226 instabilis, 271

Trichurinæ, 225

Trichuris, 225 crenatus, 299

depressiusculus, 300

ovis, 299

Trinoton lituratum, 86

luridum, $8 t$

Trinotum lituratum, st

luridum, 84

Triodontophorus, 281

Trombidiidæ, 96, 99

Trombidium holosericeum, 100

Tropisurus fissispinus, $25 \mathrm{t}$

Trypanoplasma, $32 \mathrm{~S}$

Trypanosoma, 328

americanum, 336

brucei, 314,330

equinum, 332

equiperdum, 333

evansi, 314,332

gambiense, 314

lewisi, 314

theileri, 329

Trypanosomatida, 322, 328 
Trypanosomes, 314,328

classification of, 322,328

morphology of, 325,329

parasitism of, 314,329

reproduction, 329

transmission, 314,329

transmission by flies, 45, 314, 329

Trypanosomes, flies as carriers of, $45,314,329$

leeches as carriers of, 314

lice as carriers of, 314

mosquitoes as carriers of, 314

Trypanosomiasis, 11, 45, 314, 328

human, 46, 314

investigations by Bruce, 45, 314, 330

Tsetse flies, $44,314,330$

control, 43

method of reprochuction, 44

relationship to trypanosomiasis, 45, 314,330

Tsetse fly disease, 44, 314, 330

investigations by Bruce, 41, 314, 330

Tunicata, 3

Turnsick, 204

Typhoid fever, 11,

$\mathrm{U}$

Uncinaria, 281

Uncinariasis, 291
Uncinaria canina, 291

cernua, 293

radiata, 293

stenocephala, 292

trigonocephala, 291

\section{T}

Vermes, 150

Vermicides, use and action of, 121, 186

Vermifuges, use and action of, 121, 186

Verminous bronchitis and pneumonia of cattle, 259

of children, 231

of the goat, 256

of the horse, 261

of the pig, 231, 260

of the sheep, 256

Viviparous, application of the term, 219

II

Warble flies, 53 , $5-$

White diarrhea of chicks, 345

Wood tick, 143

Worms, 155

classification of, $15 \overline{5}, 15 \overline{7}, 173$

\section{Z}

Zoöparasites, S 





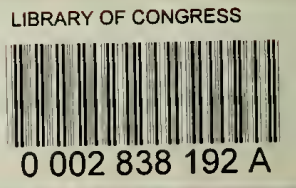

